\title{
Analysis of Benefits of an Energy Imbalance Market in the NWPP
}

$\begin{array}{ll}\text { NA Samaan } & \text { R Schellberg } \\ \text { R Bayless } & \text { S Conger } \\ \text { M Symonds } & \text { K Harris } \\ \text { TB Nguyen } & \text { M Rarity } \\ \text { C Jin } & \text { S Wallace } \\ \text { D Wu } & \text { J Austin } \\ \text { R Diao } & \text { R Noteboom } \\ \text { YV Makarov } & \text { T Van Blaricom } \\ \text { L Kannberg } & \text { K McRunnel } \\ \text { T Guo } & \text { J Apperson } \\ \text { S Dennison-Leonard } & \text { M Empey } \\ \text { M Goodenough } & \text { P Etingov }\end{array}$

D Warady

R Brush

J Newkirk

P Williams

M Landauer

H Owen

W Morter

K Haraguchi

J Portouw

K Downey

S Sorey
S Williams

T Gossa

C Kalich

P Damiano

C Macarthur

T Martin

J Hoerner

S Knudsen

A Johnson

R Link

D Holcomb

October 2013 


\title{
DISCLAIMER
}

This report was prepared as an account of work sponsored by an agency of the United States Government. Neither the United States Government nor any agency thereof, nor Battelle Memorial Institute, nor any of their employees, makes any warranty, express or implied, or assumes any legal liability or responsibility for the accuracy, completeness, or usefulness of any information, apparatus, product, or process disclosed, or represents that its use would not infringe privately owned rights. Reference herein to any specific commercial product, process, or service by trade name, trademark, manufacturer, or otherwise does not necessarily constitute or imply its endorsement, recommendation, or favoring by the United States Government or any agency thereof, or Battelle Memorial Institute. The views and opinions of authors expressed herein do not necessarily state or reflect those of the United States Government or any agency thereof.

\author{
PACIFIC NORTHWEST NATIONAL LABORATORY \\ operated by \\ BATTELLE \\ for the \\ UNITED STATES DEPARTMENT OF ENERGY \\ under Contract DE-AC05-76RL01830
}

Printed in the United States of America

Available to DOE and DOE contractors from the Office of Scientific and Technical Information,

P.O. Box 62, Oak Ridge, TN 37831-0062;

ph: (865) 576-8401

fax: $(865) 576-5728$

email: reports $a$ adonis.osti.gov

Available to the public from the National Technical Information Service

5301 Shawnee Rd., Alexandria, VA 22312

ph: (800) 553-NTIS (6847)

email: ordersantis.gov <http://www.ntis.gov/about/form.aspx>

Online ordering: http://www.ntis.gov 


\section{Analysis of Benefits of an Energy Imbalance Market in the NWPP}

\begin{tabular}{|c|c|c|c|}
\hline NA Samaan (PNNL) PM & R Schellberg (IPC) & D Warady (SMUD) & S Williams (BPA) \\
\hline R Bayless (NTTG) TL & S Conger (BPA) & R Brush (NWE) & T Gossa (PGE) \\
\hline M Symonds (BPA) TL & K Harris (CG) & J Newkirk (PSE) & C Kalich (AVA) \\
\hline TB Nguyen (PNNL) & M Rarity (PSE) & P Williams (BPA) & P Damiano (CG) \\
\hline C Jin (PNNL) & S Wallace (NTTG) & M Landauer (CG) & C Macarthur (DGT) \\
\hline D Wu (PNNL) & $\mathrm{J}$ Austin (PAC) & H Owen (CHPD) & T Martin (TPWR) \\
\hline R Diao (PNNL) & R Noteboom (GCPD) & W Morter (SCL) & J Hoerner (PSE) \\
\hline YV Makarov (PNNL) & T Van Blaricom (SMUD) & K Haraguchi (BPA) & S Knudsen (BPA) \\
\hline L Kannberg (PNNL) & K McRunnel (GCPD) & J Portouw (PAC) & A Johnson (BPA) \\
\hline T Guo (Energy Exemplar) & J Apperson (PAC) & K Downey (PAC) & R Link (PAC) \\
\hline S Dennison-Leonard (NWPP) & M Empey (UAMPS) & S Sorey (SMUD) & D Holcomb (SMUD) \\
\hline M Goodenough (Powerex) & P Etingov (PNNL) & & \\
\hline
\end{tabular}

October 2013

Prepared for

the Northwest Power Pool

under Contract DE-AC05-76RL01830

Pacific Northwest National Laboratory

Richland, Washington 99352 



\section{Executive Summary}

The Northwest Power Pool (NWPP) Market Assessment Committee (MC) Initiative, which was officially launched on March 19, 2012, set out to explore a range of alternatives that could help the Balancing Authorities and scheduling utilities in the NWPP area address growing operational and commercial challenges affecting the regional power system.

The MC formed an Analytical Team with technical representatives from each of the member Balancing Areas in the NWPP and with staff of Pacific Northwest National Laboratory (PNNL). This Analytical Team was instructed to conduct extensive studies of intra-hour operation of the NWPP system in the year 2020 and of the NWPP region with 14,671 MW of wind penetration. The effort utilized a subhourly production cost model (the PLEXOS ${ }^{\circledR}$ computer model) that inputs data from the Western Electricity Coordinating Council (WECC)-wide Production Cost Model (PCM) to evaluate potential production cost savings.

The Analytical Team was given two general options to evaluate. These are the following:

- Energy Imbalance Market (EIM): establishment of an automated, organized NWPP area market for economically supplying energy imbalance within the hour.

- Enhanced Market-Operational Tools (EMT) that might augment or replace an EIM.

The Analytical built on the WECC-wide PCM data from prior work done in the WECC and carried forward the evolution of the original WECC Transmission Expansion Planning Policy Committee (TEPPC) 2020 PC0 data base. A large number of modifications and improvements were made to this case and the data were subjected to extensive review by the team members to improve the model representation of the Northwest (NW). MC meetings that were open to the public were held for interested parties to review and provide input to the study.

Results for the test, base, and sensitivity case studies performed by the MC Initiative Analytical Team indicate that there are a wide range of benefits that could be obtained from the operation of an EIM in the NWPP depending on what assumptions are made. The instructions from the MC were to determine a "minimum high confidence" range of potential benefits. The results for the Base Case indicate that the EIM benefits ranged from approximately $\$ 40$ million to $\$ 70$ million in annual savings from the operation of an EIM in the NWPP footprint.

A number of additional relevant sensitivity cases were performed, including low and high water conditions, low and high natural gas prices, and various flexible reserve requirements, resource operations, and amounts of resource capability held back during the preschedule period. Along with the results for the Base Case, the results for these studies yielded EIM benefits that clustered within the range of $\$ 70$ million to $\$ 80$ million dollars per year with potential benefits ranging from approximately $\$ 125$ million to as little as \$17 million per year.

Because the design and operation of an EIM could enable participating Balancing Authorities (BAs) to collectively lower the quantity of resources they must carry to meet within-hour balancing needs, a sensitivity case was also performed to analyze the impact that such reductions might have on the benefits

from an EIM. The results for this sensitivity case indicate that such reductions could increase the benefits 
from the operation of an EIM in the NWPP into the range of approximately $\$ 130$ million to $\$ 160$ million per year. Also, a sensitivity case for a WECC-wide EIM was performed with the results indicating that the potential benefits to the NWPP could increase into the range of \$197 million to \$233 million per year.

While there may be potential reliability benefits from the coordinated dispatch process underlying the operation of an EIM, reliability benefits from an EIM were out of the scope of this study. The EIM benefit analyses that were performed by the Analytical Team are provided in this report. A separate MC working group developed the costs associated with implementing an EIM. These cost estimates will be combined with the benefit results of this study and reported in the MC Final Report.

\section{Modeling Approach:}

The approach taken by the Analytical Team to model potential benefits of an EIM focused on quantifying the relative differences between the production costs expected under two different BA operating regimes. These are the following:

a. "Business-as-usual” (BAU) conditions: sub-hourly operations without an energy imbalance market. In this operating regime, a BA dispatches its own resources to meet its own loads and imbalances while holding schedules with other BAs constant over the operating hour.

b. With an energy imbalance market. Assumed BA members in the NWPP EIM operate as a combined virtual Balancing Area to meet the intra-hour imbalances.

For almost all model runs, the Analytical Team designed the BAU and EIM scenarios such that they would be identical in the day-ahead trading, unit-commitment, and scheduling process, as well as through the completion of the same-day hourly scheduling. The divergence in the two cases was in the treatment of intra-hour dispatch.

Under the BAU scenarios, each BA was required to hold the interchange schedules that reflected final day-ahead and hourly scheduling outcomes. Management of intra-hour variability and uncertainty (forecasting errors) associated with load, wind and solar was the responsibility of each individual BA.

In the EIM scenarios, the BAs were allowed to share their collective intra-hour dispatch capabilities without being constrained by their interchange schedules (which were relaxed in the EIM scenarios). These capabilities were only limited by the real-time physical capability of the transmission system and the available generating units that were dispatched according to economic merit.

In order to help mitigate differences and debates caused by differing efficiency assumptions of prescheduled trading and contracts, interchange schedules held between Balancing Authorities over the intrahour real-time period were modeled using the following approach:

1. Known contracts and joint ownership of generating plants were represented.

2. Generating resources in WECC were optimized in the day-ahead unit commitment and hour-ahead scheduling periods with the only obligation for each BA being to carry specified amounts of contingency and balancing reserves. This is equivalent to making the assumption of perfectly effective trading and contracting with perfect information.

These interchange schedules between BAs were held constant during the real-time hourly period in the BAU scenario but were relaxed between NWPP BAs in the EIM scenario. Reserve requirements for 
each BA were held constant in both cases, except in one EIM sensitivity case where balancing reserves were calculated for the NWPP footprint. Thus, the approach used in this study purposefully yielded minimum EIM benefits that one can be highly confident the actual EIM benefits will exceed while accounting for the diversity and economic optimization benefits of combining the resource stacks of the BAs. Marginal production costs were used to represent the bidding behavior of the generation bids into the EIM.

In addition, the PCM algorithm assumed that every generator available during a given real-time period would offer into the EIM its entire dispatchable range at its incremental or decremental costs of operation, even though there is no requirement that they do so in actual operations. This assumption is especially relevant for hydroelectric and wind generation, which were assigned incremental costs of zero. Accordingly, the modeling results reflect an essentially "perfect” real-time market with only physical transmission constraints and the machine capability of generators limiting the degree to which online resources could be economically redispatched.

It should be noted that while this assumption may result in somewhat optimistic estimates of the EIM benefits, the assumption of perfect scheduling during the pre-scheduling period results in a more pessimistic estimate of the EIM benefits. Any inefficiency of trading and contracting that occurs in actual operations because of time constraints, unavailability of information, etc. under the BAU scenario will be removed in an EIM, resulting in higher EIM benefits.

One of the more challenging tasks in the process was representing the complex monthly, weekly, hourly and intra-hour "budgeting" process for flexible hydroelectric facilities. This involves considering not just the immediate market value of the generation and the unit capabilities, but also how operational and economic decisions made in one time frame might affect operational capabilities and economic conditions in future time frames while adhering to the required water budget and wind conditions. Modeling limitations in PLEXOS sometimes required the use of phantom "excess hydro"” to solve troublesome 10 minute time segments within the operating hour. This occurred when a time segment was short of resources even though the time segments surrounding the troublesome segment had committed thermal energy available, which operators in actual operations would adjust the amounts of hydro and thermal generation dispatched between the time segments to cover such shortages. To more accurately compare the production costs of the cases in this event, the Analytical Team developed an approach external to PLEXOS that values this additional excess hydro generation at the cost of available thermal generation in the surrounding 10 minute segments. This excess hydro generation was valued at two different price levels to provide a range of values for comparative purposes.

For each sensitivity case, two different price levels for the excess hydro generation in both the EIM and BAU scenarios were valued at $\$ 42.00$ per MWh and \$57.50 per MWh. The one exception is that the values for excess hydro generation were adjusted in the high and low natural gas price cases to track the implied heat rates derived from the calculated level of production from gas-fired generation units and the assumed natural gas prices per MMBtu at Henry Hub located near Earth, Louisiana.

\footnotetext{
${ }^{1}$ The phase "excess hydro generation" is shorthand reference alluding to difficulty, within the production cost modeling process, of accurately reflecting how operators of hydroelectric projects must often "budget" production capability across multiple time periods to manage myriad constraints, including available water, effects on downstream operations, and legal obligations to fulfill objectives other than power production (such as flood control and mitigation of environmental impacts).
} 
Despite these challenges, the expert economic dispatch analysts who participated in the Analytical Team expressed a reasonable level of confidence in the results while acknowledging the complexities of the modeling process.

\section{Overview of Benefit Range and Sensitivities:}

Table ES-1 presents in summary form the characteristics of the Base Case and the key sensitivity cases modeled in PLEXOS. Table ES-2 reports the range of calculated NWPP EIM benefits.

The results in Table ES-2 can be viewed differently depending on the perspective of an individual regarding, among other things, the following:

- Different weights are given to the uncertainty associated with what is necessarily an assumptiondriven modeling process,

- Different strategies and positions are taken by entities within the overall NWPP footprint,

- Different levels of urgency exist to find near-term and long-term solutions for the issues described in the problem statement, and

- Different views about how the basic logic for optimizing a thermally based system-often described as a "heat-rate swap" - may actually play out in a market footprint where often some hydro production might displace other hydro production, which is more difficult to capture in a model that assigns zero cost to all hydro production. 
Table ES-1. Characteristics of the Base Case and the Key Sensitivity Cases Modeled in PLEXOS

\begin{tabular}{|c|c|c|}
\hline \multicolumn{3}{|r|}{ Case Descriptions } \\
\hline $\begin{array}{l}\text { Base “Core” } \\
\text { Case }\end{array}$ & $\begin{array}{l}\text { Base Case } \\
\text { (Minimum } \\
\text { Achievable Benefits) }\end{array}$ & $\begin{array}{l}\text { - } 95 \% \text { Confidence Interval (CI) used to calculate balancing reserve (load- } \\
\text { following and regulation) requirements for each BA } \\
\text { - } \quad \text { Held reserves constant between the EIM and BAU scenarios } \\
\text { - } \quad \text { Footprint: NWPP EIM } \\
\text { - Annual average nominal natural gas price of } \$ 5.62 \text { per MMBtu at Henry } \\
\text { - } \quad 2006 \text { hub in } 2020\end{array}$ \\
\hline \multirow[t]{2}{*}{$\begin{array}{l}\text { Flexible } \\
\text { Reserves } \\
\text { Requirement }\end{array}$} & $\begin{array}{l}\text { Increased Flex } \\
\text { Reserve }(99.5 \% \mathrm{CI}) \\
\text { Case }\end{array}$ & $\begin{array}{l}\text { - Increased the CI used to calculate balancing reserve requirements to } \\
\text { 99.5\% for each BA. } \\
\text { - Held reserves constant between the EIM and BAU scenarios. }\end{array}$ \\
\hline & $\begin{array}{l}\text { Reduced EIM Flex } \\
\text { Reserve Case }\end{array}$ & $\begin{array}{l}\text { - Reduced the flex reserve obligation in the EIM scenario (about } 40 \% \text { load- } \\
\text { following reduction in comparison with the BAU scenario for the Base } \\
\text { Case). Load-following reserves were calculated based on the NWPP EIM } \\
\text { footprint being a single entity. } \\
\text { Day-ahead and hour-ahead commitments and dispatch for the EIM } \\
\text { scenario were based on the reduced flex reserve requirements. }\end{array}$ \\
\hline \multirow[t]{2}{*}{ Inefficiencies } & 3\% Held-back Case & $\begin{array}{l}\text { - Reduced by } 3 \% \text { the available hydro energy from flexible hydro plants and } \\
\text { the maximum available capacities for thermal plants in the day-ahead and } \\
\text { hour-ahead periods, causing more units to be committed. }\end{array}$ \\
\hline & 6\% Held-back Case & $\begin{array}{l}\text { - Reduced by } 6 \% \text { the available hydro energy from flexible hydro plants and } \\
\text { the maximum available capacities for thermal plants in the day-ahead and } \\
\text { hour-ahead periods, causing more units to be committed. }\end{array}$ \\
\hline \multirow[t]{2}{*}{ Footprints } & $\begin{array}{l}\text { WECC-Wide EIM } \\
\text { Case }\end{array}$ & $\begin{array}{l}\text { - Changed the EIM footprint to WECC-wide, otherwise the same as the } \\
\text { Base Case. }\end{array}$ \\
\hline & $\begin{array}{l}\text { NWPP EIM w/o } \\
\text { PAC Case }\end{array}$ & $\begin{array}{l}\text { - Changed the NWPP EIM footprint to exclude PAC, otherwise the same as } \\
\text { the Base Case. }\end{array}$ \\
\hline \multirow[t]{2}{*}{$\begin{array}{l}\text { Natural Gas } \\
\text { Prices }\end{array}$} & High Gas Price Case & $\begin{array}{l}\text { - Increased the annual average nominal natural gas price to } \$ 8.40 \text { per } \\
\text { MMBtu at Henry Hub in } 2020 \text {. }\end{array}$ \\
\hline & Low Gas Price Case & $\begin{array}{l}\text { - Decreased the annual average nominal natural gas price to } \$ 3.80 \text { per } \\
\text { MMBtu at Henry Hub in } 2020 \text {. }\end{array}$ \\
\hline \multirow[t]{3}{*}{$\begin{array}{l}\text { Hydro } \\
\text { Alternatives }\end{array}$} & High Water Case & $\begin{array}{l}\text { - Substituted the } 2006 \text { hydro energy in the Base Case with } 2011 \text { hydro } \\
\text { energy to represent high water conditions throughout the WECC. }\end{array}$ \\
\hline & Low Water Case & $\begin{array}{l}\text { - Substituted the } 2006 \text { hydro energy in the Base Case with } 2001 \text { hydro } \\
\text { energy to represent low water conditions throughout the WECC. }\end{array}$ \\
\hline & $\begin{array}{l}\text { Hydro Modeling } \\
\text { Improvement Case }\end{array}$ & $\begin{array}{l}\text { - Optimized the real-time dispatch in 12-hour increments to better represent } \\
\text { the information that hydro schedulers have when making decisions. } \\
\text { - Individual hydro plant units were aggregated into fewer units. } \\
\text { - Hydro energy constraints were enforced weekly rather than monthly. }\end{array}$ \\
\hline
\end{tabular}


Table ES-2. Range of Calculated NWPP EIM Benefits in 2020 (\$million)

\begin{tabular}{|c|c|c|c|}
\hline & \multirow{2}{*}{ Case Description } & \multicolumn{2}{|c|}{$\begin{array}{l}\text { Valuation of Excess Hydro } \\
\text { Generation }\end{array}$} \\
\hline & & $\begin{array}{c}\text { Equivalent } \\
\$ 42.00 \text { per MWh }\end{array}$ & $\begin{array}{c}\text { Equivalent } \\
\$ 57.50 \text { per MWh }\end{array}$ \\
\hline Base & $\begin{array}{l}\text { Base Case } \\
\text { (Minimum Achievable Benefits) }\end{array}$ & $\$ 41.2$ & $\$ 70.7$ \\
\hline \multirow{2}{*}{$\begin{array}{l}\text { Flexible } \\
\text { Reserves } \\
\text { Requirement }\end{array}$} & Increased flex reserve $(99.5 \% \mathrm{CI})$ case & $\$ 51.3$ & $\$ 78.0$ \\
\hline & Reduced EIM Flex Reserve Case & $\$ 130.6$ & $\$ 158.2$ \\
\hline \multirow[t]{2}{*}{ Inefficiencies } & 3\% Holdback Case & $\$ 71.2$ & $\$ 90.3$ \\
\hline & 6\% Holdback Case & $\$ 113.7$ & $\$ 124.9$ \\
\hline \multirow[t]{2}{*}{ Footprints } & $\begin{array}{l}\text { NWPP Savings in WECC-Wide Case } \\
\text { (Indicative Only) }\end{array}$ & $\$ 197.0$ & $\$ 233.0$ \\
\hline & NWPP EIM w/o PAC Case & $\$ 37.4$ & $\$ 63.2$ \\
\hline \multirow[t]{2}{*}{ Natural Gas Prices } & High Gas Price Case $^{1}$ & $\$ 79.4$ & $\$ 122.7$ \\
\hline & Low Gas Price Case ${ }^{2}$ & $\$ 16.7$ & $\$ 34.8$ \\
\hline \multirow{3}{*}{$\begin{array}{l}\text { Hydro } \\
\text { Alternatives }\end{array}$} & High Water Case & $\$ 60.1$ & $\$ 84.9$ \\
\hline & Low Water Case & $\$ 17.1$ & $\$ 49.5$ \\
\hline & Hydro Improvement Case & $\$ 71.6$ & $\$ 82.2$ \\
\hline
\end{tabular}

\section{Parsing the Energy Imbalance Market Benefits from PLEXOS}

As requested by the MC Participants, the Analytical Team explored potential approaches for estimating how the EIM benefits calculated by PLEXOS might be allocated (or "parsed") among the BAs participating in the MC Initiative. Due to limitations in the capabilities of the PCM to accurately compute Locational Imbalance Prices (LIPs) for many periods when there was an overabundance of hydro and wind generation having zero marginal cost, parsing based on the nodal prices estimated by the model was not feasible.

The relative amounts of transactions between the BAs were determined to be representative of the NWPP EIM benefits, as well as the overall reduction in the societal production costs. The Analytical Team ultimately elected to use a methodology that assumed that intra-hour transactions between the BAs

\footnotetext{
${ }^{1}$ Excess hydro energy being valued at higher electricity prices of $\$ 62.78 / \mathrm{MWh}$ and $\$ 85.94 / \mathrm{MWh}$ (rather than \$42.00/MWh and \$57.50/MWh

${ }^{2}$ The excess hydro energy being valued at lower electricity prices of $\$ 28.40 / \mathrm{MWh}$ and $\$ 34.80 / \mathrm{MWh}$ (rather than \$42.00/MWh and \$57.50/MWh
} 
in the NWPP EIM would occur only because both parties financially benefit. Therefore, the parsing results should reflect all BAs receiving a share of the societal benefits.

The parsing methodology measured the volume of intra-hour transactions between the BAs in the NWPP EIM and then assumed that the total annual benefits calculated by the PCM would flow to each of the BAs in proportion to their respective shares of the overall transaction volume.

This was the most workable approach the Analytical Team was able to identify, but it yields results that are not necessarily representative of the actual benefits any particular market participant or BA would experience. Actual benefits could be affected by many factors that this methodology could not capture, such as overall market share, market position, shifts in the market, conditions that influence operations and/or performance in competitive markets, congestion, and treatment of transmission usage for energy imbalance transactions.

Moreover, although the parsing process allocated a portion of the gross benefits to each of the BAs in the NWPP EIM, it does not necessarily follow that the calculated benefits would flow to either the operator of that BA or to the load-serving entities within that BA. The parsing results simply reflect the estimated transaction volumes into and out of particular BAs, but they provide no information about which parties within the BA are actually transacting, what they might do with any savings, or the additional earnings they gain through participation in the EIM.

Table ES-3 reports the parsing results for the Base Case with the excess hydro generation being valued at \$42.00/MWh.

Table ES-3. Parsed Societal Benefits for the Base Case by BA Participating in the NWPP EIM

\begin{tabular}{ccc}
\hline Balancing Authority & $\begin{array}{c}\text { Transaction Volume } \\
\text { Percentage }\end{array}$ & $\begin{array}{c}\text { Share of Savings in } \\
\mathrm{k} \$\end{array}$ \\
\hline AVA & $4.77 \%$ & $\$ 1,963$ \\
BCTC & $17.59 \%$ & $\$ 7,239$ \\
BPA & $25.77 \%$ & $\$ 10,605$ \\
IPC & $5.225 \%$ & $\$ 2,148$ \\
Mid C & $3.385 \%$ & $\$ 1,391$ \\
NWMT & $3.64 \%$ & $\$ 1,498$ \\
PAC & $9.85 \%$ & $\$ 4,053$ \\
PGN & $5.11 \%$ & $\$ 2,103$ \\
PSE & $5.03 \%$ & $\$ 2,070$ \\
SCL & $6.90 \%$ & $\$ 2,839$ \\
BANC & $9.25 \%$ & $\$ 3,807$ \\
TIDC & $1.84 \%$ & $\$ 757$ \\
TPWR & $1.33 \%$ & $\$ 547$ \\
WAUW & $0.32 \%$ & $\$ 132$ \\
NWPP & $100 \%$ & $\$ 41,152$ \\
\hline
\end{tabular}





\title{
Acknowledgments
}

The Pacific Northwest National Laboratory project team and Northwest Power Pool MC EIM/EMT Working Groups would like to express their appreciation to the following people and organizations for their support of this project, their contributions advancing the state of the art of intra-hour analysis and modeling, and for providing the contract support, IT, room and travel scheduling, and all the other tasks necessary for the study to succeed.

\author{
NWPP Analytical Team Tasks Leadership \\ Rich Bayless (NTTG) \\ Mark Symonds (BPA) \\ Kevin Harris (CG) \\ Ron Schellberg (IPC) \\ Steven Wallace (NTTG) \\ Jamie Austin (PAC) \\ Debra Warady (SMUD) \\ Sid Conger (BPA) \\ Stan Williams (BPA) \\ Teyent Gossa (PGE) \\ Joshua Newkirk (PSE) \\ Matt Rarity (PSE) \\ Marv Landauer (CG) \\ Pacific Northwest National Laboratory (PNNL) \\ Landis Kannberg \\ Dale King \\ Carl Imhoff \\ Mark Morgan \\ Steve Shankle \\ Rolando Lara \\ Sue Arey \\ Maura Zimmerschied \\ Megan Peters \\ Lorena Ruiz \\ Katie Dickenson \\ Northwest Power and Conservation Council \\ Ben Kujala \\ Bonneville Power Administration (BPA) \\ Rachel Dibble \\ Aimee Higby \\ Columbia Grid \\ Patrick Damiano \\ Katy Roberts
}




\section{Energy Exemplar \\ Tao Guo \\ Guangjuan Liu \\ David Llewellyn \\ Shami Davis}

Northwest Power Pool (NWPP)

Sarah Dennison Leonard

Jerry Rust

Northern Tier Transmission Group (NTTG)

Sharon Helms

Western Electricity Coordinating Council

Michelle Mizumori

Matt Hunsaker

Western Governors Association and PUC EIM

Jason Marks

Travis Kavulla

Doug Larson

National Renewable Energy Laboratory (NREL)

Michael Milligan

Kara Clark

\section{U.S. Department of Energy (DOE)}

Charlton Clark

Gil Bindewald

Larry Mansueti

Kevin Lynn 


\section{Acronyms and Abbreviations}

ACE

AECO

AESO

AGC

APS

AVA

BA

BAA

BANC

BAU

BCHA

BCTC

BEPC

BPA

CAISO

CC

CCGT

CI

CL

COI

CT

DA

DOPD

EIM

GCPD

GT

HA

HTC

IPC

IRP

LADWP

LIP

$\mathrm{MC}$

NREL

NW

NWMT
Area Control Error

Alberta Energy Company

Alberta Electric System Operator

automatic generation control

Arizona Public Service

Avista Corporation

Balancing Authority

Balancing Authority area

Balancing Authority of Northern California

Business as Usual

British Columbia Hydro and Power Authority

British Columbia Hydro and Power Authority

Basin Electric Power Cooperative

Bonneville Power Administration

California Independent System Operator

combined cycle

combined-cycle gas turbine

confidence interval

confidence level

California-Oregon Intertie

combustion turbine

day-ahead

Public Utility District No. 1 of Douglas County, WA

energy imbalance market

Public Utility District of Grant County, WA

gas turbine

hour-ahead

hydrothermal coordination

Idaho Power Company

Integrated Resource Plan

Los Angeles Department of Water and Power

Locational Imbalance Price

Market Assessment Committee

National Renewable Energy Laboratory

Northwest

NorthWestern Energy 


\begin{tabular}{ll} 
NWPP & Northwest Power Pool \\
OTC & Operating Transfer Capability \\
PAC & PacifiCorp \\
PCM & Production Cost Model \\
PG\&E & Pacific Gas \& Electric \\
PGN & Portland General Electric \\
PNNL & Pacific Northwest National Laboratory \\
PSC & Public Service Company of Colorado \\
PSE & Puget Sound Energy \\
PUC & Public Utility Commission \\
PUD & Public Utility District \\
RPS & Renewable Portfolio Standard \\
RT & real time \\
SCE & Southern California Edison \\
SCL & Seattle City Light \\
ST & short term \\
TEPPC & Transmission Expansion Planning Policy Committee \\
TIDC & Turlock Irrigation District \\
TPWR & Tacoma Power \\
UC/ED & unit commitment/economic dispatch \\
USE & unserved energy \\
VGS & Variable Generation Subcommittee \\
WAPA & Western Area Power Administration \\
WAUW & Western Area Power Administration - Upper Great Plains West Region \\
WECC & Western Electricity Coordinating Council \\
& \\
\hline &
\end{tabular}




\section{Contents}

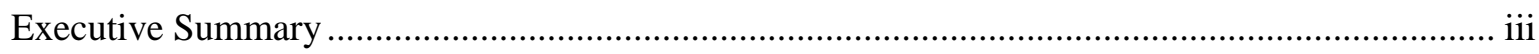

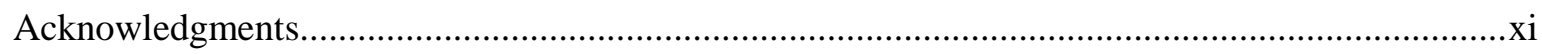

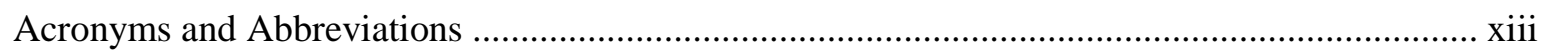

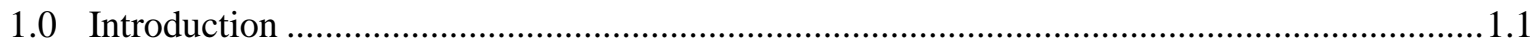

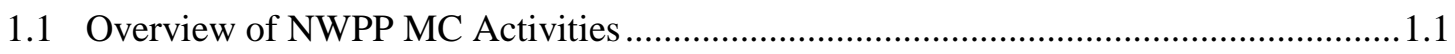

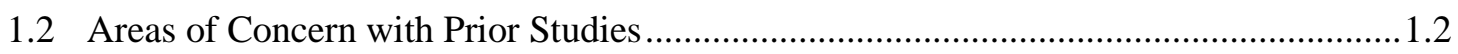

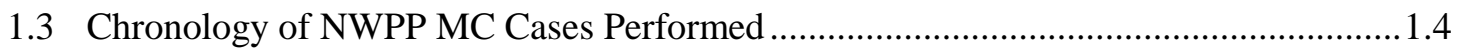

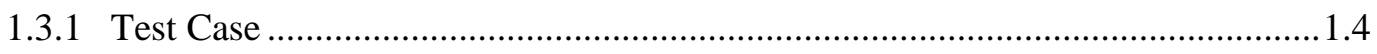

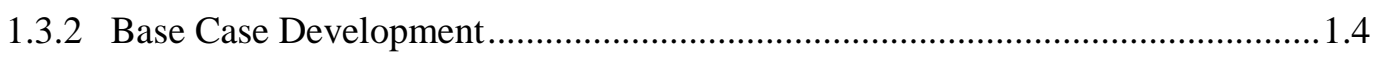

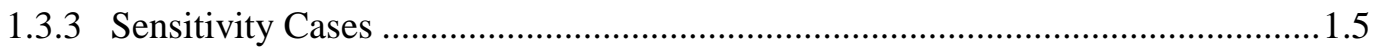

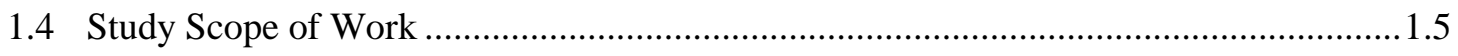

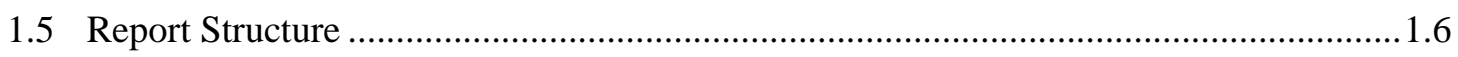

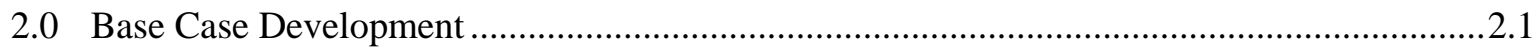

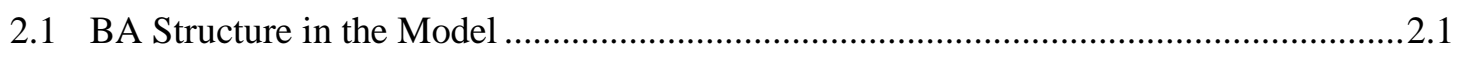

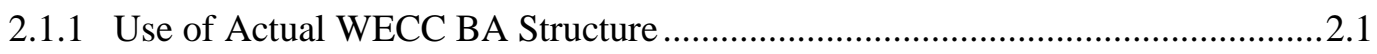

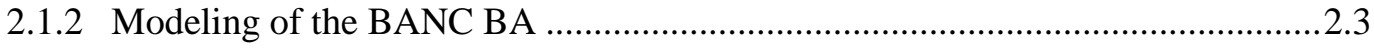

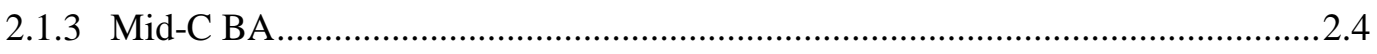

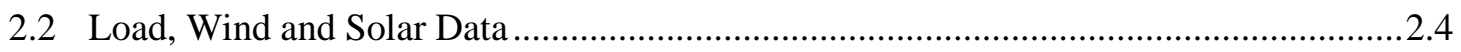

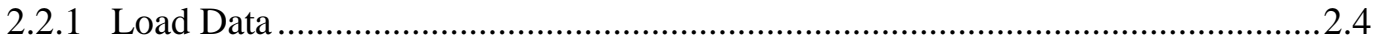

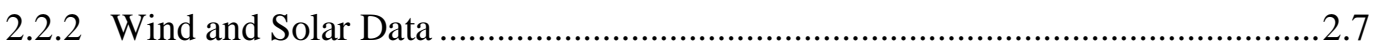

2.2.3 Changes in Wind Energy Allocation for NWPP BAs .......................................... 2.9

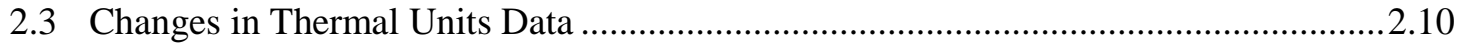

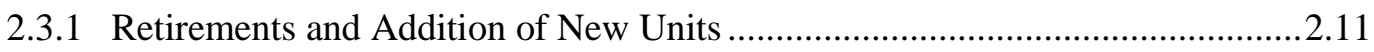

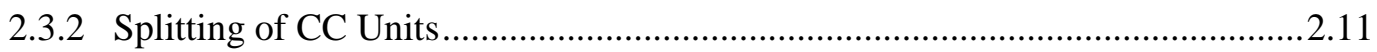

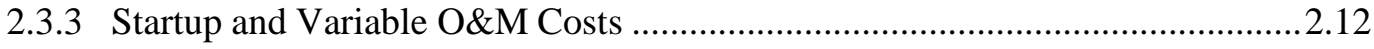

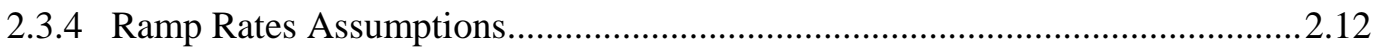

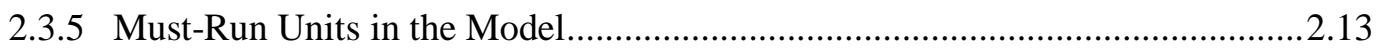

2.3.6 Natural Gas Price Forecast .............................................................................2.13

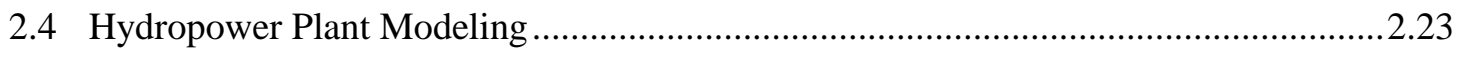

2.4.1 Hydropower Plant Modeling in PLEXOS .......................................................2.2.

2.4.2 Changes in Hydro Generation Plant Modeling ..................................................2.27

2.4.3 Hydro Plant Ramp Rates Corrections …….....................................................2.2.29

2.4.4 Modeling of MidC Hydro Units .....................................................................2.29

2.4.5 Development of High and Low Hydro Scenarios ............................................2.31 


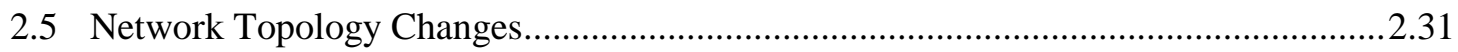

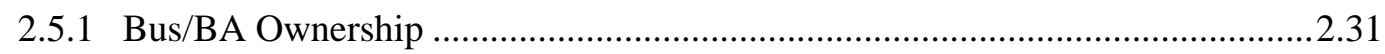

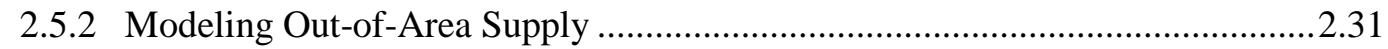

2.5.3 Transmission Topology, Constraints, Flowgates and Nomograms .....................2.33

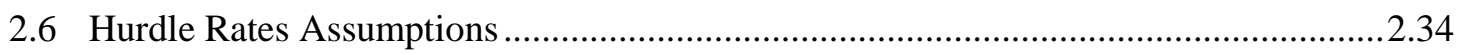

2.6.1 Hurdle Rates between Regional Markets ….......................................................2.34

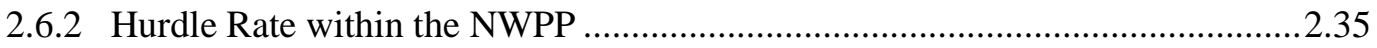

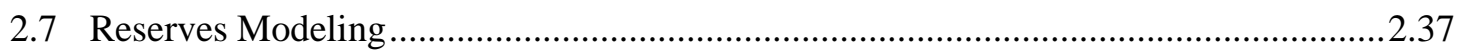

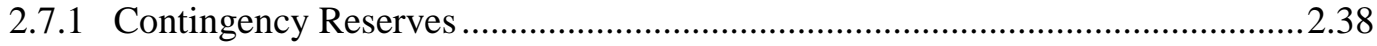

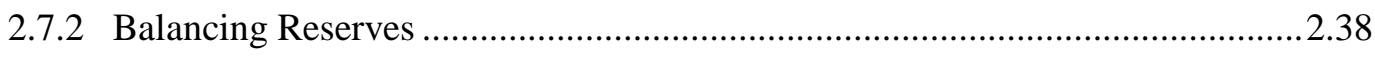

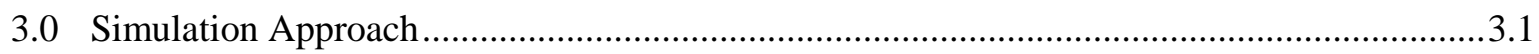

3.1 Rules of Production Cost Modeling ...............................................................................

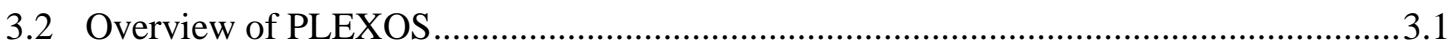

3.2.1 PLEXOS Mid-Term (MT) Simulation and Short-Term (ST) Simulation..............3.2

3.2.2 PLEXOS SCUC/ED Algorithm …….................................................................3.3

3.2.3 PLEXOS 3-Stage Sequential DA-HA-RT Simulations .......................................... 3.4

3.2.4 Soft Constraint Violation Penalties in the Model....................................................3.8

3.3 Description of Base Case and Sensitivity Cases .............................................................. 3.8

3.4 Benefits of an EIM Relative to the Efficiency of the BAU..........................................10

3.5 Methodologies for Parsing the EIM Benefits for Individual BAs in the NWPP............3.11

3.5.1 Using Locational Imbalance Prices (LIPs) to Track Costs and Benefits ............3.11

3.5.2 Using Generation Cost Changes vs. Zonal Exchange Changes in Each

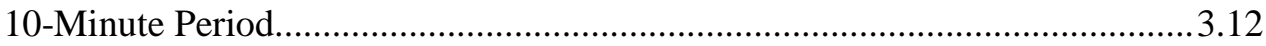

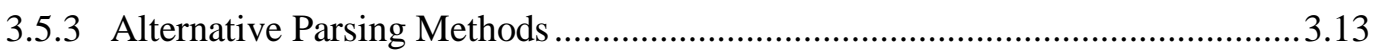

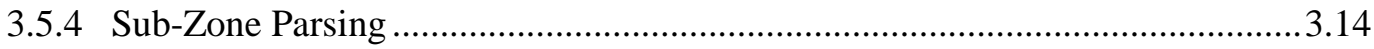

3.6 Modeling Changes Matrix Compared to Previous Studies .............................................14

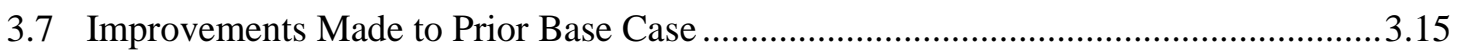

3.7.1 Flexible Reserves Derivation and Modeling Approach .....................................3.16

3.7.2 Full Energy Market Versus EIM benefits ...........................................................16

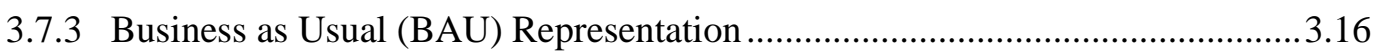

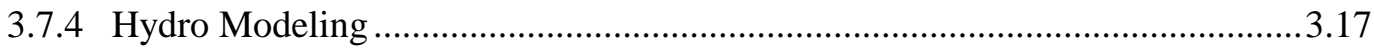

4.0 Simulation Results Analysis .................................................................................. 4-1

4.1 Comparison of Base Case HA Simulation Results vs. Historical Generation Mix of Selected NWPP BAs ............................................................................................... 4-1

4.1.1 BANC Comparison ................................................................................ 4-1

4.1.2 PacifiCorp Comparison ............................................................................. 4-8

4.1.3 Portland General Electric Comparison........................................................ 4-15

4.1.4 Bonneville Power Administration Comparison............................................... 4-21

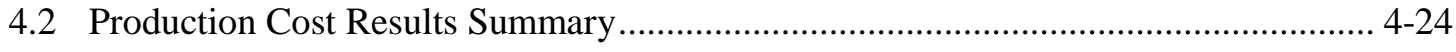


4.2.1 Base Case (Case 1.86A) ......................................................................... 4-25

4.2.2 Increased Flexible Reserve Case (Case 1.86B)............................................ 4-31

4.2.3 3\% Held-back Case (Case 1.86C) ................................................................. 4-36

4.2.4 WECC-Wide EIM (Case 1.86D) ................................................................. 4-41

4.2.5 High Gas Price Case (Case 1.86E) ................................................................. 4-46

4.2.6 Low Gas Price Case (Case 1.86F) ................................................................ 4-51

4.2.7 Reduced NWPP EIM Flexible Reserve Case (Case 1.86G)............................. 4-56

4.2.8 NWPP EIM w/o PAC Case (Case 1.86H) ........................................................ 4-62

4.2.9 6\% Held-back Case (Case 1.86I) .................................................................... 4-67

4.2.10 Low Water Case (Case 1.86J) .................................................................... 4-72

4.2.11 High Water Case (Case 1.86K) .................................................................. 4-77

4.2.12 Hydro Modeling Improvement Case (Case 1.94)............................................ 4-82

4.3 NWPP EIM Benefits Range Summary …............................................................ 4-87

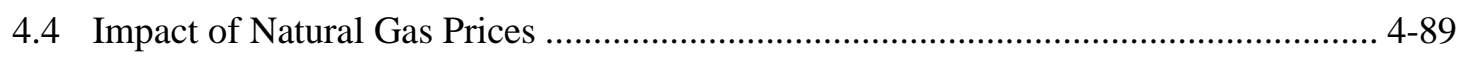

4.5 Impact of Low and High Hydro Conditions............................................................ 4-89

4.6 Impact of Different Footprints .......................................................................... 4-90

4.7 Impact of Reduction in Flexible Reserve Requirements ........................................... 4-91

4.8 Impact of Holding Back More Resources in the DA-HA Periods ............................... 4-91

4.9 NWPP EIM Benefits Parsing Results .................................................................. 4-92

4.9.1 Transaction-Based Parsing Results with PAC in the NWPP EIM .................... 4-93

4.9.2 Transaction-Based Parsing Results without PAC in the NWPP EIM ............... 4-94

4.10 Transmission Congestion Analysis .........................................................................95

4.10.1 Path Utilization Analysis Approach ..............................................................4.96

4.10.2 Base Case (Case 1.86A) Transmission Loading ................................................4.97

4.10.3 Reduced EIM Flex Reserve Case (Case 1.86G) Transmission Loading .............4.98

4.10.4 Hydro Modeling Improvement Case (Case 1.94) Transmission Loading...........4.99

4.11 Comparison of Thermal Unit Capacities Committed during the HA Period in the

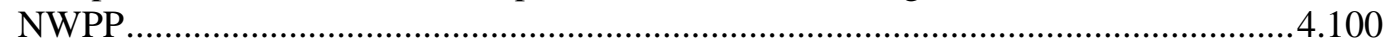

4.12 Comparison of Generation Mix in the BAU and EIM Scenarios for Selected Cases .4.100

5.0 Study Results, Conclusions, and Limitations ................................................................. 5.1

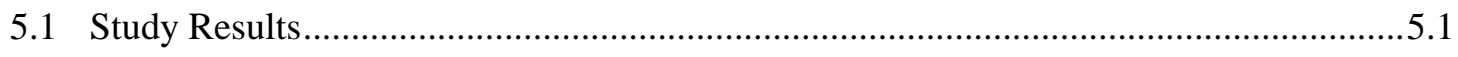

5.2 Limitations of Production Cost Modeling...................................................................

5.3 Suggested Improvements for Additional Analyses .....................................................5.4

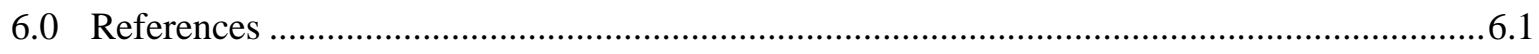

Appendix A Wind Crosswalk Data..................................................................................

Appendix B PNNL Flex Reserve Calculation Approach............................................................. B.1

Appendix C Allocation of MidC Hydro Plants to Balancing Areas .............................................. C.1

Appendix D Remote Units Providing only Contingency Reserve.............................................. D.1

Appendix E Flows at Selected WECC Paths and BA-to-BA Flowgates ...................................... E.1 
Appendix F Reserve Shift Analysis: Impact of Half-Hour Wind Scheduling on Load-Following Requirements . 


\section{Figures}

Figure 1.1. Recent WECC Balancing Authorities Coordination Studies.......................................1.4

Figure 2.1. Current Balancing Authorities in WECC. .................................................................2.2

Figure 2.2. TEPPC Topology Diagram for 2020 PC0 Base Case................................................2.3

Figure 2.3. Actual Load, Hourly Average and Interpolated Load for 2009.................................2.5

Figure 2.4. Error between Interpolated Load Curve and Actual Load Curve (normalized by peak

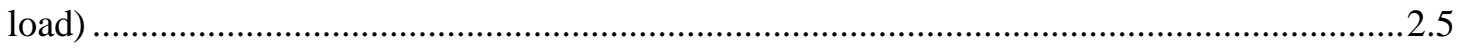

Figure 2.5. Imposing the Load Variance in 2009 to the Interpolated Load in 2020 .....................2.6

Figure 2.6. Generated Load Data for 2020 ..........................................................................2.6

Figure 2.7. Peak Load of Different Balancing Authorities in WECC TEPPC 2020 PC0 Case......2.7

Figure 2.8. Installed Wind Capacities in 2020 for WECC BAs.....................................................

Figure 2.9. Installed Solar Capacities in 2020 for WECC BAs ...................................................2.8

Figure 2.10. Monthly 2020 Natural Gas Trading Hub Prices (Nominal\$/MMBtu) ....................2.16

Figure 2.11. System Hourly Load Profile .............................................................................2.24

Figure 2.12. Hydro Dispatch from MT Optimization ................................................................2.24

Figure 2.13. Hydro Re-optimized in ST Optimization ...........................................................2.25

Figure 2.14. Hydro Energy-Raise (Spin-Up) Reserve Re-optimized in ST Optimization............2.25

Figure 2.15. Hydro Generation Profile from MT Optimization..................................................2.26

Figure 2.16. Hydro Generation Profile from MT optimization is used in the ST Optimization...2.26

Figure 2.17. Hydro Energy-Raise (Spin-Up) Reserve Re-optimized in ST Optimization............2.27

Figure 2.18. Regional Markets Structure for Hurdle Rates ........................................................2.34

Figure 2.19. NWPP BA Structure for Hurdle Rates ...............................................................2.35

Figure 2.20. PSE 95\% CI of Flex Reserves, Actual Requirements and Swinging-Door Simulated

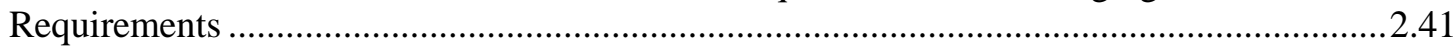

Figure 3.1. PLEXOS Mid-term and Short-term Scheduling Modules ..........................................3.2

Figure 3.2. PLEXOS Security-Constrained Unit Commitment and Economic Dispatch Algorithm3.4

Figure 3.3. Three-Stage DA-HA-RT Sequential Simulation Approach ........................................ 3.5

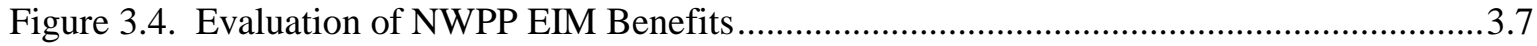

Figure 3.5. Calculations of the Changes in Dispatch Costs Versus Changes in Zonal Exchanges

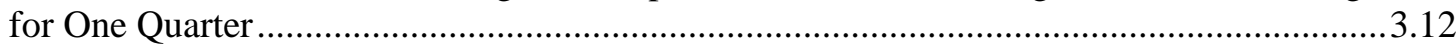

Figure 3.6. The Average Prices Received by a Seller on a Typical Day in January .....................3.13

Figure 4.1. BANC Actual Generation \& Load Compared to Forecast (Base Case HA Simulation

Results) ............................................................................................................. 4-2

Figure 4.2. BANC Capacity Balance on the Peak Hour of Each Month for the Base Case HA

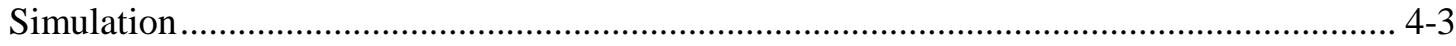

Figure 4.3. BANC Energy Balance by Month for the Base Case HA Simulation........................ 4-3

Figure 4.4. BANC Energy by Fuel Type for the Base Case HA Simulation ................................. 4-4

Figure 4.5. Historical Central Valley Project Generation* vs. Base Case HA Simulation............ 4-5 
Figure 4.6. Historical SMUD Upper American River Project Generation vs. Base Case HA Simulation 4-6

Figure 4.7. Historical SMUD Natural Gas-Fired Generation vs. Base Case HA Simulation ........ 4-7

Figure 4.8. PacifiCorp Loads and Resources, Actuals vs. Modeled ........................................... 4-8

Figure 4.9. PacifiCorp Capacity Balance on Peak Day for the Base Case HA Simulation ........... 4-9

Figure 4.10. PacifiCorp Energy Balance by Month for the Base Case HA Simulation............... 4-10

Figure 4.11. Base Case HA Energy Mix for PAC BA vs. 2013 PAC IRP Energy Mix for Year 2020 4-11

Figure 4.12. PacifiCorp Actual vs. Base Case HA for Dispatched Coal ................................... 4-13

Figure 4.13. PacifiCorp Actual vs. Base Case HA for Dispatched Gas..................................... 4-14

Figure 4.14. PacifiCorp Actual vs. Base Case HA for Hydro................................................... 4-15

Figure 4.15. Portland General Electric Loads and Resources, Actuals vs. Modeled.................. 4-16

Figure 4.16. Portland General Electric Capacity Balance on Peak Day in the Base Case HA

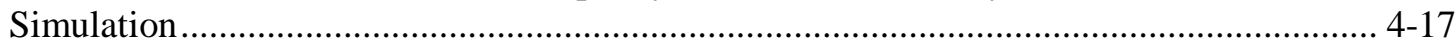

Figure 4.17. Portland General Electric Energy Balance by Month for the Base Case HA

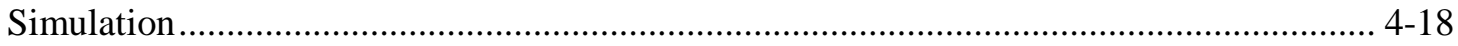

Figure 4.18. Portland General Electric Actual vs. Base Case HA for Dispatched Coal............. 4-19

Figure 4.19. Portland General Electric Actual vs. Base Case HA for Dispatched Gas .............. 4-20

Figure 4.20. Portland General Electric Actual vs. Base Case HA for Hydro ............................. 4-20

Figure 4.21. BPA Loads and Resources, Actuals vs. Modeled............................................... 4-21

Figure 4.22. BPA Capacity Balance on Peak Day for the Base Case HA Simulation................. 4-22

Figure 4.23. BPA BA Energy Balance by Month for the Base Case HA Simulation.................. 4-23

Figure 4.24. Historical BPA Control Area Resources Mix vs. Base Case HA Simulation ......... 4-24

Figure 4.25. Average Capacity Reductions in Load Following Up and Down Requirements for

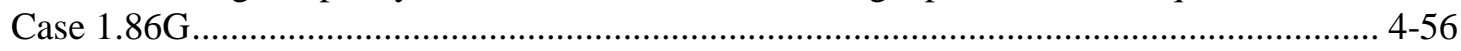

Figure 4.26. NWPP EIM Benefits Continuum .................................................................... 4-88

Figure 4.27. Congestion Metric Definitions ........................................................................96

Figure 4.28. Most Heavily Used Transmission Paths in the Base Case at U75, Year 2020 ........4.97

Figure 4.29. Most Heavily Used Transmission Paths in Case 1.86G at U75, Year 2020............4.98

Figure 4.30. Most Heavily Used Transmission Paths in Case 1.94 at U75, Year 2020...............4.99 


\section{Tables}

Table 2-1. Thirty-Two Balancing Authorities in WECC 2.7

Table 2-2. Comparison of NWPP BAs Installed Wind Capacity in Different Studies

Table 2-3. Installation Capacity of Different Generation Categories for TEPPC 2020 PC0 Case2.10

Table 2-4. Assumed Ramp Rates for Gas Units . 2.13

Table 2-5. Classification of Generic Turbine to Ramp Rate Type. 2.13

Table 2-6 Nominal 2020\$ Natural Gas Price Forecast and Natural Gas Trading Hub Basis Price Differentials (\$/MMBtu).

Table 2-7. Nominal 2020\$ Natural Gas Price Forecast by Natural Gas Trading Hub (\$/MMBtu)2.15

Table 2-8. Source Gas Hub, Transport Charges, and Final Exit/Scheduling Fees for Each Load Area

Table 2-9. Gas-Fired Plant Exceptions List. 2.18

Table 2-10. Nominal 2020\$ Natural Gas Burner Tip Prices by Location (\$/MMBtu)..... 2.19

Table 2-11. High Nominal 2020\$ Natural Gas Burner Tip Prices by Location (\$/MMBtu) ........2.21 Table 2-12. Low Nominal 2020\$ Natural Gas Burner Tip Prices by Location (\$/MMBtu).........2.22

Table 2-13 FY 2001-2009 Average MW Weighted Availability by Month for Selected Hydro Plants in BPA. 2.28

Table 2-14. Remotely Owned Generation Units in the Model 2.32

Table 2-15. Hurdle Rates Imposed on BA-to-BA Energy Transfers on DA, HA and BAU Simulations 2.36

Table 2-16. Hour-Ahead Load Forecast Error Metrics 2.40

Table 2-17. Summary of Balancing Reserves Assumptions..... 2.41

Table 3-1. Penalty Price Input Used in the Model .3.8

Table 3-2. Definition of Sensitivity Cases.... 3.9

Table 3-3. Study Improvements in Comparison with Prior Studies 3.14

Table 4-1. Comparison Between the Resource Capacity Mix for PacifiCorp in the Base Case and its 2013 IRP for Year 2020.

Table 4-2. Summary of Generation Cost and Savings for the NWPP and WECC in Case 1.86A4-27 Table 4-3. Hydro Generation and Energy Constraint Violations in Case 1.86A 4-28

Table 4-4. WECC Dump and Unserved Energy, Reserve Shortfall and Exchange Violations in Case 1.86A.

Table 4-5 Generation, Demand, and Average Production Cost for the NWPP and WECC, and the NWPP Net Interchange in Case 1.86A. 4-30

Table 4-6. Summary of Generation Cost and Savings for the NWPP and WECC in Case 1.86B4-32

Table 4-7. Hydro Generation and Energy Constraint Violations in Case 1.86B 4-33

Table 4-8. WECC Dump and Unserved Energy, Reserve Shortfall and Exchange Violations in Case 1.86B. 4-34 
Table 4-9 Generation, Demand, and Average Production Cost for NWPP and WECC, and NWPP

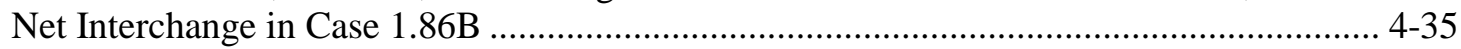

Table 4-10. Summary of Generation Cost and Savings for the NWPP and WECC in Case 1.86C4-37

Table 4-11. Hydro Generation and Energy Constraints Violation in Case 1.86C 4-38

Table 4-12. WECC Dump and Unserved Energy, Reserve Shortfall and Exchange Violations in Case 1.86C. 4-39

Table 4-13 Generation, Demand, and Average Production Cost for NWPP and WECC, and NWPP Net Interchange in Case 1.86C.

Table 4-14. Summary of Generation Cost and Savings for the NWPP and WECC in Case 1.86D4-42

Table 4-15. Hydro Generation and Energy Constraints Violation in Case 1.86D. 4-43

Table 4-16. WECC Dump and Unserved Energy, Reserve Shortfall and Exchange Violations in Case 1.86D. $4-44$

Table 4-17. Generation, Demand, and Average Production Cost for NWPP and WECC, and NWPP Net Interchange in Case 1.86D. 4-45

Table 4-18. Summary of Generation Cost and Savings for the NWPP and WECC in Case 1.86E4-47

Table 4-19. Hydro Generation and Energy Constraints Violation in Case 1.86E 4-48

Table 4-20. WECC Dump and Unserved Energy, Reserve Shortfall and Exchange Violations in Case 1.86E 4-49

Table 4-21. Generation, Demand, and Average Production Cost for NWPP and WECC, and NWPP Net Interchange in Case 1.86E 4-50

Table 4-22. Summary of Generation Cost and Savings for the NWPP and WECC in Case 1.86F4-52 Table 4-23. Hydro Generation and Energy Constraints Violation in Case 1.86F. 4-53

Table 4-24. WECC Dump and Unserved Energy, Reserve Shortfall and Exchange Violations in Case $1.86 \mathrm{~F}$ 4-54

Table 4-25. Generation, Demand, and Average Production Cost for NWPP and WECC, and NWPP Net Interchange in Case 1.86F.

Table 4-26. Summary of Generation Cost and Savings for the NWPP and WECC in Case 1.86G4-58

Table 4-27. Hydro Generation and Energy Constraints Violation in Case 1.86G 4-59

Table 4-28. WECC Dump and Unserved Energy, Reserve Shortfall and Exchange Violations in Case $1.86 \mathrm{G}$. 4-60

Table 4-29. WECC Generation, Demand, and Average Production Cost for NWPP and WECC, and NWPP Net Interchange in Case 1.86G

Table 4-30. Summary of Generation Cost and Savings for the NWPP and WECC in Case 1.86H4-63

Table 4-31. Hydro Generation and Energy Constraints Violation in Case $1.86 \mathrm{H}$ 4-64

Table 4-32. WECC Dump and Unserved Energy, Reserve Shortfall and Exchange Violations in Case $1.86 \mathrm{H}$.

Table 4-33. Generation, Demand, and Average Production Cost for NWPP and WECC, and NWPP Net Interchange in Case 1.86H ............................................................................ 4-66

Table 4-34. Summary of Generation Cost and Savings for the NWPP and WECC in Case 1.86I4-68

Table 4-35. Hydro Generation and Energy Constraints Violation in Case 1.86I..... 4-69

Table 4-36. WECC Dump and Unserved Energy, Reserve Shortfall and Exchange Violations in Case $1.86 \mathrm{I}$ 4-70 
Table 4-37. Generation, Demand, and Average Production Cost for NWPP and WECC, and NWPP Net Interchange in Case 1.86I.

Table 4-38. Summary of Generation Cost and Savings for the NWPP and WECC in Case 1.86J4-73

Table 4-39. Hydro Generation and Energy Constraints Violation in Case 1.86J ..... 4-74

Table 4-40. WECC Dump and Unserved Energy, Reserve Shortfall and Exchange Violations in Case $1.86 \mathrm{~J}$

Table 4-41. Generation, Demand, and Average Production Cost for NWPP and WECC, and NWPP Net Interchange in Case 1.86J

Table 4-42. Summary of Generation Cost and Savings for the NWPP and WECC in Case 1.86K4-78

Table 4-43. Hydro Generation and Energy Constraints Violation in Case 1.86K

Table 4-44. WECC Dump and Unserved Energy, Reserve Shortfall and Exchange Violations in Case $1.86 \mathrm{~K}$.

Table 4-45. Generation, Demand, and Average Production Cost for NWPP and WECC, and NWPP Net Interchange in Case 1.86K....

Table 4-46. Summary of Generation Cost and Savings for the NWPP and WECC in Case 1.944-83

Table 4-47. Hydro Generation and Energy Constraints Violation in Case 1.94. 4-84

Table 4-48. Dump and Unserved Energy, Reserve Shortfall and Exchange Violations in Case 1.94 . 4-85

Table 4-49. Generation, Demand, and Average Production Cost for NWPP and WECC, and

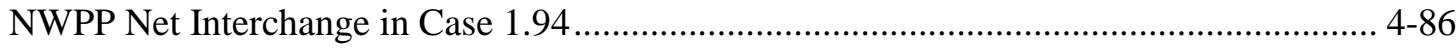

Table 4-50. Range of Calculated NWPP EIM Benefits in 2020 (\$million)................................ 4-87

Table 4-51. NWPP EIM Benefits Range as Percentage of Total NWPP Productions Cost ......... 4-88

Table 4-52. Comparison of NWPP EIM Benefits for the Low and High Natural Gas Price Cases vs. the Base Case 4-89

Table 4-53. Comparison of NWPP EIM Benefits for the Low and High Hydro Cases vs. Base Case. 4-90

Table 4-54. Comparison of NWPP EIM Benefits with different EIM footprints vs. the Base Case4-90

Table 4-55. Comparison of NWPP EIM Benefits with Different Flexible Reserve Requirements vs. the Base Case 4-91

Table 4-56. Comparison of NWPP EIM Benefits with Different Percentages of Holding Back Resources in the DA-HA Periods vs. the Base Case

Table 4-57. Parsed Societal Benefits for the Base Case by BAs Participating in the NWPP EIM4-92

Table 4-58. Percentages of Energy Imbalance Transaction Volumes by Primary Driver for Each BA in the NWPP EIM for the Base Case 4-93

Table 4-59. Average Percentage of Annual Energy Imbalance Transaction Volumes for Each BA in the NWPP EIM 4-94

Table 4-60. Average Percentage of Annual Energy Imbalance Transaction Volumes for Each BA in the NWPP EIM for the NWPP EIM without PAC Case (Case 1.86H) 4-94

Table 4-61. Maximum Transmission Flows on Selected BA-to-BA Flowgates for the Base Case4.95 Table 4-62. NWPP BAU and EIM Generation Mix Comparisons for Selected Cases (GWh) ..4.102 



\subsection{Introduction}

\subsection{Overview of NWPP MC Activities}

Electric power systems throughout the Northwest Power Pool (NWPP) area are experiencing dramatic increases in the amount of renewable generation being added to their systems. Because the Northwest systems are predominantly hydro-based systems, which can be energy limited, capacity constrained or both, it has become increasingly difficult to balance the increasing variability on the systems that results from the limited dispatchability of high wind generation penetration.

The lack of energy to balance wind (mostly on a daily and day-to-day basis) is one part of the problem; especially under poor hydro conditions. However, the substantial increase in the need for available flexible capacity being placed on hydro-based systems that have their ramping capability limited by non-power constraints is another part of the problem; especially during the hour and intra hour time frames-which is the main focus of the energy imbalance market (EIM).

Northwest Balancing Area operators have found that they need additional tools to manage intra-hour ramps and the increasing demand for balancing capacity associated with the variable energy resources now on their systems and the expected additions in the future.

The NWPP Market Assessment and Coordination Committee (MC) Initiative began in March 2012 and was established to analyze this issue and identify better tools to

- systematically share load and resource diversity across Northwest (NW) systems

- better manage and use increasingly constrained transmission systems

- contain the costs and compliance risks associated with operating Balancing Authorities (BAs).

In the process, the MC sought to address cost causation and cost allocation as proposed alternatives were developed, leverage existing tools and platforms as feasible, and preserve the value of the existing NWPP Contingency Reserve Sharing Program and other regional cooperative efforts.

The mission of the MC Initiative was to develop a decision-quality assessment of options to address the challenges identified, to additionally identify ways to improve the efficiency and reliability of regional power system operations, and then make recommendations to the member participants for moving forward.

A committee structure was established with two Working Groups (WGs) and one Analytical Team under the MC:

- Enhanced Market and Operational Tools (EMT) Working Group

- Energy Imbalance Market (EIM) Working Group

- Analytical Team 
The Working Groups identified two options to evaluate. They are the following:

- Energy Imbalance Market (EIM): establishment of an automated, organized NWPP area market for supplying economical imbalance energy within the hour.

- Enhanced Market-Operational Tools (EMT) which might augment or replace an EIM or organized market. These could include systems like those proposed by the Joint Initiatives and other balancing initiatives and would include new enhanced methods to facilitate bilateral markets, automation, technological improvements, or enhanced reserve pooling [1].

Each option was examined by the Working Groups. Alternatives were developed to a high-level functional design by the EIM and EMT Working Groups for their respective options, and potential implementation/operating costs quantified. The Analytical Team performed benefit analyses for the EIM option and reviewed several EMT options.

Each approach was compared with the alternative of Business as Usual (BAU) (how things are done now) and also compared with the other approaches. A benefit/cost evaluation was performed for each option. In addition to the overall benefits to the NWPP (societal benefits), the benefits and costs of the two options were also estimated for each of the participating BAs.

The Analytical Team comprised technical representatives from each of the participating members and representatives from Pacific Northwest National Laboratory (PNNL) who were retained to assist and facilitate the analysis. The specific mission assigned to the Analytical Team by the MC was the following:

- Determine potential NWPP societal and individual BA benefits for the following:

- $\quad$ a real-time (RT) Energy Imbalance Market (EIM)

- $\quad$ and/or alternative Emerging Market Tools and methods (EMT).

- Compare the results of these options to results based on operations under the bilateral market structure and RT operating mode that exist today (BAU).

- Compare BAU and EIM on a future system with expected additional variable resources, loads, and other planned system changes. The WECC Transmission Expansion Planning Policy Committee (TEPPC) 2020 PC0 case [2] was used in this study.

- Determine a minimal, conservatively achievable amount of benefits.

- Employ an understandable model that incorporates a better representation of the NWPP (fix issues with prior studies.)

Implementation costs were developed through a parallel process at the Working Group level. This report focuses on the analyses and results for the EIM scenarios performed by the Analytical Team.

\subsection{Areas of Concern with Prior Studies}

The intent of the MC Initiative was to focus on Northwest (NW) issues and systems. EIMs now exist in several regions of the country, but the MC sought an analysis specific to NW attributes and concerns. The Working Groups and Analytical Team began with a review of existing EIMs and prior analyses of 
benefits. The California Independent System Operator (CAISO) and Alberta Electric System Operator (AESO) are both organized markets that include centralized unit commitment processes as well as realtime EIMs.

The MC Initiative was focused on analyzing the benefits directly attributable to the emerging market tools and a security constrained economic dispatch (SCED), more commonly referred to as an EIM, and not on analyzing the benefits of either a centralized unit commitment process that could supplant the existing unit commitment process or full consolidation of the activities of the BAs as some of the previous studies mentioned below had contemplated.

Several EIM-related benefit studies have been done for the Western system over the past several years. These include

- WECC/Energy and Environmental Economics (E3) EIM (Hourly, WECC wide) [1]

- Columbia Grid BPA EIM (Hourly, NWPP)

- Public Utility Commission EIM (PLEXOS, WECC-wide) [6]

- WECC Variable Generation Subcommittee (VGS) Full BA Consolidation and Reserve Sharing (WECC-wide) [4]

- WECC/VGS benefits of intra-hour scheduling [5]

These studies have been performed by E3, the National Renewable Energy Laboratory (NREL), PNNL, Energy Exemplar, and WECC staff, and with participation from various Western Interconnection entities. The studies ranged from hourly production cost model studies to intra-hour simulations and have looked at various methods for BA cooperation and markets including an EIM.

Results from these studies have shown dramatic differences in the levels of benefits predicted for an EIM. This led the MC to want NW-specific and more detailed analysis. It appeared the large benefits shown in prior EIM studies mostly centered on the savings from reduced reserve requirements for the system with an EIM compared to BAU. The NWPP desired an analysis of EIM and EMT approaches that potentially better fit the NWPP area-its constrained hydro system and wind penetration levels.

Several of the prior studies used traditional hourly production cost simulation models to quantify operational savings over a test year. These were limited by their inability to capture operational changes within the hour given the increased intra-hour variability with existing and planned levels of variable generation. Others used new techniques and the intra-hour features of the PLEXOS model to work around these limitations; however, their results were impacted by required simplifying assumptions and approximations.

Following review of the prior studies, the NWPP MC Working Groups found four areas of concern with prior studies performed for WECC and the PUC EIM on which the MC wished to focus in new analyses:

1. Flexible reserves derivation and modeling approach

a. Were wind forecast benefits inappropriately assigned to EIM benefits? 
2. Full energy market versus EIM benefits

a. What was actually modeled in prior studies?

b. What are the benefits of an EIM only?

3. BAU representation

a. Were existing efficiencies from contracts, trading and exchanges considered in the comparisons to an EIM?

4. Hydro modeling

a. Need to incorporate specific and better representation of NW hydro operations.

The MC decided to build on the work from the prior studies and improve the modeling of the NW in these four areas. PNNL provided the latest PCM models they had improved and advanced in the WECC VGS studies [4]-[5], and the PLEXOS program was chosen to be the model platform. PNNL and Energy Exemplar personnel were employed to assist. Extensive review and scrubbing of NW PCM data was completed by the Analytical Team. Changes to the model were made to improve these four areas, as will be discussed in Sections 2 and 3 of this report. Figure 1.1 shows how the model used in this study relates to the models used in other recent WECC BAs coordination studies.

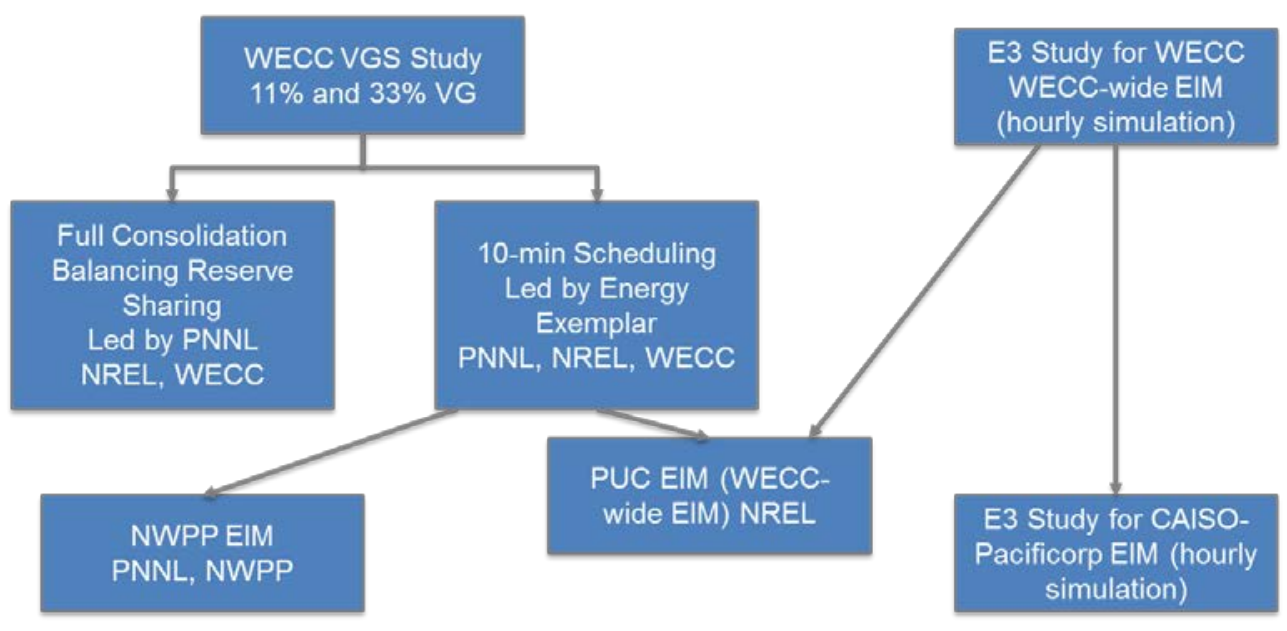

Figure 1.1. Recent WECC Balancing Authorities Coordination Studies

\subsection{Chronology of NWPP MC Cases Performed}

\subsubsection{Test Case}

A test case was performed to quickly gain experience with the PLEXOS model and test how to model preschedule efficiencies; it was performed on the latest case used in the WECC VGS studies.

\subsubsection{Base Case Development}

A number of test cases, each with improvements, were performed which ultimately led to the creation of the Base Case, which is named Case 1.86a. These intermediate step cases involved the following: 
Modify data to reflect more realistic set of assumptions for the future.

- Determine the preschedule period schedules that best represent contracts, trades, and exchanges.

- $\quad$ Make changes to address the four problem areas with prior studies.

- Determine the amounts of balancing reserves to carry into the day-ahead, hour-ahead and RT periods for both the BAU and EIM runs.

\subsubsection{Sensitivity Cases}

A number of sensitivity studies were performed to test the robustness of the results to major assumption changes. Also several cases were done to evaluate the benefits of EMT options. The EIM sensitivity cases included different reserve levels, a WECC-wide EIM footprint, high and low natural gas prices, wet and dry water conditions, NWPP EIM without PacifiCorp, and different operating methods used for hydro in the operating hour.

\subsection{Study Scope of Work}

The purpose of the project is to provide a realistic basis for comparison of the proposed EIM and current operations, and other prospective approaches, as they might be implemented in the NWPP footprint. This project is to support the activities of the NWPP Members' Market Assessment and Coordination Initiative (the "MC Initiative”). The effort has proceeded according to the following distinct steps:

- Develop a production cost model that encompasses the fundamental simulation tool, databases, and assumptions needed to model a realistic representation of the NWPP system and its current operational practices (Base Case).

- Implement a version of the Base Case having an EIM consistent with that proposed by the MC Initiative (“Base Case with EIM”).

- Analyze simulation results of the different sensitivity cases to assess the impact of an EIM relative to BA operations as anticipated to be in effect in 2020 (based on current operational practices) in the absence of an EIM.

- Distribute the data and models for the Base Case and Base Case with EIM for use by participants in the MC Initiative ("MC Participants") for additional simulation of alternatives of interest.

The MC Participant organizations are the following:

1. Avista Corporation

2. Balancing Authority of Northern California

3. Bonneville Power Administration

4. British Columbia Hydro and Power Authority

5. Eugene Water \& Electric Board 
6. Iberdrola Renewables, LLC

7. Idaho Power Company

8. NaturEner Wind Holding, LLC

9. NorthWestern Energy

10. PacifiCorp

11. Portland General Electric Company

12. Puget Sound Energy

13. Public Utility District No. 1 of Chelan County, Washington

14. Public Utility District No. 1 of Clark County, Washington

15. Public Utility District No. 1 of Cowlitz County, Washington

16. Public Utility District No. 1 of Douglas County, Washington

17. Public Utility District No. 2 of Grant County, Washington

18. Public Utility District No. 1 of Snohomish County, Washington

19. Seattle City Light

20. Tacoma Power

21. Turlock Irrigation District

22. Western Area Power Administration, Upper Great Plains

\subsection{Report Structure}

The first section of this report provides an overview of the study. The second section covers the different assumptions and details of the modeling approach used in the study. The third section describes the technical approach used in the study. The fourth section provides detailed analyses of the results from the study. The fifth section contains a summary of the outcomes of the study and suggests improvements for future studies. The sixth section includes a list of references. Finally, several appendices containing more detailed information about the data used in the NWPP EIM analysis are located at the end of the report with one of these appendices (Appendix F) containing an approach for determining the impact that half-hour wind scheduling has on load-following requirements. 


\subsection{Base Case Development}

This section covers the data used in the model and changes that have been made to the TEPPC 2020 case.

\subsection{BA Structure in the Model}

The study used values from the TEPPC 2020 PC0 case [2] to develop the Base Case in PLEXOS. The WECC-wide nodal model in the PROMOD software package, as provided by TEPPC, was used to convert the data used by the PLEXOS model. The model is based on the WECC 2020 HS1A power flow base case. Although the underlying assumption of the Analytical Team was that the TEPPC values will be used, several changes (including the BA structure) were made when developing the Base Case in PLEXOS.

\subsubsection{Use of Actual WECC BA Structure}

WECC currently consists of 38 BAs with six of these being generation-only BAs. The 38 BAs are shown in Figure 2.1. The model used for the TEPPC case has 39 load areas and 32 BAs. Each BA has its own single load profile with the following exceptions:

- CAISO is divided into four load areas (Pacific Gas and Electric Company [PG\&E] Valley, PG\&E Bay, Southern California Edison [SCE] and San Diego Gas and Electric [SDGE]),

- Idaho Power Company (IPC) is divided into three load areas (Treasure Valley, Magic Valley and Far East), and

- PacifiCorp East (PACE) is divided into three load areas (PACE ID, PACE WY, and PACE UT).

In the model for the TEPPC case, the BAs in WECC are grouped into 7 sub-regions. The six generation-only BAs are not modeled, but instead their generation resources are modeled as belonging to other BAs. In this study, PLEXOS was modified from the TEPPC case so that the 32 BAs that are not generation-only BAs were reduced to 28 BAs by combining the following:

- Nevada Power Company (NEVP) and Sierra Pacific Power Company (SPPC) to form a consolidated NV Energy BA,

- Public Utility District No. 1 of Chelan County, WA (CHPD), Public Utility District No. 1 of Douglas County, WA (DOPD), and Public Utility District of Grant County, WA (GCPD) to form a MidC BA.

- PACE and PACW to form a consolidated PacifiCorp (PAC) BA

Although several BAs are combined to make a larger BA, PLEXOS still used the original 39 load profiles for the unit commitment and dispatch of resources. 


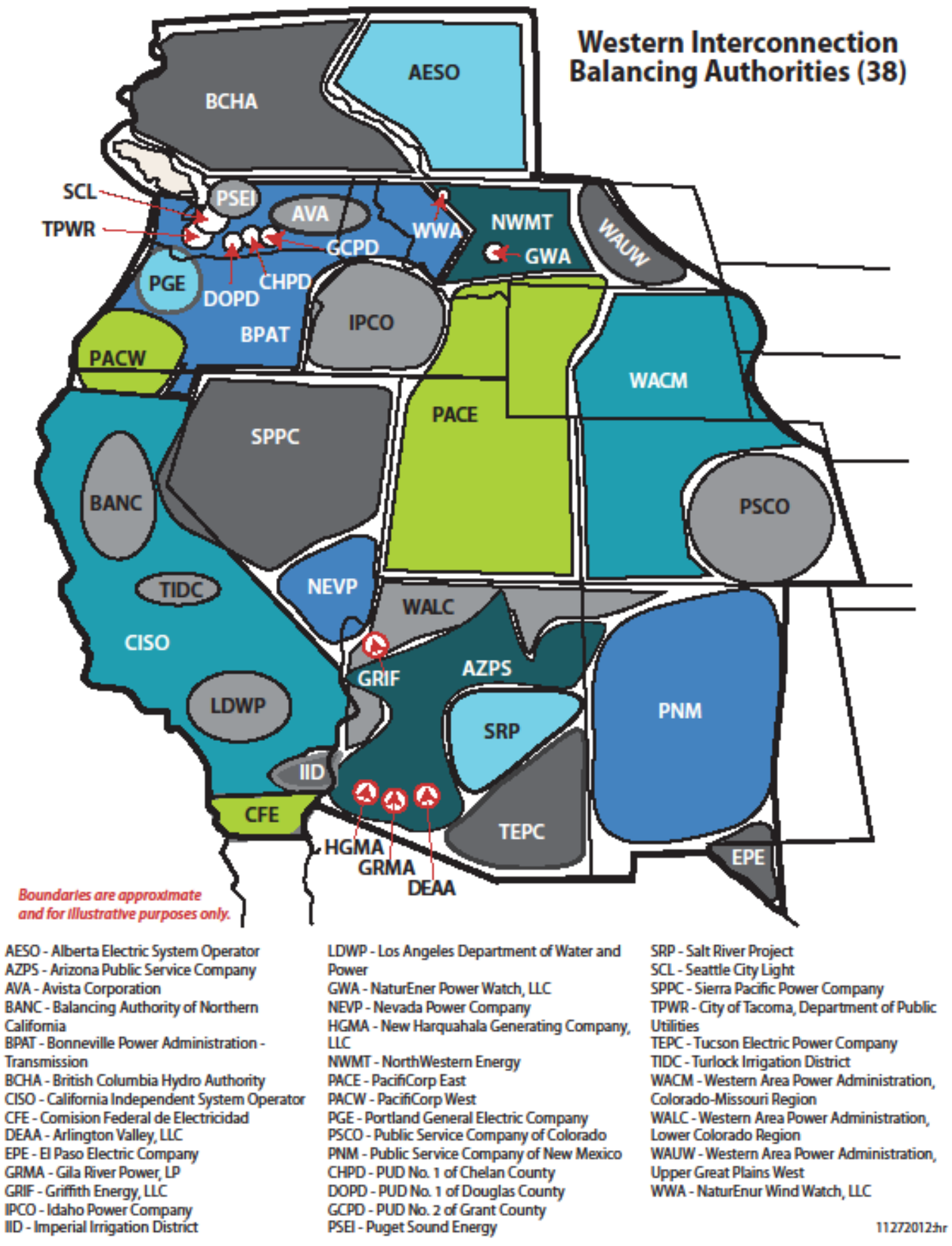

Figure 2.1. Current Balancing Authorities in WECC. ${ }^{1}$

${ }^{1}$ Source: http://www.wecc.biz/library/WECC\%20Documents/Publications/WECC_BA_Map.pdf 


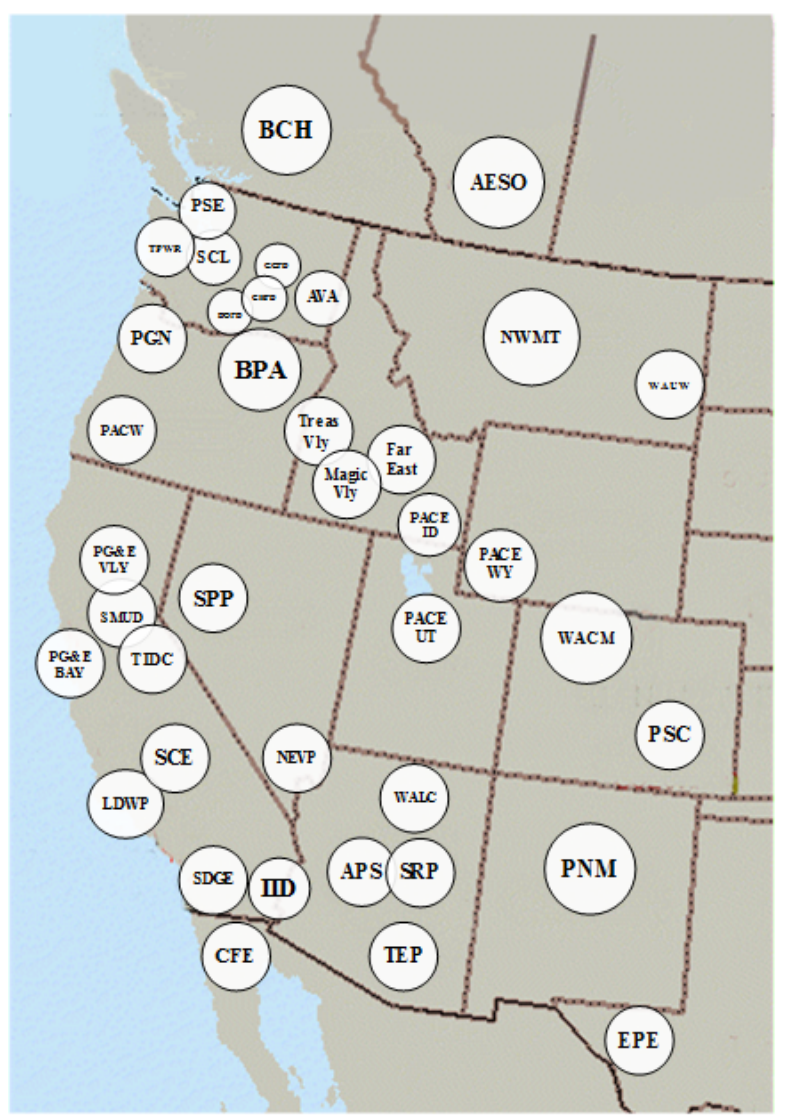

Legend

AESO Alberta Electric System Operator

APS Arizona Public Service

AVA Avista

$\mathrm{BCH}$ British Columbia Hydro

BPA Bonneville Power Administration

CFE Comision Federal de Electricidad

CHPD Chelan Co PUD

DCPD Douglas Co PUD

EPE El Paso Electric

Far East Far East (ldaho Power)

GCPD Grant Co PUD

IID Imperial Irrigation District

LDWP Los Angeles Dept of Water \& Power

Magic Vly Magic Valley (Idaho Power)

NEVP Nevada Power

NWMT Northwestern Montana

PACW PacifiCorpWest

PACE ID PacifiCorpEast-Idaho

PACE UT PacifiCorpEast-Utah

PACE WY PacifiCorp East --Wyoming

PG\&E Bay Pacific Gas \& Electric Bay Area

PG\&E VLYPacific Gas \& Electric Valley Area

PGN Portland Gen Electric

PNM Public Service New Mexico

PSC Public Service Colorado (Xcel)

PSE Puget Sound Energy

SCE Southern California Edison

SCL Seattle City Light

SDGE San Diego Gas \& Electric

SMUD Sacramento Municipal District

SPP Sierra Pacific Power

SRP Salt River Project

TEP Tucson Electric Power

TIDC Turlock Irrigation Distric

TPWR Tacoma Power

TreasVly Treasure Valley (Idaho Power)

WACM Western Area Power Admin Colorado/Missouri

WALC Western Area Power Admin Lower Colorado

WAUW Western Area Power Admin Upper Missouri

Figure 2.2. TEPPC Topology Diagram for 2020 PC0 Base Case

\subsubsection{Modeling of the BANC BA}

The Sacramento Municipal Utility District (SMUD), Modesto Irrigation District (MID), Roseville Electric, and Redding Electric Utility have formed the Balancing Authority of Northern California (BANC), a Joint Power Authority (JPA) that gives utility ownership to each of the entities. In the past, SMUD served as a Balancing Authority, integrating resource plans ahead of time and maintaining load and resource balance for all four utilities.

A significant amount of effort was spent to correctly model the newly formed Balancing Authority in PLEXOS. The revisions made are the following:

a. The City of Roseville substations (11 buses) and supply were moved into BANC from the PG\&E Valley BA.

b. The City of Redding substations (57 buses) and supply were moved into BANC from the PG\&E Valley BA

c. Interface ownership was cleaned up to avoid the pancaking of hurdle rates for energy flowing from the BPA to the BANC and from the CAISO to the BANC.

d. Moved the third AC intertie line, Captain Jack-Olinda $500 \mathrm{kV}$ line (COTP), in WECC Path 66 (COI) to account for the entitlement of transmission that BANC has from the Pacific Northwest. This line serves as the interface between the Bonneville Power Administration (BPA) BA and BANC. 


\subsubsection{Mid-C BA}

CHPD, DOPD, and GCPD are individual BAs located close together in the Northwest region that only have hydro resources to serve their load. For the purposes of this study, they are combined to form a Mid-C BA. The decision to combine these BAs was a manifestation of both the physical hydrological characteristics of their resources (i.e., run of river) and the 1997 Agreement for the Hourly Coordination of Projects on the Mid-Columbia River [13], commonly referred to as the Hourly Coordination Agreement, for which "Central ") is the control center for the total system of projects that provides instructions to the entities that are intended to optimize the amount of energy from the available water. This results in a more coordinated dispatch.

\subsection{Load, Wind and Solar Data}

This section discusses the methods and assumptions chosen for generating the necessary load, wind, and solar data used for the analyses in this study.

\subsubsection{Load Data}

Since no load data with 1-minute resolution are provided for the study year 2020, these data need to be generated based on selecting reasonable assumptions. The available load data for the study were the following:

1. hourly loads for the year 2020 for the 39 load areas from the TEPPC 2020 PC0 case.

2. actual minute-by-minute load data for the year 2009 for the 32 BAs that are not generation-only BAs.

With this information, the approach used was to impose the minute-to-minute variability of the 2009 load data on to the 2020 hourly load data. The procedures applied to generate the required 1-minute load data for the study year 2020 are the following [4]:

1. Compute a time series of hourly average load data for all 32 BAs in 2009, Load_1h_avg_2009, with 1-minute resolution.

2. Apply the nonlinear interpolation method in MATLAB ${ }^{\circledR}$ to Load_1h_avg_2009 and obtain a new interpolated load series, Load_2009_interpolated, shown in Figure 2.3.

3. Calculate the error between Load_actual_2009 and Load_2009_interpolated, indicating the differences between the actual load and the interpolated load, shown in Figure 2.4.

4. Normalize the error based on the peak load in 2009 for each BA individually and scale the error by multiplying the peak load in 2020, to obtain Error_2020_load. The error for the day 2/29/2020 is taken directly from the error data on the previous day, 2/28/2020.

5. Take the provided hourly load data in 2020 and interpolate the 1-hour resolution data to obtain interpolated load data, Load_2020_interpolated, with 1-minute resolution.

6. Apply the Error_2020_load to Load_2020_interpolated and obtain the desired load curves in 2020, with 1-minute resolution, shown in Figure 2.5.

\footnotetext{
${ }^{1}$ Central means the control center for the total system of Projects which at the time of execution of this Agreement is at Grant facilities in Ephrata, Washington.
} 
This procedure was applied to each of the $32 \mathrm{BAs}$, which generated the 1-minute load curves for the entire year 2020 shown in Figure 2.6. It should be noted that for the BAs having more than one load profile, the same minute-to-minute variability were applied to all load profiles since the 2009 data were available only at the BA level. The peak load in each BA is plotted in Figure 2.7. The names of the BAs corresponding to the BA numbers in the different figures are reported in Table 2-1

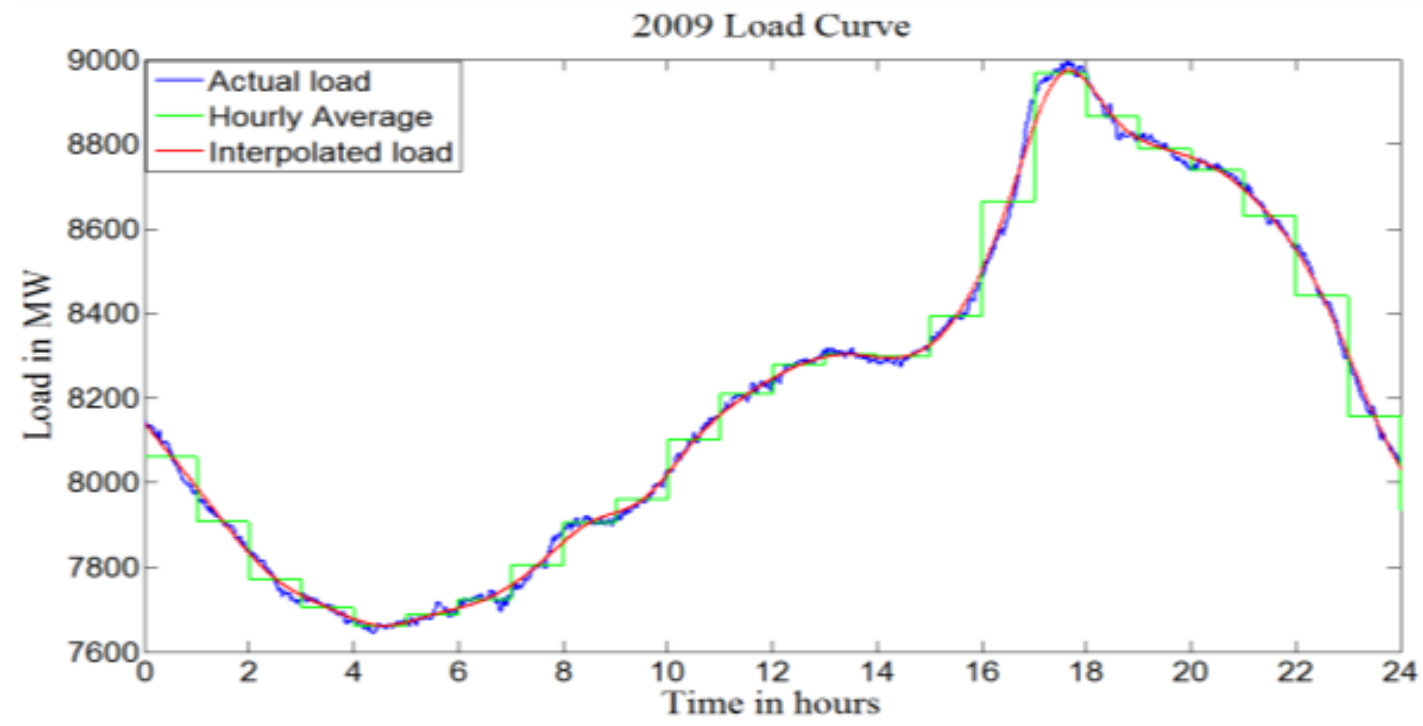

Figure 2.3. Actual Load, Hourly Average and Interpolated Load for 2009

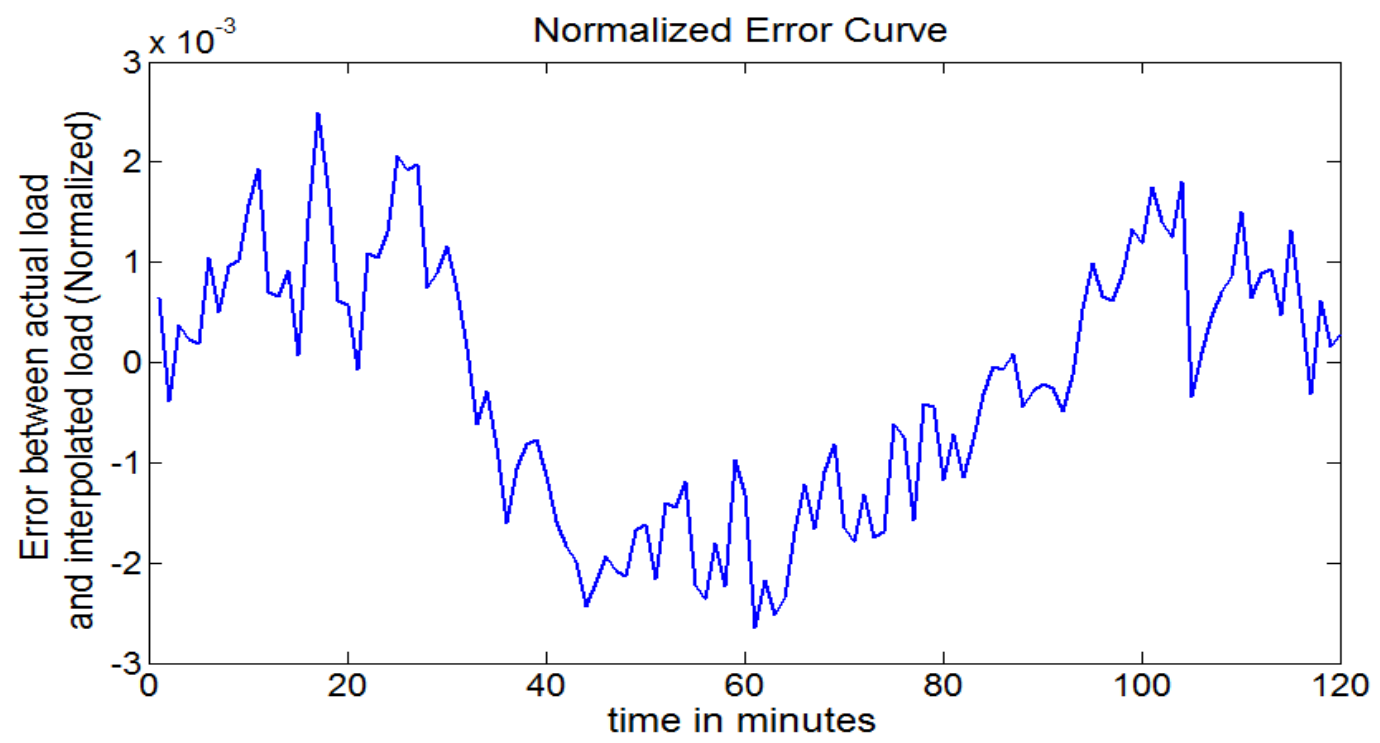

Figure 2.4. Error between Interpolated Load Curve and Actual Load Curve (normalized by peak load) 


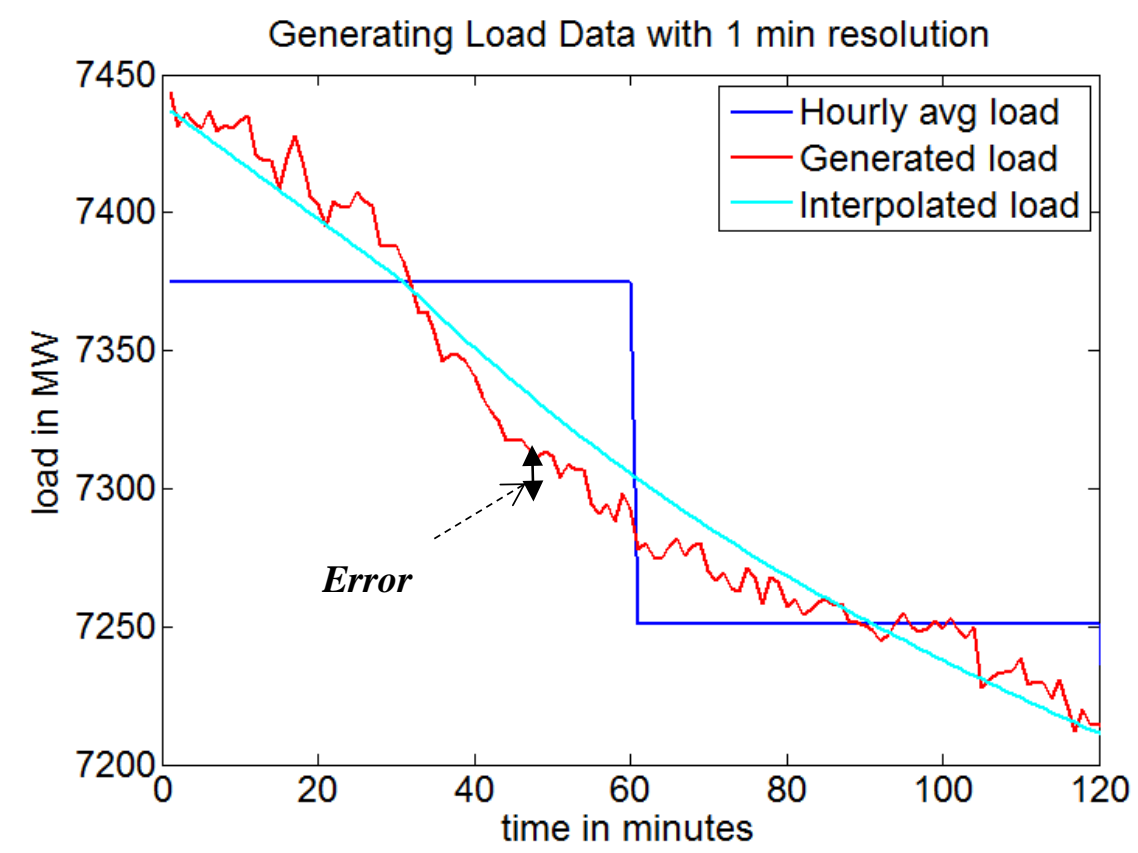

Figure 2.5. Imposing the Load Variance in 2009 to the Interpolated Load in 2020

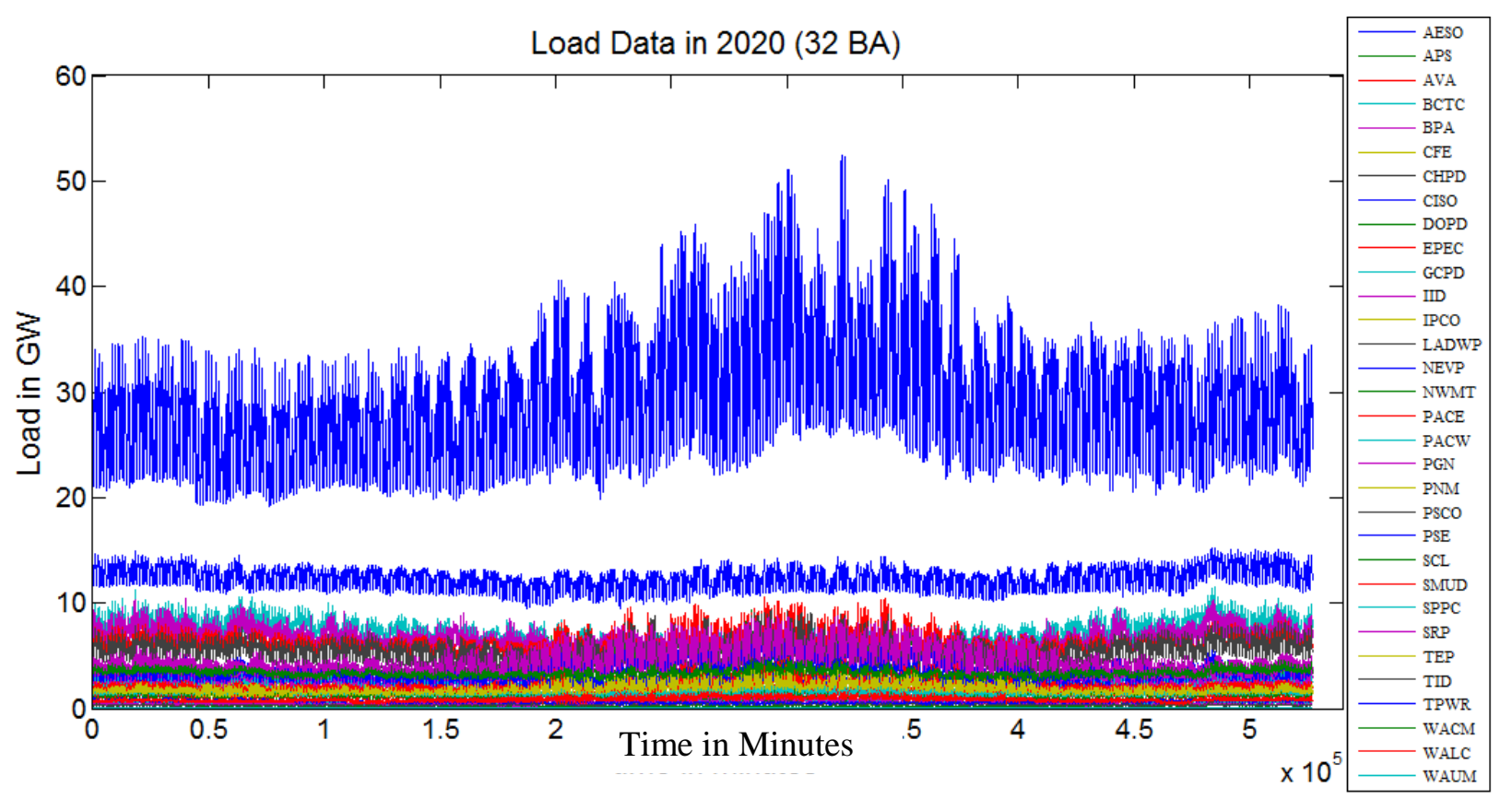

Figure 2.6. Generated Load Data for 2020 


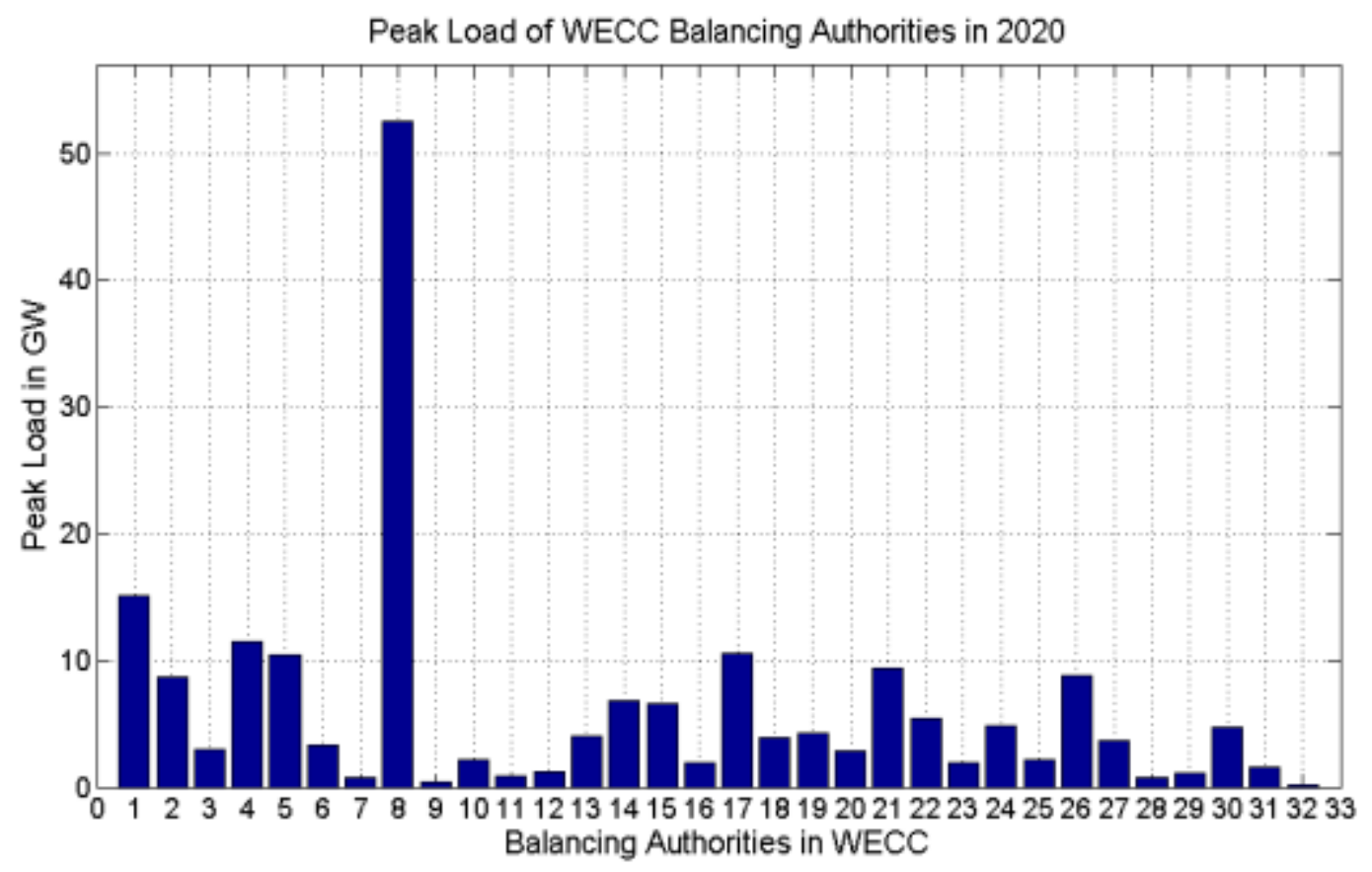

Figure 2.7. Peak Load of Different Balancing Authorities in WECC TEPPC 2020 PC0 Case

Table 2-1. Thirty-Two Balancing Authorities in WECC

\begin{tabular}{|c|c|c|c|c|c|c|c|}
\hline No. & $\begin{array}{c}\text { BA } \\
\text { Name }\end{array}$ & No. & $\begin{array}{c}\text { BA } \\
\text { Name }\end{array}$ & No. & $\begin{array}{c}\text { BA } \\
\text { Name } \\
\end{array}$ & No. & $\begin{array}{c}\text { BA } \\
\text { Name }\end{array}$ \\
\hline 1 & 'AESO' & 9 & 'DOPD' & 17 & 'PACE' & 25 & 'SPPC' \\
\hline 2 & 'APS' & 10 & 'EPEC' & 18 & 'PACW' & 26 & 'SRP' \\
\hline 3 & 'AVA' & 11 & 'GCPD' & 19 & 'PGN' & 27 & 'TEP' \\
\hline 4 & 'BCTC' & 12 & 'IID' & 20 & 'PNM' & 28 & 'TID' \\
\hline 5 & 'BPA' & 13 & 'IPCO' & 21 & 'PSCO' & 29 & 'TPWR' \\
\hline 6 & 'CFE' & 14 & 'LDWP' & 22 & 'PSE' & 30 & 'WACM' \\
\hline 7 & 'CHPD' & 15 & 'NEVP' & 23 & 'SCL' & 31 & 'WALC' \\
\hline 8 & 'CAISO' & 16 & 'NWMT' & 24 & 'BANC' & 32 & 'WAUM' \\
\hline
\end{tabular}

\subsubsection{Wind and Solar Data}

The wind and solar data for 2020 were collected from the $15.5 \%$ renewables case (calculated as a percentage of WECC demand) defined by TEPPC [7]. Time series data for wind and solar production were generated based on 2006 weather models. The TEPPC 2020 PC0 case assumes that all Renewable Portfolio Standards (RPSs) in 2020 are met with the level of the RPSs in 2020 being derived based on assuming a linear progression for those RPSs that have target dates later than 2020. Using this approach yielded a WECC-wide (including BAs in Mexico and Canada) RPS of approximately a 15.5\% renewables penetration. This $15.5 \%$ renewables penetration level was met by wind (8\%), solar (3\%), geothermal (2.4\%), biomass (1.3\%) and small hydro (0.77\%). 
The installed wind capacity for each BA in the original TEPPC PC0 case is shown in Figure 2.8. The installed solar capacity for each BA, which includes both Photovoltaic (PV) and Concentrated Solar Power (CSP) facilities (with 6-hours storage), is shown in Figure 2.9.

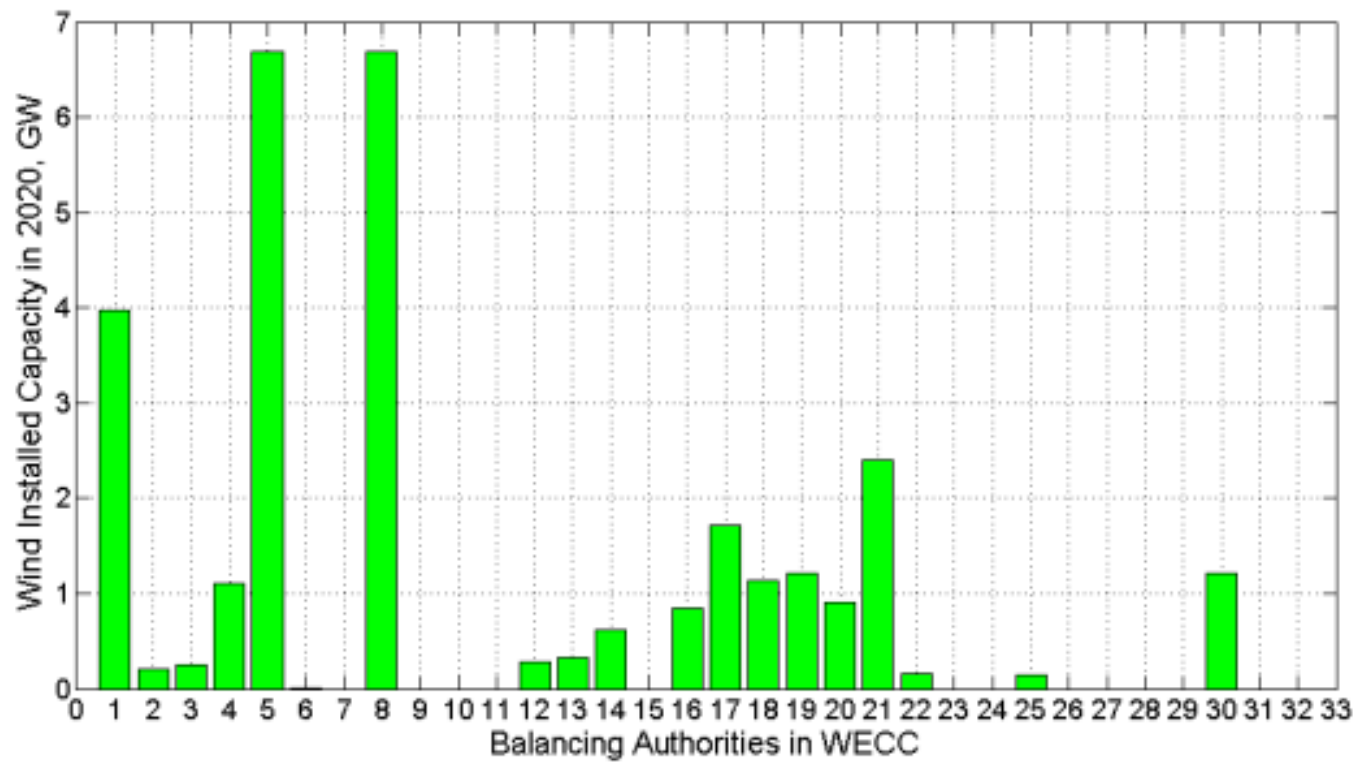

Figure 2.8. Installed Wind Capacities in 2020 for WECC BAs

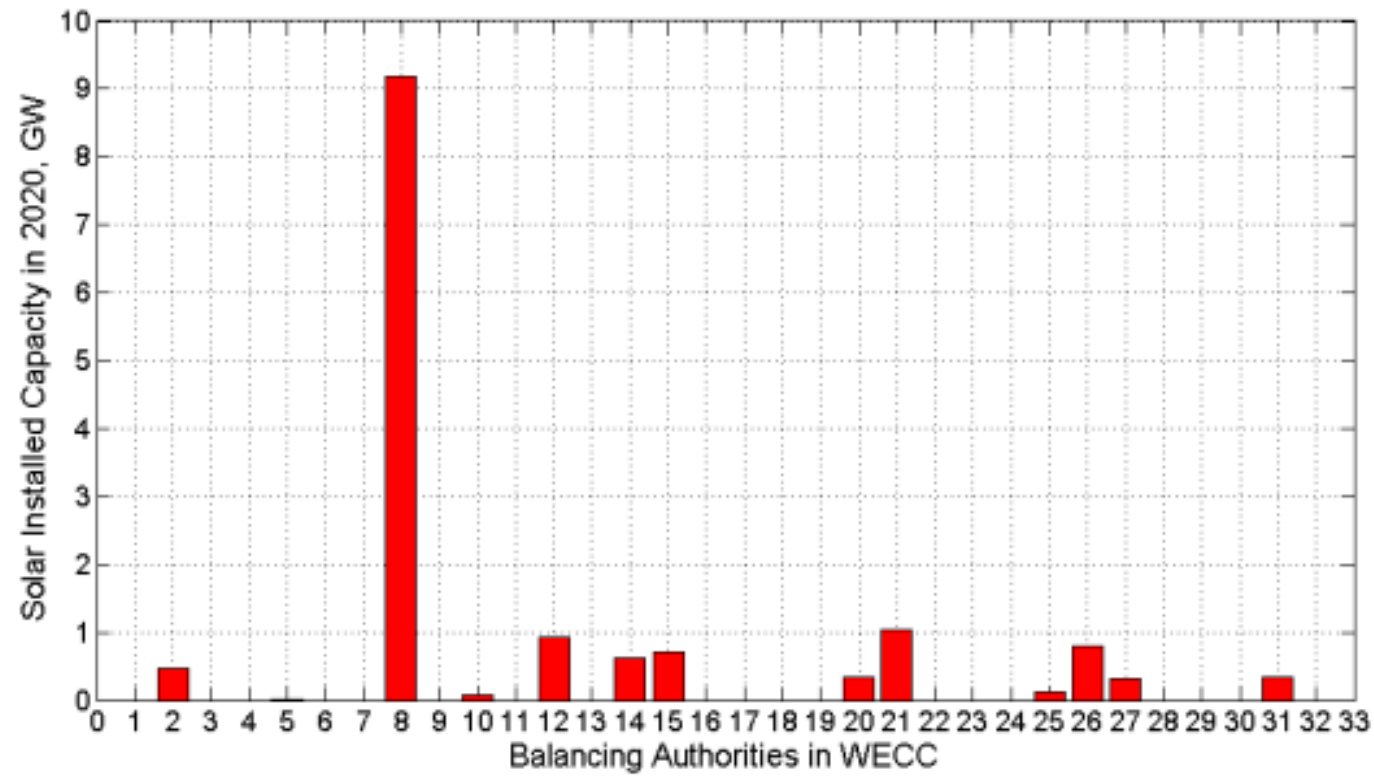

Figure 2.9. Installed Solar Capacities in 2020 for WECC BAs

The wind generation data are based on western wind data sets that were developed by 3Tier [9] and used by NREL. These wind data have a 10-minute resolution; 3Tier, Inc., provided a methodology for deriving 1-minute interpolations. 
Day-ahead forecasts for hourly wind generation are also available from the same data sets. The hourahead forecasts for wind generation are based on a T-31 minute persistence model.

PNNL used and improved upon the wind generation data by disaggregating the wind profiles at the bus level. With this refined data, PNNL was able to generate day-ahead and hour-ahead forecasts for wind at the bus level and more realistically simulate the diversity of wind generation.

The solar generation data were obtained from NREL. These data are based on hourly, satellitederived data from the State University of New York-Clean Power Research and a statistical model that synthesized the subhourly variations [10]. Power production data were developed for multiple solar technologies, including 50-MW fixed photovoltaics, 50-MW one-axis tracking photovoltaics, and 100MW concentrating solar power plants with assumed 6-hour thermal energy storage. These data were developed for 1,488 grid locations that correspond to the Western Renewable Energy Zones.

Day-ahead and hour-ahead forecasts for solar generation were developed by PNNL using a methodology that quantifies forecast-error based on a Clearness Index [4], [11] . A simplified definition of a Clearness Index at any time $\mathrm{T}$ in a day is the ratio between actual solar energy production at time $\mathrm{T}$ divided by the maximum possible solar energy production at time $\mathrm{T}$ in the same day.

Wind and solar generation are treated as fixed schedule generation in PLEXOS and their curtailment is not allowed.

\subsubsection{Changes in Wind Energy Allocation for NWPP BAs}

The wind that was modeled in each BA in the starting data set (TEPPC 2020 PC0 case) was corrected with input from the participants in two steps. First, the existing amount of renewables in each BA was corrected for substation location and electrical size. Second, supplemental wind was added and allocated to each BA to meet Renewable Portfolio Standard (RPS) requirements that are expected during the 10year horizon at the proper substation and expected size. Table 2-2 reports the final installed wind capacities that were modeled for the NWPP EIM study and how they compare with numbers that were used in other studies.

Within the NWPP, there are no wind power plants in BANC, SCL, TPWR, MidC and WAUM. Accordingly none were modeled for these BAs. Wind power plants owned by Glacier Wind are located in its own BA in Montana, separate from the Northwestern Montana (NWMT) BA. The TEPPC data had $40 \mathrm{MW}$ of wind capacity modeled for the NWMT BA at bus number 62071 (Gt Falls). This amount was increased to $250 \mathrm{MW}$ to more accurately reflect the existing Glacier Wind resources.

The detailed changes that were made in this study to the wind power plants data for each BA by substation (bus) are reported in Appendix A. 
Table 2-2. Comparison of NWPP BAs Installed Wind Capacity in Different Studies

\begin{tabular}{cccc}
\hline NWPP BA & $\begin{array}{c}\text { NREL PUC EIM } \\
\text { case (MW) }\end{array}$ & $\begin{array}{c}\text { TEPPC 2020 PCO } \\
(\mathrm{MW})\end{array}$ & $\begin{array}{c}\text { NWPP EIM case } \\
(\mathrm{MW})\end{array}$ \\
\hline AVA & 323 & 246 & 105 \\
BCTC & 0 & 1,105 & 1,381 \\
BPA & 6,693 & 6,694 & 7,089 \\
IPC & 330 & 334 & 800 \\
NWMT & 833 & 842 & 478 \\
PAC & 2,603 & 2,855 & 3,613 \\
PGN & 805 & 1,214 & 870 \\
PSE & 1,067 & 153 & 545 \\
& 12,654 & 13,443 & 14,881
\end{tabular}

\subsection{Changes in Thermal Units Data}

Installed generation capacities in the WECC are organized into 16 categories, which include traditional and renewable generation. Table 2-3 contains a summary of these for the TEPPC 2020 PC0 case.

Table 2-3. Installation Capacity of Different Generation Categories for TEPPC 2020 PC0 Case

\begin{tabular}{lr}
\hline \multicolumn{1}{c}{ Category } & Installed Capacity (MW) \\
\hline Biomass RPS & 2,444 \\
CC & 59,024 \\
Coal & 38,300 \\
Combustion Turbine (CT) & 26,516 \\
DR & 7,450 \\
Geothermal & 5,126 \\
Hydro & 69,358 \\
Internal Combustion (IC) & 770 \\
Negative Bus Load & 528 \\
Nuclear & 9,681 \\
Other Steam & 564 \\
Pumped Storage & 3,787 \\
Pumping Load & 2,514 \\
Solar & 14,888 \\
Steam & 6,376 \\
Wind & 35,949 \\
Grand Total & 283,276 \\
\hline
\end{tabular}


The following sections provide detailed explanations of the changes that were made to the thermal units in the TEPPC 2020 PC0 case.

\subsubsection{Retirements and Addition of New Units}

The list of retirements for existing units was adjusted to reflect the best available data as of December $1^{\text {st }}, 2012$. The changes made are the following:

1. List of retirements from the TEPPC 2022 case

a. Replaced the Boardman coal-fired plant in PGN with a G-Frame combined cycle (CC) plant.

b. Replaced the Reid Gardner 1-3 coal-fired units in NVE with 3 LMS100 gas turbines (GT).

c. Public Service Company of Colorado (PSC) units:

$\circ$ Retired the Arapahoe 3 and 4, Cameo 1 and 2, Cherokee 1-4 and Valmont coal-fired units.

○ Added a $2 \times 1$ CC and 4 LMS100 GT.

2. Retired the Corette coal-fired plant in NWMT.

3. Retired unit 1 of the Centralia coal-fired plant in BPA.

4. Four Corners coal-fired plant in APS:

a. Retired Units 1-3.

b. Arizona Public Service (APS) purchased SCE share of units 4 and 5.

c. SCE replaced the capacity with a 416 MW CC.

5. All non-nuclear California Once-Through Cooling (OTC) units were retired prior to 2020 in the TEPPC 2020 PC0 case. In this study, we returned to service the units with retirement dates later than 2020 and retired the WECC generic replacements for these OTC units in California.

6. Changed Marsh Landing from running $8 \times$ E-Frame gas turbines to $4 \times$ F-Frame gas turbines.

7. Adjusted the LMS100 GT ratings provided by the California Independent System Operator (ISO) from $100 \mathrm{MW}$ to $93 \mathrm{MW}$ along the California coast and $92 \mathrm{MW}$ inland.

\subsubsection{Splitting of CC Units}

In the TEPPC PC0 case, the combined-cycle gas turbine (CCGT) units at a given power plant were lumped together and modeled as one whole plant, rather than as independent units. This means a typical F-Frame CCGT with a $2 \times 1$ or $3 \times 1$ configuration (\# of GTs $\times$ \# of steam turbines) is modeled as one unit with several segments of heat rate. This results in units with a typical rating of 530 or $795 \mathrm{MW}$. With the high minimum rating of 55\% of the maximum rating, this created large inflexible units.

The main cost of committing a CC unit is the startup cost of each turbine. To increase operational flexibility, all F-Frame CCs were split into an equivalent number of $1 \times 1$ CCs based on the number of turbines. This is in line with the actual commitment and dispatch of units seen in the market. This change resulted in splitting 62 CC plants into $1271 \times 1$ units. 


\subsubsection{Startup and Variable O\&M Costs}

The original startup cost of F-Frame CC by turbine varied from $\$ 5,000-\$ 22,000$, with an average of $\$ 15,000$ per turbine. We observed low utilization of CC plants in the output of PLEXOS. To standardize startup cost, we assumed a generic variable operations and maintenance (O\&M) contract for an F-Frame CC that has startup costs of $\$ 15,000$ per turbine with a free start every 36 hours of operation. Assuming 16 hours of operation per day, with a free start every 36 hours, yields 36/16 $=2.25$ starts in 36 hours. Taking into account the free start every 36 hours produces $(2.25-1) / 2.25=55.56 \%$ of $\$ 15,000$ or a maximum startup cost of $\$ 8,333$ per turbine.

Translating the generic F-Frame startup cost into other types of turbines yields the following:

- E-Frame unit: assume the startup cost is 75\% of an F-Frame, or \$6,250 per turbine start

- G-Frame unit: assume the startup cost is $115 \%$ of an F-Frame, or $\$ 9,583$ per turbine start

- H-Frame unit: assume the startup cost is $130 \%$ of an F-Frame, or \$10,5833 per turbine start

- Older gas turbine (GT): assume the startup cost is $\$ 5 / \mathrm{MW}$

- Aero derivative units do not have a startup cost but do incur a startup fuel cost. It is assumed the startup fuel cost is equal to 10 minutes of operation at a heat rate (HR) of $10 \mathrm{MMBtu} / \mathrm{MWh}$, or \$9.17/MW. For example, a 45 MW LM6000 has a startup fuel cost of $\$ 412$.

\subsubsection{Ramp Rates Assumptions}

In an hourly production cost model, hourly ramp rates are typically not a constraint on the system. When modeling a 10-minute market they do become a constraint by limiting a unit's ability to respond to change in net load or contribute to reserves.

When reviewing the original ramp rates for this analysis, some issues were found. Most of the ramp rates were set to the maximum rating divided by 60 minutes (MW/min). For example, a $90 \mathrm{MW}$ quick start unit would have a $1.5 \mathrm{MW} /$ minute ramp rate. Its ability to respond to a quick start (10 minutes) results in a dispatch of only $15 \mathrm{MW}$. By definition a quick start unit is capable of producing $100 \%$ output in 10 minutes.

Generic ramp rates were created to overcome this deficiency as follows:

- $\mathrm{ST}^{1}$-NG: ${ }^{2}$ Ramp Rate: With a minimum of $7 \mathrm{MW} / \mathrm{min}$ and a maximum of $11 \mathrm{MW} / \mathrm{min}$, and values in between being equal to $6.43+0.00571 \times$ Max Rating

- ST-Coal: Ramp Rate: With a minimum of $5 \mathrm{MW} / \mathrm{min}$ and a maximum of $9 \mathrm{MW} / \mathrm{min}$, and values in between being equal to $4.43+0.00571 \times$ Max Rating

- Ramping characteristics of other units are listed in Table 2-4 and Table 2-5.

\footnotetext{
${ }^{1} \mathrm{ST}=$ Steam

${ }^{2} \mathrm{NG}=$ natural gas
} 
Table 2-4. Assumed Ramp Rates for Gas Units

\begin{tabular}{lcc} 
Ramp Rate Types & $\begin{array}{c}\text { Ramp Rate } \\
\text { MW/Min }\end{array}$ & $\begin{array}{c}\text { Full Ramp } \\
\text { (Min) }\end{array}$ \\
GT (Frame-F) & 12 & \\
GT (Quick Start) & 15 & \\
CCGT & 15 & \\
IC & & 5 \\
\hline
\end{tabular}

Table 2-5. Classification of Generic Turbine to Ramp Rate Type

\begin{tabular}{ll}
$\begin{array}{l}\text { Turbine Type } \\
\text { CG }\end{array}$ & $\begin{array}{l}\text { Ramp Rate Type } \\
\text { GT (Frame-F) }\end{array}$ \\
\hline LM & GT (Quick Start) \\
\hline Frame-E & GT (Quick Start) \\
\hline Frame-F & GT (Frame-F) \\
\hline Older GT & GT (Quick Start)
\end{tabular}

\subsubsection{Must-Run Units in the Model}

The following changes were made for must-run units in the model.

First, based on the operating experience of Avista, the Potlatch biomass plant is a base load plant and its output is flat at around 50-60 MW to meet internal needs. So Potlatch 3 was retired and Potlatch 4 was changed to be a must-run unit with $55 \mathrm{MW}$ minimum and maximum capacities without any Equivalent Forced Outage Rate.

Second, while all the nuclear units are must-run units in the original TEPPC 2020 PC0 model, the input data included maintenance schedules. The maintenance schedule of the Columbia Generation Station nuclear power plant in the BPA BA was removed and the plant was dispatched at its maximum capacity of $1160 \mathrm{MW}$ all the time. The other nuclear units in the model have around a 1 month maintenance schedule for refueling except for the Diablo Canyon Unit 2, which has no scheduled maintenance. The San Onofre nuclear power plant, which SCE decided to shutdown in 2013, was also classified as a must- run plant in the model except for when maintenance was scheduled.

Finally, three new must-run CT units were added at Mill Creek $230 \mathrm{kV}$ for NWMT; the maximum and minimum ratings for every unit are $50 \mathrm{MW}$ and $27.5 \mathrm{MW}$ respectively. The average heat rate for these units is 10.2 MMBtu/MWh.

\subsubsection{Natural Gas Price Forecast}

The natural gas price forecast for the NWPP EIM analysis is composed of two primary components: natural gas prices at various trading hubs and the costs to move the gas from the hubs to the burner tip. The natural gas price forecast used for the NWPP EIM analysis was developed by forecasting nominal 2020 \$ monthly natural gas prices at Henry Hub, Louisiana and nominal 2020\$ monthly price bases differentials at various Western U.S. and Canada gas trading hubs. The price basis differentials were added to the Henry Hub prices to derive natural gas prices for the various gas trading hubs. Subsequently, natural gas prices at these hubs and transportation costs were assigned to various areas in WECC so that burner tip prices could be calculated. 


\subsubsection{Forecast of Natural Gas Trading Hub Prices}

The natural gas price forecast used was an existing one developed by BPA in February 2012 to analyze the merits of signing a long-term contract with one of its Direct Service Industries Customers (Alcoa). BPA's gas analysts make their gas price forecasts in nominal dollars, which are informed by reviewing proprietary consultant price forecasts (which are made in nominal dollars). This approach differs from the approach used by some entities that start with a price forecast made in real dollars and apply annual price escalators through time to derive future nominal prices.

BPA's forecasting approach was adopted by the NWPP technical analysis team because, unlike studies that rely on values derived from historical data, it is forward looking and conducive to reflecting the major impacts that relatively recent and foreseen ongoing change in supply, demand, and infrastructure might have on the level of natural gas prices, gas price basis differentials between the various hubs, and the monthly gas price differentials at a given hub. Such major recent and ongoing changes are largely due to substantial exploitation of large shale deposits [natural gas deposits and associated gas from oil and Natural Gas Liquids (NGL) production] at diverse locations and major natural gas pipeline (i.e., Ruby) and storage expansions that are largely not reflected in historical data.

The monthly Henry Hub natural gas prices and monthly trading hub price differentials used in the NWPP EIM analyses are reported in Table 2-6. The average annual nominal natural gas price forecasted at Henry Hub for 2020 was $\$ 5.62 / \mathrm{MMBtu}$. The forecast of monthly natural gas prices in 2020 by trading hub are reported in Table 2-7 and plotted in Figure 2.10

Table 2-6 Nominal 2020\$ Natural Gas Price Forecast and Natural Gas Trading Hub Basis Price Differentials (\$/MMBtu)

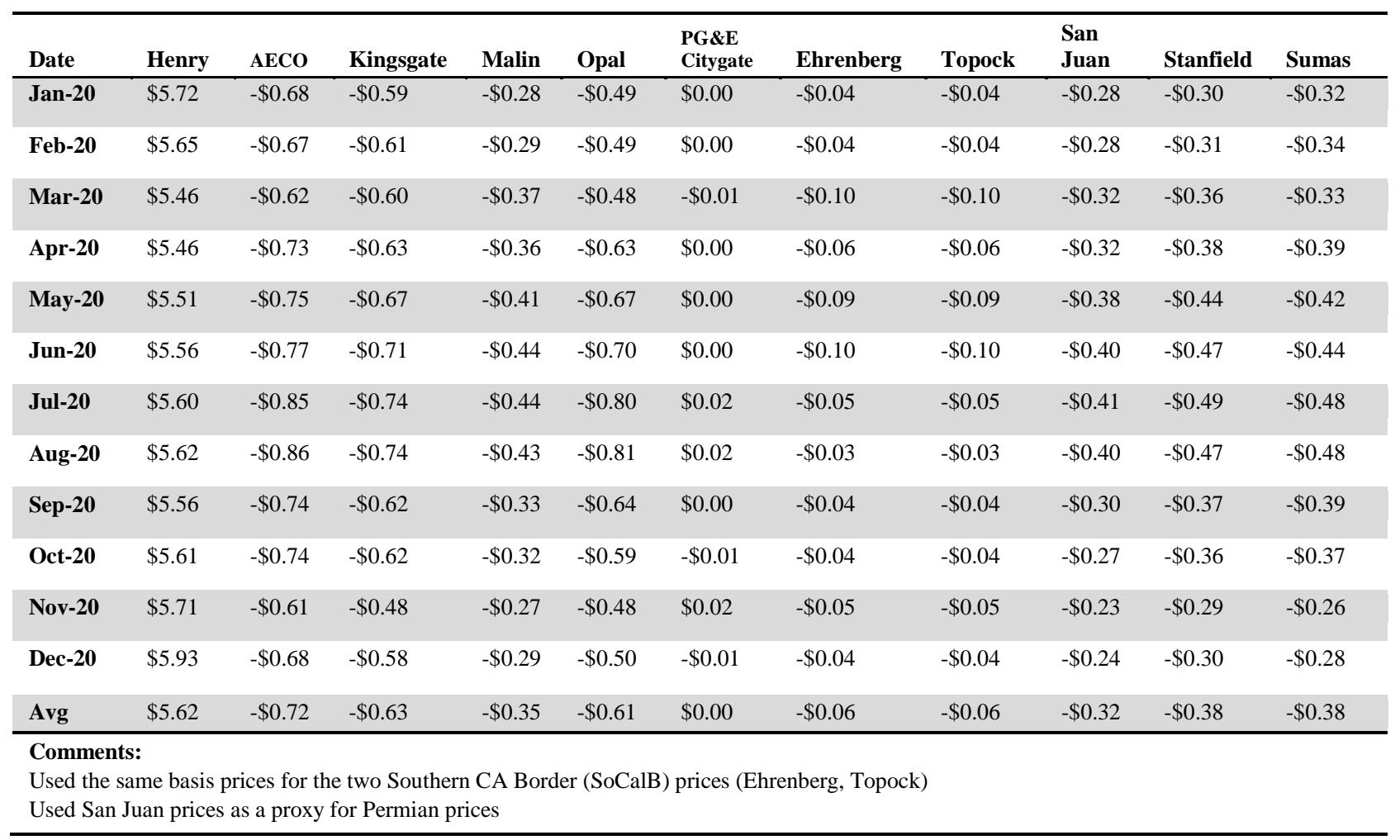


Table 2-7. Nominal 2020\$ Natural Gas Price Forecast by Natural Gas Trading Hub (\$/MMBtu)

\begin{tabular}{|c|c|c|c|c|c|c|c|c|c|c|c|}
\hline Date & Henry & $\underline{\text { AECO }}$ & $\underline{\text { Kingsgate }}$ & Malin & Opal & $\begin{array}{l}\text { PG\&E } \\
\text { Citygate } \\
\end{array}$ & Ehrenberg & Topock & 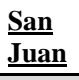 & Stanfield & $\underline{\text { Sumas }}$ \\
\hline Jan-20 & $\$ 5.72$ & $\$ 5.04$ & $\$ 5.13$ & $\$ 5.44$ & $\$ 5.23$ & $\$ 5.72$ & $\$ 5.68$ & $\$ 5.68$ & $\$ 5.44$ & $\$ 5.41$ & $\$ 5.39$ \\
\hline Feb-20 & $\$ 5.65$ & $\$ 4.97$ & $\$ 5.03$ & $\$ 5.36$ & $\$ 5.16$ & $\$ 5.65$ & $\$ 5.61$ & $\$ 5.61$ & $\$ 5.37$ & $\$ 5.33$ & $\$ 5.30$ \\
\hline Mar-20 & $\$ 5.46$ & $\$ 4.84$ & $\$ 4.86$ & $\$ 5.09$ & $\$ 4.98$ & $\$ 5.44$ & $\$ 5.36$ & $\$ 5.36$ & $\$ 5.14$ & $\$ 5.10$ & $\$ 5.13$ \\
\hline Apr-20 & $\$ 5.46$ & $\$ 4.73$ & $\$ 4.83$ & $\$ 5.10$ & $\$ 4.83$ & $\$ 5.47$ & $\$ 5.40$ & $\$ 5.40$ & $\$ 5.14$ & $\$ 5.08$ & $\$ 5.08$ \\
\hline May-20 & $\$ 5.51$ & $\$ 4.76$ & $\$ 4.84$ & $\$ 5.10$ & $\$ 4.84$ & $\$ 5.51$ & $\$ 5.42$ & $\$ 5.42$ & $\$ 5.13$ & $\$ 5.07$ & $\$ 5.09$ \\
\hline Jun-20 & $\$ 5.56$ & $\$ 4.79$ & $\$ 4.85$ & $\$ 5.12$ & $\$ 4.86$ & $\$ 5.56$ & $\$ 5.46$ & $\$ 5.46$ & $\$ 5.16$ & $\$ 5.09$ & $\$ 5.12$ \\
\hline Jul-20 & $\$ 5.60$ & $\$ 4.75$ & $\$ 4.86$ & $\$ 5.16$ & $\$ 4.80$ & $\$ 5.61$ & $\$ 5.55$ & $\$ 5.55$ & $\$ 5.19$ & $\$ 5.10$ & $\$ 5.12$ \\
\hline Aug-20 & $\$ 5.62$ & $\$ 4.76$ & $\$ 4.88$ & $\$ 5.19$ & $\$ 4.81$ & $\$ 5.64$ & $\$ 5.59$ & $\$ 5.59$ & $\$ 5.22$ & $\$ 5.15$ & $\$ 5.14$ \\
\hline Sep-20 & $\$ 5.56$ & $\$ 4.82$ & $\$ 4.94$ & $\$ 5.23$ & $\$ 4.92$ & $\$ 5.56$ & $\$ 5.52$ & $\$ 5.52$ & $\$ 5.26$ & $\$ 5.19$ & $\$ 5.16$ \\
\hline Oct-20 & $\$ 5.61$ & $\$ 4.87$ & $\$ 4.99$ & $\$ 5.28$ & $\$ 5.02$ & $\$ 5.60$ & $\$ 5.57$ & $\$ 5.57$ & $\$ 5.34$ & $\$ 5.25$ & $\$ 5.23$ \\
\hline Nov-20 & $\$ 5.71$ & $\$ 5.10$ & $\$ 5.23$ & $\$ 5.44$ & $\$ 5.23$ & $\$ 5.73$ & $\$ 5.66$ & $\$ 5.66$ & $\$ 5.48$ & $\$ 5.42$ & $\$ 5.45$ \\
\hline Dec-20 & $\$ 5.93$ & $\$ 5.25$ & $\$ 5.35$ & $\$ 5.64$ & $\$ 5.43$ & $\$ 5.93$ & $\$ 5.89$ & $\$ 5.89$ & $\$ 5.69$ & $\$ 5.63$ & $\$ 5.65$ \\
\hline Avg & $\$ 5.62$ & $\$ 4.89$ & $\$ 4.98$ & $\$ 5.26$ & $\$ 5.01$ & $\$ 5.62$ & $\$ 5.56$ & $\$ 5.56$ & $\$ 5.30$ & $\$ 5.24$ & $\$ 5.24$ \\
\hline $\begin{array}{l}\text { Commen } \\
\text { Used the } \\
\text { Used San }\end{array}$ & \multicolumn{10}{|c|}{ Comments: } & \\
\hline
\end{tabular}

Some additional monthly natural gas prices were derived from the information reported in Table 2-7. SoCal Citygate prices were derived from the Southern California Border (SoCalB) hub (Ehrenberg and Topock) prices by adding a transportation fee of $\$ 0.11042 / \mathrm{MMBtu}$ that was assumed to be charged on $75 \%$ of the gas volume and adjusting for a shrinkage factor of 0.00379 . Also, some of the available hub natural gas prices (i.e., AECO and Kingsgate, Opal and Stanfield, Opal and SoCalB) were averaged for certain areas of WECC where no trading hub prices are reported and readily available forecasted San Juan prices were used in lieu of Permian prices, which weren't readily available and have historically been similar to San Juan prices. 


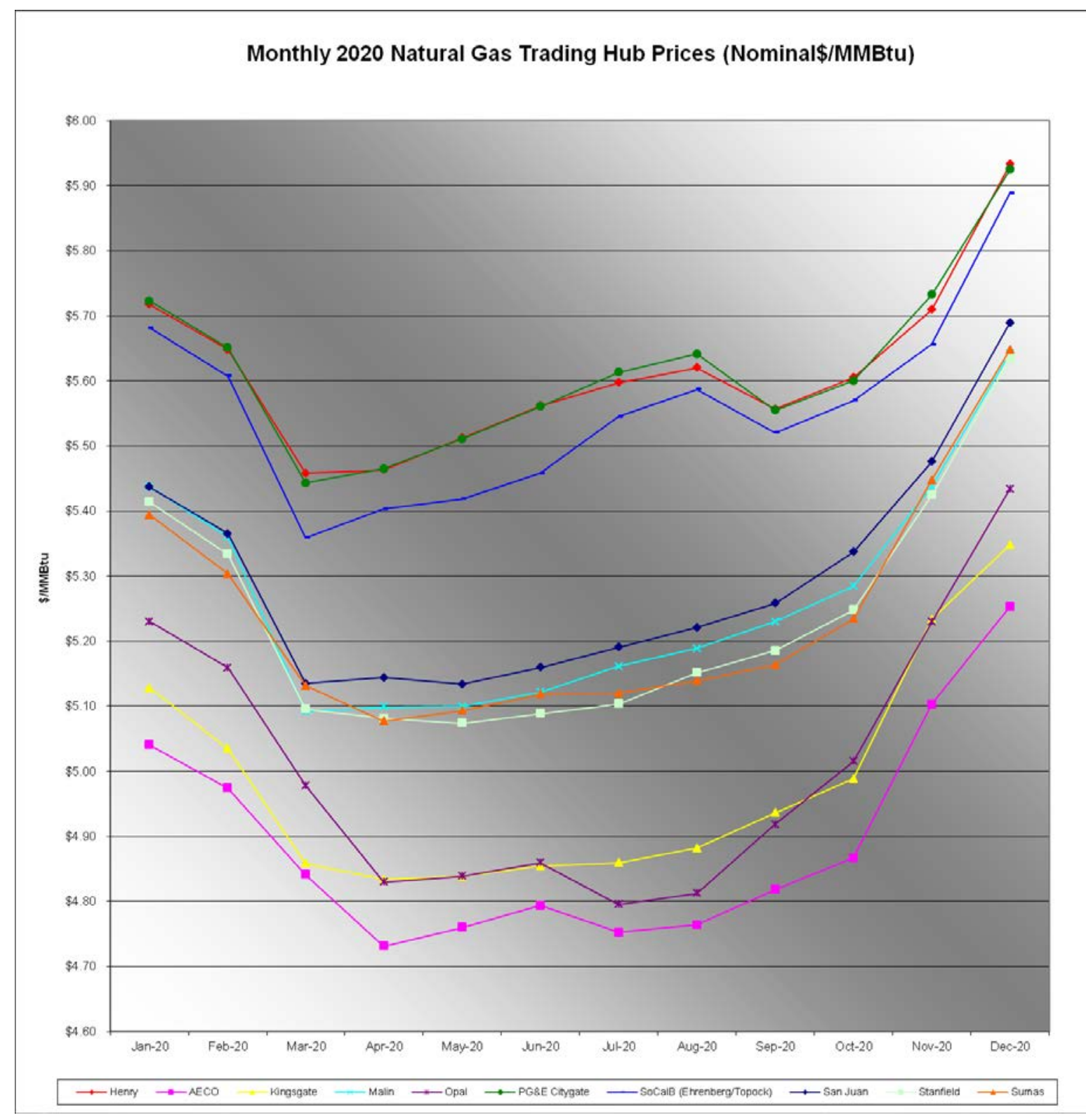

Figure 2.10. Monthly 2020 Natural Gas Trading Hub Prices (Nominal\$/MMBtu)

\subsubsection{Forecast of Burner Tip Prices}

Burner tip prices are composed of the hub natural gas price, local transportation charges, scheduling and exit fees, and taxes. A list of the natural gas hub source/sources, local transportation charges, exit and scheduling fees, and taxes used to compute burner tip prices for each WECC Load Area are reported in Table 2-8.

Some of the gas-fired resources located in these load areas purchase gas from different gas hubs than those generally assigned to a given load area. A list of these resources is provided in Table 2-9. The nominal 2020\$ natural gas burner tip prices (\$MMBtu) by location are reported in Table 2-10. 
Table 2-8. Source Gas Hub, Transport Charges, and Final Exit/Scheduling Fees for Each Load Area

\begin{tabular}{|c|c|c|c|c|c|c|}
\hline \multirow[b]{2}{*}{ Area } & \multirow[b]{2}{*}{ Load Area } & \multirow[b]{2}{*}{ Gas Hub } & \multirow{2}{*}{$\begin{array}{c}\text { Transport } \\
\text { Charges } \\
\text { Fees }(\$ / M M B t u) \\
\end{array}$} & \multicolumn{3}{|c|}{ Final Exit/Scheduling Fees And Taxes } \\
\hline & & & & $\begin{array}{l}\text { Exit Fees } \\
(\$ / M M B t u)\end{array}$ & $\begin{array}{c}\text { Scheduling Fees } \\
(\$ / M M B t u)\end{array}$ & Taxes \\
\hline Canada & AESO & AECO \& Kingsgate (50/50) & 0.15 & 0.05 & 0.05 & $0 \%$ \\
\hline Canada & ВСТС & Sumas & 0.10 & 0.05 & 0.05 & $0 \%$ \\
\hline NW & AVA & Kingsgate & 0.10 & 0.05 & 0.05 & $0 \%$ \\
\hline NW & BPA & Stanfield & 0.00 & 0.05 & 0.05 & $0 \%$ \\
\hline NW & CHPD & Stanfield & 0.00 & 0.05 & 0.05 & $0 \%$ \\
\hline NW & DOPD & Stanfield & 0.00 & 0.05 & 0.05 & $0 \%$ \\
\hline NW & GCPD & Stanfield & 0.00 & 0.05 & 0.05 & $0 \%$ \\
\hline NW & TPWR & Sumas & 0.10 & 0.05 & 0.05 & $0 \%$ \\
\hline NW & SCL & Sumas & 0.10 & 0.05 & 0.05 & $0 \%$ \\
\hline NW & PSE & Sumas & 0.10 & 0.05 & 0.05 & $0 \%$ \\
\hline NW & PGN & Sumas & 0.10 & 0.05 & 0.05 & $0 \%$ \\
\hline NW & FAR EAST & Opal \& Stanfield (50/50) & 0.00 & 0.05 & 0.05 & $0 \%$ \\
\hline NW & MAGIC VLY & Opal \& Stanfield (50/50) & 0.00 & 0.05 & 0.05 & $0 \%$ \\
\hline NW & TREAS VLY & Opal \& Stanfield (50/50) & 0.00 & 0.05 & 0.05 & $0 \%$ \\
\hline NW & PACE_ID & Opal \& Stanfield (50/50) & 0.00 & 0.05 & 0.05 & $0 \%$ \\
\hline NW & PACE_UT & Opal \& SoCalB (50/50) & 0.20 & 0.05 & 0.05 & $0 \%$ \\
\hline NW & PACE_WY & Opal \& Stanfield (50/50) & 0.00 & 0.05 & 0.05 & $0 \%$ \\
\hline NW & PACW & Malin & 0.00 & 0.05 & 0.05 & $0 \%$ \\
\hline NW & SPP & Malin & 0.45 & 0.05 & 0.05 & $0 \%$ \\
\hline NW & NWMT & Opal & 0.45 & 0.05 & 0.05 & $0 \%$ \\
\hline NW & WAUW & Opal & 0.45 & 0.05 & 0.05 & $0 \%$ \\
\hline CA & LDWP & SoCal Citygate & 0.24 & 0.05 & 0.05 & $0 \%$ \\
\hline CA & SMUD & PG\&E Citygate & 0.34 & 0.05 & 0.05 & $0 \%$ \\
\hline CA & TIDC & PG\&E Citygate & 0.34 & 0.05 & 0.05 & $0 \%$ \\
\hline CAISO & PG\&E_BAY & PG\&E Citygate & 0.34 & 0.05 & 0.05 & $0 \%$ \\
\hline CAISO & PG\&E_VLY & PG\&E Citygate & 0.34 & 0.05 & 0.05 & $0 \%$ \\
\hline CAISO & SCE & SoCal Citygate & 0.22 & 0.05 & 0.05 & $0 \%$ \\
\hline CAISO & SDGE & SoCal Citygate & 0.22 & 0.05 & 0.05 & $0 \%$ \\
\hline MEX & CFE & SoCal Citygate & 0.22 & 0.05 & 0.05 & $0 \%$ \\
\hline $\mathrm{RM}$ & PSC & San Juan & 0.20 & 0.05 & 0.05 & $0 \%$ \\
\hline $\mathrm{RM}$ & WACM & San Juan & 0.20 & 0.05 & 0.05 & $0 \%$ \\
\hline SW & APS & SoCal Border & 0.00 & 0.05 & 0.05 & $0 \%$ \\
\hline SW & EPE & San Juan & 0.10 & 0.05 & 0.05 & $0 \%$ \\
\hline SW & IID & SoCal Border & 0.00 & 0.05 & 0.05 & $0 \%$ \\
\hline SW & NEVP & SoCal Border & 0.00 & 0.05 & 0.05 & $0 \%$ \\
\hline SW & PNM & San Juan & 0.10 & 0.05 & 0.05 & $0 \%$ \\
\hline SW & SRP & SoCal Border & 0.00 & 0.05 & 0.05 & $0 \%$ \\
\hline SW & TEP & SoCal Border & 0.00 & 0.05 & 0.05 & $0 \%$ \\
\hline SW & WALC & SoCal Border & 0.00 & 0.05 & 0.05 & $0 \%$ \\
\hline
\end{tabular}


Table 2-9. Gas-Fired Plant Exceptions List

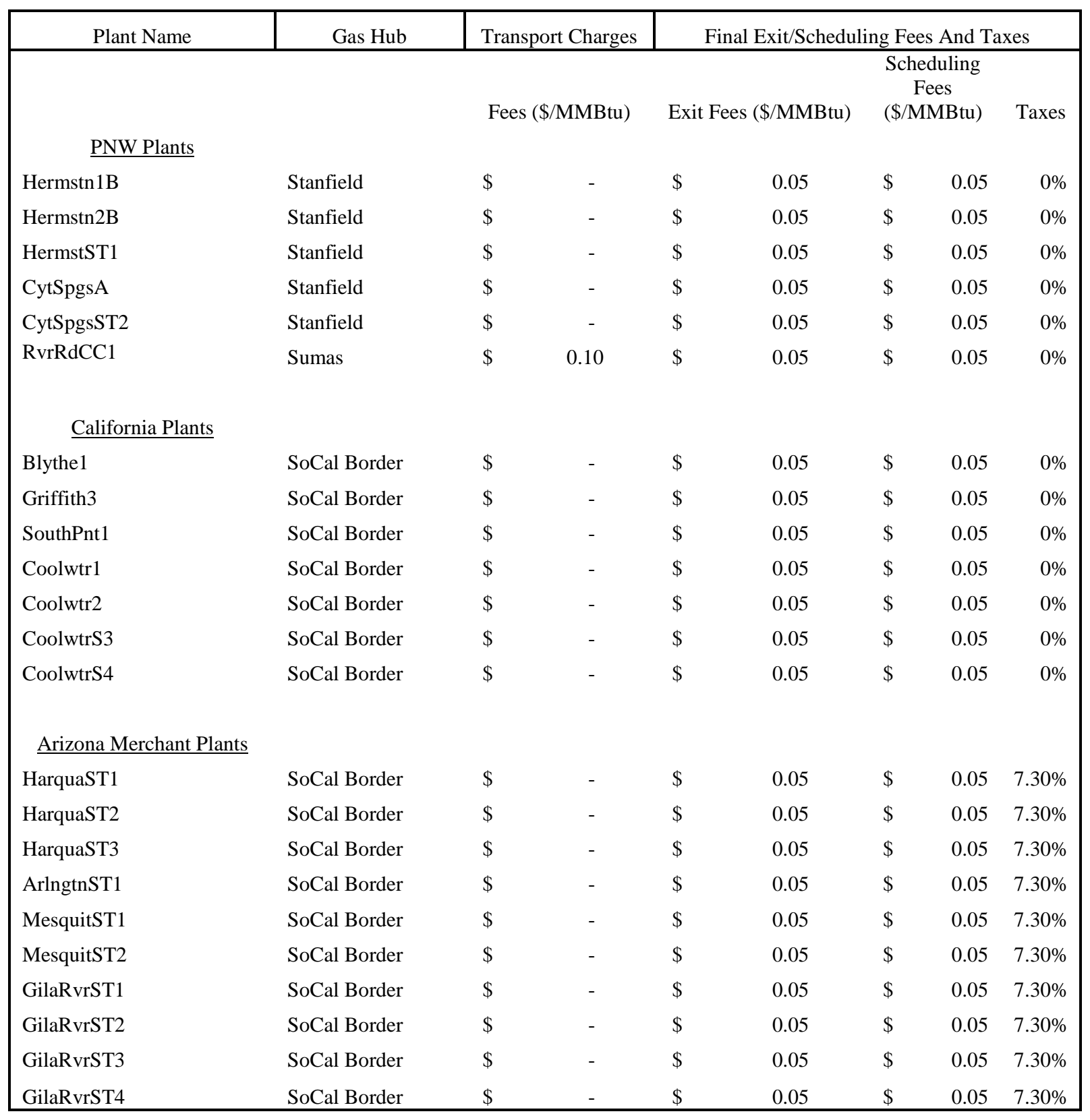


Table 2-10. Nominal 2020\$ Natural Gas Burner Tip Prices by Location (\$/MMBtu)

\begin{tabular}{|c|c|c|c|c|c|c|c|c|c|c|c|c|}
\hline Date & BC & AESO & $\begin{array}{c}\text { West } \\
\text { Cascades } \\
\end{array}$ & Stanfield & AVA & IPC & PACE & PACW & SPP & $\frac{\text { NWMT/ }}{\text { WAUM }}$ & $\frac{\text { PSC \& WACM }}{\text { in CO }}$ & $\frac{\text { WACM }}{\text { WY }}$ \\
\hline Jan-20 & $\$ 5.59$ & $\$ 5.33$ & $\$ 5.64$ & $\$ 5.51$ & $\$ 5.33$ & $\$ 5.42$ & $\$ 5.76$ & $\$ 5.54$ & $\$ 5.99$ & $\$ 5.78$ & $\$ 5.74$ & $\$ 5.64$ \\
\hline Feb-20 & $\$ 5.50$ & $\$ 5.26$ & $\$ 5.55$ & $\$ 5.43$ & $\$ 5.24$ & $\$ 5.35$ & $\$ 5.68$ & $\$ 5.46$ & $\$ 5.91$ & $\$ 5.71$ & $\$ 5.67$ & $\$ 5.57$ \\
\hline Mar-20 & $\$ 5.33$ & $\$ 5.10$ & $\$ 5.38$ & $\$ 5.20$ & $\$ 5.06$ & $\$ 5.14$ & $\$ 5.47$ & $\$ 5.19$ & $\$ 5.64$ & $\$ 5.53$ & $\$ 5.44$ & $\$ 5.34$ \\
\hline Apr-20 & $\$ 5.28$ & $\$ 5.03$ & $\$ 5.33$ & $\$ 5.18$ & $\$ 5.03$ & $\$ 5.06$ & $\$ 5.42$ & $\$ 5.20$ & $\$ 5.65$ & $\$ 5.38$ & $\$ 5.44$ & $\$ 5.34$ \\
\hline Мay-20 & $\$ 5.29$ & $\$ 5.05$ & $\$ 5.34$ & $\$ 5.17$ & $\$ 5.04$ & $\$ 5.06$ & $\$ 5.43$ & $\$ 5.20$ & $\$ 5.65$ & $\$ 5.39$ & $\$ 5.43$ & $\$ 5.33$ \\
\hline Jun-20 & $\$ 5.32$ & $\$ 5.07$ & $\$ 5.37$ & $\$ 5.19$ & $\$ 5.05$ & $\$ 5.07$ & $\$ 5.46$ & $\$ 5.22$ & $\$ 5.67$ & $\$ 5.41$ & $\$ 5.46$ & $\$ 5.36$ \\
\hline Jul-20 & $\$ 5.32$ & $\$ 5.06$ & $\$ 5.37$ & $\$ 5.20$ & $\$ 5.06$ & $\$ 5.05$ & $\$ 5.47$ & $\$ 5.26$ & $\$ 5.71$ & $\$ 5.35$ & $\$ 5.49$ & $\$ 5.39$ \\
\hline Aug-20 & $\$ 5.34$ & $\$ 5.07$ & $\$ 5.39$ & $\$ 5.25$ & $\$ 5.08$ & $\$ 5.08$ & $\$ 5.50$ & $\$ 5.29$ & $\$ 5.74$ & $\$ 5.36$ & $\$ 5.52$ & $\$ 5.42$ \\
\hline Sep-20 & $\$ 5.36$ & $\$ 5.13$ & $\$ 5.41$ & $\$ 5.29$ & $\$ 5.14$ & $\$ 5.15$ & $\$ 5.52$ & $\$ 5.33$ & $\$ 5.78$ & $\$ 5.47$ & $\$ 5.56$ & $\$ 5.46$ \\
\hline Oct-20 & $\$ 5.43$ & $\$ 5.18$ & $\$ 5.48$ & $\$ 5.35$ & $\$ 5.19$ & $\$ 5.23$ & $\$ 5.59$ & $\$ 5.39$ & $\$ 5.84$ & $\$ 5.57$ & $\$ 5.64$ & $\$ 5.54$ \\
\hline Nov-20 & $\$ 5.65$ & $\$ 5.42$ & $\$ 5.70$ & $\$ 5.53$ & $\$ 5.43$ & $\$ 5.43$ & $\$ 5.74$ & $\$ 5.54$ & $\$ 5.99$ & $\$ 5.78$ & $\$ 5.78$ & $\$ 5.68$ \\
\hline Dec-20 & $\$ 5.85$ & $\$ 5.55$ & $\$ 5.90$ & $\$ 5.73$ & $\$ 5.55$ & $\$ 5.63$ & $\$ 5.96$ & $\$ 5.74$ & $\$ 6.19$ & $\$ 5.98$ & $\$ 5.99$ & $\$ 5.89$ \\
\hline Avg & $\$ 5.44$ & $\$ 5.19$ & $\$ 5.49$ & $\$ 5.34$ & $\$ 5.18$ & $\$ 5.22$ & $\$ 5.58$ & $\$ 5.36$ & $\$ 5.81$ & $\$ 5.56$ & $\$ 5.60$ & $\$ 5.50$ \\
\hline Date & \multicolumn{2}{|c|}{ PNM/EPE } & $\underline{\mathbf{A Z}}$ & \multicolumn{2}{|c|}{ AZ Merchant } & NEVP & \multicolumn{3}{|c|}{$\underline{\text { SCE }}$} & SDGE & LADWP & PG\&E \\
\hline Jan-20 & & $\$ 5.64$ & $\$ 5.78$ & & $\$ 6.20$ & $\$ 5.78$ & \multicolumn{2}{|c|}{$\$ 5.78$} & $\$ 6.11$ & $\$ 6.11$ & $\$ 6.12$ & $\$ 6.16$ \\
\hline Feb-20 & & $\$ 5.57$ & $\$ 5.71$ & & $\$ 6.12$ & $\$ 5.71$ & \multicolumn{2}{|c|}{$\$ 5.71$} & $\$ 6.03$ & $\$ 6.03$ & $\$ 6.05$ & $\$ 6.09$ \\
\hline Mar-20 & & $\$ 5.34$ & $\$ 5.46$ & & $\$ 5.86$ & $\$ 5.46$ & \multicolumn{2}{|c|}{$\$ 5.46$} & $\$ 5.78$ & $\$ 5.78$ & $\$ 5.80$ & $\$ 5.88$ \\
\hline Apr-20 & & $\$ 5.34$ & $\$ 5.50$ & & $\$ 5.91$ & $\$ 5.50$ & \multicolumn{2}{|c|}{$\$ 5.50$} & $\$ 5.83$ & $\$ 5.83$ & $\$ 5.84$ & $\$ 5.90$ \\
\hline May-20 & & $\$ 5.33$ & $\$ 5.52$ & & $\$ 5.92$ & $\$ 5.52$ & \multicolumn{2}{|c|}{$\$ 5.52$} & $\$ 5.84$ & $\$ 5.84$ & $\$ 5.86$ & $\$ 5.95$ \\
\hline Jun-20 & & $\$ 5.36$ & $\$ 5.56$ & & $\$ 5.96$ & $\$ 5.56$ & \multicolumn{2}{|c|}{$\$ 5.56$} & $\$ 5.88$ & $\$ 5.88$ & $\$ 5.90$ & $\$ 6.00$ \\
\hline Jul-20 & & $\$ 5.39$ & $\$ 5.65$ & & $\$ 6.06$ & $\$ 5.65$ & \multicolumn{2}{|c|}{$\$ 5.65$} & $\$ 5.97$ & $\$ 5.97$ & $\$ 5.99$ & $\$ 6.05$ \\
\hline Aug-20 & & $\$ 5.42$ & $\$ 5.69$ & & $\$ 6.10$ & $\$ 5.69$ & \multicolumn{2}{|c|}{$\$ 5.69$} & $\$ 6.01$ & $\$ 6.01$ & $\$ 6.03$ & $\$ 6.08$ \\
\hline Sep-20 & & $\$ 5.46$ & $\$ 5.62$ & & $\$ 6.03$ & $\$ 5.62$ & \multicolumn{2}{|c|}{$\$ 5.62$} & $\$ 5.95$ & $\$ 5.95$ & $\$ 5.96$ & $\$ 5.99$ \\
\hline Oct-20 & & $\$ 5.54$ & $\$ 5.67$ & & $\$ 6.08$ & $\$ 5.67$ & \multicolumn{2}{|c|}{$\$ 5.67$} & $\$ 5.99$ & $\$ 5.99$ & $\$ 6.01$ & $\$ 6.04$ \\
\hline Nov-20 & & $\$ 5.68$ & $\$ 5.76$ & & $\$ 6.18$ & $\$ 5.76$ & \multicolumn{2}{|c|}{$\$ 5.76$} & $\$ 6.08$ & $\$ 6.08$ & $\$ 6.10$ & $\$ 6.17$ \\
\hline Dec-20 & & $\$ 5.89$ & $\$ 5.99$ & & $\$ 6.43$ & $\$ 5.99$ & \multicolumn{2}{|c|}{$\$ 5.99$} & $\$ 6.31$ & $\$ 6.31$ & $\$ 6.33$ & $\$ 6.36$ \\
\hline Avg & & $\$ 5.50$ & $\$ 5.66$ & & $\$ 6.07$ & $\$ 5.66$ & \multicolumn{2}{|c|}{$\$ 5.66$} & $\$ 5.98$ & $\$ 5.98$ & $\$ 6.00$ & $\$ 6.05$ \\
\hline
\end{tabular}




\subsubsection{Development of High and Low Natural Gas Trading Hub Price Cases}

High and low natural gas price cases were developed to evaluate the impact that natural gas prices might have on EIM benefits. These prices were developed from a probability distribution of simulated annual average nominal 2020\$ Henry Hub natural gas prices that was done in February 2012 while analyzing the merits of signing a long-term contract with Alcoa. Natural gas prices at the $20^{\text {th }}$ percentile and $80^{\text {th }}$ percentile of the probability distribution were considered to be reasonable approximations of how low and high the general level of natural gas prices might be by 2020. The selection criterion focused on what the general level of natural gas price might be as opposed to what the natural gas price risk might be in a given year (2020). The low annual average Henry Hub natural gas price selected is \$3.80/MMBtu and the high annual average Henry Hub natural gas price selected is \$8.40/MMBtu.

High and low burner tip prices were developed using the same methodology and values provided in previous sections except that the levels of the Henry Hub prices were modified. This was done by raising and lowering the overall level of the annual average Henry Hub prices while keeping the proportional level of the monthly prices relative to the annual average price constant through the use of monthly shaping factors. No other changes were made to data, since the purpose of these analyses was to isolate only the impacts that the level of the natural gas prices might have on EIM benefits. The high and low nominal 2020\$ natural gas burner tip prices (\$MMBtu) by location are reported in Table 2-11 and Table 2-12. 
Table 2-11. High Nominal 2020\$ Natural Gas Burner Tip Prices by Location (\$/MMBtu)

\begin{tabular}{|c|c|c|c|c|c|c|c|c|c|c|c|}
\hline Date & BC & AESO & $\underset{\text { Cascades }}{\text { West }}$ & Stanfield & AVA & IPC & PACE & PACW & SPP & $\begin{array}{l}\text { NWMT/ } \\
\text { WAUM }\end{array}$ & WACM WY \\
\hline Jan-20 & $\$ 8.43$ & $\$ 8.17$ & $\$ 8.48$ & $\$ 8.35$ & $\$ 8.16$ & $\$ 8.26$ & $\$ 8.59$ & $\$ 8.37$ & $\$ 8.82$ & $\$ 8.62$ & $\$ 8.47$ \\
\hline Feb-20 & $\$ 8.30$ & $\$ 8.06$ & $\$ 8.35$ & $\$ 8.24$ & $\$ 8.04$ & $\$ 8.15$ & $\$ 8.48$ & $\$ 8.26$ & $\$ 8.71$ & $\$ 8.51$ & $\$ 8.37$ \\
\hline Mar-20 & $\$ 8.04$ & $\$ 7.81$ & $\$ 8.09$ & $\$ 7.90$ & $\$ 7.77$ & $\$ 7.84$ & $\$ 8.18$ & $\$ 7.90$ & $\$ 8.35$ & $\$ 8.24$ & $\$ 8.04$ \\
\hline Apr-20 & $\$ 7.99$ & $\$ 7.74$ & $\$ 8.04$ & $\$ 7.89$ & $\$ 7.74$ & $\$ 7.77$ & $\$ 8.13$ & $\$ 7.91$ & $\$ 8.36$ & $\$ 8.09$ & $\$ 8.05$ \\
\hline May-20 & $\$ 8.03$ & $\$ 7.78$ & $\$ 8.08$ & $\$ 7.91$ & $\$ 7.77$ & $\$ 7.79$ & $\$ 8.16$ & $\$ 7.93$ & $\$ 8.38$ & $\$ 8.12$ & $\$ 8.07$ \\
\hline Jun-20 & $\$ 8.08$ & $\$ 7.83$ & $\$ 8.13$ & $\$ 7.95$ & $\$ 7.81$ & $\$ 7.83$ & $\$ 8.22$ & $\$ 7.98$ & $\$ 8.43$ & $\$ 8.17$ & $\$ 8.12$ \\
\hline Jul-20 & $\$ 8.10$ & $\$ 7.83$ & $\$ 8.15$ & $\$ 7.98$ & $\$ 7.84$ & $\$ 7.83$ & $\$ 8.25$ & $\$ 8.04$ & $\$ 8.49$ & $\$ 8.12$ & $\$ 8.17$ \\
\hline Aug-20 & $\$ 8.13$ & $\$ 7.86$ & $\$ 8.18$ & $\$ 8.04$ & $\$ 7.87$ & $\$ 7.87$ & $\$ 8.29$ & $\$ 8.08$ & $\$ 8.53$ & $\$ 8.15$ & $\$ 8.21$ \\
\hline Sep-20 & $\$ 8.12$ & $\$ 7.88$ & $\$ 8.17$ & $\$ 8.04$ & $\$ 7.89$ & $\$ 7.91$ & $\$ 8.28$ & $\$ 8.09$ & $\$ 8.54$ & $\$ 8.22$ & $\$ 8.21$ \\
\hline Oct-20 & $\$ 8.21$ & $\$ 7.96$ & $\$ 8.26$ & $\$ 8.13$ & $\$ 7.97$ & $\$ 8.01$ & $\$ 8.37$ & $\$ 8.16$ & $\$ 8.61$ & $\$ 8.35$ & $\$ 8.32$ \\
\hline Nov-20 & $\$ 8.48$ & $\$ 8.25$ & $\$ 8.53$ & $\$ 8.36$ & $\$ 8.27$ & $\$ 8.26$ & $\$ 8.57$ & $\$ 8.37$ & $\$ 8.82$ & $\$ 8.61$ & $\$ 8.51$ \\
\hline Dec-20 & $\$ 8.79$ & $\$ 8.49$ & $\$ 8.84$ & $\$ 8.68$ & $\$ 8.49$ & $\$ 8.58$ & $\$ 8.90$ & $\$ 8.69$ & $\$ 9.14$ & $\$ 8.93$ & $\$ 8.83$ \\
\hline Avg. & $\$ 8.22$ & $\$ 7.97$ & $\$ 8.27$ & $\$ 8.12$ & $\$ 7.97$ & $\$ 8.01$ & $\$ 8.37$ & $\$ 8.15$ & $\$ 8.60$ & $\$ 8.34$ & $\$ 8.28$ \\
\hline Date & $\begin{array}{c}\text { PSC \& } \\
\text { WACM in CO }\end{array}$ & PNM/EPE & AZ & $\stackrel{\stackrel{\text { AZ }}{\text { Merchant }}}{\text {. }}$ & NEVP & SoCalB & SCE & SDGE & LADWP & PG\&E & \\
\hline Jan-20 & $\$ 8.57$ & $\$ 8.47$ & $\$ 8.62$ & $\$ 9.25$ & $\$ 8.62$ & $\$ 8.62$ & $\$ 8.95$ & $\$ 8.95$ & $\$ 8.97$ & $\$ 8.99$ & \\
\hline Feb-20 & $\$ 8.47$ & $\$ 8.37$ & $\$ 8.51$ & $\$ 9.13$ & $\$ 8.51$ & $\$ 8.51$ & $\$ 8.84$ & $\$ 8.84$ & $\$ 8.86$ & $\$ 8.89$ & \\
\hline Mar-20 & $\$ 8.14$ & $\$ 8.04$ & $\$ 8.17$ & $\$ 8.76$ & $\$ 8.17$ & $\$ 8.17$ & $\$ 8.50$ & $\$ 8.50$ & $\$ 8.52$ & $\$ 8.59$ & \\
\hline Apr-20 & $\$ 8.15$ & $\$ 8.05$ & $\$ 8.21$ & $\$ 8.81$ & $\$ 8.21$ & $\$ 8.21$ & $\$ 8.55$ & $\$ 8.55$ & $\$ 8.56$ & $\$ 8.61$ & \\
\hline May-20 & $\$ 8.17$ & $\$ 8.07$ & $\$ 8.25$ & $\$ 8.85$ & $\$ 8.25$ & $\$ 8.25$ & $\$ 8.59$ & $\$ 8.59$ & $\$ 8.60$ & $\$ 8.68$ & \\
\hline Jun-20 & $\$ 8.22$ & $\$ 8.12$ & $\$ 8.32$ & $\$ 8.92$ & $\$ 8.32$ & $\$ 8.32$ & $\$ 8.65$ & $\$ 8.65$ & $\$ 8.67$ & $\$ 8.75$ & \\
\hline Jul-20 & $\$ 8.27$ & $\$ 8.17$ & $\$ 8.42$ & $\$ 9.04$ & $\$ 8.42$ & $\$ 8.42$ & $\$ 8.76$ & $\$ 8.76$ & $\$ 8.77$ & $\$ 8.82$ & \\
\hline Aug-20 & $\$ 8.31$ & $\$ 8.21$ & $\$ 8.47$ & $\$ 9.09$ & $\$ 8.47$ & $\$ 8.47$ & $\$ 8.81$ & $\$ 8.81$ & $\$ 8.83$ & $\$ 8.86$ & \\
\hline Sep-20 & $\$ 8.31$ & $\$ 8.21$ & $\$ 8.38$ & $\$ 8.99$ & $\$ 8.38$ & $\$ 8.38$ & $\$ 8.71$ & $\$ 8.71$ & $\$ 8.73$ & $\$ 8.75$ & \\
\hline Oct-20 & $\$ 8.42$ & $\$ 8.32$ & $\$ 8.45$ & $\$ 9.07$ & $\$ 8.45$ & $\$ 8.45$ & $\$ 8.78$ & $\$ 8.78$ & $\$ 8.80$ & $\$ 8.82$ & \\
\hline Nov-20 & $\$ 8.61$ & $\$ 8.51$ & $\$ 8.59$ & $\$ 9.21$ & $\$ 8.59$ & $\$ 8.59$ & $\$ 8.92$ & $\$ 8.92$ & $\$ 8.94$ & $\$ 9.00$ & \\
\hline Dec-20 & $\$ 8.93$ & $\$ 8.83$ & $\$ 8.93$ & $\$ 9.58$ & $\$ 8.93$ & $\$ 8.93$ & $\$ 9.27$ & $\$ 9.27$ & $\$ 9.29$ & $\$ 9.30$ & \\
\hline Avg. & $\$ 8.38$ & $\$ 8.28$ & $\$ 8.44$ & $\$ 9.06$ & $\$ 8.44$ & $\$ 8.44$ & $\$ 8.78$ & $\$ 8.78$ & $\$ 8.79$ & $\$ 8.84$ & \\
\hline
\end{tabular}


Table 2-12. Low Nominal 2020\$ Natural Gas Burner Tip Prices by Location (\$/MMBtu)

\begin{tabular}{|c|c|c|c|c|c|c|c|c|c|c|c|}
\hline Date & BC & AESO & $\begin{array}{c}\text { West } \\
\text { Cascades } \\
\end{array}$ & Stanfield & AVA & IPC & PACE & PACW & SPP & $\begin{array}{l}\text { NWMT/ } \\
\text { WAUM }\end{array}$ & $\begin{array}{c}\text { WACM } \\
\text { WY } \\
\end{array}$ \\
\hline Jan-20 & $\$ 3.75$ & $\$ 3.49$ & $\$ 3.80$ & $\$ 3.67$ & $\$ 3.48$ & $\$ 3.57$ & $\$ 3.91$ & $\$ 3.69$ & $\$ 4.14$ & $\$ 3.93$ & $\$ 3.79$ \\
\hline Feb-20 & $\$ 3.68$ & $\$ 3.43$ & $\$ 3.73$ & $\$ 3.61$ & $\$ 3.41$ & $\$ 3.52$ & $\$ 3.86$ & $\$ 3.63$ & $\$ 4.08$ & $\$ 3.88$ & $\$ 3.74$ \\
\hline Mar-20 & $\$ 3.57$ & $\$ 3.34$ & $\$ 3.62$ & $\$ 3.43$ & $\$ 3.29$ & $\$ 3.37$ & $\$ 3.70$ & $\$ 3.43$ & $\$ 3.88$ & $\$ 3.76$ & $\$ 3.57$ \\
\hline Apr-20 & $\$ 3.51$ & $\$ 3.27$ & $\$ 3.56$ & $\$ 3.42$ & $\$ 3.27$ & $\$ 3.29$ & $\$ 3.65$ & $\$ 3.43$ & $\$ 3.88$ & $\$ 3.61$ & $\$ 3.58$ \\
\hline May-20 & $\$ 3.51$ & $\$ 3.27$ & $\$ 3.56$ & $\$ 3.39$ & $\$ 3.26$ & $\$ 3.27$ & $\$ 3.65$ & $\$ 3.42$ & $\$ 3.87$ & $\$ 3.61$ & $\$ 3.55$ \\
\hline Jun-20 & $\$ 3.52$ & $\$ 3.28$ & $\$ 3.57$ & $\$ 3.39$ & $\$ 3.26$ & $\$ 3.28$ & $\$ 3.66$ & $\$ 3.42$ & $\$ 3.87$ & $\$ 3.61$ & $\$ 3.56$ \\
\hline Jul-20 & $\$ 3.51$ & $\$ 3.25$ & $\$ 3.56$ & $\$ 3.39$ & $\$ 3.25$ & $\$ 3.24$ & $\$ 3.66$ & $\$ 3.45$ & $\$ 3.90$ & $\$ 3.54$ & $\$ 3.58$ \\
\hline Aug-20 & $\$ 3.52$ & $\$ 3.26$ & $\$ 3.57$ & $\$ 3.43$ & $\$ 3.27$ & $\$ 3.27$ & $\$ 3.68$ & $\$ 3.47$ & $\$ 3.92$ & $\$ 3.55$ & $\$ 3.60$ \\
\hline Sep-20 & $\$ 3.57$ & $\$ 3.33$ & $\$ 3.62$ & $\$ 3.49$ & $\$ 3.34$ & $\$ 3.36$ & $\$ 3.72$ & $\$ 3.53$ & $\$ 3.98$ & $\$ 3.67$ & $\$ 3.66$ \\
\hline Oct-20 & $\$ 3.62$ & $\$ 3.37$ & $\$ 3.67$ & $\$ 3.54$ & $\$ 3.38$ & $\$ 3.42$ & $\$ 3.78$ & $\$ 3.57$ & $\$ 4.02$ & $\$ 3.75$ & $\$ 3.73$ \\
\hline Nov-20 & $\$ 3.80$ & $\$ 3.57$ & $\$ 3.85$ & $\$ 3.68$ & $\$ 3.59$ & $\$ 3.58$ & $\$ 3.90$ & $\$ 3.69$ & $\$ 4.14$ & $\$ 3.93$ & $\$ 3.83$ \\
\hline Dec-20 & $\$ 3.93$ & $\$ 3.63$ & $\$ 3.98$ & $\$ 3.82$ & $\$ 3.63$ & $\$ 3.72$ & $\$ 4.04$ & $\$ 3.83$ & $\$ 4.28$ & $\$ 4.07$ & $\$ 3.97$ \\
\hline Avg. & $\$ 3.62$ & $\$ 3.37$ & $\$ 3.67$ & $\$ 3.52$ & $\$ 3.37$ & $\$ 3.41$ & $\$ 3.77$ & $\$ 3.55$ & $\$ 4.00$ & $\$ 3.74$ & $\$ 3.68$ \\
\hline Date & $\begin{array}{c}\text { PSC \& } \\
\text { WACM in CO } \\
\end{array}$ & PNM/EPE & $\mathbf{A Z}$ & $\begin{array}{c}\text { AZ } \\
\text { Merchant }\end{array}$ & NEVP & SoCalB & SCE & SDGE & LADWP & PG\&E & \\
\hline Jan-20 & $\$ 3.89$ & $\$ 3.79$ & $\$ 3.93$ & $\$ 4.22$ & $\$ 3.93$ & $\$ 3.93$ & $\$ 4.25$ & $\$ 4.25$ & $\$ 4.27$ & $\$ 4.31$ & \\
\hline Feb-20 & $\$ 3.84$ & $\$ 3.74$ & $\$ 3.88$ & $\$ 4.17$ & $\$ 3.88$ & $\$ 3.88$ & $\$ 4.20$ & $\$ 4.20$ & $\$ 4.22$ & $\$ 4.26$ & \\
\hline Mar-20 & $\$ 3.67$ & $\$ 3.57$ & $\$ 3.69$ & $\$ 3.96$ & $\$ 3.69$ & $\$ 3.69$ & $\$ 4.01$ & $\$ 4.01$ & $\$ 4.03$ & $\$ 4.11$ & \\
\hline Apr-20 & $\$ 3.68$ & $\$ 3.58$ & $\$ 3.74$ & $\$ 4.01$ & $\$ 3.74$ & $\$ 3.74$ & $\$ 4.05$ & $\$ 4.05$ & $\$ 4.07$ & $\$ 4.13$ & \\
\hline May-20 & $\$ 3.65$ & $\$ 3.55$ & $\$ 3.74$ & $\$ 4.01$ & $\$ 3.74$ & $\$ 3.74$ & $\$ 4.05$ & $\$ 4.05$ & $\$ 4.07$ & $\$ 4.16$ & \\
\hline Jun-20 & $\$ 3.66$ & $\$ 3.56$ & $\$ 3.76$ & $\$ 4.03$ & $\$ 3.76$ & $\$ 3.76$ & $\$ 4.08$ & $\$ 4.08$ & $\$ 4.09$ & $\$ 4.20$ & \\
\hline Jul-20 & $\$ 3.68$ & $\$ 3.58$ & $\$ 3.84$ & $\$ 4.12$ & $\$ 3.84$ & $\$ 3.84$ & $\$ 4.15$ & $\$ 4.15$ & $\$ 4.17$ & $\$ 4.24$ & \\
\hline Aug-20 & $\$ 3.70$ & $\$ 3.60$ & $\$ 3.87$ & $\$ 4.15$ & $\$ 3.87$ & $\$ 3.87$ & $\$ 4.19$ & $\$ 4.19$ & $\$ 4.21$ & $\$ 4.26$ & \\
\hline Sep-20 & $\$ 3.76$ & $\$ 3.66$ & $\$ 3.82$ & $\$ 4.10$ & $\$ 3.82$ & $\$ 3.82$ & $\$ 4.14$ & $\$ 4.14$ & $\$ 4.16$ & $\$ 4.19$ & \\
\hline Oct-20 & $\$ 3.83$ & $\$ 3.73$ & $\$ 3.86$ & $\$ 4.14$ & $\$ 3.86$ & $\$ 3.86$ & $\$ 4.18$ & $\$ 4.18$ & $\$ 4.19$ & $\$ 4.22$ & \\
\hline Nov-20 & $\$ 3.93$ & $\$ 3.83$ & $\$ 3.91$ & $\$ 4.20$ & $\$ 3.91$ & $\$ 3.91$ & $\$ 4.23$ & $\$ 4.23$ & $\$ 4.25$ & $\$ 4.32$ & \\
\hline Dec-20 & $\$ 4.07$ & $\$ 3.97$ & $\$ 4.07$ & $\$ 4.37$ & $\$ 4.07$ & $\$ 4.07$ & $\$ 4.39$ & $\$ 4.39$ & $\$ 4.41$ & $\$ 4.44$ & \\
\hline Avg. & $\$ 3.78$ & $\$ 3.68$ & $\$ 3.84$ & $\$ 4.12$ & $\$ 3.84$ & $\$ 3.84$ & $\$ 4.16$ & $\$ 4.16$ & $\$ 4.18$ & $\$ 4.24$ & \\
\hline
\end{tabular}




\subsection{Hydropower Plant Modeling}

\subsubsection{Hydropower Plant Modeling in PLEXOS}

There are two different models for hydro units in PLEXOS, and each model represents the main objective of the hydropower plant operation. These models are as follows:

- Fixed Schedule: the user inputs the hourly schedules for the hydro generators in PLEXOS.

- Hydrothermal coordination (HTC): HTC dispatches hydropower plants responsive to the marginal cost of thermal generation. Hydro generators are modeled with monthly energy limits and maximum and minimum capacity.

The mid-term (MT) scheduling module in PLEXOS minimizes the system cost at the multiple-hour interval in a monthly optimization window. The cost minimization of the monthly MT optimization honors the monthly hydro energy limits. The solution of the monthly MT optimization includes the decomposed monthly hydro energy limits into the short-term (ST) optimization windows (for the detailed descriptions of MT optimization and ST-optimization, please see Section 3.2 Overview of PLEXOS). There are two methods available for applying the decomposed hydro energy limits in the ST optimization. These are the following:

- Treat the decomposed hydro energy limits as hard constraints. The unused hydro energy can be banked into the future.

- Treat the decomposed hydro energy limits as soft constraints: the shadow price from the MT optimization is used to price the constrained object. For example, the monthly hydro energy is decomposed into days, and the shadow price from the MT optimization will be used to price the hydro generator dispatch cost in the ST optimization. This approach allows banking to and borrowing from the future.

The following four diagrams (Figure 2.11 through Figure 2.14) illustrate how the MT optimization decomposes the monthly hydro energy into the ST optimizations. 


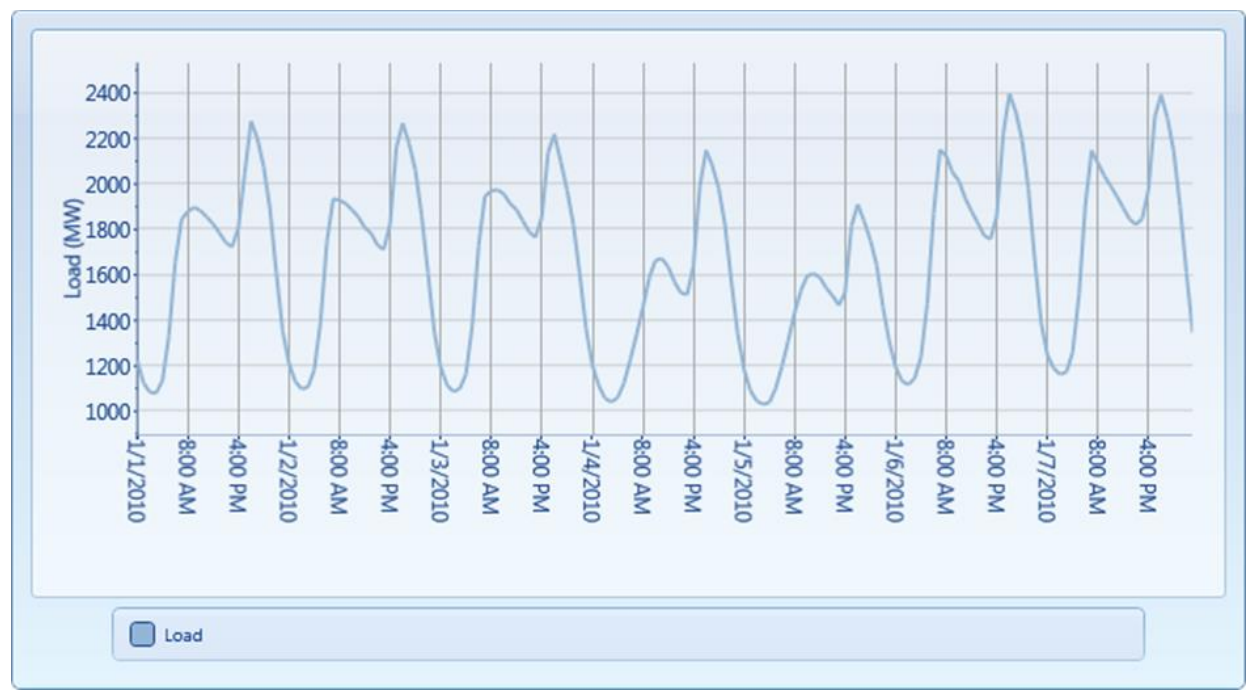

Figure 2.11. System Hourly Load Profile

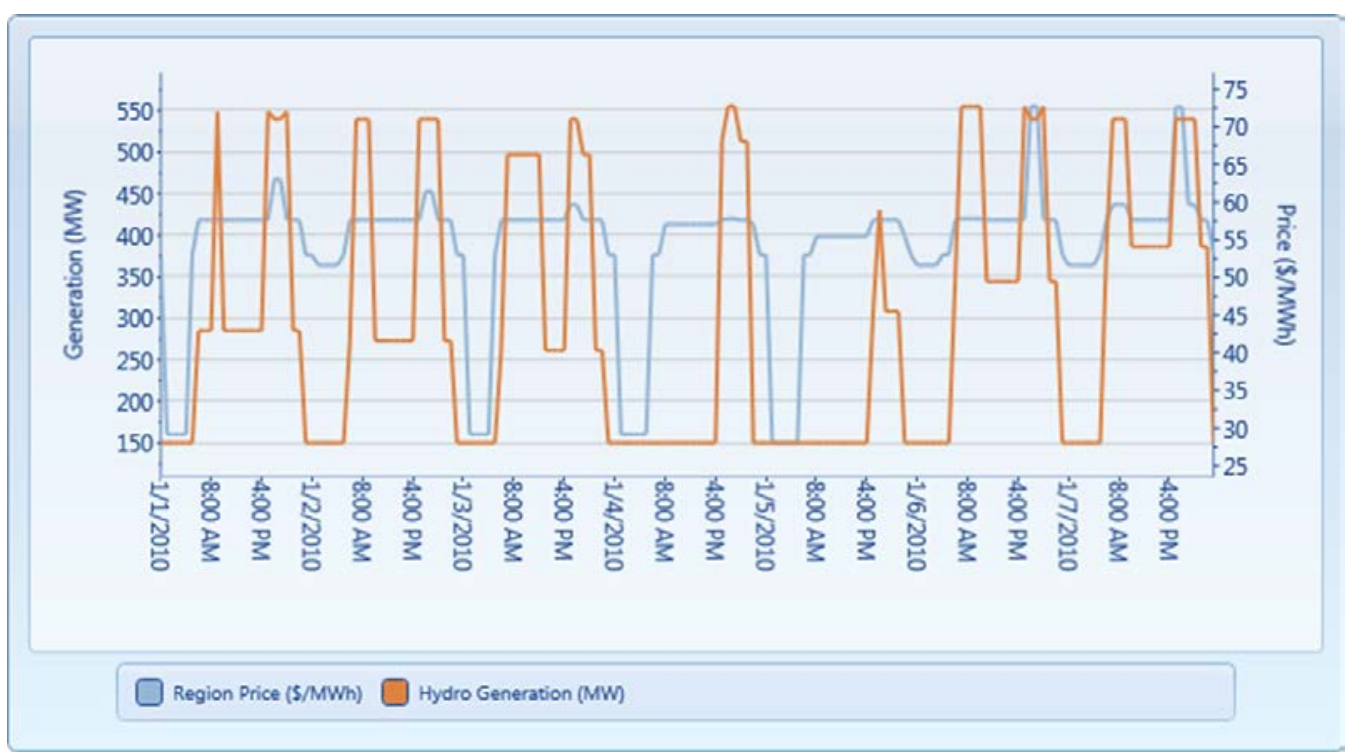

Figure 2.12. Hydro Dispatch from MT Optimization 


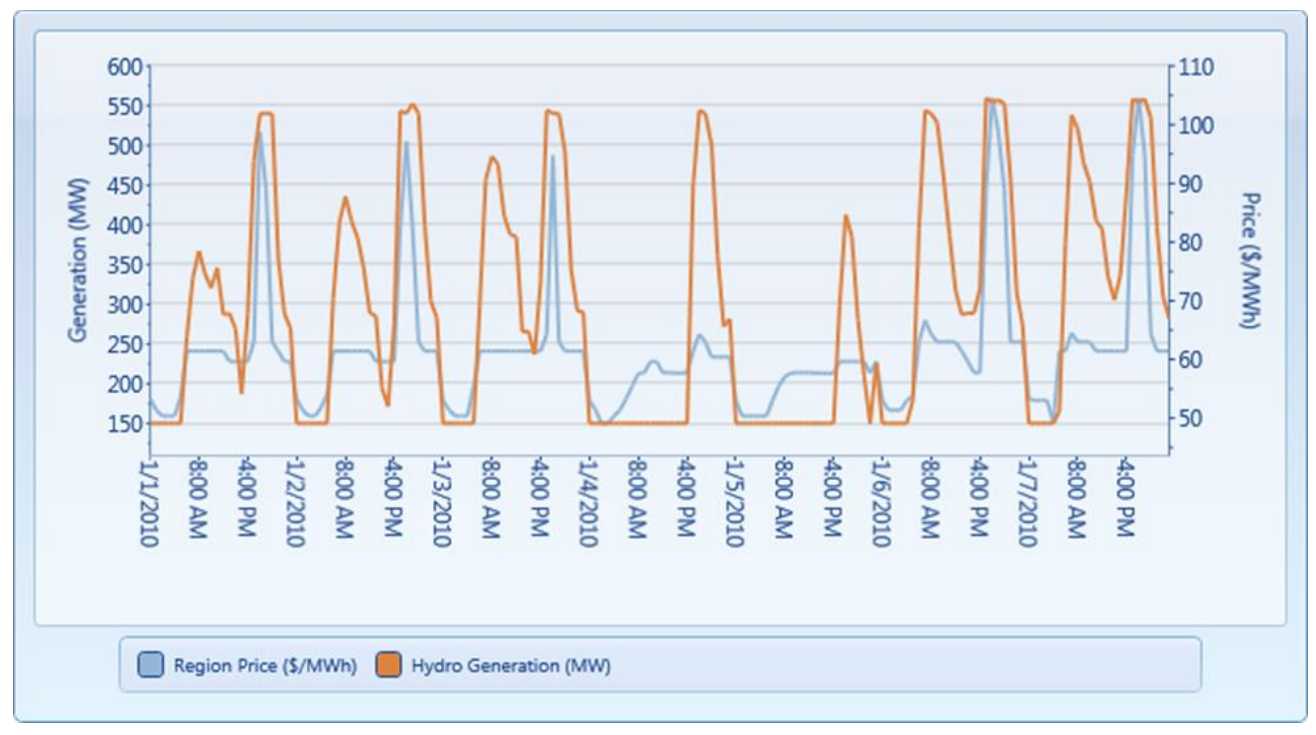

Figure 2.13. Hydro Re-optimized in ST Optimization

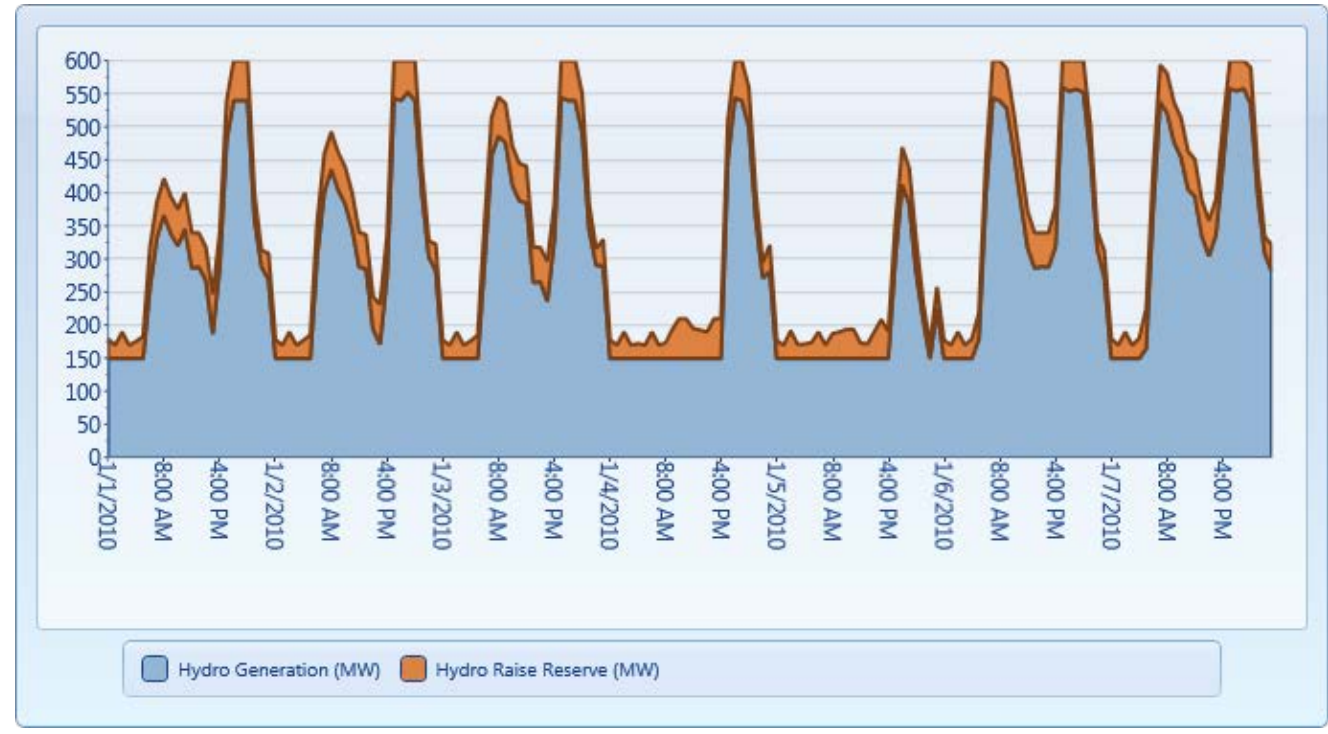

Figure 2.14. Hydro Energy-Raise (Spin-Up) Reserve Re-optimized in ST Optimization

To mimic the HTC logic in other computer software, a special option is adopted to use the hydro generation profiles produced from the MT optimization in the ST optimization. In this special option, the MT optimization provides the hydro generation profiles for the ST optimization. The ST optimization allows hydro generation to deviate from the generation profiles from the MT optimization.

The following diagrams (Figure 2.15 through Figure 2.17) illustrate how the hydro generation profiles from the MT optimization are used in the ST optimization. 


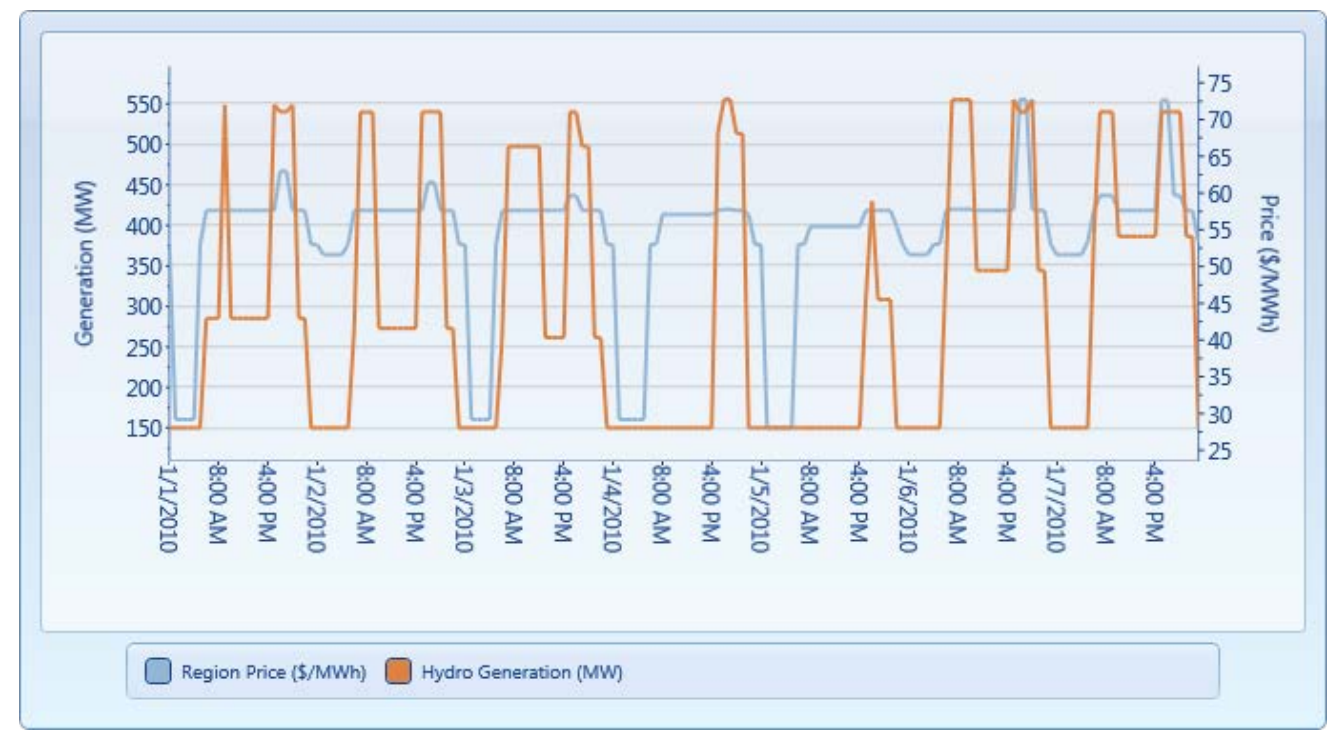

Figure 2.15. Hydro Generation Profile from MT Optimization

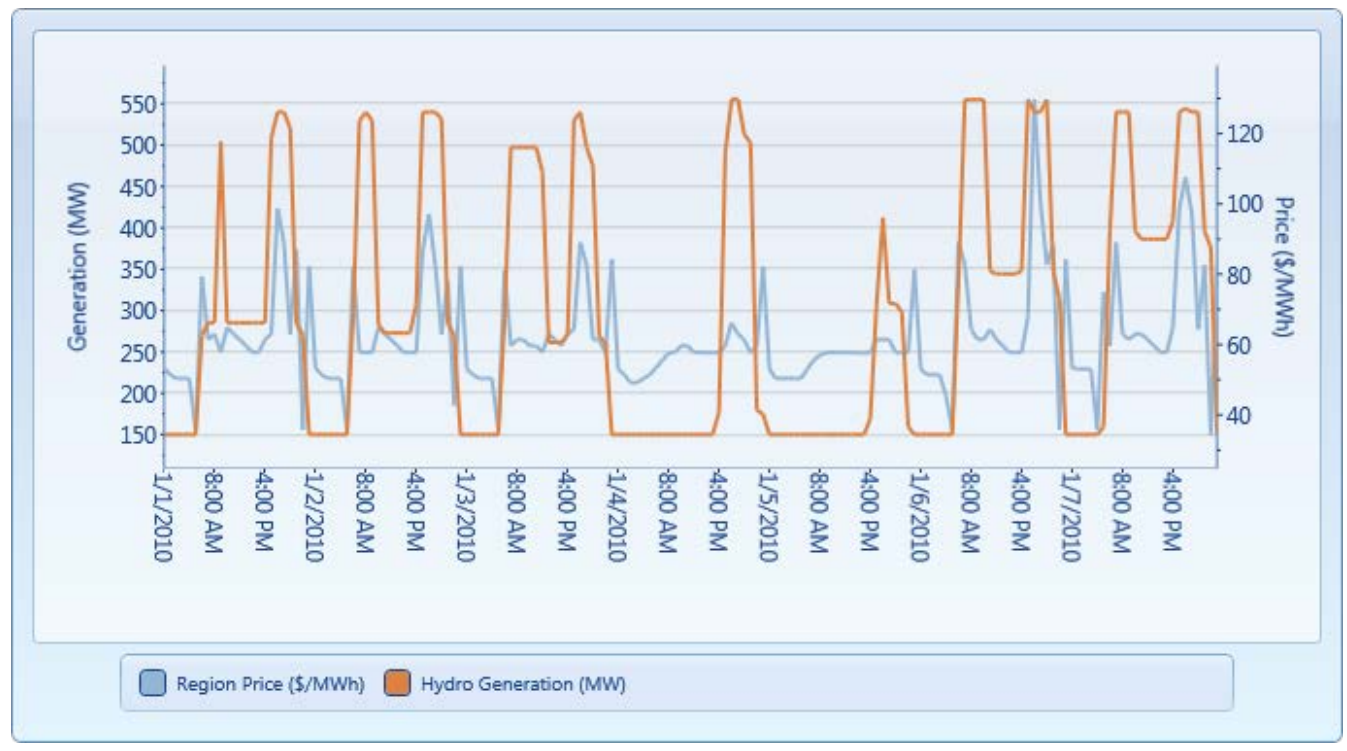

Figure 2.16. Hydro Generation Profile from MT optimization is used in the ST Optimization 


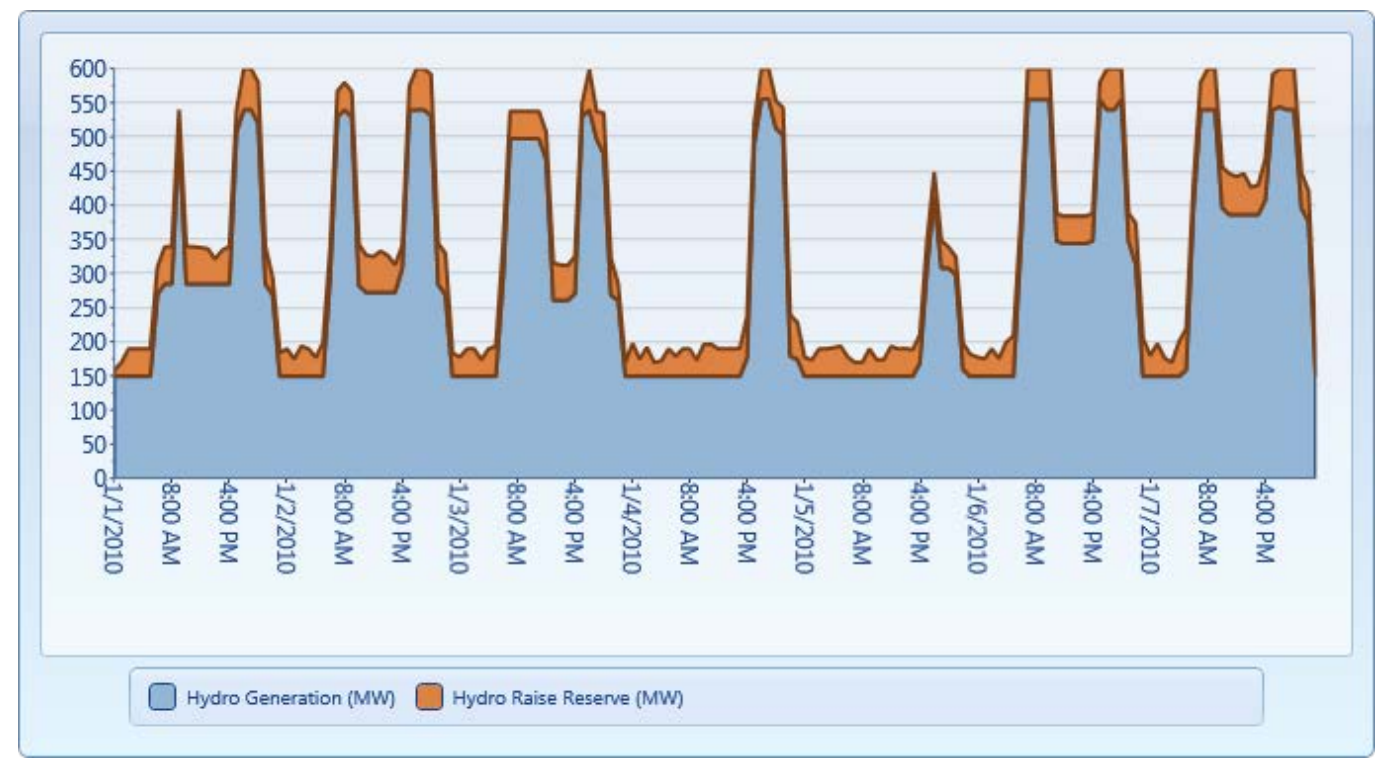

Figure 2.17. Hydro Energy-Raise (Spin-Up) Reserve Re-optimized in ST Optimization

Comparing the hydro generation profiles in Figure 2.16 and Figure 2.17, one can notice that the hydro generation profile from the MT optimization in Figure 2.16 is honored in the ST optimization with slight revisions in Figure 2.17.

Comparing the hydro re-optimization in the ST optimization in Figure 2.14 and the hydro generation profiles from the ST optimization usages in Figure 2.17, one can notice in Figure 2.14 that the hydro re-optimization produces hydro generation profiles that are more impacted by economics. In the hydro re-optimization, perfect foresight is assumed. In the case of the ST optimization honoring the hydro generation profiles from the MT optimization, the hydro generation is less optimal and yields results that are closer to the HTC logic used in other computer software.

In this study, the approach that the hydro generation profiles from the MT optimization usages are honored in the ST optimization is adopted with the exception of case 1.94, where a forward-looking, 12hour optimization window was applied in the ST. Also in the ST optimization, the decomposed hydro energy limits from the MT optimization are modeled as soft constraints that can be violated at penalty prices included in the objective function.

\subsubsection{Changes in Hydro Generation Plant Modeling}

\subsubsection{Revising Models for Selected Hydro Plants in the NWPP}

For the purposes of this study, the Analytical Team implemented modeling improvements for selected hydro generation plants in the Northwest hydro system. These improvements were both a reflection of the modeling capabilities present in the PLEXOS model (see prior section), as well as physical characteristics of the Northwest projects. They include the following:

1. Better specification of hydro generation between fixed shape and HTC units. These are the only two approaches available for modeling hydro generation in PLEXOS. Balancing the contributions 
between fixed shape and HTC hydro generation can better match observed hydro operations. (see Section 2.4.2.2)

2. Reduced reserve commitment. PLEXOS has the capability to reflect reserves available to be committed in terms of either the lesser of the available capacity not being used for energy production or as a percentage of the specified maximum capacity. For BPA, a percentage of the specified maximum capacity better approximates the physical limit the Federal Columbia River Power System is capable of providing for reserves. (see Section 2.4.2.3)

3. Reduced hydro project capacities consistent with O\&M and head obligations. For the HTC projects modeled in PLEXOS, it is important to characterize the monthly HTC profiles in great detail, including monthly energy limits, and maximum and minimum power ratings of the hydro generation plants. Physically, O\&M tends to consume $10-20 \%$ of the maximum generation capability of a project. As a result, Grand Coulee (GCL), Chief Joseph (CHJ), John Day (JDA), and The Dalles (TDA) each had their maximum capacity reduced by approximately 10-20\% compared to what previously had been in PLEXOS. Also, GCL had its capacity reduced to $4,000 \mathrm{MW}$ in Spring due to the head loss associated with its storage reservoir being evacuated.

Table 2-13 FY 2001-2009 Average MW Weighted Availability by Month for Selected Hydro Plants in BPA

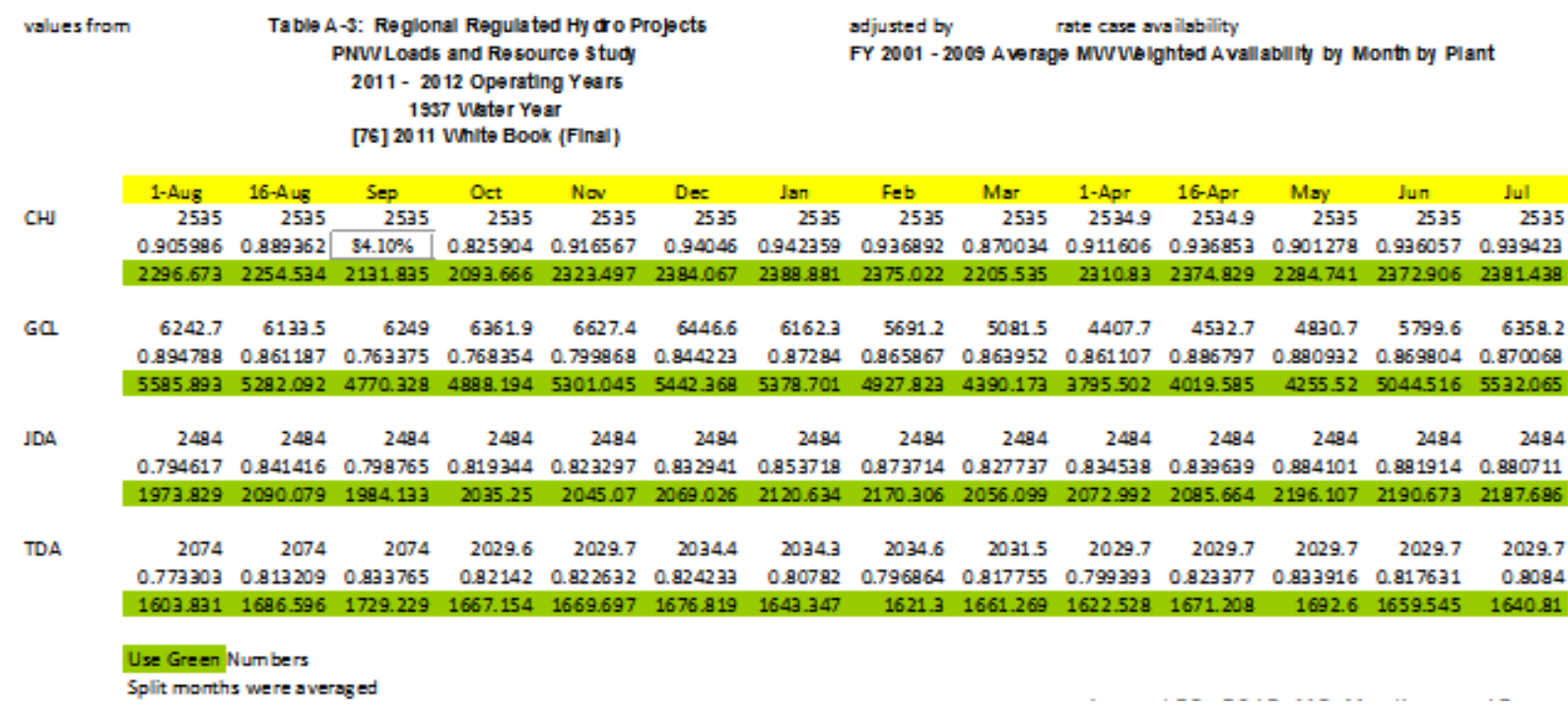

\subsubsection{Converting Load-Following Hydro Units in TEPPC to Fixed-Shape Hydro Units}

In the original TEPPC case, three types of hydro generation were modeled: HTC, load following, and fixed shape. Because only two of these types of hydro generation are available in PLEXOS (HTC and fixed shape), most of the hydro plants that have load-following capabilities in the original TEPPC case were converted to fixed shape generation in this study. The hourly generation profiles for those units were obtained from the simulation output produced by PROMOD for the original TEPPC PC0 case. The maximum capacities of some units were also modified based on comments received from members of the NWPP. 


\subsubsection{Converting Some Fixed-Shape Hydro Units into HTC Units}

To facilitate the use of fixed-shape hydro generation units to respond to imbalance needs in an EIM, some of the fixed-shape hydro generation units in the original TEPPC PC0 case were converted to HTC units. This was done in BAs where most of the hydro capacity was previously modeled as either fixed shape or load following (which were converted to fixed shape for the purposes of this study) and/or hydro capacity is a high share of the local supply within the BA and there is a need for flexible hydro units to meet balancing reserve requirements.

To model as HTC units, the hourly one-year fixed shape generation was converted to monthly energy limits, and minimum and maximum power ratings. The monthly HTC profiles were reviewed by the owning BA entities and adjustments were made as needed.

\subsubsection{Limiting Reserve Provision of Selected Hydro Plants}

In response to some prior studies, the Analytical Team identified a need to limit the unused hydroelectric generation available for reserve requirements on hydro plants modeled as HTC. In this study, balancing reserve commitment only comes from HTC plants and not from those that have fixed shape generation. Left unaddressed, unlimited reserve commitment from hydro resources tends to reduce unit commitment from other resource types that would otherwise be committed in earlier phases of the modeling process that are intended to emulate day-ahead and hour-ahead commitment. This is particularly true in circumstances in which the unit commitment phase of the modeling process is not the same for both the BAU and EIM scenarios, as it is in the MC Initiative. For some BAs in the Northwest, this unlimited reserve commitment from hydro resources is standard operating procedure with their hydro resource(s) being physically and hydraulically capable of deploying maximum generation on any dispatch interval. For other BAs, physical limitations, hydraulic constraints or both present a limit on the capability of that entity to provide reserves. The BAs in the NWPP each specified a percentage of the maximum generation to be used in PLEXOS. For BPA, this limit was modeled as $12 \%$ of maximum generation, or approximately 1,600 MW.

\subsubsection{Hydro Plant Ramp Rates Corrections}

In the TEPPC 2020 PC0 case no ramp rates were available for some of the hydro units in the WECC and the ramp rates of the Federal Columbia River Power System (FCRPS) hydro units were not correct. Accordingly, ramp rates for several hydro units were updated with actual values obtained from BAs in the NWPP. Specifically, they are the following: Chief Joseph, Grand Coulee, The Dalles, John Day, Little Goose, and Lower Monumental. Also, the ramp rates for Hoover were updated based on publically available information.

\subsubsection{Modeling of MidC Hydro Units}

For this study the modeling of Mid-Columbia hydro-electric projects were limited to the non-federal projects, namely Wanapum and Priest Rapids, owned by Grant Public Utility District (PUD); Rocky Reach and Rock Island, owned by Chelan PUD; and Wells, owned by Douglas PUD. 
For much of the year these projects are energy constrained projects. That is, there is not enough water in the river to operate at full capacity all hours of the day. The projects also have limited reservoir storage. The storage is generally sufficient to shift generation from one period of the day to another but restricts the ability to shape generation from one day to the next. In addition, Wanapum, Rock Island and Rocky Reach are subject to energy transfers designed to mitigate the effects of reservoir encroachment on the upstream projects.

The projects are also subject to a number of non-generation constraints. The most influential of these are the total dissolved gas limits which constrain the amount of spill and the Vernita Bar fish spawning requirements that impose flow constraints.

Each of the projects has contractual arrangements with remote BAs for a share of the energy and capacity of the project. The remote BAs request their share of the project output using a dynamic generation request signal. The request is limited to the contractual share of the capacity (both maximum and minimum) and energy (inflow and storage).

The generation of the non-federal projects is coordinated through the Mid-Columbia Hourly Coordination Agreement is such that it appears to operate much like a dynamically scheduled jointly owned unit to the BAs. The generation is pooled and allocated back to the BAs on a 4-second interval based on the individual generation request signals. Grant PUD serves as the operator for Mid-Columbia Hourly Coordination.

\subsubsection{Project Data}

The Analytical Team wanted to improve on previous efforts to model the Mid-Columbia generation. Previous efforts appeared to have overestimated the ability of these projects to respond to economic dispatch in an EIM. The Analytical Team asked the project owners (Douglas, Chelan and Grant PUDs) to provide realistic project capacity, actual project generation for 2006, and the contractual share of the projects for each BA.

Chelan and Grant PUDs provided data for Rocky Reach, Rock Island, Wanapum and Priest Rapids. To supply realistic capacity numbers, Chelan and Grant considered the following:

- reservoir elevation during operations

- unit outages for maintenance

- effects of encroachment energy transfers.

For the Wells project, capacity numbers were derived from operating data.

\subsubsection{Allocation to HTC and Fixed Shape}

The Analytical Team worked with Chelan and Grant PUDs to determine a reasonable amount of capacity available for EIM dispatch during the hour. The use of capacity is limited by the amount of energy inherent in the river flow, by the reservoir storage and by the non-power constraints. In general, Wanapum, Rocky Reach and Wells are the least constrained projects and Rock Island and Priest Rapids are more constrained. The Rock Island reservoir is significantly smaller than those of the other projects. The Priest Rapids discharge is constrained by the Vernita Bar fish spawning flow requirements. 
Based on the input from Chelan and Grant, the Analytical Team assigned a portion of each project to HTC and the remainder to fixed shape. HTC and fixed shape were the two options available in PLEXOS to simulate the operation of the hydro projects. Capacity that is assigned to HTC is available for dispatch in an EIM. By assigning only a portion of the projects to HTC, the Analytical Team forced PLEXOS to limit the dispatch of the Mid-Columbia units to a range that approximated the actual constraints of the system. For more detailed information regarding the modeling of the MidC hydro plants, refer to Appendix C.

\subsubsection{Development of High and Low Hydro Scenarios}

The Low Hydro energy case (Case 1.86J) was developed based on information from the Base Case (1.86A). Monthly scaling factors for a dry water year were developed by scaling modeled hydro generation to the 2001 monthly generation. Monthly scaling factors were calculated for each WECC SubRegion: NWPP, California, Southwest and Rocky Mountain.

The High Hydro energy case (Case 1.86K) was developed based on information from the Base Case (1.86A). Monthly scaling factors for a wet water year were developed by scaling modeled hydro generation to the 2011 monthly generation. Monthly scaling factors were calculated for each WECC SubRegion: NWPP, California, Southwest and Rocky Mountain.

In both these cases, historic data for the BCTC were not available. In general, hydro scaling factors for the BCTC fall between the scaling factors for the NWPP and normal (scalar of 1.00). These Canadian scaling factors reduced the scaling factors for the NWPP by $50 \%$.

\subsection{Network Topology Changes}

\subsubsection{Bus/BA Ownership}

Bus/BA ownership is critical in this study because it will significantly affect the exchanges between different BAs and flows on WECC transmission paths. Therefore, the Analytical Team started with the Bus/BA ownership designations contained in PLEXOS, which were based on data in the TEPPC 2020 case, to identify the incorrect ownership designations that needed to be changed. The ownership designations of more than 200 buses were corrected in the model.

Based on the corrected bus ownerships, the Analytical Team identified the transmission elements of the "81" BA-to-BA flowgates in which hurdle rates could be applied. PLEXOS calculated the net exchange for each BA by summing the flows from the BA buses to the buses owned by other BAs while taking into consideration the direction of the flows.

\subsubsection{Modeling Out-of-Area Supply}

Two modeling techniques were used to allow BAs to receive credit for remote generation. These are the following: 


\subsubsection{Remote Units that can Provide Energy and Reserves}

In PLEXOS, a generator must be connected to a BA to receive credit for the generation and available spinning reserve capability of a unit. The connecting buses for all single owner units were changed from the BA in which they are located to the BA of their owners. This technique allows remote generation to respond to changes in the controlling BA. Thus, when exchanges are locked in the BAU run, remote generation can still respond to changes in the real time load. This yields outcomes such that any change in remote generation exports corresponds to an equal change in imports to the BA of its owners; yielding zero change to net exchange. Table 2-14 contains a list of such remote units in the model.

Table 2-14. Remotely Owned Generation Units in the Model

\begin{tabular}{llll}
\hline \multicolumn{1}{c}{ Unit Name } & Connecting Bus \# & Bus Name & $\begin{array}{l}\text { New BA } \\
\text { Area }\end{array}$ \\
\hline MintFrm_CC1 & 47675 & MntFrm G & PSE \\
GEPST1 & 47687 & GEC G1 & PSE \\
ChhlsGn3 & 47590 & Cheh S1 & PACW \\
Lancaster CC_1 & 47568 & Lancas S & AVA \\
HermstST1 & 47641 & HPP S1 & PACW \\
Hermstn1B & 45454 & Herm 1G & PACW \\
Hermstn2B & 45456 & Herm 2G & PACW \\
KlmthCgn & 45448 & KFallCT1 & BPA \\
KlamGT1 & 47660 & Klam Add & BPA \\
KlamGT2 & 47660 & Klam Add & BPA \\
Springerville 4 & 16519 & Spr Gen4 & SRP \\
Cholla4 & 14903 & Cholla4 & PACE \\
MRCHN23C & 18621 & Mrchnt1 & CAISO \\
Blythe1 & 19322 & BlyEng1 & CAISO \\
Griffith3 & 19311 & Griffth1 & NEVP \\
ArlngtnST1 & 15147 & ARL-ST1 & APS \\
Mirant3 & 18441 & Mirant1 & CAISO \\
Valmy1 & 64131 & Valmy G1 & IPC \\
JmBrdgr1 & 60086 & Bridger1 & IPC \\
JmBrdgr2 & 60087 & Bridger1 & PACW \\
JmBrdgr3 & 60088 & Bridger1 & PACW \\
JmBrdgr4 & 60089 & Bridger1 & PACW \\
\hline
\end{tabular}

The limitation of this modeling approach is that in reality single units within a power plant are not assigned to individual BAs since for jointly owned power plants each BA can dispatch the plant output up to its maximum share. Consequently, the plant operator dispatches different units in the plant to economically meet dispatch requirements of different BAs. 


\subsubsection{Remote Units Providing Contingency Reserve Only}

In PLEXOS, users can select generation units that are available to provide different types of reserve to each BA. Accordingly, a generation unit can be easily modeled to provide reserve to a BA that is different from the one where the energy is injected. In addition, different types of reserves provided by one generation unit can also be modeled separately. It is not necessary for a generation unit to provide different types of reserves to the same BA. Moreover, for each generation unit, one can also specify a percentage of its available reserves for each BA.

For example, the Colstrip coal plant, which is one of the larger remote generators for several BAs in the NW, can provide spinning contingency reserve for different BAs (AVA, NWMT, PSE, PGN and PAC) based on their percent ownership even though the plant ownership in the model is assigned only to NWMT. The list of remote units that are dispatched by a single BA but can provide contingency reserve to other BAs is given in Appendix D.

\subsubsection{Transmission Topology, Constraints, Flowgates and Nomograms}

All of the transmission path ratings, both for WECC and other internal paths, were reviewed to make sure that all the important paths were included and that each had the proper rating, and each included all the component lines that make up the paths by 2020. The starting point for the path ratings was the list of paths used in the original TEPPC PCO case. Changes made to the paths and ratings used in that case are the following:

\section{Canada:}

- The Alberta to British Columbia path rating was reduced to reflect a more reasonable typical rating.

- The Northwest to British Columbia path was corrected to reflect the recent upgrade of the south-to-north direction to $3000 \mathrm{MW}$.

\section{Northwest:}

- The Pacific DC Intertie (PDCI) line rating was increased to 3220 MW to reflect the upgrade project.

- The nomograms for California-Oregon Intertie (COI)/North of John Day, PDCI/North of John Day and COI/Hemingway-Summer Lake were corrected to reflect the recent upgrades of the COI path.

- The West of Cascades North and South paths and ratings were corrected. The Cascades Crossing project (assuming a double circuit line) was added but given a separate rating from the West of Cascades South Path.

- The West of McNary and West of Slatt paths were modified to include the addition of the new McNary-John Day line.

- The South of Allston path was modified to reflect the I-5 Corridor project.

- The ratings of the West of Hatwai, North of Hanford and West of John Day paths were corrected. 


\section{Northeast and Basin}

- The Borah West and Bridger West paths were corrected to include the Gateway West project.

- The Aeolus South and Aeolus West paths were added with the Gateway West project.

- The Idaho to Northwest path was corrected to include the Hemingway-Boardman project along with the rating increase.

- The ratings of the new Montana-Alberta Intertie Line project path were corrected.

- The Path C, Idaho to Montana, TOT3 and TOT4B path ratings were corrected.

- The Midpoint West cutplane and Interstate WY-UT cutplane were added.

\section{California and Desert Southwest}

- To properly model the BANC BA, the COI was split into two separate paths with the COI connected to CAISO and the COTP connected to BANC (ratings were split pro rata).

- The Palo Verde East, Southern California import nomogram, SDGE import nomogram, NV Energy Southern Cutplane, Perkins-Mead-Marketplace, and Interstate AZ-CA paths were corrected.

\subsection{Hurdle Rates Assumptions}

The objective of imposing hurdle rates is to limit exchange between areas based on the economic hurdle needed to compete in a neighboring market. Two levels of hurdle rates were applied in this analysis: those between regional markets and those within the NWPP.

\subsubsection{Hurdle Rates between Regional Markets}

The hurdle rates between regional markets are used as an economic hurdle to participation in a neighboring market. The modeled regional markets are NWPP, Alberta, CAISO, Los Angeles Department of Water and Power (LADWP), Southwest, Rocky Mountain and Comisión Federal de Electricidad, México (CFE). The default hurdle rate is $\$ 6 / \mathrm{MWh}$ while the hurdle rate to exit CAISO is $\$ 10 / \mathrm{MWh}$. Internal hurdle rates are only considered within the NWPP. Figure 2.18 shows the modeled regions.

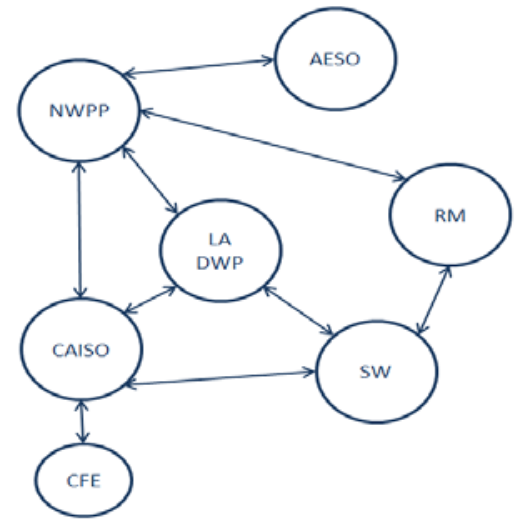

Figure 2.18. Regional Markets Structure for Hurdle Rates 


\subsubsection{Hurdle Rate within the NWPP}

When considering applying a hurdle rate within the NWPP, there are several issues to overcome. For instance, BAs acquire firm transmission to liquid hubs to make transactions, remote generation must have a firm path to the controlling BA, and hurdle rates must be applied between BAs to impose a minimum threshold for surplus power sales to neighboring BAs. Taking these factors into account, the default hurdle rate within the NWPP was set to \$2.5/MWh, with the following exceptions:

- BPA and MidC are considered the Hubs within the Northwest. No hurdle rate is applied when power leaves BPA or MidC.

- BAs in Washington and Oregon have the rights to most of the Colstrip plant output. These BAs utilize the majority of the power transfer capability on Path 8 (transmission out of NWMT). To account for this export from NWMT, no hurdle rate is applied from NWMT to BPA or AVA.

- PacifiCorp East and West are modeled as a control area. Transmission rights cannot be split; therefore no hurdle rate is applied between PACE to IPC to PACW.

The arrows in Figure 2.19 indicate the application of an internal hurdle rate in the NWPP.

A summary of the hurdle rates imposed on the 81 BA-to-BA flowgates is given in Table 2-15. These hurdle rates are applied in the DA, HA and BAU simulations. On the EIM simulations, the hurdle rate between NWPP BAs is set to zero.

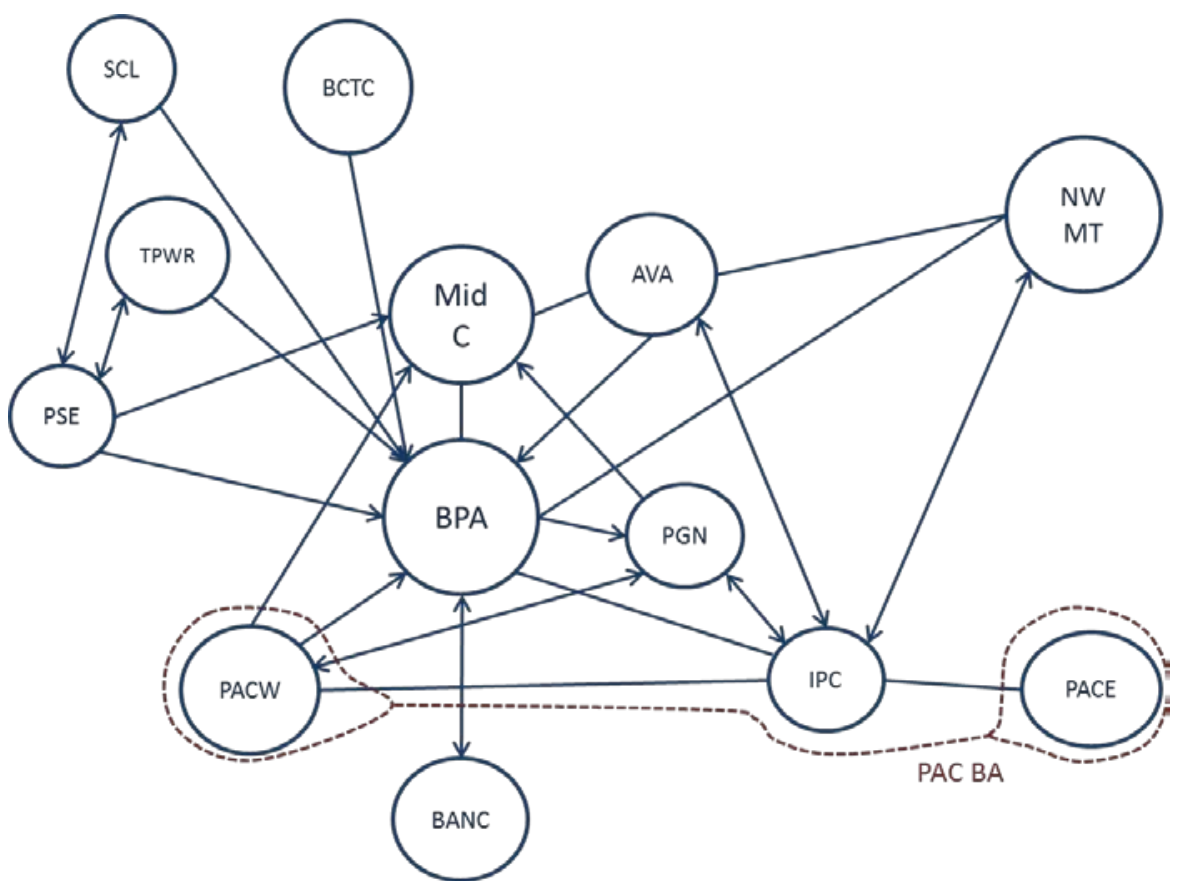

Figure 2.19. NWPP BA Structure for Hurdle Rates 
Table 2-15. Hurdle Rates Imposed on BA-to-BA Energy Transfers on DA, HA and BAU Simulations

\begin{tabular}{|c|c|c|c|}
\hline & & $\begin{array}{c}\text { Used Hurdle Rates } \\
\text { From-To } \\
\end{array}$ & $\begin{array}{l}\text { \$/MWh } \\
\text { To-From }\end{array}$ \\
\hline 1 & AESO_BCTC & 6 & 6 \\
\hline 2 & AESO_NWMT & 6 & 6 \\
\hline 3 & APS_CAISO & 6 & 10 \\
\hline 4 & APS_IID & 0 & 0 \\
\hline 5 & APS_LDWP & 6 & 6 \\
\hline 6 & APS_PNM & 0 & 0 \\
\hline 7 & APS_WALC & 0 & 0 \\
\hline 8 & AVA_BPA & 2.5 & 0 \\
\hline 9 & AVA_IPC & 2.5 & 2.5 \\
\hline 10 & AVA_NWMT & 2.5 & 0 \\
\hline 11 & BPA_BCTC & 0 & 2.5 \\
\hline 12 & BPA_CAISO & 6 & 10 \\
\hline 13 & BPA_CHPD & 0 & 0 \\
\hline 14 & BPA_DOPD & 0 & 0 \\
\hline 15 & BPA-GCPD & 0 & 0 \\
\hline 16 & BPA_LDWP & 6 & 6 \\
\hline 17 & BPA_NWMT & 0 & 0 \\
\hline 18 & BPA_PACW & 0 & 0 \\
\hline 19 & BPA_PGN & 0 & 2.5 \\
\hline 20 & BPA_PSE & 0 & 2.5 \\
\hline 21 & BPA_SPP & 6 & 6 \\
\hline 22 & BPA_TPWR & 0 & 2.5 \\
\hline 23 & CAISO_CFE & 10 & 6 \\
\hline 24 & CAISO_LDWP & 10 & 6 \\
\hline 25 & CAISO_SPP & 10 & 6 \\
\hline 26 & CAISO_TIDC & 10 & 6 \\
\hline 27 & CHPD_AVA & 0 & 2.5 \\
\hline 28 & DOPD_CHPD & 0 & 0 \\
\hline 29 & DOPD_GCPD & 0 & 0 \\
\hline 30 & EPE_TEP & 0 & 0 \\
\hline 31 & GCPD_AVA & 0 & 2.5 \\
\hline 32 & GCPD_PACW & 0 & 2.5 \\
\hline 33 & IID_CĀISO & 6 & 10 \\
\hline 34 & IPC_BPA & 0 & 0 \\
\hline 35 & IPC_PACE & 0 & 0 \\
\hline 36 & IPC_PACW & 0 & 0 \\
\hline 37 & IPC_PGN & 2.5 & 2.5 \\
\hline 38 & IPC_SCL & 0 & 0 \\
\hline 39 & IPC_SPP & 6 & 6 \\
\hline 40 & LDWP_PACE & 6 & 6 \\
\hline 41 & LDWP_SPP & 6 & 6 \\
\hline 42 & NEVP_CAISO & 6 & 10 \\
\hline 43 & NEVP_LDWP & 6 & 6 \\
\hline 44 & PACE_APS & 6 & 6 \\
\hline 45 & PACE_NEVP & 6 & 6 \\
\hline 46 & PACE_NWMT & 2.5 & 2.5 \\
\hline
\end{tabular}


Table 2.15. (Contd)

\begin{tabular}{|c|c|c|c|}
\hline & & $\begin{array}{c}\text { Used Hurdle Rates } \\
\text { From-To } \\
\end{array}$ & $\begin{array}{l}\text { \$/MWh } \\
\text { To-From }\end{array}$ \\
\hline 47 & PACE_SPP & 6 & 6 \\
\hline 48 & PACE_WALC & 6 & 6 \\
\hline 49 & PACW_AVA & 2.5 & 2.5 \\
\hline 50 & PACW_CAISO & 6 & 10 \\
\hline 51 & PACW_PGN & 2.5 & 2.5 \\
\hline 52 & PNM_EPE & 0 & 0 \\
\hline 53 & PNM_TEP & 0 & 0 \\
\hline 54 & PNM_WALC & 0 & 0 \\
\hline 55 & PSC_PNM & 6 & 6 \\
\hline 56 & PSC_WACM & 0 & 0 \\
\hline 57 & PSE_CHPD & 2.5 & 0 \\
\hline 58 & PSE_GCPD & 2.5 & 0 \\
\hline 59 & PSE_TPWR & 2.5 & 2.5 \\
\hline 60 & SCL_BPA & 2.5 & 0 \\
\hline 61 & SCL_PSE & 2.5 & 2.5 \\
\hline 62 & BANC_BPA & 6 & 2.5 \\
\hline 63 & BANC_CAISO & 6 & 10 \\
\hline 64 & BANC_TIDC & 0 & 0 \\
\hline 65 & SPP_NEVP & 0 & 0 \\
\hline 66 & SRP_APS & 0 & 0 \\
\hline 67 & SRP_CAISO & 6 & 10 \\
\hline 68 & SRP_TEP & 0 & 0 \\
\hline 69 & TEP_APS & 0 & 0 \\
\hline 70 & WACM_PACE & 6 & 6 \\
\hline 71 & WACM_PNM & 6 & 6 \\
\hline 72 & WACM_WALC & 6 & 6 \\
\hline 73 & WACM_WAUW & 6 & 6 \\
\hline 74 & WALC_CAISO & 6 & 10 \\
\hline 75 & WALC_IID & 0 & 0 \\
\hline 76 & WALC_LDWP & 6 & 6 \\
\hline 77 & WALC_NEVP & 0 & 0 \\
\hline 78 & WALC_PSC & 6 & 6 \\
\hline 79 & WALC_SRP & 0 & 0 \\
\hline 80 & WALC_TEP & 0 & 0 \\
\hline 81 & WAUW_NWMT & 2.5 & 2.5 \\
\hline
\end{tabular}

\subsection{Reserves Modeling}

Operating reserves are divided into contingency and balancing reserves. The contingency reserves are divided into spinning and non-spinning reserves. The balancing reserves are divided into loadfollowing and regulation reserves. In this study each BA is required to provide the different types of reserves through its own generation units. 


\subsubsection{Contingency Reserves}

The contingency spinning reserve requirement for each BA is assumed to be $3 \%$ of the BA hourly average load in the DA and HA simulation or the 10-minute average load in the BAU and EIM simulations. In addition, an equivalent amount of non-spinning reserve is required. It was assumed that all hydro units and fast starting thermal units can provide non-spinning contingency reserves.

\subsubsection{Balancing Reserves}

\subsubsection{Regulating Reserves}

Regulating reserves are balancing reserves utilized on a continuous basis to balance short-term, moment-to-moment fluctuations in load and resource generation. As this type of reserves must be constantly ready to respond to system balancing needs, regulating reserves must be met with spinning capacity. Regulating reserves are further restricted to resources that meet specific control or ramp rate requirements, such as automatic generation control (AGC), as identified by participants.

\section{Approach Used in this Study}

The flex reserve sub-team considered the merits of maintaining the regulating reserves methodology utilized by WECC and PUC in their EIM studies, which was modeled as one percent of load. Given the availability of BA intra-hour load and wind data, the team decided that the PNNL-proposed algorithm [12] would provide a more accurate representation of regulating reserves requirements for each BA rather than one based on hourly load values.

The PNNL regulating reserves algorithm calculates regulating values by subtracting the 10 -minute average load from the 1-minute average load, and the 10-minute average wind generation from the 1-minute average wind generation. Using a year's worth of load and wind data resulted in 525,600 minute-level regulating reserves values, which were then sorted to create a regulating-reserves distribution for each month and operating hour. The regulating reserves requirement for each month and hour were set by calculating a 95\% confidence interval (CI) for each distribution, where the values corresponding to the $2.5 \%$ and $97.5 \%$ percentiles provide the decremental regulating capacity (to balance decreases in load or increases in generation) and incremental regulating capacity (to balance increases in load or decreases in generation), respectively. Thus, procuring regulating reserve capacity equivalent to the values at those CI percentiles — based on actual load, wind and solar data - would be sufficient to balance $95 \%$ of the minute-level deviations from the 10-minute average in the operating hour.

\subsubsection{Load-Following (Flex) Reserves}

Beyond the 10-minute time frame, additional balancing reserves are necessary to manage longer-term changes in load and wind, and compensate for forecast errors, over the course of the operating hour. These reserves are commonly termed "load following” reserves, and in this study the term "flex" reserves is used.

Previous EIM modeling efforts (e.g., WECC and PUC) assumed that the quantity of flex reserves should be less in the EIM scenario than in the BAU scenario. This is due to the diversity benefit that is 
expected when renewable resource and load scheduling errors are netted over a broader footprint. However, participants in the present study expect that each BA will be required to have sufficient capacity to manage their own energy imbalances in both the BAU and EIM scenarios. While it is widely understood that an organized market capable of netting scheduling errors and generation imbalance will reduce the capacity needed to provide imbalance energy, under an EIM each BA will still be responsible for their own Area Control Error (ACE) and other reliability metrics, necessitating that each BA commits sufficient balancing capacity for their own needs, identical to the BAU scenario. With that as a foundational assumption, the EIM is envisioned to provide a means to optimize the dispatch of flex reserves over the larger NWPP footprint.

\section{Approach Used in this Study}

The primary drivers of flex reserves are the uncertainties in load and wind forecasts and the resulting forecast errors balanced in RT. To derive flex reserve requirements, simulated hourly load and wind forecast errors were generated for each BA. These errors were then sorted by the operating hour (to account for temporal changes in the need for flex reserves) and the 95\% CI of hourly errors sets the flex reserve requirement. Larger or smaller CIs can be determined based on the risk preferences of BA operators. All study cases rely on a 95\% CI for flex reserves, with the exception of Case 1.86B which sets a larger flex reserves target at a $99.5 \% \mathrm{CI}$.

Two methodologies are used in this study to simulate the load and wind forecast errors. The forecast error for wind is based on 30-minute persistence forecasts, in which the wind generation observed at 30 minutes prior to the next hour is set as the schedule for the subsequent hour. The load forecast error methodology, called the "Swinging Door Algorithm," uses a statistical distribution to simulate load errors. This error is assumed to follow the shape of a truncated normal distribution (TND), which is characterized by a mean, a standard deviation and an autocorrelation coefficient. The mean and standard deviation are calculated as a percentage of the peak load and determine the shape of the TND.

The methodology utilizes the autocorrelation to reflect the relationship of a forecast error at time $t$ with that of the forecast error at time $t-1$. Typically, if there is a large forecast error at time $t$, it is likely, especially for load, and to a lesser degree for wind, that there will be a similar error in both direction and magnitude at time $t-1$. The autocorrelation coefficient is calculated from actual time series data of load errors from NWPP participants.

These three statistical values (standard deviation, mean and autocorrelation) enable the simulation of load forecast errors that are used in both the DA and HA load forecasts. BPA, PGN, and PSE provided these three statistical values for HA load forecast error, which are summarized in Table 2-16.

As shown in Table 2-16, in this study the Swinging Door Algorithm utilized a standard deviation of $0.48 \%$ of peak load, a mean error of $0 \%$ of peak load and an autocorrelation coefficient of 0.355 for generating HA load forecast errors. The recommended values for the mean and standard deviation are averages of BPA and PSE values while the autocorrelation is the average of BPA, PSE, and PGN values. These load forecast error statistical values were used to derive the HA load forecast error and consequently the load HA forecast values. 
Table 2-16. Hour-Ahead Load Forecast Error Metrics

\begin{tabular}{lccc}
\hline \multicolumn{1}{c}{ Entity } & Mean/Peak & Standard Deviation/Peak & Autocorrelation \\
\hline BPA & $0.0 \%$ & $0.54 \%$ & 0.232 \\
PGN & $1.1 \%$ & $0.95 \%$ & 0.522 \\
PSE & $0.0 \%$ & $0.41 \%$ & 0.310 \\
Algorithm Inputs & $\mathbf{0 . 0 \%}$ & $\mathbf{0 . 4 8 \%}$ & $\mathbf{0 . 3 5 5}$ \\
\hline
\end{tabular}

Another important input to this methodology is the CI to assume for the flex reserve calculations. PSE uses 95\% to compute their balancing requirements while BPA uses 99.5\%. Subject matter experts at BPA assessed the impacts of using each of the CIs and concluded that the $95 \%$ CI generally worked well, although it is expected at this lower CI there will be insufficient reserves for some significant wind ramps. The PNNL algorithm allows for the possibility of using BA-specific CIs but thorough data on this appeared to be difficult to obtain. Therefore, the selection of the CI for the Base Case became a tradeoff between those used by PSE and BPA.

The PNNL methodology applied this CI by including 95\% of the 31, 30 or 29 days of each month in the year 2020 for each hour of the day. This yielded 24 up and down flex capacity reserve obligations per month, one calculated for each hour of the day. In contrast, BPA included $99.5 \%$ of all 8760 hours in the assumed year to calculate one flat flex reserve obligation that was applied to all hours.

From the perspective of calculating a conservative societal benefit, both the $95 \% \mathrm{CI}$ and the shaped hourly flex reserve obligation represent reasonable assumptions for the Base Case in this study. Since BPA holds reserves at a flat shape and higher CI (99.5\%), the study using a lower reserve quantity and an hourly reserve shape would produce results that show less benefit than if modeled with a higher CI and flat reserve. A sensitivity case (1.86B) was run at the $99.5 \% \mathrm{CI}$ to reflect the base balancing reserve service provided by BPA.

\subsubsection{Benchmarking with PSE Data}

To benchmark the PNNL flex reserve methodology, actual calculated balancing reserve values provided by PSE were compared to the modeled reserve requirements. Figure 2.20 shows the results of this test at a 95\% CI using actual PSE wind and load data for a year. The hourly flex reserve quantities derived from a forecast error algorithm developed by PNNL match values calculated by PSE and PNNL based on the actual load forecast error supplied by PSE and a 30-minute persistence forecast for wind resources of PSE.

The test results reported in Figure 2.20 indicate that the PNNL flex reserve algorithm is a reasonable methodology for computing flex reserves for the NWPP EIM study. Accordingly, it was used with the assumptions that have been discussed in this section. These assumptions are summarized in Table 2-17. 


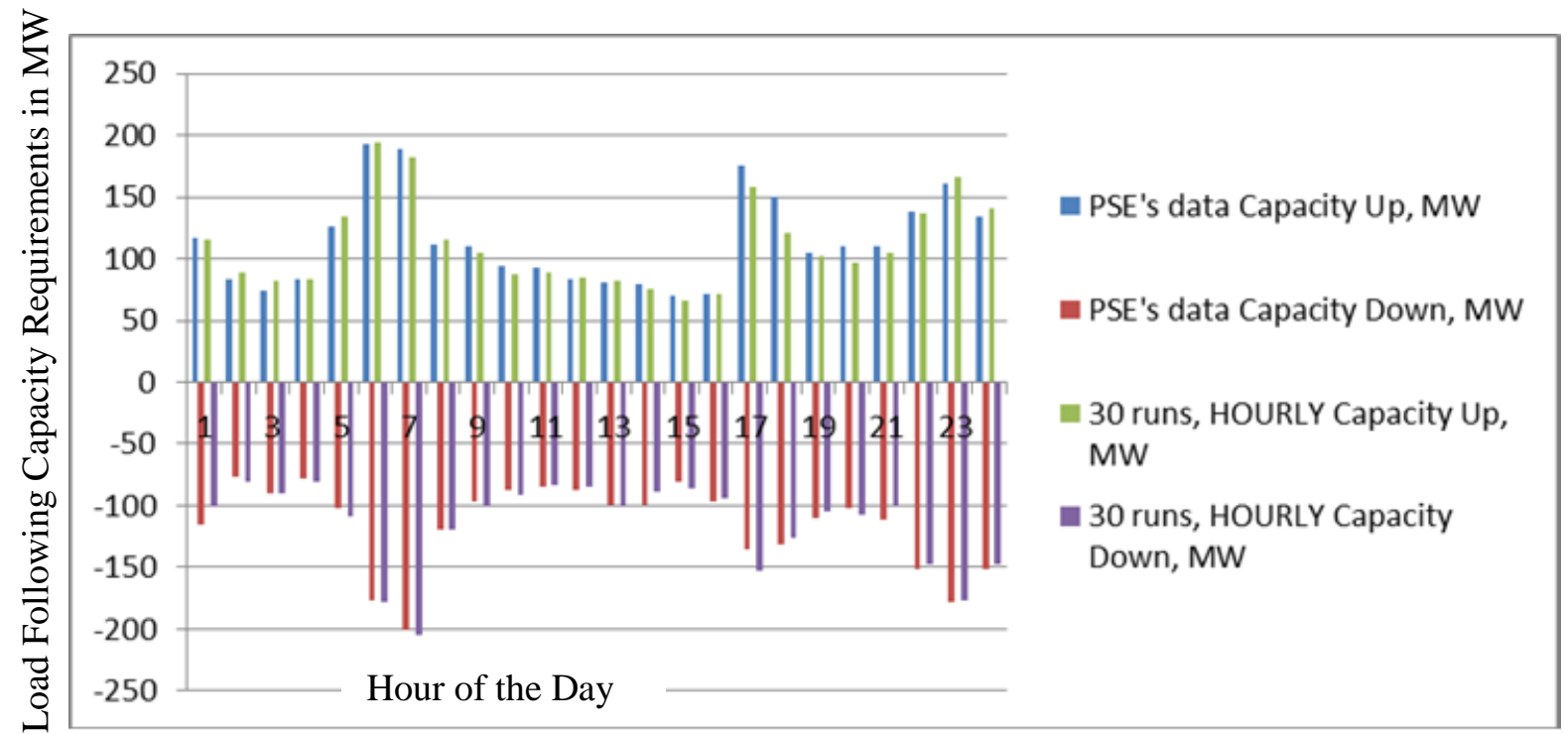

Figure 2.20. PSE 95\% CI of Flex Reserves, Actual Requirements and Swinging-Door Simulated Requirements

Table 2-17. Summary of Balancing Reserves Assumptions

\begin{tabular}{ll}
\hline \multicolumn{1}{c}{ Flex Reserve Input } & \multicolumn{1}{c}{ Study Assumption } \\
\hline Wind HA forecast error basis & $t-31$ persistence \\
Load HA forecast error: & \\
Standard deviation & $0.48 \%$ of peak load \\
Mean & $0 \%$ of peak load \\
Autocorrelation & 0.355 \\
Confidence interval & $95 \%$ \\
Flex reserve shape & Per hour of day per month \\
\hline
\end{tabular}





\subsection{Simulation Approach}

\subsection{Rules of Production Cost Modeling}

Production cost simulation is widely used in short- and long-term planning in the power industry. The following rules are applicable to commercially available production-cost software packages:

1. Production cost models assume a single-owner dispatch, i.e., it optimizes the entire modeled footprint

2. The assumptions in rule number 1 cannot be changed.

3. However, layers of constraints can be incorporated that help mimic the behavior seen in the market. The problem is in determining what set of constraints mimic historic behavior. The following constraints can be applied when modeling:

a. Topology: Divide the modeled footprint into geographic areas based on load and/or transmission constraints within the system.

b. Reserves: Apply reserve requirements to individual areas, and/or aggregated areas, pools and regions. This sets a minimum level of commitment to meet reserve requirements.

c. Local generation requirements: Used to force minimum local generation requirements for unit commitment and dispatch.

d. Hurdle rates: Used to impede economic commitment and dispatch between areas.

e. Minimum up or down times: Used to model physical limitations of different types of power plants that impact commitment decisions.

f. Startup costs: Impacts unit commitment and de-commitment decisions.

g. Bidding: Used to change the placement of resources within a local and regional supply stack.

\subsection{Overview of PLEXOS}

PLEXOS ${ }^{\circledR}$ for Power Systems is a proven power market simulation software package that uses cutting-edge mathematical programming and stochastic optimization techniques combined with the latest user-interface and data handling approaches to provide the most comprehensive, easy-to-use and robust analytical framework for power market modeling and simulation.

PLEXOS capabilities include energy-AS-DC-OPF co-optimization with the optimization interval ranging from multiple-hours to one-minute.

To enforce the medium- and long-term constraints, such as monthly hydro energy, yearly emission limits, etc., PLEXOS uses both a MT-optimization and ST-optimization approach. The MT optimization minimizes the system cost in an optimization window covering the longest constraint periods to decompose the medium- and long-term constraints into the ST optimization windows. The ST optimization will minimize the system cost in a shorter window honoring the decomposed medium- and long-term constraints. The following subsection describes the MT and ST optimization. 


\subsubsection{PLEXOS Mid-Term (MT) Simulation and Short-Term (ST) Simulation}

PLEXOS includes the following three integrated algorithms:

- Long-term security assessment

- The long-term security assessment algorithm schedules maintenance outages by examining either daily or weekly capacity reserve margins. Based on the user-defined maintenance rates and average times needed to make repairs, maintenance events are scheduled in a manner that levels the daily or weekly capacity reserve margin. Also, the random forced outage events are produced based on the user-defined, forced outage rates and average times needed to make repairs.

- Mid-term simulation

- $\quad$ The mid-term schedule algorithm decomposes medium-term fuel, emission, and energy constraints into the short-term optimization windows for the short-term simulation.

- Short-term simulation

- The short-term schedule algorithm performs chronological unit commitment and economic dispatch of resources.

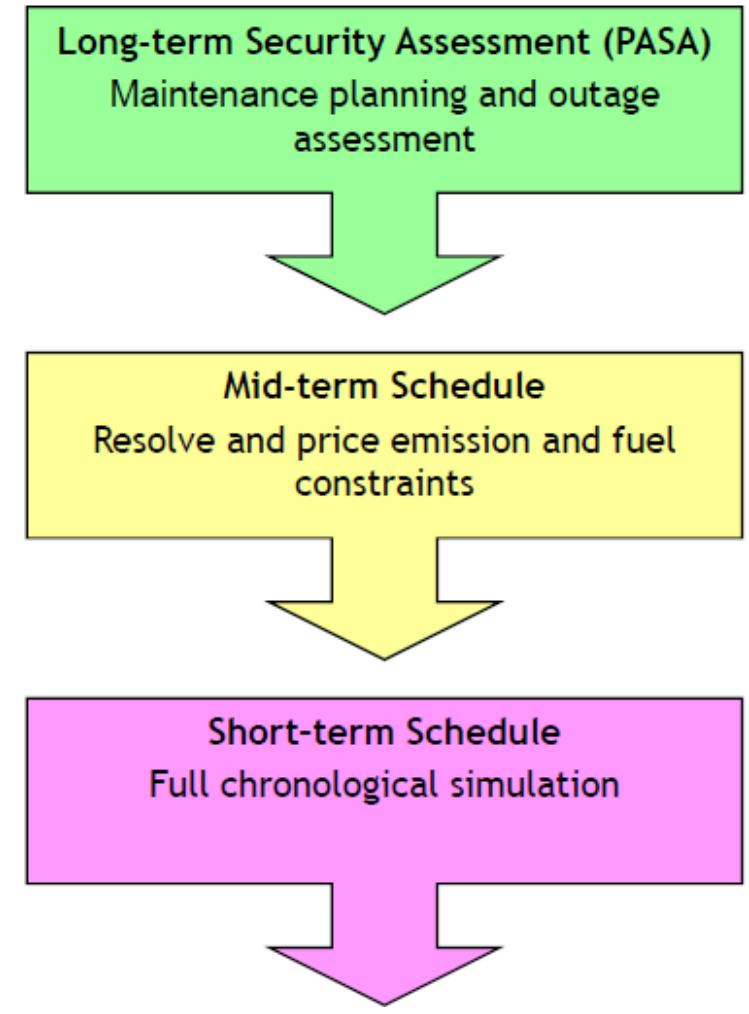

Figure 3.1. PLEXOS Mid-term and Short-term Scheduling Modules

The MT and ST scheduling modules minimize system costs while honoring a group of constraints that include the following:

a. system energy balance constraints;

b. ancillary service requirement constraints; 
c. generator generation and ancillary services (AS) provision constraints;

d. resource constraints such as fuel, energy, emission, etc. limits;

e. generator chronological constraints;

f. transmission binding constraints;

g. user-defined constraints;

h. other constraints.

Though the optimization formulations are the same, the differences between the MT optimization and ST optimization are the following:

1. The time interval in the ST optimization can range from multiple hours to one minute. The intervals in the MT optimization are multiple intervals in the ST optimization with the interval in the MT optimization being referred to as the "time bucket." For example, if the interval in the ST optimization is 10 minutes, the intervals (or time buckets) in the MT optimization could be a single 10-minute period up to multiple 10-minute periods.

2. Since the time buckets in the MT optimization are multiple intervals in the ST optimization, the MToptimization window can be long enough to cover the longest constraint period. For example, the ST-optimization window can range from a fraction of an hour to one week. In contrast, the MToptimization window can range from a week to a year to cover weekly, monthly or yearly constraints.

3. Depending on how the MT-optimization window is sliced into time buckets, the time intervals in the time buckets can be consecutive or independent. In the former case, the chronological constraints are enforced in the MT optimization between time buckets. In the latter case, the chronological constraints are ignored in the MT optimization.

In this study, when decomposing the monthly hydro energy into the ST-optimization window, the time buckets in the MT optimization are independent and the MT optimization window is monthly.

\subsubsection{PLEXOS SCUC/ED Algorithm}

The security constrained unit commitment (SCUC) algorithm in PLEXOS consists of two major logics: Unit Commitment using Mixed Integer Programming and Network Applications. The SCUC/Economic Dispatch (ED) simulation algorithm is depicted in Figure 3.2. 


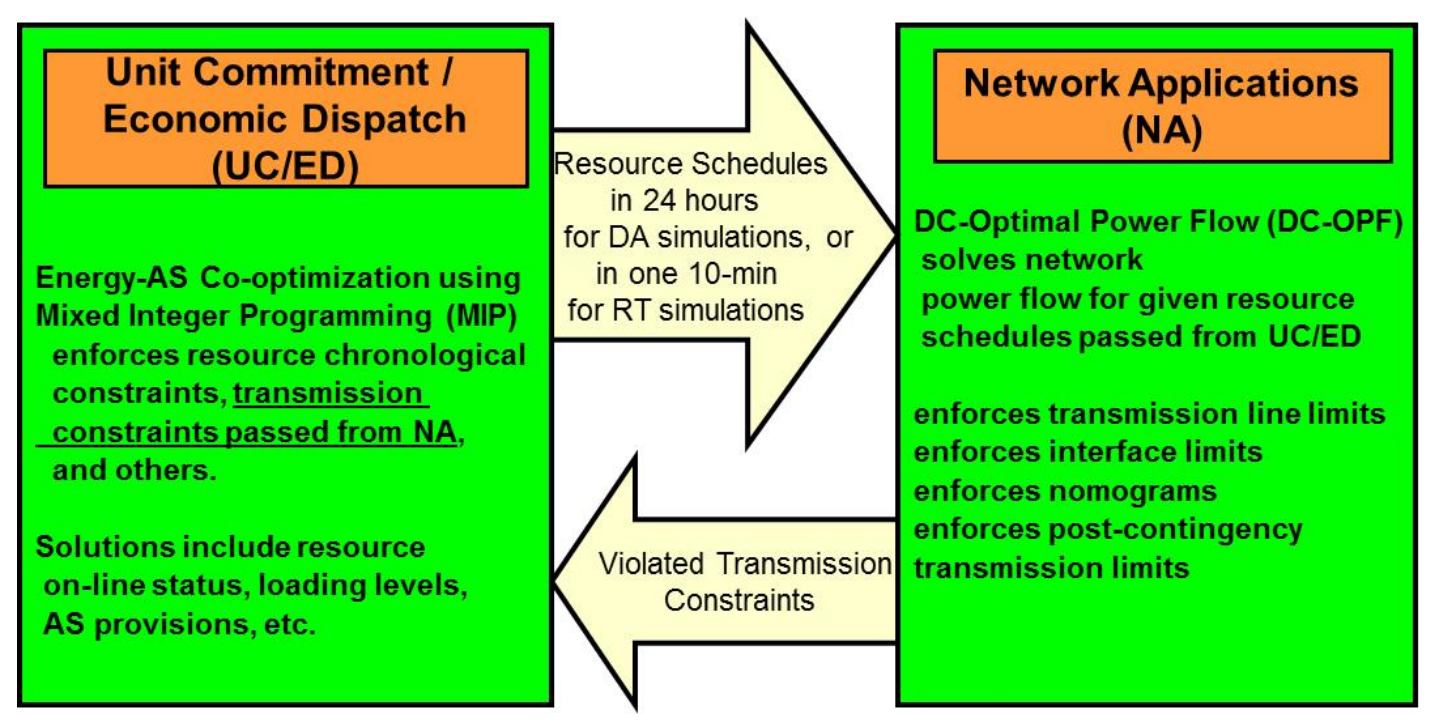

Figure 3.2. PLEXOS Security-Constrained Unit Commitment and Economic Dispatch Algorithm

The unit commitment and economic dispatch (UC/ED) logic performs the energy-AS co-optimization using mixed integer programming that enforces all resource and operation constraints. The UC/ED logic commits and dispatches resources to balance the system energy demand while meeting the system reserve requirements.

The resource schedules from the UC/ED are passed to the network applications logic. The network applications logic solves the DC optimal power flow (OPF) in a manner that enforces the power flow limits and nomograms. The network applications logic also performs the contingency analysis, if the contingencies are defined. If there are any transmission limit violations, these transmission limits are passed to the UC/ED logic for the rerun of UC/ED. The iterations continue until all transmission limit violations are resolved. Thus, the co-optimization solution of energy-AS-DC-OPF is reached.

The same algorithm used in PLEXOS for the SCUC/ED is used by many ISO market scheduling software packages (some ISO market scheduling software packages may use AC-OPF in the network applications logic).

\subsubsection{PLEXOS 3-Stage Sequential DA-HA-RT Simulations}

In this study, the system operation is treated in PLEXOS in a three-stage sequential manner: day ahead (DA)-hour ahead (HA)-RT, as shown in Figure 3.3. The DA simulation mimics the DA unit commitment in the real world; the HA simulation mimics the intra-day unit commitment in real time; the RT simulation mimics the sub-hourly economic dispatch in the real world. The detailed assumptions of the three-stage simulations are described in the following three subsections. 


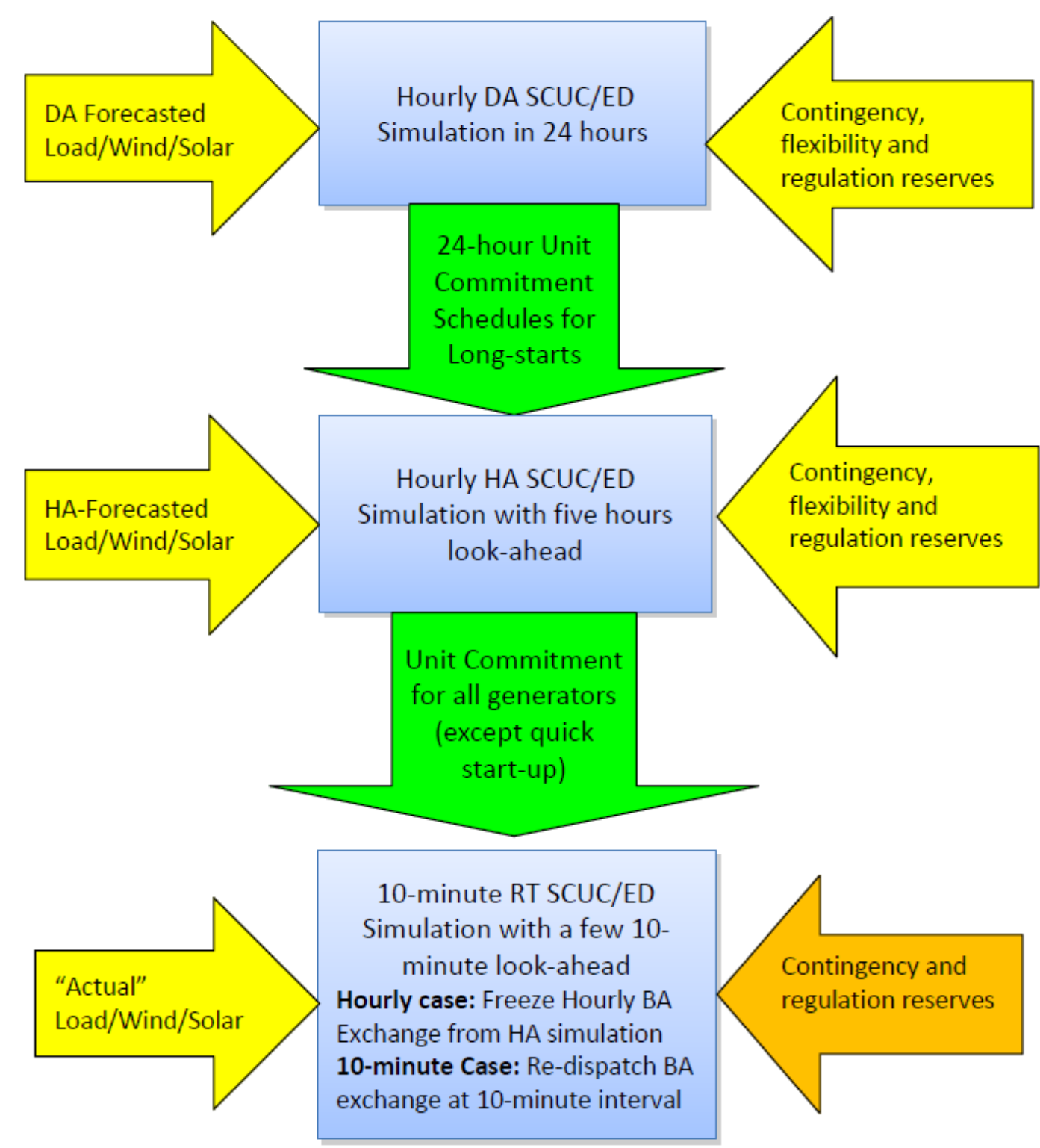

Figure 3.3. Three-Stage DA-HA-RT Sequential Simulation Approach

\subsubsection{Day-Ahead Commitment}

With day-ahead forecasts for load, wind, and solar as inputs, PLEXOS runs the unit commitment at the BA level according to generation constraints (minimum up time, minimum down time, ramp rate, maximum and maximum capacity, etc.) The main components of this stage are the following:

- Day-ahead forecasted load/wind/solar generation time series data are used;

- The SCUC/ED optimization window is 24 hours with hourly intervals;

- The contingency, flexibility up/down, and regulation up/down reserves constraints are met. 


\subsubsection{Hour-ahead Dispatch with Limited Commitment}

Using refined hour-ahead load, wind, and solar forecasts, PLEXOS runs the hour-ahead dispatch at the BA level. At this stage, only fast-starting units can be committed. Final interchange schedules between BAs are calculated according to results from the dispatch. The main components of this stage are the following:

- The hour-ahead forecasted load/wind/solar generation time series data are used;

- The SCUC/ED optimization window is one hour plus five-hour look-ahead with hourly intervals;

- The unit commitment patterns from the DA simulation are frozen for generators with minimum up/down times greater than five hours;

- The contingency, flexibility up/down, and regulation up/down reserves constraints are met.

\subsubsection{Real-time Dispatch}

With real-time (10-minute interval) load, wind, and solar data provided and unit commitment fixed from the hour ahead dispatch, PLEXOS runs the final dispatch, taking into account all specified constraints (minimum up and down time, maximum up and down time, minimum and maximum capacity, ramp rate, reserve requirement, fuel cost, etc.).

To model the Control Performance Standard 2 (CPS2) reliability requirement at the BA level in the

BAU scenario, the BA interchange schedules from the hour-ahead dispatch are locked down such that the deviations are within the $\mathrm{L}_{10}$ band at each hour ( $+\mathrm{L}_{10}$ and $-\mathrm{L}_{10}$ at each hour) to form the exchange up and down limit schedule. The value of $\mathrm{L}_{10}$ was assumed to be $10 \mathrm{MW}$ for all BAs to limit economical transactions in this band as it is mainly a reliability criterion.

In the EIM scenario, the exchanges between the BAs within the EIM were free to be rescheduled at 10-minute intervals (within the $\mathrm{L}_{10}$ band), and the BA exchanges outside of the EIM were still locked down with the deviations being within the assumed $10 \mathrm{MW} \mathrm{L}_{10}$ band.

The main components of the 10-minute simulation are the following:

- The actual 10-minute load/wind/solar generation time series data are used;

- The SCED optimization window is 10 minutes plus five sequential 10-minute increment periods;

- The unit commitment patterns from the HA simulation are frozen for all units including peaking units;

- The contingency and regulation up/down reserves constraints are modeled in a similar manner to what was used for the DA and HA periods. However, the up/down flexible reserves constraints are no longer included in the RT period as the flex reserves are deployed during the RT period. The implication is that the capacity held in the HA simulation for the flexibility reserves is deployed to cover the load and renewable generation variability and uncertainty at the 10-minute interval.

In all three stages, the transmission network was modeled at the nodal level. The optimization calculations were done on a WECC-wide basis at the BA level. 
In order to quantify the benefit of an EIM relative to current operations, two scenarios were developed that differed during the RT period. These are the BAU scenario and the EIM scenario.

\subsubsection{NWPP BAU Modeling}

In the BAU scenario, each BA is required to meet its own reserve requirements. Power transfers between the BAs are subject to hurdle rates imposed on the transmission paths as specified in this study.

\subsubsection{NWPP EIM Modeling}

In this scenario, the BAs specified as being members of the NWPP EIM were grouped into a single large BA before the final dispatch of resources. The BAs that were grouped to form the NWPP EIM footprint are AVA, BCTC, BPA, IPC, MidC, NWMT, PAC, PGN, PSE, SCL, BANC, TIDC, TPWR, and WAUW. In this scenario, hurdle rates were not applied to power transferred between the BAs that are members of the NWPP EIM. However, power transfers between the NWPP EIM and other BAs and between BAs outside of the NWPP EIM were subjected to hurdle rates imposed on the transmission paths between them. In addition, the net exchanges between NWPP EIM and other BAs and between BAs outside of the NWPP EIM were locked down to HA values. The production cost benefit from an EIM is the cost difference between the BAU scenario and the EIM scenario as illustrated in Figure 3.4.

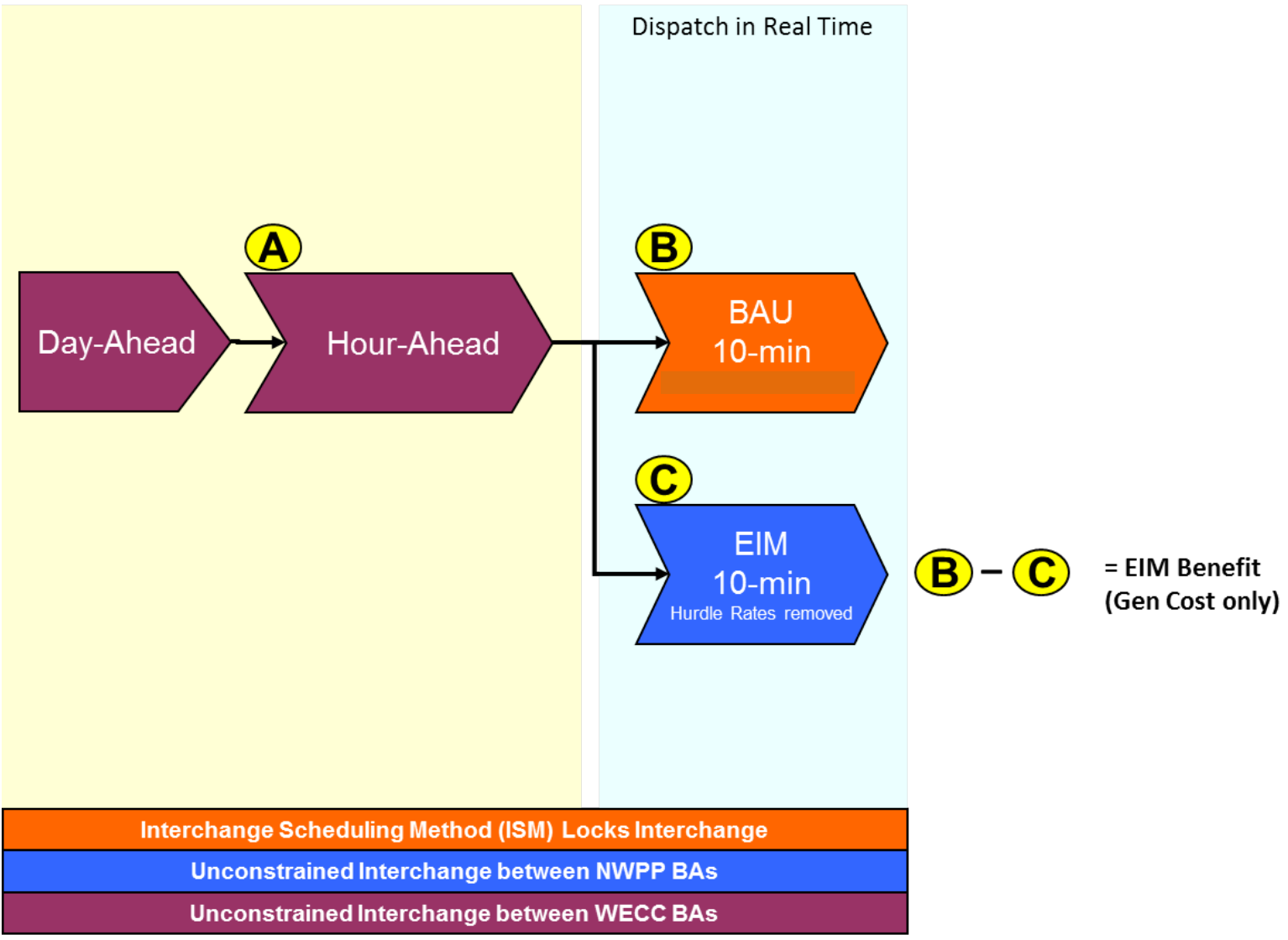

Figure 3.4. Evaluation of NWPP EIM Benefits 


\subsubsection{Soft Constraint Violation Penalties in the Model}

During the UC/ED process, many constraints are implemented in the model and enforced during the simulation process. By default, these constraints are "hard" constraints. Such constraints make it harder, and sometimes impossible, for a model to obtain a feasible solution. To reduce this computational burden, PLEXOS provides a means to allow certain constraints to be violated but with a penalty added to the objective function. The relative quantity of each violation type can be controlled by introducing different penalty price levels. If the optimization algorithm can not find an optimal solution without violating any of the soft constraints, it will then try to find a solution that minimizes the penalty costs associated violating the soft constraints.

In this study, the penalty prices for limit violations of various variables are reported in Table 3-1. The relative ranking of three of the violation types—hydro plant maximum energy, BA net exchange, and WECC-wide unserved energy - is especially worth noting. When the system had to violate some constraints to balance supply and demand, it was decided that the system would first violate hydro plant maximum energy, then WECC-wide unserved energy, and finally BA net exchange. This is reflected in the relative level of the penalty prices of $1 \mathrm{e} 5,1 \mathrm{e}$, and 1e10 \$/MWh for the three violation types mentioned above, respectively.

Table 3-1. Penalty Price Input Used in the Model

\begin{tabular}{|c|c|c|}
\hline Penalty Type & Penalty Price & Unit \\
\hline Max Ramp Up Penalty & 450 & \$/MW \\
\hline Max Ramp Down Penalty & 450 & $\$ / M W$ \\
\hline Hydro Max Energy Penalty & 100,000 & $\$ / M W h$ \\
\hline Fixed Pump Load Penalty & $100,000,000$ & $\$ / M W h$ \\
\hline Dump Energy & -1000 & $\$ / \mathrm{MWh}$ \\
\hline Line Limit Penalty & $2000 / 6000$ & $\$ / M W h$ \\
\hline Phase Shifter Penalty & $50 / 100 / 200 / 300 / 1000$ & $\$ /$ degree \\
\hline Interface Limit Penalty & 6,000 & $\$ / M W h$ \\
\hline Storage Target Constraint Penalty & $1,000,000$ & $\$ / M W h$ \\
\hline Nomograms Constraint Penalty & 6,000 & $\$ / M W h$ \\
\hline BA Net Exchange Penalty & $10,000,000,000$ & $\$ / M W h$ \\
\hline Reserve Limit Constraint Penalty & 1,000 & $\$ / M W h$ \\
\hline Unserved Energy & $10,000,000$ & $\$ / M W h$ \\
\hline Reserve Shortage & 250 & $\$ / M W h$ \\
\hline
\end{tabular}

\subsection{Description of Base Case and Sensitivity Cases}

The Base Case, named 1.86A, was formed by implementing in PLEXOS the various changes discussed in the previous sections and setting the flex reserves target at a 95\% CI. The sensitivity cases are variations from the Base Case and are defined in Table 3-2 Simulation results for the Base Case and all the sensitivity cases are discussed in Section 4.2. 
Table 3-2. Definition of Sensitivity Cases

\begin{tabular}{|c|c|c|}
\hline $\begin{array}{l}\text { Case } \\
\text { no. }\end{array}$ & Case name & Case description \\
\hline 1 & $\begin{array}{c}1.86 \mathrm{~A} \\
\text { (Base Case) }\end{array}$ & $\begin{array}{l}\text { - 95\% Confidence Interval (CI) used to calculate balancing reserve (load } \\
\text { following and regulation) requirements for each BA } \\
\text { - Held reserves constant between the EIM and BAU scenarios } \\
\text { - Footprint: NWPP EIM } \\
\text { - Annual average nominal natural gas price of } \$ 5.62 \text { per MMBtu at Henry Hub } \\
\text { in } 2020 \\
\text { - } 2006 \text { hydro energy used to represent average water ( } 2003 \text { for CA) } \\
\end{array}$ \\
\hline 2 & $\begin{array}{l}1.86 \mathrm{~B} \\
\text { (Increased Flex Reserve } \\
\text { Case) }\end{array}$ & $\begin{array}{l}\text { - Same as 1.86A but with a 99.5\% CI for flex reserves in the BAU and EIM } \\
\text { scenarios }\end{array}$ \\
\hline 3 & $\begin{array}{c}1.86 \mathrm{C} \\
\text { (3\% Held-back Case) }\end{array}$ & $\begin{array}{l}\text { - Same as } 1.86 \mathrm{~A} \text { but with } 3 \% \text { of the available hydro energy from flexible } \\
\text { hydro plants and } 3 \% \text { of the maximum available thermal capacity held back in } \\
\text { the DA and HA periods. } \\
\text { - There is no hydro energy or thermal capacity held back in the real-time } \\
\text { dispatch in the BAU and EIM scenarios }\end{array}$ \\
\hline 4 & $\begin{array}{l}\text { 1.86D } \\
\text { (WECC-Wide EIM } \\
\text { Case) }\end{array}$ & $\begin{array}{l}\text { - Same as 1.86A but with a WECC-wide EIM (only one large region that } \\
\text { covers all BAs in the WECC for the EIM scenario) } \\
\text { - The BAU scenario is the same as the BAU scenario for 1.86A }\end{array}$ \\
\hline 5 & $\begin{array}{c}1.86 \mathrm{E} \\
\text { (High Natural Gas Price } \\
\text { Case) }\end{array}$ & $\begin{array}{l}\text { - Same as 1.86A but with a high natural gas price assumption in the BAU and } \\
\text { EIM scenarios as discussed in Section 2.3.5 }\end{array}$ \\
\hline 6 & $\begin{array}{l}1.86 \mathrm{~F} \\
\text { (Low Natural Gas Price } \\
\text { Case) }\end{array}$ & $\begin{array}{l}\text { - Same as } 1.86 \mathrm{~A} \text { but with a low natural gas price assumption in the BAU and } \\
\text { EIM scenarios as discussed in Section 2.3.6 }\end{array}$ \\
\hline 7 & $\begin{array}{l}1.86 \mathrm{G} \\
\text { (Reduced EIM Flex } \\
\text { Reserve Case) }\end{array}$ & $\begin{array}{l}\text { - Same as } 1.86 \mathrm{~A} \text { but with reduced load-following reserves within the NWPP } \\
\text { footprint for the EIM scenario. } \\
\text { - The BAU scenarios is the same as the BAU scenarios for 1.86A }\end{array}$ \\
\hline 8 & $\begin{array}{l}1.86 \mathrm{H} \\
\text { (NWPP EIM w/o PAC } \\
\text { Case) }\end{array}$ & $\begin{array}{l}\text { - Same as } 1.86 \mathrm{~A} \text { but with PAC not included in the NWPP for the BAU and } \\
\text { EIM scenario. }\end{array}$ \\
\hline 9 & $\begin{array}{c}1.86 \mathrm{I} \\
\text { (6\% Held-back Case) }\end{array}$ & $\begin{array}{l}\text { - Same as } 1.86 \mathrm{~A} \text { but with } 6 \% \text { of the available hydro energy from flexible } \\
\text { hydro plants and } 6 \% \text { of the maximum available thermal capacity held back in } \\
\text { the DA and HA periods. } \\
\text { - There is no hydro energy or thermal capacity held back in the real-time } \\
\text { dispatch in the BAU and EIM scenarios. }\end{array}$ \\
\hline 10 & $\begin{array}{c}1.86 \mathrm{~J} \\
\text { (Low Water Case) }\end{array}$ & $\begin{array}{l}\text { - Same as 1.86A but with low hydro generation in the PNW (dry year 2001) in } \\
\text { the BAU and EIM scenarios as discussed in Section 2.4.6 }\end{array}$ \\
\hline 11 & $\begin{array}{c}1.86 \mathrm{~K} \\
\text { (High Water Case) }\end{array}$ & $\begin{array}{l}\text { - Same as 1.86A but with high hydro generation in the PNW (wet year 2011) } \\
\text { in the BAU and EIM scenarios as discussed in Section 2.4.6 }\end{array}$ \\
\hline 12 & $\begin{array}{c}1.94 \\
\text { (Hydro Modeling } \\
\text { Improvement Case) }\end{array}$ & $\begin{array}{l}\text { - Same as 1.86A but with improved modeling of hydro generation scheduling } \\
\text { in the BAU and EIM scenarios. } \\
\text { - Optimized the real-time dispatch in 12-hour increments to better represent } \\
\text { the information that hydro scheduler have when making decisions. } \\
\text { - Individual hydro plant units were aggregated into fewer units. } \\
\text { - Hydro energy constraints were enforced weekly rather than monthly. }\end{array}$ \\
\hline
\end{tabular}




\subsection{Benefits of an EIM Relative to the Efficiency of the BAU}

In the course of developing the study methodology, the NWPP MC made the following comment on the Western PUC EIM study:

"When the automated energy market results of the EIM case are compared to the Business as Usual (BAU) without consideration for the present efficiencies and enhancements, ascribing the entire difference to the EIM could skew results. Even without an automated centralized market, it is expected that BAU efficiencies will continue to increase, rather than diminish, in the future."

Given the direction from the NWPP MC executives to identify a minimal, conservatively achievable range of annual benefits ascribable to an EIM, the methodology employed in this study was to model a highly efficient bilateral market in the BAU scenario. This task was accomplished by optimizing the dispatch of resources throughout the WECC during the day-ahead and hour-ahead periods in PLEXOS. This highly efficient dispatch of resources lowered the production costs in the BAU scenario, which impacted the magnitude of the benefits ascribed to an EIM because the benefits of an EIM were derived by subtracting the production costs of the EIM scenario from the production costs of the BAU scenario. Therefore, all other things being equal, a lower production cost for the BAU scenario reduced the difference in production costs between the BAU scenario and the EIM scenario.

Utilities in the Pacific Northwest have undertaken multiple efforts over time to increase the efficiency of the dispatch of resources within the region. For example, numerous BAs receive energy each hour from outside their Balancing Authority Area (BAA) by way of ownership rights to efficient generating resources such as the Mid-Columbia hydroelectric projects built by Chelan, Douglas and Grant Public Utility Districts, the Columbia Generating Station nuclear plant and several coal-fired plants located east of the Cascade Mountains.. Accordingly, the energy produced from these types of projects were appropriately modeled to reflect their value in the BAU scenario, rather than ascribing the benefits that have been gained from these long-standing regional efforts to an EIM that has not been developed.

Both the efficient dispatch resulting from the WECC-wide optimization of resources, as well as the numerous bilateral arrangements, were reflected in the BAU and EIM scenarios by locking the interchange schedules that result from the day-ahead and hour-ahead time steps in PLEXOS. In the BAU scenario, each BA was responsible for dealing with the variability of its loads and generation from variable energy resources with its own resources for the one-hour scheduling interval. In the EIM scenario, the BAs in the NWPP EIM optimized their dispatch of resources for each 5-minute interval inside the one-hour scheduling interval. This approach was a key factor in the derivation of a minimal, conservatively achievable annual range of benefits ascribable to an EIM.

\footnotetext{
${ }^{1}$ Letter to Mr. Jason Marks, Chair, Western PUC EIM Task Force, August 31, 2012, page 3.
} 


\subsection{Methodologies for Parsing the EIM Benefits for Individual BAs in the NWPP}

\subsubsection{Using Locational Imbalance Prices (LIPs) to Track Costs and Benefits}

At the outset of this investigation, the parties envisioned using results directly from the production cost model to parse the benefits from an EIM on a zonal basis. By comparing the results between the BAU and EIM scenarios, any change in the dispatch in the EIM scenario would be the result of a more efficient dispatch.

$$
\begin{aligned}
\text { BAU Cost } & =\text { RT BAU Gen Cost }- \text { HA Sales }- \text { RT ACE Sales } \\
\text { EIM Cost } & =\text { RT EIM Gen Cost }- \text { HA Sales }- \text { RT EIM Sales } \\
\text { EIM Benefit } & =\text { BAU Cost }- \text { EIM Cost } \\
& =(\text { RT BAU Gen Cost }- \text { RT ACE Sales })-(\text { RT EIM Gen Cost }- \text { RT EIM Sales })
\end{aligned}
$$

With the DA/HA exchanges fixed and the same in the two cases, HA Sales falls out of the benefit calculation. The Gen Cost component is a direct output from PLEXOS. The RT ACE Sales and RT EIM Sales components are calculated by (actual RT exchange minus the HA schedules) times the zonal generation LIPs for that zone. For this parsing algorithm to work correctly, the LIPs must appropriately reflect the value of the energy being sold.

Review of the results, however, indicated that for several reasons, the LIPs produced by PLEXOS caused the zonal parsing of benefits by this method to be unusable. The results from PLEXOS produced LIPs that resulted in the benefits for many zones turning negative, which should not occur in this type of system optimization. The LIPs were heavily influenced by zero cost generation (hydro, wind and solar). Also, excess hydro energy was injected into the solution at no cost.

While zero cost generation is appropriate for system-wide benefit calculations, valuations of hydro generation at prices near the thermal replacement cost would allow this parsing method to produce more rational results. In actual operation, the valuations of hydro generation would reflect the future value of the generation relative to the current time periods. When future market prices are expected to be lower than current prices, hydro operators are more likely to increase the current generation by releasing more water from storage and reducing the generation in the future. Conversely, when future market prices are expected to be higher than current prices, hydro operators are more likely to decrease the current generation by releasing less water from storage and increasing the generation in the future. Accordingly, valuations of hydro generation in real-time bidding will be similar to the marginal cost of the thermal resource on the margin.

Without appropriate valuations of hydro generation, tracking transactional beneficiaries with the current tools (all production cost models), is very difficult. The closest the NWPP study got in this effort was in Case 1.94, where the hydro was dispatched in 12-hour slices that were fixed in real time. This produced results in which the LIPs became more stable; however, excess hydro energy and other free resources were still prevalent.

Another issue surfaced when using the LIPs from PLEXOS. The prices for the selling zones were substantially lower than for the buying zones. The study did not reconcile how to adjust the parsing method for these differences. In normal bilateral transactions, the prices are specified in the terms of the 
contracts. The parsing method described above yielded two sets of prices. In theory there should only be a price spread if there was congestion. However, the output results also had other factors leaking into the LIPs that made dealing with these spreads necessary, if the LIPs could be fashioned.

\subsubsection{Using Generation Cost Changes vs. Zonal Exchange Changes in Each 10-Minute Period}

Once it was apparent that using the LIPs from PLEXOS would not produce satisfactory parsing results, several other pricing methods were investigated. One approach was to calculate settlement values that "split the savings" between the buying zones and the selling zones. This method had the advantage that the net sum of the transactions in the EIM balanced close to zero. This method also had issues with there being many periods where the seller price exceeds the buyer price because of the free energy problem.

When tracking zonal benefits, the crux of the problem is which generators are responding to the varying loads and renewable generation. For example, when the marginal units are inside a zone, the costs for the zone vary without a change in the zonal exchange. This creates what appear to be irrational dispatches when evaluating benefits at the zonal boundary. When the marginal units are outside the zone, the dispatches may appear more rational. However, the zonal dispatch costs and amounts of zonal exchanges for a 10-minute dispatch will still be heavily influenced by variability within the zone. For a typical zone where the zone has large concentrations of hydro and wind energy, calculations of the changes in dispatch costs versus changes in zonal exchanges had the appearance shown in Figure 3.5 for one quarter.

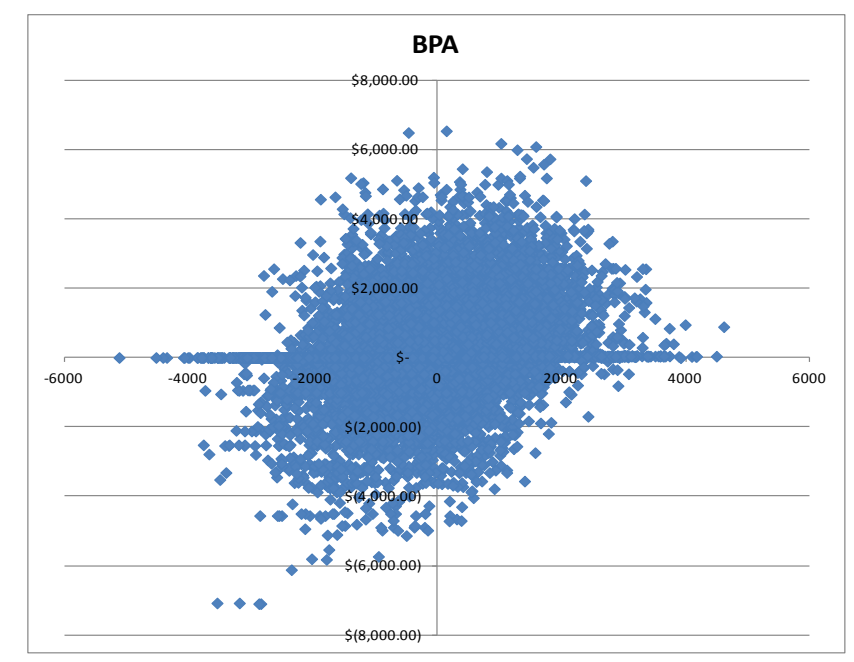

Figure 3.5. Calculations of the Changes in Dispatch Costs Versus Changes in Zonal Exchanges for One Quarter

Another issue with period-to-period calculations involves the free energy issue. Due to free energy, the zonal prices are below thermal dispatch costs for many periods. For example, Figure 3.6 is a plot of the average prices received by a seller on a typical day in January. These prices are well below the lowest typical marginal prices paid for coal-fired generation of \$20/MWh. 


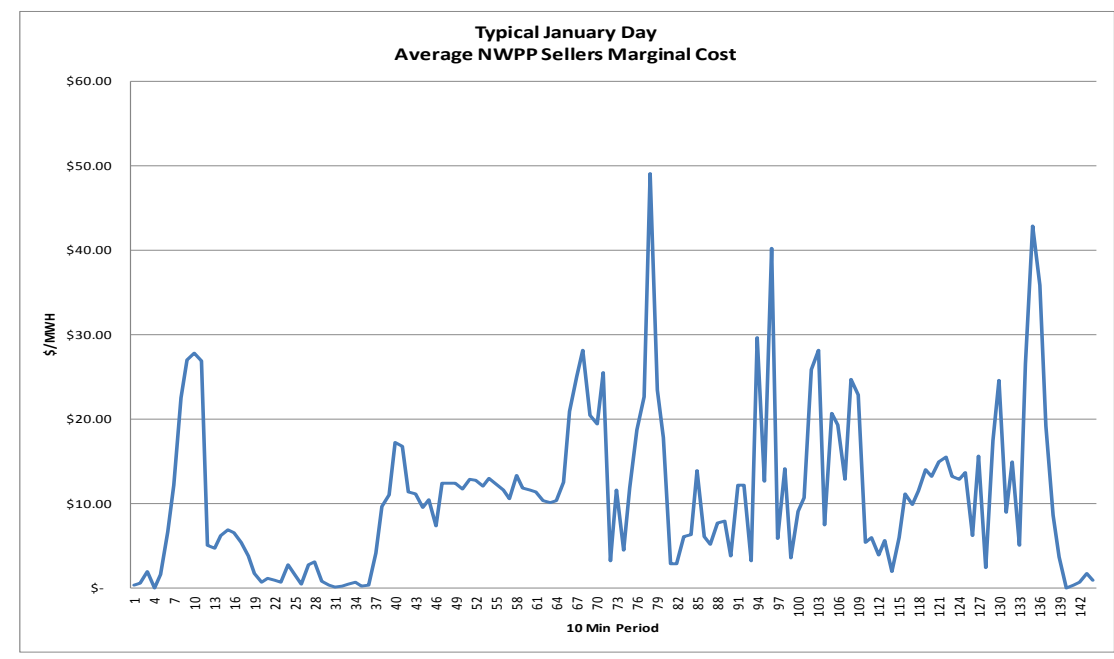

Figure 3.6. The Average Prices Received by a Seller on a Typical Day in January

\subsubsection{Alternative Parsing Methods}

Once it was determined that the methods described above were not going to produce satisfactory parsing methods in the allotted time available, other alternatives were considered. These are the following:

1. Parsing based on the amount of MWh used to serve load (Load Ratio)

- Absolute amount of MWh served-does not reflect use of an EIM

- Most load served via pre-real-time transactions

2. Parsing based on MWh of Gen produced

- Absolute amount of MWh produced - similar to load metric, again does not reflect use of an EIM

3. Parsing based on Gen Cost

- Zones without thermal costs would not receive an allocation

4. Parsing based on MWh Load + Gen (Average of MWh Load and MWh Gen above)

- Does not reflect use of an EIM

5. Parsing based on Annual Energy Surpluses/Deficits (MWh Gen - MWh Load)

- Does not reflect use of an EIM

6. Parsing based on 10-minute transaction volume

- Allocations stable across many scenarios

- Assumes that benefits flow to those transacting in an EIM; otherwise, transactions would not occur. Reflects actual use of an EIM.

- EIM volume is related to load and wind variations and the marginal units responding to the variations 
- $\quad$ Transaction-based pricing which uses the relative amounts of transactions between the NWPP BAs as representative of both the EIM benefits and the overall reduction in the societal production costs. This approach assumes that the intra-hour transactions between the BAs in the NWPP EIM would occur only because both parties financially benefit. Therefore, the parsing results should reflect all the BAs receiving a share of the societal benefits.

The Analytical Team ultimately elected to use the last alternative as the best alternative for parsing.

\subsubsection{Sub-Zone Parsing}

Sub-zone parsing was not performed as it was beyond the scope of this study. However, when considering sub-zone parsing, several questions/issues arise. For instance, when a zone includes multiple parties, how does the parsing work? In a few instances, some zones contain more than a single transmission service provider. In these instances, another layer of parsing may need to take place. For a few zones, additional transaction parsing was performed to get an inkling of which of the potential subzone parties were contributing to the overall zonal transaction volume. Even in this effort, the sums of the intra-zonal transactions exceeded the totals of the zonal transactions due to netting of transactions within the zone.

\subsection{Modeling Changes Matrix Compared to Previous Studies}

The matrix reported in Table 3-3 summarizes the significant study improvements made by the Analytical Team compared to the revisions made in prior studies to the 2020 TEPPC PC0 case, which all prior studies were based on. A discussion of the specific changes made in each category can be found in Section 2. They are also described further in Section 3.7.

Table 3-3. Study Improvements in Comparison with Prior Studies

\begin{tabular}{lllll}
\hline Assumption & WECC E3 & PUC EIM & VGS & NWPP \\
\hline Remote Generation & Limited & Limited & Limited & Modeled in proper BA \\
Hurdle Rates & High & High & $\begin{array}{l}\text { Low, miduium Only for transmission } \\
\text { and high }\end{array}$ & $\begin{array}{l}\text { No } \\
\text { pancakes }\end{array}$ \\
Hydro Reserves Improvements & No & No & Yes \\
Natural Gas Prices & Average & Average & High & Average, low and high \\
Greenhouse Gas Tax & No & No & No & No \\
Coal Plant Retirements & No & No & No & Yes \\
Seams Treatment & Yes & Issue & No & Yes \\
Include CAISO \& AESO & Yes & Issue & Yes & Yes \\
Transmission Hurdle Rates & Hurdles L & Hurdles L & Hurdles G & Transmission rates \\
Losses & Yes & Yes & Yes & Yes \\
Contingency Reserves Held & Yes & Yes & Yes & Yes \\
Interchange Schedule Method & No & No & Yes & Yes \\
Topology (Number of BAs) & 24 & 24 & 34 & 28 \\
Flexible Reserves & NREL & NREL & PNNL & PNNL/NWPP Practice \\
\hline
\end{tabular}




\subsection{Improvements Made to Prior Base Case}

As stated in the Section 1, several EIM and intra-hour type studies have been performed for the Western system over the past several years. These include the following:

- WECC E3 EIM (Hourly, WECC wide) [3]

- CG BPA EIM (Hourly, NWPP)

- PUC EIM (PLEXOS, WECC wide) [6]

- VGS Full BA Consolidation (WECC wide) [4]

- WECC/VGS version PUC EIM and 10-min scheduling [5]

- E3 analysis for PAC-CAISO EIM benefits [8]

These studies have been performed by E3, NREL, PNNL, WECC staff, and with participation from various Western Interconnection participants. These studies ranged from hourly production cost model studies to intra-hour simulations and have looked at various methods for improving balancing area cooperation and developing additional markets, including an EIM. The specific studies were usually looking at varying aspects, issues and designs, and therefore cannot necessarily be compared on an equivalent basis. As such, results from these studies have shown dramatic differences in the levels of benefits that might be indicated for an EIM.

The data inputs to the model used by the NWPP EIM study began as a product of these previous studies and then included modifications to the system to more completely represent the NWPP operations and improve the topology representation. Extensive data "scrubbing" was performed by the NWPP Analytical Team on the NWPP system with each of the MC analysis team members reviewing their respective areas.

Several of the prior studies used traditional hourly production cost simulation models to quantify operational savings over a test year. These were limited in their ability to capture specific operational changes within the hour that the NWPP EIM initiative was targeted to identify; especially, given the increased intra-hour variability with existing and planned levels of variable generation in the PNW. Several of the previous studies also required the use of simplifying assumptions and approximations for logistical and run time reasons.

The MC decided to build on the excellent work from these prior studies and improve the models for the Northwest. PNNL provided the latest PCMs, which they had improved and advanced, and PLEXOS was chosen to be the model platform. PNNL and Energy Exemplar personnel were employed to assist in the study. The original base case for all of the listed previous studies was the TEPPC 2020 PC0 case.

Extensive review and scrubbing of NW PCM data were completed by the Analytical Team. The changes made in PLEXOS are described in this section as well as in the previous sections. 


\subsubsection{Flexible Reserves Derivation and Modeling Approach}

a. The reserves calculation methodology was based on calculations performed via traditional reserve methods used by the NW BAs.

b. The reserves were held constant in the Base Case and most of the sensitivity cases (except in case 1.86G). The resource sufficiency obligation was not reduced (except in the sensitivity case, 1.86G). This was done to quantify the direct benefits of an EIM from the diversity in energy imbalances and the economic dispatch of a combined resource stack within the EIM footprint.

c. The reserves were calculated by the PNNL Flex Reserve algorithm for all the BAs. Results from this model are consistent with results from the approaches used by BPA (PGST and TOT - power generation and transmission groups, respectively) and PSE.

\subsubsection{Full Energy Market Versus EIM benefits}

a. The Analytical Team chose to implement an Interchange Scheduling Methodology (ISM) in PLEXOS that forced the unit commitments and interchange schedules of the individual BAs. This approach was considered superior to using artificially high hurdle rates in the BAU scenario that prevent efficient HA exchange schedules between WECC BAs. The interchange schedules between the BAs during the HA period were derived by the security constrained optimization of the combined WECC-wide generation stack and subsequently frozen in the real-time simulations. The known contractual obligations were accounted for in this process.

b. The members of the NWPP EIM were limited to covering energy imbalances during the real time period with redispatched generation that is more efficient than the generation associated with the HA scheduled interchanges. These results were computed and compared to the results from the BAU scenarios, where each BA had to meet its own imbalance energy with its own generation. The prescheduled bilateral transactions were designed to be efficient so that the EIM benefits reflected only the diversity of energy imbalances and heat rate swaps from higher to lower cost generation during the real time period. The EIM benefits did not get credited with cleaning up inefficient preschedule trading, which in reality would be the case to some extent. The goal was to determine a minimum achievable amount of EIM benefits.

\subsubsection{Business as Usual (BAU) Representation}

a. Improvements were made to the TEPPC 2020 PCM Hourly Case to allow for sub-hourly modeling effects.

b. One-minute load and resource data were used.

c. Operating characteristics (ramp rates, etc.) were added to better model real-time operations.

d. Existing dynamic transfers and exchanges, which allow individual BAs to operate more like virtual single BAs, were added by either combining the BAs (where the dynamic schedules were significant) or by dividing generation and assigning it to the relevant BAs.

e. Remotely owned generation, when known, was moved electrically and operated in the BA of the owner.

f. When known, information regarding unit ownership, gas prices and locations, improved heat rates, and firm contracts was included. Accordingly, the information used for modeling the power plants in the NWPP was more thorough and had greater granularity than prior studies.

g. The representation of generators included the separation of simple-cycle and combined-cycle gas fired units at power plants, more accurate location and assignment of the generation to the BA of 
the owner (which can be a utility within the BA), and separating lumped generation when appropriate.

h. Topology updates were made to reflect the latest transmission information in the NWPP for existing and transmission that is under construction. Corrections were made to locate transmission terminations into the correct BA such that net interchange values could be correctly calculated.

\subsubsection{Hydro Modeling}

a. A better representation of intra-hour hydro operations in the NW was developed. Despite these improvements, PLEXOS has limitations in its capability to represent actual operator interventions and actions taken for intra-hour hydro operations when energy is constrained. The Analytical Team developed several solutions to mitigate these issues.

b. Project limits on hydro unit capability were reduced to address reserve obligations and to reflect capability reductions due to outages, maintenance, and head loss.

Specific details of these changes to the Base Case are discussed in Section 2.4 



\subsection{Simulation Results Analysis}

\subsection{Comparison of Base Case HA Simulation Results vs. Historical Generation Mix of Selected NWPP BAs}

The purpose of this section is to compare the HA simulation results of the Base Case (1.86A) with historical data of selected NWPP BAs.

\subsubsection{BANC Comparison}

The Balancing Authority of Northern California (BANC) performs balancing services for its loadserving entity members: Sacramento Municipal Utility District (SMUD), Modesto Irrigation District, City of Roseville and City of Redding. In addition, the Western Area Power Administration (WAPA) is a subcontrol area within BANC. With its load-serving entity members and WAPA, BANC's footprint includes about 4,500 MW of generation capacity, and BANC serves a peak load of about 5,200 MW.

The hour-ahead simulation for the Base Case is the foundation upon which the energy imbalance market analysis is built. Consequently, these hour-ahead values were reviewed for their reasonableness and a summary of this analysis for BANC is provided in this section. This review revealed that the Base Case represents actual generation and loads of BANC sufficiently well.

Figure 4.1 shows a comparison between actual generation and load of BANC. Generation for the 2006 through 2012 period ranged from 11,600 to 15,100 GWh, and the generation forecast of 12,400 GWh for year 2020 falls within this historical range. In addition, loads ranged from 17,100 to 18,000 GWh during the past seven years, and the Base Case assumes an annual growth rate of about 3\%, resulting in a load of 23,000 GWh for year 2020. 


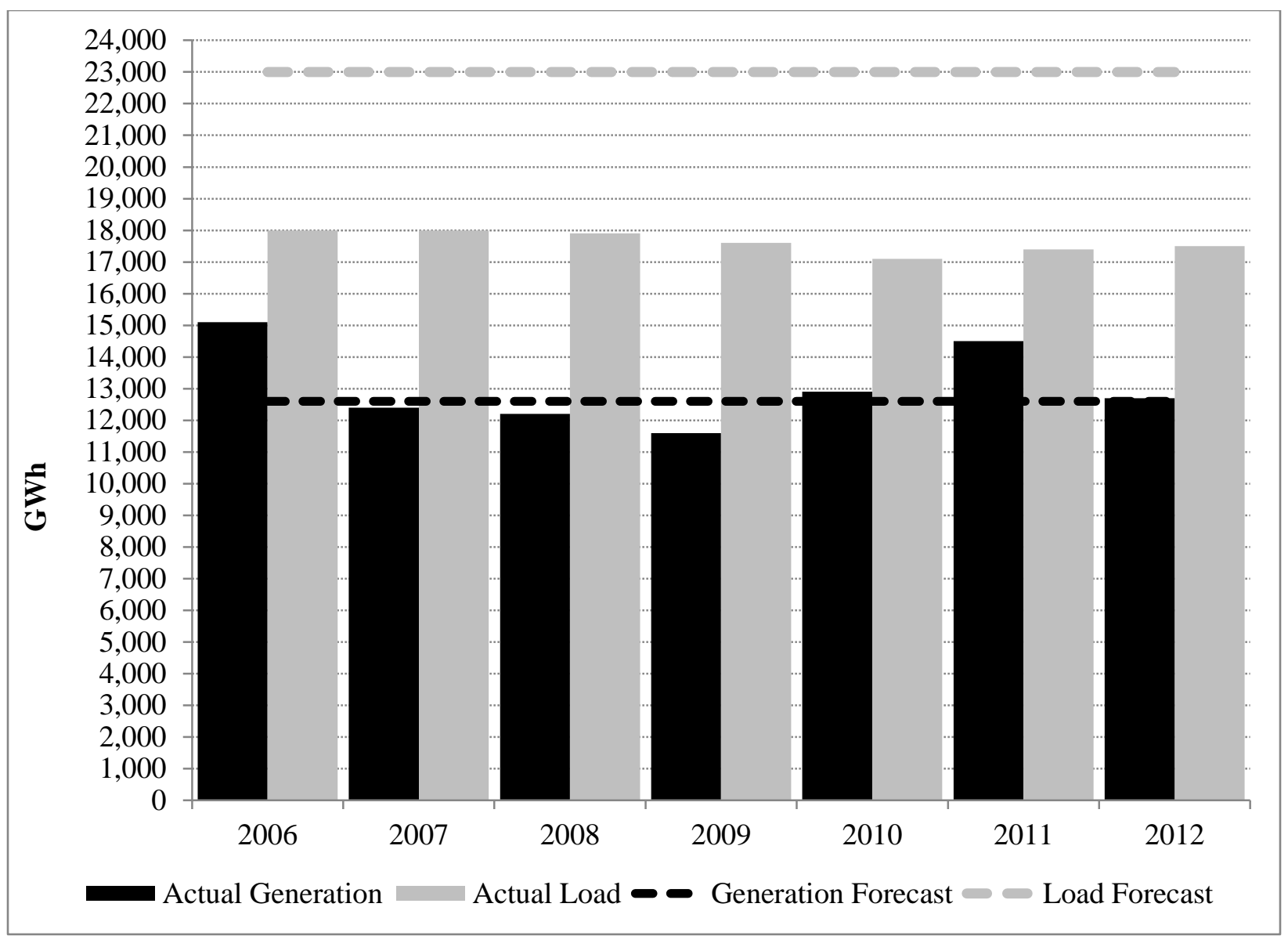

Figure 4.1. BANC Actual Generation \& Load Compared to Forecast (Base Case HA Simulation Results)

Figure 4.1 shows that the actual annual generation of BANC varies widely; this is due to the prevalence of hydroelectric power plants. Figure 4.2 shows a capacity breakdown for the peak hour of each month, and hydroelectric capacity accounts for more than $50 \%$ of total generation capacity in all months. (Refer to dark and light blue bars for total hydroelectric capacity.)

With a load that is typically higher than supply, BANC is usually a net importer of energy. Figure 4.3 shows monthly energy demand and supply. Energy demand growth, about 5,000 GWh, is largely met with imports. 


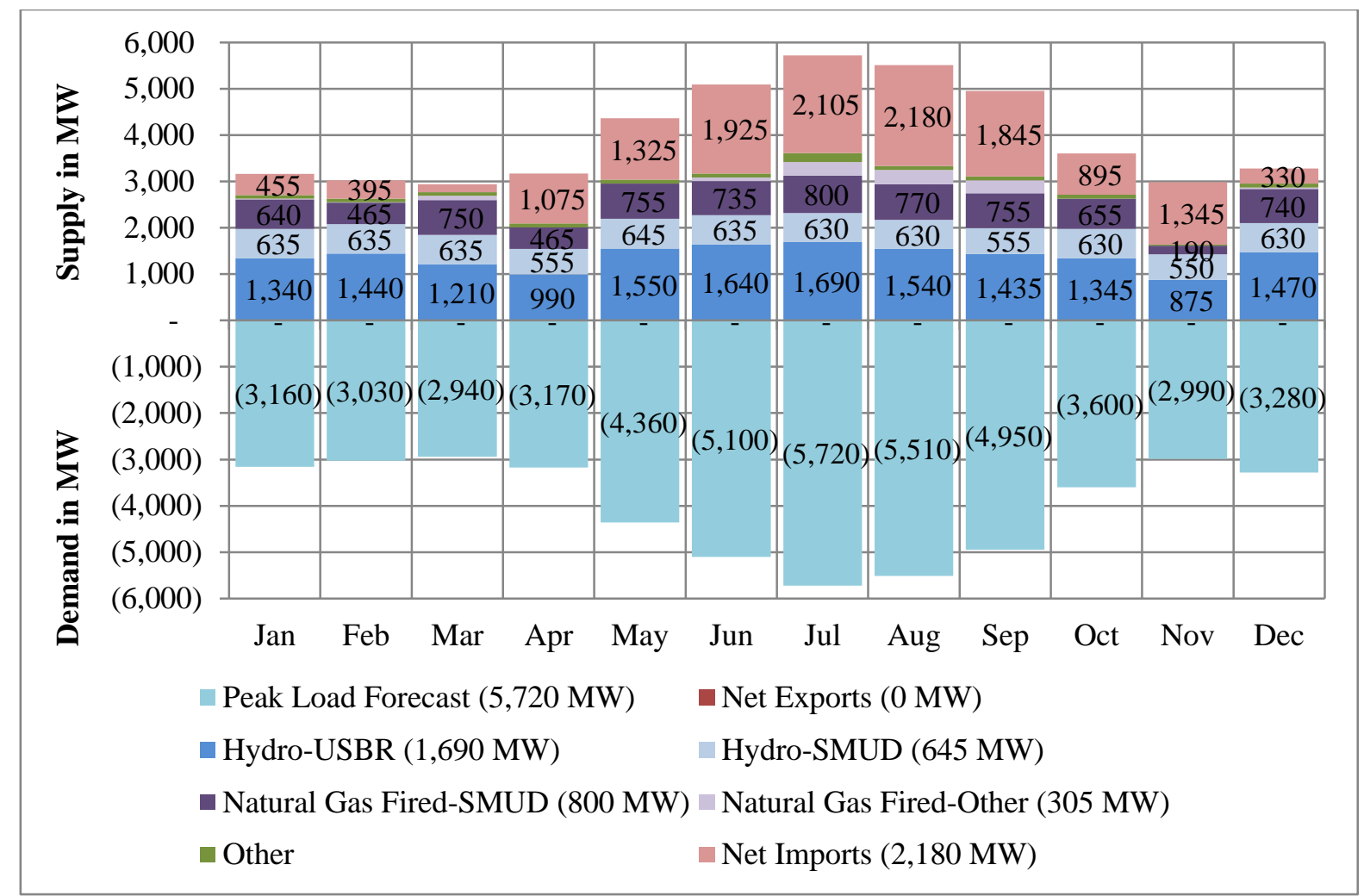

Figure 4.2. BANC Capacity Balance on the Peak Hour of Each Month for the Base Case HA Simulation

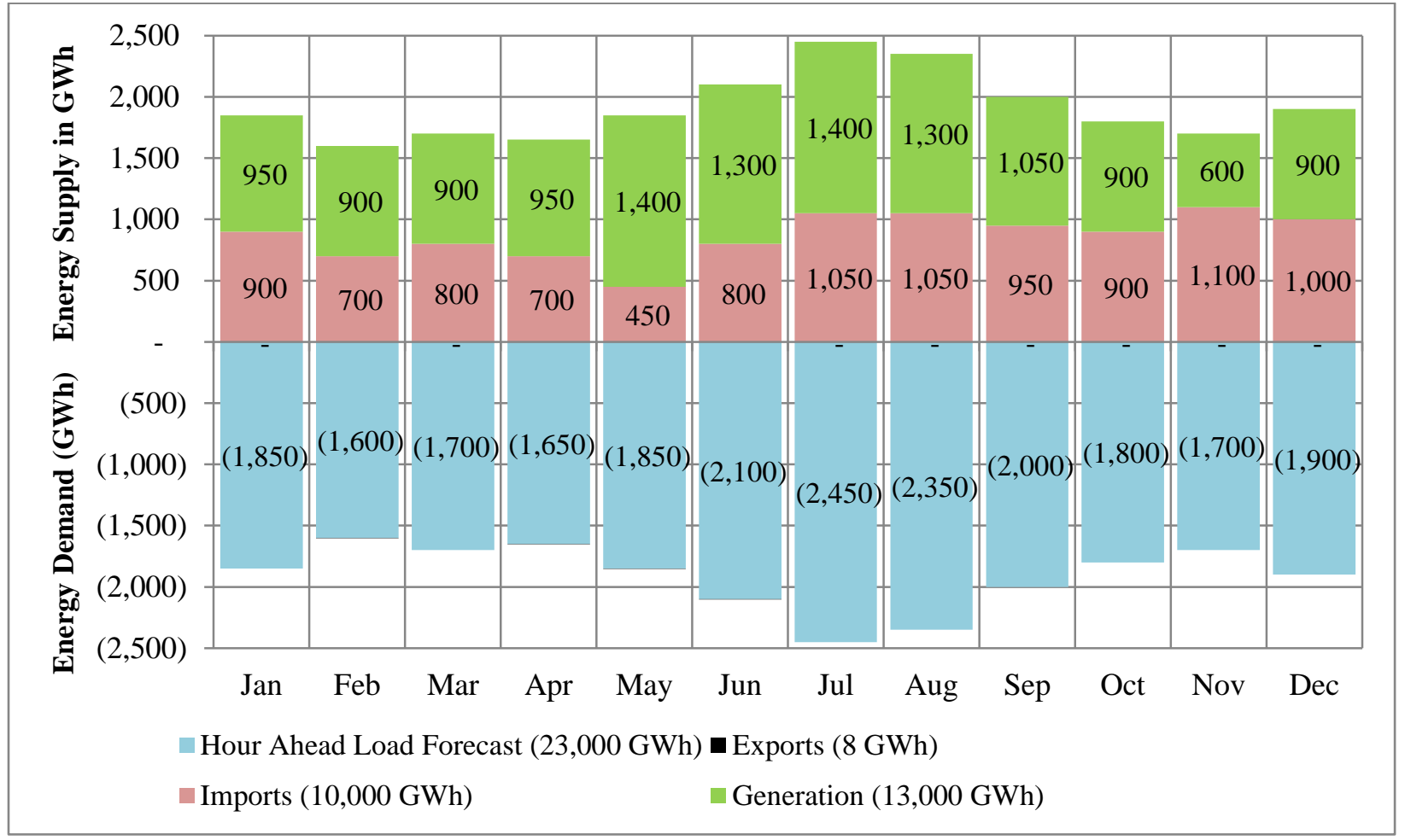

Figure 4.3. BANC Energy Balance by Month for the Base Case HA Simulation 
An analysis of generation by fuel type shows that hydroelectric generation meets a significant part, $55 \%$, of the energy demand. (Refer to Figure 4.4.) In the Base Case, median hydrologic conditions were assumed. This chart also reveals that $95 \%$ of the generation of BANC is supplied from hydroelectric and gas-fired generation produced by the U.S. Bureau of Reclamation (USBR) and SMUD.

Since hydroelectric and gas-fired generation produced by the USBR and SMUD account for most of the generation of BANC, comparisons between the forecasts (Base Case HA simulation results) and actual data were performed. The results of these comparisons are illustrated in Figure 4.5, Figure 4.6, and Figure 4.7. These comparisons reveal that the annual forecasts for generation are similar to the historical data, being about 3\% higher for the hydroelectric plants and 7\% lower for the natural gas-fired plants. They also reveal that the monthly historical values vary significantly; however, the historical patterns from month to month are similar for actual and forecast generation.

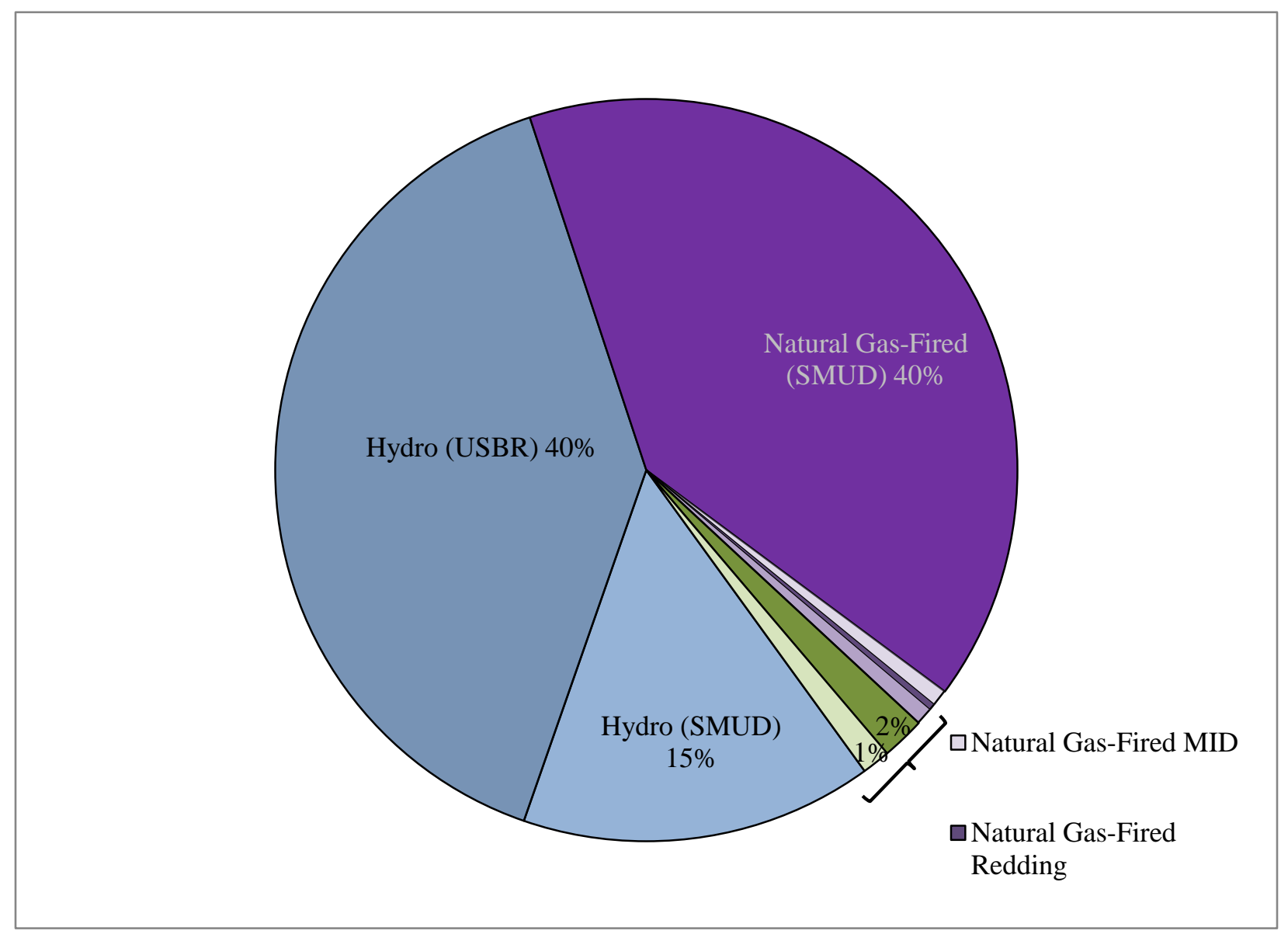

Figure 4.4. BANC Energy by Fuel Type for the Base Case HA Simulation 


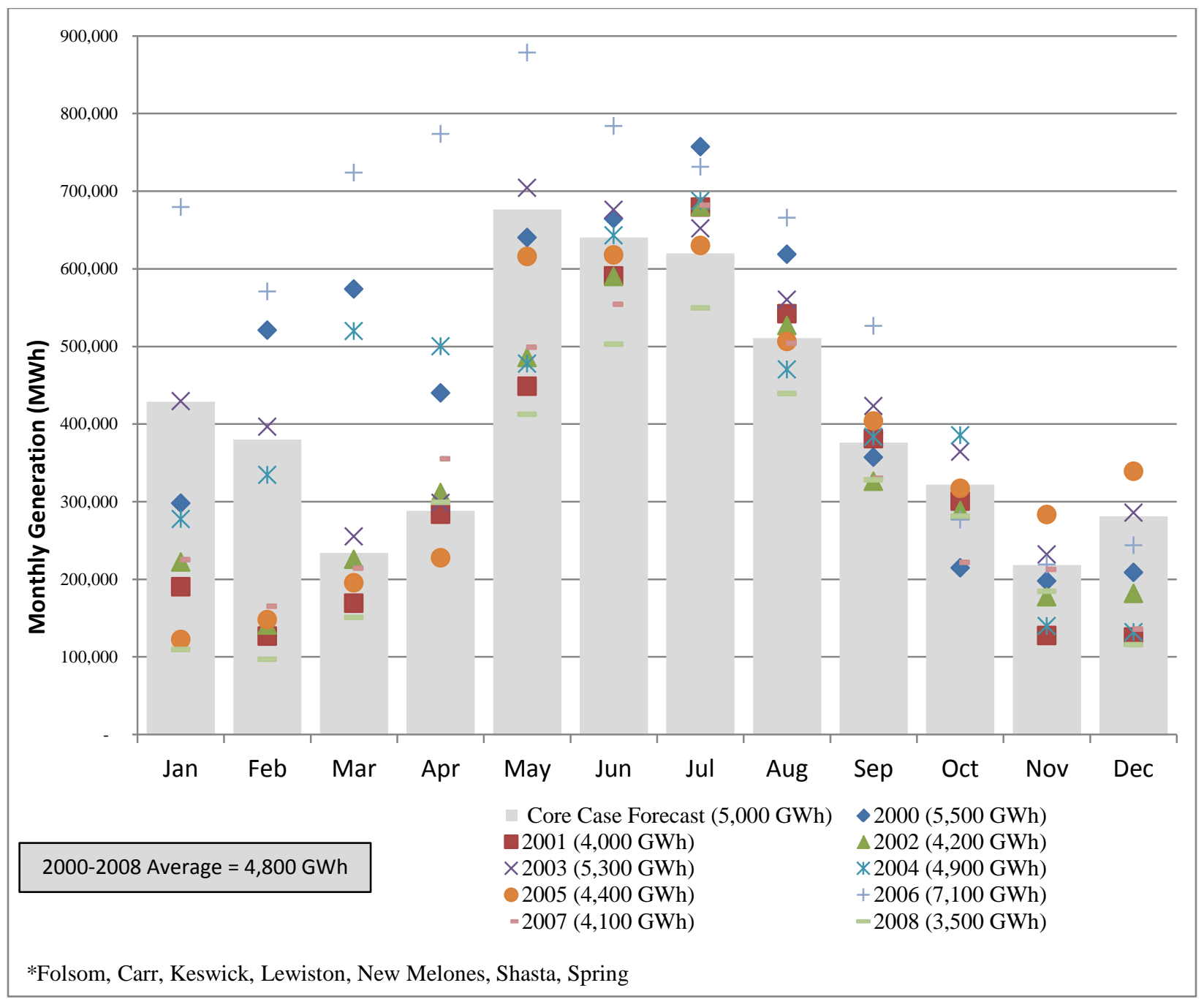

Figure 4.5. Historical Central Valley Project Generation* vs. Base Case HA Simulation 


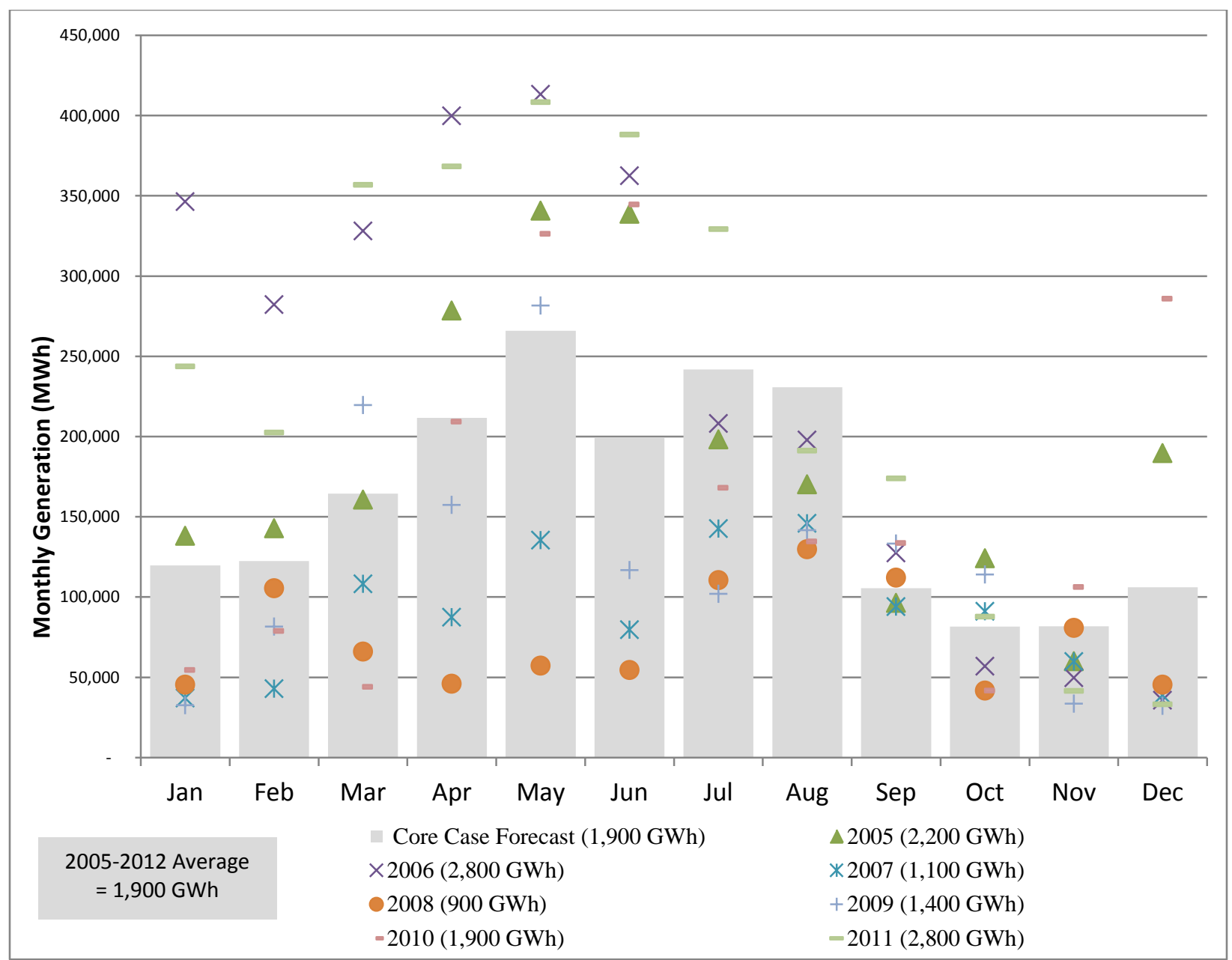

Figure 4.6. Historical SMUD Upper American River Project Generation vs. Base Case HA Simulation 


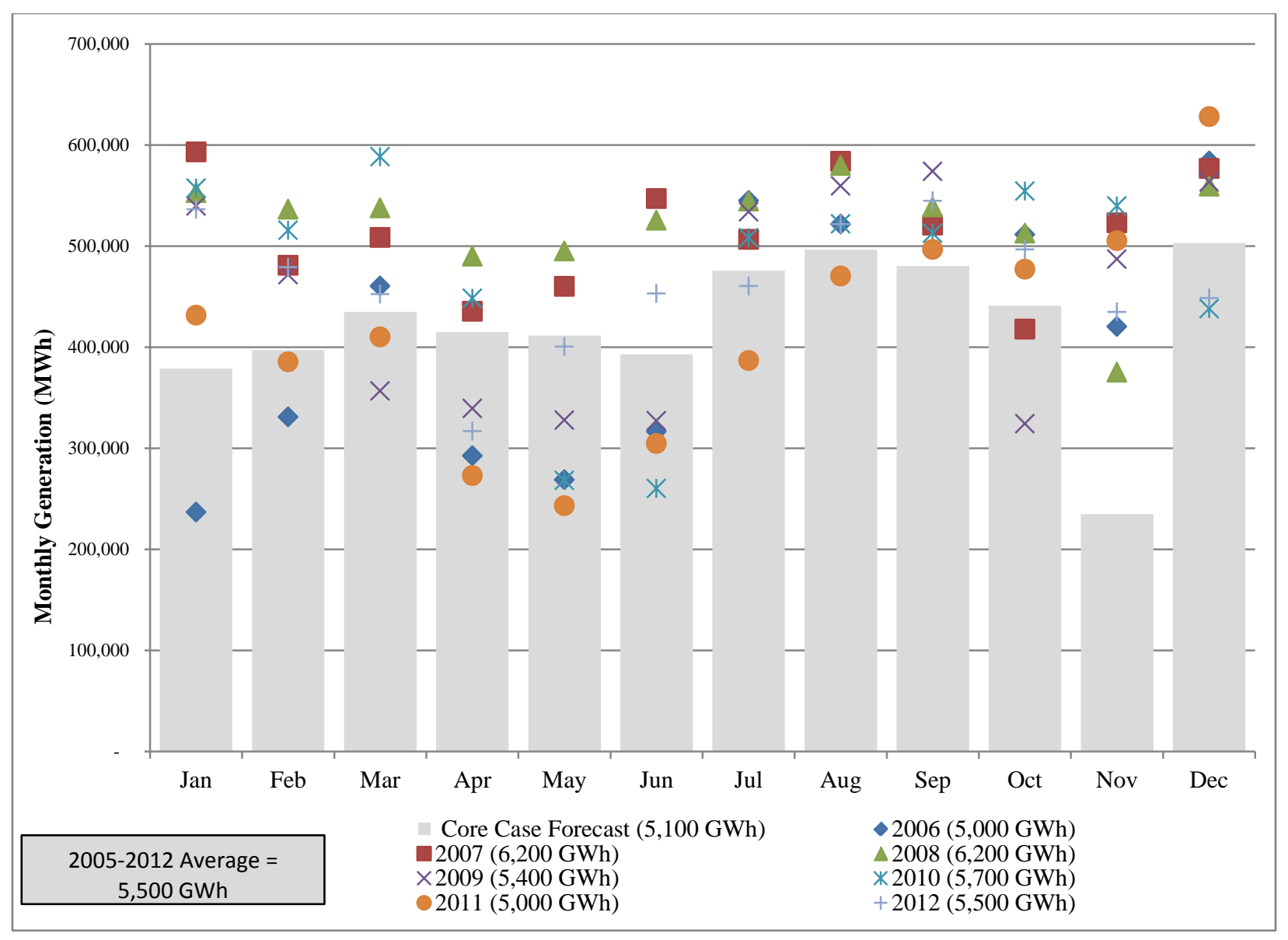

Figure 4.7. Historical SMUD Natural Gas-Fired Generation vs. Base Case HA Simulation 


\subsubsection{PacifiCorp Comparison}

PacifiCorp (PAC) has two balancing areas spanning six states in the Western Interconnection. These BAs are the following: 1) PacifiCorp West (PACW) in Oregon, Washington and Northern California and 2) PacifiCorp East (PACE) in Wyoming, Utah and SE Idaho.

The hour-ahead simulation for the Base Case is the foundation upon which the energy imbalance market analysis is built. Consequently, these hour-ahead values were reviewed for their reasonableness and a summary of this analysis for PAC is provided in this section. This review revealed that the loads and resources in the Base Case for PAC during year 2020 are comparable to the average annual actual loads and resources for years 2006 through 2012, as reported in its FERC “Form 1” filings.

Figure 4.8 shows a comparison between actual generation and load of PAC. Generation from 2006 through 2012 ranged from 53,666 to 59,875 GWh, and loads for the same period ranged from 56,500 to $59,400 \mathrm{GWh}$, whereas the Base Case forecast for generation is 57,210 GWh and for loads is 58,242 GWh for year 2020.

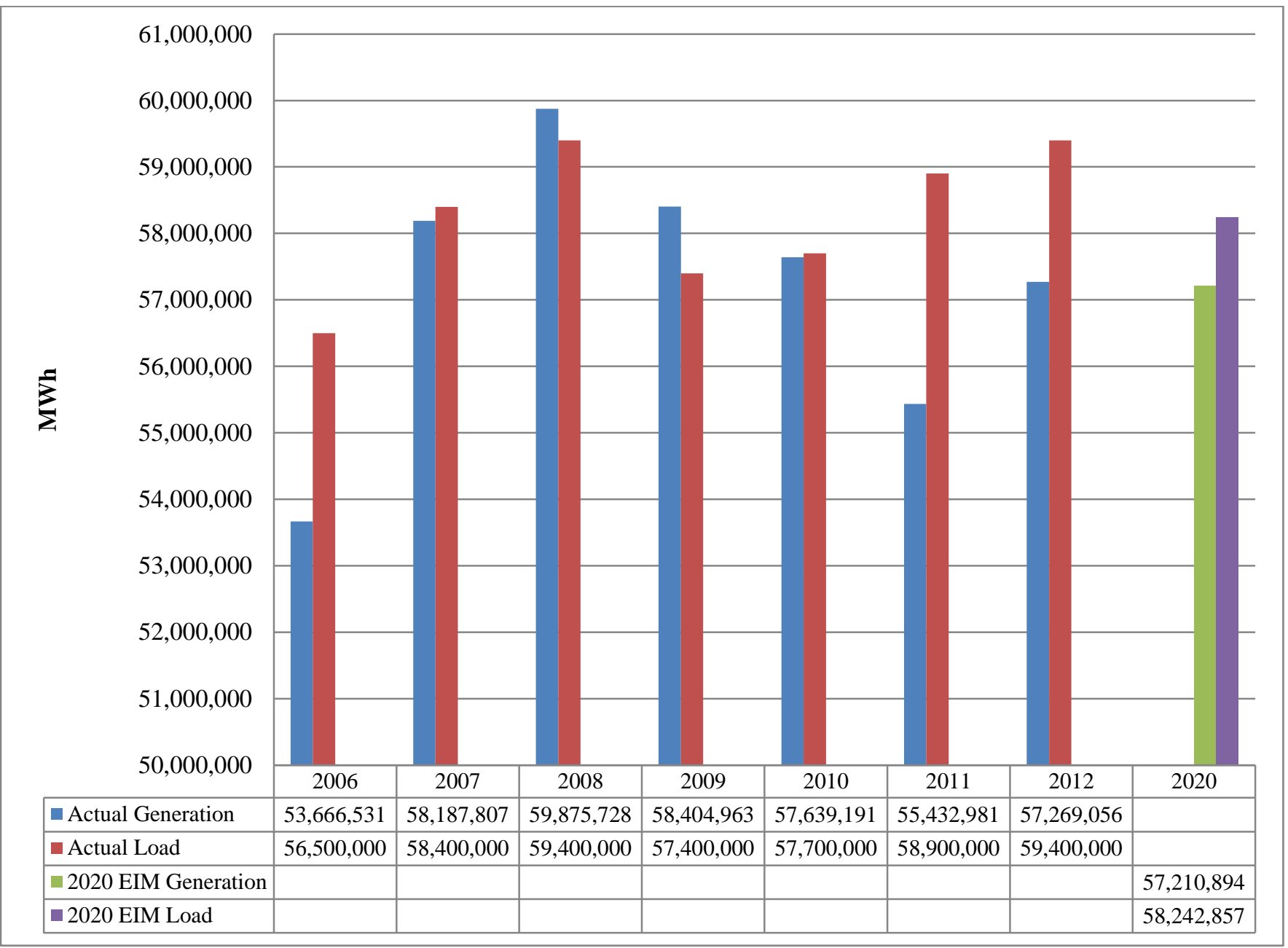

Figure 4.8. PacifiCorp Loads and Resources, Actuals vs. Modeled 
Figure 4.9 below shows the capacity balance of PacifiCorp on a peak day. This figure indicates that PAC is practically balanced, based on looking at the capacity balance results for the peak hour of each month from the hour-ahead simulation run for the Base Case.

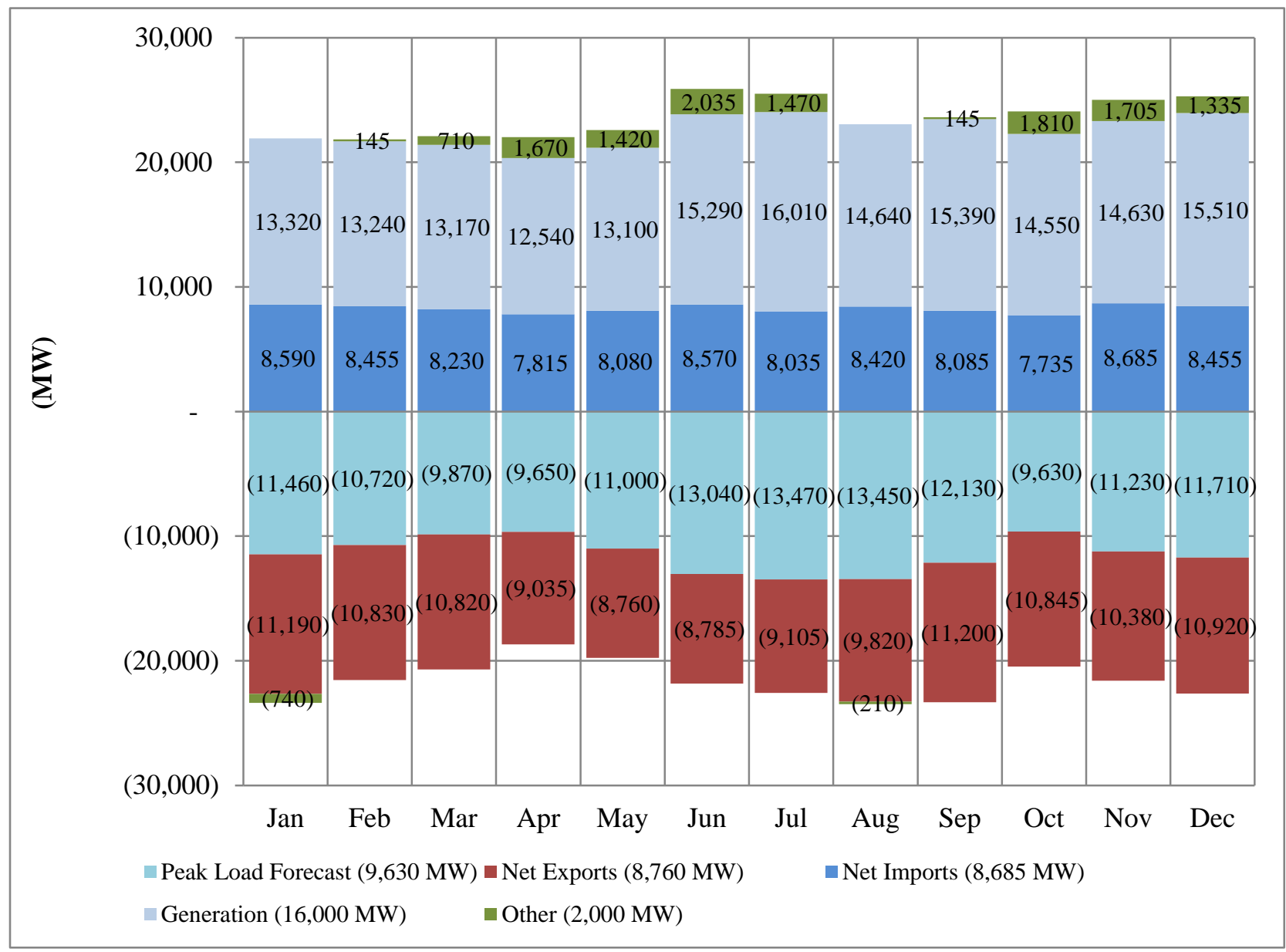

Figure 4.9. PacifiCorp Capacity Balance on Peak Day for the Base Case HA Simulation 
The annual energy supply of PAC is greater than its annual energy demand (86,120 GWh and 76,840 GWh, respectively); however, the monthly energy values shown in Figure 4.10 may not balance since the monthly energy supply and demand values include imports and exports that were simulated during the hour-ahead simulation run for the Base Case.

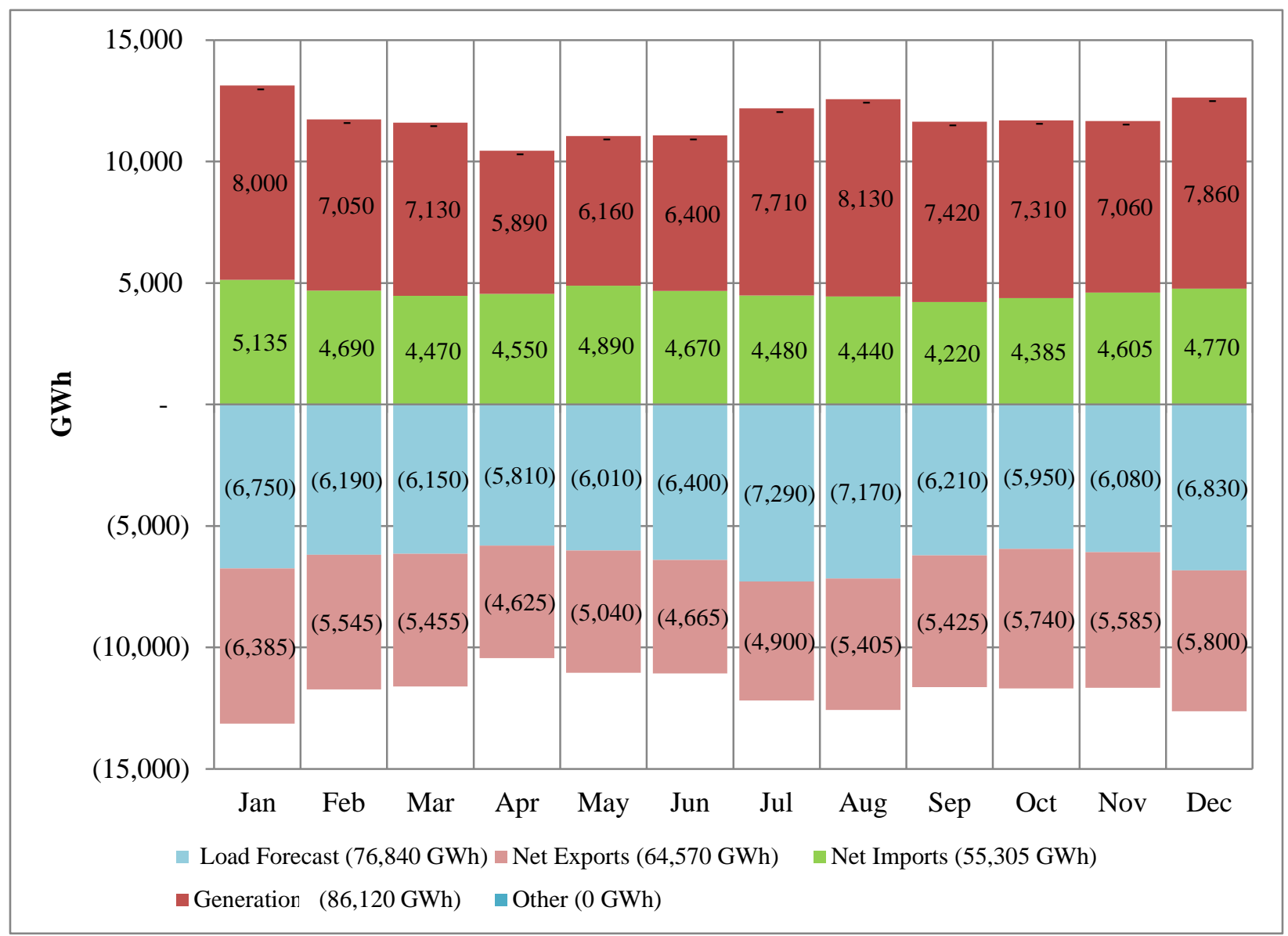

Figure 4.10. PacifiCorp Energy Balance by Month for the Base Case HA Simulation 
PAC either owns or holds rights to resources that cover its expected system peak capacity of 11,005 MW for year 2020, as forecasted in the 2013 PAC Integrated Resource Plan (IRP). Figure 4.11 shows a comparison between the HA energy mix for the PAC BA in the Base Case and in the 2013 PAC IRP for Year 2020. This information was used to validate the assumptions used in the Base Case regarding the capacity resource mix of PAC.

\section{NWPP-EIM_2020 PAC Energy Resources Mix}

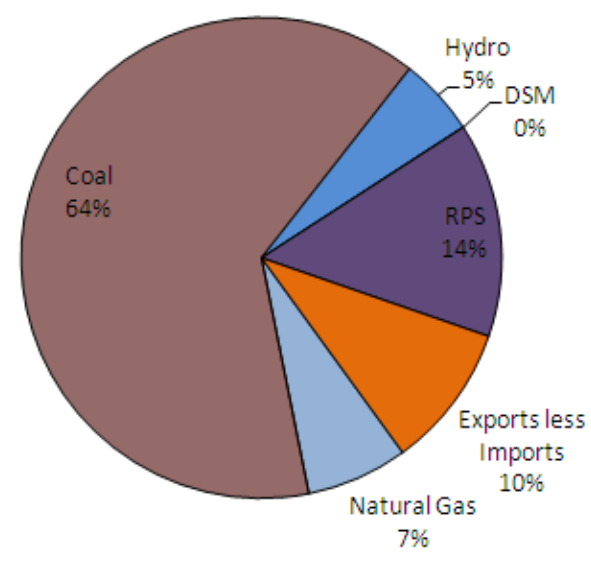

\section{PAC 2013 IRP_2020 Resource Energy Mix}

“Preferred Portfolio"

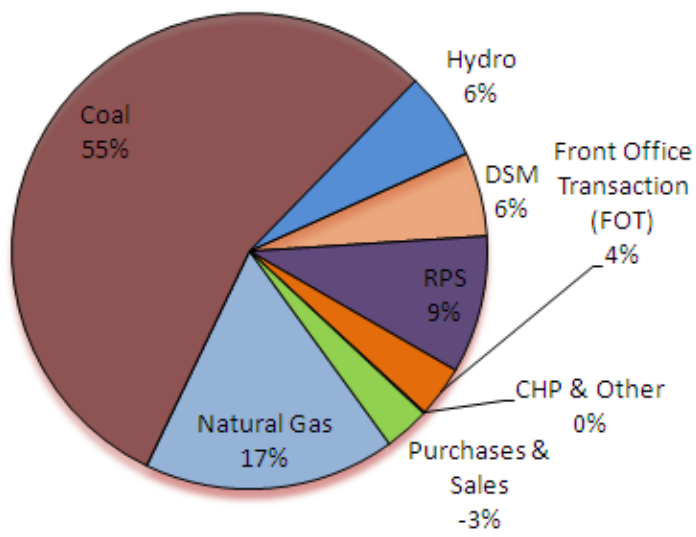

Figure 4.11. Base Case HA Energy Mix for PAC BA vs. 2013 PAC IRP Energy Mix for Year 2020

The amounts of thermal plant capacity reported for PAC in Table 4-1 for the Base Case and the PAC IRP do not constitute an apples-to-apples comparison. All resources within the PAC BA are allocated to PAC in PLEXOS, whereas, the PAC IRP just reports the resources of PAC; hence, it is not completely accurate to compare the two. Major discrepancies appear when comparing the total capacities for the coal-fired and natural gas-fired resources. Although the totals for the natural gas-fired resources may appear within close proximity, this is due in part to major differences in the data that contribute toward offsetting the differences between these two sets of data, including the following:

In the 2013 IRP Capacity Mix:

- PAC retires the Carbon 1 \& 2 coal-fired units, 172 MW, in 2014

- $\quad$ PAC repowers the Naughton 3 coal-fired unit, 330 MW, with a natural gas-fired unit in 2015 In the Base Case:

- $\quad$ PAC was not allocated its shares in the following coal-fired units:

o Colstrip 3 \& 4-148 MW,

o Craig - $168 \mathrm{MW}$ and

o Hayden 1 \& $2-78 \mathrm{MW}$

- The PAC BA was allocated the generation resources of the Deseret Power Electric Cooperative, Utah Associated Municipal Power Systems (UAMPS), the Utah Precious Metals Association 
(UPMA) and other IPP resources that are physically located within the PACW and PACE BAs but are not owned by PacifiCorp.

PAC owns 1,145 MW of hydroelectric generation capacity and purchases the output from another 136 MW of hydroelectric resources owned by others. Only 853.43 MW of this hydro capacity is considered dependable capacity primarily due to hydro restrictions associated with non-power operational limitations that impact water levels, such as licensing requirements for fish, aquatic habitat and flood control.

PAC owns or purchases under contract 2,186 MW of wind resources. Wind resources plus other RPS resources (geothermal, solar etc.,) comprise the total aggregate MW of RPS resources reported in Error! Not a valid bookmark self-reference..

Table 4-1. Comparison Between the Resource Capacity Mix for PacifiCorp in the Base Case and its 2013 IRP for Year 2020.

\begin{tabular}{|c|c|c|c|c|c|}
\hline \multicolumn{3}{|c|}{$\begin{array}{c}\text { NWPP - EIM scenario 1.86 A (Base Case) - PacifiCorp } \\
\text { Capacity Mix (MW) }\end{array}$} & \multicolumn{3}{|c|}{$\begin{array}{l}\text { PacifiCorp } 2013 \text { IRP Capacity Mix } \\
\text { (MW) }\end{array}$} \\
\hline Natural Gas-Fired & $3,330.90$ & $20 \%$ & Natural Gas-Fired & $3,305.68$ & $25 \%$ \\
\hline Coal & $7,246.50$ & $43 \%$ & Coal & $5,649.91$ & $42 \%$ \\
\hline Hydro & $1,541.00$ & $9 \%$ & Hydro & 853.43 & $6 \%$ \\
\hline DSM & 853.00 & $5 \%$ & DSM & 699.00 & $5 \%$ \\
\hline \multirow[t]{3}{*}{ RPS } & \multirow[t]{3}{*}{$3,740.00$} & \multirow[t]{3}{*}{$22 \%$} & RPS & $2,300.00$ & $17 \%$ \\
\hline & & & Purchases & 311.90 & $2 \%$ \\
\hline & & & $\begin{array}{l}\text { Front Office } \\
\text { Transaction }\end{array}$ & 200.00 & $2 \%$ \\
\hline Total & 16,711 & $100 \%$ & Total & 13,320 & $100 \%$ \\
\hline
\end{tabular}

Since PAC owns $90 \%$ of the resources in its BA, it was deemed valid to compare the total megawatt hours dispatched for PAC between the Base Case and the 2013 PAC IRP. Recognizing the fundamental differences in the comparison, results shown in Figure 4.11 support the validity of the resource assumptions used for PacifiCorp in the NWPP EIM analysis.

Since coal, natural gas, and hydro account for most of the PacifiCorp resources, comparisons were made between the modeled and actual resources. The results of these comparisons are plotted in Figure 4.12, Figure 4.13, and Figure 4.14, respectively. These comparisons reveal that the annual average generation results from PLEXOS are generally 30\% greater than the actual amounts of generation for coal and hydro and $20 \%$ lower for natural gas. Secondly, when comparing the monthly modeled and actual profiles, the amounts of generation for coal and hydro compared reasonably well but natural gas did not. 


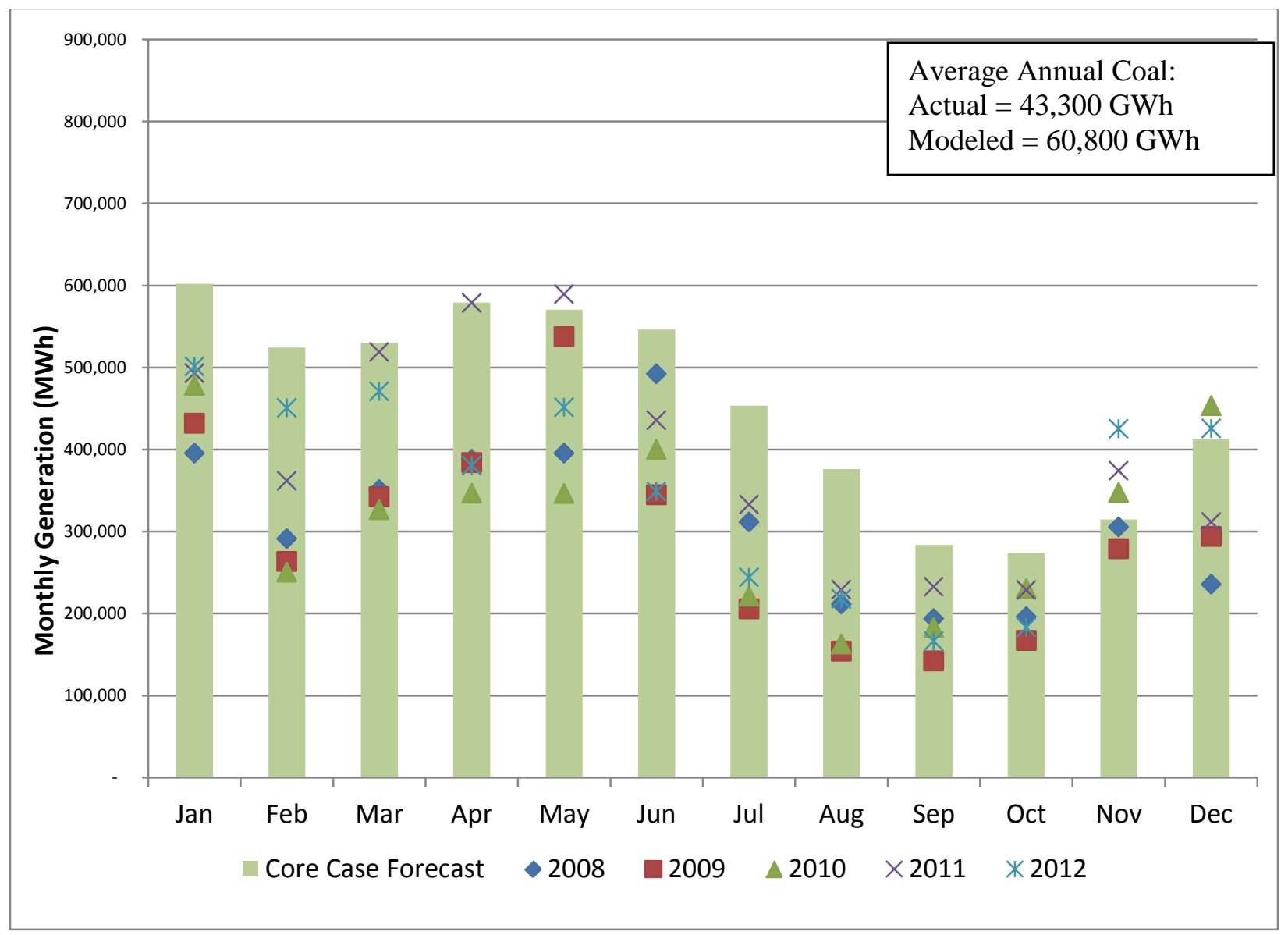

Figure 4.12. PacifiCorp Actual vs. Base Case HA for Dispatched Coal 


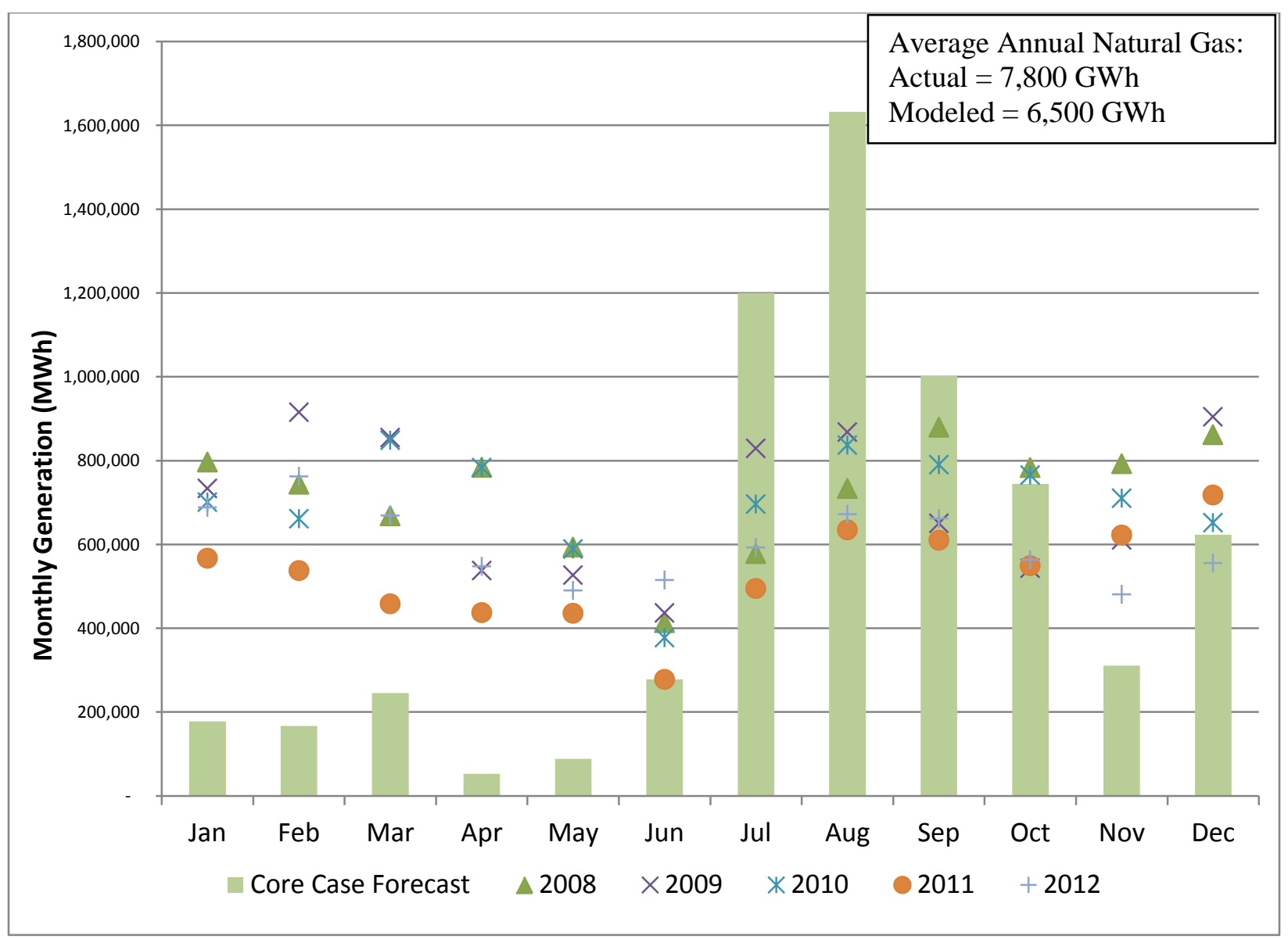

Figure 4.13. PacifiCorp Actual vs. Base Case HA for Dispatched Gas 


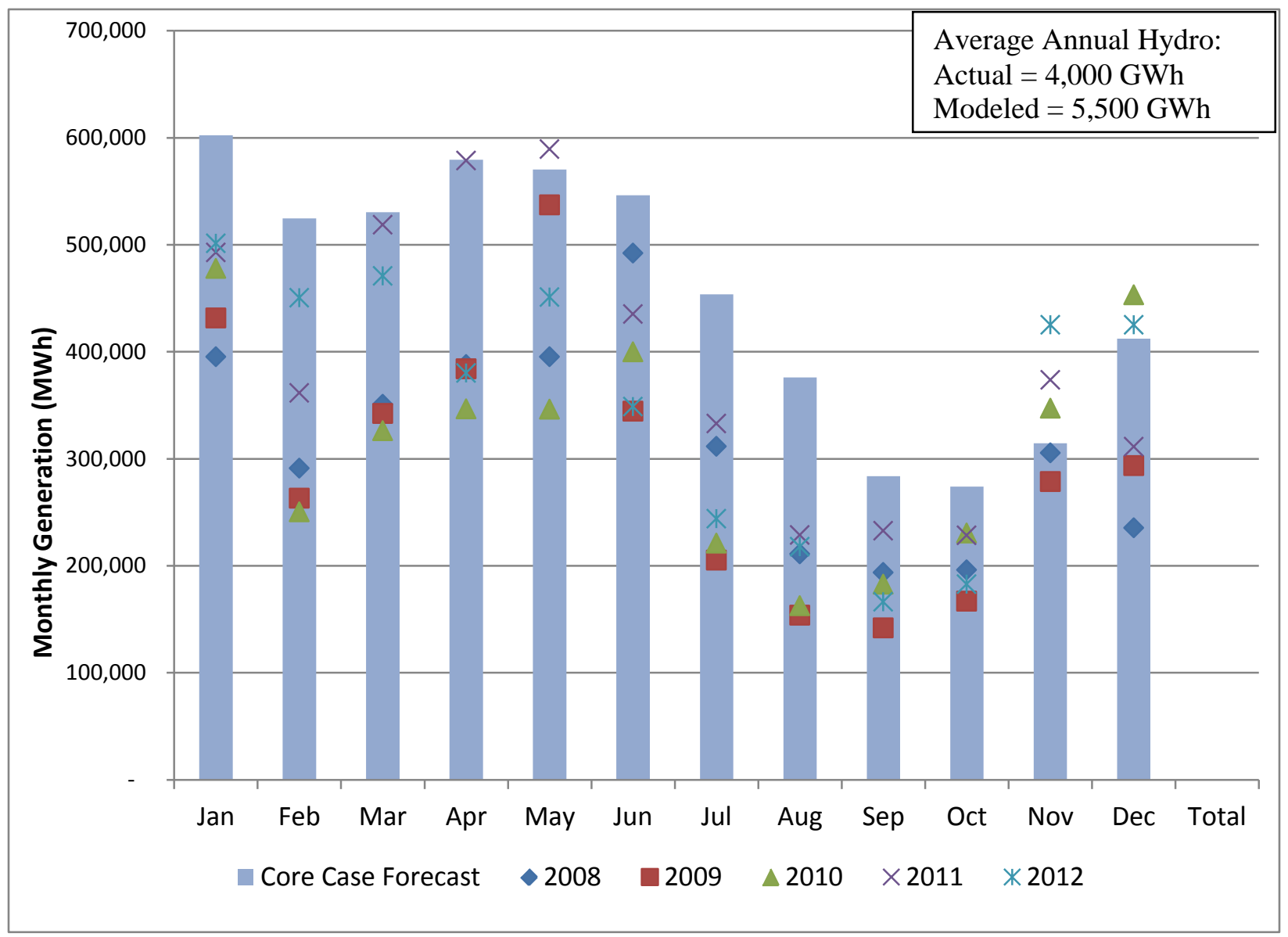

Figure 4.14. PacifiCorp Actual vs. Base Case HA for Hydro

\subsubsection{Portland General Electric Comparison}

PGE serves load in 52 Oregon cities. Its current power supply portfolio is a diverse mix of generating resources that includes hydropower, coal and natural gas combustion, and wind resources.

The hour-ahead simulation for the Base Case is the foundation upon which the NWPP EIM analysis is built. Consequently, these hour-ahead values were reviewed for their reasonableness and a summary of this analysis for PGE is provided in this section. This review revealed that the loads and resources for PGE during year 2020 in the Base Case are comparable with the average annual actual values from its most recent four-year loads and resources, as reported in its FERC "Form 1" filings (years 2009 through 2012). 
Figure 4.15 shows a comparison between the actual generation and load of PGE. Generation from 2009 through 2012 ranged from 13,661 to 10,096 GWh, and loads for the same period ranged from 18,463 to $19,030 \mathrm{GWh}$, whereas the forecast in the Base Case for generation is 11,976 GWh and for loads is $23,566 \mathrm{GWh}$ for year 2020.

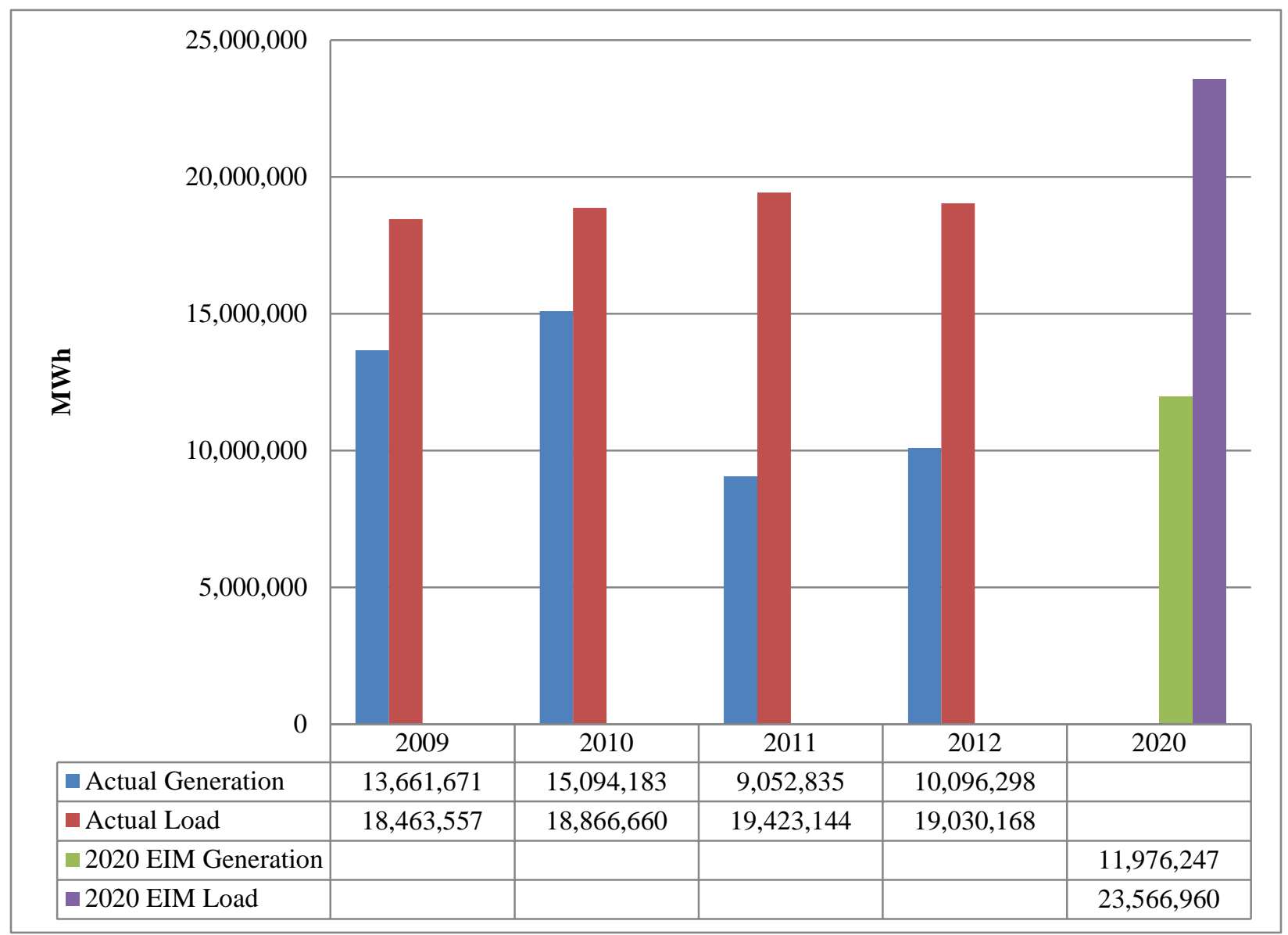

Figure 4.15. Portland General Electric Loads and Resources, Actuals vs. Modeled 
Figure 4.16 below shows the capacity balance of PGE on a peak day. This figure indicates that PGE is balanced, based on looking at the capacity breakdown in the Base Case for the peak hour of each month.

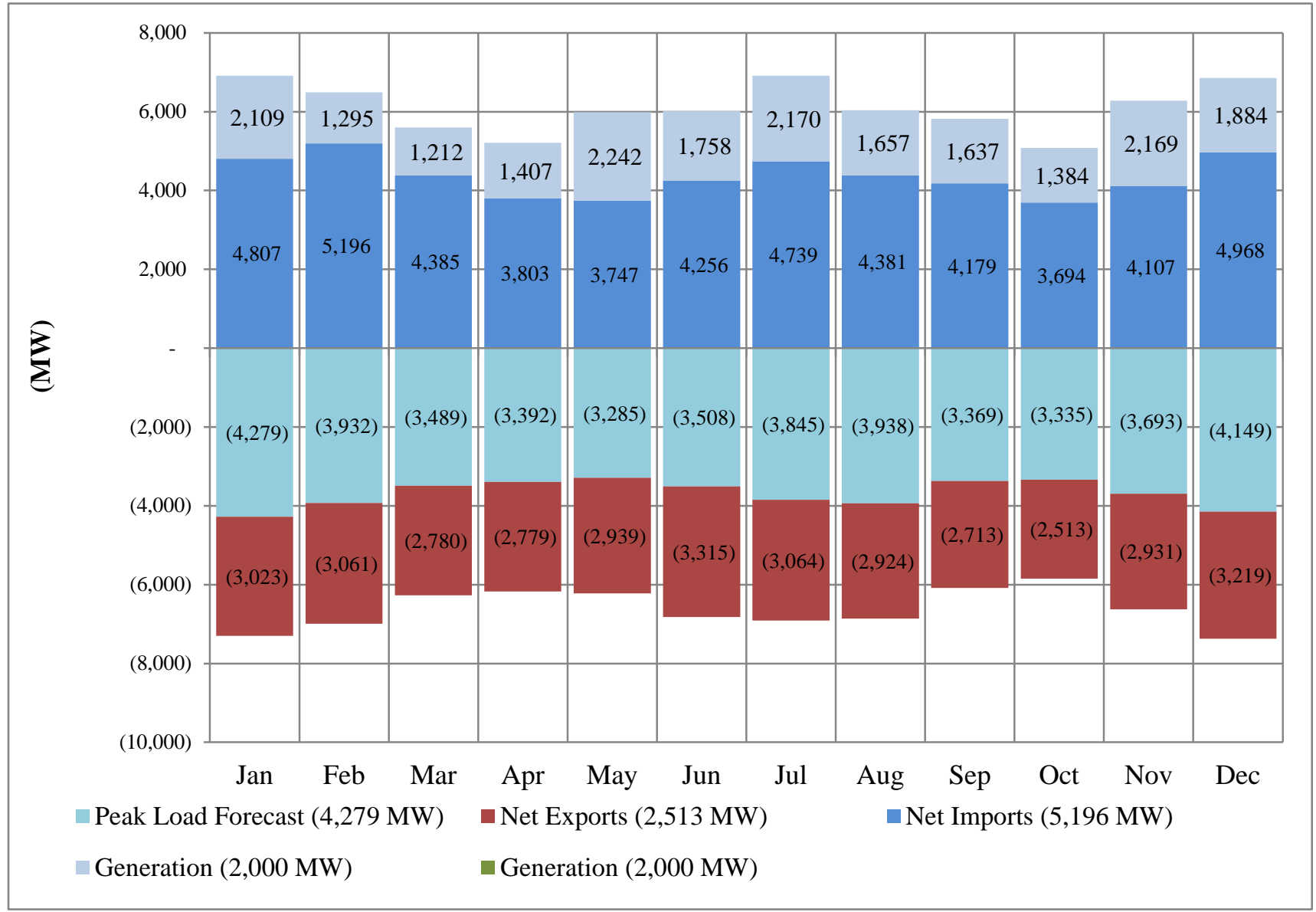

Figure 4.16. Portland General Electric Capacity Balance on Peak Day in the Base Case HA Simulation 
The annual energy supply of PGE is less than its annual energy demand (12,000 GWh and 23,560 GWh, respectively), however, the monthly energy values shown in Figure 4.17 may not balance since the monthly energy supply and demand values include imports and exports that were simulated during the hour-ahead simulation run for the Base Case.

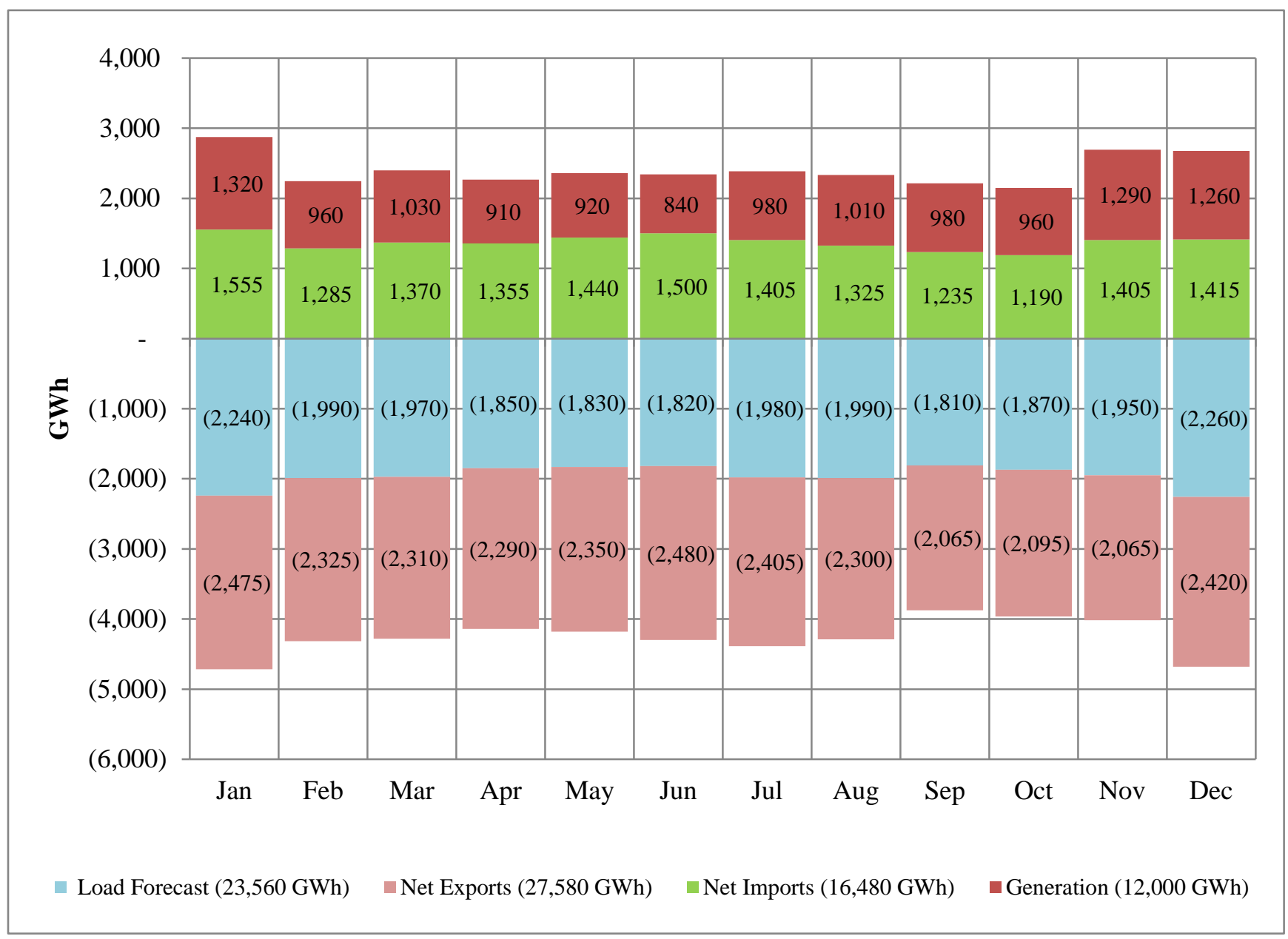

Figure 4.17. Portland General Electric Energy Balance by Month for the Base Case HA Simulation 
Since coal, natural gas, and hydro account for most of the PGE resources, comparisons were made between the modeled and actual resources. The results of these comparisons are plotted in Figure 4.18, Figure 4.19, and Figure 4.20, respectively.

Figure 4.18 does not show any coal-fired generation for PGE for the Base Case in Year 2020. The reasons for this are the following: 1) In the Base Case, the output of Colstrip 1 through 4 was not assigned to the BA of the plant share owners due to modeling limitation. All of the output from these resources was designated to Northwestern Energy; 2) The Boardman plant is planned to be retired by 2020. For the purpose of this study, the Boardman plant is replaced with a combined cycle natural gasfired plant, which is included in the Base Case for Year 2020 and reflected in Figure 4.19. Figure 4.20 shows the hydro generation of PGE from contracted resources such as the Mid-Columbia projects as well as plants owned by PGE.

The monthly comparisons in Figure 4.18 indicate that, in general, the natural gas-fired generation values for the Base Case closely approximate actual generation during July through December, understate the actual generation in January through March, and overstate the actual generation in April through June. The monthly comparisons in Figure 4.19 indicate that, in general, the hydro generation values for the Base Case closely approximate actual generation on an annual and month-by-month basis.

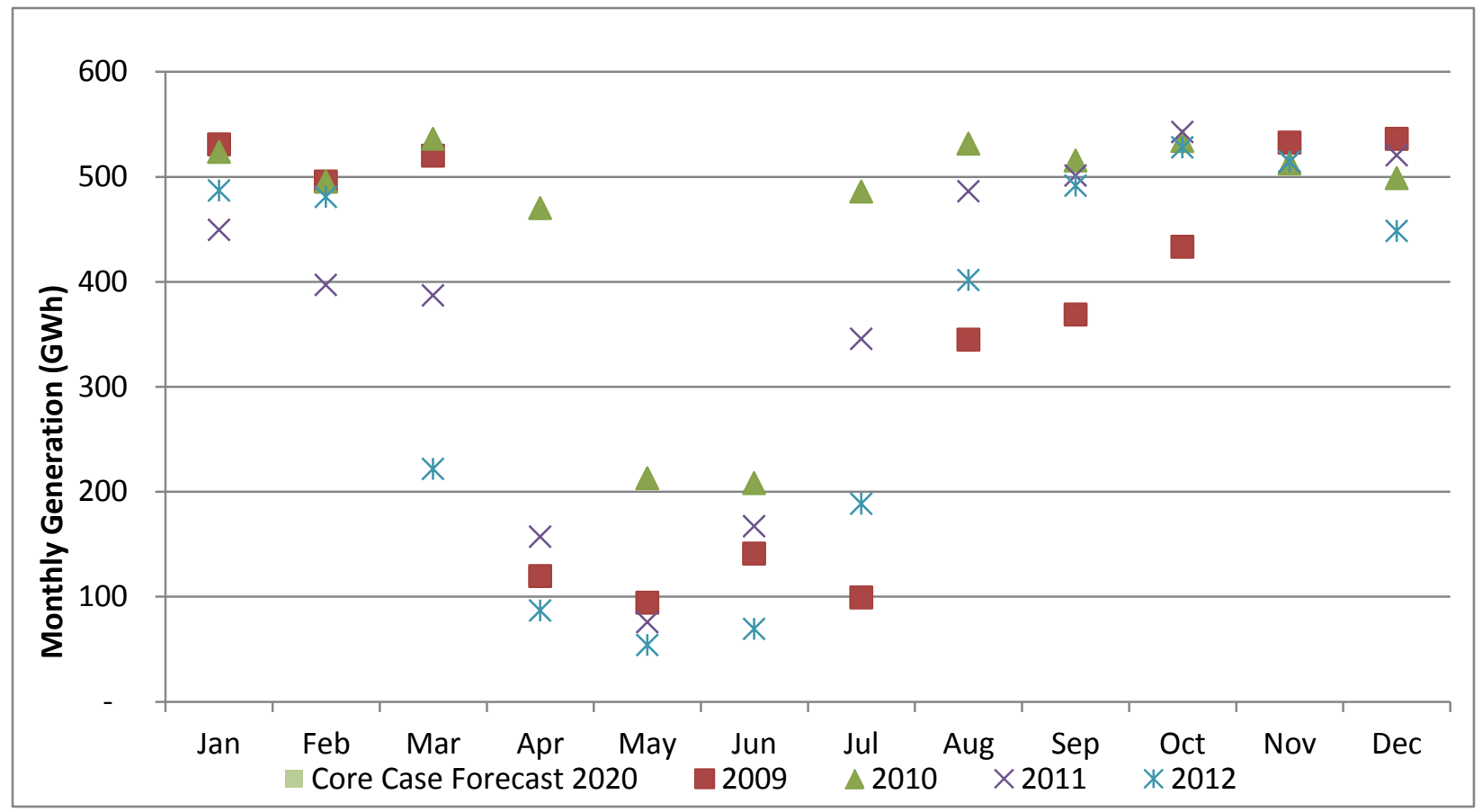

Figure 4.18. Portland General Electric Actual vs. Base Case HA for Dispatched Coal 


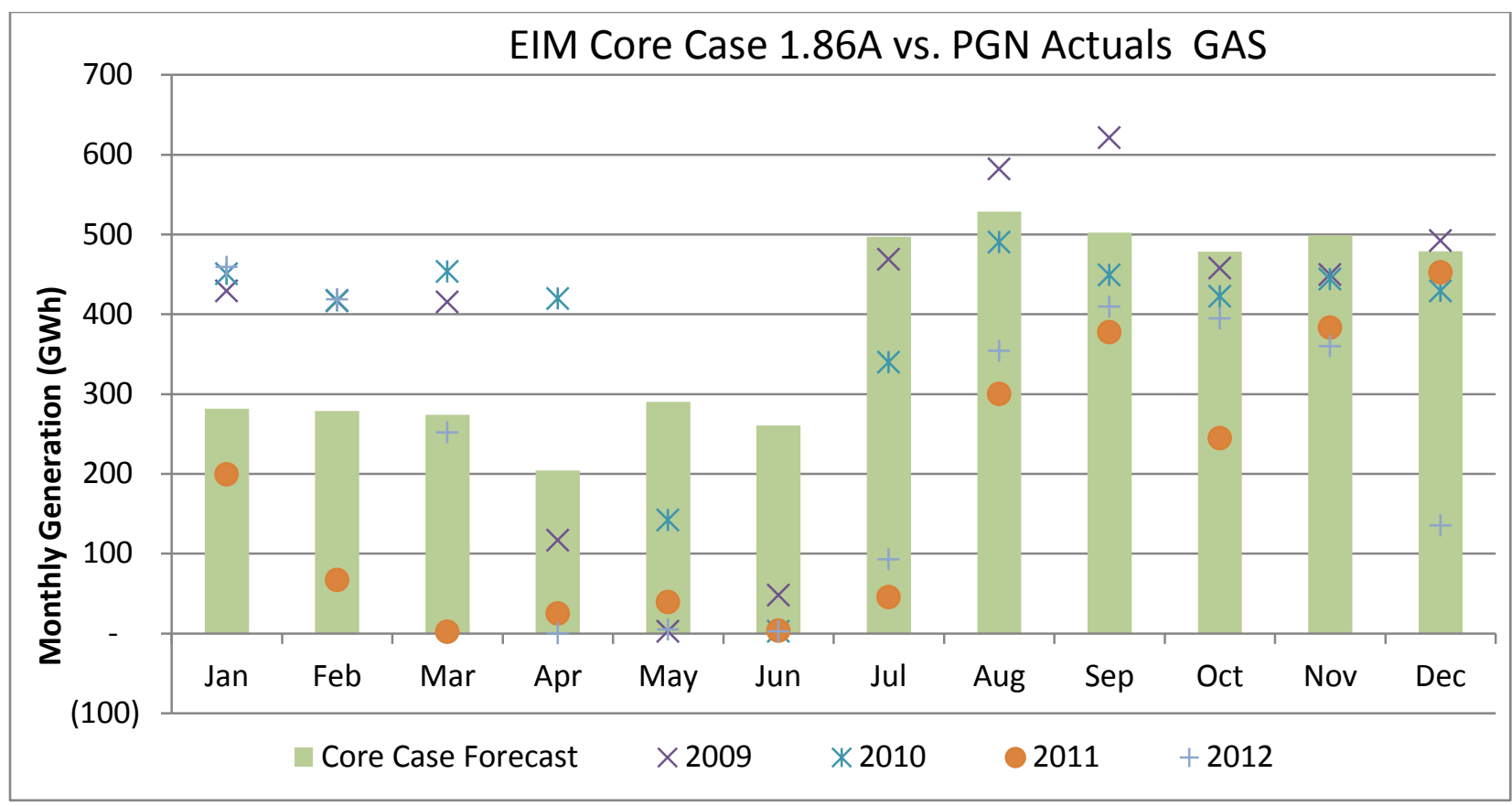

Figure 4.19. Portland General Electric Actual vs. Base Case HA for Dispatched Gas

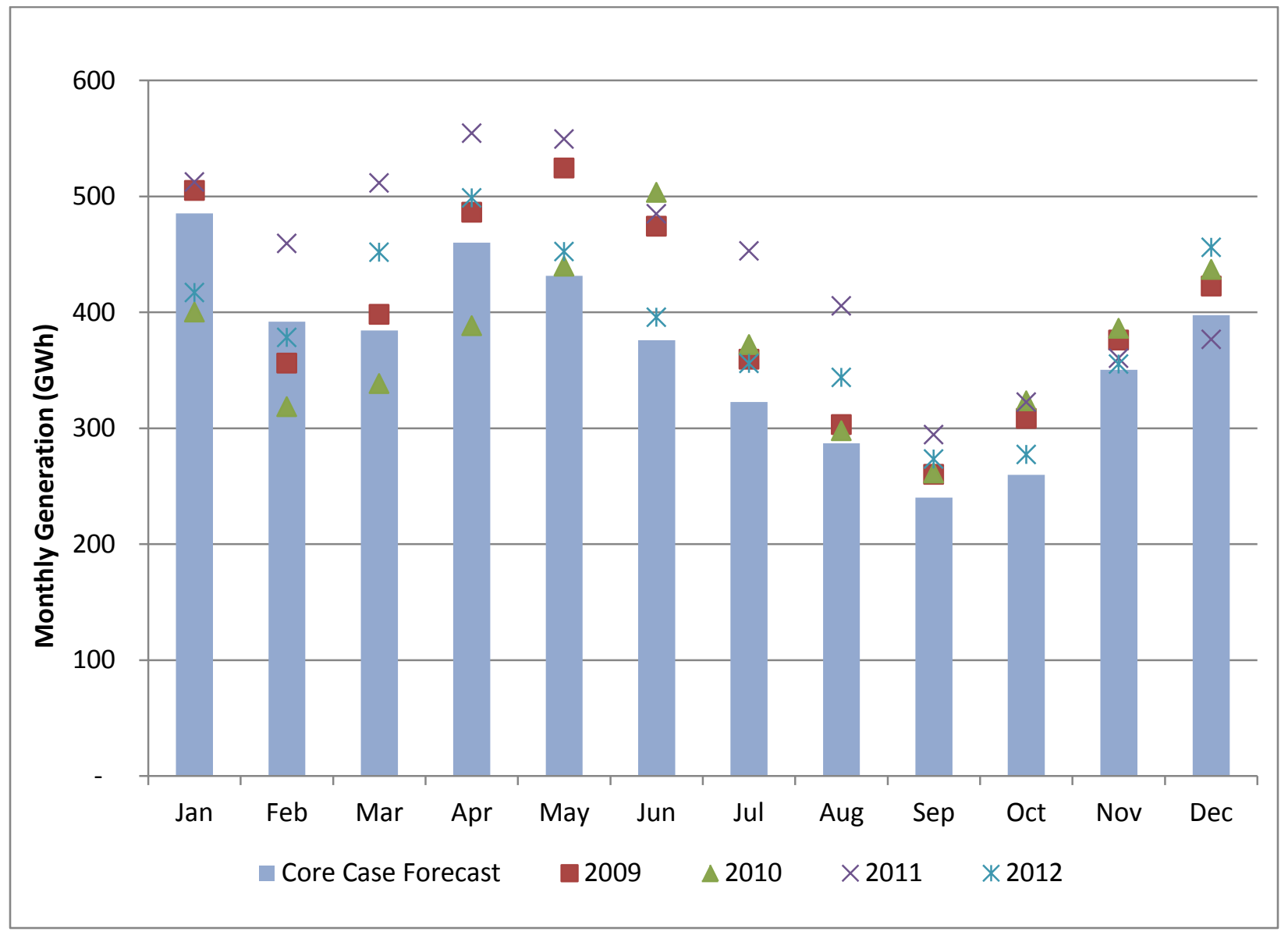

Figure 4.20. Portland General Electric Actual vs. Base Case HA for Hydro 


\subsubsection{Bonneville Power Administration Comparison}

The BPA Control Area consists of areas in Washington, Oregon and Idaho. The Base Case, hourahead simulation is the foundation upon which the NWPP EIM analysis is built. Consequently, these hour-ahead values have been reviewed for their reasonableness and a summary of this analysis for BPA is provided in this section. The loads and resources for the BPA compare well with historical trends from 2006-2012. Notable is the difference in expected wind generation during the period of analysis. Loads, thermal generation and hydroelectric generation are within the bounds of historical observations.

Figure 4.21 compares historical generation and load with the load resource balance in the Base Case for the BPA. The generation of the BPA has tended to vary between 12,000 and 14,000 aMW with the increase in the net supply position between the EIM Base Case and the historical observations being largely a result of the increase in wind generation in the BPA control area. The historical loads of the BPA have been roughly 6,000 aMW, with some evident trends reflective of the economic downturn in 2008 and a gradual recovery through 2012.

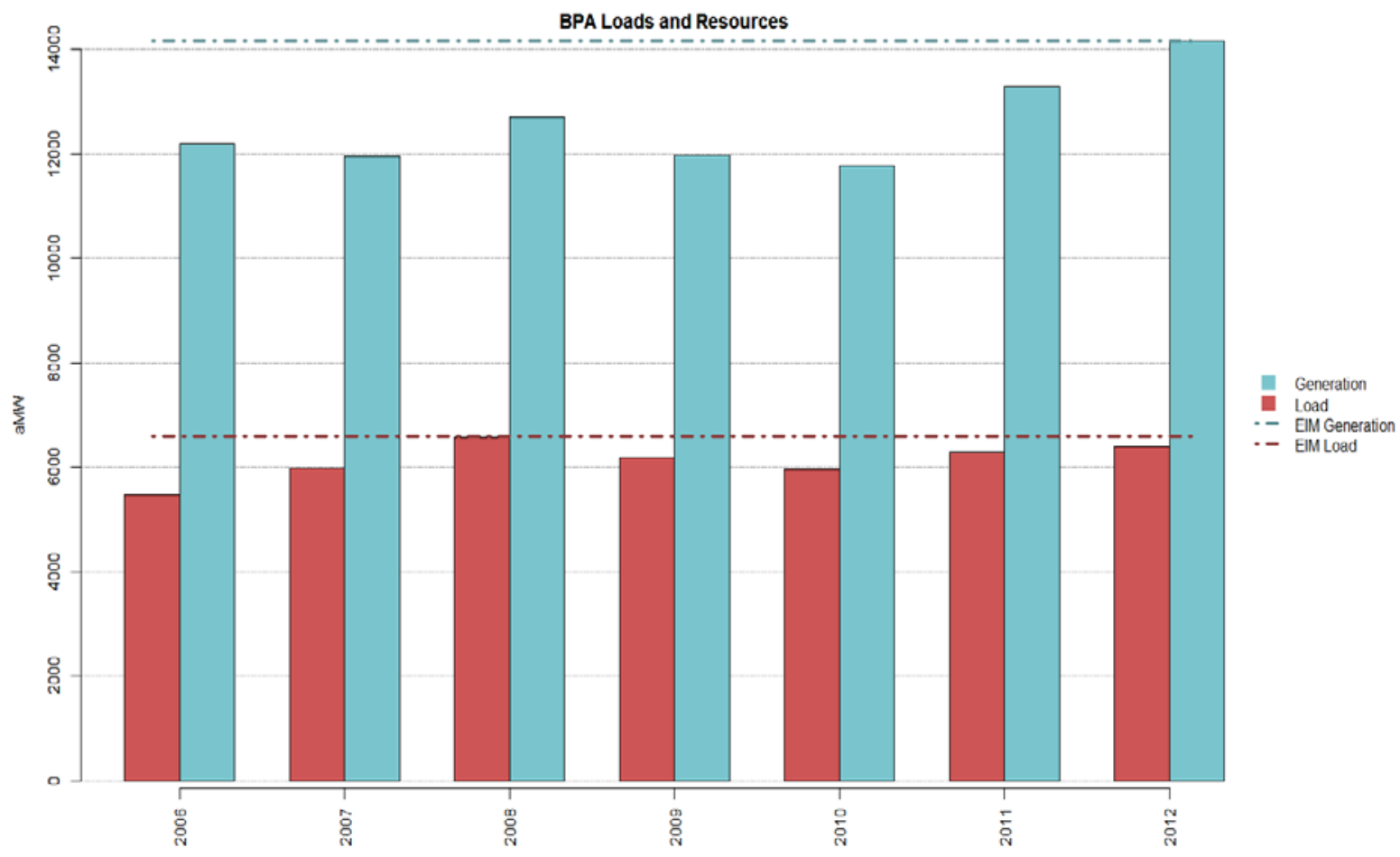

Figure 4.21. BPA Loads and Resources, Actuals vs. Modeled 
Figure 4.22 shows the resource mix and net capacity position for the BPA during the peak load hour for each month of the EIM analysis. The net capacity position is largely a result of the assumed hydroelectric generation. Under typical hydro conditions, BPA generates surplus energy during all peak load hours.

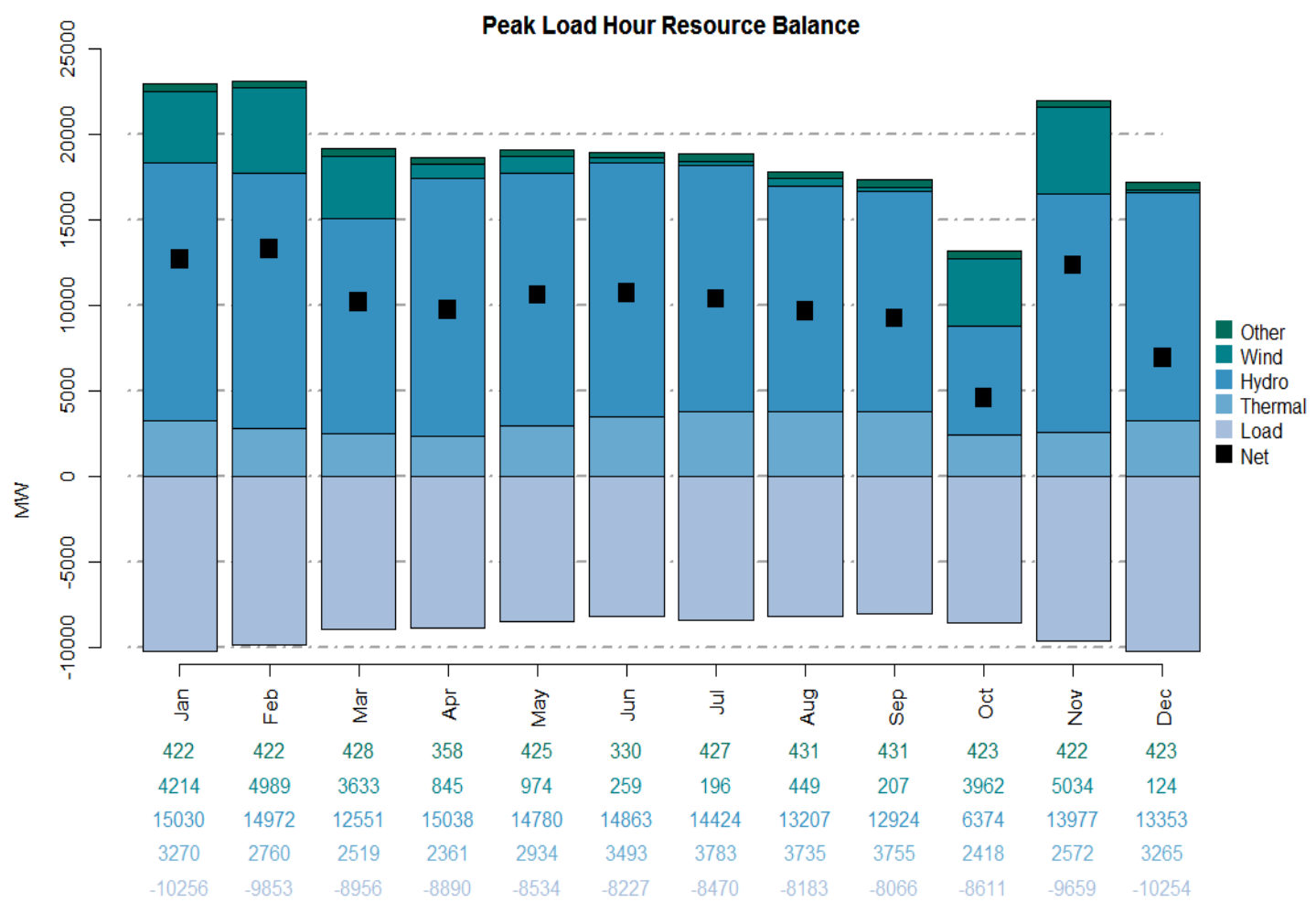

Figure 4.22. BPA Capacity Balance on Peak Day for the Base Case HA Simulation 
The monthly energy balances shown in Figure 4.23 indicate that BPA has a substantial amount of surplus energy during all months. The relative magnitude of the exports and imports is consistent with the observation that generation is forecast to be well above load in the BPA control area.

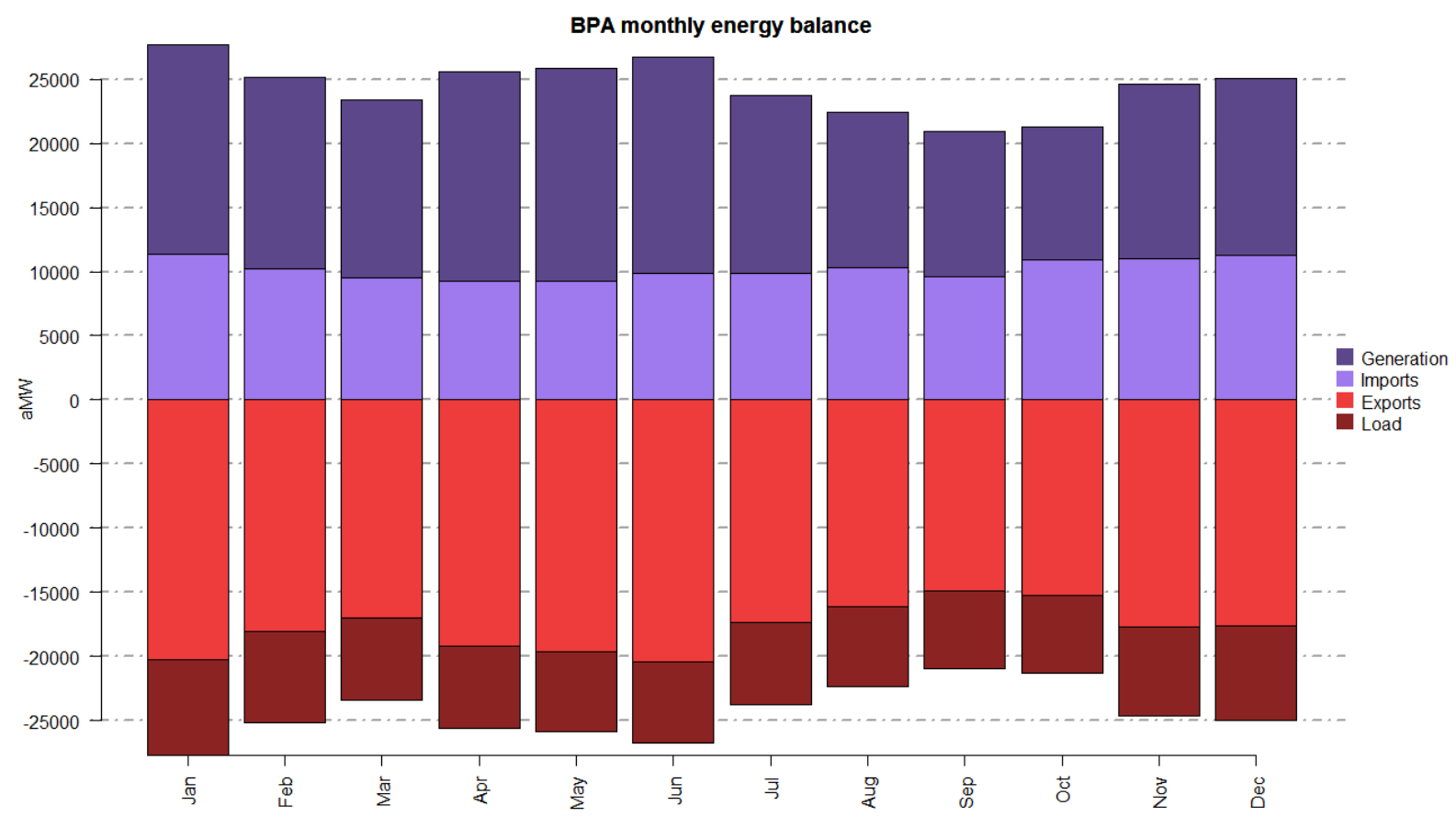

Figure 4.23. BPA BA Energy Balance by Month for the Base Case HA Simulation

Figure 4.24 shows the aggregate fuel mix in the BPA control area for the EIM Base Case and actual data for the last 7 years. This figure indicates that the amount of hydroelectric generation varies substantially from year to year. However, it also indicates that the level of hydro generation for the EIM Base Case in 2020 is consistent with the actual hydro generation in 2006, which is the year chosen to represent hydro generation for the Base Case. Additionally, an evident trend in the control area is the continued increase in expected generation from wind. The forecast wind generation during the EIM period is roughly 50\% higher than what was observed in 2012. Overall, a comparison of these data indicates that the results for the EIM Base Case are consistent with the historical data. 


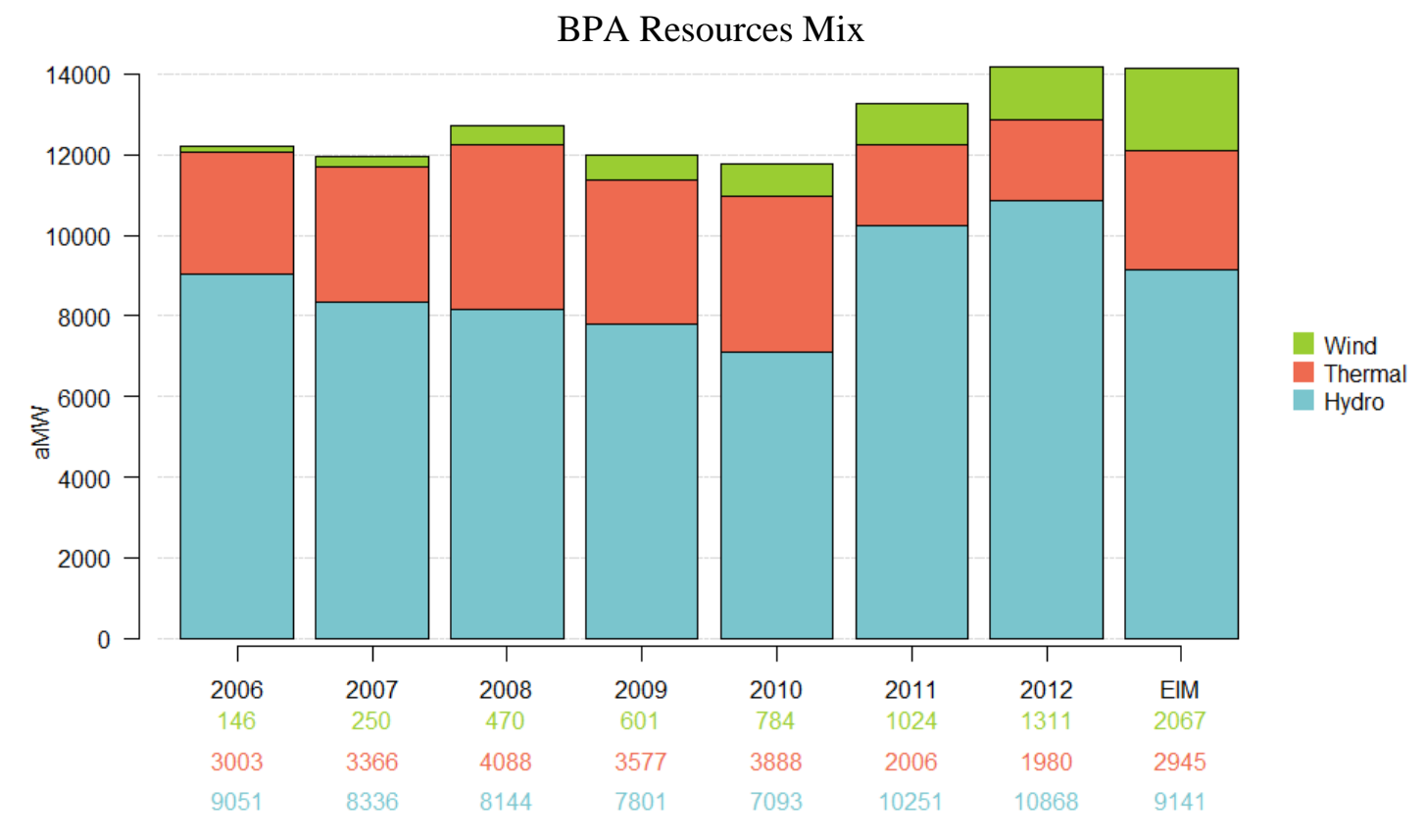

Figure 4.24. Historical BPA Control Area Resources Mix vs. Base Case HA Simulation

\subsection{Production Cost Results Summary}

The Analytical Team spent several months developing the Base Case. Several test cases were developed with the simulation results of each case being examined for further model improvements. Ultimately, these intermediate step test cases led to the development of the Base Case, Case 1.86A. Additionally, several sensitivity cases, which are cases $1.86 \mathrm{~B}$ to $1.86 \mathrm{~K}$ and 1.94 (described in Table 3-2), were developed to evaluate the impact that changes in certain key factors might have on the level and variability of the benefits from an EIM.

One of the more challenging tasks in the process was representing the complex "budgeting" process for flexible hydroelectric facilities. This involves considering not just the immediate market value of the generation and the unit capabilities, but also how the operational and economic decisions made in one time frame might affect operational capabilities and economic conditions in future time frames while adhering to the required water budget and balancing the output from non-dispatchable resources. Modeling limitations in PLEXOS sometimes required the use of phantom "excess hydro"” to solve troublesome 10 minute time segments within the operating hour. This occurred when a time segment was short of resources even though the time segments surrounding the troublesome segment had committed thermal energy available, which operators in actual operations would adjust the amounts of hydro and

\footnotetext{
${ }^{1}$ The phase "excess hydro generation" is shorthand reference alluding to difficulty, within the production cost modeling process, of accurately reflecting how operators of hydroelectric projects must often "budget" production capability across multiple time periods to manage myriad constraints, including available water, effects on downstream operations, and legal obligations to fulfill objectives other than power production (such as flood control and mitigation of environmental impacts).
} 
thermal generation dispatched between the time segments to cover the shortage. To more accurately compare the production costs of the cases when this occurred, the Analytical Team developed an approach external to PLEXOS that values this additional excess hydro generation at the cost of available thermal generation in the surrounding 10 minute segments. This excess hydro generation was valued at two different price levels to provide a range of values for comparative purposes.

For the Base Case and each sensitivity case, the amounts of excess hydro generation in both the EIM and BAU scenarios were each valued at two different price levels, which are \$42.00 per MWh and \$57.50 per MWh. These values were derived based on the natural gas prices used for the Base Case (the average annual price at Henry Hub is $\$ 5.62 / \mathrm{MMBtu}$ ) and assumed implied heat rates for gas-fired resources of 7.5 $\mathrm{MMBtu} / \mathrm{MWh}$ and 10.2 MMBtu/MWh, respectively. The one exception is that the prices used to value the excess hydro generation were adjusted in the high and low natural gas price cases to account for the assumed higher and lower natural gas prices per MMBtu at Henry Hub located near Erath, Louisiana.

The following sections give a brief summary of the simulation results of each case.

\subsubsection{Base Case (Case 1.86A)}

A high level summary of the total cost savings for Case 1.86A is reported in Table 4-2, with more detailed information being provided in Tables 4-3, 4-4, and 4-5. The generation costs for the NWPP EIM footprint and for WECC for the BAU and EIM scenarios are reported in Table 4-2 by month for the year 2020. ${ }^{1}$ The differences in the total generation costs between the EIM and BAU scenarios are mainly concentrated in the NWPP EIM footprint, as reported in Column 7 of Table 4-2. This is due to high penalty prices being applied by PLEXOS to the net exchange constraint violations during the HA period that result from the BAs outside the NWPP being unable to deliver energy that is scheduled. ${ }^{2}$ The savings in generation costs for the NWPP EIM footprint are negative (which are negative EIM benefits) for all months except the months in the second quarter. The savings in generation costs are positive in the second quarter because the use of excess hydro generation in the BAU scenario, relative to the EIM scenario, is less in this quarter than the other three quarters.

The savings in annual total generation costs reported near the bottom of Table 4-2 are negative. However, an additional computation needs to be performed external to PLEXOS to make the cost saving values comparable since the amount of hydro energy associated with the hydro energy constraint violations is higher in the BAU scenario than in the EIM scenario (see Column 4 of Table 4-3).

Hydro energy constraint violations in the PLEXOS model represents the release of free hydro energy in excess of the amount input into PLEXOS. While not a capability that exists in the current version of PLEXOS, in actual operations the thermal resources in PLEXOS would be redispatched in a manner that would allow the amount of this free hydro energy to be replenished back to its original prescribed balance. The value of this redispatched energy would be based on the prices resulting from the thermal resources on the margin. In this study, this redispatched energy is valued by pricing the excess hydro eng

\footnotetext{
${ }^{1}$ The EIM is modeled in the NWPP footprint, which for the purposes of EIM modeling only excludes AESO (Alberta Electric System Operator) and Sierra Pacific. AESO and Sierra Pacific are both members of the NWPP reserve sharing group.

${ }^{2}$ Section 3.2.3.3 describes the exchange constraints utilized in this case and provides a description of the exchange constraint methodology.
} 
generation in a range represented by $\$ 42.00 / \mathrm{MWh}$ and $\$ 57.50 / \mathrm{MWh} .{ }^{1}$ Once the differences in the values of the excess hydro generation between the BAU scenario and the EIM scenario are added to the negative savings in generation costs, the total savings from implementing an EIM became positive.

Table 4-4 reports total dump and unserved energy, reserve shortfall and exchange violations by month for all the BAs in the WECC. All these violations are very small compared to the total load served and stable over both the BAU and EIM scenarios, which make the simulation results reliable and the cases comparable.

Table 4-5 reports the generation, demand, and average production costs for the NWPP and WECC, and the NWPP net interchange. These data indicate that the NWPP EIM footprint exports energy to the rest of the WECC. This is because the day-ahead and hour-ahead periods were optimized WECC-wide before the implementation of the EIM, which allows the low cost generation in the hydro-dominated, NWPP EIM footprint to find a market in the rest of the WECC. ${ }^{2}$

As reported at the bottom of Table 4-2, the annual total savings between the BAU scenario and the EIM scenario within the NWPP footprint are \$41.2 million and \$70.7 million, which correspond to the prices for excess hydro generation being \$42.00/MWh and \$57.50/MWh, respectively.

\footnotetext{
${ }^{1}$ Section 4.2 introduction describes the excess hydro pricing utilized in this case and provides a description of the excess hydro pricing methodology.

${ }^{2}$ Sections 3.2 describes the optimization process utilized in the modeling and Section 2.4 describes the hydro methodologies employed, including a description of the production cost modeling practice to price hydro, wind and solar energy at $\$ 0$ per MWh.
} 
Table 4-2. Summary of Generation Cost and Savings for the NWPP and WECC in Case 1.86A

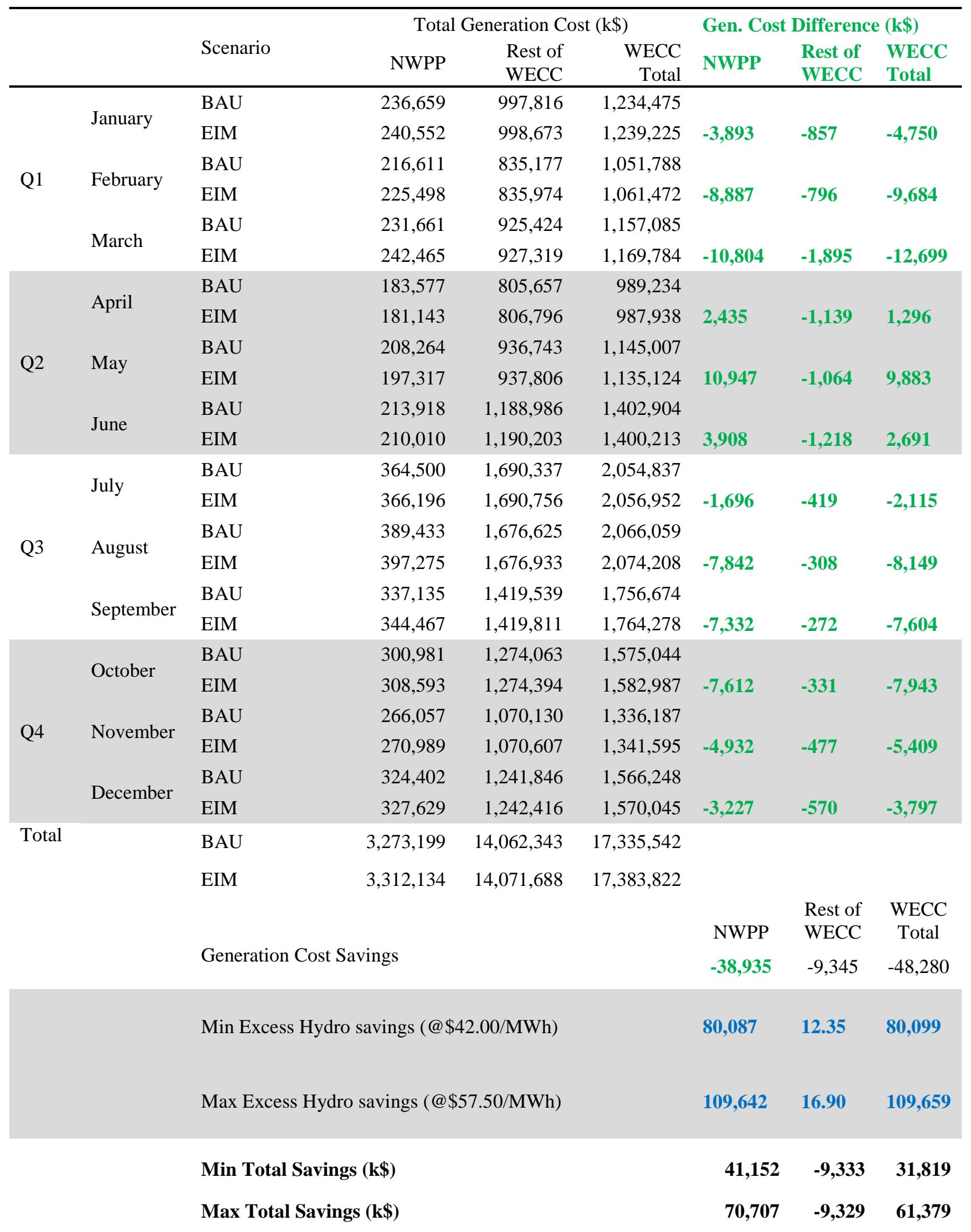


Table 4-3. Hydro Generation and Energy Constraint Violations in Case 1.86A

\begin{tabular}{|c|c|c|c|c|c|c|c|}
\hline & & \multirow[b]{2}{*}{ Scenario } & \multicolumn{3}{|c|}{ Hydro Violation (GWh) } & \multicolumn{2}{|c|}{ Total HTC Hydro (GWh) } \\
\hline & & & NWPP & $\begin{array}{l}\text { Rest of } \\
\text { WECC }\end{array}$ & $\begin{array}{c}\text { WECC } \\
\text { Total }\end{array}$ & NWPP & WECC Total \\
\hline \multirow{6}{*}{ Q1 } & \multirow{2}{*}{ January } & BAU & 178 & 16 & 194 & 12,275 & 13,590 \\
\hline & & EIM & 19 & 16 & 35 & 12144 & 13459 \\
\hline & \multirow{2}{*}{ February } & BAU & 227 & 15 & 243 & 10,573 & 11,970 \\
\hline & & EIM & 39 & 16 & 54 & 10,394 & 11,792 \\
\hline & \multirow{2}{*}{ March } & BAU & 270 & 24 & 294 & 9,710 & 11,073 \\
\hline & & EIM & 50 & 24 & 74 & 9,494 & 10,857 \\
\hline \multirow{6}{*}{ Q2 } & \multirow{2}{*}{ April } & BAU & 109 & 13 & 122 & 10,689 & 12,269 \\
\hline & & EIM & 29 & 13 & 42 & 10,768 & 12,349 \\
\hline & \multirow{2}{*}{ May } & BAU & 92 & 11 & 102 & 9,866 & 12,036 \\
\hline & & EIM & 7 & 10 & 18 & 10,178 & 12,347 \\
\hline & \multirow{2}{*}{ June } & BAU & 117 & 19 & 136 & 10,800 & 12,829 \\
\hline & & EIM & 16 & 18 & 33 & 10,830 & 12,858 \\
\hline \multirow{6}{*}{ Q3 } & \multirow{2}{*}{ July } & BAU & 159 & 16 & 175 & 8,629 & 10,565 \\
\hline & & EIM & 7 & 16 & 23 & 8,485 & 10,421 \\
\hline & \multirow{2}{*}{ August } & BAU & 213 & 10 & 223 & 8,402 & 10,025 \\
\hline & & EIM & 38 & 10 & 48 & 8,231 & 9,853 \\
\hline & \multirow{2}{*}{ September } & BAU & 209 & 13 & 222 & 7,435 & 8,801 \\
\hline & & EIM & 46 & 13 & 59 & 7,274 & 8,640 \\
\hline \multirow{6}{*}{ Q4 } & \multirow{2}{*}{ October } & BAU & 256 & 11 & 267 & 7,907 & 9,055 \\
\hline & & EIM & 61 & 12 & 73 & 7,719 & 8,868 \\
\hline & \multirow{2}{*}{ November } & BAU & 235 & 8 & 243 & 8,828 & 9,924 \\
\hline & & EIM & 45 & 8 & 53 & 8,651 & 9,747 \\
\hline & \multirow{2}{*}{ December } & BAU & 213 & 7 & 219 & 10,911 & 12,222 \\
\hline & & EIM & 13 & 7 & 19 & 10,741 & 12,052 \\
\hline \multirow{2}{*}{ Total } & & BAU & 2,276 & 164 & 2,440 & 116,024 & 134,357 \\
\hline & & EIM & 370 & 162 & 532 & 114,909 & 133,241 \\
\hline
\end{tabular}


Table 4-4. WECC Dump and Unserved Energy, Reserve Shortfall and Exchange Violations in Case $1.86 \mathrm{~A}$

\begin{tabular}{|c|c|c|c|c|c|c|c|c|c|c|c|}
\hline & & \multirow{2}{*}{ Scenario } & \multirow{2}{*}{$\begin{array}{l}\text { Dump } \\
\text { GWh }\end{array}$} & \multirow{2}{*}{$\begin{array}{l}\text { USE } \\
\text { (unserved } \\
\text { GWh) }\end{array}$} & \multicolumn{5}{|c|}{ Total BAs Reserve Shortfall (GWh) } & \multicolumn{2}{|c|}{$\begin{array}{c}\text { Total BAs Exchange } \\
\text { Violation (GWh) }\end{array}$} \\
\hline & & & & & Spin & $\begin{array}{l}\text { Reg. } \\
\text { up }\end{array}$ & $\begin{array}{l}\text { Reg. } \\
\text { down }\end{array}$ & $\begin{array}{l}\text { Non } \\
\text { spin }\end{array}$ & Total & $\mathrm{Up}^{1}$ & $\mathrm{Dn}^{2}$ \\
\hline \multirow{6}{*}{ Q1 } & \multirow{2}{*}{ January } & BAU & 0.3 & 6.7 & 13.3 & 3.7 & 0.2 & 4.0 & 21 & 0.4 & 0.0 \\
\hline & & EIM & 0.0 & 6.7 & 16.8 & 4.3 & 0.1 & 3.5 & 25 & 0.4 & 0.0 \\
\hline & \multirow{2}{*}{ February } & BAU & 0.6 & 8.4 & 17.4 & 4.3 & 0.4 & 6.3 & 28 & 0.4 & 0.0 \\
\hline & & EIM & 0.2 & 8.3 & 22.2 & 6.2 & 0.3 & 6.1 & 35 & 0.3 & 0.0 \\
\hline & \multirow{2}{*}{ March } & BAU & 0.4 & 7.3 & 15.2 & 3.5 & 0.2 & 4.6 & 23 & 0.6 & 0.0 \\
\hline & & EIM & 1.2 & 7.3 & 24.2 & 6.2 & 0.4 & 8.0 & 39 & 0.5 & 0.0 \\
\hline \multirow{6}{*}{ Q2 } & \multirow{2}{*}{ April } & BAU & 0.4 & 8.3 & 12.5 & 3.6 & 0.4 & 3.4 & 20 & 0.8 & 0.0 \\
\hline & & EIM & 0.2 & 8.3 & 10.5 & 2.2 & 0.4 & 2.8 & 16 & 0.7 & 0.0 \\
\hline & \multirow{2}{*}{ May } & BAU & 0.5 & 9.5 & 11.8 & 2.7 & 0.3 & 2.0 & 17 & 1.0 & 0.0 \\
\hline & & EIM & 0.2 & 9.4 & 9.8 & 1.2 & 0.2 & 1.4 & 13 & 0.8 & 0.0 \\
\hline & \multirow{2}{*}{ June } & BAU & 0.2 & 5.2 & 17.7 & 3.8 & 0.1 & 4.7 & 26 & 1.0 & 0.0 \\
\hline & & EIM & 0.0 & 5.1 & 15.8 & 1.9 & 0.1 & 2.5 & 20 & 0.8 & 0.1 \\
\hline \multirow{6}{*}{ Q3 } & \multirow{2}{*}{ July } & BAU & 0.2 & 3.2 & 23.4 & 3.9 & 0.1 & 4.7 & 32 & 1.6 & 0.0 \\
\hline & & EIM & 0.0 & 3.2 & 17.7 & 1.7 & 0.4 & 1.8 & 21 & 1.1 & 0.2 \\
\hline & \multirow{2}{*}{ August } & BAU & 1.2 & 6.8 & 18.1 & 4.0 & 0.6 & 6.4 & 29 & 1.1 & 0.1 \\
\hline & & EIM & 0.0 & 6.8 & 16.5 & 3.4 & 0.4 & 4.9 & 25 & 0.5 & 0.2 \\
\hline & \multirow{2}{*}{ September } & BAU & 2.0 & 7.1 & 12.2 & 2.2 & 0.7 & 3.9 & 19 & 0.8 & 0.0 \\
\hline & & EIM & 0.0 & 7.1 & 14.3 & 3.2 & 0.6 & 3.3 & 21 & 0.6 & 0.1 \\
\hline \multirow{6}{*}{ Q4 } & \multirow{2}{*}{ October } & BAU & 3.6 & 4.2 & 15.0 & 3.0 & 1.0 & 6.6 & 26 & 1.3 & 0.0 \\
\hline & & EIM & 0.0 & 4.2 & 15.0 & 3.0 & 0.4 & 6.3 & 25 & 0.6 & 0.0 \\
\hline & \multirow{2}{*}{ November } & BAU & 1.8 & 5.7 & 16.5 & 4.5 & 0.6 & 7.6 & 29 & 1.0 & 0.0 \\
\hline & & EIM & 0.0 & 5.6 & 15.4 & 3.7 & 0.2 & 5.5 & 25 & 0.6 & 0.1 \\
\hline & \multirow{2}{*}{ December } & BAU & 0.5 & 4.7 & 19.7 & 4.7 & 0.3 & 7.5 & 32 & 0.8 & 0.0 \\
\hline & & EIM & 0.0 & 4.7 & 15.9 & 2.7 & 0.2 & 4.2 & 23 & 0.5 & 0.0 \\
\hline \multirow{2}{*}{ Total } & & BAU & 12 & 77 & 193 & 44 & 5 & 62 & 303 & 10.7 & 0.1 \\
\hline & & EIM & 2 & 77 & 194 & 40 & 4 & 50 & 288 & 7.5 & 0.9 \\
\hline
\end{tabular}

${ }^{1}$ Up refers to the energy amount violating the constraint: (BA RT net exchange $<$ BA HA net exchange +10 MW)

${ }^{2}$ Dn refers to the energy amount violating the constraint: (BA RT net exchange > BA HA net exchange - $10 \mathrm{MW}$ ) 
Table 4-5 Generation, Demand, and Average Production Cost for the NWPP and WECC, and the NWPP Net Interchange in Case 1.86A

\begin{tabular}{|c|c|c|c|c|c|c|c|c|c|}
\hline & & Scenario & $\begin{array}{c}\text { NWPP } \\
\text { Generation } \\
\text { (GWh) }\end{array}$ & $\begin{array}{l}\text { NWPP } \\
\text { Demand } \\
\text { (GWh) }\end{array}$ & $\begin{array}{c}\text { NWPP } \\
\text { Average } \\
\text { Production } \\
\text { Cost } \\
(\$ / \mathrm{MWh})\end{array}$ & $\begin{array}{c}\text { WECC } \\
\text { Generation } \\
\text { (GWh) }\end{array}$ & $\begin{array}{l}\text { WECC } \\
\text { Demand } \\
\text { (GWh) }\end{array}$ & $\begin{array}{c}\text { WECC } \\
\text { Average } \\
\text { Production } \\
\text { Cost } \\
\text { (\$/MWh) }\end{array}$ & $\begin{array}{l}\text { NWPP } \\
\text { Net } \\
\text { Exchange } \\
(\mathrm{GWh})^{1}\end{array}$ \\
\hline \multirow{6}{*}{ Q1 } & \multirow{2}{*}{ January } & BAU & 38,449 & 32,368 & 6.16 & 86,695 & 86,702 & 14.24 & $-6,081$ \\
\hline & & EIM & 38429 & 32368 & 6.26 & 86,695 & 86,702 & 14.29 & $-6,062$ \\
\hline & \multirow{2}{*}{ February } & BAU & 33,219 & 28,897 & 6.52 & 76,997 & 77,005 & 13.66 & $-4,323$ \\
\hline & & EIM & 33,201 & 28,897 & 6.79 & 76,997 & 77,005 & 13.78 & $-4,304$ \\
\hline & \multirow{2}{*}{ March } & BAU & 32,846 & 28,739 & 7.05 & 80,481 & 80,488 & 14.38 & $-4,106$ \\
\hline & & EIM & 32,825 & 28,739 & 7.39 & 80,482 & 80,488 & 14.53 & $-4,086$ \\
\hline \multirow{6}{*}{ Q2 } & \multirow{2}{*}{ April } & BAU & 32,199 & 26,702 & 5.70 & 77,358 & 77,366 & 12.79 & $-5,497$ \\
\hline & & EIM & 32,175 & 26,702 & 5.63 & 77,358 & 77,366 & 12.77 & $-5,473$ \\
\hline & \multirow{2}{*}{ May } & BAU & 33,963 & 27,162 & 6.13 & 83,346 & 83,355 & 13.74 & $-6,802$ \\
\hline & & EIM & 33,942 & 27,162 & 5.81 & 83,346 & 83,355 & 13.62 & $-6,780$ \\
\hline & \multirow{2}{*}{ June } & BAU & 34,096 & 27,701 & 6.27 & 87,456 & 87,461 & 16.04 & $-6,395$ \\
\hline & & EIM & 34,071 & 27,701 & 6.16 & 87,456 & 87,461 & 16.01 & $-6,370$ \\
\hline \multirow{6}{*}{ Q3 } & \multirow{2}{*}{ July } & BAU & 34,101 & 30,588 & 10.69 & 97,736 & 97,739 & 21.02 & $-3,513$ \\
\hline & & EIM & 34,093 & 30,588 & 10.74 & 97,736 & 97,739 & 21.05 & $-3,505$ \\
\hline & \multirow{2}{*}{ August } & BAU & 32,699 & 29,972 & 11.91 & 96,098 & 96,104 & 21.50 & $-2,727$ \\
\hline & & EIM & 32,693 & 29,972 & 12.15 & 96,097 & 96,104 & 21.58 & $-2,720$ \\
\hline & \multirow{2}{*}{ September } & BAU & 29,776 & 27,067 & 11.32 & 85,666 & 85,671 & 20.50 & $-2,709$ \\
\hline & & EIM & 29,770 & 27,067 & 11.57 & 85,664 & 85,671 & 20.59 & $-2,703$ \\
\hline \multirow{6}{*}{ Q4 } & \multirow{2}{*}{ October } & BAU & 30,549 & 27,528 & 9.85 & 82,611 & 82,611 & 19.07 & $-3,021$ \\
\hline & & EIM & 30,542 & 27,528 & 10.10 & 82,607 & 82,611 & 19.16 & $-3,013$ \\
\hline & \multirow{2}{*}{ November } & BAU & 32,940 & 29,190 & 8.08 & 81,490 & 81,494 & 16.40 & $-3,750$ \\
\hline & & EIM & 32,930 & 29,190 & 8.23 & 81,488 & 81,494 & 16.46 & $-3,740$ \\
\hline & \multirow{2}{*}{ December } & BAU & 36,162 & 32,780 & 8.97 & 88,548 & 88,552 & 17.69 & $-3,382$ \\
\hline & & EIM & 36,153 & 32,780 & 9.06 & 88,548 & 88,552 & 17.73 & $-3,373$ \\
\hline \multirow{2}{*}{ Total } & & BAU & 401,000 & 348,694 & 9.39 & $1,024,483$ & $1,024,548$ & 16.92 & $-52,306$ \\
\hline & & EIM & 400,823 & 348,694 & 9.50 & $1,024,473$ & $1,024,548$ & 16.97 & $-52,129$ \\
\hline
\end{tabular}

\footnotetext{
${ }^{1}$ The negative value indicates that net exchange is energy export.
} 


\subsubsection{Increased Flexible Reserve Case (Case 1.86B)}

In this sensitivity case, the $\mathrm{CI}$ for the balancing reserves is changed from the $95 \%$ used in the Base Case (Case 1.86A) to 99.5\%, resulting in an increased balancing reserve requirement for each BA. To meet the increased reserve requirement, some generation is shifted to more expensive units, which increases the generation costs for the NWPP in both the BAU and the EIM scenarios compared with the Base Case. This can be observed by comparing the generation costs reported in Table 4-6 with the comparable values for the Base Case reported in Table 4-2. The savings in the generation costs between the BAU scenario and the EIM scenario are more than in the Base Case, which indicates that the benefits from an EIM increase as the reserve requirement increases as a result of having more generating units that are online and available to deal with the energy imbalances.

Also due to this increased balancing reserve requirement, more thermal units are committed during the real-time 10-minute dispatches, whose generation capacity and ramping capability are used to meet BA exchange constraints, which reduce the burden on hydro units. This in turn reduces the amount of hydro energy associated with the hydro energy constraint violations in both the BAU and EIM scenarios compared with the Base Case, as can be observed by comparing the results reported in Table 4-7 with the results for the Base Case reported in Table 4-3. Despite the reductions, the hydro violations continued to occur mainly within the NWPP footprint as in the Base Case. Overall, the increased reserve requirement reduced the amount of dump and unserved energy, reserve shortfalls, and exchange violations for all the BAs in the WECC in both the BAU and EIM scenarios compared with the Base Case, as can be observed by comparing the results reported in Table 4-8 with the results for the Base Case reported in Table 4-4.

Compared to the Base Case, annual total savings in the NWPP increased due to the reduction in the negative differences in generation costs between the BAU and EIM scenarios being greater than the reduction in the excess hydro savings. This can be observed by comparing the results in the generation cost summary tables between this sensitivity case and the Base Case (Table 4-6 and Table 4-2, respectively). Additionally, it can be observed that the generation costs for the BAU and EIM scenarios for the non-NWPP BAs are slightly reduced due to roughly a 3\% increase in imports from the NWPP compared with the Base Case. Also, the amounts of generation, the average production costs (\$/MWh), and the amounts of net exchange energy in both the BAU and EIM scenarios increase compared with the Base Case, as can be observed by comparing the results reported in Table 4-9 with the results for the Base Case reported in Table 4-5.

As reported in Table 4-6, the annual total savings between the BAU scenario and the EIM scenario within the NWPP footprint are \$51.3 million and \$78.0 million, which correspond to the prices for excess hydro generation being \$42.00/MWh and \$57.50/MWh, respectively. These annual total savings are greater than the annual total savings received under the Base Case, which are \$41.2 million and \$70.7 million, respectively. 
Table 4-6. Summary of Generation Cost and Savings for the NWPP and WECC in Case 1.86B

\begin{tabular}{|c|c|c|c|c|c|c|c|c|}
\hline & & \multirow{2}{*}{ Scenario } & \multicolumn{3}{|c|}{ Total Generation Cost (k\$) } & \multicolumn{3}{|c|}{ Gen. Cost Difference (k\$) } \\
\hline & & & NWPP & $\begin{array}{l}\text { Rest of } \\
\text { WECC }\end{array}$ & WECC Total & NWPP & $\begin{array}{l}\text { Rest of } \\
\text { WECC }\end{array}$ & $\begin{array}{c}\text { WECC } \\
\text { Total }\end{array}$ \\
\hline \multirow{6}{*}{ Q1 } & \multirow{2}{*}{ January } & BAU & 245,916 & 998,369 & $1,244,285$ & & & \\
\hline & & EIM & 247,274 & 999,237 & $1,246,512$ & $-1,359$ & -868 & $-2,227$ \\
\hline & \multirow{2}{*}{ February } & BAU & 229,979 & 831,549 & $1,061,528$ & & & \\
\hline & & EIM & 235,536 & 832,373 & $1,067,909$ & $-5,557$ & -824 & $-6,381$ \\
\hline & \multirow{2}{*}{ March } & BAU & 247,446 & 919,740 & $1,167,186$ & & & \\
\hline & & EIM & 254,957 & 920,951 & $1,175,908$ & $-7,512$ & $-1,211$ & $-8,723$ \\
\hline \multirow{6}{*}{ Q2 } & \multirow{2}{*}{ April } & BAU & 190,070 & 812,961 & $1,003,031$ & & & \\
\hline & & EIM & 187,418 & 814,000 & $1,001,418$ & 2,652 & $-1,039$ & 1,613 \\
\hline & \multirow{2}{*}{ May } & BAU & 221,486 & 936,848 & $1,158,334$ & & & \\
\hline & & EIM & 208,766 & 938,439 & $1,147,205$ & 12,720 & $-1,591$ & 11,129 \\
\hline & \multirow{2}{*}{ June } & BAU & 220,881 & $1,187,515$ & $1,408,396$ & & & \\
\hline & & EIM & 215,752 & $1,188,692$ & $1,404,445$ & 5,128 & $-1,177$ & 3,951 \\
\hline \multirow{6}{*}{ Q3 } & \multirow{2}{*}{ July } & BAU & 374,214 & $1,684,204$ & $2,058,418$ & & & \\
\hline & & EIM & 374,856 & $1,684,566$ & $2,059,422$ & -642 & -362 & $-1,004$ \\
\hline & \multirow{2}{*}{ August } & BAU & 395,074 & $1,671,934$ & $2,067,009$ & & & \\
\hline & & EIM & 402,176 & $1,672,236$ & $2,074,411$ & $-7,101$ & -302 & $-7,403$ \\
\hline & \multirow{2}{*}{ September } & BAU & 345,443 & $1,415,048$ & $1,760,491$ & & & \\
\hline & & EIM & 351,811 & $1,415,240$ & $1,767,051$ & $-6,368$ & -192 & $-6,560$ \\
\hline \multirow{6}{*}{ Q4 } & \multirow{2}{*}{ October } & BAU & 313,132 & $1,268,008$ & $1,581,140$ & & & \\
\hline & & EIM & 319,991 & $1,268,382$ & $1,588,372$ & $-6,859$ & -374 & $-7,232$ \\
\hline & \multirow{2}{*}{ November } & BAU & 274,432 & $1,065,723$ & $1,340,155$ & & & \\
\hline & & EIM & 279,059 & $1,066,515$ & $1,345,573$ & $-4,627$ & -792 & $-5,419$ \\
\hline & \multirow{2}{*}{ December } & BAU & 335,462 & $1,238,354$ & $1,573,816$ & & & \\
\hline & & EIM & 337,256 & $1,239,048$ & $1,576,304$ & $-1,793$ & -694 & $-2,488$ \\
\hline \multirow[t]{8}{*}{ Total } & & BAU & 3,393,535 & $14,030,253$ & $17,423,788$ & & & \\
\hline & & EIM & $3,414,852$ & $14,039,680$ & $17,454,532$ & & & \\
\hline & & & & & & NWPP & $\begin{array}{l}\text { Rest of } \\
\text { WECC }\end{array}$ & $\begin{array}{l}\text { WECC } \\
\text { Total }\end{array}$ \\
\hline & & \multicolumn{4}{|c|}{ Generation Cost Savings } & $-21,316$ & $-9,427$ & $-30,744$ \\
\hline & & \multicolumn{4}{|c|}{ Min Excess Hydro Savings (@\$42.00/MWh) } & 72,566 & 54 & 72,620 \\
\hline & & \multicolumn{4}{|c|}{ Max Excess Hydro Savings (@\$57.50/MWh) } & 99,347 & 74 & 99,421 \\
\hline & & \multicolumn{4}{|c|}{ Min Total Savings (k\$) } & 51,250 & $-9,373$ & 41,877 \\
\hline & & \multicolumn{4}{|c|}{ Max Total Savings (k\$) } & 78,030 & $-9,353$ & 68,677 \\
\hline
\end{tabular}


Table 4-7. Hydro Generation and Energy Constraint Violations in Case 1.86B

\begin{tabular}{|c|c|c|c|c|c|c|c|}
\hline & & \multirow[b]{2}{*}{ Scenario } & \multicolumn{3}{|c|}{ Hydro Violation (GWh) } & \multicolumn{2}{|c|}{ Total HTC Hydro (GWh) } \\
\hline & & & NWPP & $\begin{array}{l}\text { Rest of } \\
\text { WECC } \\
\end{array}$ & $\begin{array}{r}\text { WECC } \\
\text { Total } \\
\end{array}$ & NWPP & $\begin{array}{r}\text { WECC } \\
\text { Total } \\
\end{array}$ \\
\hline \multirow{6}{*}{ Q1 } & \multirow{2}{*}{ January } & BAU & 145 & 17 & 162 & 12,234 & 13,548 \\
\hline & & EIM & 15 & 16 & 31 & 12140 & 13,454 \\
\hline & \multirow{2}{*}{ February } & BAU & 197 & 13 & 210 & 10,542 & 11,937 \\
\hline & & EIM & 15 & 13 & 28 & 10,371 & 11,766 \\
\hline & \multirow{2}{*}{ March } & BAU & 223 & 26 & 250 & 9,663 & 11,028 \\
\hline & & EIM & 21 & 26 & 47 & 9,465 & 10,829 \\
\hline \multirow{6}{*}{ Q2 } & \multirow{2}{*}{ April } & BAU & 93 & 13 & 106 & 10,663 & 12,244 \\
\hline & & EIM & 23 & 13 & 36 & 10,762 & 12,343 \\
\hline & \multirow{2}{*}{ May } & BAU & 60 & 7 & 67 & 9,806 & 11,972 \\
\hline & & EIM & 2 & 7 & 9 & 10,172 & 12,337 \\
\hline & \multirow{2}{*}{ June } & BAU & 93 & 21 & 114 & 10,761 & 12,792 \\
\hline & & EIM & 5 & 19 & 24 & 10,818 & 12,847 \\
\hline \multirow{6}{*}{ Q3 } & \multirow{2}{*}{ July } & BAU & 144 & 15 & 159 & 8,615 & 10,550 \\
\hline & & EIM & 3 & 15 & 18 & 8,481 & 10,416 \\
\hline & \multirow{2}{*}{ August } & BAU & 192 & 14 & 206 & 8,381 & 10,007 \\
\hline & & EIM & 21 & 14 & 35 & 8,214 & 9,840 \\
\hline & \multirow{2}{*}{ September } & BAU & 198 & 15 & 213 & 7,424 & 8,792 \\
\hline & & EIM & 38 & 15 & 53 & 7,266 & 8,634 \\
\hline \multirow{6}{*}{ Q4 } & \multirow{2}{*}{ October } & BAU & 227 & 11 & 238 & 7,879 & 9,028 \\
\hline & & EIM & 38 & 12 & 49 & 7,695 & 8,844 \\
\hline & \multirow{2}{*}{ November } & BAU & 209 & 7 & 216 & 8,805 & 9,899 \\
\hline & & EIM & 25 & 7 & 32 & 8,631 & 9,726 \\
\hline & \multirow{2}{*}{ December } & BAU & 159 & 4 & 163 & 10,861 & 12,170 \\
\hline & & EIM & 8 & 4 & 12 & 10,738 & 12,046 \\
\hline \multirow{2}{*}{\multicolumn{2}{|c|}{ Total }} & BAU & 1,941 & 163 & 2,104 & 115,635 & 133,968 \\
\hline & & EIM & 213 & 163 & 375 & 103,401 & 133,083 \\
\hline
\end{tabular}


Table 4-8. WECC Dump and Unserved Energy, Reserve Shortfall and Exchange Violations in Case 1.86B

\begin{tabular}{|c|c|c|c|c|c|c|c|c|c|c|c|}
\hline & & \multirow[t]{2}{*}{ Scenario } & \multirow[t]{2}{*}{$\begin{array}{l}\text { Dump } \\
\text { GWh }\end{array}$} & \multirow{2}{*}{$\begin{array}{c}\text { USE } \\
\text { (Unserved } \\
\text { GWh) }\end{array}$} & \multicolumn{5}{|c|}{ Total BAs Reserve Shortfall (GWh) } & \multicolumn{2}{|c|}{$\begin{array}{c}\text { Total BAs } \\
\text { Exchange } \\
\text { Violations } \\
\text { (GWh) }\end{array}$} \\
\hline & & & & & Spin & $\begin{array}{l}\text { Reg. } \\
\text { up }\end{array}$ & $\begin{array}{l}\text { Reg. } \\
\text { down }\end{array}$ & $\begin{array}{l}\text { Non } \\
\text { spin }\end{array}$ & Total & Up & Dn \\
\hline \multirow{6}{*}{ Q1 } & \multirow{2}{*}{ January } & BAU & 0 & 4 & 8.9 & 5.6 & 0.3 & 3.2 & 18 & 0.3 & 0.0 \\
\hline & & EIM & 0 & 4 & 9.6 & 5.2 & 0.2 & 2.3 & 17 & 0.2 & 0.0 \\
\hline & \multirow{2}{*}{ February } & BAU & 0 & 3 & 14.5 & 6.2 & 0.4 & 5.4 & 27 & 0.3 & 0.0 \\
\hline & & EIM & 0 & 3 & 12.8 & 5.7 & 0.5 & 2.7 & 22 & 0.3 & 0.0 \\
\hline & \multirow{2}{*}{ March } & BAU & 0 & 3 & 11.3 & 4.0 & 0.3 & 2.9 & 18 & 0.4 & 0.0 \\
\hline & & EIM & 0 & 3 & 16.8 & 6.6 & 0.6 & 4.0 & 28 & 0.3 & 0.0 \\
\hline \multirow{6}{*}{ Q2 } & \multirow{2}{*}{ April } & BAU & 1 & 4 & 8.9 & 4.3 & 0.8 & 2.1 & 16 & 0.4 & 0.0 \\
\hline & & EIM & 0 & 4 & 7.7 & 2.4 & 0.6 & 2.1 & 13 & 0.5 & 0.0 \\
\hline & \multirow{2}{*}{ May } & BAU & 0 & 5 & 8.7 & 3.6 & 0.4 & 1.6 & 14 & 0.5 & 0.0 \\
\hline & & EIM & 1 & 5 & 6.5 & 1.0 & 0.5 & 0.3 & 8 & 0.6 & 0.0 \\
\hline & \multirow{2}{*}{ June } & BAU & 0 & 2 & 15.1 & 5.0 & 0.1 & 3.0 & 23 & 0.9 & 0.2 \\
\hline & & EIM & 0 & 2 & 11.2 & 1.2 & 0.2 & 0.8 & 13 & 1.0 & 0.0 \\
\hline \multirow{6}{*}{ Q3 } & \multirow{2}{*}{ July } & BAU & 0 & 1 & 19.5 & 5.1 & 0.2 & 3.3 & 28 & 1.2 & 0.0 \\
\hline & & EIM & 0 & 1 & 14.0 & 1.2 & 0.4 & 1.0 & 17 & 0.9 & 0.2 \\
\hline & \multirow{2}{*}{ August } & BAU & 1 & 1 & 15.5 & 5.8 & 1.2 & 4.6 & 27 & 0.8 & 0.0 \\
\hline & & EIM & 0 & 1 & 13.7 & 4.3 & 1.2 & 3.7 & 23 & 0.5 & 0.1 \\
\hline & \multirow{2}{*}{ September } & BAU & 1 & 2 & 12.4 & 4.0 & 1.0 & 3.3 & 21 & 0.7 & 0.0 \\
\hline & & EIM & 0 & 2 & 13.3 & 4.2 & 0.8 & 3.0 & 21 & 0.6 & 0.1 \\
\hline \multirow{6}{*}{ Q4 } & \multirow{2}{*}{ October } & BAU & 3 & 1 & 12.5 & 4.3 & 1.4 & 5.2 & 23 & 1.3 & 0.0 \\
\hline & & EIM & 0 & 1 & 12.3 & 3.6 & 0.5 & 4.1 & 20 & 0.8 & 0.1 \\
\hline & \multirow{2}{*}{ November } & BAU & 1 & 2 & 11.7 & 5.6 & 0.5 & 4.4 & 22 & 0.7 & 0.0 \\
\hline & & EIM & 0 & 2 & 10.6 & 3.8 & 0.2 & 3.0 & 18 & 0.4 & 0.0 \\
\hline & \multirow{2}{*}{ December } & BAU & 0 & 2 & 16.0 & 6.3 & 0.3 & 4.3 & 27 & 0.5 & 0.0 \\
\hline & & EIM & 0 & 2 & 13.4 & 3.3 & 0.6 & 3.0 & 20 & 0.4 & 0.0 \\
\hline \multirow{2}{*}{ Total } & & BAU & 8 & 32 & 155 & 60 & 7 & 43 & 265 & 8.0 & 0.3 \\
\hline & & EIM & 1 & 32 & 142 & 43 & 6 & 30 & 221 & 6 & 1 \\
\hline
\end{tabular}


Table 4-9 Generation, Demand, and Average Production Cost for NWPP and WECC, and NWPP Net Interchange in Case 1.86B

\begin{tabular}{|c|c|c|c|c|c|c|c|c|c|}
\hline & & Scenario & $\begin{array}{c}\text { NWPP } \\
\text { Generation } \\
\text { (GWh) }\end{array}$ & $\begin{array}{l}\text { NWPP } \\
\text { Demand } \\
\text { (GWh) }\end{array}$ & $\begin{array}{c}\text { NWPP } \\
\text { Average } \\
\text { Production } \\
\text { Cost } \\
(\$ / \mathrm{MWh})\end{array}$ & $\begin{array}{c}\text { WECC } \\
\text { Generation } \\
\text { (GWh) }\end{array}$ & $\begin{array}{l}\text { WECC } \\
\text { Demand } \\
\text { (GWh) }\end{array}$ & $\begin{array}{c}\text { WECC } \\
\text { Average } \\
\text { Production } \\
\text { Cost } \\
\text { (\$/MWh) }\end{array}$ & $\begin{array}{c}\text { NWPP } \\
\text { Net } \\
\text { Exchange } \\
\text { (GWh) }\end{array}$ \\
\hline \multirow{6}{*}{ Q1 } & \multirow{2}{*}{ January } & BAU & 38,564 & 32,368 & 7.60 & 86,776 & 86,779 & 14.34 & $-6,196$ \\
\hline & & EIM & 38,544 & 32,368 & 7.64 & 86,775 & 86,779 & 14.36 & $-6,176$ \\
\hline & \multirow{2}{*}{ February } & BAU & 33,442 & 28,897 & 7.96 & 77,040 & 77,043 & 13.78 & $-4,545$ \\
\hline & & EIM & 33,422 & 28,897 & 8.15 & 77,040 & 77,043 & 13.86 & $-4,525$ \\
\hline & \multirow{2}{*}{ March } & BAU & 33,090 & 28,739 & 8.61 & 80,586 & 80,589 & 14.48 & $-4,350$ \\
\hline & & EIM & 33,069 & 28,739 & 8.87 & 80,586 & 80,589 & 14.59 & $-4,329$ \\
\hline \multirow{6}{*}{ Q2 } & \multirow{2}{*}{ April } & BAU & 32,203 & 26,702 & 7.12 & 77,467 & 77,470 & 12.95 & $-5,501$ \\
\hline & & EIM & 32,176 & 26,702 & 7.02 & 77,466 & 77,470 & 12.93 & $-5,474$ \\
\hline & \multirow{2}{*}{ May } & BAU & 34,006 & 27,162 & 8.15 & 83,445 & 83,449 & 13.88 & $-6,844$ \\
\hline & & EIM & 33,983 & 27,162 & 7.69 & 83,445 & 83,449 & 13.75 & $-6,821$ \\
\hline & \multirow{2}{*}{ June } & BAU & 34,190 & 27,701 & 7.97 & 87,477 & 87,479 & 16.10 & $-6,489$ \\
\hline & & EIM & 34,166 & 27,701 & 7.79 & 87,477 & 87,479 & 16.05 & $-6,465$ \\
\hline \multirow{6}{*}{ Q3 } & \multirow{2}{*}{ July } & BAU & 34,271 & 30,588 & 12.23 & 97,765 & 97,766 & 21.05 & $-3,682$ \\
\hline & & EIM & 34,264 & 30,588 & 12.25 & 97,765 & 97,766 & 21.06 & $-3,676$ \\
\hline & \multirow{2}{*}{ August } & BAU & 32,787 & 29,972 & 13.18 & 96,113 & 96,113 & 21.51 & $-2,815$ \\
\hline & & EIM & 32,782 & 29,972 & 13.42 & 96,112 & 96,113 & 21.58 & $-2,810$ \\
\hline & \multirow{2}{*}{ September } & BAU & 29,919 & 27,067 & 12.76 & 85,685 & 85,686 & 20.55 & $-2,852$ \\
\hline & & EIM & 29,915 & 27,067 & 13.00 & 85,683 & 85,686 & 20.62 & $-2,848$ \\
\hline \multirow{6}{*}{ Q4 } & \multirow{2}{*}{ October } & BAU & 30,748 & 27,528 & 11.38 & 82,625 & 82,625 & 19.14 & $-3,220$ \\
\hline & & EIM & 30,740 & 27,528 & 11.62 & 82,625 & 82,623 & 19.07 & $-3,212$ \\
\hline & \multirow{2}{*}{ November } & BAU & 33,103 & 29,190 & 9.40 & 82,625 & 81,553 & 16.43 & $-3,913$ \\
\hline & & EIM & 33,095 & 29,190 & 9.56 & 82,625 & 81,552 & 19.32 & $-3,904$ \\
\hline & \multirow{2}{*}{ December } & BAU & 36,305 & 32,780 & 10.23 & 88,576 & 88,576 & 17.77 & $-3,525$ \\
\hline & & EIM & 36,296 & 32,780 & 10.29 & 88,576 & 88,576 & 17.79 & $-3,516$ \\
\hline & \multirow{2}{*}{ Total } & BAU & 402,628 & 348,694 & 9.73 & $1,026,179$ & $1,025,130$ & 17.00 & $-53,934$ \\
\hline & & EIM & 402,452 & 348,694 & 9.79 & $1,026,177$ & $1,025,127$ & 17.03 & $-53,758$ \\
\hline
\end{tabular}




\subsubsection{3\% Held-back Case (Case 1.86C)}

This sensitivity case is another variation of the Base Case (Case 1.86A), where $3 \%$ of the available hydro energy from flexible hydro plants (modeled as HTC hydro plants) and 3\% of the maximum available capacities from thermal plants are held back in the DA and HA dispatch. Because the available hydro energy and thermal capacity are reduced in the DA and HA periods relative to the Base Case, less energy is scheduled for export from the NWPP to other BAs in the WECC and more energy and capacity are available in the NWPP for energy imbalance purposes. This can be observed by comparing the net exchange values for the NWPP reported in Table 4-13 with the comparable values for the Base Case reported in Table 4-5; which indicate that the amount of energy exported from the NWPP is reduced by about $4.4 \%$ in comparison with the Base Case. Consequently, generation costs for the NWPP in both the BAU and EIM scenarios are reduced while the generation costs for the WECC are increased because the relatively inexpensive energy exported from the NWPP is replaced with relatively more expensive energy in the BAs outside the NWPP. This can be observed by comparing the generation costs reported in Table 4-10 with the comparable values for the Base Case reported in Table 4-2.

Also, the reduced hydro energy and thermal capacity in the DA and HA periods significantly reduced the amount of hydro energy associated with the hydro energy constraint violations in both the BAU and EIM scenarios compared with the Base Case because the energy and capacity that are held back are released during the real-time, 10 -minute dispatches. This can be observed by comparing the hydro energy violations reported in Table 4-11 with the comparable values for the Base Case reported in Table 4-3. Overall, the reduced hydro energy and thermal capacity in the DA and HA periods reduced the amount of dump and unserved energy, reserve shortfalls, and exchange violations for all the BAs in the WECC in both the BAU and EIM scenarios compared with the Base Case, as can be observed by comparing the results reported in Table 4-12 with the comparable values for the Base Case reported in Table 4-4.

Also, the amounts of generation, the average production costs (\$/MWh), and the amounts of net exchange energy in both the BAU and EIM scenarios decreased compared with the Base Case, as can be observed by comparing the results reported in Table 4-13 with the comparable values for the Base Case reported in Table 4-5.

Compared to the Base Case, the annual total savings in the NWPP increased. This outcome is due to the increase in the differences in generation costs between the BAU and EIM scenarios, which are positive for this sensitivity case and negative in the Base Case, being greater than the reduction in the excess hydro savings. This can be observed by comparing the results in the generation cost summary tables between this sensitivity case and the Base Case (Table 4-10 and Table 4-2, respectively).

As reported in Table 4-10, the annual total savings between the BAU scenario and the EIM scenario within the NWPP footprint are \$71.2 million and \$90.3 million, which correspond to the prices for excess hydro generation being \$42.00/MWh and \$57.50/MWh, respectively. These annual total savings are greater than the annual total savings received under the Base Case, which are \$41.2 million and \$70.7 million, respectively. 
Table 4-10. Summary of Generation Cost and Savings for the NWPP and WECC in Case 1.86C

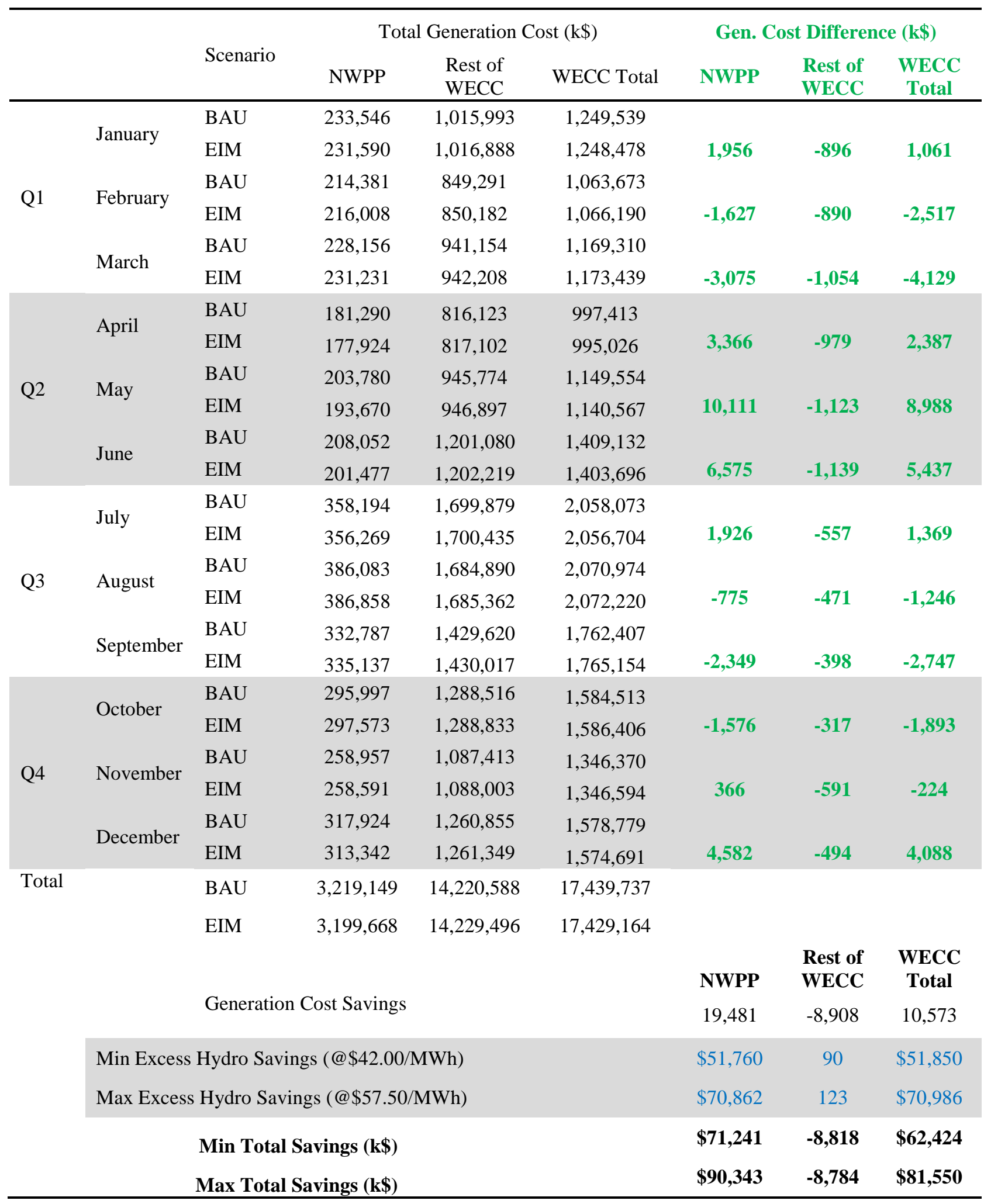


Table 4-11. Hydro Generation and Energy Constraints Violation in Case 1.86C

\begin{tabular}{|c|c|c|c|c|c|c|c|}
\hline & & \multirow[b]{2}{*}{ Scenario } & \multicolumn{3}{|c|}{ Hydro Violation (GWh) } & \multicolumn{2}{|c|}{ Total HTC Hydro (GWh) } \\
\hline & & & NWPP & $\begin{array}{l}\text { Rest of } \\
\text { WECC }\end{array}$ & WECC & NWPP & WECC Total \\
\hline \multirow{6}{*}{ Q1 } & \multirow{2}{*}{ January } & BAU & 102 & 12 & 113 & 12,091 & 13,397 \\
\hline & & EIM & 12 & 12 & 24 & 12,137 & 13,447 \\
\hline & \multirow{2}{*}{ February } & BAU & 120 & 13 & 133 & 10,411 & 11,803 \\
\hline & & EIM & 10 & 13 & 23 & 10,365 & 11,760 \\
\hline & \multirow{2}{*}{ March } & BAU & 145 & 18 & 163 & 9,536 & 10,888 \\
\hline & & EIM & 15 & 18 & 33 & 9,458 & 10,815 \\
\hline \multirow{6}{*}{ Q2 } & \multirow{2}{*}{ April } & BAU & 58 & 16 & 74 & 10,612 & 12,195 \\
\hline & & EIM & 16 & 16 & 31 & 10,755 & 12,338 \\
\hline & \multirow{2}{*}{ May } & BAU & 44 & 9 & 53 & 9,794 & 11,962 \\
\hline & & EIM & 2 & 9 & 11 & 10,172 & 12,339 \\
\hline & \multirow{2}{*}{ June } & BAU & 53 & 16 & 69 & 10,675 & 12,701 \\
\hline & & EIM & 6 & 16 & 22 & 10,820 & 12,846 \\
\hline \multirow{6}{*}{ Q3 } & \multirow{2}{*}{ July } & BAU & 99 & 11 & 110 & 8,556 & 10,487 \\
\hline & & EIM & 1 & 9 & 10 & 8,479 & 10,408 \\
\hline & \multirow{2}{*}{ August } & BAU & 138 & 12 & 150 & 8,319 & 9,944 \\
\hline & & EIM & 10 & 11 & 21 & 8,203 & 9,827 \\
\hline & \multirow{2}{*}{ September } & BAU & 159 & 10 & 169 & 7,382 & 8,745 \\
\hline & & EIM & 17 & 9 & 26 & 7,245 & 8,607 \\
\hline \multirow{6}{*}{ Q4 } & \multirow{2}{*}{ October } & BAU & 164 & 10 & 174 & 7,809 & 8,956 \\
\hline & & EIM & 25 & 10 & 35 & 7,683 & 8,830 \\
\hline & \multirow{2}{*}{ November } & BAU & 161 & 7 & 168 & 8,740 & 9,835 \\
\hline & & EIM & 13 & 7 & 20 & 8,619 & 9,713 \\
\hline & \multirow{2}{*}{ December } & BAU & 121 & 5 & 125 & 10,773 & 12,082 \\
\hline & & EIM & 4 & 5 & 8 & 10,732 & 12,042 \\
\hline \multirow{2}{*}{ Total } & & BAU & 1,363 & 136 & 1,499 & 114,700 & 132,994 \\
\hline & & EIM & 131 & 134 & 265 & 114,667 & 132,971 \\
\hline
\end{tabular}


Table 4-12. WECC Dump and Unserved Energy, Reserve Shortfall and Exchange Violations in Case 1.86C

\begin{tabular}{|c|c|c|c|c|c|c|c|c|c|c|c|}
\hline & & \multirow[t]{2}{*}{ Scenario } & \multirow{2}{*}{$\begin{array}{l}\text { Dump } \\
\text { GWh }\end{array}$} & \multirow{2}{*}{$\begin{array}{c}\text { USE } \\
\text { (Unserved } \\
\text { GWh) }\end{array}$} & \multicolumn{5}{|c|}{ Total BAs Reserve Shortfall (GWh) } & \multicolumn{2}{|c|}{$\begin{array}{c}\text { Total BAs } \\
\text { Exchange } \\
\text { Violation (GWh) }\end{array}$} \\
\hline & & & & & Spin & $\begin{array}{c}\text { Reg. } \\
\text { up }\end{array}$ & $\begin{array}{l}\text { Reg. } \\
\text { down }\end{array}$ & $\begin{array}{l}\text { Non } \\
\text { spin }\end{array}$ & Total & Up & Dn \\
\hline \multirow{6}{*}{ Q1 } & \multirow{2}{*}{ January } & BAU & 0.3 & 1.5 & 7.3 & 2.1 & 0.3 & 2.1 & 11.7 & 0.3 & 0.0 \\
\hline & & EIM & 0.0 & 1.5 & 7.5 & 2.0 & 0.2 & 1.3 & 10.9 & 0.2 & 0.0 \\
\hline & \multirow{2}{*}{ February } & BAU & 0.3 & 1.9 & 8.1 & 2.1 & 0.5 & 2.4 & 13.2 & 0.2 & 0.0 \\
\hline & & EIM & 0.2 & 1.9 & 9.2 & 2.4 & 0.5 & 2.1 & 14.0 & 0.2 & 0.0 \\
\hline & \multirow{2}{*}{ March } & BAU & 0.5 & 1.4 & 10.0 & 2.1 & 0.3 & 3.4 & 15.8 & 0.3 & 0.0 \\
\hline & & EIM & 0.1 & 1.4 & 10.5 & 2.2 & 0.4 & 2.8 & 15.9 & 0.3 & 0.0 \\
\hline \multirow{6}{*}{ Q2 } & \multirow{2}{*}{ April } & BAU & 0.4 & 1.9 & 6.0 & 1.2 & 0.6 & 1.5 & 9.3 & 0.4 & 0.0 \\
\hline & & EIM & 0.1 & 1.9 & 6.3 & 1.2 & 0.4 & 1.7 & 9.5 & 0.4 & 0.0 \\
\hline & \multirow{2}{*}{ May } & BAU & 0.6 & 2.3 & 5.6 & 1.1 & 0.4 & 1.0 & 8.1 & 0.4 & 0.0 \\
\hline & & EIM & 0.1 & 2.3 & 4.8 & 0.6 & 0.3 & 0.3 & 6.0 & 0.3 & 0.0 \\
\hline & \multirow{2}{*}{ June } & BAU & 0.2 & 1.4 & 9.3 & 1.6 & 0.1 & 2.2 & 13.2 & 0.9 & 0.2 \\
\hline & & EIM & 0.0 & 1.4 & 7.8 & 0.6 & 0.1 & 0.5 & 9.0 & 0.9 & 0.3 \\
\hline \multirow{6}{*}{ Q3 } & \multirow{2}{*}{ July } & BAU & 0.2 & 0.9 & 13.0 & 1.8 & 0.1 & 3.2 & 18.2 & 1.1 & 0.0 \\
\hline & & EIM & 0.0 & 0.9 & 9.2 & 0.5 & 0.4 & 0.5 & 10.6 & 0.8 & 0.2 \\
\hline & \multirow{2}{*}{ August } & BAU & 1.5 & 1.0 & 11.4 & 2.2 & 0.7 & 4.1 & 18.4 & 0.8 & 0.0 \\
\hline & & EIM & 0.0 & 1.0 & 6.6 & 0.8 & 0.4 & 1.2 & 9.0 & 0.4 & 0.1 \\
\hline & \multirow{2}{*}{$\begin{array}{l}\text { Septembe } \\
\text { r }\end{array}$} & BAU & 2.1 & 1.3 & 8.6 & 1.9 & 0.7 & 3.5 & 14.7 & 0.6 & 0.0 \\
\hline & & EIM & 0.0 & 1.3 & 7.6 & 1.2 & 0.7 & 1.5 & 10.9 & 0.5 & 0.1 \\
\hline \multirow{6}{*}{ Q4 } & \multirow{2}{*}{ October } & BAU & 3.8 & 0.5 & 7.5 & 1.6 & 1.1 & 3.6 & 13.8 & 0.9 & 0.0 \\
\hline & & EIM & 0.0 & 0.5 & 7.5 & 1.4 & 0.4 & 2.8 & 12.2 & 0.5 & 0.0 \\
\hline & \multirow{2}{*}{ November } & BAU & 1.9 & 0.9 & 8.2 & 2.0 & 0.6 & 4.3 & 15.1 & 0.7 & 0.0 \\
\hline & & EIM & 0.1 & 0.9 & 6.3 & 1.3 & 0.2 & 2.3 & 10.1 & 0.5 & 0.1 \\
\hline & \multirow{2}{*}{ December } & BAU & 0.5 & 1.0 & 10.5 & 1.9 & 0.3 & 3.7 & 16.4 & 0.5 & 0.0 \\
\hline & & EIM & 0.0 & 1.0 & 8.2 & 1.0 & 0.3 & 1.7 & 11.2 & 0.4 & 0.0 \\
\hline \multirow{2}{*}{ Total } & & BAU & 12 & 16 & 106 & 22 & 6 & 35 & 168 & 7.1 & 0.2 \\
\hline & & EIM & 0 & 16 & 91 & 15 & 4 & 19 & 129 & 5.4 & 0.8 \\
\hline
\end{tabular}


Table 4-13 Generation, Demand, and Average Production Cost for NWPP and WECC, and NWPP Net Interchange in Case 1.86C

\begin{tabular}{|c|c|c|c|c|c|c|c|c|c|}
\hline & & Scenario & $\begin{array}{c}\text { NWPP } \\
\text { Generation } \\
\text { (GWh) }\end{array}$ & $\begin{array}{l}\text { NWPP } \\
\text { Demand } \\
\text { (GWh) }\end{array}$ & $\begin{array}{c}\text { NWPP } \\
\text { Average } \\
\text { Produc- } \\
\text { tion Cost } \\
\text { (\$/MWh) }\end{array}$ & $\begin{array}{c}\text { WECC } \\
\text { Genera- } \\
\text { tion } \\
\text { (GWh) }\end{array}$ & $\begin{array}{l}\text { WECC } \\
\text { Demand } \\
\text { (GWh) }\end{array}$ & $\begin{array}{c}\text { WECC } \\
\text { Average } \\
\text { Product- } \\
\text { ion Cost } \\
\text { (\$/MWh) }\end{array}$ & $\begin{array}{l}\text { NWPP } \\
\text { Net } \\
\text { Exchange } \\
\text { (GWh) }\end{array}$ \\
\hline \multirow{6}{*}{ Q1 } & \multirow{2}{*}{ January } & BAU & 38,145 & 32,368 & 7.22 & 86,649 & 86,651 & 14.42 & $-5,777$ \\
\hline & & EIM & 38,116 & 32,368 & 7.15 & 86,649 & 86,651 & 14.41 & $-5,748$ \\
\hline & \multirow{2}{*}{ February } & BAU & 32,980 & 28,897 & 7.42 & 76,974 & 76,975 & 13.82 & $-4,083$ \\
\hline & & EIM & 32,952 & 28,897 & 7.48 & 76,973 & 76,975 & 13.85 & $-3,813$ \\
\hline & \multirow{2}{*}{ March } & BAU & 32,552 & 28,739 & 7.94 & 80,438 & 80,439 & 14.54 & $--3,787$ \\
\hline & & EIM & 32,526 & 28,739 & 8.05 & 80,438 & 80,439 & 14.59 & $-3,787$ \\
\hline \multirow{6}{*}{ Q2 } & \multirow{2}{*}{ April } & BAU & 32,059 & 26,702 & 6.79 & 77,326 & 77,328 & 12.90 & $-5,357$ \\
\hline & & EIM & 32,027 & 26,702 & 6.66 & 77,326 & 77,328 & 12.87 & $-5,325$ \\
\hline & \multirow{2}{*}{ May } & BAU & 33,779 & 27,162 & 7.50 & 83,296 & 83,298 & 13.80 & $-6,618$ \\
\hline & & EIM & 33,750 & 27,162 & 7.13 & 83,295 & 83,298 & 13.69 & $-6,588$ \\
\hline & \multirow{2}{*}{ June } & BAU & 33,851 & 27,701 & 7.51 & 87,417 & 87,418 & 16.12 & $-6,150$ \\
\hline & & EIM & 33,822 & 27,701 & 7.27 & 87,417 & 87,418 & 16.06 & $-6,121$ \\
\hline \multirow{6}{*}{ Q3 } & \multirow{2}{*}{ July } & BAU & 33,919 & 30,588 & 11.71 & 97,738 & 97,739 & 21.06 & $-3,331$ \\
\hline & & EIM & 33,909 & 30,588 & 11.65 & 97,738 & 97,739 & 21.04 & $-3,321$ \\
\hline & \multirow{2}{*}{ August } & BAU & 32,553 & 29,972 & 12.88 & 96,117 & 96,116 & 21.55 & $-2,581$ \\
\hline & & EIM & 32,544 & 29,972 & 12.91 & 96,115 & 96,116 & 21.56 & $-2,572$ \\
\hline & \multirow{2}{*}{ September } & BAU & 29,609 & 27,067 & 12.29 & 85,665 & 85,664 & 20.57 & $-2,542$ \\
\hline & & EIM & 29,600 & 27,067 & 12.38 & 85,663 & 85,664 & 20.61 & $-2,533$ \\
\hline \multirow{6}{*}{ Q4 } & \multirow{2}{*}{ October } & BAU & 30,300 & 27,528 & 10.75 & 82,598 & 82,594 & 19.18 & $-2,772$ \\
\hline & & EIM & 30,290 & 27,528 & 10.81 & 82,594 & 82,594 & 19.21 & $-2,762$ \\
\hline & \multirow{2}{*}{ November } & BAU & 32,672 & 29,190 & 8.87 & 81,468 & 81,467 & 16.53 & $-3,482$ \\
\hline & & EIM & 32,654 & 29,190 & 8.86 & 81,466 & 81,467 & 16.53 & $-3,464$ \\
\hline & \multirow{2}{*}{ December } & BAU & 35,852 & 32,780 & 9.70 & 88,520 & 88,521 & 17.84 & $-3,072$ \\
\hline & & EIM & 35,841 & 32,780 & 9.56 & 88,520 & 88,521 & 17.79 & $-3,061$ \\
\hline \multirow{2}{*}{ Total } & & BAU & 398,271 & 348,694 & 9.23 & $1,024,207$ & $1,024,211$ & 17.03 & $-49,577$ \\
\hline & & EIM & 398,032 & 348,694 & 9.18 & $1,024,195$ & $1,024,211$ & 17.02 & $-49,338$ \\
\hline
\end{tabular}




\subsubsection{WECC-Wide EIM (Case 1.86D)}

This sensitivity case represents a WECC-wide EIM where net exchanges between all the BAs within the WECC are allowed to deviate from the HA net exchange schedules during the real-time, 10-minute periods, rather than just the BAs within the NWPP EIM. The BAU scenario is the same as the BAU scenario for the Base Case in which real-time exchanges among all the BAs within the WECC are frozen to match the HA net exchange schedules. The WECC-wide EIM takes advantage of WECC-wide resources to meet WECC-wide energy imbalances. Since the resources in the NWPP usually have lower production costs than resources in other BAs within the WECC, export energy from the NWPP increased by $8.9 \%$ in comparison with the BAU scenario, which in turn increases the production costs per MWh in the NWPP. This can be observed by comparing the values for the net exchanges and production costs per MWh for the NWPP reported in Table 4-17 with the comparable values for the Base Case reported in Table 4-5. For these reasons, total generation costs between the BAU scenario and the EIM scenario increased significantly. This can be observed by comparing the generation costs reported in Table 4-14 with the comparable values for the Base Case reported in Table 4-2.

Also, it can observed in Table 4-15 and Table 4-16 that without exchange constraints in the EIM scenario, there are no hydro violations anywhere within the WECC and the amounts of energy associated with dump and unserved energy, and reserve shortfalls for all the BAs in the WECC are dramatically reduced from the BAU scenario.

Compared to the Base Case, annual total savings in the NWPP decreased due to the increases in the negative differences in generation costs between the BAU and EIM scenarios being greater than the increase in the excess hydro savings. This outcome can be observed by comparing the generation cost summary tables between this sensitivity case and the Base Case (Table 4-14 and Table 4-2, respectively).

As reported in Table 4-14, the annual total savings between the BAU scenario and the EIM scenario within the NWPP footprint are $-\$ 58.2$ million and $-\$ 22.9$ million, which correspond to the prices for excess hydro generation being $\$ 42.00 / \mathrm{MWh}$ and $\$ 57.50 / \mathrm{MWh}$, respectively. These results indicate that even after valuing the excess hydro generation, the EIM benefits are negative for the NWPP. These annual total savings are substantially below the annual total savings received under the Base Case, which are \$41.2 million and \$70.7 million, respectively. In contrast, the total WECC-wide generation costs are substantially reduced since the lower cost energy from the NWPP displaces higher cost energy outside of the NWPP. The WECC-wide, total annual savings are \$307.0 million and \$344.8 million, when excess hydro generation is valued at $\$ 42.00 / \mathrm{MWh}$ and $\$ 57.50 / \mathrm{MWh}$, respectively. These savings are substantially higher than the WECC-wide total annual savings reported in Table 4-2 for the Base Case, which are \$31.8 million and \$61.4 million, respectively.

However, if one were to value the increased NWPP export sales of 4,646 GWh (compared to the BAU scenario) under the WECC-wide EIM at \$45/MWh, sales revenues would be increased by \$209.1 million. Adding this number to the total annual savings of $-\$ 58.2$ million and $-\$ 22.9$ million, which correspond to the prices for excess hydro generation being $\$ 42.00 / \mathrm{MWh}$ and $\$ 57.50 / \mathrm{MWh}$, respectively, total annual saving for the NWPP would range from \$150.9 million to \$ 186.2 million. Compared to the results for the Base Case and the other sensitivity cases, these results indicate that the NWPP benefits received under the WECC-wide EIM exceed the NWPP benefits received from the cases having similar assumptions for an EIM that is limited to the NWPP. However, the results for this sensitivity case are 
considered INDICATIVE ONLY since the data and model inputs for entities located outside the NWPP EIM footprint could not be rigorously vetted by the NWPP MC participants.

Table 4-14. Summary of Generation Cost and Savings for the NWPP and WECC in Case 1.86D

\begin{tabular}{|c|c|c|c|c|c|c|c|c|}
\hline & & \multirow[b]{2}{*}{ Scenario } & \multicolumn{3}{|c|}{ Total Generation Cost $(\mathrm{k} \$)$} & \multicolumn{3}{|c|}{ Gen. Cost Difference (k\$) } \\
\hline & & & NWPP & $\begin{array}{l}\text { Rest of } \\
\text { WECC }\end{array}$ & Total & NWPP & $\begin{array}{l}\text { Rest of } \\
\text { WECC }\end{array}$ & $\begin{array}{c}\text { WECC } \\
\text { Total }\end{array}$ \\
\hline \multirow{6}{*}{ Q1 } & \multirow{2}{*}{ January } & BAU & 236,659 & 997,816 & $1,234,475$ & & & \\
\hline & & EIM & 248,127 & 968,089 & $1,216,216$ & $-11,468$ & 29,727 & 18,259 \\
\hline & \multirow{2}{*}{ February } & BAU & 216,611 & 835,177 & $1,051,788$ & & & \\
\hline & & EIM & 227,094 & 810,443 & $1,037,537$ & $-10,483$ & 24,735 & 14,252 \\
\hline & \multirow{2}{*}{ March } & BAU & 231,661 & 925,424 & $1,157,085$ & & & \\
\hline & & EIM & 245,760 & 901,719 & $1,147,479$ & $-14,099$ & 23,705 & 9,606 \\
\hline \multirow{6}{*}{ Q2 } & \multirow{2}{*}{ April } & BAU & 183,577 & 805,657 & 989,234 & & & \\
\hline & & EIM & 190,789 & 768,353 & 959,141 & $-7,211$ & 37,304 & 30,093 \\
\hline & \multirow{2}{*}{ May } & BAU & 208,264 & 936,743 & $1,145,007$ & & & \\
\hline & & EIM & 216,910 & 891,947 & $1,108,857$ & $-8,645$ & 44,795 & 36,150 \\
\hline & \multirow{2}{*}{ June } & BAU & 213,918 & $1,188,986$ & $1,402,904$ & & & \\
\hline & & EIM & 225,047 & $1,150,870$ & $1,375,916$ & $-11,129$ & 38,116 & 26,987 \\
\hline \multirow{6}{*}{ Q3 } & \multirow{2}{*}{ July } & BAU & 364,500 & $1,690,337$ & $2,054,837$ & & & \\
\hline & & EIM & 381,486 & $1,657,960$ & $2,039,446$ & $-16,986$ & 32,376 & 15,390 \\
\hline & \multirow{2}{*}{ August } & BAU & 389,433 & $1,676,625$ & $2,066,059$ & & & \\
\hline & & EIM & 400,730 & $1,654,995$ & $2,055,724$ & $-11,296$ & 21,631 & 10,334 \\
\hline & \multirow{2}{*}{ September } & BAU & 337,135 & $1,419,539$ & $1,756,674$ & & & \\
\hline & & EIM & 350,721 & 1,398,013 & 1,748,733 & $-13,585$ & 21,526 & 7,941 \\
\hline \multirow{6}{*}{ Q4 } & \multirow{2}{*}{ October } & BAU & 300,981 & $1,274,063$ & $1,575,044$ & & & \\
\hline & & EIM & 323,980 & $1,244,539$ & $1,568,520$ & $-22,999$ & 29,524 & 6,525 \\
\hline & \multirow{2}{*}{ November } & BAU & 266,057 & $1,070,130$ & 1,336,187 & & & \\
\hline & & EIM & 277,762 & $1,045,588$ & 1,323,350 & $-11,705$ & 24,542 & 12,837 \\
\hline & \multirow{2}{*}{ December } & BAU & 324,402 & $1,241,846$ & $1,566,248$ & & & \\
\hline & & EIM & 338,582 & $1,211,486$ & $1,550,069$ & $-14,180$ & 30,360 & 16,180 \\
\hline \multirow[t]{8}{*}{ Total } & & BAU & 3,273,199 & $14,062,343$ & $17,335,542$ & & & \\
\hline & & EIM & $3,426,987$ & $13,704,001$ & $17,130,988$ & & & \\
\hline & & & & & & NWPP & $\begin{array}{l}\text { Rest of } \\
\text { WECC }\end{array}$ & $\begin{array}{c}\text { WECC } \\
\text { Total }\end{array}$ \\
\hline & & \multicolumn{4}{|c|}{ Generation Cost Savings } & $-153,788$ & 358,342 & 204,554 \\
\hline & & \multicolumn{4}{|c|}{ Min Excess Hydro Savings (@\$42.00/MWh) } & 95,598 & 6,856 & 102,453 \\
\hline & & \multicolumn{4}{|c|}{ Max Excess Hydro Savings (@\$57.50/MWh) } & 130,878 & 9,386 & 140,264 \\
\hline & & \multicolumn{4}{|c|}{ Min Total Savings (k\$) } & $-58,190$ & 365,198 & 307,008 \\
\hline & & \multicolumn{4}{|c|}{ Max Total Savings (k\$) } & $-22,910$ & 367,728 & 344,818 \\
\hline
\end{tabular}


Table 4-15. Hydro Generation and Energy Constraints Violation in Case 1.86D

\begin{tabular}{|c|c|c|c|c|c|c|c|}
\hline & & \multirow[b]{2}{*}{ Scenario } & \multicolumn{3}{|c|}{ Hydro Violation (GWh) } & \multicolumn{2}{|c|}{ Total HTC Hydro (GWh) } \\
\hline & & & NWPP & $\begin{array}{l}\text { Rest of } \\
\text { WECC }\end{array}$ & $\begin{array}{c}\text { WECC } \\
\text { Total }\end{array}$ & NWPP & WECC Total \\
\hline \multirow{6}{*}{ Q1 } & \multirow{2}{*}{ January } & BAU & 178 & 16 & 194 & 12,275 & 13,590 \\
\hline & & EIM & $\mathbf{0}$ & $\mathbf{0}$ & $\mathbf{0}$ & 12,125 & 13,423 \\
\hline & \multirow{2}{*}{ February } & BAU & 227 & 15 & 243 & 10,573 & 11,970 \\
\hline & & EIM & $\mathbf{0}$ & $\mathbf{0}$ & $\mathbf{0}$ & 10,356 & 11,738 \\
\hline & \multirow{2}{*}{ March } & BAU & 270 & 24 & 294 & 9,710 & 11,073 \\
\hline & & EIM & $\mathbf{0}$ & $\mathbf{0}$ & $\mathbf{0}$ & 9,445 & 10,783 \\
\hline \multirow{6}{*}{ Q2 } & \multirow{2}{*}{ April } & BAU & 109 & 13 & 122 & 10,689 & 12,269 \\
\hline & & EIM & $\mathbf{0}$ & $\mathbf{0}$ & $\mathbf{0}$ & 10,739 & 12,307 \\
\hline & \multirow{2}{*}{ May } & BAU & 92 & 11 & 102 & 9,866 & 12,036 \\
\hline & & EIM & 0 & 0 & $\mathbf{0}$ & 10,171 & 12,330 \\
\hline & \multirow{2}{*}{ June } & BAU & 117 & 19 & 136 & 10,800 & 12,829 \\
\hline & & EIM & 0 & 0 & 0 & 10,811 & 12,821 \\
\hline \multirow{6}{*}{ Q3 } & \multirow{2}{*}{ July } & BAU & 159 & 16 & 175 & 8,629 & 10,565 \\
\hline & & EIM & $\mathbf{0}$ & 0 & $\mathbf{0}$ & 8,478 & 10,398 \\
\hline & \multirow{2}{*}{ August } & BAU & 213 & 10 & 223 & 8,402 & 10,025 \\
\hline & & EIM & $\mathbf{0}$ & $\mathbf{0}$ & $\mathbf{0}$ & 8,193 & 9,805 \\
\hline & \multirow{2}{*}{ September } & BAU & 209 & 13 & 222 & 7,435 & 8,801 \\
\hline & & EIM & 0 & 0 & 0 & 7,228 & 8,581 \\
\hline \multirow{6}{*}{ Q4 } & \multirow{2}{*}{ October } & BAU & 256 & 11 & 267 & 7,907 & 9,055 \\
\hline & & EIM & 0 & 0 & 0 & 7,658 & 8,795 \\
\hline & \multirow{2}{*}{ November } & BAU & 235 & 8 & 243 & 8,828 & 9,924 \\
\hline & & EIM & 0 & 0 & $\mathbf{0}$ & 8,607 & 9,695 \\
\hline & \multirow{2}{*}{ December } & BAU & 213 & 7 & 219 & 10,911 & 12,222 \\
\hline & & EIM & 0 & 0 & 0 & 10,730 & 12,035 \\
\hline \multirow{2}{*}{ Total } & & BAU & 2,276 & 163 & 2,440 & 116,024 & 134,357 \\
\hline & & EIM & $\mathbf{0}$ & 0 & 0 & 114,543 & 132,713 \\
\hline
\end{tabular}


Table 4-16. WECC Dump and Unserved Energy, Reserve Shortfall and Exchange Violations in Case 1.86D

\begin{tabular}{|c|c|c|c|c|c|c|c|c|c|c|c|}
\hline & & \multirow{2}{*}{ Scenario } & \multirow{2}{*}{$\begin{array}{l}\text { Dump } \\
\text { GWh }\end{array}$} & \multirow{2}{*}{$\begin{array}{l}\text { USE } \\
\text { (Unserve } \\
\text { d GWh) }\end{array}$} & \multicolumn{5}{|c|}{ Total BAs Reserve Shortfall (GWh) } & \multicolumn{2}{|c|}{$\begin{array}{c}\text { Total BAs Exchange } \\
\text { Violation (GWh) }\end{array}$} \\
\hline & & & & & Spin & $\begin{array}{c}\text { Reg. } \\
\text { up }\end{array}$ & $\begin{array}{l}\text { Reg. } \\
\text { down }\end{array}$ & $\begin{array}{l}\text { Non } \\
\text { spin }\end{array}$ & Total & Up & Dn \\
\hline \multirow{6}{*}{ Q1 } & \multirow{2}{*}{ January } & BAU & 0.3 & 6.7 & 13.3 & 3.7 & 0.2 & 4.0 & 21 & 0.4 & 0.0 \\
\hline & & EIM & 0.0 & 0.0 & 0.0 & 1.2 & 0.2 & 0.0 & 1 & N/A & N/A \\
\hline & \multirow{2}{*}{ February } & BAU & 0.6 & 8.4 & 17.4 & 4.3 & 0.4 & 6.3 & 28 & 0.4 & 0.0 \\
\hline & & EIM & 0.0 & 0.0 & 0.1 & 0.6 & 0.3 & 0.0 & 1 & N/A & N/A \\
\hline & \multirow{2}{*}{ March } & BAU & 0.4 & 7.3 & 15.2 & 3.5 & 0.2 & 4.6 & 23 & 0.6 & 0.0 \\
\hline & & EIM & 0.0 & 0.0 & 0.0 & 0.0 & 0.7 & 0.0 & 1 & N/A & N/A \\
\hline \multirow{6}{*}{ Q2 } & \multirow{2}{*}{ April } & BAU & 0.4 & 8.3 & 12.5 & 3.6 & 0.4 & 3.4 & 20 & 0.8 & 0.0 \\
\hline & & EIM & 0.0 & 0.0 & 0.0 & 0.0 & 0.4 & 0.0 & 0 & N/A & N/A \\
\hline & \multirow{2}{*}{ May } & BAU & 0.5 & 9.5 & 11.8 & 2.7 & 0.3 & 2.0 & 17 & 1.0 & 0.0 \\
\hline & & EIM & 0.0 & 0.0 & 0.0 & 0.0 & 0.7 & 0.0 & 1 & N/A & N/A \\
\hline & \multirow{2}{*}{ June } & BAU & 0.2 & 5.2 & 17.7 & 3.8 & 0.1 & 4.7 & 26 & 1.0 & 0.0 \\
\hline & & EIM & 0.0 & 0.0 & 0.0 & 0.0 & 0.3 & 0.0 & 0 & N/A & N/A \\
\hline \multirow{6}{*}{ Q3 } & \multirow{2}{*}{ July } & BAU & 0.2 & 3.2 & 23.4 & 3.9 & 0.1 & 4.7 & 32 & 1.6 & 0.0 \\
\hline & & EIM & 0.0 & 0.0 & 0.0 & 0.0 & 0.5 & 0.0 & 0 & N/A & N/A \\
\hline & \multirow{2}{*}{ August } & BAU & 1.2 & 6.8 & 18.1 & 4.0 & 0.6 & 6.4 & 29 & 1.1 & 0.1 \\
\hline & & EIM & 0.0 & 0.0 & 0.0 & 0.0 & 0.5 & 0.0 & 0 & N/A & N/A \\
\hline & \multirow{2}{*}{ September } & BAU & 2.0 & 7.1 & 12.2 & 2.2 & 0.7 & 3.9 & 19 & 0.8 & 0.0 \\
\hline & & EIM & 0.0 & 0.0 & 0.1 & 0.0 & 0.8 & 0.0 & 1 & N/A & N/A \\
\hline \multirow{6}{*}{ Q4 } & \multirow{2}{*}{ October } & BAU & 3.6 & 4.2 & 15.0 & 3.0 & 1.0 & 6.6 & 26 & 1.3 & 0.0 \\
\hline & & EIM & 0.0 & 0.0 & 0.2 & 0.0 & 1.0 & 0.0 & 1 & N/A & N/A \\
\hline & \multirow{2}{*}{ November } & BAU & 1.8 & 5.7 & 16.5 & 4.5 & 0.6 & 7.6 & 29 & 1.0 & 0.0 \\
\hline & & EIM & 0.0 & 0.0 & 0.0 & 0.0 & 0.4 & 0.0 & 0 & N/A & N/A \\
\hline & \multirow{2}{*}{ December } & BAU & 0.5 & 4.7 & 19.7 & 4.7 & 0.3 & 7.5 & 32 & 0.8 & 0.0 \\
\hline & & EIM & 0.0 & 0.0 & 0.0 & 0.4 & 1.0 & 0.0 & 1 & N/A & N/A \\
\hline \multirow{2}{*}{ Total } & & BAU & 12 & 77 & 193 & 44 & 5 & 62 & 303 & 10.7 & 0.1 \\
\hline & & EIM & 0 & 0 & 0 & 2 & 7 & 0 & 10 & N/A & N/A \\
\hline
\end{tabular}


Table 4-17. Generation, Demand, and Average Production Cost for NWPP and WECC, and NWPP Net Interchange in Case 1.86D

\begin{tabular}{|c|c|c|c|c|c|c|c|c|c|}
\hline & & Scenario & $\begin{array}{c}\text { NWPP } \\
\text { Generation } \\
\text { (GWh) }\end{array}$ & $\begin{array}{l}\text { NWPP } \\
\text { Demand } \\
\text { (GWh) }\end{array}$ & $\begin{array}{c}\text { NWPP } \\
\text { Average } \\
\text { Production } \\
\text { Cost } \\
(\$ / \mathrm{MWh})\end{array}$ & $\begin{array}{c}\text { WECC } \\
\text { Generation } \\
\text { (GWh) }\end{array}$ & $\begin{array}{l}\text { WECC } \\
\text { Demand } \\
\text { (GWh) }\end{array}$ & $\begin{array}{c}\text { WECC } \\
\text { Average } \\
\text { Production } \\
\text { Cost } \\
\text { (\$/MWh) }\end{array}$ & $\begin{array}{l}\text { NWPP } \\
\text { Net } \\
\text { Exchange } \\
\text { (GWh) }\end{array}$ \\
\hline \multirow{6}{*}{ Q1 } & \multirow{2}{*}{ January } & BAU & 38,449 & 32,368 & 7.31 & 86,695 & 86,702 & 14.24 & $-6,081$ \\
\hline & & EIM & 38,820 & 32,368 & 7.67 & 86,702 & 86,702 & 14.03 & $-6,453$ \\
\hline & \multirow{2}{*}{ February } & BAU & 33,219 & 28,897 & 7.50 & 76,997 & 77,005 & 13.66 & $-4,323$ \\
\hline & & EIM & 33,454 & 28,897 & 7.86 & 77,005 & 77,005 & 13.47 & $-4,557$ \\
\hline & \multirow{2}{*}{ March } & BAU & 32,846 & 28,739 & 8.06 & 80,481 & 80,488 & 14.38 & $-4,106$ \\
\hline & & EIM & 33,120 & 28,739 & 8.55 & 80,488 & 80,488 & 14.26 & $-4,380$ \\
\hline \multirow{6}{*}{ Q2 } & \multirow{2}{*}{ April } & BAU & 32,199 & 26,702 & 6.88 & 77,358 & 77,366 & 12.79 & $-5,497$ \\
\hline & & EIM & 32,724 & 26,702 & 7.15 & 77,366 & 77,366 & 12.40 & $-6,022$ \\
\hline & \multirow{2}{*}{ May } & BAU & 33,963 & 27,162 & 7.67 & 83,346 & 83,355 & 13.74 & $-6,802$ \\
\hline & & EIM & 34,724 & 27,162 & 7.99 & 83,355 & 83,355 & 13.30 & $-7,563$ \\
\hline & \multirow{2}{*}{ June } & BAU & 34,096 & 27,701 & 7.72 & 87,456 & 87,461 & 16.04 & $-6,395$ \\
\hline & & EIM & 34,649 & 27,701 & 8.12 & 87,461 & 87,461 & 15.73 & $-6,948$ \\
\hline \multirow{6}{*}{ Q3 } & \multirow{2}{*}{ July } & BAU & 34,101 & 30,588 & 7.58 & 97,736 & 97,739 & 21.02 & $-3,513$ \\
\hline & & EIM & 34,501 & 30,588 & 12.47 & 97,739 & 97,739 & 20.87 & $-3,913$ \\
\hline & \multirow{2}{*}{ August } & BAU & 32,699 & 29,972 & 7.58 & 96,098 & 96,104 & 21.50 & $-2,727$ \\
\hline & & EIM & 32,928 & 29,972 & 13.37 & 96,104 & 96,104 & 21.39 & $-2,956$ \\
\hline & \multirow{2}{*}{ September } & BAU & 29,776 & 27,067 & 7.58 & 85,666 & 85,671 & 20.50 & $-2,709$ \\
\hline & & EIM & 30,028 & 27,067 & 12.96 & 85,671 & 85,671 & 20.41 & $-2,961$ \\
\hline \multirow{6}{*}{ Q4 } & \multirow{2}{*}{ October } & BAU & 30,549 & 27,528 & 7.58 & 82,611 & 82,611 & 19.07 & $-3,021$ \\
\hline & & EIM & 30,987 & 27,528 & 11.77 & 82,611 & 82,611 & 18.99 & $-3,458$ \\
\hline & \multirow{2}{*}{ November } & BAU & 32,940 & 29,190 & 7.58 & 81,490 & 81,494 & 16.40 & $-3,750$ \\
\hline & & EIM & 33,199 & 29,190 & 9.52 & 81,494 & 81,494 & 16.24 & $-4,009$ \\
\hline & \multirow{2}{*}{ December } & BAU & 36,162 & 32,780 & 7.58 & 88,548 & 88,552 & 17.69 & $-3,382$ \\
\hline & & EIM & 36,511 & 32,780 & 10.33 & 88,552 & 88,552 & 17.50 & $-3,731$ \\
\hline \multirow{2}{*}{ Total } & & BAU & 401,000 & 348,694 & 9.39 & $1,024,483$ & $1,024,548$ & 16.92 & $-52,306$ \\
\hline & & EIM & 405,646 & 348,694 & 9.83 & $1,024,548$ & $1,024,548$ & 16.72 & $-56,952$ \\
\hline
\end{tabular}




\subsubsection{High Gas Price Case (Case 1.86E)}

This sensitivity case represents a situation in which there are high natural gas prices (the average annual price at Henry Hub is $\$ 8.40 / \mathrm{MMBtu}$ ) in comparison with the natural gas prices used for the Base Case (the average annual price at Henry Hub is \$5.62/MMBtu). The generation costs, value of excess hydro generation, and total savings are reported in Table 4-18. These results indicate that generation costs rose substantially for the NWPP and WECC in the BAU and EIM scenarios compared to the results from the BAU and EIM scenarios for the Base Case. This can be observed by comparing the values reported in Table 4-18 with the comparable values for the Base Case reported in Table 4-2.

However, relative to the results for the Base Case, the changes in generation cost savings between the BAU and EIM scenarios for the NWPP and WECC were only \$1.1 million and \$2.5 million, respectively. The reason for this outcome is that most of the low cost resources in the NWPP were already committed during the day-ahead and hour-ahead periods, resulting in there being few lower cost resources available for use in the EIM. Nonetheless, annual total savings for the NWPP largely increased due to the excess hydro generation being valued at higher electricity prices of \$62.78/MWh and \$85.94/MWh (rather than \$42.00/MWh and \$57.50/MWh in the Base Case) resulting from higher fuel costs for natural gas-fired resources. Like in the Base Case, the valuation of excess hydro generation in this sensitivity case was based on assumed implied heat rates for gas-fired resources of 7.5 MMBtu/MWh and 10.2 MMBtu/MWh, respectively.

The amounts of energy associated with hydro violations that occurred inside and outside the NWPP in both the BAU and EIM scenarios did not change much from the results for the Base Case. This outcome can be observed by comparing the results reported in Table 4-19 with the comparable values for the Base Case reported in Table 4-3. Similarly, the amounts of total energy associated with dump and unserved energy, reserve shortfalls, and exchange violations for all the BAs in the WECC in both the BAU and EIM scenarios did not change much from the results for the Base Case. This can be observed by comparing the results reported in Table 4-20 with the comparable values for the Base Case reported in Table 4-4.

Also, because of higher natural gas prices, there are more energy exports from the NWPP to other BAs in the WECC in both the BAU and EIM scenarios compared with the Base Case, but the differences between the BAU and EIM scenarios do not change much. This can be observed by comparing the net exchange values for the NWPP reported in Table 4-21 with the comparable values for the Base Case reported in Table 4-5.

As reported in Table 4-18, the annual total savings between the BAU scenario and the EIM scenario within the NWPP footprint are \$79.4 million and \$122.7 million, and 10.2 MMBtu/MWh, respectively. These annual total savings are greater than the annual total savings received under the Base Case, which are \$41.2 million and \$70.7 million, respectively. 
Table 4-18. Summary of Generation Cost and Savings for the NWPP and WECC in Case 1.86E

\begin{tabular}{|c|c|c|c|c|c|c|c|c|}
\hline & & \multirow{2}{*}{ Scenario } & \multicolumn{3}{|c|}{ Total Generation Cost $(\mathrm{k} \$)$} & \multicolumn{3}{|c|}{ Gen. Cost Difference (k\$) } \\
\hline & & & NWPP & $\begin{array}{l}\text { Rest of } \\
\text { WECC }\end{array}$ & $\begin{array}{c}\text { WECC } \\
\text { Total }\end{array}$ & NWPP & $\begin{array}{l}\text { Rest of } \\
\text { WECC }\end{array}$ & $\begin{array}{c}\text { WECC } \\
\text { Total }\end{array}$ \\
\hline \multirow{6}{*}{ Q1 } & \multirow{2}{*}{ January } & BAU & 280,959 & $1,245,838$ & $1,526,797$ & & & \\
\hline & & EIM & 285,360 & $1,247,032$ & $1,532,392$ & $-4,401$ & $-1,194$ & $-5,595$ \\
\hline & \multirow{2}{*}{ February } & BAU & 254,910 & $1,026,939$ & $1,281,849$ & & & \\
\hline & & EIM & 264,575 & $1,028,211$ & $1,292,786$ & $-9,665$ & $-1,272$ & $-10,937$ \\
\hline & \multirow{2}{*}{ March } & BAU & 278,882 & $1,146,951$ & $1,425,833$ & & & \\
\hline & & EIM & 288,950 & $1,148,835$ & $1,437,785$ & $-10,067$ & $-1,885$ & $-11,952$ \\
\hline \multirow{6}{*}{ Q2 } & \multirow{2}{*}{ April } & BAU & 216,026 & 986,281 & $1,202,307$ & & & \\
\hline & & EIM & 213,766 & 987,845 & $1,201,611$ & 2,260 & $-1,564$ & 696 \\
\hline & \multirow{2}{*}{ May } & BAU & 248,637 & $1,156,169$ & $1,404,806$ & & & \\
\hline & & EIM & 234,879 & $1,157,515$ & $1,392,394$ & 13,758 & $-1,346$ & 12,412 \\
\hline & \multirow{2}{*}{ June } & BAU & 258,192 & $1,504,414$ & $1,762,605$ & & & \\
\hline & & EIM & 253,093 & $1,506,106$ & $1,759,199$ & 5,099 & $-1,692$ & 3,407 \\
\hline \multirow{6}{*}{ Q3 } & \multirow{2}{*}{ July } & BAU & 471,940 & $2,201,638$ & $2,673,578$ & & & \\
\hline & & EIM & 474,834 & $2,202,439$ & $2,677,273$ & $-2,894$ & -801 & $-3,695$ \\
\hline & \multirow{2}{*}{ August } & BAU & 516,053 & $2,172,597$ & $2,688,650$ & & & \\
\hline & & EIM & 523,384 & $2,173,047$ & $2,696,431$ & $-7,332$ & -449 & $-7,781$ \\
\hline & \multirow{2}{*}{ September } & BAU & 431,880 & $1,830,552$ & $2,262,432$ & & & \\
\hline & & EIM & 440,386 & $1,830,922$ & $2,271,308$ & $-8,506$ & -370 & $-8,876$ \\
\hline \multirow{6}{*}{ Q4 } & \multirow{2}{*}{ October } & BAU & 379,308 & $1,636,689$ & $2,015,998$ & & & \\
\hline & & EIM & 385,936 & $1,637,267$ & 2,023,203 & $-6,628$ & -578 & $-7,205$ \\
\hline & \multirow{2}{*}{ November } & BAU & 318,548 & $1,348,545$ & $1,667,093$ & & & \\
\hline & & EIM & 324,242 & $1,349,489$ & $1,673,730$ & $-5,694$ & -944 & $-6,637$ \\
\hline & \multirow{2}{*}{ December } & BAU & 402,813 & $1,580,827$ & $1,983,640$ & & & \\
\hline & & EIM & 406,574 & $1,581,679$ & $1,988,253$ & $-3,761$ & -852 & $-4,613$ \\
\hline \multirow[t]{8}{*}{ Total } & & BAU & $4,058,147$ & $17,837,440$ & $21,895,588$ & & & \\
\hline & & EIM & $4,095,978$ & $17,850,387$ & $21,946,365$ & & & \\
\hline & & & & & & NWPP & $\begin{array}{l}\text { Rest of } \\
\text { WECC }\end{array}$ & $\begin{array}{c}\text { WECC } \\
\text { Total }\end{array}$ \\
\hline & & \multicolumn{4}{|c|}{ Generation Cost Savings } & $-37,831$ & $-12,947$ & $-50,777$ \\
\hline & & \multicolumn{4}{|c|}{ Min Excess Hydro Savings (@\$62.78/MWh) } & 117,273 & -34 & 117,239 \\
\hline & & \multicolumn{4}{|c|}{ Max Excess Hydro Savings (@\$85.94/MWh) } & 160,364 & -48 & 160,316 \\
\hline & & \multicolumn{4}{|c|}{ Min Total Savings (k\$) } & 79,442 & $-12,981$ & 66,461 \\
\hline & & \multicolumn{4}{|c|}{ Max Total Savings (k\$) } & 122,533 & $-12,995$ & 109,538 \\
\hline
\end{tabular}


Table 4-19. Hydro Generation and Energy Constraints Violation in Case 1.86E

\begin{tabular}{|c|c|c|c|c|c|c|c|}
\hline & & \multirow[b]{2}{*}{ Scenario } & \multicolumn{3}{|c|}{ Hydro Violation (GWh) } & \multicolumn{2}{|c|}{ Total HTC Hydro (GWh) } \\
\hline & & & NWPP & $\begin{array}{l}\text { Rest of } \\
\text { WECC }\end{array}$ & WECC & NWPP & WECC Total \\
\hline \multirow{6}{*}{ Q1 } & \multirow{2}{*}{ January } & BAU & 176 & 14 & 189 & 12,257 & 13,569 \\
\hline & & EIM & 21 & 14 & 35 & 12,147 & 13,458 \\
\hline & \multirow{2}{*}{ February } & BAU & 229 & 19 & 248 & 10,576 & 11,977 \\
\hline & & EIM & 34 & 20 & 53 & 10,389 & 11,791 \\
\hline & \multirow{2}{*}{ March } & BAU & 233 & 22 & 256 & 9,674 & 11,035 \\
\hline & & EIM & 46 & 22 & 69 & 9,490 & 10,851 \\
\hline \multirow{6}{*}{ Q2 } & \multirow{2}{*}{ April } & BAU & 124 & 13 & 137 & 10,705 & 12,286 \\
\hline & & EIM & 36 & 13 & 49 & 10,775 & 12,355 \\
\hline & \multirow{2}{*}{ May } & BAU & 104 & 12 & 116 & 9,857 & 12,028 \\
\hline & & EIM & 7 & 12 & 19 & 10,177 & 12,348 \\
\hline & \multirow{2}{*}{ June } & BAU & 125 & 20 & 144 & 10,797 & 12,826 \\
\hline & & EIM & 14 & 19 & 34 & 10,826 & 12,855 \\
\hline \multirow{6}{*}{ Q3 } & \multirow{2}{*}{ July } & BAU & 151 & 16 & 167 & 8,621 & 10,557 \\
\hline & & EIM & 6 & 16 & 22 & 8,484 & 10,420 \\
\hline & \multirow{2}{*}{ August } & BAU & 188 & 17 & 205 & 8,378 & 10,007 \\
\hline & & EIM & 20 & 17 & 37 & 8,214 & 9,843 \\
\hline & \multirow{2}{*}{ September } & BAU & 220 & 14 & 235 & 7,445 & 8,813 \\
\hline & & EIM & 39 & 14 & 53 & 7,266 & 8,634 \\
\hline \multirow{6}{*}{ Q4 } & \multirow{2}{*}{ October } & BAU & 235 & 13 & 247 & 7,886 & 9,036 \\
\hline & & EIM & 53 & 13 & 66 & 7,710 & 8,861 \\
\hline & \multirow{2}{*}{ November } & BAU & 223 & 6 & 229 & 8,817 & 9,911 \\
\hline & & EIM & 43 & 7 & 50 & 8,649 & 9,744 \\
\hline & \multirow{2}{*}{ December } & BAU & 195 & 6 & 201 & 10,901 & 12,211 \\
\hline & & EIM & 14 & 6 & 20 & 10,743 & 12,054 \\
\hline \multirow{2}{*}{ Total } & & BAU & 2,202 & 172 & 2,374 & 115,914 & 134,256 \\
\hline & & EIM & 334 & 173 & 507 & 114,869 & 133,212 \\
\hline
\end{tabular}


Table 4-20. WECC Dump and Unserved Energy, Reserve Shortfall and Exchange Violations in Case $1.86 \mathrm{E}$

\begin{tabular}{|c|c|c|c|c|c|c|c|c|c|c|c|}
\hline & & \multirow[t]{2}{*}{ Scenario } & \multirow[t]{2}{*}{$\begin{array}{l}\text { Dump } \\
\text { GWh }\end{array}$} & \multirow[t]{2}{*}{$\begin{array}{l}\text { USE } \\
\text { (unserved } \\
\text { GWh) }\end{array}$} & \multicolumn{5}{|c|}{ BA Reserve Shortfall (GWh) } & \multicolumn{2}{|c|}{$\begin{array}{l}\text { Total BAs } \\
\text { Exchange } \\
\text { Violation } \\
\text { (GWh) }\end{array}$} \\
\hline & & & & & Spin & $\begin{array}{l}\text { Reg. } \\
\text { up }\end{array}$ & $\begin{array}{l}\text { Reg. } \\
\text { down }\end{array}$ & $\begin{array}{l}\text { Non } \\
\text { spin }\end{array}$ & Total & Up & Dn \\
\hline \multirow{6}{*}{ Q1 } & \multirow{2}{*}{ January } & BAU & 0.24 & 6.88 & 14.61 & 4.38 & 0.25 & 5.74 & 24.98 & 0.68 & 0.00 \\
\hline & & EIM & 0.04 & 6.88 & 16.89 & 5.00 & 0.17 & 3.63 & 25.70 & 0.66 & 0.03 \\
\hline & \multirow{2}{*}{ February } & BAU & 0.46 & 7.97 & 20.60 & 5.53 & 0.43 & 6.41 & 32.97 & 0.38 & 0.00 \\
\hline & & EIM & 0.69 & 7.95 & 23.15 & 6.74 & 0.38 & 6.32 & 36.60 & 0.34 & 0.02 \\
\hline & \multirow{2}{*}{ March } & BAU & 0.23 & 7.09 & 15.06 & 2.99 & 0.19 & 3.94 & 22.19 & 0.60 & 0.00 \\
\hline & & EIM & 0.63 & 7.07 & 24.41 & 6.13 & 0.35 & 7.32 & 38.22 & 0.54 & 0.02 \\
\hline \multirow{6}{*}{ Q2 } & \multirow{2}{*}{ April } & BAU & 0.54 & 6.74 & 13.14 & 3.71 & 0.45 & 3.19 & 20.49 & 0.84 & 0.00 \\
\hline & & EIM & 0.24 & 6.72 & 11.43 & 2.63 & 0.41 & 2.86 & 17.33 & 0.68 & 0.02 \\
\hline & \multirow{2}{*}{ May } & BAU & 0.53 & 8.42 & 12.12 & 2.73 & 0.36 & 2.19 & 17.40 & 0.86 & 0.00 \\
\hline & & EIM & 0.14 & 8.37 & 9.78 & 1.24 & 0.28 & 1.42 & 12.72 & 0.70 & 0.03 \\
\hline & \multirow{2}{*}{ June } & BAU & 0.23 & 5.49 & 19.41 & 3.41 & 0.14 & 4.44 & 27.40 & 1.27 & 0.06 \\
\hline & & EIM & 0.20 & 5.38 & 17.49 & 1.95 & 0.09 & 2.60 & 22.13 & 1.13 & 0.24 \\
\hline \multirow{6}{*}{ Q3 } & \multirow{2}{*}{ July } & BAU & 0.25 & 3.62 & 24.16 & 3.49 & 0.15 & 4.24 & 32.04 & 1.54 & 0.02 \\
\hline & & EIM & 0.00 & 3.57 & 19.26 & 1.76 & 0.39 & 1.81 & 23.21 & 1.02 & 0.15 \\
\hline & \multirow{2}{*}{ August } & BAU & 1.39 & 6.28 & 19.19 & 3.38 & 0.60 & 5.31 & 28.48 & 1.18 & 0.03 \\
\hline & & EIM & 0.00 & 6.29 & 16.48 & 2.44 & 0.44 & 4.74 & 24.10 & 0.61 & 0.16 \\
\hline & \multirow{2}{*}{ September } & BAU & 2.15 & 6.65 & 15.37 & 2.58 & 0.68 & 4.56 & 23.18 & 0.76 & 0.04 \\
\hline & & EIM & 0.00 & 6.64 & 17.89 & 3.18 & 0.58 & 6.46 & 28.11 & 0.58 & 0.12 \\
\hline \multirow{6}{*}{ Q4 } & \multirow{2}{*}{ October } & BAU & 3.47 & 4.75 & 14.92 & 6.00 & 1.76 & 8.46 & 31.14 & 0.99 & 0.01 \\
\hline & & EIM & 0.00 & 4.76 & 14.84 & 4.74 & 0.74 & 5.13 & 25.45 & 0.55 & 0.04 \\
\hline & \multirow{2}{*}{ November } & BAU & 1.71 & 5.06 & 19.29 & 9.38 & 1.10 & 9.12 & 38.89 & 0.82 & 0.00 \\
\hline & & EIM & 0.32 & 5.04 & 16.48 & 7.08 & 0.36 & 5.26 & 29.18 & 0.52 & 0.09 \\
\hline & \multirow{2}{*}{ December } & BAU & 0.52 & 4.59 & 24.85 & 12.50 & 2.81 & 10.24 & 50.40 & 0.84 & 0.00 \\
\hline & & EIM & 0.00 & 4.58 & 17.30 & 5.99 & 0.75 & 4.51 & 28.55 & 0.60 & 0.07 \\
\hline \multirow{2}{*}{ Total } & & BAU & 12 & 74 & 213 & 60 & 9 & 68 & 350 & 10.8 & 0.2 \\
\hline & & EIM & 2 & 73 & 205 & 49 & 5 & 52 & 311 & 7.9 & 1.0 \\
\hline
\end{tabular}


Table 4-21. Generation, Demand, and Average Production Cost for NWPP and WECC, and NWPP Net Interchange in Case 1.86E

\begin{tabular}{|c|c|c|c|c|c|c|c|c|c|}
\hline & & Scenario & $\begin{array}{l}\text { NWPP } \\
\text { Generation } \\
\text { (GWh) }\end{array}$ & $\begin{array}{l}\text { NWPP } \\
\text { Demand } \\
\text { (GWh) }\end{array}$ & $\begin{array}{c}\text { NWPP } \\
\text { Average } \\
\text { Production } \\
\text { Cost } \\
(\$ / \mathrm{MWh})\end{array}$ & $\begin{array}{c}\text { WECC } \\
\text { Generation } \\
\text { (GWh) }\end{array}$ & $\begin{array}{l}\text { WECC } \\
\text { Demand } \\
\text { (GWh }\end{array}$ & $\begin{array}{c}\text { WECC } \\
\text { Average } \\
\text { Production } \\
\text { Cost } \\
\text { (\$/MWh) }\end{array}$ & $\begin{array}{l}\text { NWPP } \\
\text { Net } \\
\text { Exchange } \\
\text { (GWh) }\end{array}$ \\
\hline \multirow{6}{*}{ Q1 } & \multirow{2}{*}{ January } & BAU & 38,486 & 32,368 & 8.68 & 86,727 & 86,720 & 17.61 & $-6,118$ \\
\hline & & EIM & 38,466 & 32,368 & 8.82 & 86,720 & $\mathbf{8 6 , 7 2 7}$ & 17.67 & $-6,009$ \\
\hline & \multirow{2}{*}{ February } & BAU & 33,250 & 28,897 & 8.82 & 77,021 & 77,013 & 16.64 & $-4,354$ \\
\hline & & EIM & 33,231 & 28,897 & 9.16 & 77,014 & 77,021 & 16.78 & $-4,334$ \\
\hline & \multirow{2}{*}{ March } & BAU & 32,915 & 28,739 & 9.70 & 80,514 & 80,507 & 17.71 & $-4,175$ \\
\hline & & EIM & 32,893 & 28,739 & 10.05 & 80,508 & 80,514 & 17.86 & $-4,154$ \\
\hline \multirow{6}{*}{ Q2 } & \multirow{2}{*}{ April } & BAU & 32,281 & 26,702 & 8.09 & 77,384 & 77,390 & 15.54 & $-5,579$ \\
\hline & & EIM & 32,257 & 26,702 & 8.01 & 77,383 & 77,390 & 15.53 & $-5,555$ \\
\hline & \multirow{2}{*}{ May } & BAU & 34,075 & 27,162 & 9.15 & 83,365 & 83,372 & 16.85 & $-6,913$ \\
\hline & & EIM & 34,055 & 27,162 & 8.65 & 83,364 & 83,372 & 16.70 & $-6,893$ \\
\hline & \multirow{2}{*}{ June } & BAU & 34,291 & 27,701 & 9.32 & 87,427 & 87,432 & 20.16 & $-6,590$ \\
\hline & & EIM & 34,267 & 27,701 & 9.14 & 87,427 & 87,432 & 20.12 & $-6,566$ \\
\hline \multirow{6}{*}{ Q3 } & \multirow{2}{*}{ July } & BAU & 34,326 & 30,588 & 15.43 & 97,722 & 97,725 & 27.36 & $-3,738$ \\
\hline & & EIM & 34,315 & 30,588 & 15.52 & 97,721 & 97,725 & 27.40 & $-3,727$ \\
\hline & \multirow{2}{*}{ August } & BAU & 33,020 & 29,972 & 17.22 & 96,100 & 96,104 & 27.98 & $-3,048$ \\
\hline & & EIM & 33,014 & 29,972 & 17.46 & 96,098 & 96,104 & 28.06 & $-3,042$ \\
\hline & \multirow{2}{*}{ September } & BAU & 29,942 & 27,067 & 15.96 & 85,651 & 85,655 & 26.41 & $-2,875$ \\
\hline & & EIM & 29,935 & 27,067 & 16.27 & 85,649 & 85,655 & 26.52 & $-2,686$ \\
\hline \multirow{6}{*}{ Q4 } & \multirow{2}{*}{ October } & BAU & 30,642 & 27,528 & 13.78 & 82,591 & 82,592 & 24.41 & $-3,114$ \\
\hline & & EIM & 30,633 & 27,528 & 14.02 & 82,587 & 82,592 & 24.50 & $-3,105$ \\
\hline & \multirow{2}{*}{ November } & BAU & 32,919 & 29,190 & 10.91 & 81,475 & 81,478 & 20.46 & $-3,729$ \\
\hline & & EIM & 32,909 & 29,190 & 11.11 & 81,473 & 81,478 & 20.54 & $-3,719$ \\
\hline & \multirow{2}{*}{ December } & BAU & 36,205 & 32,780 & 12.29 & 88,537 & 88,541 & 22.40 & $-3,425$ \\
\hline & & EIM & 36,196 & 32,780 & 12.40 & 88,537 & 88,541 & 22.46 & $-3,416$ \\
\hline \multirow{2}{*}{ Total } & & BAU & 402,353 & 348,694 & 11.64 & $1,024,511$ & $1,024,531$ & 21.37 & $-53,659$ \\
\hline & & EIM & 402,172 & 348,694 & 11.75 & $1,024,481$ & $1,024,552$ & 21.42 & $-53,478$ \\
\hline
\end{tabular}




\subsubsection{Low Gas Price Case (Case 1.86F)}

This sensitivity case represents a situation in which there are low natural gas prices (the average annual price at Henry Hub is \$3.80/ MMBtu) in comparison with the natural gas price used for the Base Case (the average annual price at Henry Hub is $\$ 5.62 / \mathrm{MMBtu}$ ). The generation costs, value of excess hydro generation, total annual savings, and the amounts of energy associated with hydro violations are reported in Table 4-22 and Table 4-23. The amounts of energy associated with dump and unserved energy, reserve shortfalls, and exchange violations for all the BAs in the WECC are reported in Table 4-24. Generation, demand, and average production costs for the NWPP and WECC, and net interchange for the NWPP are provided in Table 4-25.

The observations regarding the differences in the results between this low natural gas price case and the Base Case are similar to those between the Base Case and the high gas price case (Case 1.86E) regarding information for the hydro, dump and unserved energy, reserve shortfalls, and exchange violations, but differ in the opposite direction with reductions in the cost, savings, generation, and NWPP net exchange results. The annual total savings for the NWPP largely decreased due to the excess hydro generation being valued at lower electricity prices of \$28.40/MWh and \$34.80/MWh (rather than \$42.00/MWh and \$57.50/MWh in the Base Case) resulting from lower fuel costs for natural gas-fired resources. Like in the Base Case and high gas price case, the valuation of excess hydro generation in this sensitivity case was based on assumed implied heat rates for gas-fired resources of 7.5 MMBtu/MWh and 10.2 MMBtu/MWh.

As reported in Table 4-22, the annual total savings between the BAU scenario and the EIM scenario within the NWPP footprint are \$16.7 million and \$34.8 million, which correspond to the prices for excess hydro generation being $\$ 27.40 / \mathrm{MWh}$ and $\$ 38.88 / \mathrm{MWh}$, respectively. These annual total savings are smaller than the annual total savings received under the Base Case, which are \$41.2 million and \$70.7 million, respectively. 
Table 4-22. Summary of Generation Cost and Savings for the NWPP and WECC in Case 1.86F

\begin{tabular}{|c|c|c|c|c|c|c|c|c|}
\hline & & \multirow{2}{*}{ Scenario } & \multicolumn{3}{|c|}{ Total Generation Cost $(\mathrm{k} \$)$} & \multicolumn{3}{|c|}{ Gen. Cost Difference (k\$) } \\
\hline & & & NWPP & $\begin{array}{l}\text { Rest of } \\
\text { WECC }\end{array}$ & $\begin{array}{c}\text { WECC } \\
\text { Total }\end{array}$ & NWPP & $\begin{array}{l}\text { Rest of } \\
\text { WECC }\end{array}$ & $\begin{array}{c}\text { WECC } \\
\text { Total }\end{array}$ \\
\hline \multirow{6}{*}{ Q1 } & \multirow{2}{*}{ January } & BAU & 207,113 & 837,829 & $1,044,942$ & & & \\
\hline & & EIM & 209,977 & 838,424 & $1,048,401$ & $-2,863$ & -595 & $-3,458$ \\
\hline & \multirow{2}{*}{ February } & BAU & 188,344 & 715,476 & 903,820 & & & \\
\hline & & EIM & 196,731 & 716,155 & 912,885 & $-8,386$ & -679 & $-9,065$ \\
\hline & \multirow{2}{*}{ March } & BAU & 200,703 & 786,009 & 986,712 & & & \\
\hline & & EIM & 209,450 & 786,809 & 996,260 & $-8,747$ & -800 & $-9,547$ \\
\hline \multirow{6}{*}{ Q2 } & \multirow{2}{*}{ April } & BAU & 162,479 & 690,561 & 853,040 & & & \\
\hline & & EIM & 159,655 & 691,284 & 850,939 & 2,824 & -723 & 2,101 \\
\hline & \multirow{2}{*}{ May } & BAU & 178,471 & 795,324 & 973,795 & & & \\
\hline & & EIM & 169,193 & 795,994 & 965,187 & 9,278 & -670 & 8,608 \\
\hline & \multirow{2}{*}{ June } & BAU & 181,252 & 985,105 & $1,166,357$ & & & \\
\hline & & EIM & 177,207 & 985,887 & $1,163,094$ & 4,045 & -782 & 3,262 \\
\hline \multirow{6}{*}{ Q3 } & \multirow{2}{*}{ July } & BAU & 298,123 & $1,351,969$ & $1,650,092$ & & & \\
\hline & & EIM & 298,499 & 1,352,333 & $1,650,833$ & -376 & -365 & -741 \\
\hline & \multirow{2}{*}{ August } & BAU & 315,783 & $1,342,522$ & $1,658,304$ & & & \\
\hline & & EIM & 323,036 & $1,342,810$ & $1,665,846$ & $-7,253$ & -289 & $-7,542$ \\
\hline & \multirow{2}{*}{ September } & BAU & 276,268 & $1,149,628$ & $1,425,895$ & & & \\
\hline & & EIM & 283,493 & $1,149,899$ & 1,433,392 & $-7,225$ & -272 & $-7,497$ \\
\hline \multirow{6}{*}{ Q4 } & \multirow{2}{*}{ October } & BAU & 252,645 & $1,035,675$ & $1,288,320$ & & & \\
\hline & & EIM & 258,737 & $1,035,961$ & $1,294,698$ & $-6,092$ & -286 & $-6,378$ \\
\hline & \multirow{2}{*}{ November } & BAU & 227,195 & 891,277 & $1,118,472$ & & & \\
\hline & & EIM & 230,952 & 891,617 & $1,122,569$ & $-3,756$ & -340 & $-4,097$ \\
\hline & \multirow{2}{*}{ December } & BAU & 272,489 & $1,020,149$ & $1,292,638$ & & & \\
\hline & & EIM & 276,290 & $1,020,626$ & $1,296,917$ & $-3,801$ & -478 & $-4,279$ \\
\hline \multirow[t]{8}{*}{ Total } & & BAU & $2,760,866$ & $11,601,522$ & $14,362,388$ & & & \\
\hline & & EIM & 2,793,219 & $11,607,800$ & $14,401,019$ & & & \\
\hline & & & & & & NWPP & $\begin{array}{l}\text { Rest of } \\
\text { WECC }\end{array}$ & $\begin{array}{c}\text { WECC } \\
\text { Total }\end{array}$ \\
\hline & & \multicolumn{4}{|c|}{ Generation Cost Savings } & $-32,354$ & $-6,278$ & $-38,631$ \\
\hline & & \multicolumn{4}{|c|}{ Min Excess Hydro Savings (@\$28.40/MWh) } & 49,022 & 8.5 & 49,030 \\
\hline & & \multicolumn{4}{|c|}{ Max Excess Hydro Savings (@\$38.88/MWh) } & 67,112 & 11.7 & 67,123 \\
\hline & & \multicolumn{4}{|c|}{ Min Total Savings (k\$) } & 16,668 & $-6,269$ & 10,399 \\
\hline & & \multicolumn{4}{|c|}{ Max Total Savings (k\$) } & 34,758 & $-6,266$ & 28,492 \\
\hline
\end{tabular}


Table 4-23. Hydro Generation and Energy Constraints Violation in Case 1.86F

\begin{tabular}{|c|c|c|c|c|c|c|c|}
\hline & & \multirow[b]{2}{*}{ Scenario } & \multicolumn{3}{|c|}{ Hydro Violation (GWh) } & \multicolumn{2}{|c|}{ HTC Hydro Gen (GWh) } \\
\hline & & & NWPP & $\begin{array}{l}\text { Rest of } \\
\text { WECC }\end{array}$ & $\begin{array}{c}\text { WECC } \\
\text { Total }\end{array}$ & NWPP & WECC Total \\
\hline \multirow{6}{*}{ Q1 } & \multirow{2}{*}{ January } & BAU & 165 & 16 & 181 & 12,252 & 13,566 \\
\hline & & EIM & 22 & 16 & 38 & 12,146 & 13,460 \\
\hline & \multirow{2}{*}{ February } & BAU & 235 & 12 & 247 & 10,576 & 11,970 \\
\hline & & EIM & 38 & 13 & 51 & 10,394 & 11,789 \\
\hline & \multirow{2}{*}{ March } & BAU & 252 & 25 & 276 & 9,693 & 11,056 \\
\hline & & EIM & 58 & 25 & 82 & 9,503 & 10,866 \\
\hline \multirow{6}{*}{ Q2 } & \multirow{2}{*}{ April } & BAU & 96 & 16 & 112 & 10,666 & 12,249 \\
\hline & & EIM & 26 & 16 & 42 & 10,766 & 12,348 \\
\hline & \multirow{2}{*}{ May } & BAU & 60 & 11 & 71 & 9,855 & 12,024 \\
\hline & & EIM & 5 & 10 & 15 & 10,176 & 12,345 \\
\hline & \multirow{2}{*}{ June } & BAU & 88 & 17 & 105 & 10,759 & 12,786 \\
\hline & & EIM & 10 & 17 & 27 & 10,824 & 12,850 \\
\hline \multirow{6}{*}{ Q3 } & \multirow{2}{*}{ July } & BAU & 137 & 15 & 152 & 8,608 & 10,543 \\
\hline & & EIM & 5 & 15 & 19 & 8,483 & 10,417 \\
\hline & \multirow{2}{*}{ August } & BAU & 205 & 15 & 220 & 8,394 & 10,021 \\
\hline & & EIM & 30 & 15 & 46 & 8,224 & 9,851 \\
\hline & \multirow{2}{*}{ September } & BAU & 218 & 16 & 234 & 7,443 & 8,812 \\
\hline & & EIM & 55 & 15 & 70 & 7,283 & 8,651 \\
\hline \multirow{6}{*}{ Q4 } & \multirow{2}{*}{ October } & BAU & 240 & 11 & 252 & 7,893 & 9,042 \\
\hline & & EIM & 53 & 11 & 65 & 7,711 & 8,860 \\
\hline & \multirow{2}{*}{ November } & BAU & 220 & 8 & 228 & 8,815 & 9,911 \\
\hline & & EIM & 52 & 8 & 60 & 8,660 & 9,755 \\
\hline & \multirow{2}{*}{ December } & BAU & 181 & 6 & 187 & 10,900 & 12,211 \\
\hline & & EIM & 17 & 6 & 23 & 10,747 & 12,058 \\
\hline \multirow{2}{*}{ Total } & & BAU & 2,098 & 166 & 2,264 & 115,854 & 134,190 \\
\hline & & EIM & 372 & 166 & 538 & 114,915 & 133,251 \\
\hline
\end{tabular}


Table 4-24. WECC Dump and Unserved Energy, Reserve Shortfall and Exchange Violations in Case $1.86 \mathrm{~F}$

\begin{tabular}{|c|c|c|c|c|c|c|c|c|c|c|c|}
\hline & & \multirow[t]{2}{*}{ Scenario } & \multirow[t]{2}{*}{$\begin{array}{l}\text { Dump } \\
\text { GWh }\end{array}$} & \multirow{2}{*}{$\begin{array}{c}\text { USE } \\
\text { (Unserved } \\
\text { GWh) }\end{array}$} & \multicolumn{5}{|c|}{ Total BAs Reserve Shortfall (GWh) } & \multicolumn{2}{|c|}{$\begin{array}{c}\text { Total BAs } \\
\text { Exchange } \\
\text { Violation } \\
\text { GWh) }\end{array}$} \\
\hline & & & & & Spin & $\begin{array}{l}\text { Reg. } \\
\text { up }\end{array}$ & $\begin{array}{l}\text { Reg. } \\
\text { down }\end{array}$ & $\begin{array}{l}\text { Non } \\
\text { spin }\end{array}$ & Total & Up & Dn \\
\hline \multirow{6}{*}{ Q1 } & \multirow{2}{*}{ January } & BAU & 0.35 & 7.60 & 14.83 & 4.38 & 0.24 & 4.30 & 23.75 & 0.66 & 0.00 \\
\hline & & EIM & 0.01 & 7.58 & 17.06 & 4.88 & 0.15 & 4.09 & 26.18 & 0.62 & 0.01 \\
\hline & \multirow{2}{*}{ February } & BAU & 0.29 & 8.68 & 16.54 & 4.62 & 0.29 & 5.60 & 27.05 & 0.43 & 0.00 \\
\hline & & EIM & 0.16 & 8.66 & 21.53 & 6.61 & 0.31 & 5.49 & 33.94 & 0.37 & 0.02 \\
\hline & \multirow{2}{*}{ March } & BAU & 0.24 & 6.71 & 14.71 & 3.49 & 0.19 & 4.82 & 23.21 & 0.73 & 0.00 \\
\hline & & EIM & 0.04 & 6.68 & 17.13 & 4.97 & 0.34 & 5.54 & 27.98 & 0.63 & 0.03 \\
\hline \multirow{6}{*}{ Q2 } & \multirow{2}{*}{ April } & BAU & 0.35 & 8.12 & 11.70 & 3.58 & 0.44 & 2.99 & 18.71 & 1.04 & 0.00 \\
\hline & & EIM & 0.06 & 8.12 & 10.51 & 2.18 & 0.43 & 2.83 & 15.95 & 0.94 & 0.04 \\
\hline & \multirow{2}{*}{ May } & BAU & 0.51 & 7.93 & 9.54 & 2.04 & 0.38 & 1.70 & 13.66 & 0.97 & 0.00 \\
\hline & & EIM & 0.16 & 7.90 & 7.65 & 1.04 & 0.26 & 0.82 & 9.77 & 0.77 & 0.03 \\
\hline & \multirow{2}{*}{ June } & BAU & 0.25 & 6.30 & 14.83 & 3.49 & 0.19 & 3.69 & 22.20 & 1.01 & 0.05 \\
\hline & & EIM & 0.02 & 6.31 & 11.06 & 1.51 & 0.10 & 1.38 & 14.05 & 0.89 & 0.21 \\
\hline \multirow{6}{*}{ Q3 } & \multirow{2}{*}{ July } & BAU & 0.22 & 3.70 & 20.78 & 3.45 & 0.13 & 4.42 & 28.78 & 1.42 & 0.01 \\
\hline & & EIM & 0.00 & 3.70 & 15.53 & 1.50 & 0.41 & 1.88 & 19.32 & 0.94 & 0.15 \\
\hline & \multirow{2}{*}{ August } & BAU & 1.30 & 6.74 & 18.38 & 4.14 & 0.56 & 6.54 & 29.62 & 1.06 & 0.03 \\
\hline & & EIM & 0.00 & 6.74 & 14.83 & 3.35 & 0.33 & 4.25 & 22.76 & 0.49 & 0.15 \\
\hline & \multirow{2}{*}{ September } & BAU & 2.09 & 7.21 & 13.49 & 3.06 & 0.70 & 4.92 & 22.18 & 0.79 & 0.00 \\
\hline & & EIM & 0.00 & 7.24 & 14.66 & 3.20 & 0.58 & 3.75 & 22.19 & 0.55 & 0.07 \\
\hline \multirow{6}{*}{ Q4 } & \multirow{2}{*}{ October } & BAU & 3.51 & 4.94 & 13.28 & 3.12 & 0.92 & 5.15 & 22.47 & 1.03 & 0.01 \\
\hline & & EIM & 0.00 & 4.94 & 12.25 & 3.46 & 0.64 & 3.50 & 19.86 & 0.64 & 0.05 \\
\hline & \multirow{2}{*}{ November } & BAU & 2.00 & 7.36 & 16.72 & 4.59 & 0.61 & 9.96 & 31.88 & 0.88 & 0.00 \\
\hline & & EIM & 0.13 & 7.33 & 11.84 & 5.80 & 0.33 & 3.57 & 21.55 & 0.53 & 0.09 \\
\hline & \multirow{2}{*}{ December } & BAU & 0.61 & 4.47 & 21.80 & 5.71 & 0.33 & 9.40 & 37.24 & 0.61 & 0.02 \\
\hline & & EIM & 0.02 & 4.44 & 16.26 & 7.21 & 1.36 & 2.76 & 27.60 & 0.38 & 0.02 \\
\hline \multirow{2}{*}{ Total } & & BAU & 12 & 80 & 187 & 46 & 5 & 63 & 301 & 10.6 & 0.1 \\
\hline & & EIM & 1 & 80 & 170 & 46 & 5 & 40 & 261 & 7.7 & 0.9 \\
\hline
\end{tabular}


Table 4-25. Generation, Demand, and Average Production Cost for NWPP and WECC, and NWPP Net Interchange in Case 1.86F

\begin{tabular}{|c|c|c|c|c|c|c|c|c|c|}
\hline & & Scenario & $\begin{array}{c}\text { NWPP } \\
\text { Generation } \\
\text { (GWh) }\end{array}$ & $\begin{array}{l}\text { NWPP } \\
\text { Demand } \\
\text { (GWh) }\end{array}$ & $\begin{array}{c}\text { NWPP } \\
\text { Average } \\
\text { Production } \\
\text { Cost } \\
\text { (\$/MWh) }\end{array}$ & $\begin{array}{c}\text { WECC } \\
\text { Generation } \\
\text { (GWh) }\end{array}$ & $\begin{array}{l}\text { WECC } \\
\text { Demand } \\
\text { (GWh) }\end{array}$ & $\begin{array}{c}\text { WECC } \\
\text { Average } \\
\text { Production } \\
\text { Cost } \\
\text { (\$/MWh) }\end{array}$ & $\begin{array}{l}\text { NWPP } \\
\text { Net } \\
\text { Exchange } \\
\text { (GWh) }\end{array}$ \\
\hline \multirow{6}{*}{ Q1 } & \multirow{2}{*}{ January } & BAU & 38,334 & 32,368 & 6.40 & 86,643 & 86,650 & 12.06 & $-5,966$ \\
\hline & & EIM & 38,315 & 32,368 & 6.49 & 86,642 & 86,650 & 12.10 & $-5,948$ \\
\hline & \multirow{2}{*}{ February } & BAU & 33,054 & 28,897 & 6.52 & 76,930 & 76,938 & 11.75 & $-4,158$ \\
\hline & & EIM & 33,035 & 28,897 & 6.81 & 76,930 & 76,938 & 11.87 & $-4,139$ \\
\hline & \multirow{2}{*}{ March } & BAU & 32,652 & 28,739 & 6.98 & 80,409 & 80,416 & 12.27 & $-3,913$ \\
\hline & & EIM & 32,633 & 28,739 & 7.29 & 80,409 & 80,416 & 12.39 & $-3,894$ \\
\hline \multirow{6}{*}{ Q2 } & \multirow{2}{*}{ April } & BAU & 32,067 & 26,702 & 6.08 & 77,266 & 77,274 & 11.04 & $-5,365$ \\
\hline & & EIM & 32,044 & 26,702 & 5.98 & 77,266 & 77,274 & 11.01 & $-5,341$ \\
\hline & \multirow{2}{*}{ May } & BAU & 33,688 & 27,162 & 6.57 & 83,250 & 83,258 & 11.70 & $-6,526$ \\
\hline & & EIM & 33,668 & 27,162 & 6.23 & 83,250 & 83,258 & 11.59 & $-6,506$ \\
\hline & \multirow{2}{*}{ June } & BAU & 33,721 & 27,701 & 6.54 & 87,435 & 87,441 & 13.34 & $-6,020$ \\
\hline & & EIM & 33,697 & 27,701 & 6.40 & 87,435 & 87,441 & 13.30 &,- 5996 \\
\hline \multirow{6}{*}{ Q3 } & \multirow{2}{*}{ July } & BAU & 33,909 & 30,588 & 9.75 & 97,749 & 97,753 & 16.88 & $-3,321$ \\
\hline & & EIM & 33,900 & 30,588 & 9.76 & 97,749 & 97,753 & 16.89 & $-3,312$ \\
\hline & \multirow{2}{*}{ August } & BAU & 32,530 & 29,972 & 10.54 & 96,120 & 96,125 & 17.25 & $-2,558$ \\
\hline & & EIM & 32,523 & 29,972 & 10.78 & 96,118 & 96,125 & 17.33 & $-2,551$ \\
\hline & \multirow{2}{*}{ September } & BAU & 29,587 & 27,067 & 10.21 & 85,688 & 85,694 & 16.64 & $-2,520$ \\
\hline & & EIM & 29,580 & 27,067 & 10.47 & 85,686 & 85,694 & 16.73 & $-2,513$ \\
\hline \multirow{6}{*}{ Q4 } & \multirow{2}{*}{ October } & BAU & 30,461 & 27,528 & 9.18 & 82,635 & 82,636 & 15.59 & $-2,933$ \\
\hline & & EIM & 30,453 & 27,528 & 9.40 & 82,631 & 82,636 & 15.67 & $-2,925$ \\
\hline & \multirow{2}{*}{ November } & BAU & 32,870 & 29,190 & 7.78 & 81,478 & 81,484 & 13.73 & $-3,680$ \\
\hline & & EIM & 32,863 & 29,190 & 7.91 & 81,476 & 81,484 & 13.78 & $-3,672$ \\
\hline & \multirow{2}{*}{ December } & BAU & 36,098 & 32,780 & 8.31 & 88,556 & 88,560 & 14.60 & $-3,318$ \\
\hline & & EIM & 36,091 & 32,780 & 8.43 & 88,556 & 88,560 & 14.64 & $-3,311$ \\
\hline \multirow{2}{*}{ Total } & & BAU & 398,972 & 348,694 & 7.92 & $1,024,160$ & $1,024,228$ & 14.02 & $-50,278$ \\
\hline & & EIM & 398,802 & 348,694 & 8.01 & $1,024,149$ & $1,024,228$ & 14.06 & $-50,108$ \\
\hline
\end{tabular}




\subsubsection{Reduced NWPP EIM Flexible Reserve Case (Case 1.86G)}

In this sensitivity case, the impact of calculating the flexible reserve requirements based on the NWPP footprint being a single entity rather than a group of individual BA footprints was analyzed. This analysis took into account the diversity in the variability and uncertainty of loads and non-dispatchable resources that exists among the 16 BAs in the NWPP footprint under the assumption that the HA forecast errors for loads have a correlation value of zero between the 16 BAs. A T-31 minute persistence model was used to produce the forecast of wind generation during the HA period for each BA. The results from this analysis are shown in Figure 4.25 where the values reported for all BAs represents the flexible reserve requirements in the Base Case and the values reported for combined BAs (CBA) represents the reduced flexible reserves requirements in this sensitivity case. These results indicate the following:

1. On an annual basis, the average hourly load following up capacity was reduced by about 700 MW (from 2000 MW to 1300 MW or a 35\% reduction)

2. On an annual basis, the average hourly load following down capacity was reduced by about $800 \mathrm{MW}$ (from $2000 \mathrm{MW}$ to $1200 \mathrm{MW}$ or a $40 \%$ reduction)

The average hourly reductions in load following requirements per month can be observed in Figure 4.25 by comparing the differences between the results for the algebraic sum of the load following capacity requirements for all of the individual BAs in the NWPP and the requirements for the combined BAs (CBA) in the NWPP.
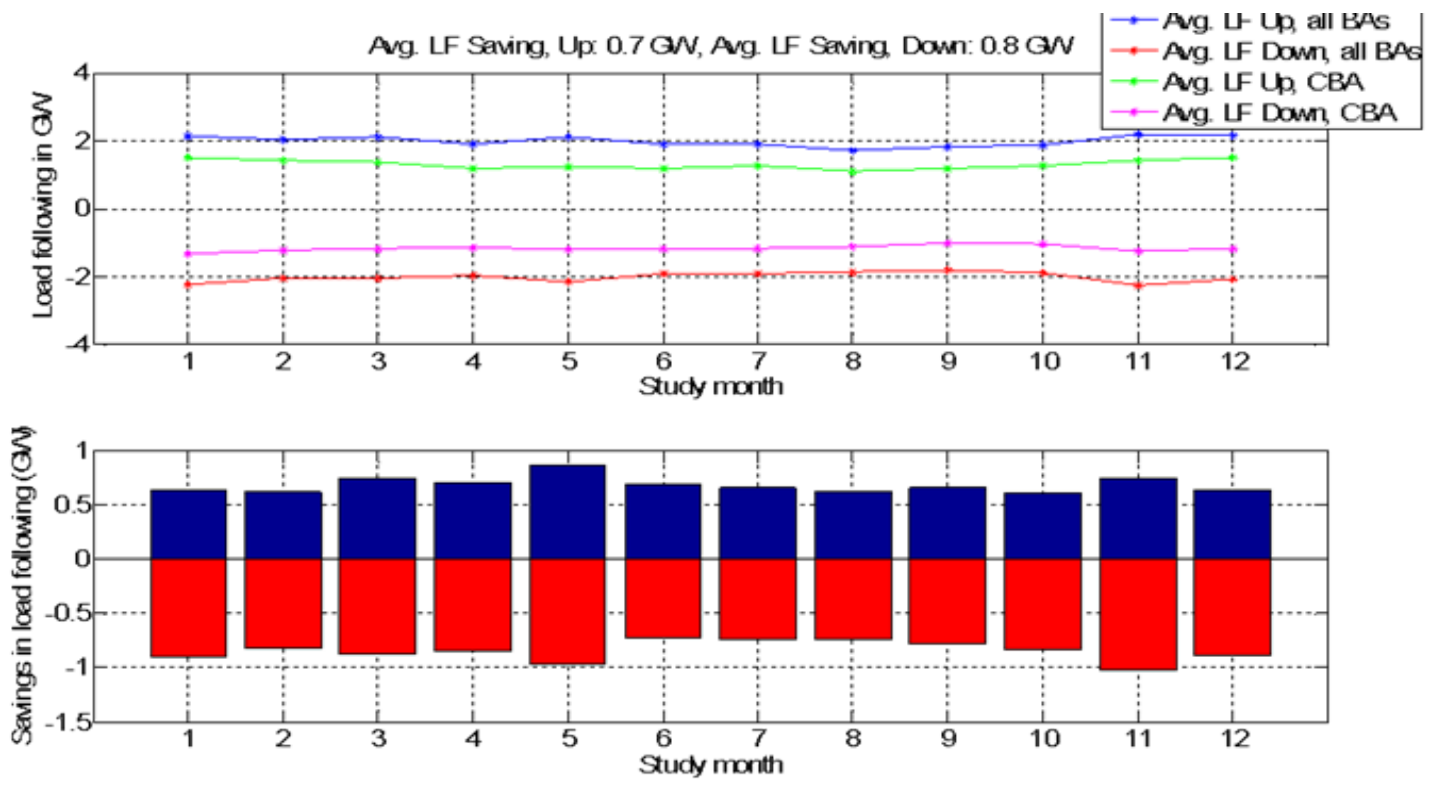

Figure 4.25. Average Capacity Reductions in Load Following Up and Down Requirements for Case $1.86 \mathrm{G}$ 
The BAU scenario is the same as the BAU scenario for the Base Case. For the EIM scenario, both the DA and HA simulations were repeated with each BA in the NWPP being required to carry less load following reserve capacity. Unlike in the Base Case and all the other sensitivity cases, this is the only sensitivity case were the DA and HA simulations were different in the BAU scenario than the EIM scenario.

The reduction in the reserves requirement resulted in fewer thermal units being committed in the NWPP, which slightly increased the amount of energy associated with the hydro violations in the EIM scenario compared with the EIM scenario in the Base Case. This can be observed by comparing the results reported in Table 4-3 and Table 4-27 where the amounts of energy associated with the hydro violations increased from $370 \mathrm{GWh}$ in the Base Case to $493 \mathrm{GWh}$ in this sensitivity case. Meanwhile, there were no significant differences in the amounts of energy associated with the dump and unserved energy, reserve shortfalls, and exchange violations for all the BAs in the WECC in comparison with the Base Case, which can be observed by comparing the results reported in Table 4-4 and Table 4-28.

The total export energy from the NWPP was reduced by 3.9\% in the EIM scenario decreasing from 52,129 GWh in the Base Case to 50,079 GWh in this sensitivity case. This can be observed by comparing the results reported in Table 4-5 and Table 4-29.

The generation costs, value of excess hydro generation, and total savings are summarized in Table 426. These results indicate that the generation costs were significantly reduced (by $\$ 55.6$ million) within the NWPP due to the reduced export energy associated with the lower load following reserve requirements. However, since the generation costs for the WECC increased by only $\$ 44.0$ million this means the production costs for the BAs outside the NWPP increased by $\$ 99.6$ million. This outcome can be observed by comparing the differences in the generation costs between the BAU scenario and the EIM scenario reported in Table 4-26.

As reported in Table 4-26, the total savings between the BAU scenario and the EIM scenario in the NWPP footprint are \$130.6 million and \$158.2 million, which correspond to the prices for excess hydro generation being $\$ 42.00 / \mathrm{MWh}$ and $\$ 57.50 / \mathrm{MWh}$, respectively. These annual total savings are substantially higher than the annual total savings received under the Base Case, which are $\$ 41.2$ million and $\$ 70.7$ million, respectively. 
Table 4-26. Summary of Generation Cost and Savings for the NWPP and WECC in Case 1.86G

\begin{tabular}{|c|c|c|c|c|c|c|c|c|}
\hline & & \multirow{2}{*}{ Scenario } & \multicolumn{3}{|c|}{ Total Generation Cost $(\mathrm{k} \$$ ) } & \multicolumn{3}{|c|}{ Gen. Cost Difference (k\$) } \\
\hline & & & NWPP & $\begin{array}{l}\text { Rest of } \\
\text { WECC } \\
\end{array}$ & $\begin{array}{c}\text { WECC } \\
\text { Total } \\
\end{array}$ & NWPP & $\begin{array}{l}\text { Rest of } \\
\text { WECC }\end{array}$ & $\begin{array}{c}\text { WECC } \\
\text { Total } \\
\end{array}$ \\
\hline \multirow{6}{*}{ Q1 } & \multirow{2}{*}{ January } & BAU & 236,659 & 997,816 & $1,234,475$ & & & \\
\hline & & EIM & 234,055 & $1,006,056$ & $1,240,111$ & 2,604 & $-8,240$ & $-5,635$ \\
\hline & \multirow{2}{*}{ February } & BAU & 216,611 & 835,177 & $1,051,788$ & & & \\
\hline & & EIM & 217,344 & 846,809 & $1,064,154$ & -733 & $-11,632$ & $-12,365$ \\
\hline & \multirow{2}{*}{ March } & BAU & 231,661 & 925,424 & $1,157,085$ & & & \\
\hline & & EIM & 231,698 & 938,774 & $1,170,472$ & -37 & $-13,350$ & $-13,387$ \\
\hline \multirow{6}{*}{ Q2 } & \multirow{2}{*}{ April } & BAU & 183,577 & 805,657 & 989,234 & & & \\
\hline & & EIM & 175,515 & 810,524 & 986,039 & 8,062 & $-4,868$ & 3,195 \\
\hline & \multirow{2}{*}{ May } & BAU & 208,264 & 936,743 & $1,145,007$ & & & \\
\hline & & EIM & 184,817 & 944,968 & $1,129,785$ & 23,447 & $-8,226$ & 15,222 \\
\hline & \multirow{2}{*}{ June } & BAU & 213,918 & $1,188,986$ & $1,402,904$ & & & \\
\hline & & EIM & 204,510 & $1,195,617$ & $1,400,127$ & 9,408 & $-6,631$ & 2,777 \\
\hline \multirow{6}{*}{ Q3 } & \multirow{2}{*}{ July } & BAU & 364,500 & $1,690,337$ & $2,054,837$ & & & \\
\hline & & EIM & 358,663 & $1,698,432$ & $2,057,094$ & 5,837 & $-8,095$ & $-2,258$ \\
\hline & \multirow{2}{*}{ August } & BAU & 389,433 & $1,676,625$ & $2,066,059$ & & & \\
\hline & & EIM & 395,492 & $1,678,966$ & $2,074,458$ & $-6,058$ & $-2,341$ & $-8,399$ \\
\hline & \multirow{2}{*}{ September } & BAU & 337,135 & $1,419,539$ & $1,756,674$ & & & \\
\hline & & EIM & 338,798 & $1,425,564$ & $1,764,362$ & $-1,662$ & $-6,025$ & $-7,687$ \\
\hline \multirow{6}{*}{ Q4 } & \multirow{2}{*}{ October } & BAU & 300,981 & $1,274,063$ & $1,575,044$ & & & \\
\hline & & EIM & 301,640 & $1,281,672$ & 1,583,312 & -659 & $-7,609$ & $-8,268$ \\
\hline & \multirow{2}{*}{ November } & BAU & 266,057 & $1,070,130$ & 1,336,187 & & & \\
\hline & & EIM & 255,564 & $1,082,983$ & $1,338,547$ & 10,493 & $-12,853$ & $-2,361$ \\
\hline & \multirow{2}{*}{ December } & BAU & 324,402 & $1,241,846$ & $1,566,248$ & & & \\
\hline & & EIM & 319,467 & $1,251,639$ & $1,571,106$ & 4,935 & $-9,793$ & $-4,858$ \\
\hline \multirow[t]{8}{*}{ Total } & & BAU & 3,273,199 & $14,062,343$ & $17,335,542$ & & & \\
\hline & & EIM & $3,217,562$ & $14,162,005$ & $17,379,567$ & & & \\
\hline & & & & & & NWPP & $\begin{array}{l}\text { Rest of } \\
\text { WECC }\end{array}$ & $\begin{array}{c}\text { WECC } \\
\text { Total }\end{array}$ \\
\hline & & \multicolumn{4}{|c|}{ Generation Cost Savings } & 55,637 & $-99,663$ & $-44,025$ \\
\hline & & \multicolumn{4}{|c|}{ Min Excess Hydro Savings (@\$42.00/MWh) } & 74,918 & -473 & 74,445 \\
\hline & & \multicolumn{4}{|c|}{ Max Excess Hydro Savings (@\$57.50/MWh) } & 102,567 & -648 & 101,919 \\
\hline & & \multicolumn{4}{|c|}{ Min Total Savings (k\$) } & 130,556 & $-100,136$ & 30,420 \\
\hline & & \multicolumn{4}{|c|}{ Max Total Savings (k\$) } & 158,204 & $-100,311$ & 57,894 \\
\hline
\end{tabular}


Table 4-27. Hydro Generation and Energy Constraints Violation in Case 1.86G

\begin{tabular}{|c|c|c|c|c|c|c|c|}
\hline & & \multirow[b]{2}{*}{ Scenario } & \multicolumn{3}{|c|}{ Hydro Violation (GWh) } & \multicolumn{2}{|c|}{ Total HTC Hydro (GWh) } \\
\hline & & & NWPP & $\begin{array}{l}\text { Rest of } \\
\text { WECC }\end{array}$ & $\begin{array}{l}\text { WECC } \\
\text { Total }\end{array}$ & NWPP & WECC Total \\
\hline \multirow{6}{*}{ Q1 } & \multirow{2}{*}{ January } & BAU & 178 & 16 & 194 & 12,275 & 13,590 \\
\hline & & EIM & 30 & 18 & 47 & 12154 & 13470 \\
\hline & \multirow{2}{*}{ February } & BAU & 227 & 15 & 243 & 10,573 & 11,970 \\
\hline & & EIM & 57 & 14 & 71 & 10,413 & 11,809 \\
\hline & \multirow{2}{*}{ March } & BAU & 270 & 24 & 294 & 9,710 & 11,073 \\
\hline & & EIM & 76 & 25 & 101 & 9,519 & 10,882 \\
\hline \multirow{6}{*}{ Q2 } & \multirow{2}{*}{ April } & BAU & 109 & 13 & 122 & 10,689 & 12,269 \\
\hline & & EIM & 37 & 12 & 49 & 10,775 & 12,355 \\
\hline & \multirow{2}{*}{ May } & BAU & 92 & 11 & 102 & 9,866 & 12,036 \\
\hline & & EIM & 11 & 9 & 21 & 10,183 & 12,351 \\
\hline & \multirow{2}{*}{ June } & BAU & 117 & 19 & 136 & 10,800 & 12,829 \\
\hline & & EIM & 21 & 21 & 42 & 10,832 & 12,863 \\
\hline \multirow{6}{*}{ Q3 } & \multirow{2}{*}{ July } & BAU & 159 & 16 & 175 & 8,629 & 10,565 \\
\hline & & EIM & 9 & 17 & 26 & 8,487 & 10,423 \\
\hline & \multirow{2}{*}{ August } & BAU & 213 & 10 & 223 & 8,402 & 10,025 \\
\hline & & EIM & 43 & 17 & 60 & 8,236 & 9,865 \\
\hline & \multirow{2}{*}{ September } & BAU & 209 & 13 & 222 & 7,435 & 8,801 \\
\hline & & EIM & 58 & 15 & 73 & 7,286 & 8,654 \\
\hline \multirow{6}{*}{ Q4 } & \multirow{2}{*}{ October } & BAU & 256 & 11 & 267 & 7,907 & 9,055 \\
\hline & & EIM & 67 & 11 & 78 & 7,725 & 8,873 \\
\hline & \multirow{2}{*}{ November } & BAU & 235 & 8 & 243 & 8,828 & 9,924 \\
\hline & & EIM & 63 & 9 & 72 & 8,670 & 9,766 \\
\hline & \multirow{2}{*}{ December } & BAU & 213 & 7 & 219 & 10,911 & 12,222 \\
\hline & & EIM & 19 & 8 & 27 & 10,748 & 12,060 \\
\hline \multirow{2}{*}{ Total } & & BAU & 2,276 & 163 & 2,440 & 116,024 & 134,357 \\
\hline & & EIM & 493 & 175 & 667 & 115,028 & 133,372 \\
\hline
\end{tabular}


Table 4-28. WECC Dump and Unserved Energy, Reserve Shortfall and Exchange Violations in Case 1.86G

\begin{tabular}{|c|c|c|c|c|c|c|c|c|c|c|c|}
\hline & & \multirow[t]{2}{*}{ Scenario } & \multirow[t]{2}{*}{$\begin{array}{l}\text { Dump } \\
\text { GWh }\end{array}$} & \multirow[t]{2}{*}{$\begin{array}{c}\text { USE } \\
\text { (Unserved } \\
\text { GWh) }\end{array}$} & \multicolumn{5}{|c|}{ Total BAs Reserve Shortfall (GWh) } & \multicolumn{2}{|c|}{$\begin{array}{c}\text { Total BAs } \\
\text { Exchange } \\
\text { Violation } \\
\text { (GWh) }\end{array}$} \\
\hline & & & & & Spin & $\begin{array}{c}\text { Reg. } \\
\text { up }\end{array}$ & $\begin{array}{l}\text { Reg. } \\
\text { down }\end{array}$ & $\begin{array}{l}\text { Non } \\
\text { spin }\end{array}$ & Total & Up & Dn \\
\hline \multirow{6}{*}{ Q1 } & \multirow{2}{*}{ January } & BAU & 0.3 & 6.7 & 13.3 & 3.7 & 0.2 & 4.0 & 21 & 0.4 & 0.0 \\
\hline & & EIM & 0.1 & 7.0 & 16.4 & 6.0 & 0.2 & 5.2 & 28 & 0.1 & 0.0 \\
\hline & \multirow{2}{*}{ February } & BAU & 0.6 & 8.4 & 17.4 & 4.3 & 0.4 & 6.3 & 28 & 0.4 & 0.0 \\
\hline & & EIM & 0.2 & 8.4 & 19.3 & 7.5 & 0.3 & 7.0 & 34 & 0.1 & 0.0 \\
\hline & \multirow{2}{*}{ March } & BAU & 0.4 & 7.3 & 15.2 & 3.5 & 0.2 & 4.6 & 23 & 0.6 & 0.0 \\
\hline & & EIM & 0.1 & 7.0 & 21.4 & 7.9 & 0.3 & 10.6 & 40 & 0.2 & 0.0 \\
\hline \multirow{6}{*}{ Q2 } & \multirow{2}{*}{ April } & BAU & 0.4 & 8.3 & 12.5 & 3.6 & 0.4 & 3.4 & 20 & 0.8 & 0.0 \\
\hline & & EIM & 0.1 & 8.1 & 9.1 & 3.4 & 0.4 & 4.5 & 17 & 0.5 & 0.0 \\
\hline & \multirow{2}{*}{ May } & BAU & 0.5 & 9.5 & 11.8 & 2.7 & 0.3 & 2.0 & 17 & 1.0 & 0.0 \\
\hline & & EIM & 0.1 & 8.8 & 5.8 & 1.8 & 0.2 & 2.0 & 10 & 0.5 & 0.0 \\
\hline & \multirow{2}{*}{ June } & BAU & 0.2 & 5.2 & 17.7 & 3.8 & 0.1 & 4.7 & 26 & 1.0 & 0.0 \\
\hline & & EIM & 0.2 & 5.2 & 11.8 & 3.2 & 0.1 & 4.1 & 19 & 0.1 & 0.0 \\
\hline \multirow{6}{*}{ Q3 } & \multirow{2}{*}{ July } & BAU & 0.2 & 3.2 & 23.4 & 3.9 & 0.1 & 4.7 & 32 & 1.6 & 0.0 \\
\hline & & EIM & 0.0 & 3.2 & 7.6 & 1.9 & 0.4 & 2.3 & 12 & 0.2 & 0.0 \\
\hline & \multirow{2}{*}{ August } & BAU & 1.2 & 6.8 & 18.1 & 4.0 & 0.6 & 6.4 & 29 & 1.1 & 0.1 \\
\hline & & EIM & 0.0 & 6.6 & 9.1 & 3.8 & 0.4 & 4.7 & 18 & 0.1 & 0.0 \\
\hline & \multirow{2}{*}{ September } & BAU & 2.0 & 7.1 & 12.2 & 2.2 & 0.7 & 3.9 & 19 & 0.8 & 0.0 \\
\hline & & EIM & 0.0 & 6.7 & 9.0 & 3.7 & 0.5 & 3.8 & 17 & 0.1 & 0.0 \\
\hline \multirow{6}{*}{ Q4 } & \multirow{2}{*}{ October } & BAU & 3.6 & 4.2 & 15.0 & 3.0 & 1.0 & 6.6 & 26 & 1.3 & 0.0 \\
\hline & & EIM & 0.0 & 4.4 & 8.6 & 3.0 & 0.5 & 6.0 & 18 & 0.1 & 0.0 \\
\hline & \multirow{2}{*}{ November } & BAU & 1.8 & 5.7 & 16.5 & 4.5 & 0.6 & 7.6 & 29 & 1.0 & 0.0 \\
\hline & & EIM & 0.1 & 5.4 & 11.5 & 4.2 & 0.3 & 5.8 & 22 & 0.3 & 0.1 \\
\hline & \multirow{2}{*}{ December } & BAU & 0.5 & 4.7 & 19.7 & 4.7 & 0.3 & 7.5 & 32 & 0.8 & 0.0 \\
\hline & & EIM & 0.0 & 5.2 & 11.5 & 3.5 & 0.3 & 5.6 & 21 & 0.3 & 0.0 \\
\hline \multirow{2}{*}{ Total } & & BAU & 12 & 77 & 193 & 44 & 5 & 62 & 303 & 10.7 & 0.1 \\
\hline & & EIM & 1 & 76 & 141 & 50 & 4 & 62 & 257 & 2.6 & 0.2 \\
\hline
\end{tabular}


Table 4-29. WECC Generation, Demand, and Average Production Cost for NWPP and WECC, and NWPP Net Interchange in Case 1.86G

\begin{tabular}{|c|c|c|c|c|c|c|c|c|c|}
\hline & & Scenario & $\begin{array}{c}\text { NWPP } \\
\text { Generation } \\
\text { (GWh) }\end{array}$ & $\begin{array}{l}\text { NWPP } \\
\text { Demand } \\
\text { (GWh) }\end{array}$ & $\begin{array}{c}\text { NWPP } \\
\text { Average } \\
\text { Production } \\
\text { Cost } \\
\text { (\$/MWh) }\end{array}$ & $\begin{array}{c}\text { WECC } \\
\text { Generation } \\
\text { (GWh) }\end{array}$ & $\begin{array}{l}\text { WECC } \\
\text { Demand } \\
\text { (GWh) }\end{array}$ & $\begin{array}{c}\text { WECC } \\
\text { Average } \\
\text { Production } \\
\text { Cost } \\
\text { (\$/MWh) }\end{array}$ & $\begin{array}{l}\text { NWPP } \\
\text { Net } \\
\text { Exchange } \\
\text { (GWh) }\end{array}$ \\
\hline \multirow{6}{*}{ Q1 } & \multirow{2}{*}{ January } & BAU & 38,449 & 32,368 & 7.31 & 86,695 & 86,702 & 14.24 & $-6,081$ \\
\hline & & EIM & 38,270 & 32,368 & 7.23 & 86,689 & 86,696 & 14.30 & $-5,902$ \\
\hline & \multirow{2}{*}{ February } & BAU & 33,219 & 28,897 & 7.50 & 76,997 & 77,005 & 13.66 & $-4,323$ \\
\hline & & EIM & 32,989 & 28,897 & 7.52 & 76,982 & 76,990 & 13.82 & $-4,092$ \\
\hline & \multirow{2}{*}{ March } & BAU & 32,846 & 28,739 & 8.06 & 80,481 & 80,488 & 14.38 & $-4,106$ \\
\hline & & EIM & 32,565 & 28,739 & 8.06 & 80,468 & 80,474 & 14.54 & $-3,825$ \\
\hline \multirow{6}{*}{ Q2 } & \multirow{2}{*}{ April } & BAU & 32,199 & 26,702 & 6.88 & 77,358 & 77,366 & 12.79 & $-5,497$ \\
\hline & & EIM & 32,085 & 26,702 & 6.57 & 77,358 & 77,366 & 12.75 & $-5,383$ \\
\hline & \multirow{2}{*}{ May } & BAU & 33,963 & 27,162 & 7.67 & 83,346 & 83,355 & 13.74 & $-6,802$ \\
\hline & & EIM & 33,736 & 27,162 & 6.80 & 83,305 & 83,314 & 13.56 & $-6,575$ \\
\hline & \multirow{2}{*}{ June } & BAU & 34,096 & 27,701 & 7.72 & 87,456 & 87,461 & 16.04 & $-6,395$ \\
\hline & & EIM & 33,938 & 27,701 & 7.38 & 87,443 & 87,448 & 16.01 & $-6,237$ \\
\hline \multirow{6}{*}{ Q3 } & \multirow{2}{*}{ July } & BAU & 34,101 & 30,588 & 11.92 & 97,736 & 97,739 & 21.02 & $-3,513$ \\
\hline & & EIM & 33,920 & 30,588 & 11.73 & 97,728 & 97,731 & 21.05 & $-3,331$ \\
\hline & \multirow{2}{*}{ August } & BAU & 32,699 & 29,972 & 12.99 & 96,098 & 96,104 & 21.50 & $-2,727$ \\
\hline & & EIM & 32,635 & 29,972 & 13.20 & 96,096 & 96,102 & 21.59 & $-2,663$ \\
\hline & \multirow{2}{*}{ September } & BAU & 29,776 & 27,067 & 12.46 & 85,666 & 85,671 & 20.50 & $-2,709$ \\
\hline & & EIM & 29,637 & 27,067 & 12.52 & 85,656 & 85,663 & 20.60 & $-2,570$ \\
\hline \multirow{6}{*}{ Q4 } & \multirow{2}{*}{ October } & BAU & 30,549 & 27,528 & 10.93 & 82,611 & 82,611 & 19.07 & $-3,021$ \\
\hline & & EIM & 30,385 & 27,528 & 10.96 & 82,603 & 82,608 & 19.17 & $-2,857$ \\
\hline & \multirow{2}{*}{ November } & BAU & 32,940 & 29,190 & 9.11 & 81,490 & 81,494 & 16.40 & $-3,750$ \\
\hline & & EIM & 32,652 & 29,190 & 8.76 & 81,464 & 81,469 & 16.43 & $-3,462$ \\
\hline & \multirow{2}{*}{ December } & BAU & 36,162 & 32,780 & 9.90 & 88,548 & 88,552 & 17.69 & $-3,382$ \\
\hline & & EIM & 35,961 & 32,780 & 9.75 & 88,544 & 88,549 & 17.74 & $-3,181$ \\
\hline \multirow{2}{*}{ Total } & & BAU & 401,000 & 348,694 & 9.39 & $1,024,483$ & $1,024,548$ & 16.92 & $-52,306$ \\
\hline & & EIM & 398,773 & 348,694 & 9.23 & $1,024,334$ & $1,024,409$ & 16.97 & $-50,079$ \\
\hline
\end{tabular}




\subsubsection{NWPP EIM w/o PAC Case (Case 1.86H)}

In this sensitivity case, it is assumed that PAC is not a member of the NWPP EIM. The BAU scenario is the same as the BAU scenario for the Base Case except that the loads and resources of PAC are not included in the values reported for the NWPP but rather are included in the values reported for the "Rest of WECC" so that the results from the BAU scenario can be compared with the results from the EIM scenario. In the EIM scenario, PAC is required to maintain the net exchange schedules during the HA period like the other WECC BAs that are not members of the NWPP.

The flexibility within the smaller NWPP EIM is reduced relative to that used in the Base Case because of the sizeable amount of generation capacity within the PAC BA. This reduction in the amount of generation capacity increases the amount of energy associated with the hydro violations within the NWPP, which no longer includes any hydro violations within the PAC BA, by more than $60 \%$ compared with results from the Base Case, which include hydro violations within the PAC BA. Also, for the same reason but to a lesser degree, the amount of energy associated with the reserve shortfalls for all the BAs in the WECC increased relative to the Base Case. These outcomes can be observed by comparing the hydro violation values reported in Table 4-31 and the total reserve shortfall values reported in Table 4-32 with the comparable values for the Base Case reported in Table 4-3 and Table 4-4, respectively.

The generation costs for the NWPP cannot be directly compared with the generation costs for the Base Case. This is because generation costs for PAC are included in the results for the Base Case but excluded from the results for this sensitivity case. However, there was only a modest change in the total generation costs for the WECC, which can be observed by comparing the generation costs reported in Table 4-30 with the comparable values for the Base Case reported in Table 4-2. While not reported in a table, the percentages of the EIM benefit for the other BAs within the NWPP did not change much from those for the Base Case once the savings accounted for by PAC in the Base Case were considered.

As reported in Table 4-30, the annual total savings between the BAU scenario and the EIM scenario within this smaller NWPP footprint are \$37.4 and \$63.2 million, which correspond to the prices for excess hydro generation being $\$ 42.00 / \mathrm{MWh}$ and $\$ 57.50 / \mathrm{MWh}$, respectively. These annual total savings are greater than the annual total savings received under the Base Case, which are \$41.2 million and \$70.7 million, respectively. 
Table 4-30. Summary of Generation Cost and Savings for the NWPP and WECC in Case 1.86H

\begin{tabular}{|c|c|c|c|c|c|c|c|c|}
\hline & & \multirow[b]{2}{*}{ Scenario } & \multicolumn{3}{|c|}{ Total Generation Cost $(\mathrm{k} \$)$} & \multicolumn{3}{|c|}{ Gen. Cost Difference (k\$) } \\
\hline & & & NWPP & $\begin{array}{l}\text { Rest of } \\
\text { WECC } \\
\end{array}$ & $\begin{array}{c}\text { WECC } \\
\text { Total } \\
\end{array}$ & NWPP & $\begin{array}{l}\text { Rest of } \\
\text { WECC }\end{array}$ & $\begin{array}{c}\text { WECC } \\
\text { Total } \\
\end{array}$ \\
\hline \multirow{6}{*}{ Q1 } & \multirow{2}{*}{ January } & BAU & 151,845 & $1,082,630$ & $1,234,475$ & & & \\
\hline & & EIM & 155,585 & $1,083,408$ & $1,238,993$ & $-3,740$ & -778 & $-4,518$ \\
\hline & \multirow{2}{*}{ February } & BAU & 137,960 & 913,828 & $1,051,788$ & & & \\
\hline & & EIM & 144,385 & 914,536 & $1,058,921$ & $-6,425$ & -708 & $-7,133$ \\
\hline & \multirow{2}{*}{ March } & BAU & 147,509 & $1,009,576$ & $1,157,085$ & & & \\
\hline & & EIM & 154,660 & $1,010,758$ & $1,165,418$ & $-7,151$ & $-1,182$ & $-8,333$ \\
\hline \multirow{6}{*}{ Q2 } & \multirow{2}{*}{ April } & BAU & 120,394 & 868,840 & 989,234 & & & \\
\hline & & EIM & 119,024 & 869,932 & 988,956 & 1,370 & $-1,092$ & 278 \\
\hline & \multirow{2}{*}{ May } & BAU & 137,380 & $1,007,627$ & $1,145,007$ & & & \\
\hline & & EIM & 128,811 & $1,008,627$ & $1,137,438$ & 8,569 & $-1,000$ & 7,569 \\
\hline & \multirow{2}{*}{ June } & BAU & 129,204 & $1,273,700$ & $1,402,904$ & & & \\
\hline & & EIM & 127,398 & $1,274,896$ & $1,402,294$ & 1,806 & $-1,196$ & 610 \\
\hline \multirow{6}{*}{ Q3 } & \multirow{2}{*}{ July } & BAU & 228,129 & $1,826,708$ & $2,054,837$ & & & \\
\hline & & EIM & 231,652 & $1,827,132$ & $2,058,784$ & $-3,524$ & -424 & $-3,948$ \\
\hline & \multirow{2}{*}{ August } & BAU & 234,943 & $1,831,115$ & $2,066,059$ & & & \\
\hline & & EIM & 239,936 & $1,831,464$ & $2,071,400$ & $-4,993$ & -349 & $-5,342$ \\
\hline & \multirow{2}{*}{ September } & BAU & 215,027 & $1,541,647$ & $1,756,674$ & & & \\
\hline & & EIM & 220,164 & $1,541,921$ & $1,762,085$ & $-5,137$ & -274 & $-5,411$ \\
\hline \multirow{6}{*}{ Q4 } & \multirow{2}{*}{ October } & BAU & 192,998 & $1,382,046$ & $1,575,044$ & & & \\
\hline & & EIM & 198,385 & $1,382,383$ & $1,580,768$ & $-5,387$ & -337 & $-5,724$ \\
\hline & \multirow{2}{*}{ November } & BAU & 181,559 & $1,154,627$ & $1,336,187$ & & & \\
\hline & & EIM & 186,091 & $1,155,326$ & $1,341,417$ & $-4,532$ & -699 & $-5,230$ \\
\hline & \multirow{2}{*}{ December } & BAU & 214,983 & $1,351,265$ & $1,566,248$ & & & \\
\hline & & EIM & 218,289 & 1,352,191 & $1,570,480$ & $-3,306$ & -925 & $-4,232$ \\
\hline \multirow[t]{8}{*}{ Total } & & BAU & $2,091,931$ & $15,243,611$ & $17,335,542$ & & & \\
\hline & & EIM & $2,124,381$ & $15,252,574$ & $17,376,955$ & & & \\
\hline & & \multirow{2}{*}{\multicolumn{4}{|c|}{ Generation Cost Savings }} & NWPP & $\begin{array}{l}\text { Rest of } \\
\text { WECC }\end{array}$ & $\begin{array}{l}\text { WECC } \\
\text { Total }\end{array}$ \\
\hline & & & & & & $-32,450$ & $-8,963$ & $-41,413$ \\
\hline & & \multicolumn{4}{|c|}{ Min Excess Hydro Savings (@\$42.00/MWh) } & 69,874 & -5 & 69,870 \\
\hline & & \multicolumn{4}{|c|}{ Max Excess Hydro Savings (@\$57.50/MWh) } & 95,661 & -7 & 95,655 \\
\hline & & \multicolumn{4}{|c|}{ Min Total Savings (k\$) } & 37,424 & $-8,968$ & 28,456 \\
\hline & & \multicolumn{4}{|c|}{ Max Total Savings (k\$) } & 63,211 & $-8,970$ & 54,241 \\
\hline
\end{tabular}


Table 4-31. Hydro Generation and Energy Constraints Violation in Case 1.86H

\begin{tabular}{|c|c|c|c|c|c|c|c|}
\hline & & \multirow{2}{*}{ Scenarios } & \multicolumn{3}{|c|}{ Hydro Violation (GWh) } & \multicolumn{2}{|c|}{ Total HTC Hydro (GWh) } \\
\hline & & & NWPP & $\begin{array}{l}\text { Rest of } \\
\text { WECC }\end{array}$ & $\begin{array}{c}\text { WECC } \\
\text { Total }\end{array}$ & NWPP & WECC Total \\
\hline \multirow{6}{*}{ Q1 } & \multirow{2}{*}{ January } & BAU & 178 & 16 & 194 & 12,033 & 13,590 \\
\hline & & EIM & 35 & 16 & 52 & 11919 & 13475 \\
\hline & \multirow{2}{*}{ February } & BAU & 227 & 15 & 243 & 10,368 & 11,970 \\
\hline & & EIM & 66 & 16 & 82 & 10,216 & 11,819 \\
\hline & \multirow{2}{*}{ March } & BAU & 270 & 24 & 294 & 9,519 & 11,073 \\
\hline & & EIM & 91 & 24 & 115 & 9,344 & 10,898 \\
\hline \multirow{6}{*}{ Q2 } & \multirow{2}{*}{ April } & BAU & 108 & 14 & 122 & 10,524 & 12,269 \\
\hline & & EIM & 33 & 14 & 48 & 10,603 & 12,349 \\
\hline & \multirow{2}{*}{ May } & BAU & 91 & 11 & 102 & 9,726 & 12,036 \\
\hline & & EIM & 8 & 11 & 19 & 10,008 & 12,318 \\
\hline & \multirow{2}{*}{ June } & BAU & 117 & 20 & 136 & 10,695 & 12,829 \\
\hline & & EIM & 20 & 18 & 38 & 10,724 & 12,857 \\
\hline \multirow{6}{*}{ Q3 } & \multirow{2}{*}{ July } & BAU & 158 & 16 & 175 & 8,554 & 10,565 \\
\hline & & EIM & 16 & 16 & 33 & 8,420 & 10,431 \\
\hline & \multirow{2}{*}{ August } & BAU & 213 & 11 & 223 & 8,338 & 10,025 \\
\hline & & EIM & 72 & 11 & 83 & 8,202 & 9,888 \\
\hline & \multirow{2}{*}{ September } & BAU & 209 & 13 & 222 & 7,371 & 8,801 \\
\hline & & EIM & 75 & 13 & 88 & 7,239 & 8,669 \\
\hline \multirow{6}{*}{ Q4 } & \multirow{2}{*}{ October } & BAU & 255 & 12 & 267 & 7,832 & 9,055 \\
\hline & & EIM & 96 & 13 & 109 & 7,679 & 8,904 \\
\hline & \multirow{2}{*}{ November } & BAU & 234 & 9 & 243 & 8,723 & 9,924 \\
\hline & & EIM & 68 & 9 & 77 & 8,570 & 9,771 \\
\hline & \multirow{2}{*}{ December } & BAU & 212 & 7 & 219 & 10,750 & 12,222 \\
\hline & & EIM & 27 & 7 & 34 & 10,597 & 12,068 \\
\hline \multirow{2}{*}{ Total } & & BAU & 2,272 & 168 & 2,440 & 114,433 & 134,357 \\
\hline & & EIM & 608 & 168 & 776 & 113,522 & 133,446 \\
\hline
\end{tabular}


Table 4-32. WECC Dump and Unserved Energy, Reserve Shortfall and Exchange Violations in Case $1.86 \mathrm{H}$

\begin{tabular}{|c|c|c|c|c|c|c|c|c|c|c|c|}
\hline & & \multirow[t]{2}{*}{ Scenarios } & \multirow[t]{2}{*}{$\begin{array}{c}\text { Dump } \\
\text { GWh }\end{array}$} & \multirow[t]{2}{*}{$\begin{array}{c}\text { USE } \\
\text { (unserved } \\
\text { GWh) }\end{array}$} & \multicolumn{5}{|c|}{ Total BAs Reserve Shortfall (GWh) } & \multicolumn{2}{|c|}{$\begin{array}{c}\text { Total BAs } \\
\text { Exchange } \\
\text { Violation } \\
\text { (GWh) }\end{array}$} \\
\hline & & & & & Spin & $\begin{array}{l}\text { Reg. } \\
\text { up }\end{array}$ & $\begin{array}{l}\text { Reg. } \\
\text { down }\end{array}$ & $\begin{array}{l}\text { Non } \\
\text { spin }\end{array}$ & Total & Up & Dn \\
\hline \multirow{6}{*}{ Q1 } & \multirow{2}{*}{ January } & BAU & 0.3 & 6.7 & 13.3 & 3.7 & 0.2 & 4.0 & 21 & 0.4 & 0.0 \\
\hline & & EIM & 0.0 & 6.7 & 20.0 & 5.1 & 0.1 & 7.8 & 33 & 0.4 & 0.0 \\
\hline & \multirow{2}{*}{ February } & BAU & 0.6 & 8.4 & 17.4 & 4.3 & 0.4 & 6.3 & 28 & 0.4 & 0.0 \\
\hline & & EIM & 0.4 & 8.3 & 25.4 & 6.7 & 0.3 & 9.6 & 42 & 0.3 & 0.0 \\
\hline & \multirow{2}{*}{ March } & BAU & 0.4 & 7.3 & 15.2 & 3.5 & 0.2 & 4.6 & 23 & 0.6 & 0.0 \\
\hline & & EIM & 0.5 & 7.3 & 27.5 & 7.3 & 0.4 & 11.5 & 47 & 0.5 & 0.0 \\
\hline \multirow{6}{*}{ Q2 } & \multirow{2}{*}{ April } & BAU & 0.4 & 8.3 & 12.5 & 3.6 & 0.4 & 3.4 & 20 & 0.8 & 0.0 \\
\hline & & EIM & 0.2 & 8.3 & 11.6 & 2.5 & 0.4 & 3.4 & 18 & 0.7 & 0.0 \\
\hline & \multirow{2}{*}{ May } & BAU & 0.5 & 9.5 & 11.8 & 2.7 & 0.3 & 2.0 & 17 & 1.0 & 0.0 \\
\hline & & EIM & 0.2 & 9.4 & 10.0 & 1.4 & 0.2 & 1.5 & 13 & 0.8 & 0.0 \\
\hline & \multirow{2}{*}{ June } & BAU & 0.2 & 5.2 & 17.7 & 3.8 & 0.1 & 4.7 & 26 & 1.0 & 0.0 \\
\hline & & EIM & 0.1 & 5.1 & 18.6 & 2.7 & 0.1 & 3.5 & 25 & 0.8 & 0.1 \\
\hline \multirow{6}{*}{ Q3 } & \multirow{2}{*}{ July } & BAU & 0.2 & 3.2 & 23.4 & 3.9 & 0.1 & 4.7 & 32 & 1.6 & 0.0 \\
\hline & & EIM & 0.0 & 3.2 & 21.0 & 2.6 & 0.3 & 4.0 & 28 & 1.1 & 0.2 \\
\hline & \multirow{2}{*}{ August } & BAU & 1.2 & 6.8 & 18.1 & 4.0 & 0.6 & 6.4 & 29 & 1.1 & 0.1 \\
\hline & & EIM & 0.0 & 6.8 & 22.1 & 5.4 & 0.3 & 8.3 & 36 & 0.5 & 0.2 \\
\hline & \multirow{2}{*}{ September } & BAU & 2.0 & 7.1 & 12.2 & 2.2 & 0.7 & 3.9 & 19 & 0.8 & 0.0 \\
\hline & & EIM & 0.0 & 7.1 & 17.1 & 4.3 & 0.5 & 5.1 & 27 & 0.6 & 0.1 \\
\hline \multirow{6}{*}{ Q4 } & \multirow{2}{*}{ October } & BAU & 3.6 & 4.2 & 15.0 & 3.0 & 1.0 & 6.6 & 26 & 1.3 & 0.0 \\
\hline & & EIM & 0.0 & 4.2 & 14.3 & 2.9 & 0.4 & 5.8 & 23 & 0.6 & 0.0 \\
\hline & \multirow{2}{*}{ November } & BAU & 1.8 & 5.7 & 16.5 & 4.5 & 0.6 & 7.6 & 29 & 1.0 & 0.0 \\
\hline & & EIM & 0.5 & 5.7 & 17.2 & 4.7 & 0.2 & 7.1 & 29 & 0.6 & 0.1 \\
\hline & \multirow{2}{*}{ December } & BAU & 0.5 & 4.7 & 19.7 & 4.7 & 0.3 & 7.5 & 32 & 0.8 & 0.0 \\
\hline & & EIM & 0.0 & 4.7 & 23.1 & 4.8 & 0.2 & 8.6 & 37 & 0.5 & 0.0 \\
\hline \multirow{2}{*}{ Total } & & BAU & 12 & 77 & 193 & 44 & 5 & 62 & 303 & 10.7 & 0.1 \\
\hline & & EIM & 2 & 77 & 228 & 50 & 3 & 76 & 358 & 7.5 & 0.8 \\
\hline
\end{tabular}


Table 4-33. Generation, Demand, and Average Production Cost for NWPP and WECC, and NWPP Net Interchange in Case $1.86 \mathrm{H}$

\begin{tabular}{|c|c|c|c|c|c|c|c|c|c|}
\hline & & Scenarios & $\begin{array}{c}\text { NWPP } \\
\text { Generation } \\
\text { (GWh) }\end{array}$ & $\begin{array}{l}\text { NWPP } \\
\text { Demand } \\
\text { (GWh) }\end{array}$ & $\begin{array}{l}\text { NWPP } \\
\text { Average } \\
\text { Produc- } \\
\text { tion Cost } \\
\text { (\$/MWh) }\end{array}$ & $\begin{array}{l}\text { WECC } \\
\text { Genera- } \\
\text { tion } \\
\text { (GWh) }\end{array}$ & $\begin{array}{l}\text { WECC } \\
\text { Demand } \\
\text { (GWh) }\end{array}$ & $\begin{array}{l}\text { WECC } \\
\text { Average } \\
\text { Produc- } \\
\text { tion Cost } \\
\text { (\$/MWh) }\end{array}$ & $\begin{array}{l}\text { NWPP } \\
\text { Net } \\
\text { Exchange } \\
\text { (GWh) }\end{array}$ \\
\hline \multirow{6}{*}{ Q1 } & \multirow{2}{*}{ January } & BAU & 30,453 & 25,619 & 5.93 & 86,695 & 86,702 & 14.24 & $-4,835$ \\
\hline & & EIM & 30433 & 25619 & 6.07 & 86,695 & 86,702 & 14.29 & $-4,814$ \\
\hline & \multirow{2}{*}{ February } & BAU & 26,163 & 22,697 & 6.08 & 76,997 & 77,005 & 13.66 & $-3,467$ \\
\hline & & EIM & 26,145 & 22,697 & 6.36 & 76,997 & 77,005 & 13.75 & $-3,448$ \\
\hline & \multirow{2}{*}{ March } & BAU & 25,714 & 22,590 & 6.53 & 80,481 & 80,488 & 14.38 & $-3,123$ \\
\hline & & EIM & 25,693 & 22,590 & 6.85 & 80,481 & 80,488 & 14.48 & $-3,102$ \\
\hline \multirow{6}{*}{ Q2 } & \multirow{2}{*}{ April } & BAU & 26,312 & 20,888 & 5.76 & 77,358 & 77,366 & 12.79 & $-5,424$ \\
\hline & & EIM & 26,287 & 20,888 & 5.70 & 77,358 & 77,366 & 12.78 & $-5,399$ \\
\hline & \multirow{2}{*}{ May } & BAU & 27,799 & 21,149 & 6.50 & 83,346 & 83,355 & 13.74 & $-6,650$ \\
\hline & & EIM & 27,779 & 21,149 & 6.09 & 83,346 & 83,355 & 13.65 & $-6,629$ \\
\hline & \multirow{2}{*}{ June } & BAU & 27,696 & 21,299 & 6.07 & 87,456 & 87,461 & 16.04 & $-6,397$ \\
\hline & & EIM & 27,672 & 21,299 & 5.98 & 87,456 & 87,461 & 16.03 & $-6,373$ \\
\hline \multirow{6}{*}{ Q3 } & \multirow{2}{*}{ July } & BAU & 26,392 & 23,302 & 9.79 & 97,736 & 97,739 & 21.02 & $-3,090$ \\
\hline & & EIM & 26,383 & 23,302 & 9.94 & 97,736 & 97,739 & 21.06 & $-3,081$ \\
\hline & \multirow{2}{*}{ August } & BAU & 24,565 & 22,800 & 10.30 & 96,098 & 96,104 & 21.50 & $-1,764$ \\
\hline & & EIM & 24,558 & 22,800 & 10.52 & 96,097 & 96,104 & 21.55 & $-1,757$ \\
\hline & \multirow{2}{*}{ September } & BAU & 22,360 & 20,856 & 10.31 & 85,666 & 85,671 & 20.50 & $-1,504$ \\
\hline & & EIM & 22,354 & 20,856 & 10.56 & 85,664 & 85,671 & 20.57 & $-1,498$ \\
\hline \multirow{6}{*}{ Q4 } & \multirow{2}{*}{ October } & BAU & 23,246 & 21,578 & 8.94 & 82,611 & 82,611 & 19.07 & $-1,668$ \\
\hline & & EIM & 23,237 & 21,578 & 9.19 & 82,607 & 82,611 & 19.14 & $-1,659$ \\
\hline & \multirow{2}{*}{ November } & BAU & 25,874 & 23,103 & 7.86 & 81,490 & 81,494 & 16.40 & $-2,770$ \\
\hline & & EIM & 25,863 & 23,103 & 8.05 & 81,489 & 81,494 & 16.46 & $-2,760$ \\
\hline & \multirow{2}{*}{ December } & BAU & 28,301 & 25,951 & 8.28 & 88,548 & 88,552 & 17.69 & $-2,350$ \\
\hline & & EIM & 28,291 & 25,951 & 8.41 & 88,548 & 88,552 & 17.74 & $-2,340$ \\
\hline \multirow{2}{*}{ Total } & & BAU & 314,875 & 271,833 & 7.70 & $1,024,483$ & $1,024,548$ & 16.92 & $-43,042$ \\
\hline & & EIM & 314,696 & 271,833 & 7.82 & $1,024,473$ & $1,024,548$ & 16.96 & $-42,862$ \\
\hline
\end{tabular}




\subsubsection{6\% Held-back Case (Case 1.86I)}

This sensitivity case is similar to Case 1.86C, but the percentage of available hydro energy from flexible hydro plants (modeled as HTC hydro plants) and the maximum available capacities from thermal plants that are held back in the DA and HA dispatch is increased from 3\% to 6\%. Similar observations can be made from the results of this sensitivity case as those discussed for Case 1.86C, but the magnitude of the differences in the same direction are greater. These outcomes can be observed by comparing the results for this sensitivity case reported in Table 4-34 through Table 4-37 with comparable results reported in Table 4-10 through Table 4-13 and Table 4-2 through Table 4-5.

As reported in Table 4-34, the annual total savings between the BAU scenario and the EIM scenario within the NWPP footprint are \$113.4 million and \$124.9 million, which correspond to the prices for excess hydro generation being $\$ 42.00 / \mathrm{MWh}$ and $\$ 57.50 / \mathrm{MWh}$, respectively. These annual total savings are greater than the annual total savings received under Case 1.86C, which are $\$ 71.2$ million and $\$ 90.3$ million, respectively, and the annual total savings received under the Base Case, which are $\$ 41.2$ million and $\$ 70.7$ million, respectively. 
Table 4-34. Summary of Generation Cost and Savings for the NWPP and WECC in Case 1.86I

\begin{tabular}{|c|c|c|c|c|c|c|c|c|}
\hline & & \multirow[b]{2}{*}{ Scenario } & \multicolumn{3}{|c|}{ Total Generation Cost $(\mathrm{k} \$)$} & \multicolumn{3}{|c|}{ Gen. cost difference (k\$) } \\
\hline & & & NWPP & $\begin{array}{l}\text { Rest of } \\
\text { WECC }\end{array}$ & $\begin{array}{c}\text { WECC } \\
\text { Total }\end{array}$ & NWPP & $\begin{array}{l}\text { Rest of } \\
\text { WECC }\end{array}$ & $\begin{array}{c}\text { WECC } \\
\text { Total }\end{array}$ \\
\hline \multirow{6}{*}{ Q1 } & \multirow{2}{*}{ January } & BAU & 232,859 & $1,039,383$ & $1,272,242$ & & & \\
\hline & & EIM & 226,442 & $1,040,320$ & $1,266,762$ & 6,417 & -937 & 5,479 \\
\hline & \multirow{2}{*}{ February } & BAU & 211,529 & 873,464 & $1,084,993$ & & & \\
\hline & & EIM & 207,794 & 874,315 & $1,082,109$ & 3,735 & -851 & 2,884 \\
\hline & \multirow{2}{*}{ March } & BAU & 224,220 & 962,644 & $1,186,863$ & & & \\
\hline & & EIM & 221,819 & 963,588 & $1,185,407$ & 2,401 & -945 & 1,456 \\
\hline \multirow{6}{*}{ Q2 } & \multirow{2}{*}{ April } & BAU & 181,811 & 830,079 & $1,011,890$ & & & \\
\hline & & EIM & 175,185 & 831,075 & $1,006,260$ & 6,626 & -996 & 5,630 \\
\hline & \multirow{2}{*}{ May } & BAU & 203,317 & 960,759 & $1,164,077$ & & & \\
\hline & & EIM & 192,807 & 961,852 & $1,154,659$ & 10,510 & $-1,092$ & 9,418 \\
\hline & \multirow{2}{*}{ June } & BAU & 203,869 & $1,219,697$ & $1,423,566$ & & & \\
\hline & & EIM & 194,422 & $1,221,049$ & $1,415,471$ & 9,446 & $-1,351$ & 8,095 \\
\hline \multirow{6}{*}{ Q3 } & \multirow{2}{*}{ July } & BAU & 353,806 & $1,714,508$ & $2,068,314$ & & & \\
\hline & & EIM & 346,618 & $1,715,150$ & $2,061,768$ & 7,188 & -642 & 6,546 \\
\hline & \multirow{2}{*}{ August } & BAU & 382,704 & $1,700,127$ & $2,082,832$ & & & \\
\hline & & EIM & 376,803 & $1,700,611$ & $2,077,414$ & 5,901 & -483 & 5,418 \\
\hline & \multirow{2}{*}{ September } & BAU & 329,292 & $1,446,237$ & $1,775,529$ & & & \\
\hline & & EIM & 325,043 & $1,446,703$ & $1,771,746$ & 4,249 & -467 & 3,783 \\
\hline \multirow{6}{*}{ Q4 } & \multirow{2}{*}{ October } & BAU & 294,635 & $1,304,555$ & $1,599,190$ & & & \\
\hline & & EIM & 289,516 & $1,304,973$ & $1,594,488$ & 5,120 & -418 & 4,702 \\
\hline & \multirow{2}{*}{ November } & BAU & 259,415 & $1,108,159$ & $1,367,574$ & & & \\
\hline & & EIM & 252,089 & $1,108,823$ & $1,360,912$ & 7,326 & -664 & 6,662 \\
\hline & \multirow{2}{*}{ December } & BAU & 317,832 & $1,284,564$ & $1,602,396$ & & & \\
\hline & & EIM & 304,596 & $1,285,045$ & $1,589,640$ & 13,236 & -481 & 12,756 \\
\hline \multirow[t]{8}{*}{ Total } & & BAU & $3,195,289$ & $14,444,174$ & $17,639,464$ & & & \\
\hline & & EIM & 3,113,135 & $14,453,501$ & $17,566,636$ & & & \\
\hline & & \multirow{2}{*}{\multicolumn{4}{|c|}{ Generation Cost Savings }} & NWPP & $\begin{array}{l}\text { Rest of } \\
\text { WECC }\end{array}$ & $\begin{array}{c}\text { WECC } \\
\text { Total }\end{array}$ \\
\hline & & & & & & 82,155 & $-9,327$ & 72,828 \\
\hline & & \multirow{2}{*}{\multicolumn{4}{|c|}{$\begin{array}{l}\text { Min Excess Hydro Savings (@\$42.0/MWh) } \\
\text { Max Excess Hydro Savings (@\$57.50/MWh) }\end{array}$}} & 31,217 & 111 & 31,328 \\
\hline & & & & & & 42,737 & 153 & 42,890 \\
\hline & & \multicolumn{4}{|c|}{ Min Total Savings (k\$) } & 113,372 & $-9,216$ & 104,156 \\
\hline & & \multicolumn{4}{|c|}{ Max Total Savings (k\$) } & 124,892 & $-9,178$ & 115,718 \\
\hline
\end{tabular}


Table 4-35. Hydro Generation and Energy Constraints Violation in Case 1.86I

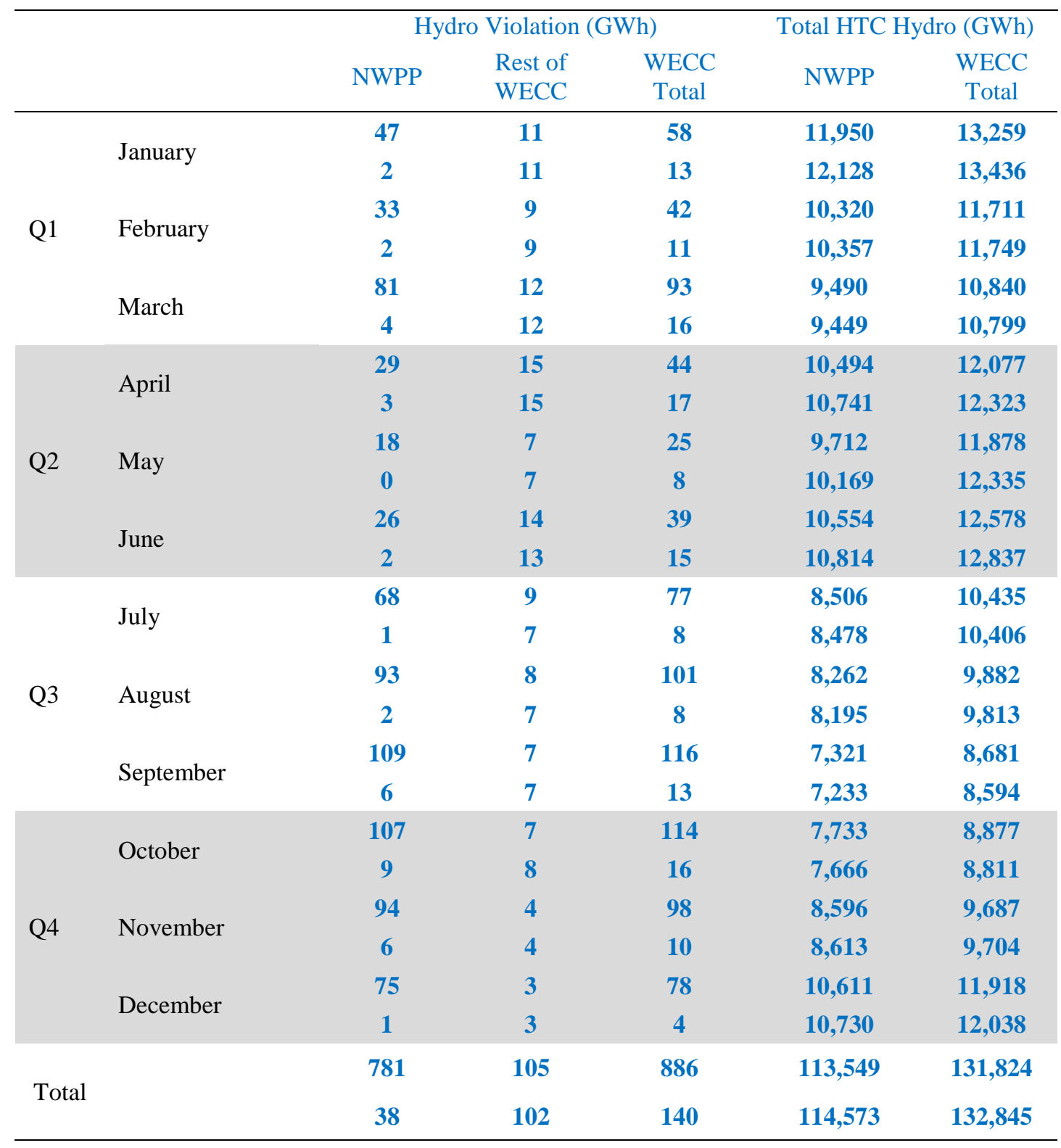


Table 4-36. WECC Dump and Unserved Energy, Reserve Shortfall and Exchange Violations in Case $1.86 \mathrm{I}$

\begin{tabular}{|c|c|c|c|c|c|c|c|c|c|c|c|}
\hline & & \multirow[t]{2}{*}{ Scenario } & \multirow[t]{2}{*}{$\begin{array}{l}\text { Dump } \\
\text { GWh }\end{array}$} & \multirow[t]{2}{*}{$\begin{array}{c}\text { USE } \\
\text { (Unserved } \\
\text { GWh) }\end{array}$} & \multicolumn{5}{|c|}{$\begin{array}{c}\text { Total BAs Reserve Shortfall } \\
\text { (GWh) }\end{array}$} & \multicolumn{2}{|c|}{$\begin{array}{c}\text { Total } \\
\text { BAs } \\
\text { Exchange } \\
\text { Violation } \\
\text { (GWh) }\end{array}$} \\
\hline & & & & & Spin & $\begin{array}{l}\text { Reg. } \\
\text { up }\end{array}$ & $\begin{array}{l}\text { Reg. } \\
\text { down }\end{array}$ & $\begin{array}{l}\text { Non } \\
\text { spin }\end{array}$ & Total & $\mathrm{Up}$ & Dn \\
\hline \multirow{6}{*}{ Q1 } & \multirow{2}{*}{ January } & BAU & 0.4 & 0.5 & 3.1 & 0.9 & 1.0 & 0.6 & 5.63 & 0.2 & 0.0 \\
\hline & & EIM & 0.1 & 0.5 & 3.5 & 1.1 & 0.8 & 0.5 & 5.81 & 0.2 & 0.0 \\
\hline & \multirow{2}{*}{ February } & BAU & 0.6 & 0.5 & 4.5 & 0.9 & 1.1 & 0.8 & 7.25 & 0.1 & 0.0 \\
\hline & & EIM & 0.1 & 0.5 & 4.0 & 0.8 & 1.0 & 0.4 & 6.12 & 0.1 & 0.0 \\
\hline & \multirow{2}{*}{ March } & BAU & 0.5 & 0.3 & 3.7 & 0.5 & 0.4 & 0.7 & 5.24 & 0.2 & 0.0 \\
\hline & & EIM & 0.0 & 0.3 & 3.8 & 0.6 & 0.4 & 0.7 & 5.44 & 0.2 & 0.0 \\
\hline \multirow{6}{*}{ Q2 } & \multirow{2}{*}{ April } & BAU & 0.7 & 1.0 & 3.8 & 0.8 & 0.8 & 0.7 & 6.12 & 0.3 & 0.0 \\
\hline & & EIM & 0.1 & 1.0 & 3.3 & 0.6 & 0.6 & 0.3 & 4.7 & 0.3 & 0.0 \\
\hline & \multirow{2}{*}{ May } & BAU & 0.7 & 1.0 & 3.0 & 0.5 & 0.6 & 0.5 & 4.50 & 0.2 & 0.0 \\
\hline & & EIM & 0.1 & 1.0 & 2.5 & 0.3 & 0.2 & 0.2 & 3.2 & 0.2 & 0.0 \\
\hline & \multirow{2}{*}{ June } & BAU & 0.3 & 0.5 & 6.2 & 0.7 & 0.2 & 1.3 & 8.33 & 0.8 & 0.2 \\
\hline & & EIM & 0.1 & 0.5 & 5.1 & 0.4 & 0.1 & 0.3 & 5.9 & 0.8 & 0.3 \\
\hline \multirow{6}{*}{ Q3 } & \multirow{2}{*}{ July } & BAU & 0.3 & 0.4 & 8.2 & 0.9 & 0.2 & 1.9 & 11.20 & 0.7 & 0.0 \\
\hline & & EIM & 0.0 & 0.4 & 5.9 & 0.2 & 0.4 & 0.2 & 6.68 & 0.5 & 0.1 \\
\hline & \multirow{2}{*}{ August } & BAU & 1.8 & 0.3 & 6.1 & 1.2 & 0.9 & 2.6 & 10.86 & 0.5 & 0.0 \\
\hline & & EIM & 0.0 & 0.3 & 3.6 & 0.2 & 0.4 & 0.4 & 4.64 & 0.3 & 0.1 \\
\hline & \multirow{2}{*}{ September } & BAU & 2.3 & 0.6 & 4.8 & 0.7 & 0.8 & 1.5 & 7.86 & 0.5 & 0.0 \\
\hline & & EIM & 0.0 & 0.6 & 4.4 & 0.6 & 0.6 & 1.0 & 6.56 & 0.4 & 0.1 \\
\hline \multirow{6}{*}{ Q4 } & \multirow{2}{*}{ October } & BAU & 3.9 & 0.2 & 3.7 & 0.6 & 1.2 & 1.1 & 6.61 & 0.7 & 0.1 \\
\hline & & EIM & 0.0 & 0.2 & 3.9 & 0.6 & 0.4 & 1.3 & 6.12 & 0.4 & 1.5 \\
\hline & \multirow{2}{*}{ November } & BAU & 2.0 & 0.2 & 4.1 & 0.9 & 0.8 & 2.1 & 7.97 & 0.5 & 0.3 \\
\hline & & EIM & 0.1 & 0.2 & 2.9 & 0.5 & 0.3 & 0.7 & 4.39 & 0.4 & 5.5 \\
\hline & \multirow{2}{*}{ December } & BAU & 0.4 & 0.3 & 4.5 & 0.9 & 0.8 & 1.8 & 8.07 & 0.4 & 0.1 \\
\hline & & EIM & 0.0 & 0.3 & 3.8 & 0.6 & 0.7 & 0.5 & 5.55 & 0.3 & 2.2 \\
\hline \multirow{2}{*}{ Total } & & BAU & 14 & 6 & 56 & 10 & 9 & 16 & 90 & 5.1 & 0.8 \\
\hline & & EIM & 1 & 6 & 47 & 6 & 6 & 6 & 65 & 4.2 & 9.8 \\
\hline
\end{tabular}


Table 4-37. Generation, Demand, and Average Production Cost for NWPP and WECC, and NWPP Net Interchange in Case 1.86I

\begin{tabular}{|c|c|c|c|c|c|c|c|c|c|}
\hline & & Scenario & $\begin{array}{l}\text { NWPP } \\
\text { Generation } \\
\text { (GWh) }\end{array}$ & $\begin{array}{l}\text { NWPP } \\
\text { Demand } \\
\text { (GWh) }\end{array}$ & $\begin{array}{c}\text { NWPP } \\
\text { Average } \\
\text { Production } \\
\text { Cost } \\
\text { (\$/MWh) }\end{array}$ & $\begin{array}{l}\text { WECC } \\
\text { Generation } \\
\text { (GWh) }\end{array}$ & $\begin{array}{l}\text { WECC } \\
\text { Demand } \\
\text { (GWh) }\end{array}$ & $\begin{array}{c}\text { WECC } \\
\text { Average } \\
\text { Production } \\
\text { Cost } \\
(\$ / \mathrm{MWh})\end{array}$ & $\begin{array}{c}\text { NWPP Net } \\
\text { Exchange } \\
\text { (GWh) }\end{array}$ \\
\hline \multirow{6}{*}{ Q1 } & \multirow{2}{*}{ January } & BAU & 37,844 & 32,368 & 7.19 & 86,611 & 86,611 & 14.69 & $-5,477$ \\
\hline & & EIM & 37,809 & 32,368 & 7.00 & 86,610 & 86,611 & 14.63 & $-5,441$ \\
\hline & \multirow{2}{*}{ February } & BAU & 32,639 & 28,897 & 7.32 & 76,946 & 76,946 & 14.10 & $-3,742$ \\
\hline & & EIM & 32,604 & 28,897 & 7.19 & 76,946 & 76,946 & 14.06 & $-3,708$ \\
\hline & \multirow{2}{*}{ March } & BAU & 32,234 & 28,739 & 7.80 & 80,391 & 80,391 & 14.76 & $-3,494$ \\
\hline & & EIM & 32,201 & 28,739 & 7.72 & 80,391 & 80,391 & 14.75 & $-3,462$ \\
\hline \multirow{6}{*}{ Q2 } & \multirow{2}{*}{ April } & BAU & 31,877 & 26,702 & 6.81 & 77,305 & 77,305 & 13.09 & $-5,175$ \\
\hline & & EIM & 31,839 & 26,702 & 6.56 & 77,304 & 77,305 & 13.02 & $-5,137$ \\
\hline & \multirow{2}{*}{ May } & BAU & 33,576 & 27,162 & 7.49 & 83,251 & 83,251 & 13.98 & $-6,414$ \\
\hline & & EIM & 33,540 & 27,162 & 7.10 & 83,251 & 83,251 & 13.87 & $-6,379$ \\
\hline & \multirow{2}{*}{ June } & BAU & 33,557 & 27,701 & 7.36 & 87,386 & 87,387 & 16.29 & $-5,856$ \\
\hline & & EIM & 33,523 & 27,701 & 7.02 & 87,386 & 87,387 & 16.20 & $-5,822$ \\
\hline \multirow{6}{*}{ Q3 } & \multirow{2}{*}{ July } & BAU & 33,704 & 30,588 & 11.57 & 97,719 & 97,719 & 21.17 & $-3,116$ \\
\hline & & EIM & 33,692 & 30,588 & 11.33 & 97,719 & 97,719 & 21.10 & $-3,104$ \\
\hline & \multirow{2}{*}{ August } & BAU & 32,347 & 29,972 & 12.77 & 96,114 & 96,113 & 21.67 & $-2,375$ \\
\hline & & EIM & 32,337 & 29,972 & 12.57 & 96,112 & 96,113 & 21.61 & $-2,365$ \\
\hline & \multirow{2}{*}{ September } & BAU & 29,378 & 27,067 & 12.17 & 85,655 & 85,653 & 20.73 & $-2,311$ \\
\hline & & EIM & 29,366 & 27,067 & 12.01 & 85,652 & 85,653 & 20.69 & $-2,298$ \\
\hline \multirow{6}{*}{ Q4 } & \multirow{2}{*}{ October } & BAU & 30,092 & 27,528 & 10.70 & 82,591 & 82,587 & 19.36 & $-2,564$ \\
\hline & & EIM & 30,077 & 27,528 & 10.52 & 82,587 & 82,587 & 19.31 & $-2,549$ \\
\hline & \multirow{2}{*}{ November } & BAU & 32,431 & 29,190 & 8.89 & 81,443 & 81,441 & 16.79 & $-3,241$ \\
\hline & & EIM & 32,404 & 29,190 & 8.64 & 81,441 & 81,441 & 16.71 & $-3,214$ \\
\hline & \multirow{2}{*}{ December } & BAU & 35,579 & 32,780 & 9.70 & 88,516 & 88,515 & 18.10 & $-2,799$ \\
\hline & & EIM & 35,564 & 32,780 & 9.29 & 88,515 & 88,515 & 17.96 & $-2,784$ \\
\hline \multirow{2}{*}{ Total } & & BAU & 395,257 & 348,694 & 9.16 & $1,023,928$ & $1,023,920$ & 17.23 & $-46,563$ \\
\hline & & EIM & 394,956 & 348,694 & 8.93 & $1,023,914$ & $1,023,920$ & 17.16 & $-46,262$ \\
\hline
\end{tabular}




\subsubsection{Low Water Case (Case 1.86J)}

This sensitivity case represents a situation in which hydro conditions throughout the WECC yield low amounts of hydro generation (dry year). This condition was reflected in PLEXOS by substituting the hydro generation that occurred during 2006 (used in the Base Case) with the hydro generation that occurred during 2001. The reduced amount of hydro generation associated with this sensitivity case resulted in the NWPP having reduced amounts of total generation and energy exports (about a 50\% reduction in energy exports) with the NWPP and WECC having higher average production costs ( $\$ / \mathrm{MWh}$ ) compared to the Base Case. This outcome can be observed by comparing the results reported in Table 4-41 with the results reported in Table 4-5.

The amounts of energy associated with the hydro violations that occurred inside and outside the NWPP increased in both the BAU and EIM scenarios relative to the Base Case. This can be observed by comparing the results reported Table 4-39 with the results reported in Table 4-3. Meanwhile, there were only minor differences in the amounts of energy associated with the dump and unserved energy, reserve shortfalls and exchange violations for all the BAs in the WECC in comparison with the Base Case. These outcomes can be observed by comparing the results reported in Table 4-40 with the results reported in Table 4-4.

Within the NWPP, the generation cost differences between the BAU scenario and the EIM scenario became more negative indicating that the generation costs for the EIM scenario increased more than for the BAU scenario. In comparison to the Base Case, total annual savings were reduced due to the magnitude of this negative difference in generation costs exceeding the increase in excess hydro savings resulting from the amounts of energy associated with the hydro reduction violations increasing more in the BAU scenario than the EIM scenario. These outcomes can be observed by comparing the results reported in Table 4-38 with the comparable values for the Base Case reported in Table 4-2.

As reported in Table 4-38, the annual total savings between the BAU scenario and the EIM scenario within the NWPP footprint are \$17.1 million and \$49.5 million, which correspond to the prices for excess hydro generation being $\$ 42.00 / \mathrm{MWh}$ and $\$ 57.50 / \mathrm{MWh}$, respectively. These annual total savings are smaller than the annual total savings received under the Base Case, which are \$41.2 million and \$70.7 million, respectively. 
Table 4-38. Summary of Generation Cost and Savings for the NWPP and WECC in Case 1.86J

\begin{tabular}{|c|c|c|c|c|c|c|c|c|}
\hline & & \multirow[b]{2}{*}{ Scenarios } & \multicolumn{3}{|c|}{ Total Generation Cost(k\$) } & \multicolumn{3}{|c|}{ Gen. Cost Difference (k\$) } \\
\hline & & & NWPP & $\begin{array}{l}\text { Rest of } \\
\text { WECC }\end{array}$ & $\begin{array}{c}\text { WECC } \\
\text { Total }\end{array}$ & NWPP & $\begin{array}{l}\text { Rest of } \\
\text { WECC }\end{array}$ & $\begin{array}{c}\text { WECC } \\
\text { Total }\end{array}$ \\
\hline \multirow{6}{*}{ Q1 } & \multirow{2}{*}{ January } & BAU & 327,653 & $1,164,896$ & $1,492,549$ & & & \\
\hline & & EIM & 332,176 & $1,165,165$ & $1,497,340$ & $-4,523$ & -268 & $-4,792$ \\
\hline & \multirow{2}{*}{ February } & BAU & 316,031 & $1,030,446$ & $1,346,476$ & & & \\
\hline & & EIM & 325,350 & $1,030,798$ & $1,356,148$ & $-9,319$ & -352 & $-9,671$ \\
\hline & \multirow{2}{*}{ March } & BAU & 303,628 & $1,052,061$ & $1,355,689$ & & & \\
\hline & & EIM & 311,142 & $1,052,575$ & $1,363,718$ & $-7,514$ & -514 & $-8,028$ \\
\hline \multirow{6}{*}{ Q2 } & \multirow{2}{*}{ April } & BAU & 332,434 & $1,046,753$ & $1,379,187$ & & & \\
\hline & & EIM & 338,177 & $1,047,101$ & $1,385,278$ & $-5,743$ & -348 & $-6,091$ \\
\hline & \multirow{2}{*}{ May } & BAU & 349,190 & $1,189,513$ & $1,538,703$ & & & \\
\hline & & EIM & 351,051 & $1,189,746$ & $1,540,796$ & $-1,860$ & -233 & $-2,093$ \\
\hline & \multirow{2}{*}{ June } & BAU & 364,042 & $1,442,049$ & $1,806,091$ & & & \\
\hline & & EIM & 369,452 & $1,442,489$ & $1,811,940$ & $-5,409$ & -440 & $-5,849$ \\
\hline \multirow{6}{*}{ Q3 } & \multirow{2}{*}{ July } & BAU & 490,843 & $1,911,968$ & $2,402,811$ & & & \\
\hline & & EIM & 495,852 & $1,912,500$ & $2,408,352$ & $-5,009$ & -532 & $-5,541$ \\
\hline & \multirow{2}{*}{ August } & BAU & 442,540 & $1,755,584$ & $2,198,123$ & & & \\
\hline & & EIM & 449,345 & $1,755,992$ & $2,205,337$ & $-6,805$ & -408 & $-7,214$ \\
\hline & \multirow{2}{*}{ September } & BAU & 372,663 & $1,476,476$ & $1,849,139$ & & & \\
\hline & & EIM & 379,588 & $1,476,816$ & $1,856,403$ & $-6,924$ & -340 & $-7,264$ \\
\hline \multirow{6}{*}{ Q4 } & \multirow{2}{*}{ October } & BAU & 333,954 & $1,320,846$ & $1,654,800$ & & & \\
\hline & & EIM & 341,785 & $1,321,143$ & $1,662,928$ & $-7,831$ & -297 & $-8,128$ \\
\hline & \multirow{2}{*}{ November } & BAU & 310,310 & $1,133,177$ & $1,443,486$ & & & \\
\hline & & EIM & 315,389 & $1,133,495$ & $1,448,884$ & $-5,079$ & -318 & $-5,397$ \\
\hline & \multirow{2}{*}{ December } & BAU & 378,313 & $1,313,772$ & $1,692,085$ & & & \\
\hline & & EIM & 383,023 & $1,314,342$ & $1,697,365$ & $-4,710$ & -569 & $-5,279$ \\
\hline \multirow[t]{8}{*}{ Total } & & BAU & $4,321,601$ & $15,837,541$ & $20,159,142$ & & & \\
\hline & & EIM & $4,392,328$ & $15,842,161$ & $20,234,489$ & & & \\
\hline & & & & & & NWPP & Rest & WECC \\
\hline & & \multicolumn{4}{|c|}{ Generation Cost Savings } & $-70,727$ & $-4,620$ & $-75,347$ \\
\hline & & \multicolumn{4}{|c|}{ Min Excess Hydro Savings (@\$42.00/MWh) } & 87,835 & 16 & 87,851 \\
\hline & & \multicolumn{4}{|c|}{ Max Excess Hydro Savings (@\$57.50/MWh) } & 120,250 & 22 & 120,272 \\
\hline & & \multicolumn{4}{|c|}{ Min Total Savings (k\$) } & 17,107 & $-4,604$ & 12,504 \\
\hline & & \multicolumn{4}{|c|}{ Max Total Savings (k\$) } & 49,523 & $-4,598$ & 44,925 \\
\hline
\end{tabular}


Table 4-39. Hydro Generation and Energy Constraints Violation in Case 1.86J

\begin{tabular}{|c|c|c|c|c|c|c|c|}
\hline & & \multirow[b]{2}{*}{ Scenario } & \multicolumn{3}{|c|}{ Hydro Violation (GWh) } & \multicolumn{2}{|c|}{ Total HTC Hydro (GWh) } \\
\hline & & & NWPP & $\begin{array}{l}\text { Rest of } \\
\text { WECC }\end{array}$ & $\begin{array}{c}\text { WECC } \\
\text { Total } \\
\end{array}$ & NWPP & WECC Total \\
\hline \multirow{6}{*}{ Q1 } & \multirow{2}{*}{ January } & BAU & 201 & 14 & 215 & 9,476 & 10,360 \\
\hline & & EIM & 26 & 14 & 40 & 9,304 & 10,188 \\
\hline & \multirow{2}{*}{ February } & BAU & 274 & 16 & 290 & 7,539 & 8,364 \\
\hline & & EIM & 87 & 15 & 102 & 7,354 & 8,179 \\
\hline & \multirow{2}{*}{ March } & BAU & 260 & 24 & 285 & 7,697 & 8,748 \\
\hline & & EIM & 72 & 24 & 97 & 7,512 & 8,563 \\
\hline \multirow{6}{*}{ Q2 } & \multirow{2}{*}{ April } & BAU & 248 & 23 & 272 & 6,195 & 7,495 \\
\hline & & EIM & 61 & 23 & 84 & 6,009 & 7,308 \\
\hline & \multirow{2}{*}{ May } & BAU & 162 & 22 & 185 & 6,041 & 7,635 \\
\hline & & EIM & 13 & 22 & 35 & 5,892 & 7,486 \\
\hline & \multirow{2}{*}{ June } & BAU & 211 & 22 & 233 & 6,554 & 8,137 \\
\hline & & EIM & 27 & 22 & 49 & 6,372 & 7,956 \\
\hline \multirow{6}{*}{ Q3 } & \multirow{2}{*}{ July } & BAU & 169 & 18 & 186 & 5,568 & 7,208 \\
\hline & & EIM & 17 & 17 & 34 & 5,416 & 7,056 \\
\hline & \multirow{2}{*}{ August } & BAU & 176 & 16 & 192 & 7,192 & 8,638 \\
\hline & & EIM & 21 & 16 & 37 & 7,038 & 8,484 \\
\hline & \multirow{2}{*}{ September } & BAU & 203 & 14 & 218 & 6,722 & 7,806 \\
\hline & & EIM & 41 & 14 & 55 & 6,562 & 7,645 \\
\hline \multirow{6}{*}{ Q4 } & \multirow{2}{*}{ October } & BAU & 259 & 13 & 273 & 7,158 & 8,153 \\
\hline & & EIM & 72 & 14 & 85 & 6,974 & 7,969 \\
\hline & \multirow{2}{*}{ November } & BAU & 232 & 10 & 242 & 7,809 & 8,657 \\
\hline & & EIM & 35 & 10 & 46 & 7,618 & 8,467 \\
\hline & \multirow{2}{*}{ December } & BAU & 187 & 7 & 194 & 9,783 & 10,773 \\
\hline & & EIM & 22 & 7 & 29 & 9,620 & 10,611 \\
\hline \multirow[t]{2}{*}{ Total } & & BAU & 2,585 & 200 & 2,785 & 87,733 & 101,973 \\
\hline & & EIM & 494 & 199 & 693 & 85,672 & 99,911 \\
\hline
\end{tabular}


Table 4-40. WECC Dump and Unserved Energy, Reserve Shortfall and Exchange Violations in Case $1.86 \mathrm{~J}$

\begin{tabular}{|c|c|c|c|c|c|c|c|c|c|c|c|}
\hline & & \multirow[t]{2}{*}{ Scenario } & \multirow[t]{2}{*}{$\begin{array}{l}\text { Dump } \\
\text { GWh }\end{array}$} & \multirow[t]{2}{*}{$\begin{array}{l}\text { USE } \\
\text { (Unserved } \\
\text { GWh) }\end{array}$} & \multicolumn{5}{|c|}{ Total BAs Reserve Shortfall (GWh) } & \multicolumn{2}{|c|}{$\begin{array}{c}\text { Total BAs } \\
\text { Exchange } \\
\text { Violation } \\
\text { (GWh) }\end{array}$} \\
\hline & & & & & Spin & $\begin{array}{c}\text { Reg. } \\
\text { up }\end{array}$ & $\begin{array}{l}\text { Reg. } \\
\text { down }\end{array}$ & $\begin{array}{l}\text { non } \\
\text { spin }\end{array}$ & Total & Up & Dn \\
\hline \multirow{6}{*}{ Q1 } & \multirow{2}{*}{ January } & BAU & 0.2 & 4.3 & 11.9 & 2.4 & 0.3 & 2.7 & 17 & 0.7 & 0.0 \\
\hline & & EIM & 0.0 & 4.3 & 15.6 & 3.6 & 0.6 & 4.4 & 24 & 0.7 & 0.1 \\
\hline & \multirow{2}{*}{ February } & BAU & 0.4 & 4.9 & 9.7 & 1.9 & 0.4 & 1.4 & 13 & 0.3 & 0.0 \\
\hline & & EIM & 0.1 & 4.9 & 12.9 & 3.7 & 0.8 & 4.8 & 22 & 0.3 & 0.0 \\
\hline & \multirow{2}{*}{ March } & BAU & 0.5 & 6.3 & 10.8 & 1.5 & 0.4 & 1.3 & 14 & 0.8 & 0.0 \\
\hline & & EIM & 0.0 & 6.3 & 15.1 & 3.6 & 0.8 & 5.4 & 25 & 0.8 & 0.0 \\
\hline \multirow{6}{*}{ Q2 } & \multirow{2}{*}{ April } & BAU & 0.4 & 4.1 & 11.3 & 2.2 & 0.4 & 4.1 & 18 & 0.5 & 0.0 \\
\hline & & EIM & 0.0 & 4.1 & 17.2 & 3.2 & 0.8 & 6.4 & 28 & 0.5 & 0.0 \\
\hline & \multirow{2}{*}{ May } & BAU & 0.4 & 6.7 & 12.2 & 2.0 & 0.3 & 1.9 & 16 & 0.8 & 0.1 \\
\hline & & EIM & 0.1 & 6.6 & 14.8 & 2.0 & 0.7 & 3.5 & 21 & 0.8 & 0.2 \\
\hline & \multirow{2}{*}{ June } & BAU & 0.1 & 5.2 & 17.7 & 2.3 & 0.2 & 3.4 & 24 & 1.4 & 0.2 \\
\hline & & EIM & 0.0 & 5.2 & 18.9 & 2.3 & 0.6 & 5.1 & 27 & 1.3 & 0.5 \\
\hline \multirow{6}{*}{ Q3 } & \multirow{2}{*}{ July } & BAU & 0.8 & 5.8 & 25.2 & 3.4 & 0.3 & 4.7 & 34 & 2.0 & 0.3 \\
\hline & & EIM & 0.0 & 5.8 & 23.9 & 2.7 & 0.7 & 5.0 & 32 & 2.0 & 0.7 \\
\hline & \multirow{2}{*}{ August } & BAU & 1.3 & 6.9 & 14.2 & 1.5 & 0.5 & 2.3 & 19 & 1.0 & 0.1 \\
\hline & & EIM & 0.0 & 6.9 & 17.4 & 2.3 & 0.6 & 4.2 & 25 & 0.9 & 0.3 \\
\hline & \multirow{2}{*}{ September } & BAU & 1.8 & 7.8 & 11.8 & 1.3 & 0.6 & 1.2 & 15 & 1.1 & 0.1 \\
\hline & & EIM & 0.0 & 7.7 & 16.9 & 3.0 & 0.8 & 4.2 & 25 & 1.1 & 0.3 \\
\hline \multirow{6}{*}{ Q4 } & \multirow{2}{*}{ October } & BAU & 3.2 & 4.7 & 10.9 & 2.1 & 0.8 & 4.7 & 19 & 1.3 & 0.0 \\
\hline & & EIM & 0.0 & 4.7 & 12.2 & 2.4 & 0.7 & 4.0 & 19 & 1.1 & 0.3 \\
\hline & \multirow{2}{*}{ November } & BAU & 2.0 & 5.3 & 13.2 & 2.9 & 0.7 & 5.3 & 22 & 0.9 & 0.0 \\
\hline & & EIM & 0.1 & 5.3 & 14.9 & 3.5 & 0.4 & 4.9 & 24 & 0.8 & 0.2 \\
\hline & \multirow{2}{*}{ December } & BAU & 1.4 & 4.2 & 17.0 & 3.0 & 0.7 & 4.3 & 25 & 0.9 & 0.0 \\
\hline & & EIM & 0.1 & 4.2 & 22.3 & 4.3 & 0.7 & 6.8 & 34 & 0.9 & 0.1 \\
\hline \multirow{2}{*}{ Total } & & BAU & 12 & 66 & 166 & 27 & 6 & 37 & 235 & 11.6 & 0.7 \\
\hline & & EIM & 0 & 66 & 202 & 37 & 8 & 59 & 306 & 11.2 & 2.6 \\
\hline
\end{tabular}


Table 4-41. Generation, Demand, and Average Production Cost for NWPP and WECC, and NWPP Net Interchange in Case 1.86J

\begin{tabular}{|c|c|c|c|c|c|c|c|c|c|}
\hline & & Scenarios & $\begin{array}{c}\text { NWPP } \\
\text { Generation } \\
\text { (GWh) }\end{array}$ & $\begin{array}{l}\text { NWPP } \\
\text { Demand } \\
\text { (GWh) }\end{array}$ & $\begin{array}{c}\text { NWPP } \\
\text { Average } \\
\text { Production } \\
\text { Cost } \\
(\$ / \mathrm{MWh})\end{array}$ & $\begin{array}{c}\text { WECC } \\
\text { Generation } \\
\text { (GWh }\end{array}$ & $\begin{array}{l}\text { WECC } \\
\text { Demand } \\
\text { (GWh) }\end{array}$ & $\begin{array}{c}\text { WECC } \\
\text { Average } \\
\text { Production } \\
\text { Cost } \\
\text { (\$/MWh) }\end{array}$ & $\begin{array}{l}\text { NWPP } \\
\text { Net } \\
\text { Exchange } \\
\text { (GWh) }\end{array}$ \\
\hline \multirow{6}{*}{ Q1 } & \multirow{2}{*}{ January } & BAU & 35,854 & 32,368 & 10.12 & 86,579 & 86,583 & 17.24 & $-3,486$ \\
\hline & & EIM & 35850 & 32,368 & 10.26 & 86,579 & 86,583 & 17.29 & $-3,483$ \\
\hline & \multirow{2}{*}{ February } & BAU & 30,227 & 28,897 & 10.94 & 76,821 & 76,825 & 17.53 & $-1,331$ \\
\hline & & EIM & 30,222 & 28,897 & 11.26 & 76,820 & 76,825 & 17.65 & $-1,325$ \\
\hline & \multirow{2}{*}{ March } & BAU & 30,853 & 28,739 & 10.56 & 80,388 & 80,394 & 16.86 & $-2,114$ \\
\hline & & EIM & 30,843 & 28,739 & 10.83 & 80,388 & 80,394 & 16.96 & $-2,104$ \\
\hline \multirow{6}{*}{ Q2 } & \multirow{2}{*}{ April } & BAU & 27,513 & 26,702 & 12.45 & 77,097 & 77,101 & 17.89 & -811 \\
\hline & & EIM & 27,507 & 26,702 & 12.66 & 77,097 & 77,101 & 17.97 & -804 \\
\hline & \multirow{2}{*}{ May } & BAU & 29,632 & 27,162 & 12.86 & 83,144 & 83,150 & 18.51 & $-2,471$ \\
\hline & & EIM & 29,628 & 27,162 & 12.92 & 83,143 & 83,150 & 18.53 & $-2,467$ \\
\hline & \multirow{2}{*}{ June } & BAU & 29,750 & 27,701 & 13.14 & 87,333 & 87,338 & 20.68 & $-2,049$ \\
\hline & & EIM & 29,742 & 27,701 & 13.34 & 87,333 & 87,338 & 20.75 & $-2,041$ \\
\hline \multirow{6}{*}{ Q3 } & \multirow{2}{*}{ July } & BAU & 30,695 & 30,588 & 16.05 & 97,820 & 97,825 & 24.56 & -107 \\
\hline & & EIM & 30,686 & 30,588 & 16.21 & 97,819 & 97,825 & 24.62 & -98 \\
\hline & \multirow{2}{*}{ August } & BAU & 31,642 & 29,972 & 14.76 & 96,128 & 96,134 & 22.87 & $-1,670$ \\
\hline & & EIM & 31,633 & 29,972 & 14.99 & 96,127 & 96,134 & 22.94 & $-1,661$ \\
\hline & \multirow{2}{*}{ September } & BAU & 29,274 & 27,067 & 13.77 & 85,695 & 85,701 & 21.58 & $-2,207$ \\
\hline & & EIM & 29,266 & 27,067 & 14.02 & 85,693 & 85,701 & 21.66 & $-2,199$ \\
\hline \multirow{6}{*}{ Q4 } & \multirow{2}{*}{ October } & BAU & 29,943 & 27,528 & 12.13 & 82,638 & 82,640 & 20.02 & $-2,415$ \\
\hline & & EIM & 29,936 & 27,528 & 12.42 & 82,635 & 82,640 & 20.12 & $-2,408$ \\
\hline & \multirow{2}{*}{ November } & BAU & 32,160 & 29,190 & 10.63 & 81,515 & 81,519 & 17.71 & $-2,970$ \\
\hline & & EIM & 32,157 & 29,190 & 10.80 & 81,513 & 81,519 & 17.77 & $-2,966$ \\
\hline & \multirow{2}{*}{ December } & BAU & 35,444 & 32,780 & 11.54 & 88,546 & 88,549 & 19.11 & $-2,665$ \\
\hline & & EIM & 35,438 & 32,780 & 11.68 & 88,544 & 88,549 & 19.17 & $-2,659$ \\
\hline \multirow{2}{*}{ Total } & & BAU & 372,988 & 348,694 & 12.39 & $1,023,703$ & $1,023,757$ & 19.69 & $-24,294$ \\
\hline & & EIM & 372,909 & 348,694 & 12.60 & $1,023,691$ & $1,023,757$ & 19.76 & $-24,215$ \\
\hline
\end{tabular}




\subsubsection{High Water Case (Case 1.86K)}

This sensitivity case represents a situation in which hydro conditions throughout the WECC yield high amounts of hydro generation (wet year). This condition was reflected in PLEXOS by substituting the hydro generation that occurred during 2006 (used in the Base Case) with the hydro generation that occurred during 2011. The increased amount of hydro generation associated with this sensitivity case resulted in the NWPP having increased amounts of total generation and energy exports (about a 23\% increase in energy exports) with the NWPP and WECC having lower average production costs (\$/MWh) compared to the Base Case. This outcome can be observed by comparing the results reported in Table 4-45 with the results reported in Table 4-5.

The amounts of energy associated with the hydro violations that occurred inside and outside the NWPP decreased in both the BAU and EIM scenarios relative to the Base Case. This can be observed by comparing the results reported in Table 4-43 with the results reported in Table 4-3. Meanwhile, there were only minor differences in the amounts of energy associated with the dump and unserved energy, reserve shortfalls and exchange violations for all the BAs in the WECC in comparison with the Base Case. These outcomes can be observed by comparing the results reported in Table 4-44 with the results reported in Table 4-4

Within the NWPP, the generation cost differences between the BAU scenario and the EIM scenario became less negative indicating that the generation costs for the EIM scenario decreased more than for the BAU scenario. In comparison to the Base Case, total annual savings increased due to the magnitude of this negative difference in generation costs being less than the decrease in excess hydro savings resulting from the amounts of energy associated with the hydro reduction violations decreasing more in the BAU scenario than the EIM scenario. These outcomes can be observed by comparing the results reported in Table 4.42 with the comparable values for the Base Case reported in Table 4-2.

As reported in Table 4-42, the annual total savings between the BAU scenario and the EIM scenario within the NWPP footprint are \$60.1 million and \$84.9 million, which correspond to the prices for excess hydro generation being \$42.00/MWh and \$57.50/MWh, respectively. These annual total savings are greater than the annual total savings received under the Base Case, which are \$41.2 million and \$70.7 million, respectively. 
Table 4-42. Summary of Generation Cost and Savings for the NWPP and WECC in Case 1.86K

\begin{tabular}{|c|c|c|c|c|c|c|c|c|}
\hline & & \multirow[b]{2}{*}{ Scenario } & \multicolumn{3}{|c|}{ Total Generation Cost(k\$) } & \multicolumn{3}{|c|}{ Gen. Cost Difference (k\$) } \\
\hline & & & NWPP & $\begin{array}{l}\text { Rest of } \\
\text { WECC } \\
\end{array}$ & Total & NWPP & Rest & Total \\
\hline \multirow{6}{*}{ Q1 } & \multirow{2}{*}{ January } & BAU & 224,659 & 952,463 & $1,177,122$ & & & \\
\hline & & EIM & 226,433 & 953,492 & $1,179,925$ & $-1,774$ & $-1,029$ & $-2,803$ \\
\hline & \multirow{2}{*}{ February } & BAU & 191,031 & 779,087 & 970,118 & & & \\
\hline & & EIM & 198,328 & 780,274 & 978,601 & $-7,296$ & $-1,187$ & $-8,483$ \\
\hline & \multirow{2}{*}{ March } & BAU & 180,851 & 763,675 & 944,525 & & & \\
\hline & & EIM & 184,113 & 765,562 & 949,675 & $-3,262$ & $-1,888$ & $-5,150$ \\
\hline \multirow{6}{*}{ Q2 } & \multirow{2}{*}{ April } & BAU & 177,500 & 751,379 & 928,880 & & & \\
\hline & & EIM & 173,681 & 752,351 & 926,032 & 3,819 & -972 & 2,848 \\
\hline & \multirow{2}{*}{ May } & BAU & 205,700 & 905,532 & $1,111,232$ & & & \\
\hline & & EIM & 194,225 & 906,565 & $1,100,790$ & 11,475 & $-1,033$ & 10,442 \\
\hline & \multirow{2}{*}{ June } & BAU & 205,816 & $1,133,102$ & $1,338,918$ & & & \\
\hline & & EIM & 199,735 & $1,134,386$ & $1,334,121$ & 6,081 & $-1,284$ & 4,797 \\
\hline \multirow{6}{*}{ Q3 } & \multirow{2}{*}{ July } & BAU & 255,755 & $1,489,557$ & $1,745,312$ & & & \\
\hline & & EIM & 250,355 & $1,490,849$ & $1,741,204$ & 5,400 & $-1,292$ & 4,108 \\
\hline & \multirow{2}{*}{ August } & BAU & 286,193 & $1,531,739$ & $1,817,932$ & & & \\
\hline & & EIM & 289,395 & $1,532,480$ & $1,821,875$ & $-3,202$ & -741 & $-3,943$ \\
\hline & \multirow{2}{*}{ September } & BAU & 280,006 & $1,324,103$ & $1,604,109$ & & & \\
\hline & & EIM & 284,894 & $1,324,693$ & $1,609,587$ & $-4,888$ & -590 & $-5,478$ \\
\hline \multirow{6}{*}{ Q4 } & \multirow{2}{*}{ October } & BAU & 265,566 & $1,205,270$ & $1,470,836$ & & & \\
\hline & & EIM & 271,186 & $1,206,047$ & $1,477,233$ & $-5,620$ & -777 & $-6,396$ \\
\hline & \multirow{2}{*}{ November } & BAU & 247,244 & $1,038,763$ & $1,286,007$ & & & \\
\hline & & EIM & 252,640 & $1,039,643$ & $1,292,283$ & $-5,397$ & -879 & $-6,276$ \\
\hline & \multirow{2}{*}{ December } & BAU & 326,098 & $1,233,090$ & $1,559,188$ & & & \\
\hline & & EIM & 328,587 & $1,233,703$ & $1,562,291$ & $-2,489$ & -613 & $-3,102$ \\
\hline \multirow[t]{8}{*}{ Total } & & BAU & $2,846,420$ & $13,107,759$ & $15,954,179$ & & & \\
\hline & & EIM & $2,853,573$ & $13,120,045$ & $15,973,618$ & & & \\
\hline & & & & & & NWPP & Rest & WECC \\
\hline & \multicolumn{5}{|c|}{ Generation Cost Savings } & $-7,153$ & $-12,286$ & $-19,439$ \\
\hline & & \multicolumn{4}{|c|}{ Min Excess Hydro Savings (@\$42.0/MWh) } & 67,209 & 273 & 67,482 \\
\hline & & \multicolumn{4}{|c|}{ Max Excess Hydro Savings (@\$57.50/MWh) } & 92,013 & 374 & 92,387 \\
\hline & & \multicolumn{4}{|c|}{ Min Total Savings (k\$) } & 60,057 & $-12,013$ & 48,044 \\
\hline & & \multicolumn{4}{|c|}{ Max Total Savings (k\$) } & 84,860 & $-11,912$ & 72,948 \\
\hline
\end{tabular}


Table 4-43. Hydro Generation and Energy Constraints Violation in Case 1.86K

\begin{tabular}{|c|c|c|c|c|c|c|c|}
\hline & & \multirow[b]{2}{*}{ Scenario } & \multicolumn{3}{|c|}{ Hydro Violation (GWh) } & \multicolumn{2}{|c|}{ Total HTC Hydro (GWh) } \\
\hline & & & NWPP & $\begin{array}{l}\text { Rest of } \\
\text { WECC }\end{array}$ & $\begin{array}{c}\text { WECC } \\
\text { Total }\end{array}$ & NWPP & WECC Total \\
\hline \multirow{6}{*}{ Q1 } & \multirow{2}{*}{ January } & BAU & 167 & 14 & 182 & 12,728 & 14,268 \\
\hline & & EIM & 19 & 14 & 33 & 12653 & 14194 \\
\hline & \multirow{2}{*}{ February } & BAU & 170 & 14 & 184 & 11,679 & 13,104 \\
\hline & & EIM & 24 & 14 & 39 & 11,550 & 12,975 \\
\hline & \multirow{2}{*}{ March } & BAU & 133 & 18 & 151 & 11,972 & 13,802 \\
\hline & & EIM & 14 & 18 & 33 & 11,878 & 13,708 \\
\hline \multirow{6}{*}{ Q2 } & \multirow{2}{*}{ April } & BAU & 107 & 18 & 125 & 10,931 & 12,939 \\
\hline & & EIM & 32 & 18 & 50 & 11,047 & 13,055 \\
\hline & \multirow{2}{*}{ May } & BAU & 79 & 16 & 95 & 9,955 & 12,376 \\
\hline & & EIM & 6 & 16 & 22 & 10,287 & 12,708 \\
\hline & \multirow{2}{*}{ June } & BAU & 95 & 24 & 119 & 11,154 & 13,487 \\
\hline & & EIM & 9 & 24 & 33 & 11,253 & 13,586 \\
\hline \multirow{6}{*}{ Q3 } & \multirow{2}{*}{ July } & BAU & 116 & 18 & 134 & 11,677 & 14,246 \\
\hline & & EIM & 5 & 16 & 21 & 11,612 & 14,179 \\
\hline & \multirow{2}{*}{ August } & BAU & 166 & 16 & 182 & 10,856 & 12,947 \\
\hline & & EIM & 13 & 15 & 27 & 10,721 & 12,810 \\
\hline & \multirow{2}{*}{ September } & BAU & 202 & 17 & 219 & 8,851 & 10,464 \\
\hline & & EIM & 39 & 15 & 54 & 8,693 & 10,304 \\
\hline \multirow{6}{*}{ Q4 } & \multirow{2}{*}{ October } & BAU & 203 & 14 & 217 & 8,955 & 10,159 \\
\hline & & EIM & 35 & 12 & 47 & 8,793 & 9,995 \\
\hline & \multirow{2}{*}{ November } & BAU & 231 & 7 & 238 & 9,344 & 10,515 \\
\hline & & EIM & 44 & 7 & 52 & 9,174 & 10,346 \\
\hline & \multirow{2}{*}{ December } & BAU & 186 & 7 & 193 & 10,880 & 12,247 \\
\hline & & EIM & 14 & 7 & 21 & 10,742 & 12,110 \\
\hline \multirow{2}{*}{ Total } & & BAU & 1,855 & 184 & 2,038 & 128,982 & 150,555 \\
\hline & & EIM & 254 & 177 & 432 & 128,403 & 149,969 \\
\hline
\end{tabular}


Table 4-44. WECC Dump and Unserved Energy, Reserve Shortfall and Exchange Violations in Case $1.86 \mathrm{~K}$

\begin{tabular}{|c|c|c|c|c|c|c|c|c|c|c|c|}
\hline & & \multirow[t]{2}{*}{ Scenario } & \multirow[t]{2}{*}{$\begin{array}{l}\text { Dump } \\
\text { GWh }\end{array}$} & \multirow[t]{2}{*}{$\begin{array}{c}\text { USE } \\
\text { (Unserved } \\
\text { GWh) }\end{array}$} & \multicolumn{5}{|c|}{ Total BAs Reserve Shortfall (GWh) } & \multicolumn{2}{|c|}{$\begin{array}{c}\text { Total BAs } \\
\text { Exchange } \\
\text { Violation } \\
\text { (GWh) }\end{array}$} \\
\hline & & & & & Spin & $\begin{array}{c}\text { Reg. } \\
\text { up }\end{array}$ & $\begin{array}{l}\text { Reg. } \\
\text { down }\end{array}$ & $\begin{array}{l}\text { non } \\
\text { spin }\end{array}$ & Total & Up & Dn \\
\hline \multirow{6}{*}{ Q1 } & \multirow{2}{*}{ January } & BAU & 0.2 & 7.8 & 13.8 & 3.9 & 0.2 & 5.8 & 24 & 0.8 & 0.0 \\
\hline & & EIM & $\mathbf{0 . 0}$ & 7.8 & 14.6 & 3.6 & 0.1 & 2.9 & 21 & 0.8 & 0.0 \\
\hline & \multirow{2}{*}{ February } & BAU & 0.5 & 8.4 & 22.9 & 5.7 & 0.4 & 8.4 & 37 & 0.6 & 0.0 \\
\hline & & EIM & 0.4 & 8.3 & 24.9 & 7.3 & 0.3 & 6.4 & 39 & 0.6 & 0.1 \\
\hline & \multirow{2}{*}{ March } & BAU & 0.3 & 8.7 & 17.9 & 5.2 & 0.2 & 7.3 & 30 & 0.5 & 0.0 \\
\hline & & EIM & 0.5 & 8.7 & 19.0 & 5.5 & 0.2 & 4.2 & 29 & 0.4 & 0.0 \\
\hline \multirow{6}{*}{ Q2 } & \multirow{2}{*}{ April } & BAU & 0.5 & 8.4 & 10.3 & 3.2 & 0.4 & 3.1 & 17 & 0.9 & 0.0 \\
\hline & & EIM & 0.1 & 8.4 & 9.5 & 2.2 & 0.4 & 2.7 & 15 & 0.7 & 0.0 \\
\hline & \multirow{2}{*}{ May } & BAU & 0.5 & 8.7 & 11.6 & 2.5 & 0.4 & 1.9 & 16 & 0.9 & 0.0 \\
\hline & & EIM & 0.1 & 8.7 & 9.3 & 1.2 & 0.3 & 0.8 & 12 & 0.7 & 0.0 \\
\hline & \multirow{2}{*}{ June } & BAU & 0.2 & 5.5 & 18.4 & 3.7 & 0.1 & 4.0 & 26 & 1.4 & 0.1 \\
\hline & & EIM & 0.1 & 5.5 & 15.1 & 1.6 & 0.1 & 1.6 & 18 & 1.3 & 0.3 \\
\hline \multirow{6}{*}{ Q3 } & \multirow{2}{*}{ July } & BAU & 0.2 & 4.5 & 24.6 & 5.2 & 0.1 & 3.6 & 34 & 2.4 & 0.2 \\
\hline & & EIM & 0.0 & 4.4 & 18.1 & 1.8 & 0.1 & 1.5 & 21 & 2.1 & 0.7 \\
\hline & \multirow{2}{*}{ August } & BAU & 0.0 & 6.4 & 15.7 & 3.4 & 0.0 & 3.4 & 22 & 1.1 & 0.1 \\
\hline & & EIM & 0.0 & 6.4 & 15.5 & 2.7 & 0.2 & 4.6 & 23 & 1.0 & 0.4 \\
\hline & \multirow{2}{*}{ September } & BAU & 1.5 & 6.5 & 13.6 & 2.9 & 0.4 & 3.5 & 20 & 1.0 & 0.0 \\
\hline & & EIM & 0.0 & 6.5 & 16.7 & 3.3 & 0.4 & 6.2 & 27 & 0.7 & 0.1 \\
\hline \multirow{6}{*}{ Q4 } & \multirow{2}{*}{ October } & BAU & 2.3 & 4.0 & 14.1 & 3.4 & 0.6 & 6.6 & 25 & 1.2 & 0.0 \\
\hline & & EIM & 0.0 & 4.0 & 12.8 & 2.5 & 0.3 & 4.7 & 20 & 0.7 & 0.1 \\
\hline & \multirow{2}{*}{ November } & BAU & 1.8 & 6.2 & 20.3 & 5.8 & 0.5 & 10.3 & 37 & 1.0 & 0.0 \\
\hline & & EIM & 0.4 & 6.1 & 18.3 & 4.8 & 0.1 & 7.4 & 31 & 0.7 & 0.1 \\
\hline & \multirow{2}{*}{ December } & BAU & 0.5 & 4.9 & 20.0 & 4.8 & 0.3 & 7.5 & 33 & 0.7 & 0.0 \\
\hline & & EIM & 0.0 & 4.8 & 16.4 & 3.2 & 0.3 & 4.8 & 25 & 0.5 & 0.0 \\
\hline \multirow{2}{*}{ Total } & & BAU & 8 & 80 & 203 & 50 & 4 & 65 & 322 & 12.6 & 0.5 \\
\hline & & EIM & 2 & 80 & 190 & 40 & 3 & 48 & 281 & 10.2 & 1.8 \\
\hline
\end{tabular}


Table 4-45. Generation, Demand, and Average Production Cost for NWPP and WECC, and NWPP Net Interchange in Case $1.86 \mathrm{~K}$

\begin{tabular}{|c|c|c|c|c|c|c|c|c|c|}
\hline & & Scenario & $\begin{array}{c}\text { NWPP } \\
\text { Generation } \\
\text { (GWh) }\end{array}$ & $\begin{array}{l}\text { NWPP } \\
\text { Demand } \\
\text { (GWh) }\end{array}$ & $\begin{array}{c}\text { NWPP } \\
\text { Average } \\
\text { Production } \\
\text { Cost } \\
(\$ / \mathrm{MWh})\end{array}$ & $\begin{array}{c}\text { WECC } \\
\text { Generation } \\
\text { (GWh) }\end{array}$ & $\begin{array}{c}\text { WECC } \\
\text { Demand } \\
\text { (GWh) }\end{array}$ & $\begin{array}{c}\text { WECC } \\
\text { Average } \\
\text { Production } \\
\text { Cost } \\
\text { (\$/MWh) }\end{array}$ & $\begin{array}{l}\text { NWPP } \\
\text { Net } \\
\text { Exchange } \\
\text { (GWh) }\end{array}$ \\
\hline \multirow{6}{*}{ Q1 } & \multirow{2}{*}{ January } & BAU & 38,853 & 32,368 & 6.94 & 86,748 & 86,755 & 13.57 & $-6,485$ \\
\hline & & EIM & 38829 & 32368 & 7.00 & 86,748 & 86,755 & 13.60 & $-6,461$ \\
\hline & \multirow{2}{*}{ February } & BAU & 34,370 & 28,897 & 6.61 & 77,067 & 77,075 & 12.59 & $-5,474$ \\
\hline & & EIM & 34,346 & 28,897 & 6.86 & 77,067 & 77,075 & 12.70 & $-5,449$ \\
\hline & \multirow{2}{*}{ March } & BAU & 35,232 & 28,739 & 6.29 & 80,766 & $\mathbf{8 0 , 7 7 5}$ & 11.69 & $-6,492$ \\
\hline & & EIM & 35,197 & 28,739 & 6.41 & 80,766 & $\mathbf{8 0 , 7 7 5}$ & 11.76 & $-6,458$ \\
\hline \multirow{6}{*}{ Q2 } & \multirow{2}{*}{ April } & BAU & 32,199 & 26,702 & 6.65 & 77,441 & 77,449 & 11.99 & $-5,497$ \\
\hline & & EIM & 32,173 & 26,702 & 6.50 & 77,441 & 77,449 & 11.96 & $-5,471$ \\
\hline & \multirow{2}{*}{ May } & BAU & 33,973 & 27,162 & 7.57 & 83,386 & 83,394 & 13.33 & $-6,811$ \\
\hline & & EIM & 33,950 & 27,162 & 7.15 & 83,386 & 83,394 & 13.20 & $-6,788$ \\
\hline & \multirow{2}{*}{ June } & BAU & 34,449 & 27,701 & 7.43 & 87,520 & 87,525 & 15.30 & $-6,748$ \\
\hline & & EIM & 34,422 & 27,701 & 7.21 & 87,520 & 87,525 & 15.24 & $-6,721$ \\
\hline \multirow{6}{*}{ Q3 } & \multirow{2}{*}{ July } & BAU & 36,840 & 30,588 & 8.36 & 97,869 & 97,874 & 17.83 & $-6,252$ \\
\hline & & EIM & 36,815 & 30,588 & 8.18 & 97,869 & 97,874 & 17.79 & $-6,227$ \\
\hline & \multirow{2}{*}{ August } & BAU & 34,650 & 29,972 & 9.55 & 96,121 & 96,128 & 18.91 & $-4,678$ \\
\hline & & EIM & 34,638 & 29,972 & 9.66 & 96,121 & 96,128 & 18.95 & $-4,666$ \\
\hline & \multirow{2}{*}{ September } & BAU & 31,049 & 27,067 & 10.34 & 85,669 & 85,673 & 18.72 & $-3,982$ \\
\hline & & EIM & 31,038 & 27,067 & 10.53 & 85,667 & 85,673 & 18.79 & $-3,971$ \\
\hline \multirow{6}{*}{ Q4 } & \multirow{2}{*}{ October } & BAU & 31,680 & 27,528 & 9.65 & 82,621 & 82,623 & 17.80 & $-4,152$ \\
\hline & & EIM & 31,669 & 27,528 & 9.85 & 82,619 & 82,623 & 17.88 & $-4,141$ \\
\hline & \multirow{2}{*}{ November } & BAU & 33,438 & 29,190 & 8.47 & 81,514 & 81,518 & 15.78 & $-4,248$ \\
\hline & & EIM & 33,427 & 29,190 & 8.65 & 81,513 & 81,518 & 15.85 & $-4,237$ \\
\hline & \multirow{2}{*}{ December } & BAU & 36,180 & 32,780 & 9.95 & 88,549 & $\mathbf{8 8 , 5 5 3}$ & 17.61 & $-3,400$ \\
\hline & & EIM & 36,171 & 32,780 & 10.02 & 88,549 & 88,553 & 17.64 & $-3,391$ \\
\hline \multirow{2}{*}{ Total } & & BAU & 412,913 & 348,695 & 8.16 & $1,025,271$ & $1,025,342$ & 15.56 & $-64,219$ \\
\hline & & EIM & 412,675 & 348,695 & 8.18 & $1,025,266$ & $1,025,342$ & 15.58 & $-63,980$ \\
\hline
\end{tabular}




\subsubsection{Hydro Modeling Improvement Case (Case 1.94)}

This sensitivity case represents an attempt to more accurately reflect the forward-looking information that hydro schedulers have when making decisions. This task was accomplished in PLEXOS by optimizing the real-time dispatch in 12-hour increments rather than the 1-hour increment used in the Base Case. Also, the hydro energy constraints were implemented on a weekly basis instead of a monthly basis and the hydro units within the same plant were aggregated in order to minimize the effort required in modeling this sensitivity case in PLEXOS.

The amounts of energy associated with the hydro violations that occurred inside and outside the NWPP were reduced by about $66 \%$ in both the BAU and EIM scenarios relative to these results for the Base Case. This outcome can be observed by comparing the results reported in Table 4-47 with the results reported in Table 4-3. Also, but to a lesser degree, there are notable overall reductions in the amounts of energy associated with the reserve shortfalls and a notable increase in the exchange violations for all the BAs in the WECC compared to the results for the Base Case. This outcome can be observed by comparing the results reported in Table 4-48 with the results reported in Table 4-4.

There were only minor increases in the amounts of total generation and energy exports for the NWPP and minor reductions in the average production costs $(\$ / M W h)$ for the NWPP and WECC compared to the Base Case. This outcome can be observed by comparing the results reported in Table 4-49 with the results reported in Table 4-5. Unlike in the Base Case, the differences in generation costs between the BAU scenario and the EIM scenario became positive (which is a positive EIM benefit) within the NWPP. This large favorable change in the differences in generation costs exceeded the decrease in the excess hydro savings, resulting in an increase in total savings compared to the results for the Base Case. This outcome can be observed by comparing the results reported in Table 4-46 with comparable values for the Base Case reported in Table 4-2.

As reported in Table 4-46, the annual total savings between the BAU scenario and the EIM scenario within the NWPP footprint are \$71.6 million and \$82.2 million, which correspond to the prices for excess hydro generation being $\$ 42.00 / \mathrm{MWh}$ and $\$ 57.50 / \mathrm{MWh}$, respectively. These annual total savings are greater than the annual total savings received under the Base Case, which are \$41.2 million and \$70.7 million, respectively. 
Table 4-46. Summary of Generation Cost and Savings for the NWPP and WECC in Case 1.94

\begin{tabular}{|c|c|c|c|c|c|c|c|c|}
\hline & & \multirow{2}{*}{ Scenarios } & \multicolumn{3}{|c|}{ Total Generation Cost (k\$) } & \multicolumn{3}{|c|}{ Gen. Cost Difference (k\$) } \\
\hline & & & NWPP & Rest & Total & NWPP & Rest & Total \\
\hline \multirow{6}{*}{ Q1 } & \multirow{2}{*}{ January } & BAU & 234,826 & 993,237 & $1,228,063$ & & & \\
\hline & & EIM & 231,369 & 993,749 & $1,225,118$ & 3,457 & -512 & 2,945 \\
\hline & \multirow{2}{*}{ February } & BAU & 215,912 & 830,485 & $1,046,397$ & & & \\
\hline & & EIM & 214,598 & 830,948 & $1,045,546$ & 1,314 & -464 & 851 \\
\hline & \multirow{2}{*}{ March } & BAU & 231,553 & 928,031 & $1,159,584$ & & & \\
\hline & & EIM & 231,256 & 928,585 & $1,159,841$ & 297 & -554 & -257 \\
\hline \multirow{6}{*}{ Q2 } & \multirow{2}{*}{ April } & BAU & 181,978 & 796,563 & 978,541 & & & \\
\hline & & EIM & 173,594 & 797,215 & 970,809 & 8,384 & -652 & 7,732 \\
\hline & \multirow{2}{*}{ May } & BAU & 204,962 & 936,100 & $1,141,061$ & & & \\
\hline & & EIM & 194,322 & 937,299 & $1,131,621$ & 10,639 & $-1,199$ & 9,440 \\
\hline & \multirow{2}{*}{ June } & BAU & 210,180 & $1,184,141$ & $1,394,321$ & & & \\
\hline & & EIM & 201,852 & $1,185,133$ & $1,386,986$ & 8,328 & -992 & 7,335 \\
\hline \multirow{6}{*}{ Q3 } & \multirow{2}{*}{ July } & BAU & 362,279 & $1,681,951$ & $2,044,230$ & & & \\
\hline & & EIM & 358,285 & $1,682,230$ & $2,040,515$ & 3,995 & -279 & 3,716 \\
\hline & \multirow{2}{*}{ August } & BAU & 392,359 & $1,676,448$ & $2,068,806$ & & & \\
\hline & & EIM & 392,701 & $1,676,663$ & $2,069,365$ & -342 & -216 & -558 \\
\hline & \multirow{2}{*}{ September } & BAU & 341,907 & $1,417,746$ & $1,759,653$ & & & \\
\hline & & EIM & 339,638 & $1,417,787$ & $1,757,425$ & 2,269 & -40 & 2,228 \\
\hline \multirow{6}{*}{ Q4 } & \multirow{2}{*}{ October } & BAU & 305,813 & $1,276,916$ & $1,582,729$ & & & \\
\hline & & EIM & 305,493 & $1,277,033$ & $1,582,526$ & 320 & -117 & 203 \\
\hline & \multirow{2}{*}{ November } & BAU & 257,000 & $1,061,537$ & $1,318,538$ & & & \\
\hline & & EIM & 254,659 & $1,061,538$ & 1,316,197 & 2,341 & -1 & 2,341 \\
\hline & \multirow{2}{*}{ December } & BAU & 313,549 & $1,244,327$ & $1,557,876$ & & & \\
\hline & & EIM & 311,831 & $1,245,136$ & $1,556,968$ & 1,717 & -809 & 908 \\
\hline \multirow[t]{8}{*}{ Total } & & BAU & $3,252,318$ & $14,027,482$ & $17,279,800$ & & & \\
\hline & & EIM & $3,209,598$ & $14,033,317$ & $17,242,916$ & & & \\
\hline & & & & & & NWPP & Rest & WECC \\
\hline & & \multicolumn{4}{|c|}{ Generation Cost Savings } & 42,720 & $-5,836$ & 36,884 \\
\hline & & \multicolumn{4}{|c|}{ Min Excess Hydro Savings (@\$42.00/MWh) } & 28,841 & 57 & 28,898 \\
\hline & & \multicolumn{4}{|c|}{ Max Excess Hydro Savings (@\$57.50/MWh) } & 39,485 & 75 & 39,563 \\
\hline & & \multicolumn{4}{|c|}{ Min Total Savings (k\$) } & 71,561 & $-5,779$ & 65,782 \\
\hline & & \multicolumn{4}{|c|}{ Max Total Savings (k\$) } & 82,205 & $-5,758$ & 76,447 \\
\hline
\end{tabular}


Table 4-47. Hydro Generation and Energy Constraints Violation in Case 1.94

\begin{tabular}{|c|c|c|c|c|c|c|c|}
\hline & & \multirow{2}{*}{ Scenario } & \multicolumn{3}{|c|}{ Hydro Violation (GWh) } & \multicolumn{2}{|c|}{ HTC Hydro Gen (GWh) } \\
\hline & & & NWPP & Rest & WECC & NWPP & WECC \\
\hline \multirow{6}{*}{ Q1 } & \multirow{2}{*}{ January } & BAU & 58 & 7 & 65 & 12,215 & 13,537 \\
\hline & & EIM & 2 & 7 & 9 & 12,173 & 13,495 \\
\hline & \multirow{2}{*}{ February } & BAU & 80 & 8 & 88 & 10,429 & 11,817 \\
\hline & & EIM & 7 & 8 & 15 & 10,421 & 11,808 \\
\hline & \multirow{2}{*}{ March } & BAU & 95 & 9 & 105 & 9,485 & 10,814 \\
\hline & & EIM & 15 & 9 & 25 & 9,453 & 10,783 \\
\hline \multirow{6}{*}{ Q2 } & \multirow{2}{*}{ April } & BAU & 39 & 7 & 46 & 10,770 & 12,386 \\
\hline & & EIM & 3 & 7 & 10 & 10,916 & 12,532 \\
\hline & \multirow{2}{*}{ May } & BAU & 31 & 7 & 38 & 9,894 & 11,991 \\
\hline & & EIM & 0 & 7 & 7 & 10,198 & 12,294 \\
\hline & \multirow{2}{*}{ June } & BAU & 37 & 6 & 43 & 10,894 & 12,935 \\
\hline & & EIM & 1 & 6 & 7 & 11,053 & 13,094 \\
\hline \multirow{6}{*}{ Q3 } & \multirow{2}{*}{ July } & BAU & 52 & 7 & 59 & 8,766 & 10,701 \\
\hline & & EIM & 1 & 7 & 8 & 8,744 & 10,678 \\
\hline & \multirow{2}{*}{ August } & BAU & 62 & 8 & 69 & 8,232 & 9,843 \\
\hline & & EIM & 3 & 8 & 11 & 8,173 & 9,783 \\
\hline & \multirow{2}{*}{ September } & BAU & 76 & 6 & 82 & 7,316 & 8,661 \\
\hline & & EIM & 7 & 6 & 14 & 7,344 & 8,689 \\
\hline \multirow{6}{*}{ Q4 } & \multirow{2}{*}{ October } & BAU & 83 & 6 & 90 & 7,626 & 8,757 \\
\hline & & EIM & 13 & 6 & 19 & 7,589 & 8,720 \\
\hline & \multirow{2}{*}{ November } & BAU & 67 & 3 & 70 & 8,964 & 10,053 \\
\hline & & EIM & 9 & 3 & 11 & 8,928 & 10,017 \\
\hline & \multirow{2}{*}{ December } & BAU & 76 & 3 & 79 & 10,948 & 12,296 \\
\hline & & EIM & 7 & 3 & 10 & 10,862 & 12,204 \\
\hline \multirow{2}{*}{ Total } & & BAU & 756 & 78 & 833 & 115,541 & 133,791 \\
\hline & & EIM & 69 & 76 & 145 & 115,854 & 134,097 \\
\hline
\end{tabular}


Table 4-48. Dump and Unserved Energy, Reserve Shortfall and Exchange Violations in Case 1.94

\begin{tabular}{|c|c|c|c|c|c|c|c|c|c|c|c|}
\hline & & \multirow[t]{2}{*}{ Scenario } & \multirow{2}{*}{$\begin{array}{l}\text { Dump } \\
\text { GWh }\end{array}$} & \multirow{2}{*}{$\begin{array}{c}\text { USE } \\
\text { (unserved } \\
\text { GWh) }\end{array}$} & \multicolumn{5}{|c|}{ Total BA Reserve Shortfall (GWh) } & \multicolumn{2}{|c|}{$\begin{array}{c}\text { Total BAs } \\
\text { Exchange } \\
\text { Violation (GWh) }\end{array}$} \\
\hline & & & & & Spin & Reg. up & $\begin{array}{l}\text { Reg. } \\
\text { down }\end{array}$ & $\begin{array}{l}\text { non } \\
\text { spin }\end{array}$ & Total & Up & Dn \\
\hline \multirow{6}{*}{ Q1 } & \multirow{2}{*}{ January } & BAU & 0.40 & 6.70 & 13.96 & 9.48 & 0.75 & 5.61 & 29.80 & 0.56 & 0.00 \\
\hline & & EIM & 0.30 & 6.69 & 12.27 & 8.52 & 0.44 & 3.39 & 24.62 & 0.48 & 0.00 \\
\hline & \multirow{2}{*}{ February } & BAU & 0.43 & 8.24 & 13.00 & 8.15 & 0.92 & 4.21 & 26.28 & 0.42 & 0.00 \\
\hline & & EIM & 0.60 & 8.23 & 12.83 & 8.74 & 0.76 & 3.23 & 25.57 & 0.33 & 0.01 \\
\hline & \multirow{2}{*}{ March } & BAU & 0.48 & 7.51 & 13.62 & 3.21 & 0.27 & 3.42 & 20.52 & 0.78 & 0.00 \\
\hline & & EIM & 0.40 & 7.50 & 13.31 & 3.21 & 0.27 & 2.64 & 19.42 & 0.67 & 0.02 \\
\hline \multirow{6}{*}{ Q2 } & \multirow{2}{*}{ April } & BAU & 0.68 & 7.90 & 8.04 & 2.03 & 0.52 & 1.20 & 11.79 & 0.60 & 0.00 \\
\hline & & EIM & 0.12 & 7.88 & 7.45 & 1.46 & 0.39 & 0.72 & 10.02 & 0.48 & 0.02 \\
\hline & \multirow{2}{*}{ May } & BAU & 0.72 & 8.37 & 8.79 & 1.68 & 0.42 & 1.08 & 11.98 & 0.87 & 0.00 \\
\hline & & EIM & 0.65 & 8.35 & 7.97 & 0.94 & 0.27 & 0.19 & 9.37 & 0.65 & 0.01 \\
\hline & \multirow{2}{*}{ June } & BAU & 0.46 & 5.33 & 12.10 & 1.85 & 0.17 & 1.32 & 15.43 & 1.47 & 0.19 \\
\hline & & EIM & 0.31 & 5.30 & 10.59 & 0.98 & 0.08 & 0.23 & 11.87 & 1.39 & 0.35 \\
\hline \multirow{6}{*}{ Q3 } & \multirow{2}{*}{ July } & BAU & 0.49 & 3.73 & 16.96 & 2.22 & 0.18 & 2.79 & 22.15 & 1.18 & 0.01 \\
\hline & & EIM & 0.00 & 3.68 & 13.89 & 0.94 & 0.24 & 0.18 & 15.25 & 0.85 & 0.14 \\
\hline & \multirow{2}{*}{ August } & BAU & 1.39 & 6.95 & 11.64 & 1.73 & 0.63 & 2.48 & 16.49 & 0.83 & 0.01 \\
\hline & & EIM & 0.00 & 6.96 & 9.66 & 0.85 & 0.27 & 0.57 & 11.34 & 0.37 & 0.05 \\
\hline & \multirow{2}{*}{ September } & BAU & 2.08 & 6.88 & 10.56 & 1.43 & 0.73 & 1.42 & 14.14 & 0.84 & 0.01 \\
\hline & & EIM & 0.00 & 6.87 & 10.15 & 1.27 & 0.40 & 0.83 & 12.65 & 0.65 & 0.15 \\
\hline \multirow{6}{*}{ Q4 } & \multirow{2}{*}{ October } & BAU & 3.82 & 4.41 & 10.53 & 1.49 & 1.11 & 2.38 & 15.50 & 1.76 & 2.05 \\
\hline & & EIM & 0.00 & 4.40 & 10.22 & 2.45 & 0.54 & 1.56 & 14.77 & 6.28 & 11.47 \\
\hline & \multirow{2}{*}{ November } & BAU & 2.30 & 5.10 & 11.18 & 3.62 & 0.69 & 3.27 & 18.77 & 15.59 & 7.27 \\
\hline & & EIM & 0.27 & 4.73 & 9.46 & 3.20 & 0.17 & 1.77 & 14.60 & 24.79 & 15.65 \\
\hline & \multirow{2}{*}{ December } & BAU & 0.73 & 4.75 & 15.48 & 4.42 & 0.40 & 5.80 & 26.09 & 2.57 & 16.96 \\
\hline & & EIM & 0.05 & 4.67 & 14.17 & 3.99 & 0.21 & 3.66 & 22.03 & 4.38 & 23.03 \\
\hline \multirow{2}{*}{ Total } & & BAU & 14 & 76 & 146 & 41 & 7 & 35 & 229 & 27.5 & 26.5 \\
\hline & & EIM & 3 & 75 & 132 & 37 & 4 & 19 & 192 & 41.3 & 50.9 \\
\hline
\end{tabular}


Table 4-49. Generation, Demand, and Average Production Cost for NWPP and WECC, and NWPP Net Interchange in Case 1.94

\begin{tabular}{|c|c|c|c|c|c|c|c|c|c|}
\hline & & Scenarios & $\begin{array}{c}\text { NWPP } \\
\text { Generation } \\
\text { (GWh) }\end{array}$ & $\begin{array}{l}\text { NWPP } \\
\text { Demand } \\
\text { (GWh) }\end{array}$ & $\begin{array}{c}\text { NWPP } \\
\text { Average } \\
\text { Production } \\
\text { Cost } \\
\text { (\$/MWh) }\end{array}$ & $\begin{array}{c}\text { WECC } \\
\text { Generation } \\
\text { (GWh) }\end{array}$ & $\begin{array}{l}\text { WECC } \\
\text { Demand } \\
\text { (GWh) }\end{array}$ & $\begin{array}{c}\text { WECC } \\
\text { Average } \\
\text { Production } \\
\text { Cost } \\
\text { (\$/MWh) }\end{array}$ & $\begin{array}{l}\text { NWPP } \\
\text { Net } \\
\text { Exchange } \\
\text { (GWh) }\end{array}$ \\
\hline \multirow{6}{*}{ Q1 } & \multirow{2}{*}{ January } & BAU & 38,466 & 32,368 & 7.25 & 86,644 & 86,650 & 14.17 & $-6,098$ \\
\hline & & EIM & 38,461 & 32,368 & 7.15 & 86,644 & 86,650 & 14.14 & $-6,093$ \\
\hline & \multirow{2}{*}{ February } & BAU & 33,238 & 28,897 & 7.47 & 76,930 & 76,937 & 13.60 & $-4,342$ \\
\hline & & EIM & 33,235 & 28,897 & 7.43 & 76,930 & 76,937 & 13.59 & $-4,338$ \\
\hline & \multirow{2}{*}{ March } & BAU & 32,752 & 28,739 & 8.06 & 80,403 & 80,410 & 14.42 & $-4,013$ \\
\hline & & EIM & 32,745 & 28,739 & 8.05 & 80,403 & 80,410 & 14.42 & $-4,006$ \\
\hline \multirow{6}{*}{ Q2 } & \multirow{2}{*}{ April } & BAU & 32,305 & 26,702 & 6.82 & 77,353 & 77,360 & 12.65 & $-5,603$ \\
\hline & & EIM & 32,292 & 26,702 & 6.50 & 77,352 & 77,360 & 12.55 & $-5,590$ \\
\hline & \multirow{2}{*}{ May } & BAU & 33,983 & 27,162 & 7.55 & 83,305 & 83,313 & 13.70 & $-6,821$ \\
\hline & & EIM & 33,970 & 27,162 & 7.15 & 83,305 & 83,313 & 13.58 & $-6,808$ \\
\hline & \multirow{2}{*}{ June } & BAU & 34,166 & 27,701 & 7.59 & 87,451 & 87,456 & 15.94 & $-6,465$ \\
\hline & & EIM & 34,147 & 27,701 & 7.29 & 87,451 & 87,456 & 15.86 & $-6,446$ \\
\hline \multirow{6}{*}{ Q3 } & \multirow{2}{*}{ July } & BAU & 34,257 & 30,588 & 11.84 & 97,728 & 97,731 & 20.92 & $-3,669$ \\
\hline & & EIM & 34,251 & 30,588 & 11.71 & 97,728 & 97,731 & 20.88 & $-3,663$ \\
\hline & \multirow{2}{*}{ August } & BAU & 32,689 & 29,972 & 13.09 & 96,098 & 96,104 & 21.53 & $-2,717$ \\
\hline & & EIM & 32,683 & 29,972 & 13.10 & 96,097 & 96,104 & 21.53 & $-2,711$ \\
\hline & \multirow{2}{*}{ September } & BAU & 29,829 & 27,067 & 12.63 & 85,651 & 85,656 & 20.54 & $-2,762$ \\
\hline & & EIM & 29,827 & 27,067 & 12.55 & 85,649 & 85,656 & 20.52 & $-2,760$ \\
\hline \multirow{6}{*}{ Q4 } & \multirow{2}{*}{ October } & BAU & 30,490 & 27,528 & 11.11 & 82,604 & 82,605 & 19.16 & $-2,962$ \\
\hline & & EIM & 30,484 & 27,528 & 11.10 & 82,600 & 82,605 & 19.16 & $-2,956$ \\
\hline & \multirow{2}{*}{ November } & BAU & 33,070 & 29,190 & 8.80 & 81,458 & 81,461 & 16.19 & $-3,880$ \\
\hline & & EIM & 33,068 & 29,190 & 8.72 & 81,457 & 81,461 & 16.16 & $-3,878$ \\
\hline & \multirow{2}{*}{ December } & BAU & 36,073 & 32,780 & 9.57 & 88,542 & 88,546 & 17.59 & $-3,293$ \\
\hline & & EIM & 36,060 & 32,780 & 9.51 & 88,542 & 88,546 & 17.58 & $-3,281$ \\
\hline \multirow{2}{*}{ Total } & & BAU & 401,318 & 348,694 & 9.33 & $1,024,169$ & $1,024,230$ & 16.87 & $-52,624$ \\
\hline & & EIM & 401,225 & 348,694 & 9.20 & $1,024,158$ & $1,024,230$ & 16.83 & $-52,530$ \\
\hline
\end{tabular}




\subsection{NWPP EIM Benefits Range Summary}

Table 4-50 summarizes the total annual savings from the operation of a NWPP EIM for the Base Case and all of the sensitivity cases where the savings vary depending on the price used to value excess hydro generation. With the exception of the sensitivity cases for high and low natural gas prices, the excess hydro generation was valued at $\$ 42.00 / \mathrm{MWh}$ and $\$ 57.50 / \mathrm{MWh}$. The excess hydro generation was valued at $\$ 62.78 / \mathrm{MWh}$ and $\$ 85.94 / \mathrm{MWh}$ in the high natural gas price case and $\$ 28.40 / \mathrm{MWh}$ and $\$ 38.88 / \mathrm{MWh}$ in the low natural gas price case.

The results reported in Table 4-50 below indicate that there are a wide range of total annual savings that could be obtained from the operation of an EIM in the NWPP depending on what assumptions are made. Depending on the price used to value excess hydro generation, the results for the Base Case indicate that the EIM benefits in the NWPP footprint ranged from approximately $\$ 40$ million to $\$ 70$ million in annual savings with the benefits ranging from $\$ 233$ million to as little as $\$ 16.7$ million for the sensitivity cases.

Table 4-50. Range of Calculated NWPP EIM Benefits in 2020 (\$million)

\begin{tabular}{|c|c|c|c|}
\hline & \multirow{2}{*}{ Case Description } & \multicolumn{2}{|c|}{$\begin{array}{l}\text { Valuation of Excess Hydro } \\
\text { Generation }\end{array}$} \\
\hline & & $\begin{array}{c}\text { Equivalent } \\
\$ 42.00 \text { per } \mathrm{MWh}\end{array}$ & $\begin{array}{c}\text { Equivalent } \\
\$ 57.50 \text { per } \mathrm{MWh}\end{array}$ \\
\hline Base & $\begin{array}{l}\text { Base Case } \\
\text { (Minimum Achievable Benefits) }\end{array}$ & $\$ 41.2$ & $\$ 70.7$ \\
\hline Flexible & Increased flex reserve $(99.5 \% \mathrm{CI})$ case & $\$ 51.3$ & $\$ 78.0$ \\
\hline $\begin{array}{l}\text { Reserves } \\
\text { Requirement }\end{array}$ & Reduced EIM Flex Reserve Case & $\$ 130.6$ & $\$ 158.2$ \\
\hline \multirow[t]{2}{*}{ Inefficiencies } & 3\% Holdback Case & $\$ 71.2$ & $\$ 90.3$ \\
\hline & 6\% Holdback Case & $\$ 113.7$ & $\$ 124.9$ \\
\hline \multirow[t]{2}{*}{ Footprints } & $\begin{array}{l}\text { NWPP Savings in WECC-Wide Case } \\
\text { (Indicative Only) }\end{array}$ & $\$ 197.0$ & $\$ 233.0$ \\
\hline & NWPP EIM w/o PAC Case & $\$ 37.4$ & $\$ 63.2$ \\
\hline \multirow[t]{2}{*}{ Natural Gas Prices } & High Gas Price Case $^{1}$ & $\$ 79.4$ & $\$ 122.7$ \\
\hline & Low Gas Price Case ${ }^{2}$ & $\$ 16.7$ & $\$ 34.8$ \\
\hline \multirow{3}{*}{$\begin{array}{l}\text { Hydro } \\
\text { Alternatives }\end{array}$} & High Water Case & $\$ 60.1$ & $\$ 84.9$ \\
\hline & Low Water Case & $\$ 17.1$ & $\$ 49.5$ \\
\hline & Hydro Improvement Case & $\$ 71.6$ & $\$ 82.2$ \\
\hline
\end{tabular}

\footnotetext{
${ }^{1}$ Excess hydro energy being valued at higher electricity prices of \$62.78/MWh and \$85.94/MWh (rather than \$42.00/MWh and \$57.50/MWh

2 The excess hydro energy being valued at lower electricity prices of $\$ 28.40 / \mathrm{MWh}$ and $\$ 34.80 / \mathrm{MWh}$ (rather than \$42.00/MWh and \$57.50/MWh
} 
Figure 4.26 is a graph of the distribution of total annual savings from the operation of a NWPP EIM for the Base Case and most of the sensitivity cases where the savings vary depending on the price used to value excess hydro generation. This graph does not include the results for the WECC-wide EIM, NWPP EIM without PacifiCorp, reduced EIM Flexible Reserves, and 6\% Held Back sensitivity cases. With the exception of the sensitivity cases for high and low natural gas prices, the excess hydro generation was valued at \$42.00/MWh and \$57.50/MWh. The excess hydro generation was valued at $\$ 62.78 / \mathrm{MWh}$ and \$85.94/MWh in the high natural gas price case and \$28.40/MWh and \$38.88/MWh in the low natural gas price case. This graph indicates the EIM benefits ranged from approximately $\$ 125$ million to as little as $\$ 17$ million with the benefits for several of the sensitivity cases being clustered between $\$ 70$ million to $\$ 80$ million per year. Table 4-51 reports the NWPP EIM benefits ranged from $1.2 \%$ to $2.7 \%$ of the total NWPP production costs if the cases with very low and very high benefits are not considered.

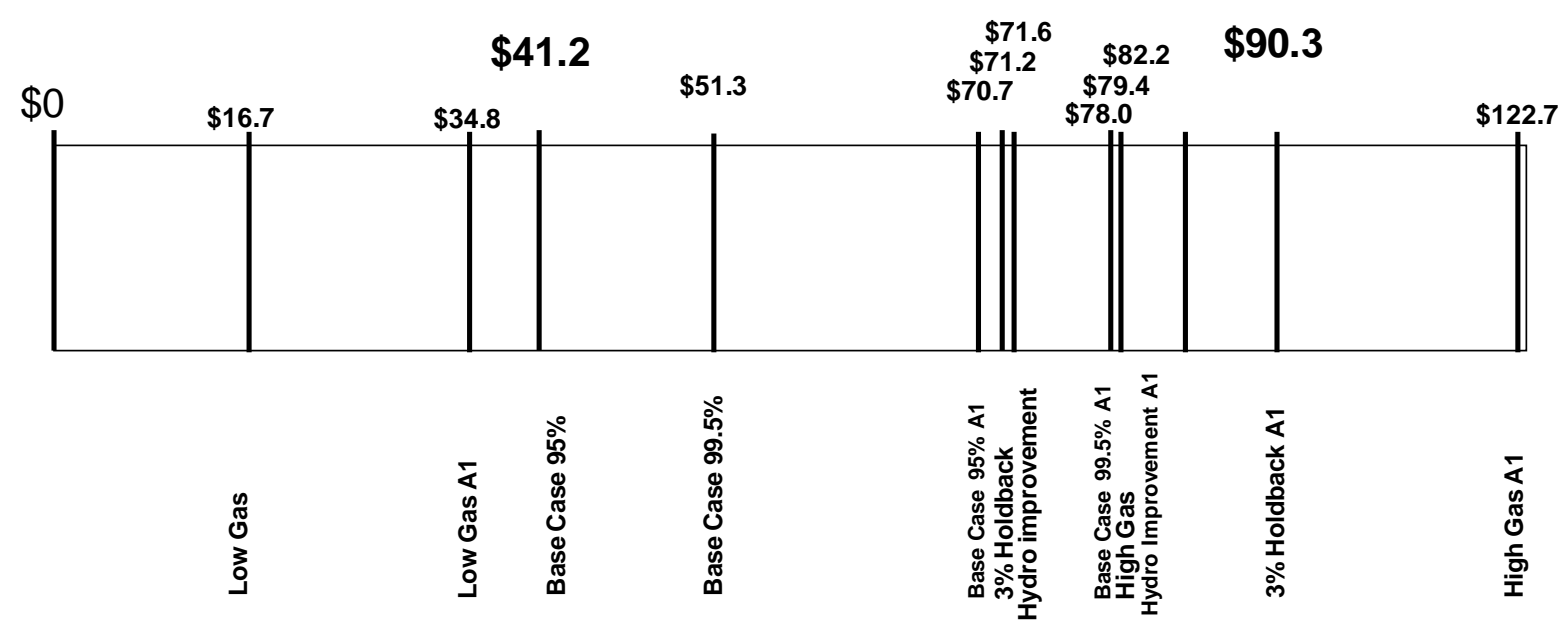

Figure 4.26. NWPP EIM Benefits Continuum ${ }^{1}$

Table 4-51. NWPP EIM Benefits Range as Percentage of Total NWPP Productions Cost

\begin{tabular}{|l|c|c|}
\hline (2020 \$ millions) & $\begin{array}{c}\text { Lower Bound } \\
\text { (Base Case } \\
\text { 95\%) } \\
\text { (Annual) }\end{array}$ & $\begin{array}{c}\text { Upper Bound } \\
\text { (3\% Holdback } \\
\text { Case) }\end{array}$ \\
\hline (Annual)
\end{tabular}

\footnotetext{
${ }^{1}$ Each case is presented with a $\$ 42.00$ per MWh and $\$ 57.50$ per MWh (A1) value for excess hydro generation.
} 


\subsection{Impact of Natural Gas Prices}

The impact that natural gas prices might have on the NWPP EIM benefits are reported in Table 4-52. The benefits from an EIM in the NWPP increase as the level of the natural gas prices increase. Relative to the Base Case, the benefits increased by about $100 \%$ in the high natural gas price case (1.86 E), while the benefits decreased by about $50 \%$ in the low natural gas price case $(1.86 \mathrm{~F})$ when the excess hydro generation was valued at $\$ 42.00 / \mathrm{MWh}$.

Table 4-52. Comparison of NWPP EIM Benefits for the Low and High Natural Gas Price Cases vs. the Base Case

\begin{tabular}{|c|c|c|}
\hline Case Description & $\begin{array}{l}\text { Valuatio } \\
\text { Hydro } \\
\text { (Annu }\end{array}$ & $\begin{array}{l}\text { Excess } \\
\text { eration } \\
\text { vings) }\end{array}$ \\
\hline $\begin{array}{l}\text { Base Case } 95 \% \text { Confidence Level for each } \\
\text { BA (Henry Hub } \$ 5.62 / \mathrm{MMbtu}) \\
\text { Implied Heat Rate (MMbtu / MWh) } \\
\text { Valuation of Excess Hydro Generation ( } \$ \text { / MWh) }\end{array}$ & $\begin{array}{c}\$ 41.2 \\
7.5 \\
\$ 42.00 / \mathrm{MWh}\end{array}$ & $\begin{array}{c}\$ 70.7 \\
\\
10.2 \\
\$ 57.50 / \mathrm{MWh}\end{array}$ \\
\hline $\begin{array}{l}\text { High Gas (Henry Hub } \$ 8.40 \text { / MMBtu) } \\
\text { Implied Heat Rate (MMbtu / MWh) } \\
\text { Valuation of Excess Hydro Generation (\$ / MWh) }\end{array}$ & $\begin{array}{c}\$ 79.4 \\
7.5 \\
\$ 62.78 / \mathrm{MWh}\end{array}$ & $\begin{array}{l}\$ 122.7 \\
10.2 \\
\$ 85.94 / \mathrm{MWh}\end{array}$ \\
\hline $\begin{array}{l}\text { Low Gas (Henry Hub } \$ 3.80 \text { / MMBtu) } \\
\text { Implied Heat Rate (MMbtu / MWh) } \\
\text { Valuation of Excess Hydro Generation ( } \$ \text { / MWh) }\end{array}$ & $\begin{array}{c}\$ 16.7 \\
7.5 \\
\$ 28.40 / \mathrm{MWh}\end{array}$ & $\begin{array}{l}\$ 34.8 \\
10.2 \\
\$ 38.88 / \mathrm{MWh}\end{array}$ \\
\hline
\end{tabular}

\subsection{Impact of Low and High Hydro Conditions}

The impact that high "wet" and low "dry" hydro conditions might have on the NWPP EIM benefits are reported in Table 4-53. The benefits from an EIM in the NWPP increase as the amounts of hydro generation increase. Relative to the Base Case, the benefits increased by about $50 \%$ in the high water case $(1.86 \mathrm{~K})$ while the benefits decreased by about $50 \%$ in the low water case $(1.86 \mathrm{~J})$ when excess hydro generation was valued at \$42.00/MWh. 
Table 4-53. Comparison of NWPP EIM Benefits for the Low and High Hydro Cases vs. Base Case

Case Description
(2020 \$ millions)
Base Case 95\% (2006 for NW \& 2003 for CA)
High Water Case (2011 Hydro Energy)
Low Water Case (2001 Hydro Energy)

Valuation of Excess Hydro Generation (Annual Savings)

$\$ 42.00$ per MWh $\$ 57.50$ per MWh

$\$ 41.2$ $\$ 70.7$

$\$ 60.1$ $\$ 84.9$

$\$ 17.1$

$\$ 49.5$

\subsection{Impact of Different Footprints}

The impact that different EIM footprints might have on the NWPP EIM benefits are reported in Table 4-54. In the sensitivity case where PAC is removed from the NWPP EIM (case 1.86H), the benefits decreased by about $10 \%$ relative to the Base Case when excess hydro generation was valued at $\$ 42.00 / \mathrm{MWh}$. In the sensitivity case of a WECC-wide EIM (case 1.86D), the benefits increased by about $350 \%$ relative to the Base Case) when excess hydro generation was valued at $\$ 42.00 / \mathrm{MWh}$. While the NWPP share of the benefits from a WECC-wide EIM exceed the benefits received using similar assumptions for an EIM limited to the NWPP, the data and model inputs for entities outside the NWPP EIM footprint could not be rigorously vetted by the NWPP MC participants, such that the results are considered INDICATIVE ONLY.

Table 4-54. Comparison of NWPP EIM Benefits with different EIM footprints vs. the Base Case

\section{Case Description}

(2020 \$ millions)

Base Case 95\% Confidence Level for each BA

NWPP EIM w/o PAC Case

NW Savings of Western Interconnection-wide EIM (Indicative Only)
Valuation of Excess Hydro Generation (Annual Savings)

$\$ 42.00$ per MWh $\$ 57.50$ per MWh

$\$ 41.2$

$\$ 70.7$

$\$ 37.4$

$\$ 63.2$

$\$ 150.9$

$\$ 186.2$ 


\subsection{Impact of Reduction in Flexible Reserve Requirements}

In this sensitivity case, load following reserves for the BAs in the NWPP were reduced by $35 \%$ as a result of calculating reserve requirements based on the NWPP footprint being a single entity rather than a group of individual BA footprints. This reduction takes into account the diversity in the variability and uncertainty of loads and non-dispatchable resources that exists throughout the NWPP footprint.

Relative to the Base Case when excess hydro generation was valued at $\$ 42.00 / \mathrm{MWh}$, the impacts that these reductions in load following requirements might have on NWPP EIM benefits were found to increase the EIM benefits by approximately 300\%, as reported in Table 4-55.

Table 4-55. Comparison of NWPP EIM Benefits with Different Flexible Reserve Requirements vs. the Base Case

\begin{tabular}{|c|c|c|}
\hline Case Description & \multicolumn{2}{|c|}{$\begin{array}{c}\text { Valuation of Excess Hyd } \\
\text { Generation } \\
\text { (Annual Savings) }\end{array}$} \\
\hline (2020 \$ millions) & $\$ 42.00$ per MWh & $\$ 57.50$ per $\mathrm{M}$ \\
\hline Base Case: 95\% Confidence Level for each BA & $\$ 41.2$ & $\$ 70.7$ \\
\hline $\begin{array}{l}\text { Flex Case: } 95 \% \text { Confidence Level for NWPP as } \\
\text { a combined area }\end{array}$ & $\$ 130.6$ & $\$ 158.2$ \\
\hline
\end{tabular}

\subsection{Impact of Holding Back More Resources in the DA-HA Periods}

In the 3\% Held Back Case (case 1.86C) and the 6\% Held Back Case (case 1.86I), 3\% and 6\% of the available hydro energy from flexible hydro plants (modeled as HTC hydro plants) and 3\% and 6\% of the maximum available capacities from thermal plants are held back in the DA and HA dispatch. Because the available hydro energy and thermal capacity are reduced in the DA and HA periods relative to the Base Case, less energy is scheduled for export from the NWPP to other BAs in the WECC and more energy and capacity are available in the NWPP for energy imbalance purposes. This situation, in turn, reduces the generation costs within the NWPP and increases the generation costs in the other BAs in the WECC.

Relative to the Base Case, the NWPP EIM benefits increased by $30 \%$ to $40 \%$ in the $3 \%$ Hold Back Case (case 1.86C) and $150 \%$ to $250 \%$ in the 6\% Hold Back Case (case 1.86I). These results are reported in Table 4-56. 
Table 4-56. Comparison of NWPP EIM Benefits with Different Percentages of Holding Back Resources in the DA-HA Periods vs. the Base Case

Case Description

(2020 \$ millions)

Base Case 95\% Confidence Level for each BA

3\% Held-back Case

6\% Held-back Case
Valuation of Excess Hydro Generation

(Annual Savings)

$\$ 42.00$ per MWh $\$ 57.50$ per MWh

$\$ 41.2$

$\$ 70.7$

$\$ 71.2$

$\$ 90.3$

$\$ 113.4$

$\$ 124.9$

\subsection{NWPP EIM Benefits Parsing Results}

Using the transaction-based parsing approach described in Section 3.5, the parsing results for the Base Case when the excess hydro generation is valued at $\$ 42.00 / \mathrm{MWh}$ are reported in Table 4-57. These results reflect how the $\$ 41.152$ million dollars in NWPP EIM benefits are parsed according to BA based on transaction volume percentages.

Table 4-57. Parsed Societal Benefits for the Base Case by BAs Participating in the NWPP EIM

\begin{tabular}{ccc}
\hline Balancing Authority & $\begin{array}{c}\text { Transaction Volume } \\
\text { Percentage }\end{array}$ & $\begin{array}{c}\text { Share of Savings in } \\
\mathrm{k} \$\end{array}$ \\
\hline AVA & $4.77 \%$ & $\$ 1,963$ \\
BCTC & $17.59 \%$ & $\$ 7,239$ \\
BPA & $25.77 \%$ & $\$ 10,605$ \\
IPC & $5.225 \%$ & $\$ 2,148$ \\
Mid C & $3.385 \%$ & $\$ 1,391$ \\
NWMT & $3.64 \%$ & $\$ 1,498$ \\
PAC & $9.85 \%$ & $\$ 4,053$ \\
PGN & $5.11 \%$ & $\$ 2,103$ \\
PSE & $5.03 \%$ & $\$ 2,070$ \\
SCL & $6.90 \%$ & $\$ 2,839$ \\
BANC & $9.25 \%$ & $\$ 3,807$ \\
TIDC & $1.84 \%$ & $\$ 757$ \\
TPWR & $1.33 \%$ & $\$ 547$ \\
WAUW & $0.32 \%$ & $\$ 132$ \\
NWPP & $100 \%$ & $\$ 41,152$ \\
\hline
\end{tabular}


An assessment was performed to evaluate the relative impacts that the primary drivers have on the transaction volumes seen in the simulations. The generators respond to wind and load variations within their BA and market opportunities for providing lower cost power to other BAs when they are responding to wind and load variations within their BA. Reported in Table 4-58 are the percentages of energy imbalance transaction volumes associated with each primary driver for each BA in the NWPP EIM under the Base Case.

Table 4-58. Percentages of Energy Imbalance Transaction Volumes by Primary Driver for Each BA in the NWPP EIM for the Base Case

\begin{tabular}{|c|c|c|c|}
\hline Zone & Wind & Load & Market \\
\hline AVA & $4 \%$ & $15 \%$ & $80 \%$ \\
\hline BCTC & $5 \%$ & $15 \%$ & $81 \%$ \\
\hline BPA & $27 \%$ & $10 \%$ & $63 \%$ \\
\hline IPC & $24 \%$ & $18 \%$ & $58 \%$ \\
\hline MidC & $0 \%$ & $10 \%$ & $90 \%$ \\
\hline NWMT & $19 \%$ & $13 \%$ & $68 \%$ \\
\hline PAC & $32 \%$ & $31 \%$ & $37 \%$ \\
\hline PGN & $26 \%$ & $23 \%$ & $51 \%$ \\
\hline PSE & $21 \%$ & $28 \%$ & $51 \%$ \\
\hline SCL & $0 \%$ & $8 \%$ & $92 \%$ \\
\hline SMUD & $0 \%$ & $12 \%$ & $88 \%$ \\
\hline TIDC & $0 \%$ & $9 \%$ & $91 \%$ \\
\hline TPWR & $0 \%$ & $20 \%$ & $80 \%$ \\
\hline WAUW & $0 \%$ & $12 \%$ & $88 \%$ \\
\hline
\end{tabular}

\subsubsection{Transaction-Based Parsing Results with PAC in the NWPP EIM}

Based on the energy imbalance transaction volumes, the parsing percentages for the BAs in the NWPP are given in Table 4-59. Unlike the parsing percentages reported in Table 4-57 that are based on only the results for the Base Case, these percentages are based on averaging the annual transaction volumes for the Base Case and sensitivity cases except for the exclusion of the results for the WECCwide EIM case (1.86D) and the NWPP EIM without PAC case $(1.86 \mathrm{H})$. In this calculation, the total energy imbalance transaction volumes include the impact of the variances from the HA schedules for both the source and sink entities. Accordingly, the transaction volumes for both the party requesting the imbalance energy and the party supplying the imbalance energy are tracked under this approach. 
Table 4-59. Average Percentage of Annual Energy Imbalance Transaction Volumes for Each BA in the NWPP EIM

\begin{tabular}{|l|r|}
\hline Transaction & Average \\
\hline Volume (MWh) & $26,068,700$ \\
\hline AVA & $4.7 \%$ \\
\hline BCTC & $17.9 \%$ \\
\hline BPA & $25.4 \%$ \\
\hline IPC & $5.1 \%$ \\
\hline MidC & $3.3 \%$ \\
\hline NWMT & $3.8 \%$ \\
\hline PAC & $10.3 \%$ \\
\hline PGN & $5.1 \%$ \\
\hline PSE & $5.0 \%$ \\
\hline SCL & $6.5 \%$ \\
\hline BANC & $9.2 \%$ \\
\hline TIDC & $1.9 \%$ \\
\hline TPWR & $1.4 \%$ \\
\hline WAUW & $0.3 \%$ \\
\hline
\end{tabular}

\subsubsection{Transaction-Based Parsing Results without PAC in the NWPP EIM}

In the sensitivity case for a NWPP EIM without PAC (case 1.86H), the PacifiCorp BA was removed from the NWPP EIM footprint, resulting in both the transaction volume and NWPP EIM benefits dropping by approximately 10\%. The results from this analysis are reported in Table 4-60.

Table 4-60. Average Percentage of Annual Energy Imbalance Transaction Volumes for Each BA in the NWPP EIM for the NWPP EIM without PAC Case (Case 1.86H)

\begin{tabular}{|l|r|}
\hline Transaction & Case $1.86 \mathrm{~h}$ \\
\hline Volume (MWh) & $23,513,955$ \\
\hline AVA & $5.05 \%$ \\
\hline BCTC & $18.51 \%$ \\
\hline BPA & $26.79 \%$ \\
\hline IPC & $6.43 \%$ \\
\hline MidC & $3.61 \%$ \\
\hline NWMT & $5.38 \%$ \\
\hline PAC & \\
\hline PGN & $5.90 \%$ \\
\hline PSE & $5.58 \%$ \\
\hline SCL & $7.58 \%$ \\
\hline SMUD & $10.81 \%$ \\
\hline TIDC & $2.13 \%$ \\
\hline TPWR & $1.53 \%$ \\
\hline WAUW & $0.34 \%$ \\
\hline
\end{tabular}




\subsection{Transmission Congestion Analysis}

Transmission paths in the WECC are defined for the Western Interconnection in a formal process that establishes the limits on the amounts of power that may flow on various segments of the transmission lines. These transmission paths and their limits are established to ensure reliable and continued operation of the grid in the face of potential line or generator outages. As such, they provide an effective medium for measuring congestion. There are 66 transmission paths in the WECC that are defined in the WECC Path Rating Catalog. In addition, there are 57 flowgates (sets of lines that are of concern) in the TEPPC PC0 case that were analyzed for congestion in the NWPP EIM study. The impacts of a NWPP EIM on the flows on the transmission lines and congestion were evaluated for each of the cases in the NWPP EIM study through a process that looks at quantitative value and risk.

In addition to analyzing the flows on the WECC and TEPPC paths, the Analytical Team analyzed the flow patterns on 81 BA-to-BA flowgates. The maximum flows for the selected BA-to-BA flowgates in the Base Case are summarized in Table 4-61. These values are raw transmission flows rather than BA-toBA transactions since these data do not account for the power injections of the remote generation units of a BA into the buses of other BAs. For example, the flows from the BANC to the CAISO include the power produced by the Sutter Energy Power Plant which is modeled as a remote generation unit of the CAISO that is located within the BANC. The results reported in Table 4-61 indicate that in the EIM case there are very few instances within the 52,704 optimization periods (total number of 10-minutes in 2020) where transmission flow constraints were violated. However an example of one instance for when a transmission flow constraint was violated is where the maximum flow limit on the transmission line from the BCTC to the BPA is $3150 \mathrm{MW}$, but this value was violated by $1241 \mathrm{MW}$ reaching to a maximum flow of $4391 \mathrm{MW}$ in one of the optimization periods.

Table 4-61. Maximum Transmission Flows on Selected BA-to-BA Flowgates for the Base Case

\begin{tabular}{lllll}
\hline & \multicolumn{3}{c}{ Case 1.86A } & \multicolumn{3}{c}{ Maximum Flow (MW) } \\
\hline From Zone & To Zone & BAU & EIM & HA \\
BCTC & AESO & 1160 & 1373 & 1160 \\
\hline BCTC & BPA & 3150 & 4391 & 3150 \\
\hline BPA & AVA & 1871 & 1916 & 1919 \\
\hline NWMT & BPA & 2287 & 2305 & 2205 \\
\hline IPC & BPA & 296 & 284 & 284 \\
\hline PACE & IPC & 3651 & 3748 & 3569 \\
\hline IPC & SPP & 500 & 564 & 500 \\
\hline IPC & PACW & 1873 & 1873 & 1873 \\
\hline IPC & PGN & 1174 & 1257 & 1175 \\
IPC & BPA & 296 & 284 & 284 \\
\hline AVA & IPC & 319 & 335 & 302 \\
\hline NWMT & PACE & 737 & 756 & 727 \\
\hline PACE & SPP & 175 & 200 & 200 \\
\hline PACE & WALC & 265 & 265 & 265 \\
\hline PACE & APS & 455 & 498 & 498 \\
\hline PACE & LDWP & 773 & 1143 & 749 \\
\hline BANC & CAISO & 1639 & 1907 & 1907 \\
\hline BPA & CAISO & 4700 & 4859 & 4784 \\
\hline PACW & CAISO & 37 & 36 & 28 \\
\hline PACW & AVA & 574 & 590 & 570 \\
\hline
\end{tabular}




\subsubsection{Path Utilization Analysis Approach}

Given the complexity and dimensionality of transmission congestion, the Analytical Team elected to use the WECC congestion metric used by TEPPC. This metric allows comparisons between actual or simulated flows on the transmission system to measure the impact of an EIM on transmission congestion. Under this congestion metric, the statistics are defined in terms of the percentage of time over the study horizon that the loadings on the transmission paths, or utilization rates, exceed $75 \%$, $90 \%$ or $99 \%$ of the Operating Transfer Capability (OTC) of the transmission path. This definition is illustrated on the flow duration curve shown in Figure 4.27 with the 75th, 90th, and 99th percentiles being labeled as U75, U90 and U99, respectively. Based upon the WECC Reliability Criteria, transmission paths are designed to be loaded up to their OTC level and be able to withstand various outage contingencies without violating the Reliability Criteria. Accordingly, high values for U75, U90 or U99 do not necessarily indicate a reliability problem. However, they are indicative of high flow conditions.

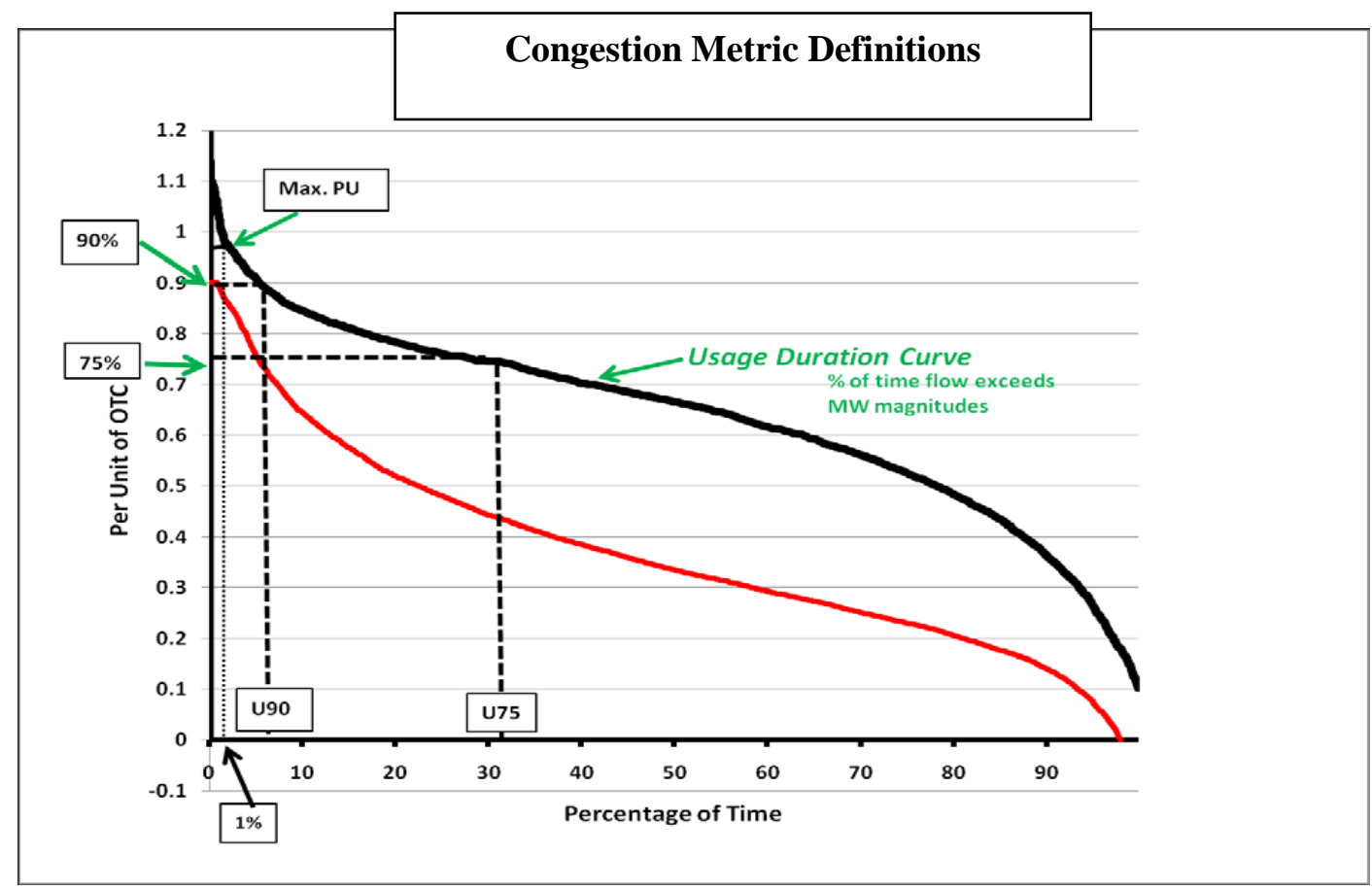

Figure 4.27. Congestion Metric Definitions

Experience has shown that loadings above approximately 75\% of the OTC may be associated with paths considered to be heavily utilized from a marketing or commercial use standpoint. The U75, U90 and U99 metrics have not been established as industry standards, but they were chosen primarily as figures of merit for comparing path usage. As noted, transmission paths loaded to these levels are designed to meet the WECC and North American Electric Reliability Corporation Reliability Criteria. 


\subsubsection{Base Case (Case 1.86A) Transmission Loading}

This section reports on the transmission loadings associated with the Base Case. The following is a comparison of actual flows during calendar year 2011and simulated flows for the HA, BAU scenario, and EIM scenario from the Base Case. The data for calendar year 2011 were provided for benchmarking the shapes of the path loadings but not the magnitude of the loadings, which are based on the results from PLEXOS for year 2020. Data used in this analysis from PLEXOS are the following:

- BAU 10-minute data

- EIM 10-minute data

- HA data

The results of the loadings on the transmission paths for the Base Case are shown in Figure 4.28. In this figure, it can be observed that there are two paths in the NWPP footprint, COI and West of Colstrip, where the flows exceed $75 \%$ of the path transfer operating limit more than $40 \%$ of the time during year 2020.

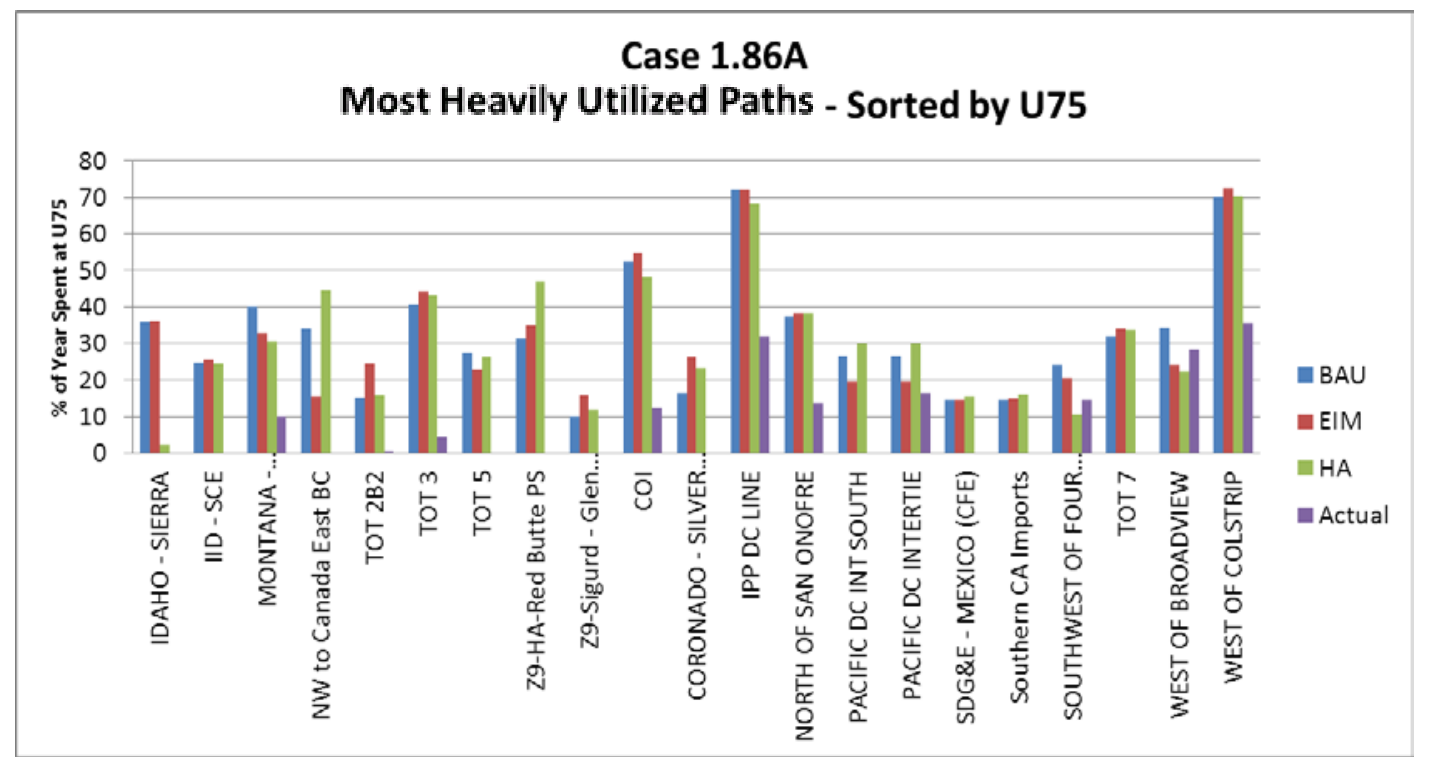

Figure 4.28. Most Heavily Used Transmission Paths in the Base Case at U75, Year 2020

Although the loadings may exceed $75 \%$ of the path transfer operating limits on the remaining paths, the durations of the transfers are of a lesser magnitude. In general, the operations associated with an EIM resulted in, on average, a $4 \%$ increase in loadings on the WECC paths within the NWPP footprint. 


\subsubsection{Reduced EIM Flex Reserve Case (Case 1.86G) Transmission Loading}

This section reports on the transmission loadings associated with the reduced EIM flexible reserves case (Case 1.86G). In this case, the load-following reserves in the NWPP are reduced in the EIM scenario with the load-following reserve for the BAU scenario being the same as in the Base Case. It was expected and the results indicated that the loadings on the transmission system within the NWPP were higher in this case as load following reserves are pooled between the BAs within the NWPP EIM.

The results of the loadings on the transmission paths for Case 1.86G are shown in Figure 4.29 In these results, the West of Crossover path is added to the list of transmission paths in the WECC where the flows exceed $75 \%$ of the path transfer operating limit more than $40 \%$ of the time in year 2020 . Also, the results for the EIM scenario indicate that the out-of-region exports decreased in response to the deficits created by the decreased reserves. Other observations made are the following:

1. increased transfer on West of Crossover

2. decreased transfer on COI

3. decreased flows on Idaho to Sierra

4. decreased flows on HA to Red Butte.

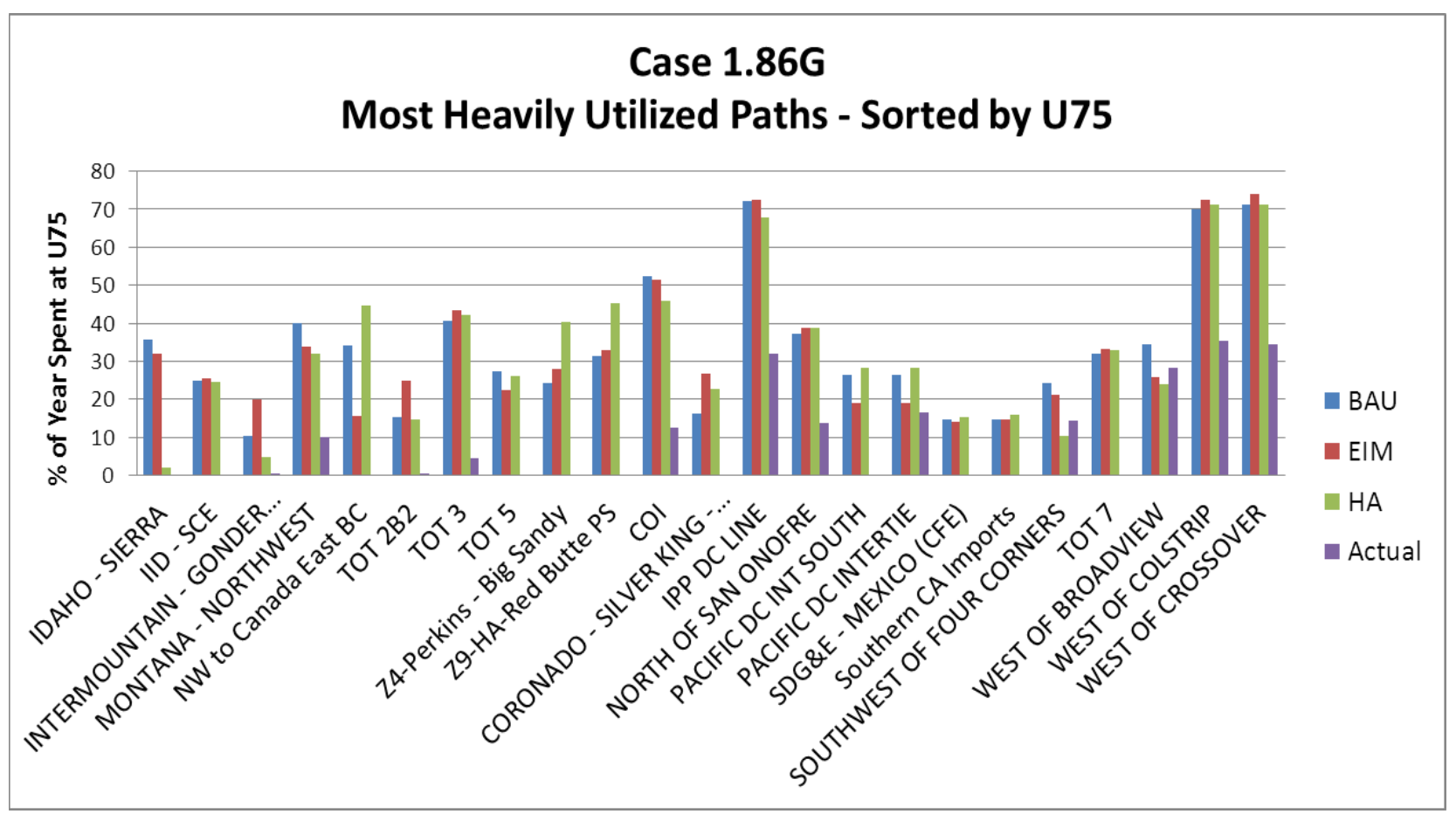

Figure 4.29. Most Heavily Used Transmission Paths in Case 1.86G at U75, Year 2020 


\subsubsection{Hydro Modeling Improvement Case (Case 1.94) Transmission Loading}

This section reports on the transmission loadings associated with the hydro modeling improvement case (Case 1.94). In this case, the loadings on the transmission paths increase within the NWPP footprint by an average of $4 \%$ in the EIM scenario relative to the BAU scenario, which is the same as the BAU scenario for the Base Case. However, in this case, the transmission path from Montana to Northwest is added to the list of transmission paths in the WECC where the flows exceed $75 \%$ of the path transfer operating limit more than $40 \%$ of the time in year 2020 . The results of the transmission loadings for this case are shown in Figure 4.30.

Additional analyses regarding the flows on the transmission paths in the WECC and from BA to BA in the Base Case are provided in Appendix E.

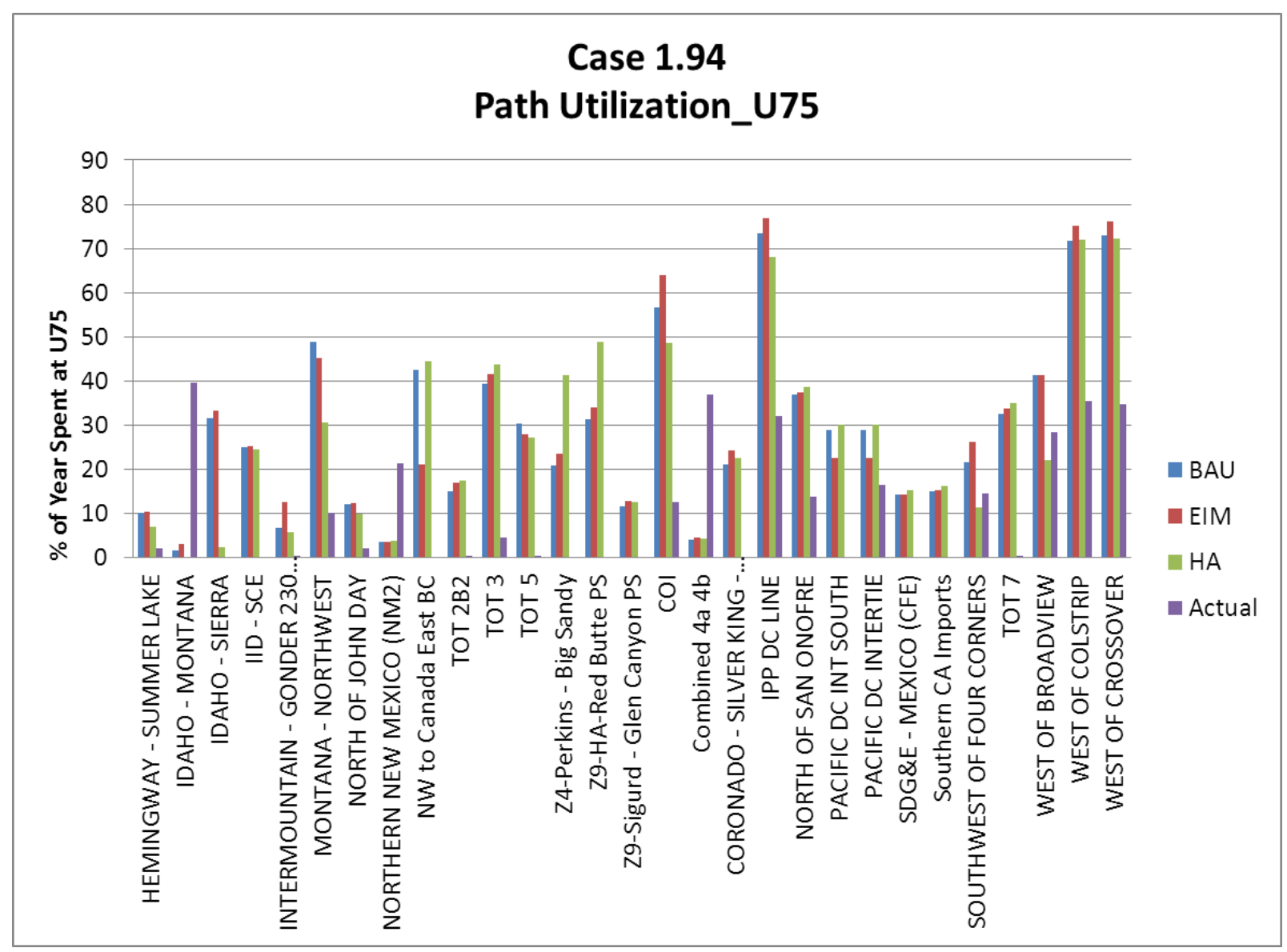

Figure 4.30. Most Heavily Used Transmission Paths in Case 1.94 at U75, Year 2020 


\subsection{Comparison of Thermal Unit Capacities Committed during the HA Period in the NWPP}

Comparisons were made between the results of the Base Case and different sensitivity cases for the differences in the amounts of thermal capacity committed during the HA period. The amounts of thermal capacity committed were based on the total of the maximum available capacity for all of the on-line thermal units within the NWPP. The results of these comparisons are the following:

a. Relative to the Base Case, there was an increase in the load following up capacity requirement in the Increased Flexible Reserve Requirement Case (case 1.86 B) of about $600 \mathrm{MW}$ while the amount of thermal capacity commitments increased by about $700 \mathrm{MW}$.

b. Relative to the Base Case, there was a decrease in the load following up capacity requirement in the Reduced Flexible Reserve Requirement Case (case 1.86G) of about $700 \mathrm{MW}$ while the amount of thermal capacity commitments decreased by about $500 \mathrm{MW}$

c. In the NWPP EIM Without PAC Case (case 1.86H), the thermal capacity in the NWPP is about 10.6 GW in comparison with about 18.6 GW in the Base Case. The PAC share is about $8 \mathrm{GW}$ in the Base Case.

d. Relative to the Base Case, there was almost no change in the amount of thermal capacity commitments in the 3\% Hold Back Case (case 1.86C) and 6\% Hold Back Case (case 1.86I).

e. Relative to the Base Case, the amount of thermal capacity commitments increased by about 100 MW in the High Natural Gas Price Case (case 1.86E) and decreased by about 50 MW in the Low Natural Gas Price Case (case 1.86F).

f. Relative to the Base Case, the amount of thermal capacity commitments increased by about 2600 MW in the Low Water Case (case 1.86J) and decreased by about 1100 MW in the High Water Case (case 1.86K).

\subsection{Comparison of Generation Mix in the BAU and EIM Scenarios for Selected Cases}

Comparisons of the real-time generation mix between the BAU and EIM scenarios for the Base Case and selected sensitivity cases are reported in Table 4-62. Observations made for the Base Case are the following:

a. There is about a $0.5 \%(1,133 \mathrm{GWh})$ decrease in hydro generation in the EIM scenario compared to in the BAU scenario due to there being higher amounts of hydro generation associated with the hydro violations in the BAU scenario.

b. There is about a $7 \%$ increase (449 GWh) in biomass generation in the EIM scenario compared to in the BAU scenario.

c. There is about a $0.5 \%$ increase (165 GWh) in CCCT generation in the EIM scenario compared to in the BAU scenario.

d. There is about a $2.6 \%$ increase ( $86 \mathrm{GWh}$ ) in geothermal generation in the EIM scenario compared to in the BAU scenario. 
e. There is about a $32.7 \%$ increase (63 GWh) in demand response usage in the EIM scenario compared to in the BAU scenario.

f. There is about a 3.2\% increase (52 GWh) in other steam generation in the EIM scenario compared to in the BAU scenario.

g. There is about a 3.6\% increase (38 GWh) in SCCT generation in the EIM scenario compared to in the BAU scenario.

h. There is about a $60 \%$ increase (27 GWh) in internal combustion generation in the EIM scenario compared to in the BAU scenario.

i. There is about a $0.3 \%$ decrease $(177 \mathrm{GWh})$ in NWPP net exports compared to in the BAU scenario.

j. There is a slight increase $0.05 \%$ (45 GWh) in the coal-fired generation in the EIM scenario compared to in the BAU scenario.

k. Nuclear generation is the same in the BAU and EIM scenarios.

l. Wind and solar generation are the same in the BAU and EIM scenarios.

In a nutshell, these results indicate that the operation of a NWPP EIM reduces the amounts of energy associated with the hydro energy violations by allowing its members greater access to the resources with its footprint. Also, the results indicate that there was almost the same amount of coal-fired generation in the BAU and EIM scenarios, which indicates that the dispatch of coal-fired units was optimal in the HA period. 
Table 4-62. NWPP BAU and EIM Generation Mix Comparisons for Selected Cases (GWh)

\begin{tabular}{|c|c|c|c|c|c|c|c|c|c|c|c|c|c|c|c|c|c|c|c|c|}
\hline 1.86A BAU & Biomass & СCCT & Hydro & SCCT & $\begin{array}{l}\text { Hyd } \\
\text { RPS }\end{array}$ & Wind & Steam & Coal & $\begin{array}{c}\text { Geother } \\
\text { mal }\end{array}$ & Nuclear & Solar & $\begin{array}{l}\text { Dmd } \\
\text { Resp }\end{array}$ & $\begin{array}{l}\text { Neg Bus } \\
\text { Ld }\end{array}$ & $\begin{array}{c}\text { Int } \\
\text { Combust }\end{array}$ & CC Recent & $\begin{array}{c}\text { CT LM } \\
6000\end{array}$ & CT Small & NI DR & IC & $\begin{array}{c}\text { Inter. } \\
\text { DR }\end{array}$ \\
\hline BAU_Q1 & 1448 & 5239 & 55650 & 262 & 843 & 13886 & 355 & 23032 & 798 & 2534 & 8 & 28 & 400 & 12 & 0 & 1 & 0 & 1 & 7 & 9 \\
\hline BAU_Q2 & 1396 & 4158 & 61028 & 291 & 1055 & 7951 & 336 & 20225 & 795 & 2534 & 9 & 51 & 400 & 7 & 0 & 1 & 0 & 1 & 7 & 13 \\
\hline BAU_Q3 & 1700 & 13138 & 45399 & 253 & 883 & 6176 & 506 & 24452 & 847 & 2561 & 10 & 70 & 404 & 13 & 103 & 7 & 0 & 0 & 37 & 16 \\
\hline BAU_Q4 & 1605 & 9270 & 47448 & 239 & 655 & 12835 & 389 & 23320 & 806 & 2561 & 7 & 45 & 404 & 13 & 17 & 1 & 0 & 0 & 21 & 15 \\
\hline BAU_Annual & 6149 & 31804 & 209525 & 1045 & 3436 & 40848 & 1587 & 91029 & 3246 & 10190 & 34 & 194 & 1607 & 45 & 120 & 11 & 1 & 3 & 72 & 53 \\
\hline 1.86A EIM & Biomass & CCCT & Hydro & SCCT & $\begin{array}{l}\text { Hyd } \\
\text { RPS }\end{array}$ & Wind & Steam & Coal & $\begin{array}{c}\text { Geother } \\
\text { mal }\end{array}$ & Nuclear & Solar & $\begin{array}{l}\text { Dmd } \\
\text { Resp }\end{array}$ & $\begin{array}{l}\text { Neg Bus } \\
\text { Ld }\end{array}$ & $\begin{array}{c}\text { Int } \\
\text { Combust }\end{array}$ & CC Recent & $\begin{array}{c}\text { CT LM } \\
6000\end{array}$ & CT Small & NI DR & IC & $\begin{array}{c}\text { Interru } \\
\text { pt DR }\end{array}$ \\
\hline EIM_Q1 & 1625 & 5326 & 55120 & 285 & 847 & 13886 & 383 & 23086 & 830 & 2534 & 8 & 74 & 400 & 20 & 0 & 1 & 0 & 1 & 8 & 22 \\
\hline EIM_Q2 & 1304 & 4043 & 61442 & 287 & 1062 & 7951 & 308 & 19949 & 834 & 2534 & 9 & 34 & 400 & 10 & 0 & 1 & 0 & 1 & 7 & 11 \\
\hline EIM_Q3 & 1837 & 13270 & 44920 & 259 & 887 & 6176 & 539 & 24574 & 850 & 2561 & 10 & 87 & 404 & 20 & 96 & 7 & 1 & 0 & 34 & 25 \\
\hline EIM_Q4 & 1832 & 9330 & 46911 & 252 & 658 & 12835 & 409 & 23466 & 818 & 2561 & 7 & 62 & 404 & 22 & 16 & 1 & 0 & 0 & 19 & 22 \\
\hline EIM_Annual & 6598 & 31969 & 208392 & 1083 & 3453 & 40848 & 1639 & 91074 & 3332 & 10190 & 34 & 257 & 1607 & 72 & 112 & 11 & 1 & 3 & 67 & 79 \\
\hline
\end{tabular}

\begin{tabular}{|c|c|c|c|c|c|c|c|c|c|c|c|c|c|c|c|c|c|c|c|c|}
\hline 1.86B BAU & Biomass & СCCT & Hydro & SCCT & $\begin{array}{l}\text { Hyd } \\
\text { RPS }\end{array}$ & Wind & Steam & Coal & $\begin{array}{c}\text { Geother } \\
\text { mal }\end{array}$ & Nuclear & Solar & $\begin{array}{l}\text { Dmd } \\
\text { Resp }\end{array}$ & $\begin{array}{c}\text { Neg Bus } \\
\text { Ld }\end{array}$ & $\begin{array}{c}\text { Int } \\
\text { Combust }\end{array}$ & CC Recent & $\begin{array}{c}\text { CT LM } \\
6000\end{array}$ & CT Small & NI DR & IC & $\begin{array}{c}\text { Inter. } \\
\text { DR }\end{array}$ \\
\hline BAU_Q1 & 1417 & 6075 & 55531 & 287 & 842 & 13886 & 378 & 22893 & 800 & 2534 & 8 & 13 & 400 & 13 & 0 & 1 & 0 & 1 & 9 & 8 \\
\hline BAU_Q2 & 1367 & 4852 & 60904 & 350 & 1055 & 7951 & 357 & 19770 & 792 & 2534 & 9 & 27 & 400 & 8 & 0 & 2 & 0 & 1 & 7 & 11 \\
\hline BAU_Q3 & 1694 & 13550 & 45353 & 308 & 884 & 6176 & 518 & 24451 & 847 & 2561 & 10 & 57 & 404 & 14 & 91 & 7 & 0 & 0 & 36 & 16 \\
\hline BAU_Q4 & 1599 & 9933 & 47349 & 274 & 654 & 12835 & 398 & 23241 & 808 & 2561 & 7 & 18 & 404 & 16 & 28 & 1 & 0 & 0 & 18 & 12 \\
\hline BAU_Annual & 6077 & 34410 & 209137 & 1219 & 3434 & 40848 & 1651 & 90355 & 3248 & 10190 & 34 & 115 & 1607 & 50 & 119 & 11 & 1 & 3 & 70 & 47 \\
\hline 1.86B EIM & Biomass & CCCT & Hydro & SCCT & $\begin{array}{l}\text { Hyd } \\
\text { RPS }\end{array}$ & Wind & Steam & Coal & $\begin{array}{c}\text { Geother } \\
\text { mal }\end{array}$ & Nuclear & Solar & $\begin{array}{l}\text { Dmd } \\
\text { Resp }\end{array}$ & $\begin{array}{l}\text { Neg Bus } \\
\text { Ld }\end{array}$ & $\begin{array}{c}\text { Int } \\
\text { Combust }\end{array}$ & CC Recent & $\begin{array}{c}\text { CT LM } \\
6000\end{array}$ & CT Small & NI DR & IC & $\begin{array}{c}\text { Inter. } \\
\text { DR }\end{array}$ \\
\hline EIM_Q1 & 1584 & 6133 & 55062 & 296 & 848 & 13886 & 388 & 22984 & 830 & 2534 & 8 & 41 & 400 & 18 & 0 & 1 & 0 & 1 & 10 & 12 \\
\hline EIM_Q2 & 1246 & 4685 & 61418 & 336 & 1063 & 7951 & 313 & 19492 & 832 & 2534 & 9 & 21 & 400 & 10 & 0 & 2 & 0 & 1 & 6 & 7 \\
\hline EIM_Q3 & 1833 & 13701 & 44890 & 307 & 887 & 6176 & 535 & 24578 & 850 & 2561 & 10 & 66 & 404 & 19 & 85 & 7 & 1 & 0 & 32 & 19 \\
\hline EIM_Q4 & 1810 & 9964 & 46863 & 276 & 658 & 12835 & 415 & 23397 & 818 & 2561 & 7 & 40 & 404 & 21 & 28 & 1 & 0 & 0 & 15 & 15 \\
\hline EIM_Annual & 6473 & 34483 & 208233 & 1215 & 3456 & 40848 & 1652 & 90451 & 3331 & 10190 & 34 & 168 & 1607 & 68 & 112 & 11 & 1 & 3 & 64 & 52 \\
\hline
\end{tabular}




\section{Table 4-62 (Cont,)}

\begin{tabular}{|c|c|c|c|c|c|c|c|c|c|c|c|c|c|c|c|c|c|c|c|c|}
\hline $1.86 \mathrm{C}$ BAU & Biomass & CCCT & Hydro & SCCT & $\begin{array}{l}\text { Hyd } \\
\text { RPS }\end{array}$ & Wind & Steam & Coal & $\begin{array}{c}\text { Geother } \\
\text { mal }\end{array}$ & Nuclear & Solar & $\begin{array}{l}\text { Dmd } \\
\text { Resp }\end{array}$ & $\begin{array}{l}\text { Neg Bus } \\
\text { Ld }\end{array}$ & $\begin{array}{c}\text { Int } \\
\text { Combust }\end{array}$ & CC Recent & $\begin{array}{l}\text { CT LM } \\
6000\end{array}$ & CT Small & NI DR & IC & $\begin{array}{c}\text { Inter. } \\
\text { DR }\end{array}$ \\
\hline BAU_Q1 & 1240 & 5484 & 55243 & 251 & 839 & 13886 & 306 & 22670 & 784 & 2534 & 8 & 7 & 400 & 12 & 0 & 1 & 0 & 1 & 5 & 6 \\
\hline BAU_Q2 & 1272 & 4349 & 60757 & 274 & 1054 & 7951 & 287 & 19989 & 779 & 2534 & 9 & 11 & 400 & 8 & 0 & 1 & 0 & 1 & 6 & 9 \\
\hline BAU_Q3 & 1568 & 13206 & 45193 & 247 & 881 & 6176 & 469 & 24311 & 846 & 2561 & 10 & 18 & 404 & 13 & 116 & 8 & 1 & 0 & 39 & 12 \\
\hline BAU_Q4 & 1416 & 9299 & 47131 & 232 & 649 & 12835 & 338 & 23064 & 801 & 2561 & 7 & 4 & 404 & 12 & 37 & 1 & 0 & 0 & 20 & 13 \\
\hline BAU_Annual & 5496 & 32337 & 208323 & 1004 & 3422 & 40848 & 1400 & 90033 & 3210 & 10190 & 34 & 41 & 1607 & 46 & 153 & 11 & 1 & 3 & 70 & 41 \\
\hline $1.86 \mathrm{C}$ EIM & Biomass & CCCT & Hydro & SCCT & $\begin{array}{l}\text { Hyd } \\
\text { RPS }\end{array}$ & Wind & Steam & Coal & $\begin{array}{c}\text { Geother } \\
\text { mal }\end{array}$ & Nuclear & Solar & $\begin{array}{l}\text { Dmd } \\
\text { Resp }\end{array}$ & $\begin{array}{l}\text { Neg Bus } \\
\text { Ld }\end{array}$ & $\begin{array}{c}\text { Int } \\
\text { Combust }\end{array}$ & CC Recent & $\begin{array}{l}\text { CT LM } \\
6000\end{array}$ & CT Small & NI DR & IC & $\begin{array}{l}\text { Interru } \\
\text { pt DR }\end{array}$ \\
\hline EIM_Q1 & 1469 & 5342 & 55048 & 259 & 847 & 13886 & 334 & 22580 & 830 & 2534 & 8 & 28 & 400 & 16 & 0 & 1 & 0 & 1 & 5 & 8 \\
\hline EIM_Q2 & 1171 & 4125 & 61412 & 273 & 1063 & 7951 & 273 & 19517 & 833 & 2534 & 9 & 16 & 400 & 9 & 0 & 1 & 0 & 1 & 5 & 5 \\
\hline EIM_Q3 & 1809 & 13017 & 44857 & 245 & 886 & 6176 & 493 & 24547 & 850 & 2561 & 10 & 35 & 404 & 16 & 101 & 8 & 1 & 0 & 29 & 9 \\
\hline EIM_Q4 & 1737 & 8934 & 46833 & 235 & 658 & 12835 & 374 & 23291 & 818 & 2561 & 7 & 24 & 404 & 16 & 33 & 1 & 0 & 0 & 16 & 9 \\
\hline EIM_Annual & 6186 & 31418 & 208151 & 1012 & 3453 & 40848 & 1473 & 89934 & 3331 & 10190 & 34 & 104 & 1607 & 57 & 134 & 11 & 1 & 3 & 55 & 31 \\
\hline
\end{tabular}

\begin{tabular}{|c|c|c|c|c|c|c|c|c|c|c|c|c|c|c|c|c|c|c|c|c|}
\hline 1.86E BAU & Biomass & CCCT & Hydro & SCCT & $\begin{array}{l}\text { Hyd } \\
\text { RPS }\end{array}$ & Wind & Steam & Coal & $\begin{array}{c}\text { Geother } \\
\text { mal }\end{array}$ & Nuclear & Solar & $\begin{array}{l}\text { Dmd } \\
\text { Resp }\end{array}$ & $\begin{array}{c}\text { Neg Bus } \\
\text { Ld }\end{array}$ & $\begin{array}{c}\text { Int } \\
\text { Combust }\end{array}$ & CC Recent & $\begin{array}{c}\text { CT LM } \\
6000\end{array}$ & CT Small & $\mathrm{NI} \mathrm{DR}$ & IC & $\begin{array}{c}\text { Inter. } \\
\text { DR }\end{array}$ \\
\hline BAU_Q1 & 1501 & 5276 & 55597 & 271 & 844 & 13886 & 413 & 23067 & 800 & 2534 & 8 & 29 & 400 & 13 & 0 & 0 & 0 & 1 & 2 & 10 \\
\hline BAU_Q2 & 1471 & 4270 & 61031 & 300 & 1056 & 7951 & 369 & 20371 & 798 & 2534 & 9 & 53 & 400 & 9 & 2 & 1 & 0 & 1 & 5 & 16 \\
\hline BAU_Q3 & 1751 & 13724 & 45377 & 240 & 884 & 6176 & 590 & 24487 & 847 & 2561 & 10 & 73 & 404 & 14 & 108 & 4 & 0 & 0 & 20 & 17 \\
\hline BAU_Q4 & 1638 & 9281 & 47407 & 244 & 654 & 12835 & 441 & 23400 & 807 & 2561 & 7 & 43 & 404 & 15 & 6 & 1 & 0 & 0 & 6 & 16 \\
\hline BAU_Annual & 6362 & 32550 & 209412 & 1053 & 3439 & 40848 & 1813 & 91325 & 3252 & 10190 & 34 & 198 & 1607 & 51 & 116 & 7 & 0 & 3 & 34 & 58 \\
\hline 1.86E EIM & Biomass & СCCT & Hydro & SCCT & $\begin{array}{l}\text { Hyd } \\
\text { RPS }\end{array}$ & Wind & Steam & Coal & $\begin{array}{c}\text { Geother } \\
\text { mal }\end{array}$ & Nuclear & Solar & $\begin{array}{l}\text { Dmd } \\
\text { Resp }\end{array}$ & $\begin{array}{l}\text { Neg Bus } \\
\text { Ld }\end{array}$ & $\begin{array}{c}\text { Int } \\
\text { Combust }\end{array}$ & CC Recent & $\begin{array}{c}\text { CT LM } \\
6000\end{array}$ & CT Small & NI DR & IC & $\begin{array}{l}\text { Interru } \\
\text { pt DR }\end{array}$ \\
\hline EIM_Q1 & 1663 & 5361 & 55113 & 289 & 847 & 13886 & 432 & 23110 & 830 & 2534 & 8 & 72 & 400 & 21 & 0 & 0 & 0 & 1 & 2 & 21 \\
\hline EIM_Q2 & 1365 & 4135 & 61444 & 296 & 1062 & 7951 & 351 & 20127 & 834 & 2534 & 9 & 37 & 400 & 13 & 2 & 1 & 0 & 1 & 5 & 12 \\
\hline EIM_Q3 & 1923 & 13868 & 44893 & 245 & 887 & 6176 & 621 & 24591 & 850 & 2561 & 10 & 74 & 404 & 20 & 99 & 4 & 0 & 0 & 18 & 22 \\
\hline EIM_Q4 & 1887 & 9325 & 46902 & 255 & 658 & 12835 & 444 & 23520 & 818 & 2561 & 7 & 63 & 404 & 24 & 6 & 1 & 0 & 0 & 5 & 22 \\
\hline EIM_Annual & 6838 & 32689 & 208353 & 1085 & 3453 & 40848 & 1848 & 91348 & 3331 & 10190 & 34 & 246 & 1607 & 78 & 106 & 7 & 0 & 3 & 30 & 77 \\
\hline
\end{tabular}


Table 4-62 (Cont.)

\begin{tabular}{|c|c|c|c|c|c|c|c|c|c|c|c|c|c|c|c|c|c|c|c|c|}
\hline $1.86 \mathrm{~F} B A U$ & Biomass & СССТ & Hydro & SCCT & $\begin{array}{l}\text { Hyd } \\
\text { RPS }\end{array}$ & Wind & Steam & Coal & $\begin{array}{c}\text { Geother } \\
\text { mal }\end{array}$ & Nuclear & Solar & $\begin{array}{l}\text { Dmd } \\
\text { Resp }\end{array}$ & $\begin{array}{l}\text { Neg Bus } \\
\text { Ld }\end{array}$ & $\begin{array}{c}\text { Int } \\
\text { Combust }\end{array}$ & CC Recent & $\begin{array}{l}\text { CT LM } \\
6000\end{array}$ & CT Small & NI DR & IC & $\begin{array}{c}\text { Inter. } \\
\text { DR }\end{array}$ \\
\hline BAU_Q1 & 1401 & 5100 & 55613 & 256 & 842 & 13886 & 281 & 22852 & 790 & 2534 & 8 & 31 & 400 & 8 & 0 & 2 & 0 & 1 & 27 & 8 \\
\hline BAU_Q2 & 1300 & 4066 & 60955 & 294 & 1054 & 7951 & 240 & 19811 & 785 & 2534 & 9 & 47 & 400 & 3 & 0 & 2 & 1 & 1 & 18 & 8 \\
\hline BAU_Q3 & 1643 & 12679 & 45380 & 292 & 882 & 6176 & 473 & 24414 & 846 & 2561 & 10 & 65 & 404 & 10 & 99 & 11 & 1 & 0 & 68 & 13 \\
\hline BAU_Q4 & 1590 & 9167 & 47413 & 242 & 653 & 12835 & 337 & 23259 & 806 & 2561 & 7 & 44 & 404 & 8 & 37 & 3 & 1 & 0 & 50 & 12 \\
\hline BAU_Annual & 5934 & 31011 & 209360 & 1084 & 3431 & 40848 & 1331 & 90335 & 3228 & 10190 & 34 & 187 & 1607 & 30 & 137 & 17 & 2 & 3 & 162 & 40 \\
\hline 1.86F EIM & Biomass & СССТ & Hydro & SCCT & $\begin{array}{l}\text { Hyd } \\
\text { RPS }\end{array}$ & Wind & Steam & Coal & $\begin{array}{c}\text { Geother } \\
\text { mal }\end{array}$ & Nuclear & Solar & $\begin{array}{l}\text { Dmd } \\
\text { Resp }\end{array}$ & $\begin{array}{l}\text { Neg Bus } \\
\text { Ld }\end{array}$ & $\begin{array}{c}\text { Int } \\
\text { Combust }\end{array}$ & CC Recent & $\begin{array}{c}\text { CT LM } \\
6000\end{array}$ & CT Small & NI DR & IC & $\begin{array}{c}\text { Inter. } \\
\text { DR }\end{array}$ \\
\hline EIM_Q1 & 1576 & 5205 & 55130 & 276 & 847 & 13886 & 295 & 22857 & 830 & 2534 & 8 & 73 & 400 & 15 & 0 & 2 & 0 & 1 & 25 & 22 \\
\hline EIM_Q2 & 1223 & 3972 & 61433 & 285 & 1061 & 7951 & 212 & 19436 & 833 & 2534 & 9 & 27 & 400 & 5 & 0 & 1 & 0 & 1 & 14 & 9 \\
\hline EIM_Q3 & 1805 & 12771 & 44919 & 296 & 887 & 6176 & 483 & 24547 & 850 & 2561 & 10 & 88 & 404 & 16 & 96 & 11 & 1 & 0 & 57 & 25 \\
\hline EIM_Q4 & 1794 & 9221 & 46915 & 257 & 660 & 12835 & 358 & 23400 & 818 & 2561 & 7 & 58 & 404 & 13 & 36 & 3 & 1 & 0 & 45 & 20 \\
\hline EIM_Annual & 6399 & 31170 & 208396 & 1115 & 3456 & 40848 & 1348 & 90240 & 3332 & 10190 & 34 & 247 & 1607 & 49 & 131 & 18 & 3 & 3 & 141 & 76 \\
\hline
\end{tabular}

\begin{tabular}{|c|c|c|c|c|c|c|c|c|c|c|c|c|c|c|c|c|c|c|c|c|}
\hline 1.86G BAU & Biomass & СССТ & Hydro & SCCT & $\begin{array}{l}\text { Hyd } \\
\text { RPS }\end{array}$ & Wind & Steam & Coal & $\begin{array}{c}\text { Geother } \\
\text { mal }\end{array}$ & Nuclear & Solar & $\begin{array}{l}\text { Dmd } \\
\text { Resp }\end{array}$ & $\begin{array}{l}\text { Neg Bus } \\
\text { Ld }\end{array}$ & $\begin{array}{c}\text { Int } \\
\text { Combust }\end{array}$ & CC Recent & $\begin{array}{c}\text { CT LM } \\
6000\end{array}$ & CT Small & NI DR & IC & $\begin{array}{c}\text { Inter. } \\
\text { DR }\end{array}$ \\
\hline BAU_Q1 & 1448 & 5239 & 55650 & 262 & 843 & 13886 & 355 & 23032 & 798 & 2534 & 8 & 28 & 400 & 12 & 0 & 1 & 0 & 1 & 7 & 9 \\
\hline BAU_Q2 & 1396 & 4158 & 61028 & 291 & 1055 & 7951 & 336 & 20225 & 795 & 2534 & 9 & 51 & 400 & 7 & 0 & 1 & 0 & 1 & 7 & 13 \\
\hline BAU_Q3 & 1700 & 13138 & 45399 & 253 & 883 & 6176 & 506 & 24452 & 847 & 2561 & 10 & 70 & 404 & 13 & 103 & 7 & 0 & 0 & 37 & 16 \\
\hline BAU_Q4 & 1605 & 9270 & 47448 & 239 & 655 & 12835 & 389 & 23320 & 806 & 2561 & 7 & 45 & 404 & 13 & 17 & 1 & 0 & 0 & 21 & 15 \\
\hline BAU_Annual & 6149 & 31804 & 209525 & 1045 & 3436 & 40848 & 1587 & 91029 & 3246 & 10190 & 34 & 194 & 1607 & 45 & 120 & 11 & 1 & 3 & 72 & 53 \\
\hline 1.86G EIM & Biomass & СССТ & Hydro & SCCT & $\begin{array}{l}\text { Hyd } \\
\text { RPS }\end{array}$ & Wind & Steam & Coal & $\begin{array}{c}\text { Geother } \\
\text { mal }\end{array}$ & Nuclear & Solar & $\begin{array}{l}\text { Dmd } \\
\text { Resp }\end{array}$ & $\begin{array}{l}\text { Neg Bus } \\
\text { Ld }\end{array}$ & $\begin{array}{c}\text { Int } \\
\text { Combust }\end{array}$ & CC Recent & $\begin{array}{c}\text { CT LM } \\
6000\end{array}$ & CT Small & NI DR & IC & $\begin{array}{l}\text { Interru } \\
\text { pt DR }\end{array}$ \\
\hline EIM_Q1 & 1639 & 4676 & 55175 & 272 & 846 & 13886 & 371 & 23032 & 831 & 2534 & 8 & 99 & 400 & 16 & 0 & 2 & 0 & 1 & 7 & 29 \\
\hline EIM_Q2 & 1330 & 3437 & 61458 & 264 & 1061 & 7951 & 278 & 20115 & 834 & 2534 & 9 & 55 & 400 & 8 & 0 & 1 & 0 & 1 & 7 & 17 \\
\hline EIM_Q3 & 1836 & 12926 & 44938 & 245 & 887 & 6176 & 502 & 24566 & 850 & 2561 & 10 & 105 & 404 & 13 & 100 & 7 & 0 & 0 & 35 & 30 \\
\hline EIM_Q4 & 1823 & 8678 & 46942 & 237 & 658 & 12835 & 396 & 23478 & 818 & 2561 & 7 & 77 & 404 & 9 & 26 & 2 & 0 & 0 & 20 & 27 \\
\hline EIM_Annual & 6628 & 29717 & 208514 & 1017 & 3451 & 40848 & 1547 & 91191 & 3333 & 10190 & 34 & 336 & 1607 & 46 & 126 & 12 & 1 & 3 & 68 & 103 \\
\hline
\end{tabular}




\subsection{Study Results, Conclusions, and Limitations}

The following discussions are based on the results from the EIM benefits analyses and do not account for the costs of implementing an EIM in the NWPP. The results produced in this study are conservative and reflect the instructions from the MC to determine a "minimum high confidence" range of potential benefits from an EIM. The representation of existing preschedule bilateral trades, coordination of BAs by dynamic schedules, and the benefits from various joint initiatives between BAs was an important component of this study. The incorporation of these existing deals into the production cost model (PLEXOS) at levels that exist today reduced the EIM benefits by approximately 50\% compared to the results calculated in prior studies performed by other entities.

\subsection{Study Results}

The conservative estimates of the benefits of a NWPP EIM in the year 2020 were clustered within the range of $\$ 70$ million to 80 million in annual savings for the various cases and scenarios studied. The minimum high confidence amount of savings was approximately $\$ 40$ million per year in the Base Case study. Low outlier cases where benefits were lower than this range occurred under low natural gas prices and low hydro generation due to poor water conditions. The upper range of the higher confidence savings was approximately $\$ 90$ million per year. Increases in the annual savings were observed with higher (i.e., more conservative) reserve requirements, higher amounts of hydro generation, higher amounts of resource capability held back during the preschedule period, higher natural gas prices, and improved resource operations. Higher upside outlier cases were observed if flexible reserve requirements could be reduced because of the load and resource diversity within the NWPP EIM footprint, where the potential savings could jump to a range between \$130 million and 158 million per year, and for a WECC-wide EIM, where the NWPP benefits could range between $\$ 197$ million to \$233 million per year.

The benefits from a NWPP EIM were small compared to the total production costs of operating the NWPP and WECC systems. The benefits ranged from approximately 1-3\% of the $\$ 3.3$ billion in production costs calculated for the NWPP by PLEXOS. The results indicate that the differences between the production costs for the BAU and EIM scenarios can vary considerably even when there are only small changes made to the assumptions and/or input data.

The benefits produced by the operation of an EIM in the NWPP are primarily driven by the economic displacement of higher-cost resources required by individual BAs operating individually in an hourly scheduling mode versus collectively operating in an EIM. When combined in real time with other BAs in the NWPP via an EIM, higher-cost generation in one BA can be replaced with lower-cost generation in another BA within the NWPP. These savings in production costs were found to create approximately $69 \%$ of the total benefits of an EIM. The total benefits also took into account the diversity in the variability and uncertainty of loads and non-dispatchable resources that exist among the BAs in the NWPP footprint.

The energy transactions and other arrangements not now known for the year 2020 were approximated in PLEXOS by optimizing the trade arrangements made in the HA time frame to develop interchange schedules and commitments. While this assumption produced the "minimum high confidence" range of results, it also understates the additional benefits that can be gained from an EIM. Inefficiencies in the preschedule period due to time constraints, unavailability of information, constraining business practices, 
and/or overly conservative margins to cover variability and load forecasting errors will be removed in an EIM. These benefits are in addition to capturing the benefits from more load and resource diversity and more efficient economic dispatch of the combination of resource stacks. Sensitivity cases were performed with energy and capacity held out of the preschedule interchanges and efficiency optimization. The results for these cases indicated significantly larger benefits for the EIM scenario than operation under the BAU scenario.

There is still substantial room for improvement in modeling hydro generation for energy constrained systems such as those in the NWPP. Excess hydro generation was used by PLEXOS when hydro generation could not be shaped properly over some periods. This excess hydro generation should have been replaced by the committed thermal generation that was available. To more accurately compare the production costs of the cases in this event, the Analytical Team developed an approach external to PLEXOS that values this additional excess hydro generation at the cost of available thermal generation in the surrounding time segments. This excess hydro generation was valued at two different price levels to provide a range of values for comparative purposes. The results from these valuations were included in the computations of total savings. A sensitivity case was also modeled using a "look ahead" technique where operators and dispatchers were assumed to have better ability to look ahead in the hour and adjust operations (as is done in real life). This approach yielded significant reductions in the amounts of excess hydro generation and significantly higher savings in production costs for the BAU scenario and EIM scenario with the total savings from an EIM increasing relative to the BAU.

Most of the cases were performed holding the same levels of capacity reserves going into the real time period in both the EIM and BAU scenarios since this was not a study of either the capacity savings which might accrue to an EIM or a resource sufficiency study. However, one such case was performed which indicated that the capacity reserve requirements could be reduced by approximately $30 \%$ with there being a substantial increase in savings for the EIM scenario compared to BAU scenario, if the BAs in the NW operated as a combined NWPP BA. The annual total savings in the range of \$130 million to $\$ 160$ million for this case was caused by fewer thermal units needing to be committed and, in turn, running at minimum generation levels. That also resulted in reducing NWPP EIM total annual export energy by $3.9 \%$ in comparison with the Base Case BAU scenario.

Several sensitivity cases examined the effect of increasing the amounts of capacity reserves to cover tail event variations by increasing the confidence interval for computing the amount of load following reserves. As expected, the higher amounts of capacity reserves held out to cover tail event variations in the individual BAs in the BAU scenarios caused an increase in the total savings from the operations of an EIM where the operations for the BAs are combined.

A sensitivity case was performed to determine the benefits of a WECC-wide EIM compared with a BAU scenario having WECC-wide hourly scheduling. The results for this sensitivity case indicate that under a WECC-wide EIM the NWPP would provide significant balancing and economic resource displacement benefits to California and overall WECC-wide societal benefits. The value of these benefits for the NWPP could be as high as \$256 million per year.

A sensitivity case was also performed to quantify the effect of a NWPP EIM that is hypothetically without PacifiCorp being a member. The results from this case indicate that the EIM benefits to the remaining NWPP members would be reduced by approximately $10 \%$. 
Overall societal benefits for a NWPP EIM were also parsed and estimated for each of the individual BAs in the NWPP EIM footprint. Because of the large volumes of wind and hydro generation having zero marginal costs in the NWPP system, the use of locational imbalance prices was problematic and parsing was performed using the volume of transactions each BA made in the year 2020 based on the results from PLEXOS. The volumes of transactions reflected the differences in the amounts of sales or purchases each utility made in the EIM scenario compared to the BAU scenario. The parsing methodology measured the volumes of intra-hour transactions between the BAs and then assumed that the proportion of total annual savings would flow to the BAs in proportion to their respective shares of the overall transaction volume.

This parsing methodology was found to produce results that are stable and robust. The percentages of the parsed benefits for each individual BA in the NWPP EIM footprint were similar for most of the cases. It is expected that the relative differences between the cost of power purchases and revenue from surplus sales in the NWPP EIM will remain approximately the same between the BAs in the NWPP EIM footprint even if there are fluctuations in the market prices.

An analysis of the amounts of loadings on the major transmission paths (flowgates) in the WECC indicates that some flowgates become heavily loaded slightly more often in the EIM scenario than in the BAU scenario. However, there are also some flowgates which experience reductions in flows. The EIM scenarios were performed based on using a security constrained dispatch algorithm, which with a few exceptions where flow limits are violated in the simulations during the real time period, holds flowgate loadings below their system operating limits.

\subsection{Limitations of Production Cost Modeling}

The production cost model (PLEXOS) used by the MC Initiative Analytical Team produced results that are a rough surrogate for the results that would be obtained by modeling an EIM. PLEXOS was not designed to simulate the operation of a market, but rather the operation of a set of power system elements. Particularly challenging in the process was representing the complex monthly, weekly, hourly and intrahour "budgeting" process for flexible hydroelectric facilities, which involves considering not just the immediate market value of the generation and unit capabilities, but also how operational and economic decisions made in one time frame might affect operational capabilities and economic conditions in future time frames.

This complexity resulted in PLEXOS not being able to accurately simulate a reasonable dispatch of significant amounts of hydroelectric resources within the NWPP for some outcomes. The Analytical Team had to develop an approach external to PLEXOS to address such outcomes. The way actual hydroelectric production decisions are made could have fairly significant effects on the modeling of hydro operations in and results from the PCM. Better modeling of the hydro generation for the energy constrained hydro systems that exist in the NW is needed.

The modeling effort used an Interchange Scheduling Method to more accurately represent the operation of individual BAs, which are responsible for balancing their own respective load and resource variability and forecast errors. Implementing this approach requires knowledge of contractual and other transactional arrangements between BAs. When these were specifically known and expected to remain in 2020, they were explicitly represented as best they could be modeled in PLEXOS. It is critical in an EIM 
analysis to try and model preschedule efficiencies well. Any inefficiencies that remain in the HA periods will be removed and the benefits attributed to the EIM.

The instructions to the Analytical Team were to find the "minimum high confidence range of benefits" and also fix the four data issues discussed in Section 3.7. For these reasons, the interchange schedules between the BAs in the BAU scenarios were set based on results from the optimization of the HA period across the WECC with the exception of the known arrangements. Accordingly, the lack of information about known contracts and arrangements is a limitation of the modeling.

Despite these challenges, the expert economic dispatch analysts who participated in the Analytical Team have expressed a reasonable level of confidence in the results while acknowledging the complexities of the modeling process.

\subsection{Suggested Improvements for Additional Analyses}

If additional studies are required for either the NWPP MC Initiative or for other analyses relative to the work performed for the MC, there are many improvements that could be made to the information and logic of the PCM. Some of these improvements are the following:

- reviewing and scrubbing of data in the WECC-wide EIM case for other areas to the extent done by members of the NWPP for the NW area

- inputting better heat rate curves for thermal units

- better operational models of energy constrained coordinated hydro systems

- more detail on Canadian hydro and system operations

- faster and better ability to perform round trips between the power flow and voltage stability programs and the production cost model. This would allow reliability analyses to be performed.

- addition of market bidding algorithms, which could replicate voluntary bidding processes into the solution

- better understanding of the implications of 15-minute scheduling for an EIM.

Lastly, a WECC-wide home for the operational simulation data base is needed so that entities located throughout the WECC interconnection can use the data base and make improvements. This availability will allow joint studies by various entities within the WECC. 


\subsection{References}

[1] Damiano P. 2013. The Northwest Power Pool Members' Market Assessment and Coordination Committee (MC) Initiative - EMT WG \& EIM WG Update. [Online.] Accessed August 15, 2013, at http://www.nwpp.org/documents/MC-Public/Jan.-25-Public-Meeting_NWPP-MC-EIM-EMTWorkgroup-Update.pdf.

[2] Western Electricity Coordinating Council. 2010. Assumptions Matrix for the 2020 TEPPC Dataset. [Online.] Accessed August 15, 2013, at http://www.wecc.biz/library/StudyReport/Documents/Assumptions\%20Matrix\%20for\%20the\%2 02020\%20TEPPC\%20Dataset.pdf.

[3] Orans R, A Olson and J Moore (E3: Energy and Environmental Economics). 2011. WECC EDT Phase 2 EIM Benefits Analysis \& Results (October 2011 Revision). [Online.] Accessed August 15, 2013, at http://www.wecc.biz/committees/EDT/Documents/E3 EIM Benefits StudyPhase_2_Report_RevisedOct2011_CLEAN2[1].pdf.

[4] Samaan N, M Milligan, YV Makarov, M Hunsaker, T Nguyen, C Jin, R Diao and R Hafen. Balancing Authority Cooperation Concepts to Reduce Variable Generation Integration Costs in the Western Interconnection: Balancing Authorities Consolidation and Sharing of Balancing Reserves. Final Project Report, Pacific Northwest National Laboratory, Richland, Washington. To be published in November 2013.

[5] Hunsaker M, N Samaan, M Milligan, T Guo, G Liu and J Toolson. 2013. Balancing Authority Cooperation Concepts to Reduce Variable Generation Integration Costs in the Western Interconnection: Intra-Hour Scheduling. Final WECC Project Report. [Online.] Accessed August 15, 2013, at

http://www.wecc.biz/committees/StandingCommittees/JGC/VGS/Shared\%20Documents/BA\%20 Cooperation\%20Study/Final\%20Report/Balancing\%20Authority\%20Cooperation\%20Concepts\% 20-\%20Intra-Hour\%20Scheduling.pdf.

[6] Milligan M, K Clark, J King, B Kirby, T Guo and G Liu. 2013. Examination of Potential Benefits of an Energy Imbalance Market in the Western Interconnection. NREL/TP-5500-57115. National Renewable Energy Laboratory, Golden, CO. [Online.] Accessed August 15, 2013, at http://www.nrel.gov/docs/fy13osti/57115.pdf.

[7] Nickell BM. 2008. TEPPC Renewable Energy Cases. [Online.] Accessed August 15, 2013, at http://www.wecc.biz/committees/StandingCommittees/PCC/LRS/Shared\%20Documents/Wind\% 20Profiles/Renewable\%20Energy\%20Generation\%20Paper.pdf.

[8] E3 - Energy and Environmental Economics. 2013. PacifiCorp-ISO Energy Imbalance Market Benefits. March 2013. [Online.] Accessed August 15, 2013, at http://www.caiso.com/Documents/PacifiCorp-ISOEnergyImbalanceMarketBenefits.pdf.

[9] 3TIER. 2010. Development of Regional Wind Resource and Wind Plant Output Datasets. NREL/SR-550-47676. Work performed by 3TIER for National Renewable Energy Laboratory, 
Golden, CO. [Online.] Accessed August 15, 2013, at http://www.nrel.gov/docs/fy10osti/47676.pdf.

[10] Orwig K, M Hummon, BM Hodge and D Lew. 2011. Solar Data Inputs for Integration and Transmission Planning Studies. NREL/PO-5500-52985. National Renewable Energy Laboratory, Golden, CO.

[11] Ma J, YV Makarov, C Loutan, and Z Xie. 2011. "Impact of wind and solar generation on the California ISO’s intra-hour balancing needs.” IEEE 2011 Power and Energy Society General Meeting, pp.1-6, 24-29, July 2011. DOI: 10.1109/PES.2011.6039410.

[12] Makarov YV, C Loutan, J Ma, and P de Mello. 2009. "Operational Impacts of Wind Generation on California Power Systems.” IEEE Transactions on Power Systems 24(2):1039-1050. DOI: 10.1109/TPWRS.2009.2016364.

[13] "1997 Agreement for the hourly coordination of the projects on the Mid-Columbia river', [Online.] Accessed August 15, 2013, at http://www.chelanpud.org/documents/MCHC_Agreement_97.pdf 
Appendix A

\section{Wind Crosswalk Data}





\section{Appendix A}

\section{Wind Crosswalk Data}

Section 2.4 gave an overview of total installed capacity for each Balancing Authority (BA) in the Northwest Power Pool (NWPP). Appendix A provides more information about the wind power plants in the model in terms of the BA ownership, the bus the plant is connected to in the model, installed capacity, if they represent a wind power plant that is currently in service.

\begin{tabular}{|c|c|c|c|}
\hline BA-Bus \# & Project Name & $\begin{array}{l}\text { Installed } \\
\text { Capacity (MW) }\end{array}$ & BA Total \\
\hline AVA_wind_48383 & Palouse Wind & \multirow{2}{*}{\multicolumn{2}{|c|}{105}} \\
\hline \multicolumn{2}{|c|}{ AVA Total } & & \\
\hline BCTC_wind_50360 & & 150 & \\
\hline BCTC_wind_50364 & & 334 & \\
\hline BCTC_wind_50455 & & 34 & \\
\hline BCTC_wind_50559 & & 504 & \\
\hline BCTC_wind_50562 & & 180 & \\
\hline BCTC_wind_50653 & & 180 & \\
\hline \multicolumn{2}{|c|}{ BCTC Total } & & 1381 \\
\hline BPA_wind_40111 & BIG EDDY & 313 & \\
\hline BPA_wind_40125 & Willow wind w1 & 72 & \\
\hline BPA_wind_40477 & LINDEN RANCH W1 & 231 & \\
\hline BPA_wind_40666 & RpsORwindWA1 & 590 & \\
\hline BPA_wind_40671 & LONGVIEW & 89 & \\
\hline BPA_wind_40686 & SPRING CREEK & 313 & \\
\hline BPA_wind_40687 & MALIN & 332 & \\
\hline BPA_wind_40723 & RpsWAwnd3 & 547 & \\
\hline BPA_wind_40913 & SACAJAWEA & 313 & \\
\hline BPA_wind_41341 & KLONDIKE 2 & 76 & \\
\hline BPA_wind_41363 & CONWIND_1 & 50 & \\
\hline BPA_wind_41402 & BIG HORN W2 & 511 & \\
\hline BPA_wind_42063 & LOWER SNAKE RVR & 343 & \\
\hline BPA_wind_47315 & 9CWIND 1_1 & 27 & \\
\hline BPA_wind_47316 & 9CWIND 2_1 & 202 & \\
\hline BPA_wind_47326 & KLOND W1_1 & 25 & \\
\hline BPA_wind_47327 & HAY CANYON W1 & 746 & \\
\hline BPA_wind_47452 & SHEPHERDS FLAT W2 & 555 & \\
\hline BPA_wind_47458 & SHEPHERDS FLAT W3 & 290 & \\
\hline BPA_wind_47573 & STATL W1 1 & 90 & \\
\hline
\end{tabular}




$$
\begin{aligned}
& \text { BPA_wind_47801 } \\
& \text { BPA_wind_47802 } \\
& \text { BPA_wind_47814 } \\
& \text { BPA_wind_47827 } \\
& \text { BPA_wind_47906 } \\
& \text { BPA_wind_47975 }
\end{aligned}
$$

BPA Total
HOPKR 1

HOPKR 2

157

PEBBLE SPRINGS W

100

HARVEST WIND 1

WHTCK W1

552

\begin{tabular}{|c|c|c|}
\hline NWMT_wind_62036 & & 188 \\
\hline NWMT_wind_62071 & 40 MW \& 210 MW Glacier wind & 250 \\
\hline NWMT_wind_62351 & & 40 \\
\hline NWMT Total & & \\
\hline PACE_ID_wind_65675 & & 125 \\
\hline PACE_ID_wind_65680 & & 164.5 \\
\hline PACE_UT_wind_66400 & & 19 \\
\hline PACE_UT_wind_67826 & & 86 \\
\hline PACE_WY_wind_65300 & & 338 \\
\hline PACE_WY_wind_65420 & & 424.5 \\
\hline PACE_WY_wind_65580 & & 168.5 \\
\hline PACE_WY_wind_65584 & & 52 \\
\hline PACE_WY_wind_65585 & & 52 \\
\hline PACE_WY_wind_65778 & & 284 \\
\hline PACE_WY_wind_67795 & & 400 \\
\hline PACW_wind_44885 & LEANING JUNIPER W1 & 100 \\
\hline PACW_wind_45233 & ECHO WIND_1 & 64 \\
\hline PACW_wind_45566 & COMBINE HILLS w1 & 41 \\
\hline PACW_wind_47816 & LEANING JUNIPER W2 & 100 \\
\hline PACW_wind_47830 & RPSCAWINDWA1 & 313 \\
\hline PAC_wind_47829 & GOODNOE HILLS & 94 \\
\hline PAC_wind_47571 & STATL W2 1 & 210 \\
\hline PAC_wind_47550 & VANSYCLE_1 & 124 \\
\hline PAC_wind_48221 & MARENGO_2 & 227 \\
\hline PAC_wind_48451 & MARENGO & 227 \\
\hline PAC Total & & \\
\hline PGN_wind_47844 & GOLDEN HILLS W1 & 106 \\
\hline PGN_wind_43950 & RpsORwnd1 & 360 \\
\hline PGN_wind_43954 & RpsCAwindOR1 & 404 \\
\hline
\end{tabular}

STAR POINT W1
100

7089

4590

2499

PGN Total 


$\begin{array}{rlrl} & & \\ \text { PSE_wind_42364 } & \text { WILDH 1 } & 229 & \\ \text { PSE_wind_42365 PSE Total } & \text { WILD HORSE } & 316 & \\ & & & \\ & & & \\ \text { TREAS VLY_wind_60306 } & 105 \\ \text { TREAS VLY_wind_60394 } & 140 \\ \text { FAR EAST_wind_60062 } & 125 & \\ \text { MAGIC VLY_wind_60360 } & 190 & \\ \text { MAGIC VLY_wind_60395 } & 140 & \\ \text { MAGIC VLY_wind_61810 } & 100 & \\ \text { IPC Total } & & \mathbf{8 0 0}\end{array}$



Appendix B

PNNL Flex Reserve Calculation Approach 



\section{Appendix B}

\section{PNNL Flex Reserve Calculation Approach}

In this appendix, the methodology we developed to simulate essential balancing functions of a BA is explained. Actual scheduled net interchange, and 1-minute resolution load and wind data along with simulated real-time and hour-ahead forecast errors are used to obtain hour-ahead generation schedules, and load-following and regulation requirement curves. These curves are then analyzed for various metrics to evaluate the flex reserve requirements.

\section{B.1 Simulation of the Hour-Ahead Schedules for Load and Wind Generation}

The curves representing the hour-ahead schedules for load and wind generation are obtained from actual data as follows:

a. Use the actual 1-minute resolution " $m$ " load data $\mathrm{L}_{\text {actual }}(\mathrm{m})$ (see blue curve shown in Figure B.1): $\mathrm{L}_{\text {actual }}(\mathrm{h})=1 / 60 \Sigma \mathrm{L}_{\text {actual }}(\mathrm{m})$ for each hour "h" in the year (see red curve shown in Figure B.1).

b. Simulate the hour-ahead forecast error e[L(h)] for each hour in the year. The forecast error is assumed to follow the truncated normal distribution (TND) with certain specified statistical characteristics.

c. Calculate the hour-ahead load schedule $\mathrm{L}_{\text {schedule }}(\mathrm{h})$ by subtracting the load forecast error, calculated in Step b, from the actual hourly average calculated in Step a. Also, incorporate a 20-minute-duration ramp into the transition from one hour schedule to the next hour schedule.

$\mathrm{L}_{\text {schedule }}(\mathrm{h})=\operatorname{Ramp}_{20 \text { min }}\left\{\mathrm{L}_{\text {actual }}(\mathrm{h})-\mathrm{e}[\mathrm{L}(\mathrm{h})]\right\}$ (see green curve shown below in Figure B.1).

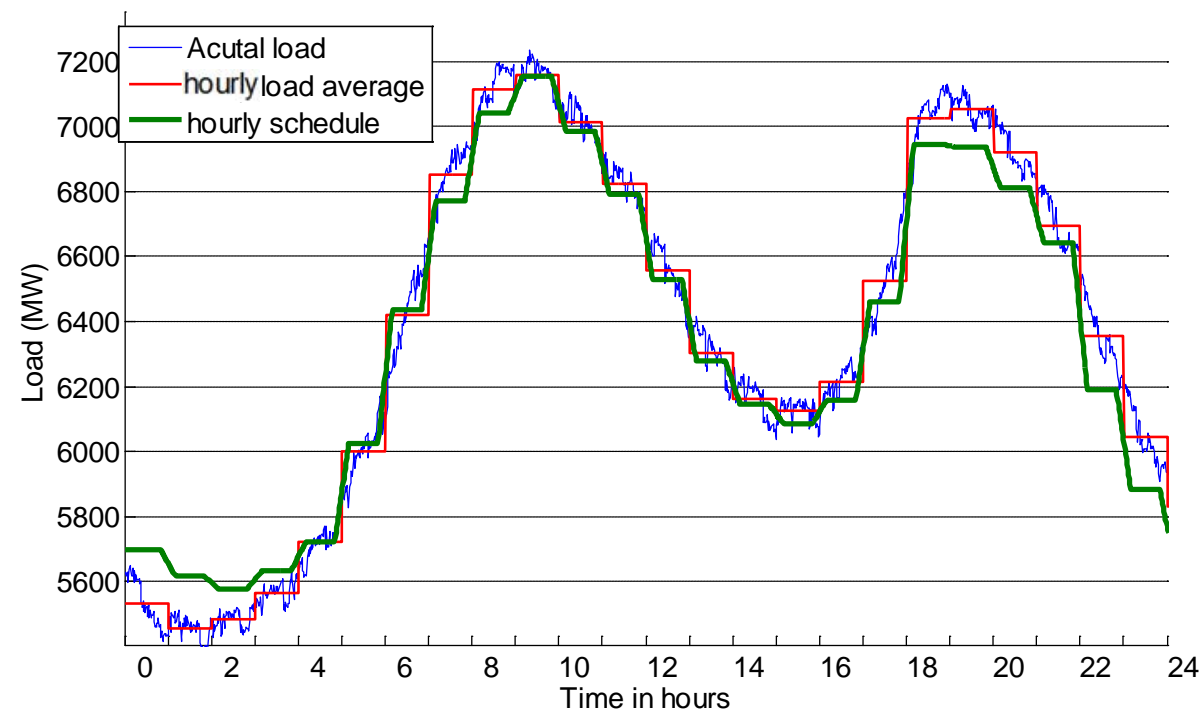

Figure B.1. Simulation of Hour-Ahead Schedule for Load 
d. We proceed along the same lines as we did for load (steps a-c) to obtain an HA schedule for wind generation. Use the actual 1-minute resolution “m” wind data $\mathrm{W}_{\text {actual }}(\mathrm{m})$ to calculate the hourly wind average $\mathrm{W}_{\text {actual }}(\mathrm{h})$ :

$\mathrm{W}_{\text {actual }}(\mathrm{h})=1 / 60 \Sigma \mathrm{W}_{\text {actual }}(\mathrm{m})$ for each hour in the year

e. Simulate the hour-ahead forecast error e[W(h)] for each hour "h" in the year. The forecast error is assumed to follow the TND with certain specified statistical characteristics.

f. Calculate the hour-ahead wind schedule $\mathrm{W}_{\text {schedule }}(\mathrm{h})$ by subtracting the wind forecast error, calculated in Step e, from the actual hourly average calculated in Step d. Also, reflect a 20-minute ramp in the transition from one hour schedule to the next hour schedule:

$\mathrm{W}_{\text {schedule }}(\mathrm{h})=\mathrm{Ramp}_{20 \text { min }}\left\{\mathrm{W}_{\text {actual }}(\mathrm{h})-\mathrm{e}[\mathrm{W}(\mathrm{h})]\right\}$

\section{B.2 Simulation of the Real-Time Schedule for Load and Wind Generation}

The real-time (10-minute ahead) schedules for load and wind are obtained from actual data as follows:

a. Use the actual 1-minute resolution "m" load data $\mathrm{L}_{\text {actual }}(\mathrm{m})$ (see blue curve shown in Figure B.2) to calculate the 10 -minute $(10 \mathrm{~m})$ load average $\mathrm{L}_{\text {actual }}(10 \mathrm{~m})$ :

$\mathrm{L}_{\text {actual }}(10 \mathrm{~m})=1 / 10 \Sigma \mathrm{L}_{\text {actual }}(\mathrm{m})$ for each 10-minute interval in the year (see green curve shown in Figure B.2).

b. Simulate the real-time forecast error e[L(10m )] for each 10 -minute interval in the year. The forecast error is assumed to follow the TND with certain specified statistical characteristics.

c. Simulate the 10 -minute-ahead real-time load schedule $\mathrm{L}_{\text {schedule }}(10 \mathrm{~m})$ by subtracting the load forecast error, calculated in Step b, from the actual 10-minute average calculated in Step a. Also simulate the 10-minute transition from one 10-minute schedule to the next 10-minute schedule (i.e., by connecting midpoints of the subsequent 10-minute schedules):

$\mathrm{L}_{\text {schedule }}(10 \mathrm{~m})=\operatorname{Ramp}_{10 \text { min }}\left\{\mathrm{L}_{\mathrm{actual}}\left(10 \mathrm{~m}_{\mathrm{i}}\right)-\mathrm{e}[\mathrm{L}(10 \mathrm{~m})]\right\}$ (see the magenta curve shown in Figure B.2). 


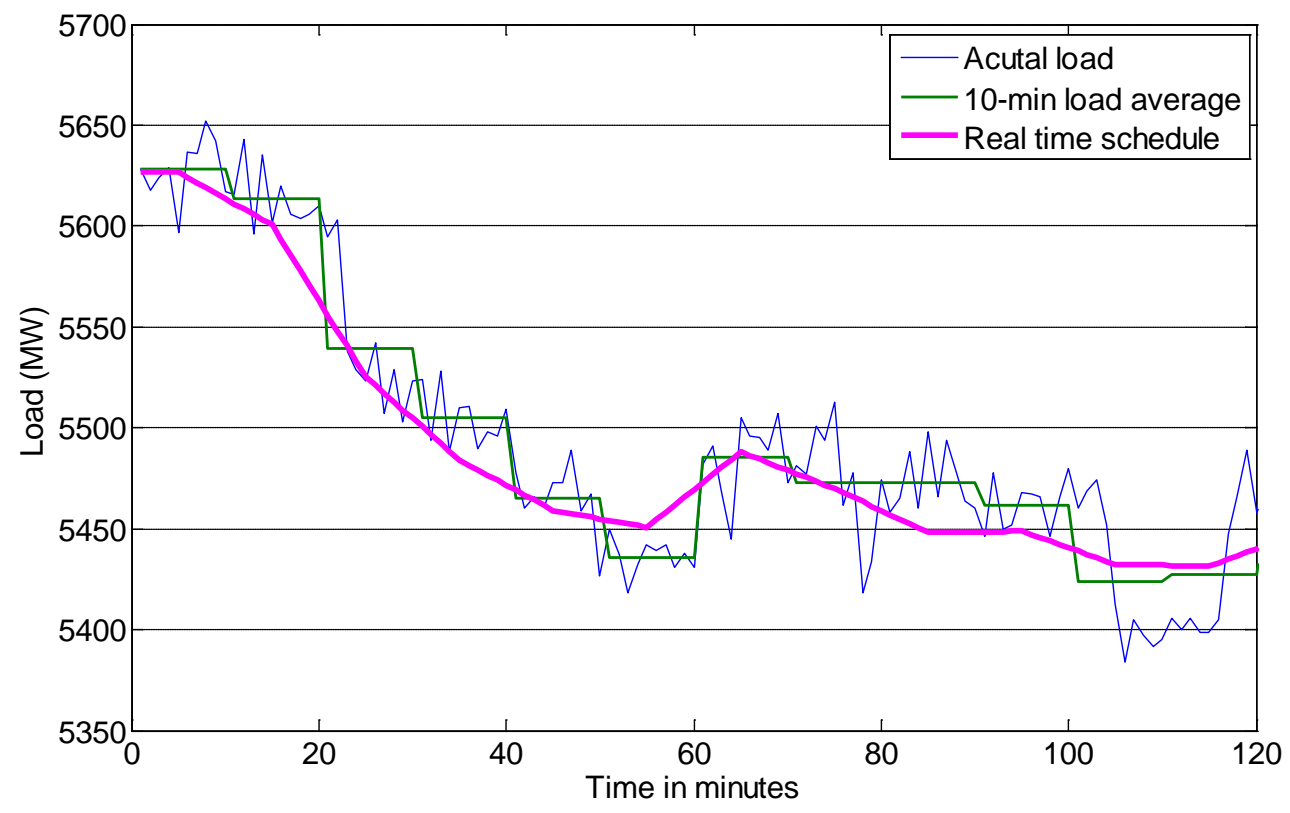

Figure B.2. Simulation of the Real-Time Schedule for Load

d. The real-time schedule for wind generation is calculated in a different manner from the load schedule. The actual 1-minute resolution " $\mathrm{m}$ " wind data $\mathrm{W}_{\text {actual }}(\mathrm{m})$ is used to calculate the realtime wind schedule $\mathrm{W}_{\text {schedule }}(\mathrm{m})$. In the absence of real-time forecast data, a strategy that is adopted for the California Independent System Operator (CAISO) and the Bonneville Power Administration (BPA) in our previous efforts will be used. The persistence model is used to simulate real-time wind forecast. It assumes that the real-time wind forecast equals the actual wind production observed 7.5 minutes before the beginning of a dispatch interval:

$\mathrm{W}_{\text {schedule }}(10 \mathrm{~m})=\mathrm{W}_{\text {actual }}(\mathrm{m}-7.5)$ for each minute in the year

Examples of the calculated real-time and hour-ahead schedules for load and wind are shown in Figure B.3 and Figure B.4, respectively. 


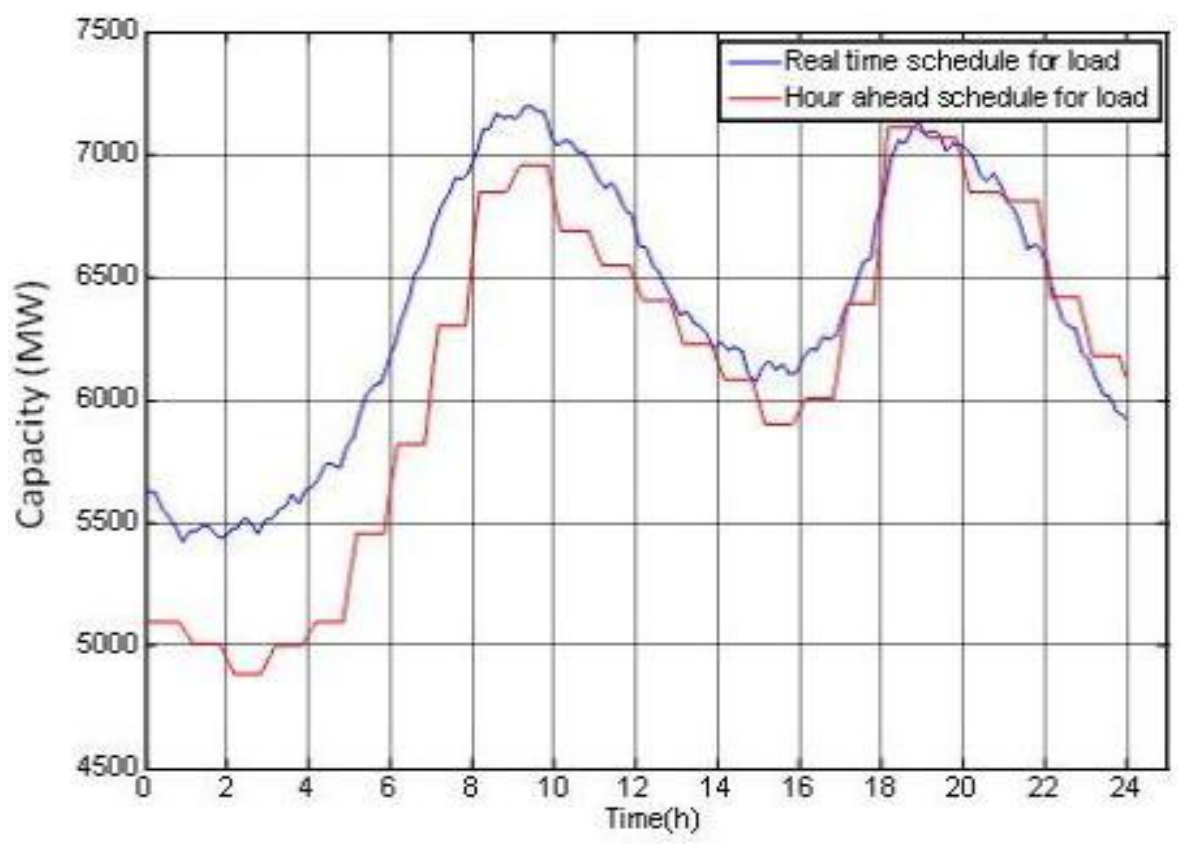

Figure B.3. Hour-Ahead and Real-Time Schedules for Load

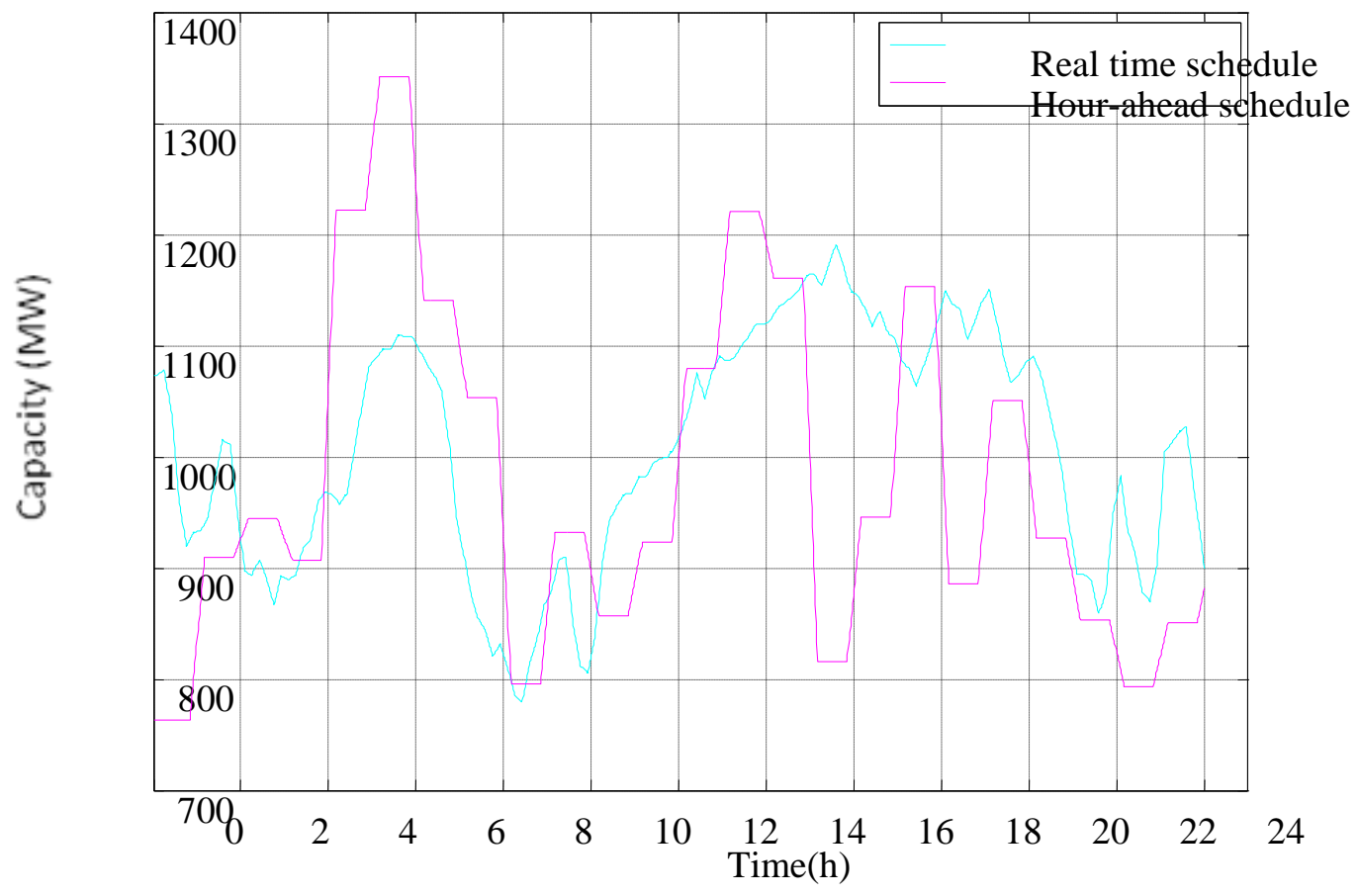

Figure B.4. Hour-Ahead and Real-Time Schedules for Wind (based on BPA wind forecast statistics) 


\section{B.3 Simulation of the Regulation and Load-Following Curves}

We treat wind as "negative load.” By doing so, we define the notion of "net load" in the ensuing analysis.

a. The minute-by-minute "Actual_net_load(m)" is calculated by subtracting the minute-by-minute actual wind generation from the minute-by-minute actual load, and by adding the net interchange:

Actual_net_load $(m)=\mathrm{L}_{\text {actual }}(\mathrm{m})-\mathrm{W}_{\text {actual }}(\mathrm{m})+$ Net_interchange $(\mathrm{m})$,

where Net_interchange $(m)=\operatorname{Ramp}_{20 \text { min }}\{$ Net_interchange(h) $\}$ for all “m” within "h.” It is assumed to be an export.

b. The net load (which is the same as hourly generation schedule), henceforth referred to as "Hourahead_schedule(h)," is calculated by subtracting the wind hourly schedule from the load hourly schedule and adding net interchange (see red curve shown in Figure B.5):

Hour-ahead_schedule $(\mathrm{h})=\mathrm{L}_{\text {schedule }}(\mathrm{h})-\mathrm{W}_{\text {schedule }}(\mathrm{h})+\mathrm{Ramp}_{20 \text { min }}\{$ Net_interchange $(\mathrm{h})\}$

c. The real-time net load schedule (or real-time generation schedule or 10-minute-ahead schedule), henceforth referred to as real-time schedule, is calculated by subtracting the wind real-time schedule from the load real-time schedule and adding net interchange (see blue curve shown below in Figure B.5):

Real-time_schedule $(10 \mathrm{~m})=\mathrm{L}_{\text {schedule }}(10 \mathrm{~m})-\mathrm{W}_{\text {schedule }}(10 \mathrm{~m})+$ Ramp $_{10 \text { min }}\{$ Net_interchange $(\mathrm{h})\}$

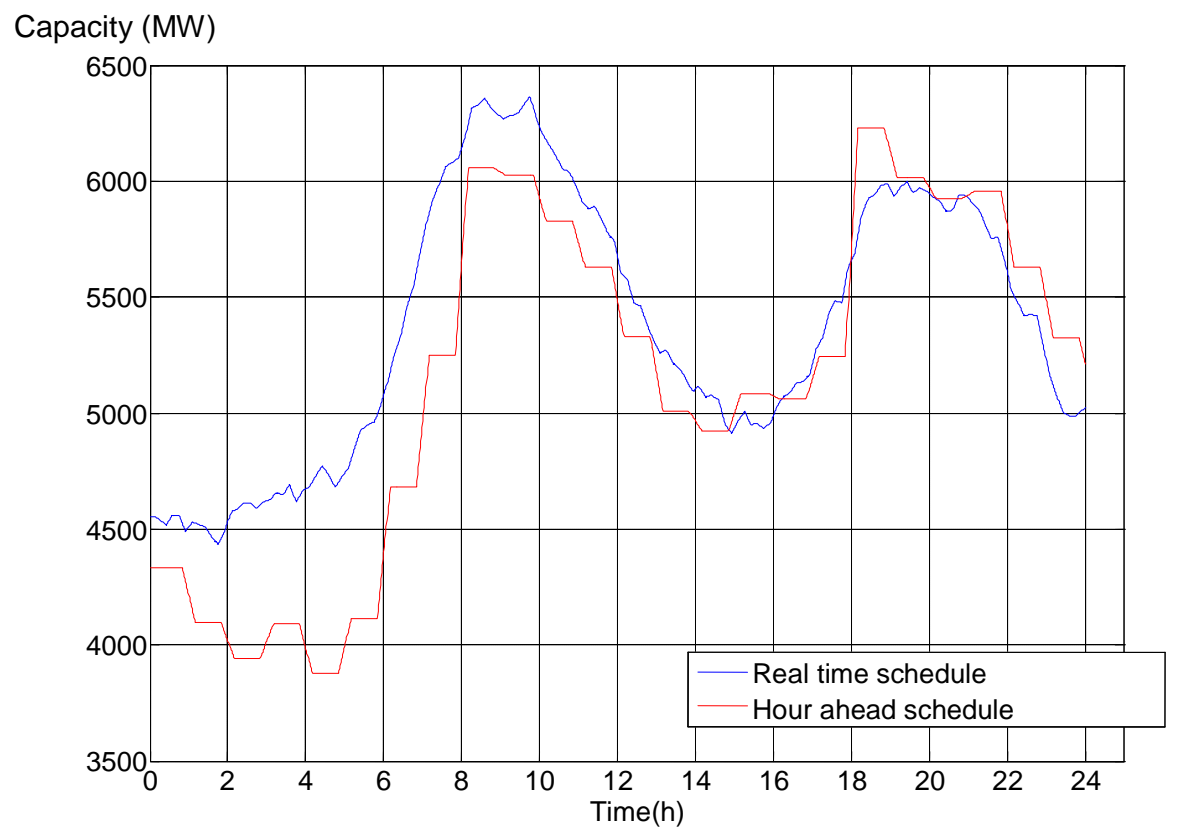

Figure B.5. Real-Time and Hour-Ahead Schedules 


\section{B.3.1 Generation Hour-Ahead Schedule Curve}

The generation of hour-ahead schedule curve represents the total amount of generation to be scheduled to serve the net load in the next operating hour.

Generation_hour-ahead_schedule $(\mathrm{m})=$ Hour_ahead_schedule $(\mathrm{h})$

$$
=\mathrm{L}_{\text {scedule }}(\mathrm{h})-\mathrm{W}_{\text {schedule }}(\mathrm{h})+\operatorname{Ramp}_{20 \text { min }}\left\{\mathrm{Net} \_ \text {interchange }(\mathrm{h})\right\}
$$

\section{B.3.2 Load-Following Curve}

The minute-to-minute load-following curve represents the load-following requirements within the hour time frame as a result of hour-ahead forecast errors and 1 hour discretization of the hour-ahead schedule. It is calculated by subtracting the hour-ahead schedule from the real-time schedule:

Load_following_curve $(\mathrm{m})=$ Real-time_schedule $(10 \mathrm{~m})$ - Hour_ahead_schedule(h)

$=\left[\mathrm{L}_{\text {schedule }}(10 \mathrm{~m})-\mathrm{W}_{\text {schedule }}(10 \mathrm{~m})+\mathrm{Ramp}_{20 \text { min }}\{\right.$ Net_interchange $\left.(\mathrm{h})\}\right]-$

$\left[\mathrm{L}_{\text {schedule }}(\mathrm{h})-\mathrm{W}_{\text {schedule }}(\mathrm{h})+\mathrm{Ramp}_{20 \text { min }}\{\right.$ Net_interchange $\left.(\mathrm{h})\}\right]$

Or, which is the same,

Load_following_curve $(m)=\left[\mathrm{L}_{\text {schedule }}(10 \mathrm{~m})-\mathrm{W}_{\text {schedule }}(10 \mathrm{~m})\right]-\left[\mathrm{L}_{\text {schedule }}(\mathrm{h})-\mathrm{W}_{\text {schedule }}(\mathrm{h})\right]$

Figure B.6 and Figure B.7 show the real-time and hour-ahead schedules for load and wind. The resulting load-following curve is shown in Figure B.8. The load-following curve is independent of the net interchange.

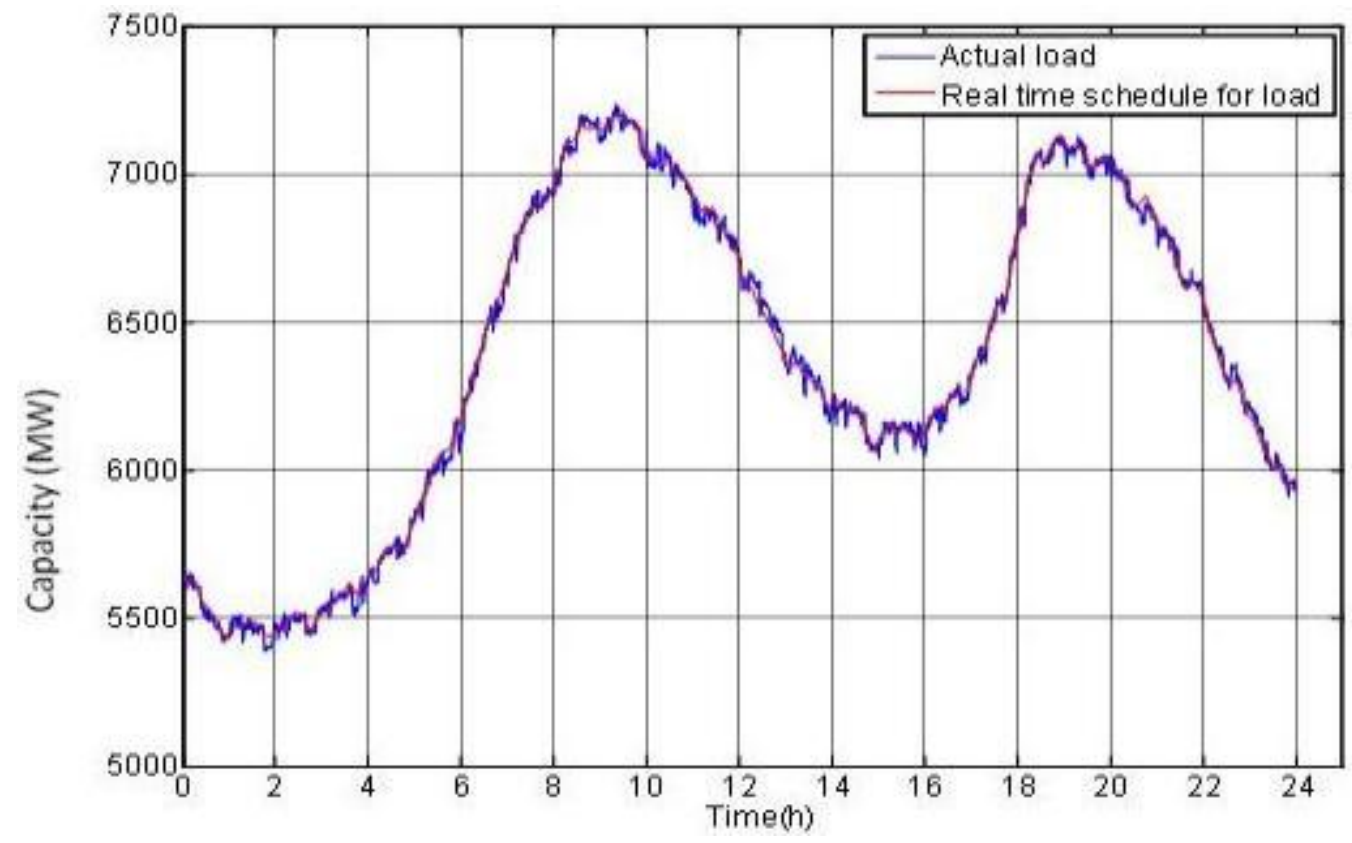

Figure B.6. Actual Load $\mathrm{L}_{\mathrm{actual}}(\mathrm{m})$ and Real-Time Load Schedule $\mathrm{L}_{\text {schedule }}(\mathrm{m})$ 


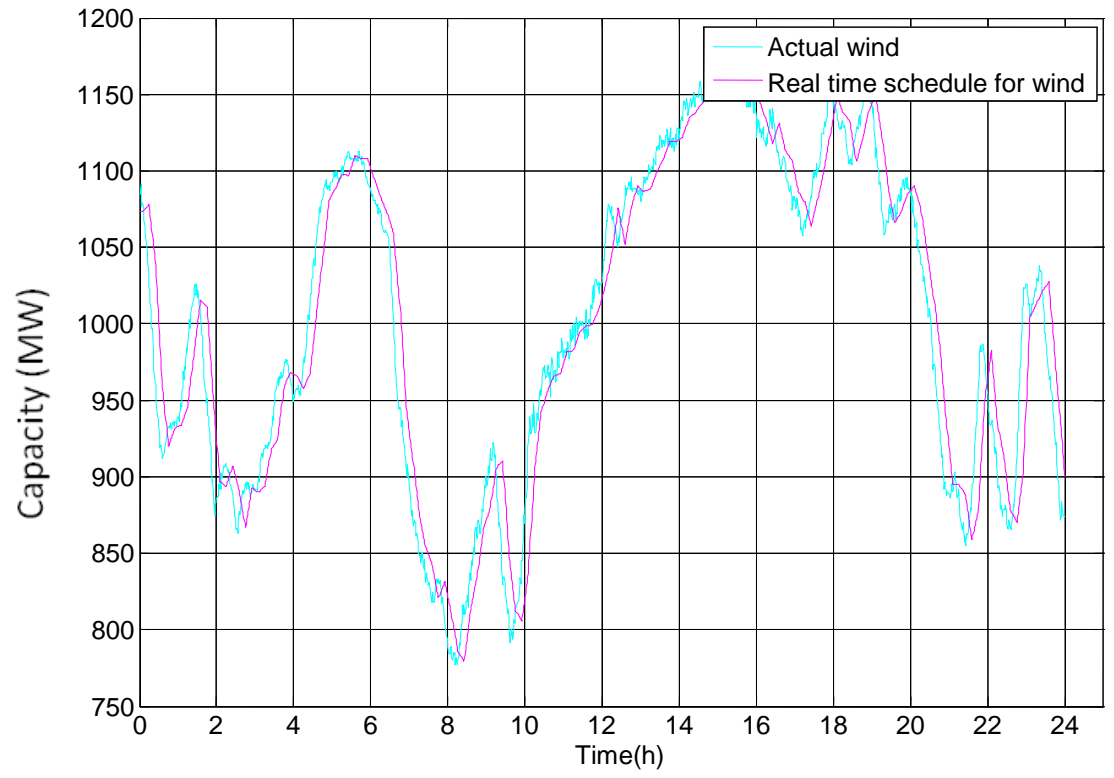

Figure B.7. Actual Wind $\mathrm{W}_{\text {actual }}(\mathrm{m})$ and Real-time Wind Schedule $\mathrm{W}_{\text {schedule }}(\mathrm{m})$

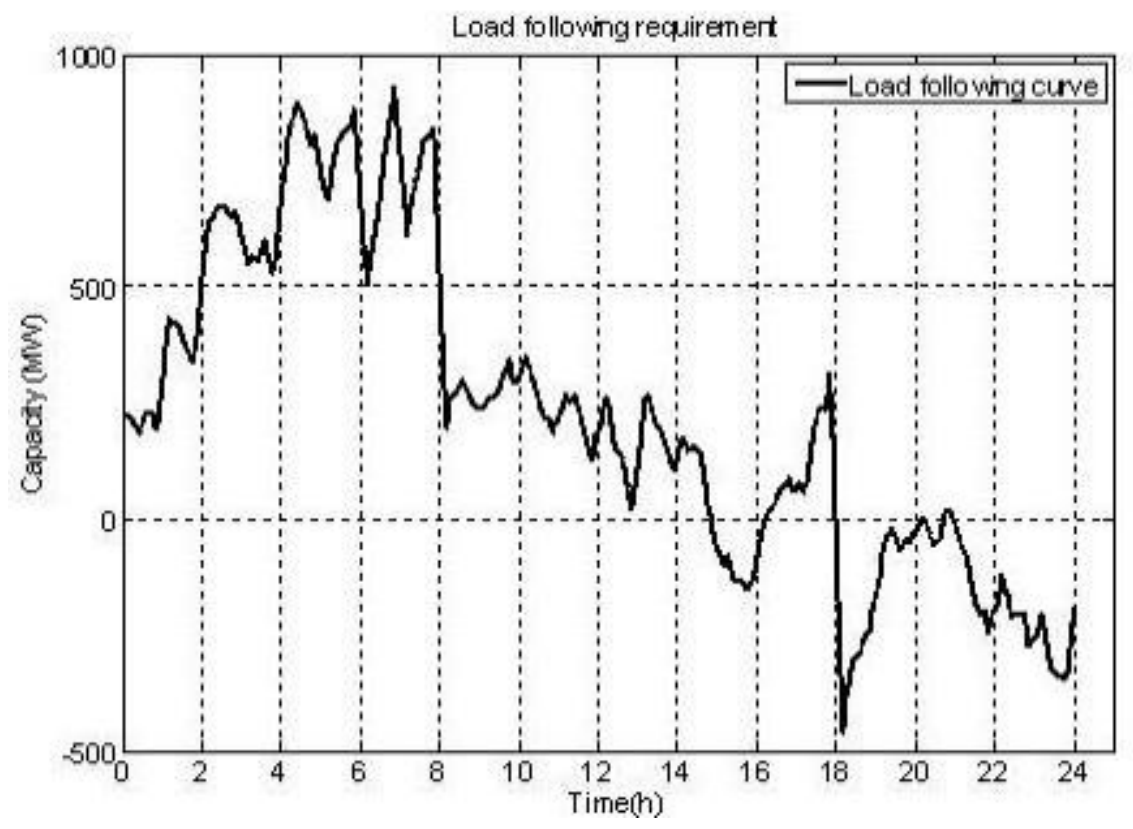

Figure B.8. Calculated Load-Following Requirements 


\section{B.3.3 Regulation Curve}

The minute-to-minute regulation curve represents the regulation requirements within the 1- to 10-minute time frame appearing as a result of real-time forecast errors and 10-minute discretization of the real-time schedule. It is calculated by subtracting the real-time schedule from the actual net load. In mathematical terms, regulation is defined as

$$
\begin{aligned}
\text { Regulation_curve }(m)= & \text { Actual_net_load }(m)-\text { Real-time_schedule }(10 \mathrm{~m}) \\
= & {\left[\mathrm{L}_{\text {actual }}(\mathrm{m})-\mathrm{W}_{\text {actual }}(\mathrm{m})+\operatorname{Ramp}_{20 \text { min }}\{\text { Net_interchange }(\mathrm{h})\}\right]-} \\
& {\left[\mathrm{L}_{\text {schedule }}(10 \mathrm{~m})-\mathrm{W}_{\text {schedule }}(10 \mathrm{~m})+\operatorname{Ramp}_{20 \text { min }}\{\text { Net_interchange }(\mathrm{h})\}\right] }
\end{aligned}
$$

or

Regulation_curve $(m)=\left[\mathrm{L}_{\text {actual }}(\mathrm{m})-\mathrm{W}_{\text {actual }}(\mathrm{m})\right]-\left[\mathrm{L}_{\text {schedule }}(10 \mathrm{~m})-\mathrm{W}_{\text {schedule }}(10 \mathrm{~m})\right]$

With $\mathrm{L}_{\text {actual }}(\mathrm{m})$ and $\mathrm{L}_{\text {schedule }}(10 \mathrm{~m})$ plotted in Figure B.6, and $\mathrm{W}_{\text {actual }}(\mathrm{m})$ and $\mathrm{W}_{\text {schedule }}(\mathrm{m})$ plotted in Figure B.7, the regulation curve would be as illustrated in Figure B.9.

It can be seen from the above equation that the regulation curve does not depend on the hourly scheduled net interchange.

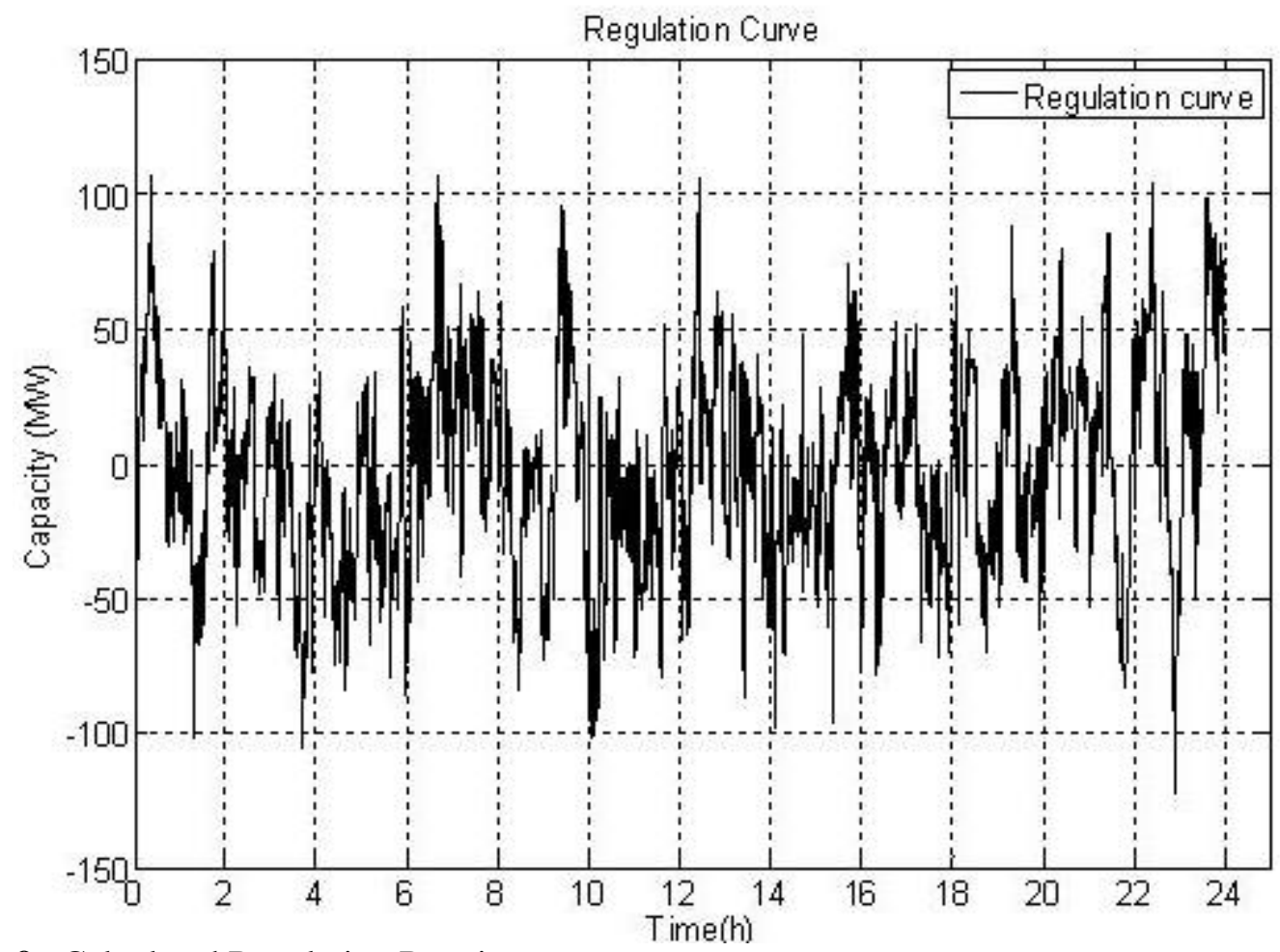

Figure B.9. Calculated Regulation Requirement 


\section{B.4 Calculation of Balancing Reserve Requirments}

a. Each minute in the load-following, or regulation curves is characterized by capacity requirements.

b. As is the case with any methodology that is based on random number generators, in this case generation of load forecast errors, we do not rely on a single realization of a forecast error time series; rather, the previous steps are repeated 20 times (Monte Carlo simulation) with a different set of time series forecast errors for each run.

c. System operators are not required to balance against each point along the generation requirement curve. Therefore, a certain percentage of points could be left not completely balanced, say, $5 \%$ of points that can be considered as statistical outliers, i.e., those below and above certain threshold requirements are not considered for further analysis. This elimination is performed independently for each month for each BA.

d. For each hour in a day within the month, the maximum incremental and decremented capacity requirements for each of the load following and regulation curves are calculated. This is achieved by comparing all the points within the selected Convidenace Interval (CI) within this hour for certain month. A sample of results is shown in Figure B.10.
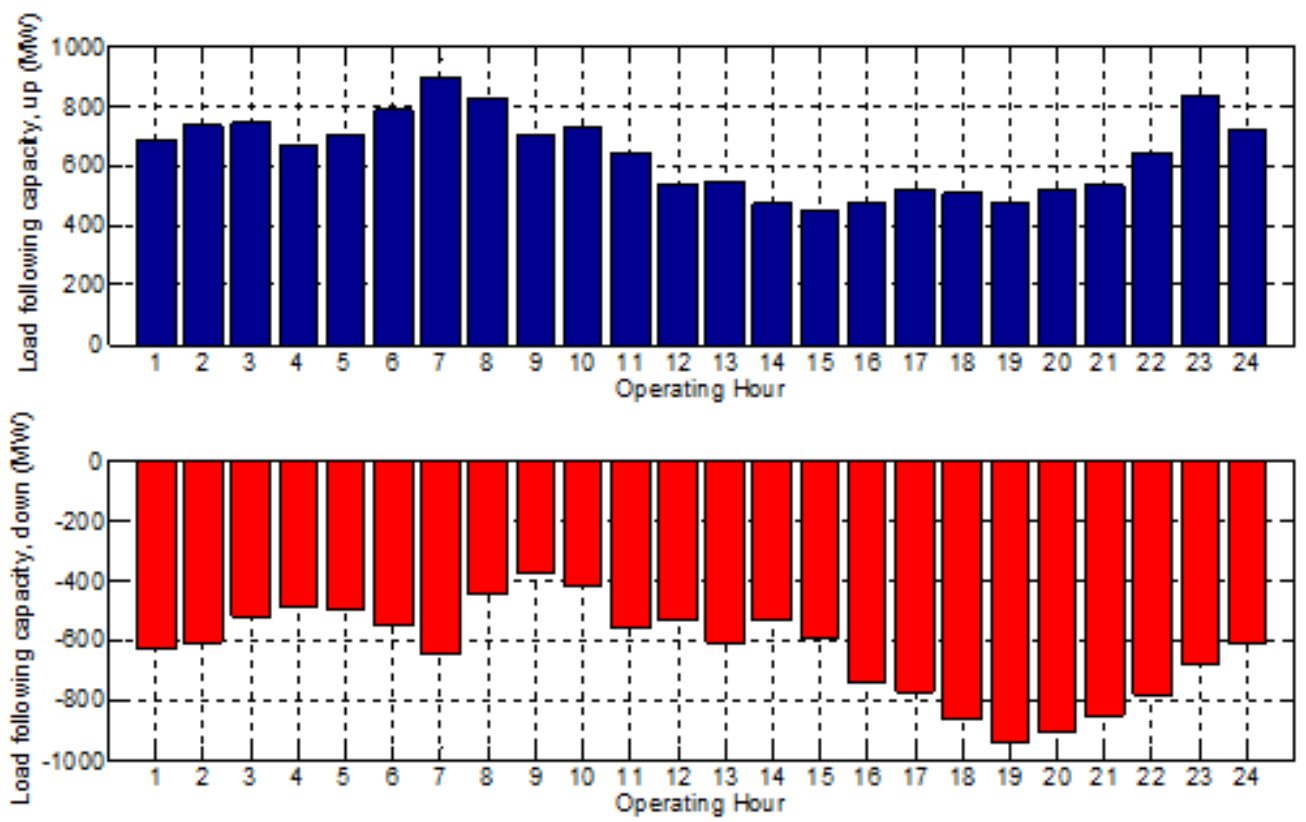

Figure B.10. Example of Load Following Capacity Requirement for 24 Operating Hours for Certain Month 



\section{Appendix C}

\section{Allocation of MidC Hydro Plants to Balancing Areas}





\section{Appendix C}

\section{Allocation of MidC Hydro Plants to Balancing Areas}

The capacity of the projects was assigned to the individual balancing areas to correspond to the contractual share of the projects. This was done by adjusting the capacity of the individual units and electrically connecting one or more of the units to the balancing areas in a manner that approximated the contractual share.

\section{C.1 Wells}

\begin{tabular}{|c|c|c|c|c|c|c|c|c|c|c|c|c|c|}
\hline & & Jan & Feb & Mar & April & May & June & July & Aug & Sept & Oct & Nov & Dec \\
\hline & Max. & 850 & 850 & 850 & 850 & 850 & 850 & 850 & 850 & 850 & 850 & 850 & 850 \\
\hline & Min. & 100 & 100 & 100 & 100 & 100 & 100 & 100 & 100 & 100 & 100 & 100 & 100 \\
\hline & Average & 357 & 336 & 312 & 422 & 423 & 452 & 407 & 337 & 239 & 246 & 267 & 325 \\
\hline \multicolumn{14}{|l|}{ Share } \\
\hline PAC & $6.59 \%$ & & & & & & & & & & & & \\
\hline PGE & $19.39 \%$ & & & & & & & & & & & & \\
\hline PSE & $29.89 \%$ & & & & & & & & & & & & \\
\hline AVA & $7.84 \%$ & & & & & & & & & & & & \\
\hline MidC & $36.29 \%$ & & & & & & & & & & & & \\
\hline \multicolumn{14}{|l|}{ Type } \\
\hline HTC & $50 \%$ & & & & & & & & & & & & \\
\hline Fixed & $50 \%$ & & & & & & & & & & & & \\
\hline
\end{tabular}

\section{C.2 Rocky Reach}

\begin{tabular}{ccccccccccccc}
\hline & Jan & Feb & Mar & April & May & June & July & Aug & Sept & Oct & Nov & Dec \\
\hline Max. & 1253 & 1035 & 1035 & 1035 & 1253 & 1253 & 1253 & 1035 & 1035 & 1035 & 1253 & 1253 \\
Min. & 100 & 100 & 100 & 100 & 100 & 100 & 100 & 100 & 100 & 100 & 100 & 100 \\
Ave. & 519 & 480 & 445 & 657 & 648 & 736 & 569 & 488 & 332 & 344 & 392 & 470
\end{tabular}

Share

PGE $3 \%$

PSE $25 \%$

AVA $3 \%$

MidC 69\%

Type

HTC 50\%

Fixed 50\% 


\section{C.3 Rock Island}

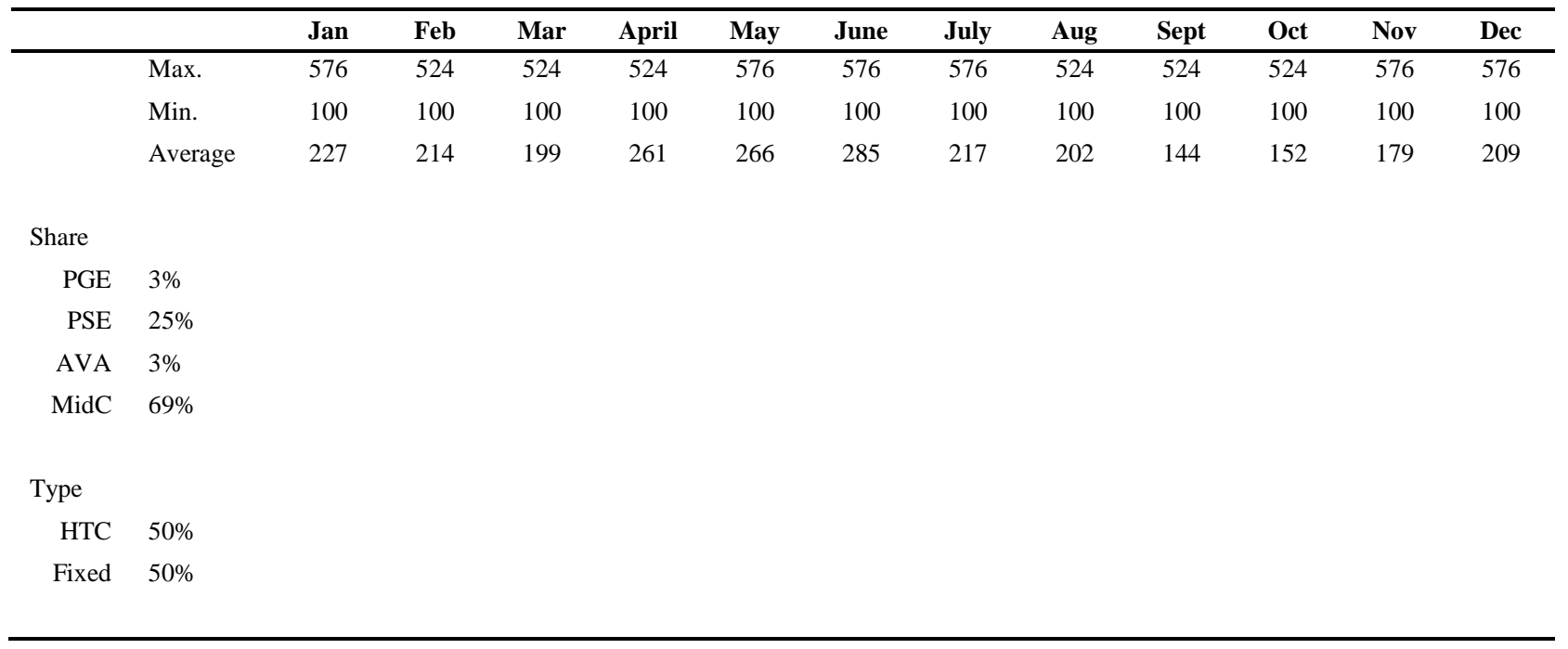

\section{C.4 Wanapum}

\begin{tabular}{|c|c|c|c|c|c|c|c|c|c|c|c|c|c|}
\hline & & Jan & Feb & Mar & April & May & June & July & Aug & Sept & Oct & Nov & Dec \\
\hline & Max. & 870 & 870 & 870 & 870 & 870 & 870 & 870 & 870 & 870 & 870 & 870 & 870 \\
\hline & Min. & 100 & 100 & 100 & 100 & 100 & 100 & 100 & 100 & 100 & 100 & 100 & 100 \\
\hline & Average & 459 & 426 & 402 & 508 & 537 & 489 & 529 & 438 & 282 & 294 & 362 & 417 \\
\hline \multicolumn{14}{|l|}{ Share } \\
\hline PGE & 9.06 & & & & & & & & & & & & \\
\hline PSE & 0.89 & & & & & & & & & & & & \\
\hline AVA & 3.98 & & & & & & & & & & & & \\
\hline BPA & 13.81 & & & & & & & & & & & & \\
\hline SCL & 0.39 & & & & & & & & & & & & \\
\hline MidC & 69.92 & & & & & & & & & & & & \\
\hline \multicolumn{14}{|l|}{ Туре } \\
\hline HTC & $50 \%$ & & & & & & & & & & & & \\
\hline Fixed & $50 \%$ & & & & & & & & & & & & \\
\hline
\end{tabular}




\section{C.5 Priest Rapids}

\begin{tabular}{|c|c|c|c|c|c|c|c|c|c|c|c|c|c|}
\hline & & Jan & Feb & Mar & April & May & June & July & Aug & Sept & Oct & Nov & Dec \\
\hline & Max. & 880 & 880 & 880 & 880 & 880 & 880 & 880 & 880 & 880 & 880 & 880 & 880 \\
\hline & Min. & 200 & 200 & 200 & 200 & 200 & 200 & 200 & 200 & 200 & 200 & 200 & 200 \\
\hline & Average & 455 & 408 & 392 & 415 & 549 & 519 & 434 & 387 & 278 & 285 & 339 & 412 \\
\hline \multicolumn{14}{|l|}{ Share } \\
\hline PAC & $1.6 \%$ & & & & & & & & & & & & \\
\hline PGE & $9.1 \%$ & & & & & & & & & & & & \\
\hline PSE & $0.9 \%$ & & & & & & & & & & & & \\
\hline AVA & $4.0 \%$ & & & & & & & & & & & & \\
\hline BPA & $13.8 \%$ & & & & & & & & & & & & \\
\hline SCL & $0.4 \%$ & & & & & & & & & & & & \\
\hline TCL & $0.4 \%$ & & & & & & & & & & & & \\
\hline MidC & $69.9 \%$ & & & & & & & & & & & & \\
\hline \multicolumn{14}{|l|}{ Туре } \\
\hline HTC & $20 \%$ & & & & & & & & & & & & \\
\hline Fixed & $80 \%$ & & & & & & & & & & & & \\
\hline
\end{tabular}

C.3 

Appendix D

Remote Units Providing only Contingency Reserve 



\section{Appendix D}

\section{Remote Units Providing only Contingency Reserve}

\begin{tabular}{|c|c|c|c|c|c|c|c|}
\hline & Unit & $\begin{array}{c}\text { Capacity } \\
\text { (MW) }\end{array}$ & Owner & Located In BA & $\begin{array}{c}\text { Owner } \\
\text { in BA }\end{array}$ & \% Share & $\begin{array}{l}\text { Cap. } \\
\text { Share } \\
\text { (MW) }\end{array}$ \\
\hline \multicolumn{8}{|l|}{ Colstrip 1,2 } \\
\hline & Colstrip 1,2 & 614 & NWMT & NWMT & NWMT & $50.00 \%$ & 307.0 \\
\hline & Colstrip 1,2 & 614 & PSE & NWMT & PSE & $50.00 \%$ & 307.0 \\
\hline \multicolumn{8}{|l|}{ Colstrip 3,4 } \\
\hline & Colstrip 3,4 & 1,480 & AVA & NWMT & AVA & $15.00 \%$ & 222.0 \\
\hline & Colstrip 3,4 & 1,480 & NWMT & NWMT & NWMT & $30.00 \%$ & 444.0 \\
\hline & Colstrip 3,4 & 1,480 & PAC & NWMT & PACW & $10.00 \%$ & 148.0 \\
\hline & Colstrip 3,4 & 1,480 & PGN & NWMT & PGN & $20.00 \%$ & 296.0 \\
\hline & Colstrip 3,4 & 1,480 & PSE & NWMT & PSE & $25.00 \%$ & 370.0 \\
\hline \multicolumn{8}{|l|}{ Intermountain 1,2 } \\
\hline & Intermountain 1,2 & 1,920 & ANHM & LDWP & CAISO & $13.20 \%$ & 253.4 \\
\hline & Intermountain 1,2 & 1,920 & BURB & LDWP & LDWP & $3.40 \%$ & 65.3 \\
\hline & Intermountain 1,2 & 1,920 & GLEN & LDWP & LDWP & $1.70 \%$ & 32.6 \\
\hline & Intermountain 1,2 & 1,920 & ICPA & LDWP & LDWP & $21.10 \%$ & 405.1 \\
\hline & Intermountain 1,2 & 1,920 & LDWP & LDWP & LDWP & $44.60 \%$ & 856.3 \\
\hline & Intermountain 1,2 & 1,920 & PAC & LDWP & PACE & $4.00 \%$ & 76.8 \\
\hline & Intermountain 1,2 & 1,920 & PASA & LDWP & CAISO & $4.40 \%$ & 84.5 \\
\hline & Intermountain 1,2 & 1,920 & RVSD & LDWP & CAISO & $7.60 \%$ & 145.9 \\
\hline & & & & $\begin{array}{c}\text { Ownership by } \\
\text { BA: }\end{array}$ & LDWP & $71 \%$ & $1,359.4$ \\
\hline & & & & & CAISO & $25 \%$ & 483.8 \\
\hline & & & & & PACE & $4 \%$ & 76.8 \\
\hline \multicolumn{8}{|l|}{ Four Corners 4,5 } \\
\hline & Four Corners 4,5 & 1,480 & APS & APS & APS & 0.15 & 222.0 \\
\hline & Four Corners 4,5 & 1,480 & EPE & APS & EPE & 0.07 & 103.6 \\
\hline & Four Corners 4,5 & 1,480 & PNM & APS & PNM & 0.13 & 192.4 \\
\hline & Four Corners 4,5 & 1,480 & APS & APS & APS & 0.48 & 710.4 \\
\hline & Four Corners 4,5 & 1,480 & SRP & APS & SRP & 0.10 & 148.0 \\
\hline & Four Corners 4,5 & 1,480 & TEP & APS & TEP & 0.07 & 103.6 \\
\hline & & & & $\begin{array}{c}\text { Ownership by } \\
\text { BA: }\end{array}$ & APS & 0.63 & 932.4 \\
\hline & & & & & $\mathrm{EPE}$ & 0.07 & 103.6 \\
\hline & & & & & PNM & 0.13 & 192.4 \\
\hline & & & & & SRP & 0.10 & 148.0 \\
\hline & & & & & TEP & 0.07 & 103.6 \\
\hline
\end{tabular}




\begin{tabular}{|c|c|c|c|c|c|c|c|}
\hline \multicolumn{8}{|l|}{ Navajo 1-3 } \\
\hline & Navajo 1-3 & 2,250 & APS & SRP & APS & 0.14 & 315.0 \\
\hline & Navajo 1-3 & 2,250 & LDWP & SRP & LDWP & 0.21 & 477.0 \\
\hline & Navajo 1-3 & 2,250 & NEVP & SRP & NEVP & 0.11 & 254.3 \\
\hline & Navajo 1-3 & 2,250 & SRP & SRP & SRP & 0.46 & $1,035.0$ \\
\hline & Navajo 1-3 & 2,250 & TEP & SRP & TEP & 0.08 & 168.8 \\
\hline \multicolumn{8}{|c|}{ Palo Verde 1-3 } \\
\hline & Palo Verde 1-3 & 4,050 & APS & APS & APS & 0.29 & $1,178.6$ \\
\hline & Palo Verde 1-3 & 4,050 & AZSA & APS & CAISO & 0.00 & 2.4 \\
\hline & Palo Verde 1-3 & 4,050 & BNNG & APS & CAISO & 0.00 & 2.4 \\
\hline & Palo Verde 1-3 & 4,050 & BURB & APS & LDWP & 0.00 & 10.5 \\
\hline & Palo Verde 1-3 & 4,050 & CLTN & APS & CAISO & 0.00 & 2.4 \\
\hline & Palo Verde 1-3 & 4,050 & EPE & APS & EPE & 0.16 & 639.9 \\
\hline & Palo Verde 1-3 & 4,050 & GLEN & APS & LDWP & 0.00 & 10.5 \\
\hline & Palo Verde 1-3 & 4,050 & IID & APS & IID & 0.00 & 15.4 \\
\hline & Palo Verde 1-3 & 4,050 & LDWP & APS & LDWP & 0.10 & 391.2 \\
\hline & Palo Verde 1-3 & 4,050 & PASA & APS & CAISO & 0.00 & 10.5 \\
\hline & Palo Verde 1-3 & 4,050 & PNM & APS & PNM & 0.10 & 413.1 \\
\hline & Palo Verde 1-3 & 4,050 & RVSD & APS & CAISO & 0.00 & 13.0 \\
\hline & Palo Verde 1-3 & 4,050 & SCE & APS & CAISO & 0.16 & 639.9 \\
\hline & Palo Verde 1-3 & 4,050 & SRP & APS & SRP & 0.17 & 708.3 \\
\hline & Palo Verde 1-3 & 4,050 & VERN & APS & CAISO & 0.00 & 11.7 \\
\hline & & & & $\begin{array}{c}\text { Ownership by } \\
\text { BA: }\end{array}$ & APS & 0.29 & 1,178.6 \\
\hline & & & & & CAISO & 0.17 & 682.4 \\
\hline & & & & & EPE & 0.16 & 639.9 \\
\hline & & & & & IID & 0.00 & 15.4 \\
\hline & & & & & LDWP & 0.10 & 412.3 \\
\hline & & & & & PNM & 0.10 & 413.1 \\
\hline & & & & & SRP & 0.17 & 708.3 \\
\hline \multicolumn{8}{|l|}{ San Juan 1} \\
\hline & San Juan 1 & 327 & PNM & PNM & PNM & 0.5000 & 163.5 \\
\hline & San Juan 1 & 327 & TEP & PNM & TEP & 0.5000 & 163.5 \\
\hline \multicolumn{8}{|l|}{ San Juan 2} \\
\hline & San Juan 2 & 316 & PNM & PNM & PNM & 0.5000 & 158.0 \\
\hline & San Juan 2 & 316 & TEP & PNM & TEP & 0.5000 & 158.0 \\
\hline \multicolumn{8}{|l|}{ San Juan 3} \\
\hline & San Juan 3 & 498 & PNM & PNM & PNM & 0.5000 & 249.0 \\
\hline & San Juan 3 & 498 & AZSA & PNM & CAISO & 0.0615 & 30.6 \\
\hline & San Juan 3 & 498 & BNNG & PNM & CAISO & 0.0410 & 20.4 \\
\hline & San Juan 3 & 498 & CLTN & PNM & CAISO & 0.0615 & 30.6 \\
\hline & San Juan 3 & 498 & TSGT & PNM & WACM & 0.0820 & 40.8 \\
\hline & San Juan 3 & 498 & GLEN & PNM & LDWP & 0.0410 & 20.4 \\
\hline
\end{tabular}




\begin{tabular}{|c|c|c|c|c|c|c|c|}
\hline & San Juan 3 & 498 & IID & PNM & IID & 0.2130 & 106.1 \\
\hline & & & & $\begin{array}{c}\text { Ownership by } \\
\text { BA: }\end{array}$ & PNM & 0.5000 & 249.0 \\
\hline & & & & & CAISO & 0.1640 & 81.7 \\
\hline & & & & & WACM & 0.0820 & 40.8 \\
\hline & & & & & LDWP & 0.0410 & 20.4 \\
\hline & & & & & IID & 0.2130 & 106.1 \\
\hline \multicolumn{8}{|l|}{ San Juan 4} \\
\hline & San Juan 4 & 507 & ANHM & PNM & CAISO & 0.1004 & 50.9 \\
\hline & San Juan 4 & 507 & FARM & PNM & PNM & 0.0843 & 42.7 \\
\hline & San Juan 4 & 507 & LAC & PNM & PNM & 0.0723 & 36.7 \\
\hline & San Juan 4 & 507 & MSR & PNM & BANC & 0.2871 & 145.6 \\
\hline & San Juan 4 & 507 & PNM & PNM & PNM & 0.3849 & 195.1 \\
\hline & San Juan 4 & 507 & UAMP & PNM & CAISO & 0.0709 & 35.9 \\
\hline & & & & $\begin{array}{c}\text { Ownership by } \\
\text { BA: }\end{array}$ & PNM & 0.5415 & 274.5 \\
\hline & & & & & CAISO & 0.1713 & 86.8 \\
\hline & & & & & BANC & 0.2871 & 145.6 \\
\hline \multicolumn{8}{|l|}{ Craig 1,2 } \\
\hline & Craig 1,2 & 820 & PAC & WACM & PACW & 0.1900 & 156 \\
\hline & Craig 1,2 & 820 & PRPA & WACM & WACM & 0.1800 & 148 \\
\hline & Craig 1,2 & 820 & PSC & WACM & PSCO & 0.1000 & 82 \\
\hline & Craig 1,2 & 820 & SRP & WACM & SRP & 0.2900 & 238 \\
\hline & Craig 1,2 & 820 & TSGT & WACM & WACM & 0.2400 & 197 \\
\hline & & & & $\begin{array}{c}\text { Ownership by } \\
\text { BA: }\end{array}$ & PSCO & 0.1000 & 82.0 \\
\hline & & & & & WACM & 0.4200 & 344.4 \\
\hline & & & & & PACW & 0.1900 & 155.8 \\
\hline & & & & & SRP & 0.2900 & 237.8 \\
\hline \multicolumn{8}{|l|}{ Hayden 1} \\
\hline & Hayden 1 & 203 & PAC & WACM & PACW & 0.2450 & 50 \\
\hline & Hayden 1 & 203 & PSC & WACM & PSCO & 0.7550 & 153 \\
\hline \multicolumn{8}{|l|}{ Hayden 2} \\
\hline & Hayden 2 & 286 & PAC & WACM & PACW & 0.1260 & 36 \\
\hline & Hayden 2 & 286 & PSC & WACM & PSCO & 0.3740 & 107 \\
\hline & Hayden 2 & 286 & SRP & WACM & SRP & 0.5000 & 143 \\
\hline \multicolumn{8}{|l|}{$\begin{array}{l}\text { Laramie River } \\
\underline{2,3}, \underline{3}\end{array}$} \\
\hline & Laramie River 2,3 & 1107 & BEPC & WACM & WACM & 0.5918 & 655 \\
\hline & Laramie River 2,3 & 1107 & LAC & WACM & PNM & 0.0091 & 10 \\
\hline & Laramie River 2,3 & 1107 & MEAN & WACM & WACM & 0.0164 & 18 \\
\hline
\end{tabular}




\begin{tabular}{|c|c|c|c|c|c|c|c|}
\hline & Laramie River 2,3 & 1107 & TSGT & WACM & WACM & 0.3618 & 401 \\
\hline & Laramie River 2,3 & 1107 & WMPA & WACM & WACM & 0.0209 & 23 \\
\hline & & & & \multirow[t]{2}{*}{$\begin{array}{c}\text { Ownership by } \\
\text { BA: }\end{array}$} & WACM & 0.9909 & $1,096.9$ \\
\hline & & & & & PNM & 0.0091 & 10.1 \\
\hline \multicolumn{8}{|l|}{ Wyodak 1} \\
\hline & Wyodak 1 & 340 & BHPL & PACE & WACM & 0.2000 & 68 \\
\hline & Wyodak 1 & 340 & PACE & PACE & PAC & 0.8000 & 272 \\
\hline \multirow{2}{*}{\multicolumn{8}{|c|}{$\begin{array}{l}\text { Gianelli (San } \\
\text { Luis) }\end{array}$}} \\
\hline & & & & & & & \\
\hline & Gianelli (San Luis) & 362 & DWR & CAISO & CAISO & 0.5500 & 199 \\
\hline & Gianelli (San Luis) & 362 & WAPA & CAISO & BANC & 0.4500 & 163 \\
\hline \multicolumn{8}{|l|}{ Luna CC } \\
\hline & Luna CC & 575 & PNM & PNM & PNM & 0.6667 & 383.3 \\
\hline & Luna CC & 575 & TEP & PNM & TEC & 0.3333 & 191.7 \\
\hline \multicolumn{8}{|l|}{ Springerville 3} \\
\hline & Springerville 3 & 400 & TSGT & TEP & WACM & 0.7500 & 300.0 \\
\hline & Springerville 3 & 400 & SRP & TEP & SRP & 0.2500 & 100.0 \\
\hline
\end{tabular}


Appendix $\mathrm{E}$

Flows at Selected WECC Paths and BA-to-BA Flowgates 



\section{Appendix E}

\section{Flows at Selected WECC Paths and BA-to-BA Flowgates}

The Pacific Northwest National Laboratory (PNNL) team has developed a Microsoft ${ }^{\circledR}$ Bing® mapbased tool to help in comparing transmission flows at different time frames for different simulation cases. The tool can be used for both Western Electricity Coordinating Council (WECC) path flows and Balancing Authority (BA)-to-BA flows. The tool is made available for Northwest Power Pool (NWPP) members to perform further transmission analysis as needed in the future. Snapshots of the tool are shown in Figure E.1.

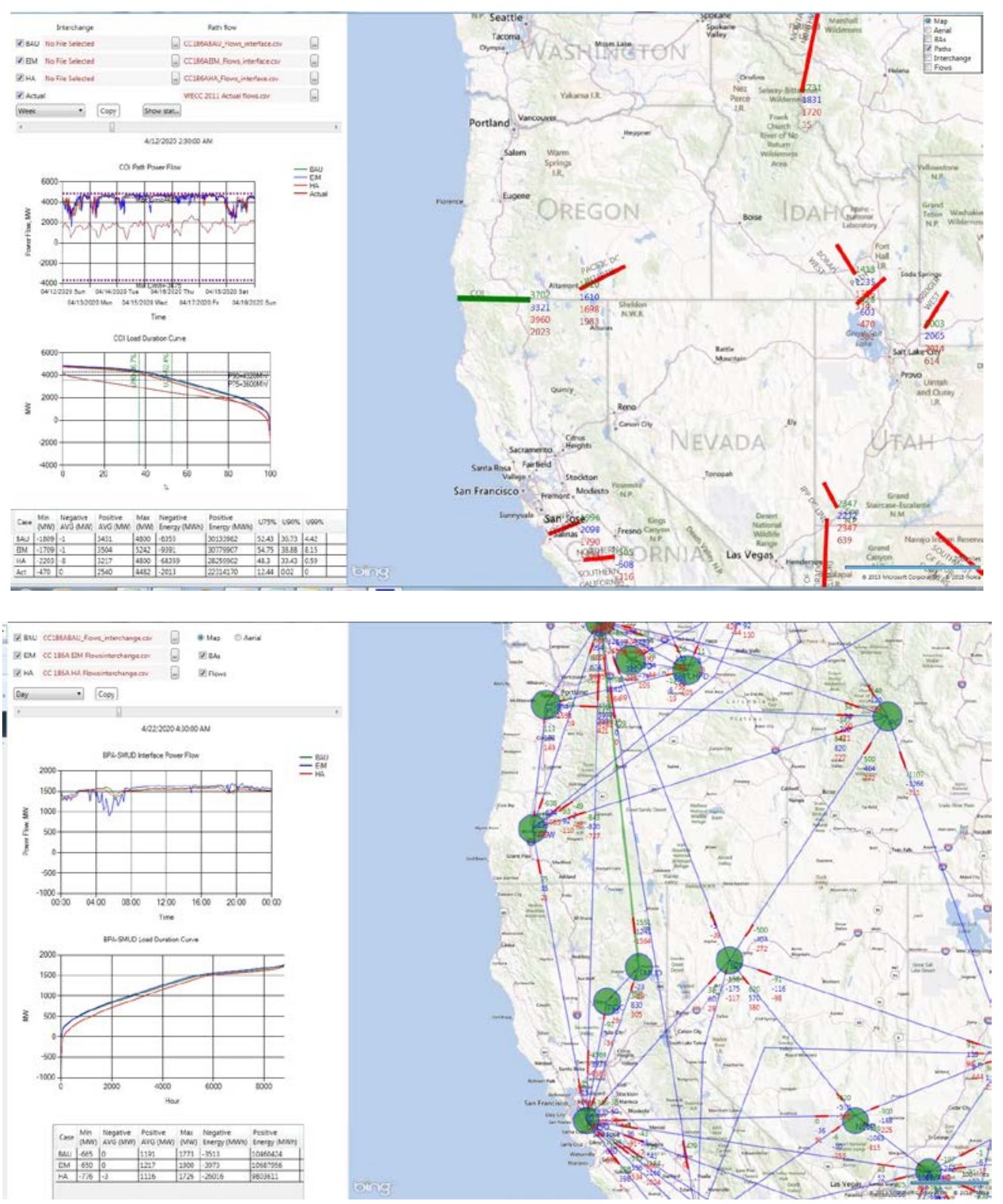

Figure E.1. Snapshots of the Bing Map-Based Visualization Tool Developed by PNNL 
Figure E.2 to Figure E.6 show comparisons of selected WECC path flows in hour-ahead (HA), business-as-usual (BAU) and Energy Imbalance Market (EIM) simulations for Core Case 1.86A in comparison to actual flows in 2011. Actual flows are used as a relative comparison and for building confidence in modeled results.
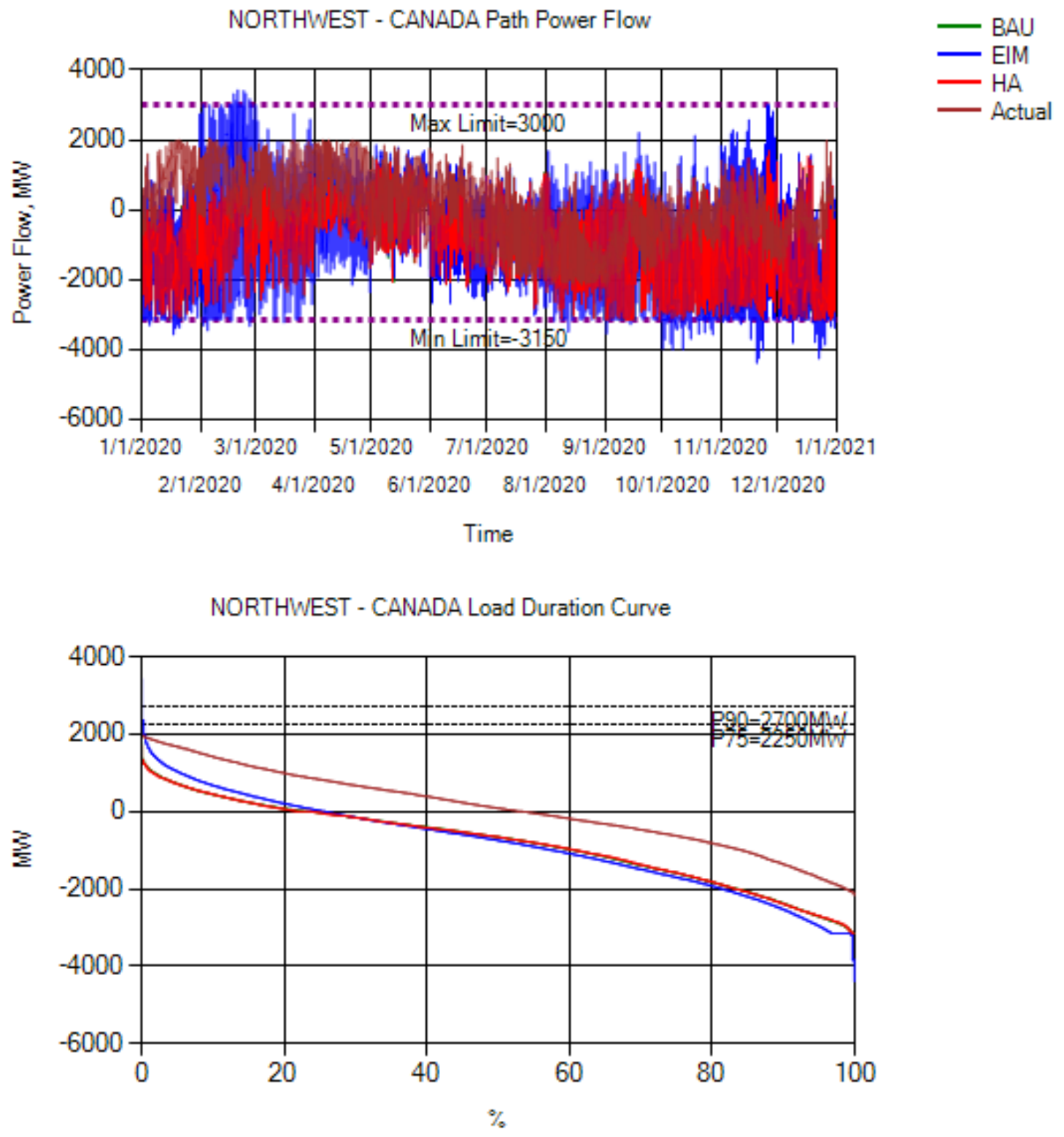

Figure E.2. WECC Path 3 (Northwest-Canada) Flow Comparison 


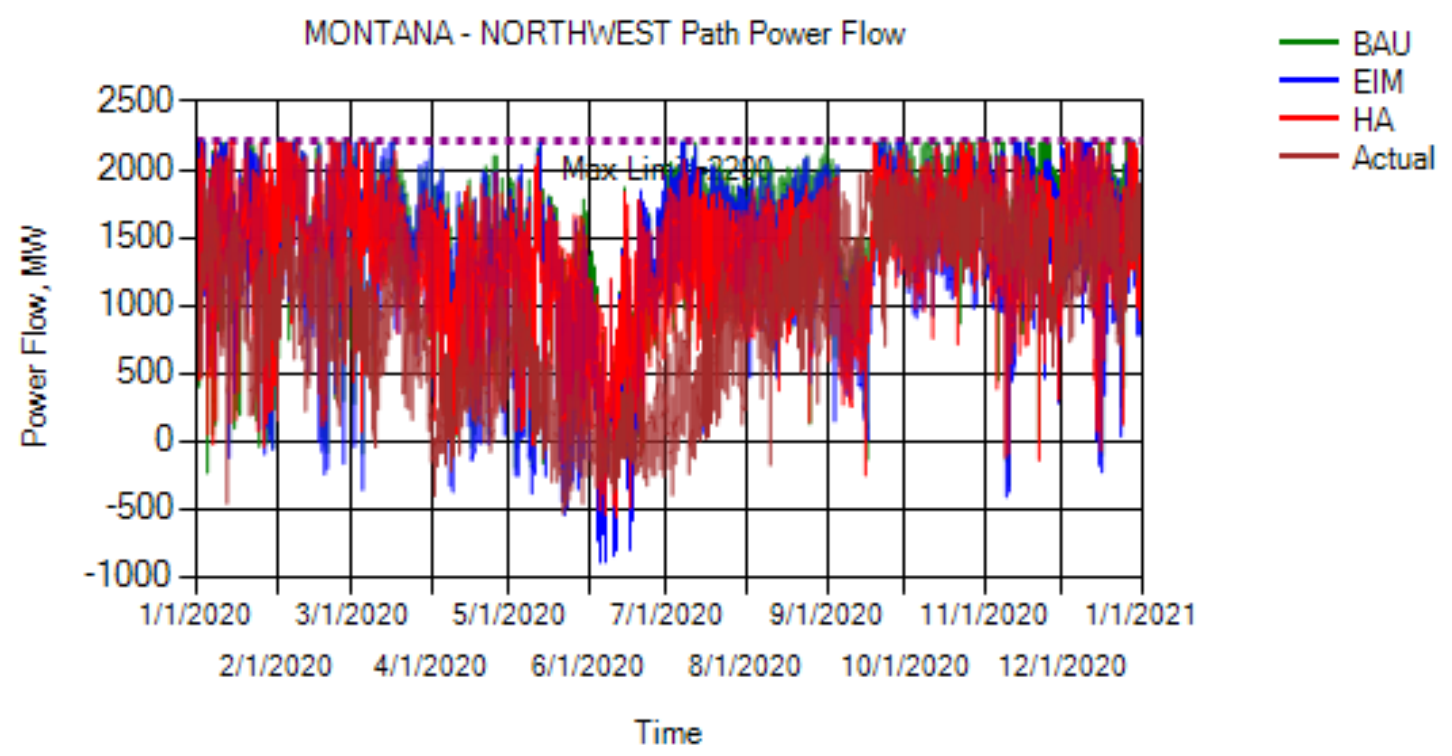

MONTANA - NORTHWEST Load Duration Curve

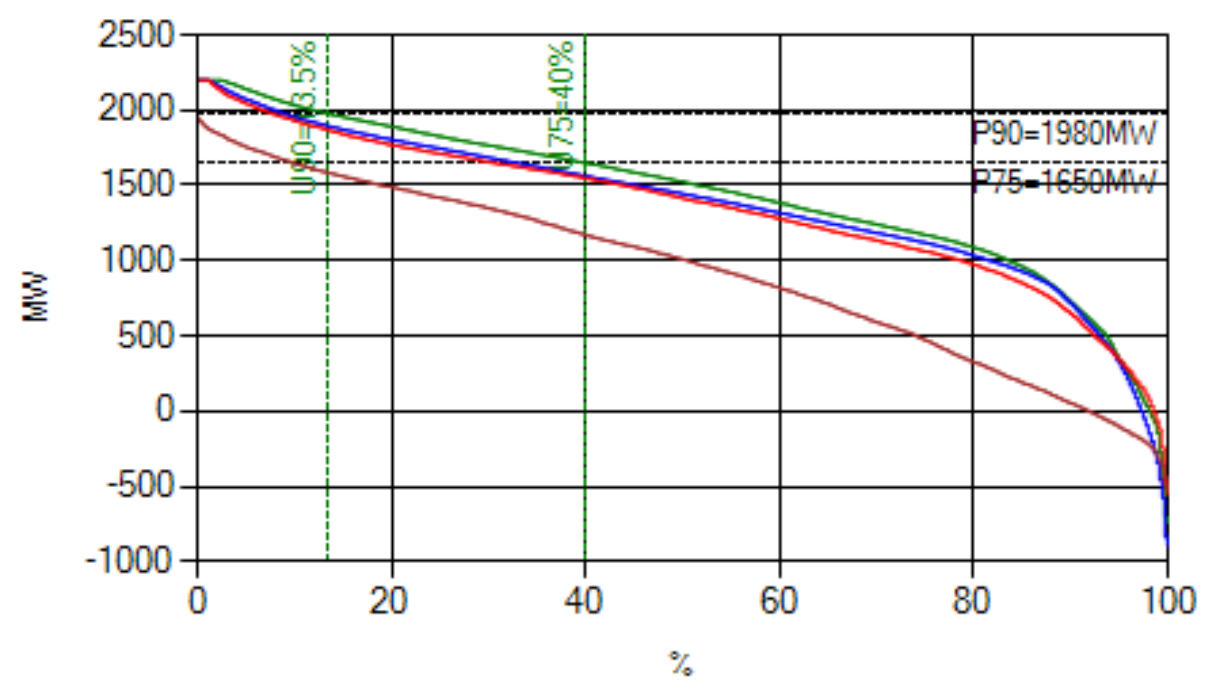

Figure E.3. WECC Path 8 (Montana - Northwest) Flow Comparison 


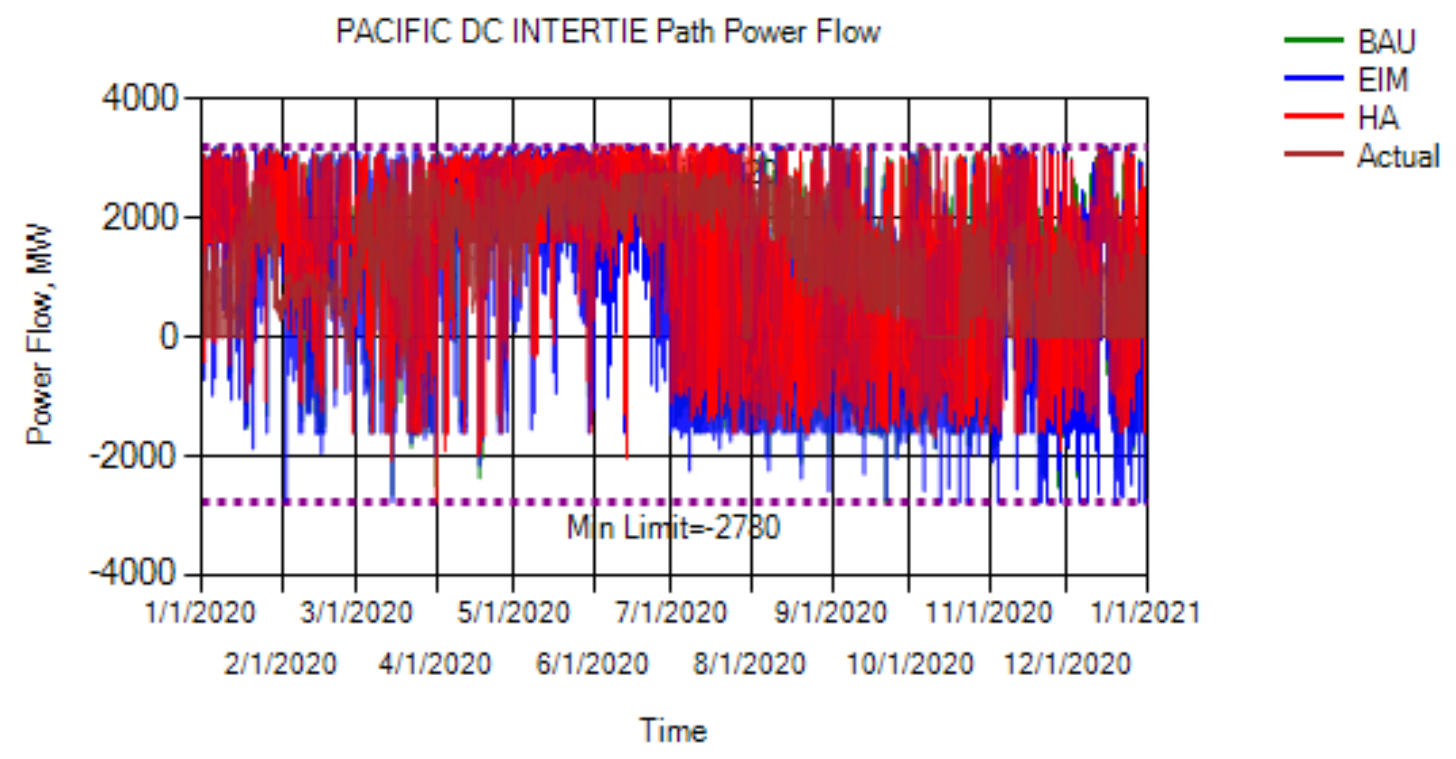

PACIFIC DC INTERTIE Load Duration Curve

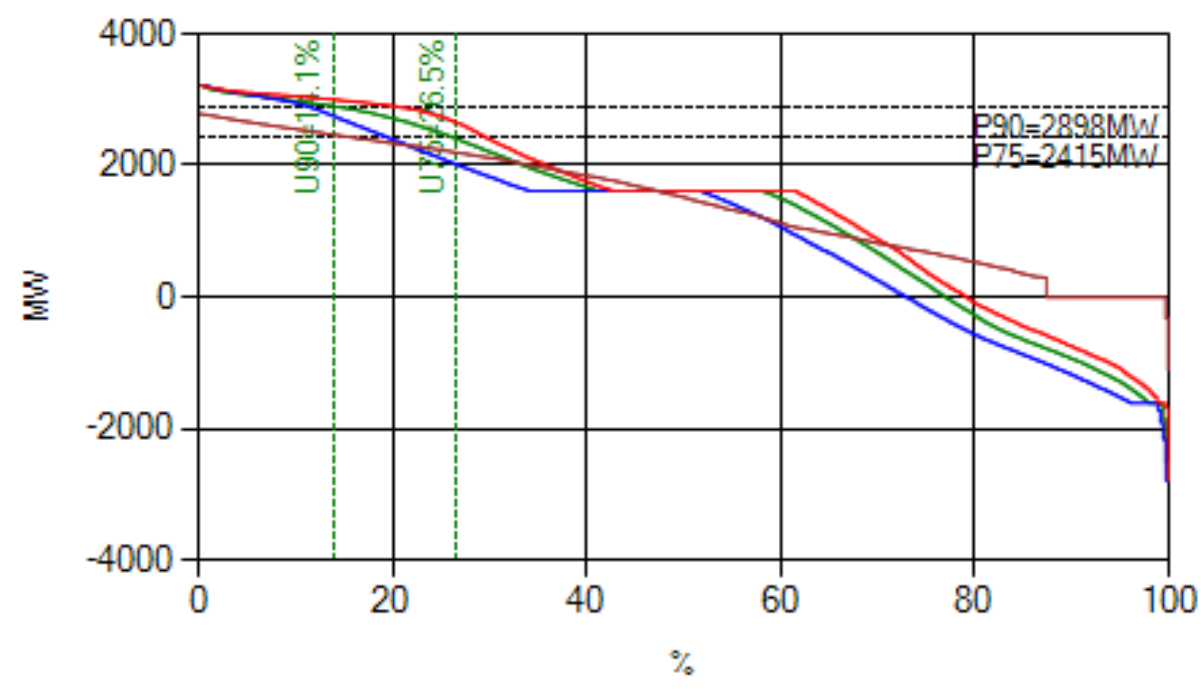

Figure E.4. WECC Path 65 (Pacific DC Intertie) Flow Comparison 

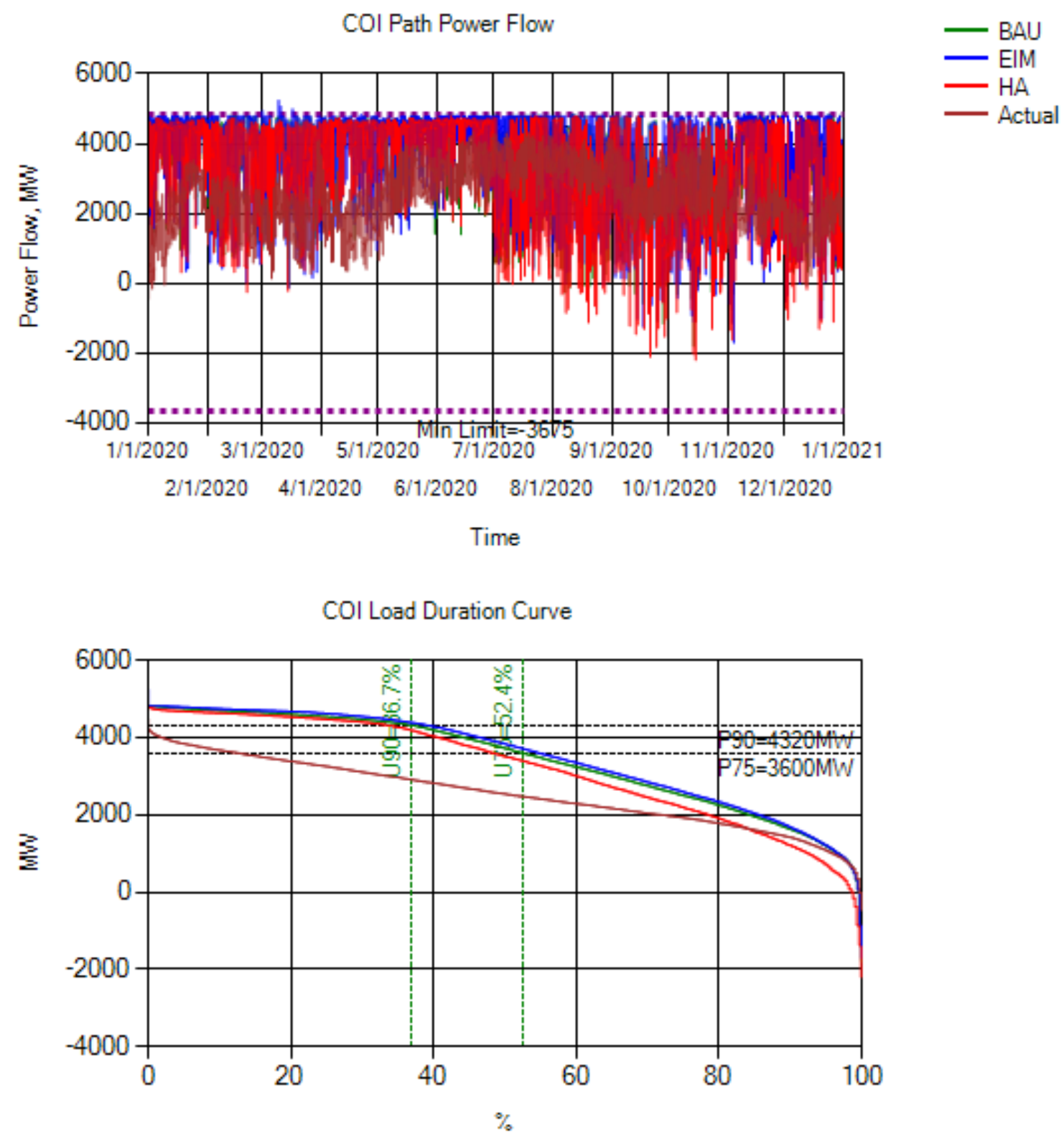

Figure E.5. WECC Path 66 (COI) Flow Comparison 

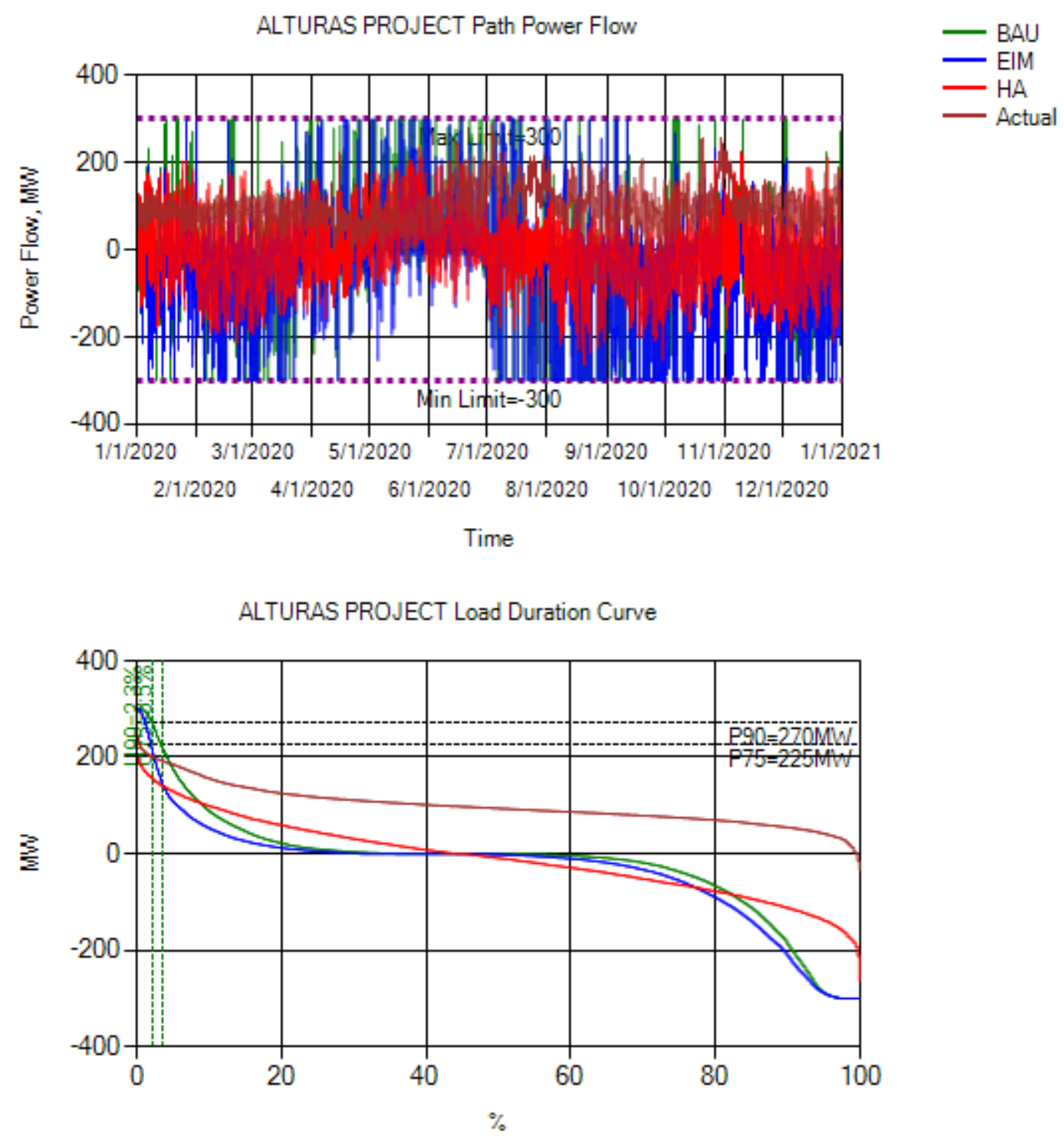

Figure E.6. WECC Path 76 (Alturas Project) Flow Comparison

Figure E.7 to Figure E.12 give BA-to-BA flows for selected BA-to-BA flowgates in the model. Comparisons are between HA, BAU and EIM flow patterns; there was no actual BA-to-BA flow data available to the study team. 


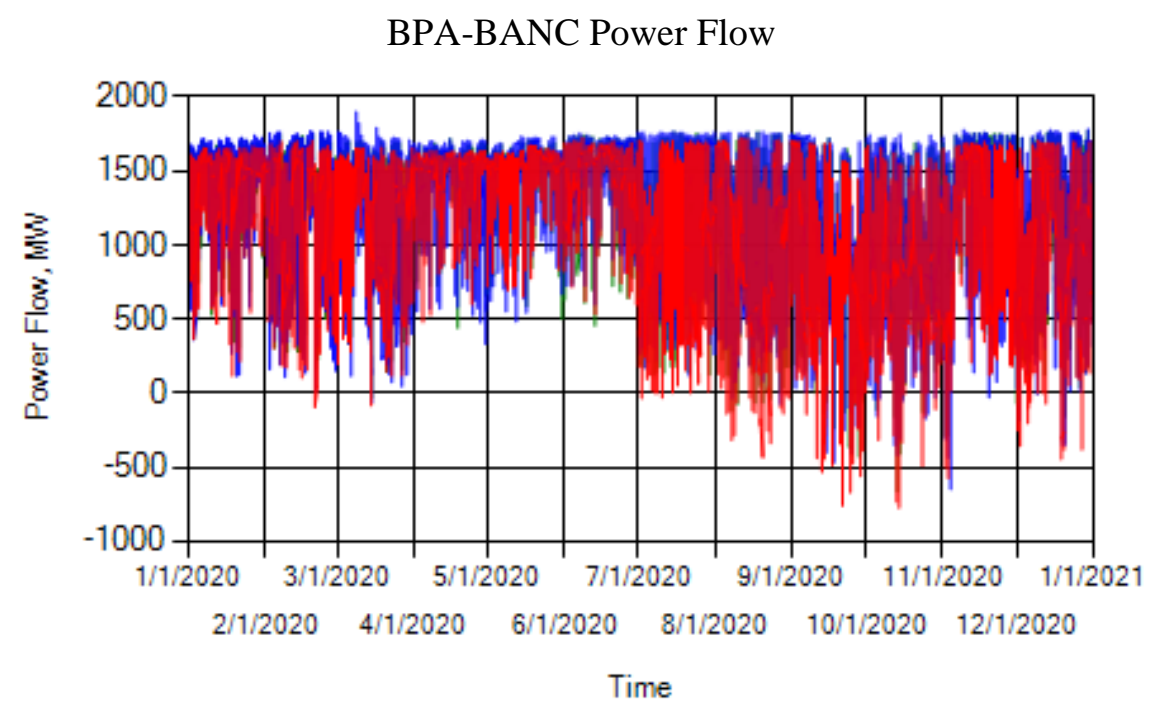

- BAU

- HA

BPA-BANC Power Flow

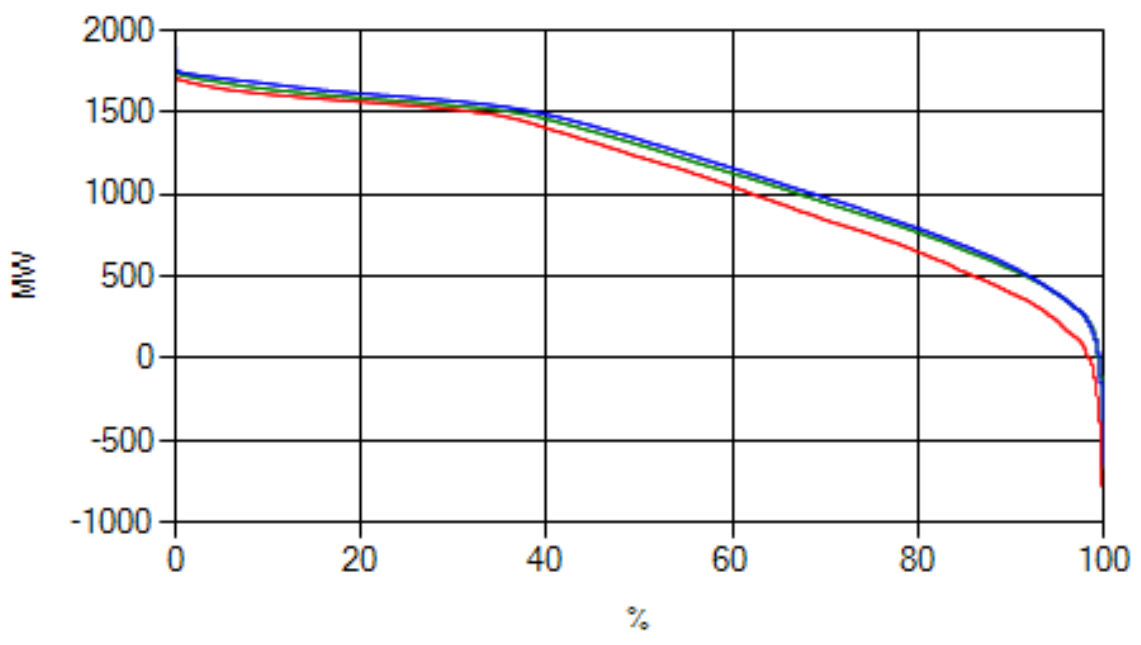

Figure E.7. BPA to BANC Transmission Flows 

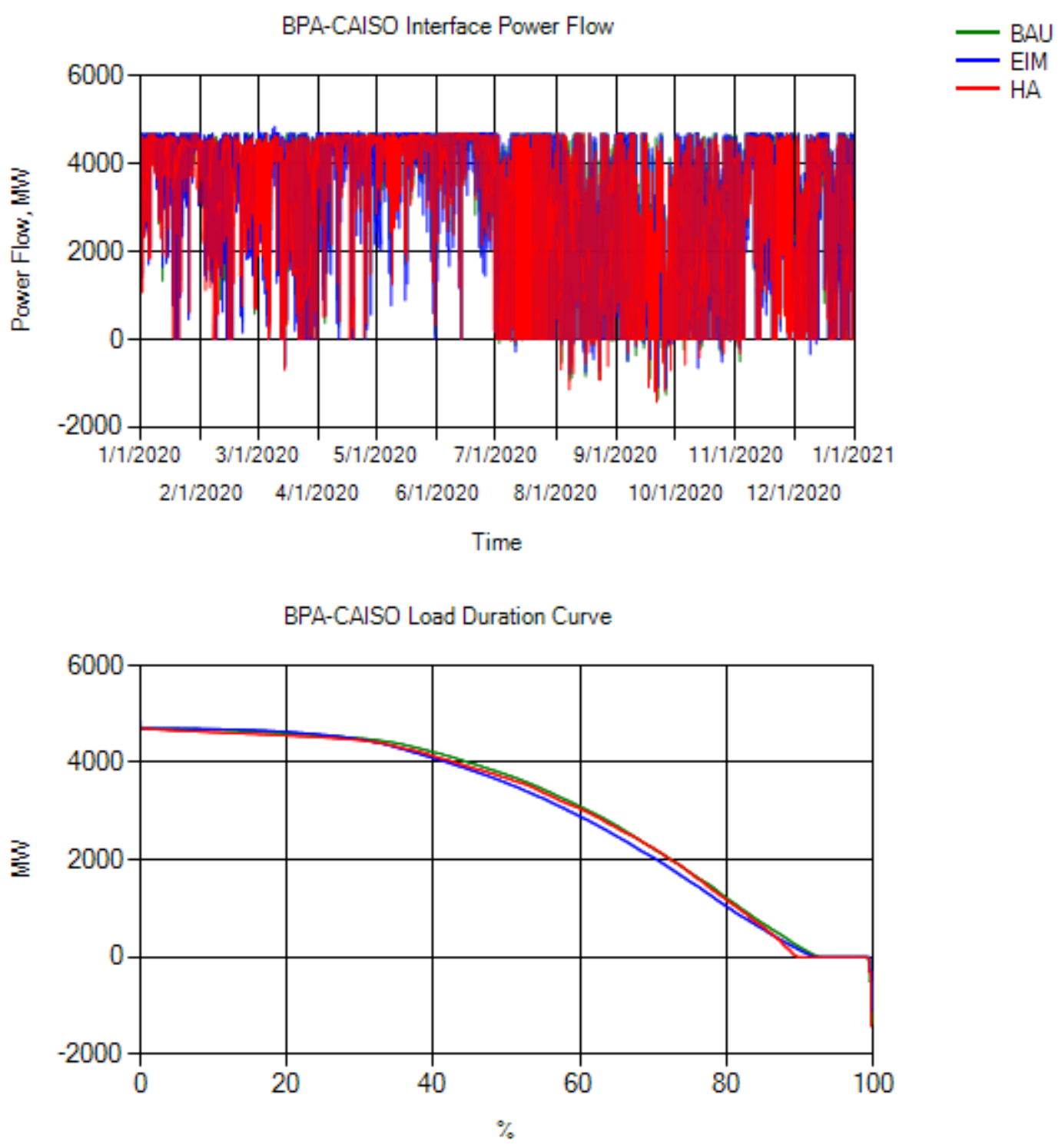

Figure E.8. BPA to CAISO Transmission Flows 

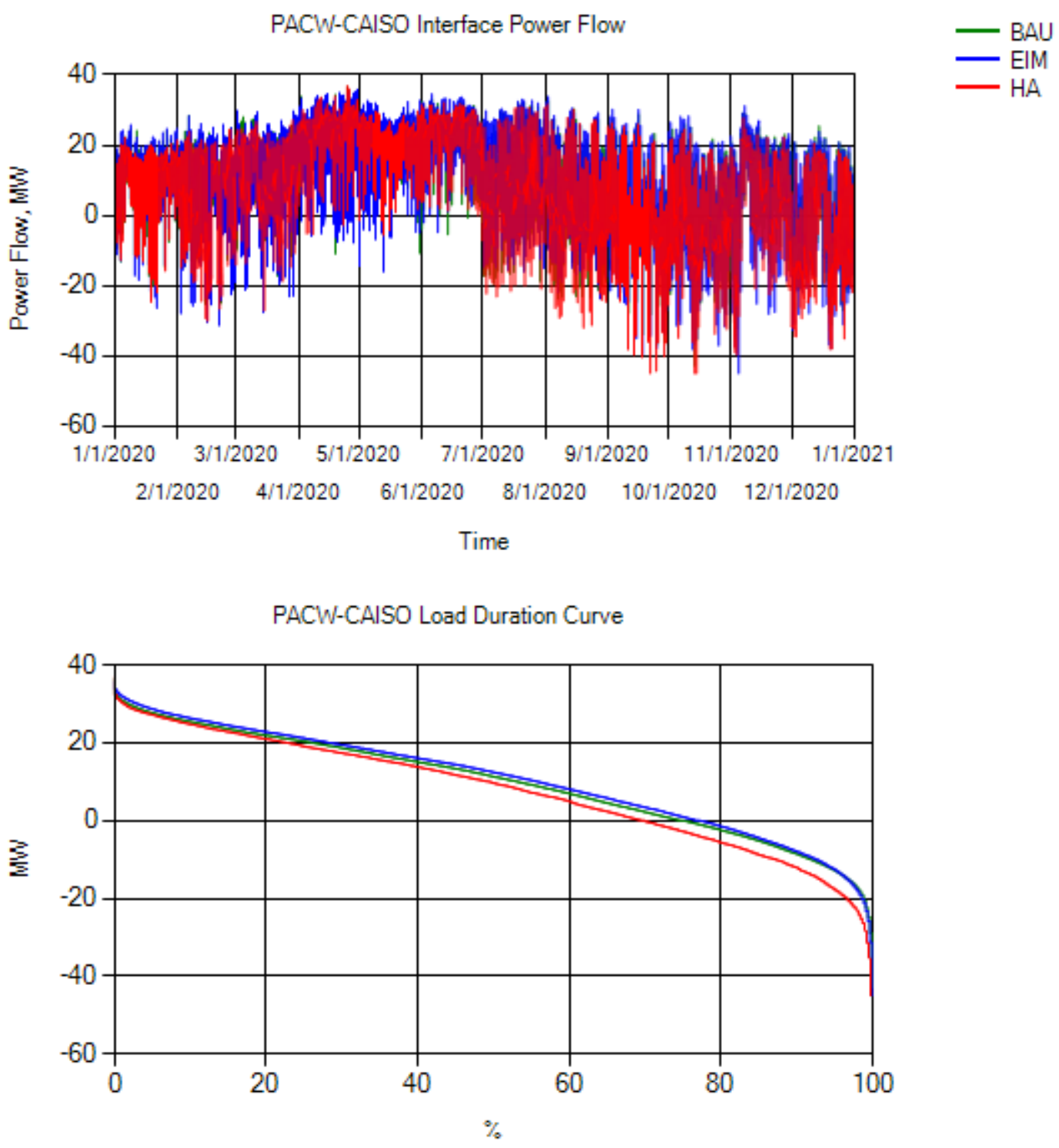

Figure E.9. PACW to CAISO Transmission Flows 

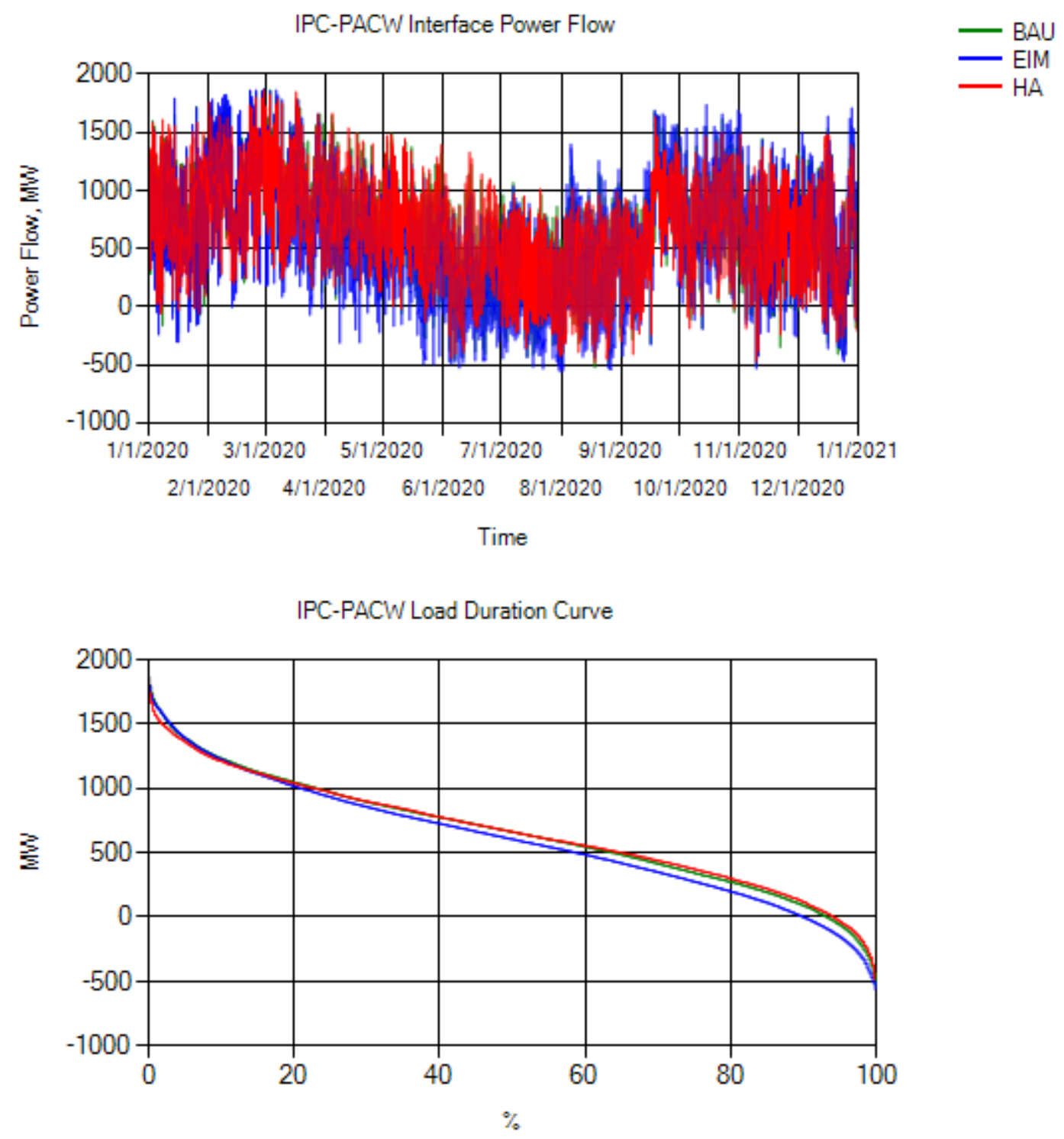

Figure E.10. IPC to PACW Transmission Flows 

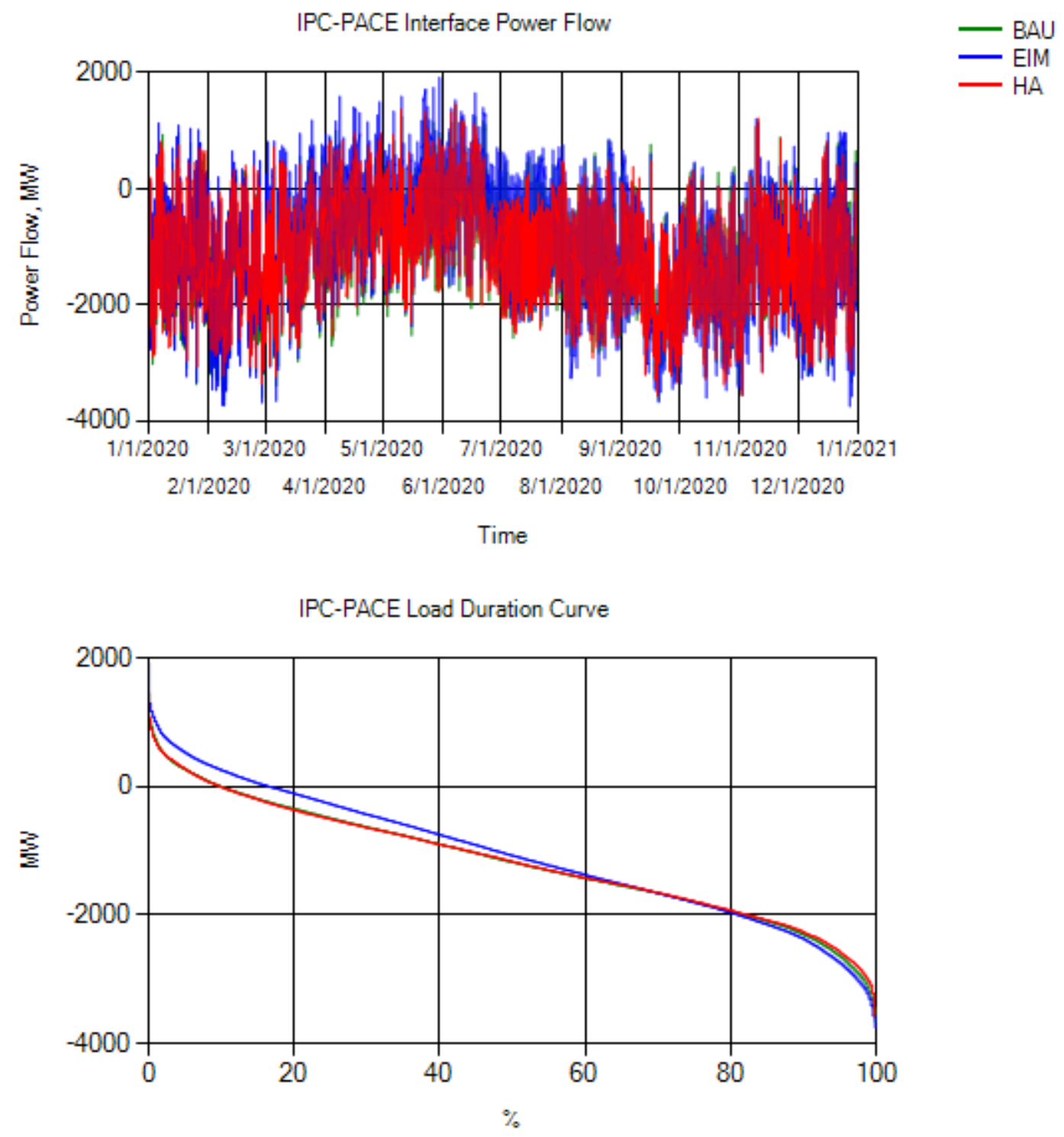

Figure E.11. IPC to PACE Transmission Flows 

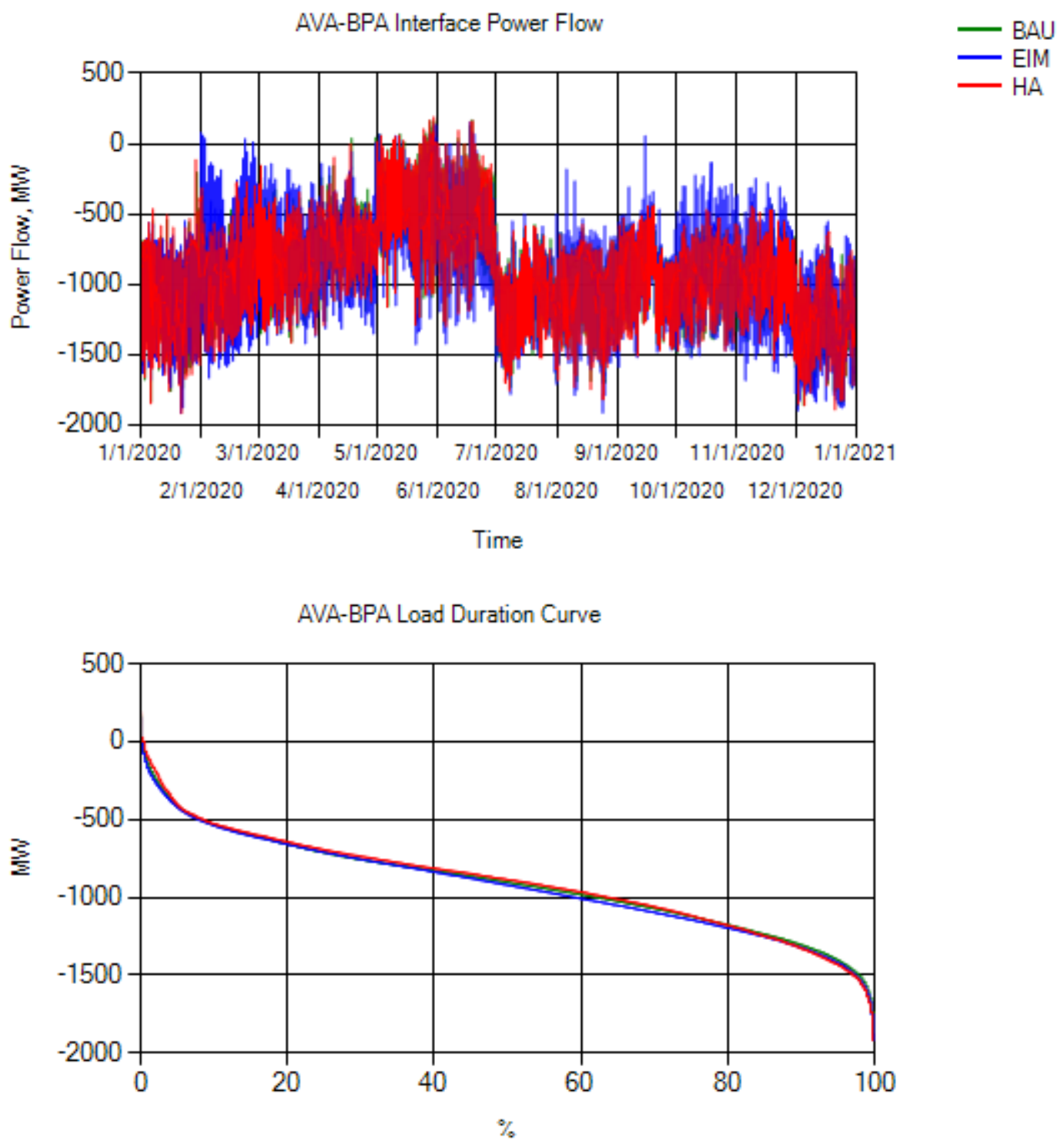

Figure E.12. AVA to BPA Transmission Flows 


\section{Appendix $\mathrm{F}$}

Reserve Shift Analysis: Impact of Half-Hour Wind Scheduling on Load-Following Requirements 



\section{Appendix F}

\section{Reserve Shift Analysis: Impact of Half-Hour Wind Scheduling on Load-Following Requirements Background}

The objective of the analysis in this section is to capture the impact of half-hour wind scheduling (applied to several specified wind farms) within BAs that normally schedule their generation on the hourly basis. While the analysis in this section is not directly related to the EIM analyses that were given in previous chapters, it highlights the benefits of a short-term alternative.

The analysis was conducted for a limited number of specified BAs that are described as source (e.g., BPA) and sink (e.g., PGN) BAs. The main idea is that if the source BA could schedule interchange for wind on a half-hourly basis, it would make the schedule follow its net load more closely. The scheduling change in the source BA is matched by adding the corresponding component to the net load in the sink BA. The load-following requirements should be calculated: (a) by the difference between the net load and modified schedule in the source BA, and (b) by the difference between modified net load and unchanged hourly schedule in the sink BA. The schedules should be ramped over 20 minutes between hours and over 10 minutes on the half-hour transitions. The analysis uses the assumptions and models developed for the ongoing study conducted by NWPP and PNNL. NWPP has provided information about the sink and source BAs, as well as wind farms participating in the half-hour scheduling process. Results are presented as hourly upward and downward load-following requirements in the source and sink BAs and compared with the results of the Core Case Reserve method, where all generators are scheduled on the hourly basis.

\section{F.1 Objectives}

In this work, PNNL team modified its original algorithms to calculate load-following requirements for selected source/sink BAs in the NWPP and run simulations based on NWPP specifications. The input data, such as load and wind generation, remain the same as the data used in the current NWPP EIM study, i.e., the $11 \%$ renewable penetration case. The changes made in load-following calculation include:

a. Modify the calculation of load-following component between source BAs and sink BAs. The source BA is defined as the one that sends wind energy from a specified wind farm to a sink BA, and the sink BA is the one that receives wind energy from a source BA.

b. Change wind forecast from hourly schedule to 30-minute schedule for a number of selected wind farms in source BAs. The rest of the wind farms in the source BA should have hourly schedules as before. No change is made to the wind and load schedules for sink BAs (hourly schedule). A persistence model is used to generate wind forecasts.

c. Adjust wind ramps within the hour: use 20-minute ramps for between-hour schedules and 10-minute ramps for within-hour schedules. 


\section{F.2 Approach}

In this section, we use the sample plots obtained from BPA as an example to demonstrate the methodologies to compute load-following requirements using the modified algorithms.

For Source BAs (e.g., BPA), the scheduling procedure is shown in Figure F.1.

a. The dashed blue curve is the net load schedule using an hourly scheduling method for load and wind, the black solid curve is the actual net load, and the dashed yellow line is the modified net load schedule considering 30-minute wind schedules. Interchange schedules are not considered.

b. For selected wind farms in the source BA, a new 30-minute schedule is created. At the beginning of the hour, the $\mathrm{T}-31$ persistence model is used to generate the first 30-minute schedule; for the second 30-minute schedule, the T-x model is used, where $x$ is flexible. In this study, we assume $x=1$.

c. For the load hourly schedules, PNNL's forecast error generator was used with the parameters set exactly as in the current NWPP EIM study.

d. For the rest of the wind farms in the source BA, only hourly schedule is considered, using the $\mathrm{T}-31$ model.

e. Ramps are created in between-hour schedules (20-minute ramp) and within-hour schedules (10-minute ramp)

f. Load following = RT schedule of net load (10-minute average of net load curve) —modified net load schedules considering 30-minute schedules of selected wind farms. That is, the difference between the average of the black solid curve and the dashed yellow curve.

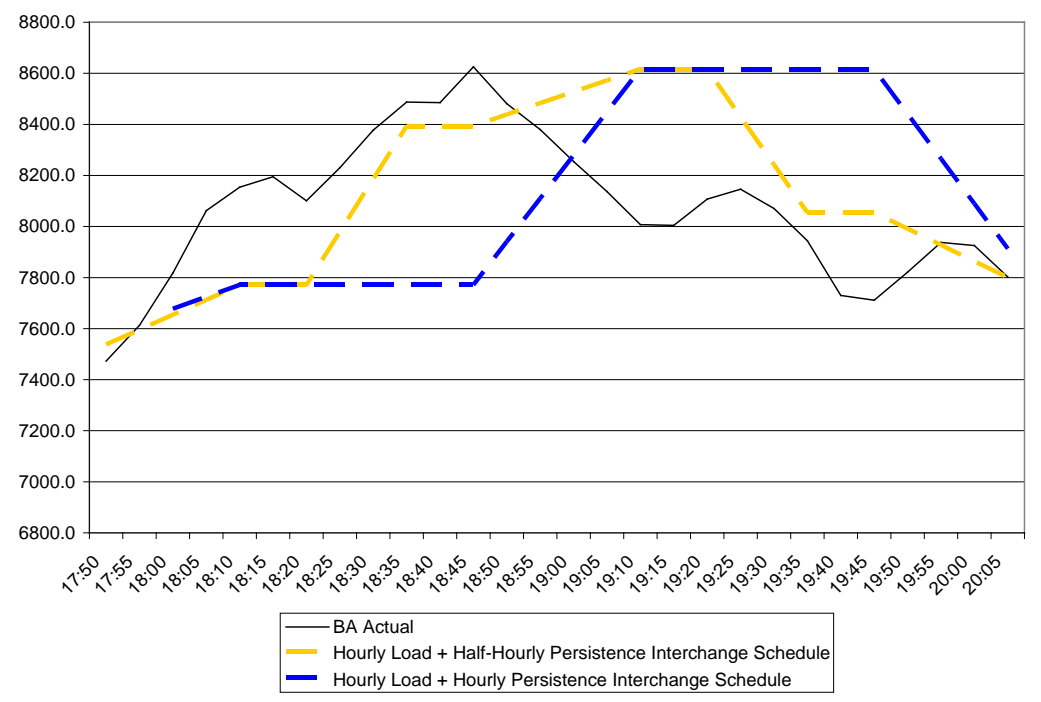

Figure F.1. Scheduling Procedure for Source BAs

For Sink BAs (e.g., PGN), the computation of the load-following component is dependent upon the change calculated in the source BA. The scheduling procedure in a sink BA is shown in Figure F.2.

a. In Figure F.2, the dashed blue curve is the original hourly schedule of net load, the solid yellow curve is the actual net load based on a modified 30-minute wind schedule in the source BA, and the solid blue curve is the net load in the original case without schedule modifications. 
b. For the net-load hourly schedules, PNNL's forecast error generator was used with the parameters set exactly as in the current NWPP EIM study.

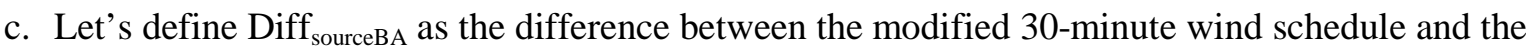
original hourly wind schedule, which is the difference between the dashed yellow curve and the dashed blue curve shown in Figure F.1. Then, the modified net load in the sink BA (the solid

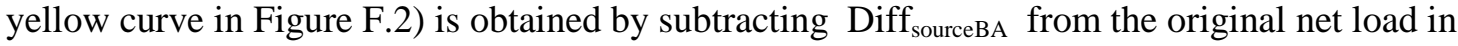
the sink BA (the dashed blue curve in Figure F.2).

d. The load-following component in a sink BA is calculated as the difference between the 10-minute average of modified net load (the solid yellow curve), and the original hourly schedule of net load (the dashed blue curve).

e. In some scenarios, only a specified fraction of wind generation of selected wind farms in the source BA is shifted to the sink BA. In these instances, only the corresponding fraction of Diff $_{\text {sourceBA }}$ is subtracted from the sink BA net load.

The rest of the analysis was exactly the same as in the methods PNNL is using for the NWPP study, including forecast error generation, result reporting method (on an hourly basis), etc. Load-following requirements in the source and sink BAs will be compared against the same quantities in the original case.

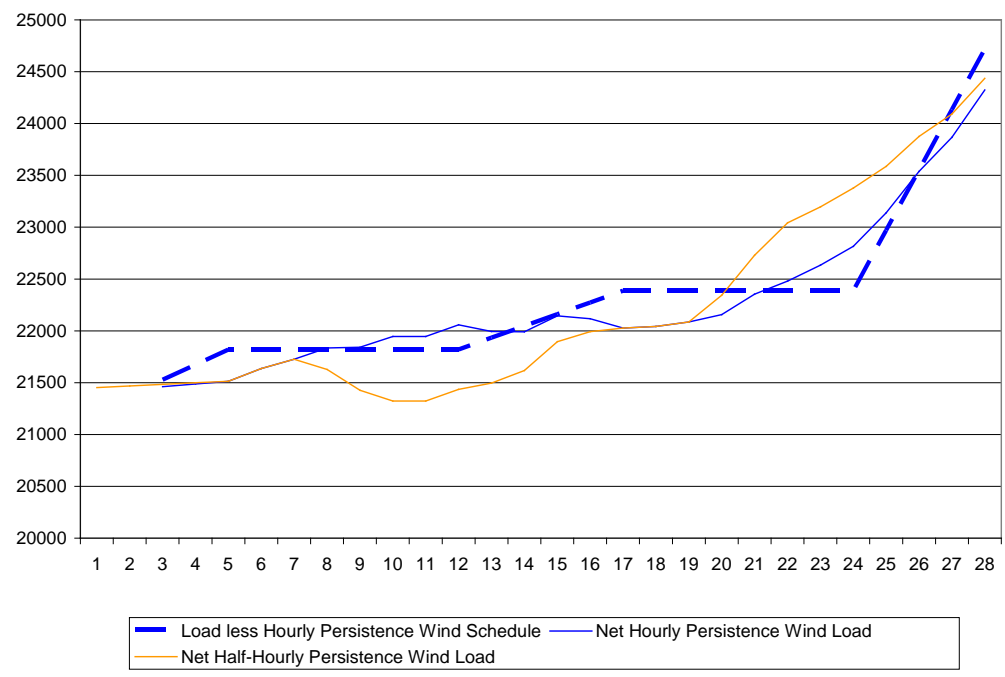

Figure F.2. Scheduling Procedure for Sink BAs

The above method also works for the wind transfers between one source BA and multiple sink BAs. The load-following requirements of sink BAs are calculated independently. For the source BA, the aggregated impact of the half-hour wind schedule can be calculated by simply summing up all the 30-minute schedules of individual wind transfers to multiple sink BAs. 


\section{F.3 Case Study One: Biglow Canyon Wind Transfer from BPA to PGN}

\section{F.3.1 Wind Farm Data Generation}

A wind farm, Biglow Canyon, with an installed capacity of 450 MW located in BPA is used as an example to show the impact of half-hour wind schedule on the load-following requirements of both source and sink BAs. This wind transfer is currently being deployed in BPA, to transfer wind energy to PGN. To generate the wind power output of this wind farm, the NREL per-unit wind production profile at each bus is used. This wind farm is connected to three buses, 47906, 47327 and 40477, with capacities of $126 \mathrm{MW}, 149 \mathrm{MW}$ and $175 \mathrm{MW}$, respectively. The output of this wind farm (shown in Figure F.3) is the sum of the individual outputs at these three buses, which are calculated using the bus-level per-unit profile multiplied by its installed capacity.

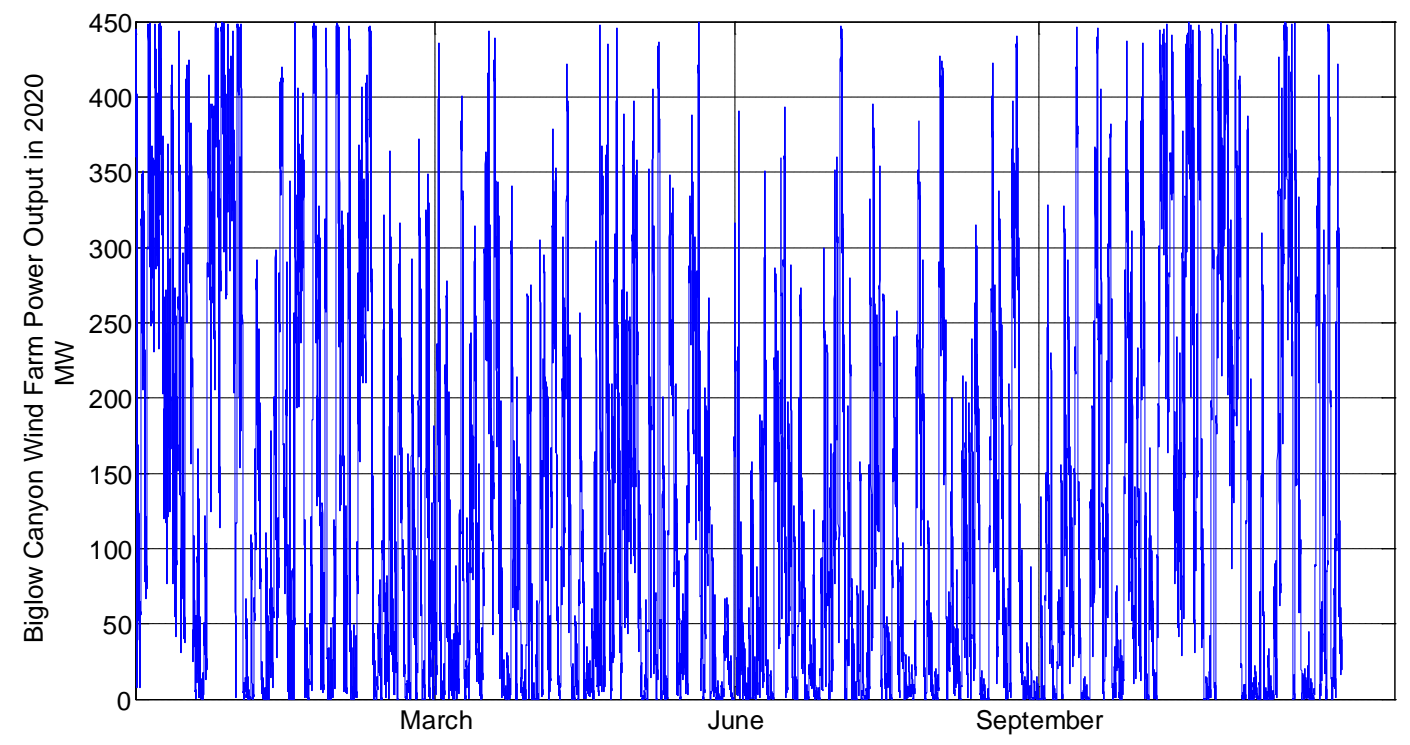

Figure F.3. Power Output of Biglow Canyon in 2020 


\section{F.3.2 Example of Hourly Load Schedule}

Figure F.4 shows the actual load in BPA and the generated hourly load schedule, with 20-minute ramps.

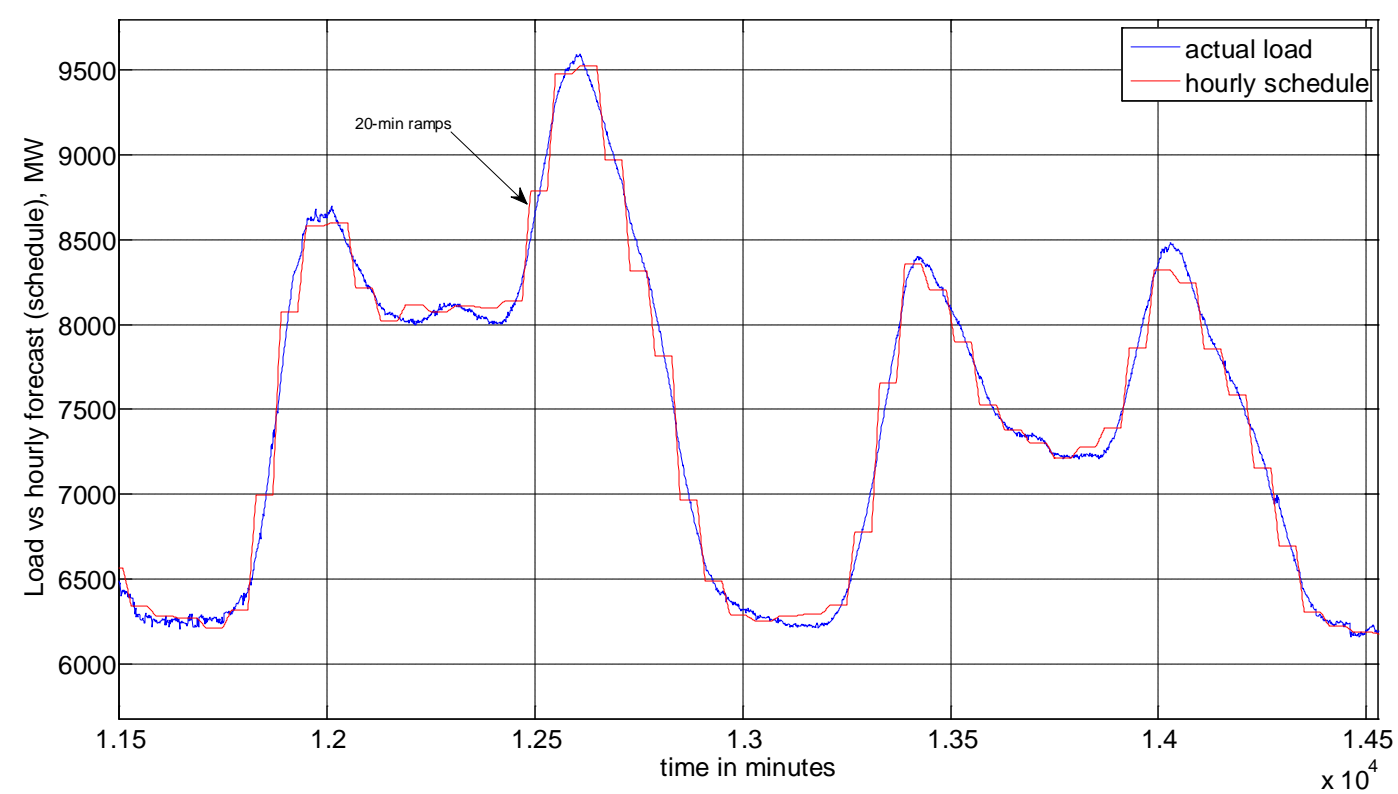

Figure F.4. Load and Hourly Load Schedule in BPA, January 2020

\section{F.3.3 Example of 30-Minute Wind Schedule for Selected Wind Farms}

Figure F.5 shows the actual wind production (blue curve), the generated hourly schedule with 20-minute ramps using the $\mathrm{T}-31$ persistence model (dashed green curve) and the generated 30-minute schedule with ramps using the modified algorithm (red curve). It clearly shows that the 30-minute wind schedule is closer to the actual wind output, compared to the hourly schedule, which provides a lower forecast error. 


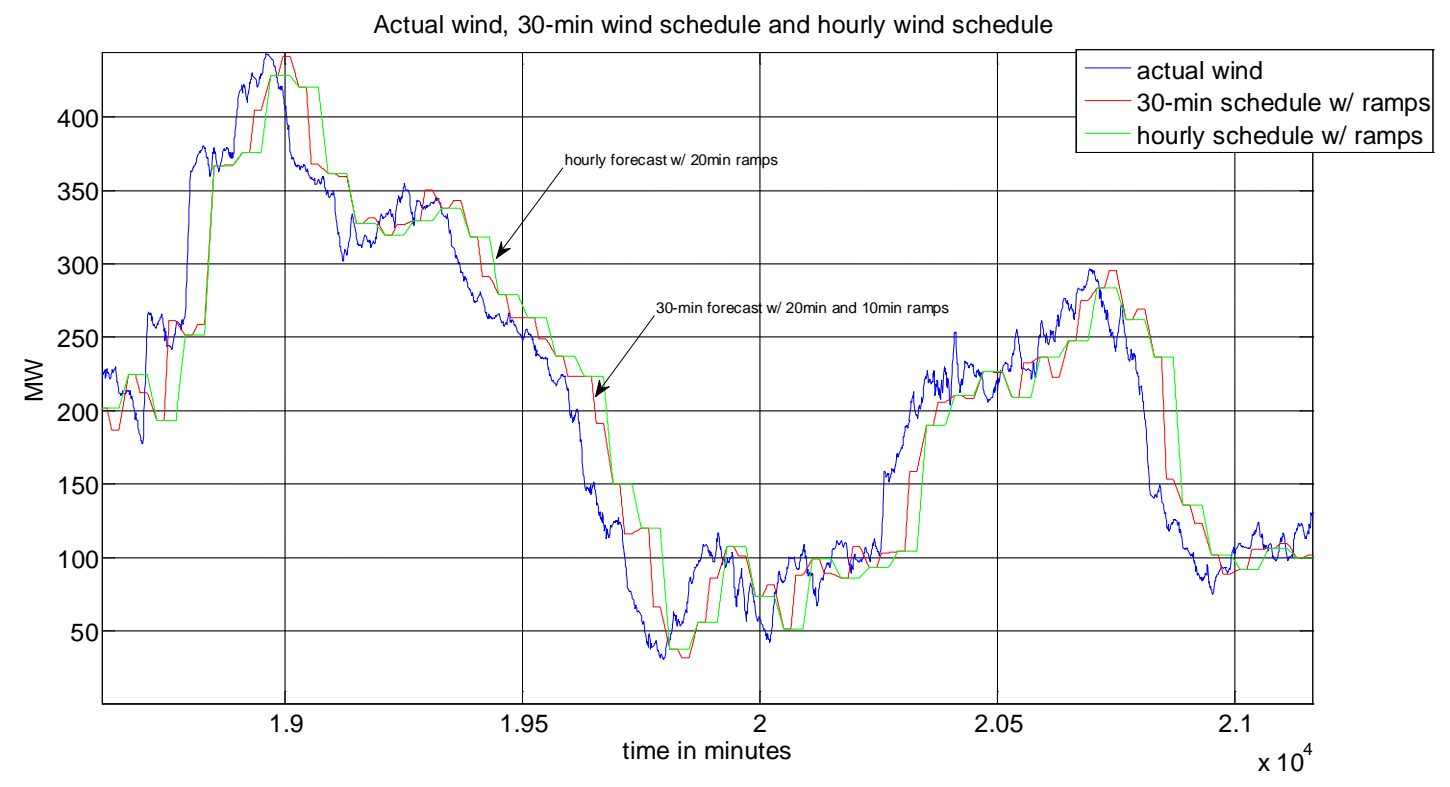

Figure F.5. 30-Minute Wind Schedules for Biglow Canyon, January 2020

Figure F.6 shows the difference between the 30-minute wind schedule and the hourly schedule in the source BA. This time series was used to modify the net load curve in the corresponding sink BA and calculate its load-following requirements. Figure F.7 plots the difference between actual wind output and 30-minute schedule for Biglow Canyon.

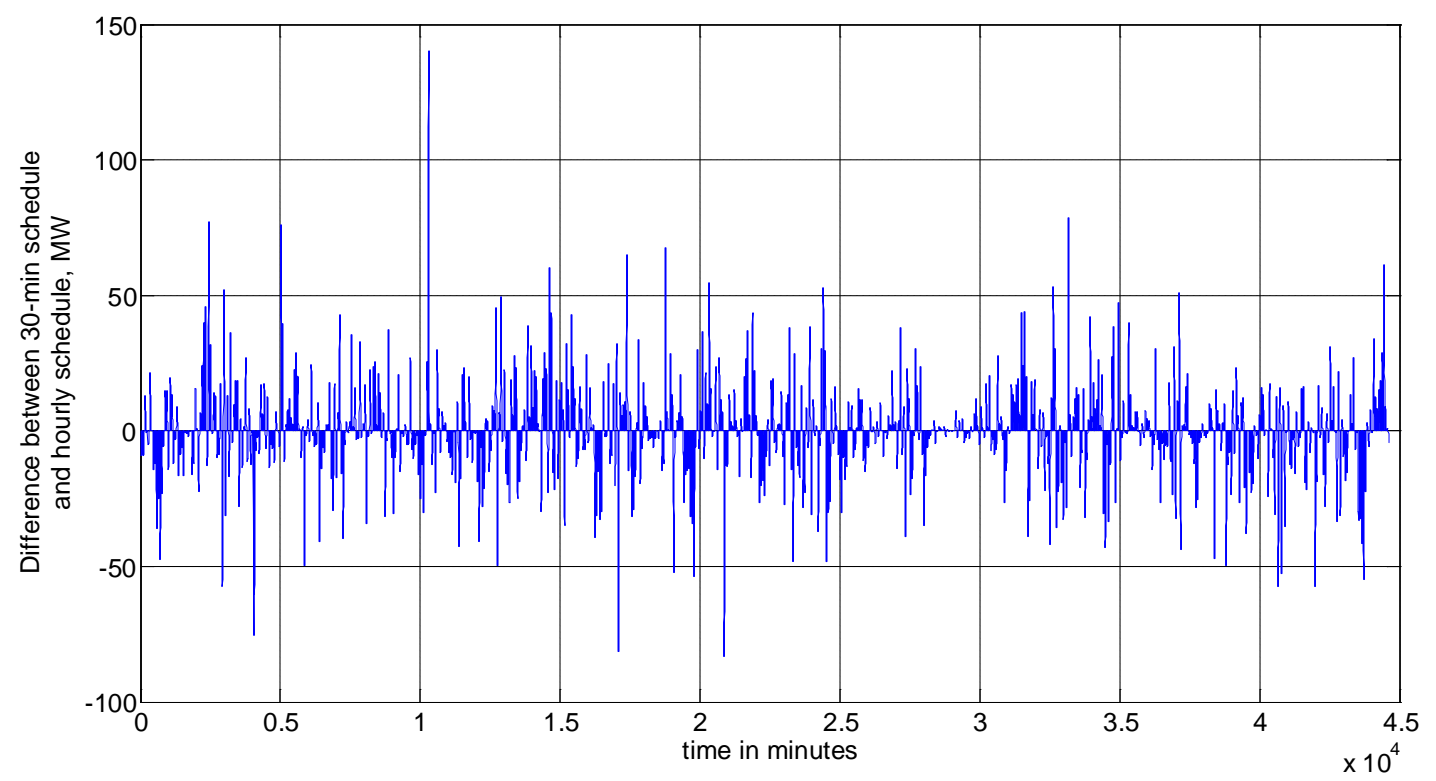

Figure F.6. Difference between 30-Minute Wind Schedule of Biglow Canyon and the Hourly Schedule, January 2020 


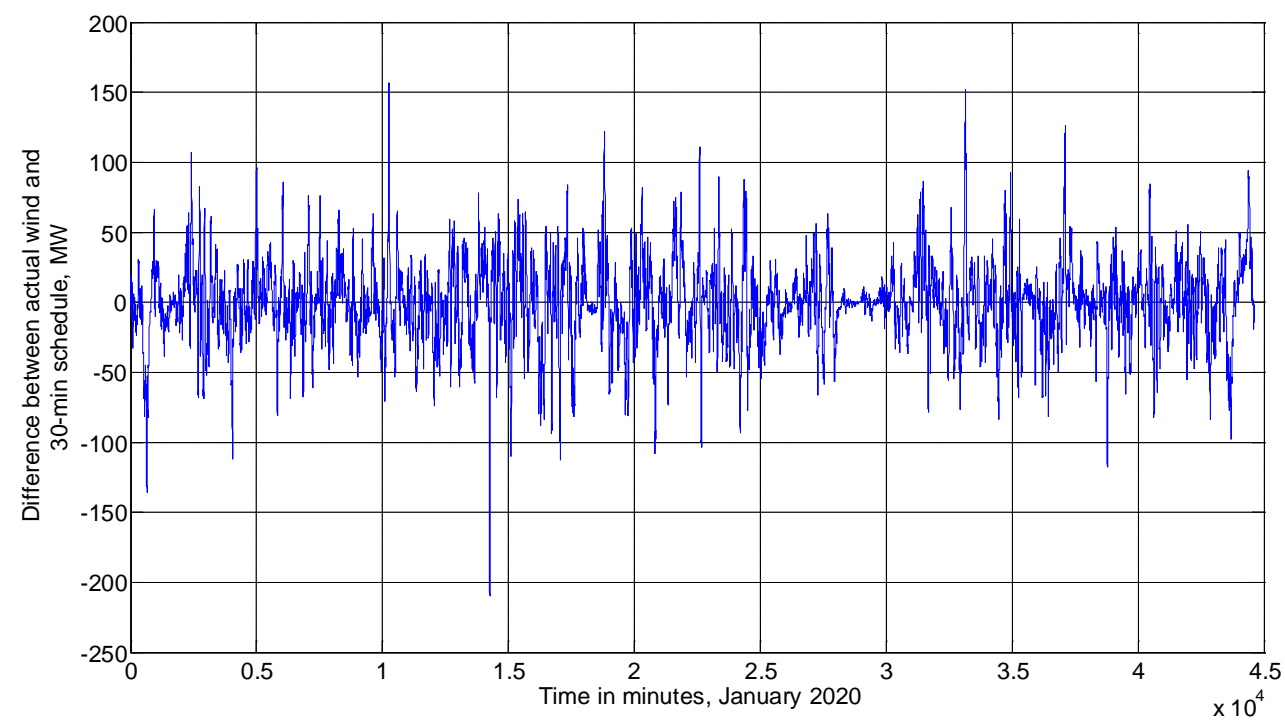

Figure F.7. Difference between Actual Wind Output and 30-Minute Schedule, January 2020

\section{F.3.4 Impact on BPA Load Following with 95\% Confidence Level}

This section shows the impact of a 30-minute wind schedule on BPA load-following requirements, calculated using a 95\% CL. The study was conducted for the 12 months in the study year 2020. In this report, only the study results for three representative months are shown: January, April and August. The results for the other months are available upon request.

\section{F.3.4.1 January 2020}
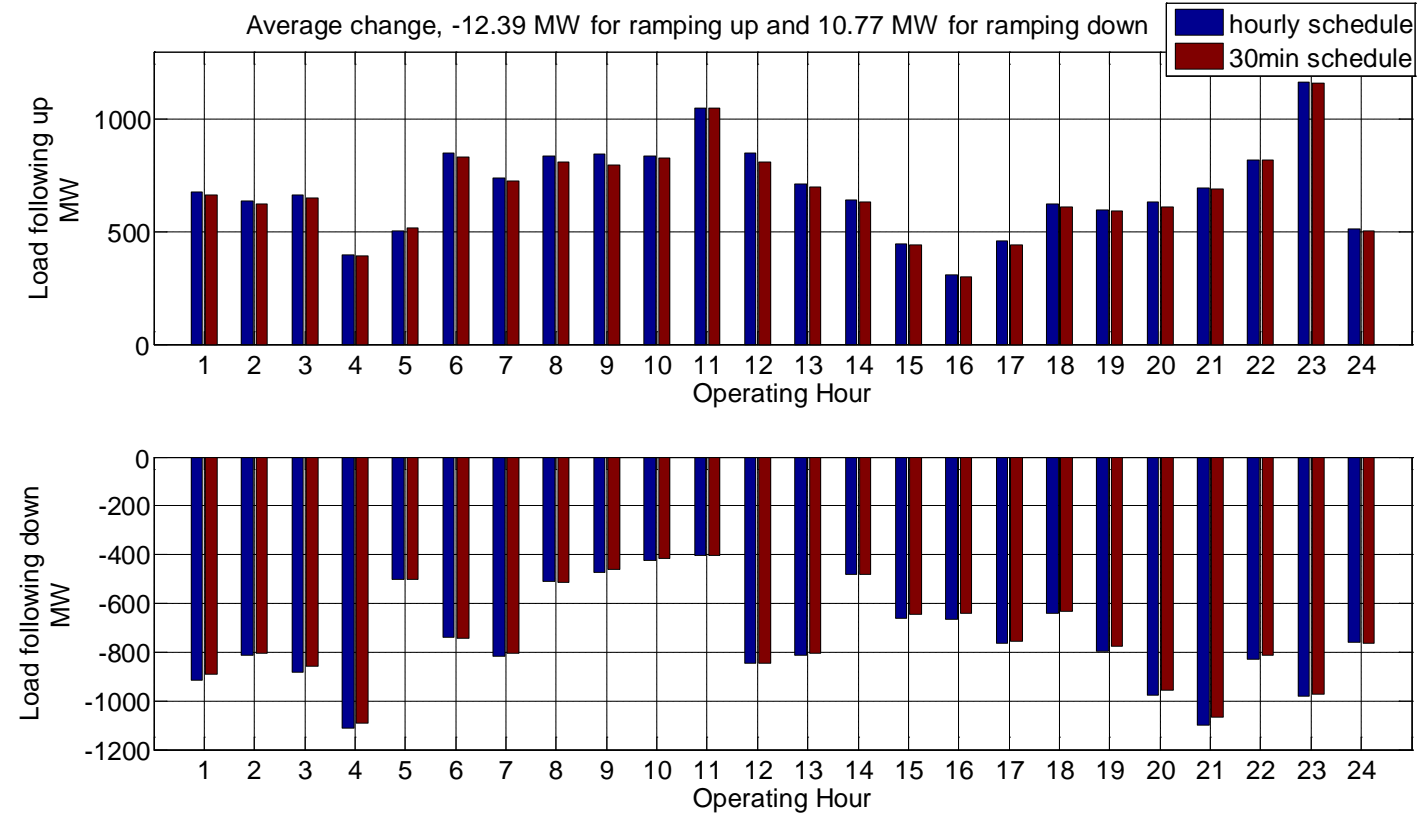

Figure F.8. Impact on BPA Load Following, 95\% CL, January 2020 
Table F.1. Difference between 30-Minute Schedule and Hourly Schedule in Figure F.8 (MW)

\begin{tabular}{|l|l|l|l|l|l|l|l|l|l|l|l|l|l|l|l|l|l|l|l|l|l|l|l|l|}
\hline Operating Hour & 1 & 2 & 3 & 4 & 5 & 6 & 7 & 8 & 9 & 10 & 11 & 12 & 13 & 14 & 15 & 16 & 17 & 18 & 19 & 20 & 21 & 22 & 23 & 24 \\
\hline Difference, up & -11 & -10 & -15 & -4 & 12 & -19 & -14 & -27 & -49 & -8 & -1 & -40 & -14 & -6 & -3 & -12 & -19 & -17 & -5 & -21 & -5 & 1 & -3 & -8 \\
\hline Difference, down & 23 & 7 & 22 & 21 & 1 & -1 & 13 & -2 & 13 & 8 & 0 & 0 & 7 & 1 & 18 & 26 & 6 & 6 & 17 & 21 & 32 & 17 & 7 & -5 \\
\hline
\end{tabular}

Due to the modified 30-minute wind schedule of Biglow Canyon, the load-following requirement of BPA is decreased by 12.39 MW for ramping up (Inc) and decreased by $10.77 \mathrm{MW}$ for ramping down (Dec), on average. It is important to note that a negative sign is used in this study for ramping down requirements, therefore a positive change (e.g., the second row of Table F.1) indicates a decreased amount of load-following requirement, and vice versa.

\section{F.3.4.2 April 2020}
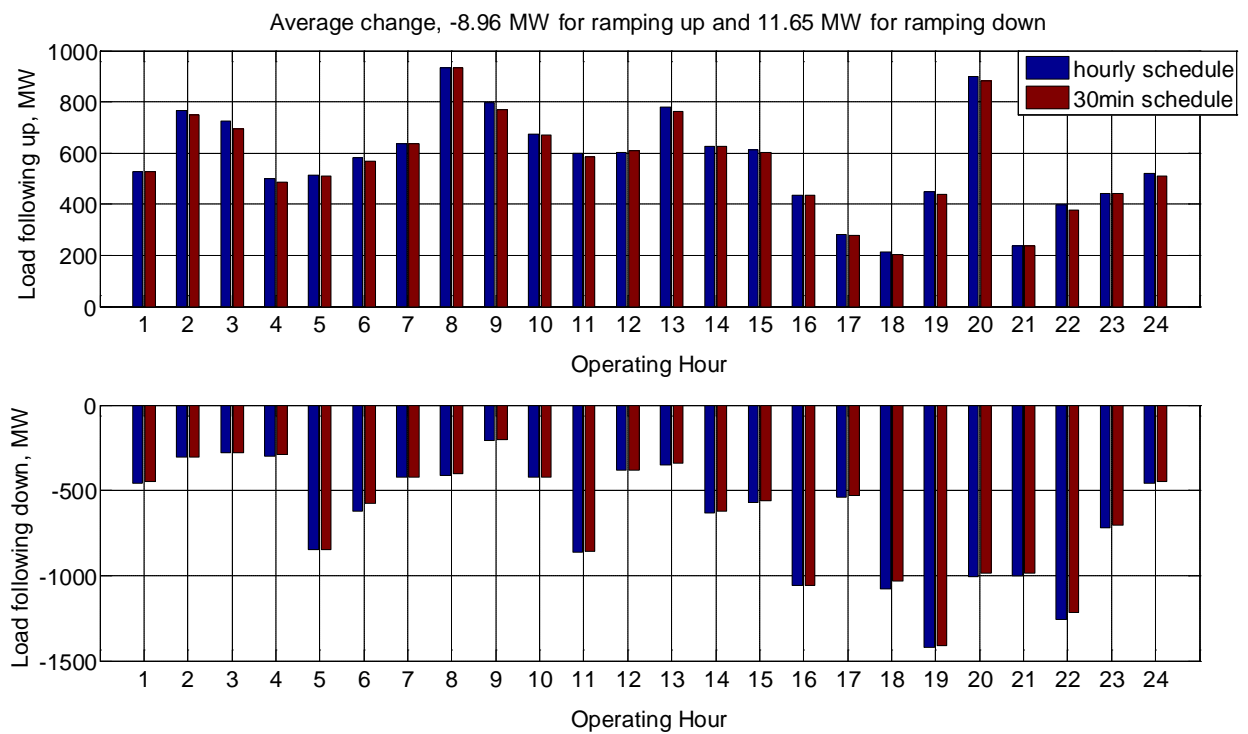

Figure F.9. Impact on BPA Load Following, 95\% CL, April 2020

Table F.2. Difference Between 30-Minute Schedule and Hourly Schedule in Figure F.9 (MW)

\begin{tabular}{|l|l|l|l|l|l|l|l|l|l|l|l|l|l|l|l|l|l|l|l|l|l|l|l|l|}
\hline Operating Hour & $\mathbf{1}$ & $\mathbf{2}$ & $\mathbf{3}$ & $\mathbf{4}$ & $\mathbf{5}$ & $\mathbf{6}$ & $\mathbf{7}$ & $\mathbf{8}$ & $\mathbf{9}$ & 10 & $\mathbf{1 1}$ & 12 & $\mathbf{1 3}$ & 14 & $\mathbf{1 5}$ & 16 & 17 & 18 & 19 & $\mathbf{2 0}$ & 21 & $\mathbf{2 2}$ & 23 & $\mathbf{2 4}$ \\
\hline Difference, up & 1 & -18 & -30 & -13 & -3 & -12 & 2 & -2 & -28 & -3 & -13 & 5 & -16 & -2 & -11 & -1 & -4 & -9 & -9 & -19 & -1 & -19 & 1 & -11 \\
\hline Difference, down & 12 & -1 & 1 & 7 & 1 & 46 & 3 & 10 & 4 & 0 & 5 & 4 & 13 & 9 & 7 & 4 & 7 & 47 & 11 & 18 & 14 & 39 & 12 & 6 \\
\hline
\end{tabular}

The load-following requirement is decreased by 8.96 MW for ramping up (Inc) and decreased by 11.65 MW for ramping down (Dec), on average. 


\section{F.3.4.3 August 2020}
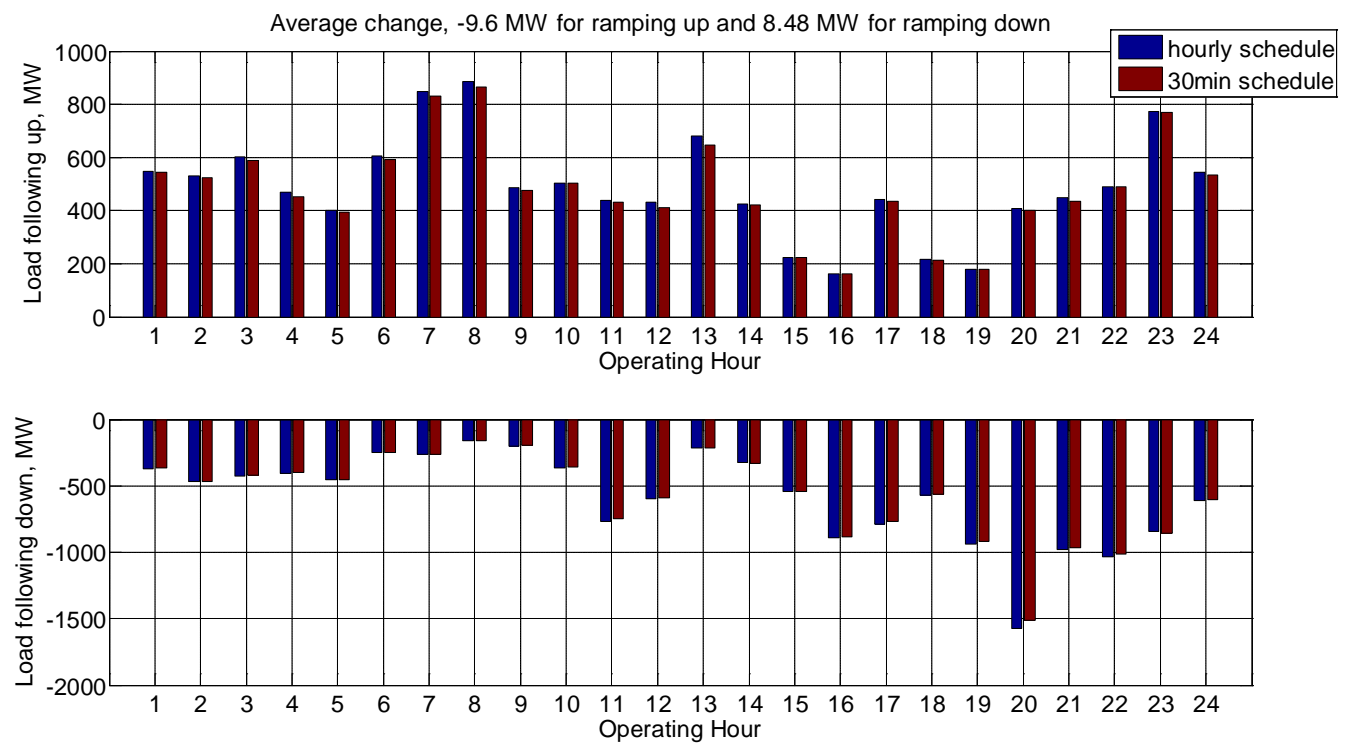

Figure F.10. Impact on BPA Load Following, 95\% CL, August 2020

Table F.3. Difference between 30-Minute Schedule and Hourly Schedule in Figure F.10 (MW)

\begin{tabular}{|l|l|l|l|l|l|l|l|l|l|l|l|l|l|l|l|l|l|l|l|l|l|l|l|l|}
\hline Operating Hour & 1 & 2 & 3 & 4 & 5 & 6 & 7 & 8 & 9 & 10 & 11 & 12 & 13 & 14 & 15 & 16 & 17 & 18 & 19 & 20 & 21 & 22 & 23 & 24 \\
\hline Difference, up & -3 & -7 & -12 & -17 & -9 & -16 & -19 & -20 & -8 & -1 & -7 & -20 & -35 & -3 & -2 & -2 & -5 & -3 & -3 & -7 & -15 & 0 & -5 & -12 \\
\hline Difference, down & 9 & 0 & 9 & 7 & 1 & 5 & 4 & 0 & 6 & 10 & 18 & 3 & 2 & -5 & 2 & 6 & 20 & 5 & 19 & 58 & 17 & 16 & -8 & 2 \\
\hline
\end{tabular}

The load-following requirement is decreased by 9.6 MW for ramping up (Inc) and decreased by 8.48 MW for ramping down (Dec), on average.

\section{F.3.5 Impact on BPA Load Following with 99.5\% Confidence Level}

This section shows the impact of the modified wind schedule on load-following requirements of BPA with a higher CL, 99.5\%. 


\section{F.3.5.1 January 2020}
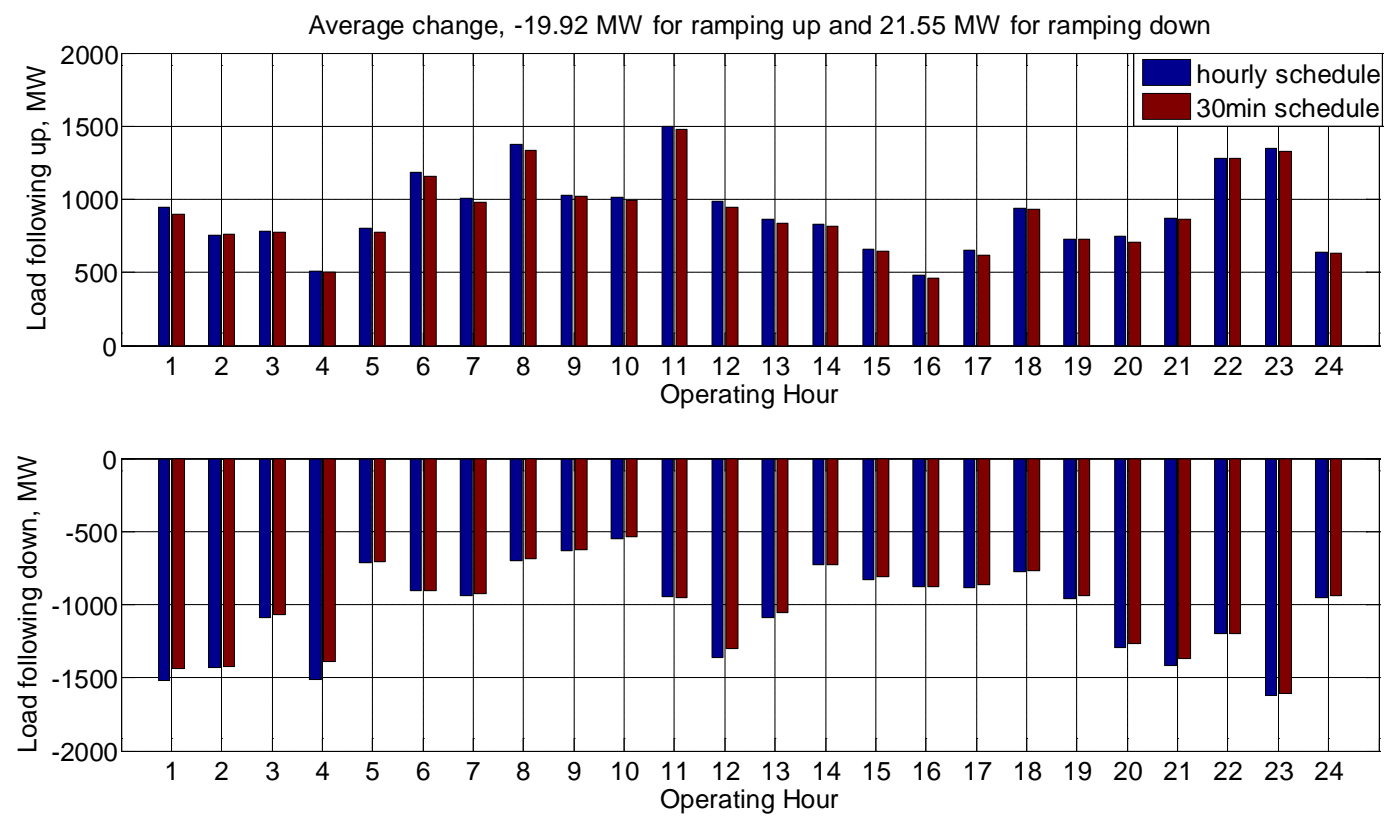

Figure F.11. Impact on BPA Load Following, 99.5\% CL, January 2020

Table F.4. Difference between 30-Minute Schedule and Hourly Schedule in Figure F.11 (MW)

\begin{tabular}{|l|l|l|l|l|l|l|l|l|l|l|l|l|l|l|l|l|l|l|l|l|l|l|l|l|}
\hline Operating Hour & 1 & 2 & 3 & 4 & 5 & 6 & 7 & 8 & 9 & 10 & 11 & 12 & 13 & 14 & 15 & 16 & 17 & 18 & 19 & 20 & 21 & 22 & 23 & 24 \\
\hline Difference, up & -47 & 2 & -5 & -7 & -30 & -30 & -30 & -38 & .9 & -18 & -25 & -45 & -21 & -17 & -14 & -23 & -33 & -4 & -1 & -40 & -6 & 0 & -25 & -12 \\
\hline Difference, down & 79 & 7 & 15 & 123 & 6 & 0 & 13 & 12 & 4 & 14 & -5 & 57 & 34 & 0 & 17 & -2 & 16 & 2 & 21 & 29 & 43 & 2 & 16 & 14 \\
\hline
\end{tabular}

The load-following requirement is decreased by 19.92 MW for ramping up (Inc) and decreased by 21.55 MW for ramping down (Dec), on average. 


\section{F.3.5.2 April 2020}
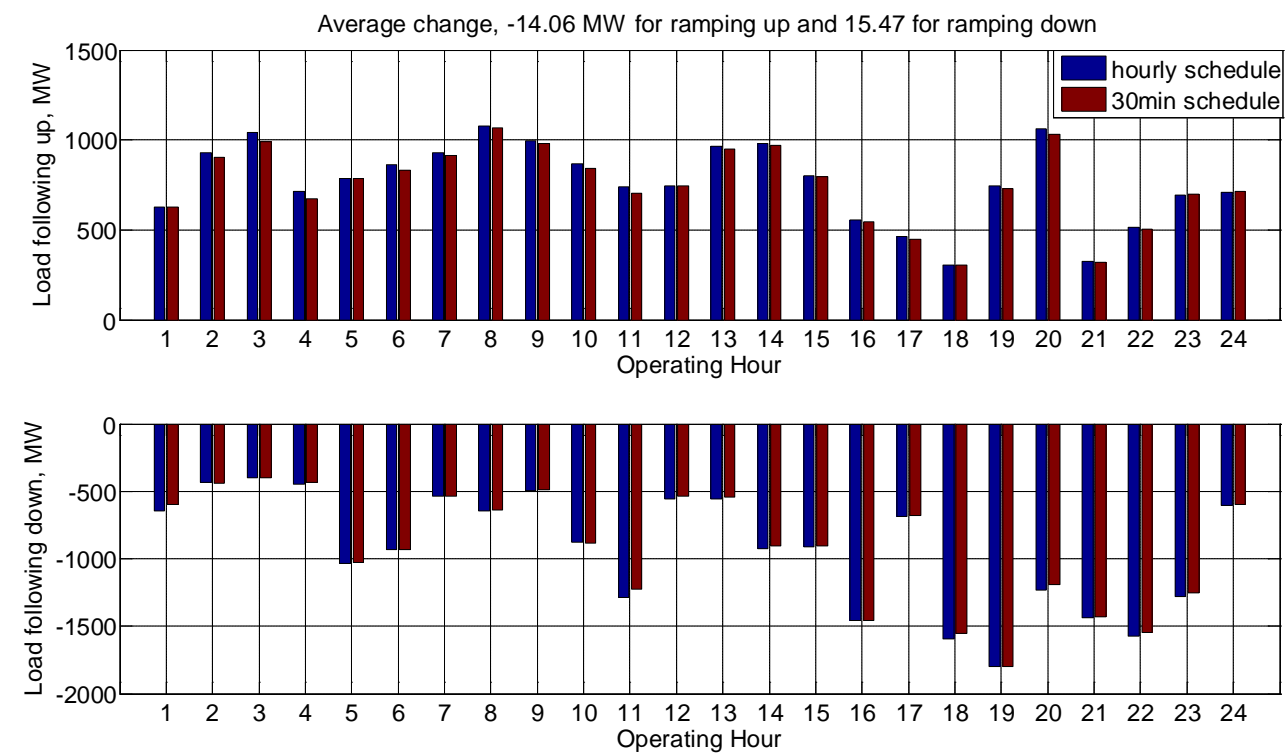

Figure F.12. Impact on BPA Load Following, 99.5\% CL, April 2020

Table F.5. Difference between 30-Minute Schedule and Hourly Schedule in Figure F.12 (MW)

\begin{tabular}{|l|l|l|l|l|l|l|l|l|l|l|l|l|l|l|l|l|l|l|l|l|l|l|l|l|}
\hline Operating Hour & 1 & 2 & 3 & 4 & 5 & 6 & 7 & 8 & 9 & 10 & 11 & 12 & 13 & 14 & 15 & 16 & 17 & 18 & 19 & 20 & 21 & 22 & 23 & 24 \\
\hline Difference, up & 1 & -25 & -49 & -43 & 0 & -28 & -16 & -9 & -13 & -27 & -34 & -1 & -15 & -6 & -6 & -8 & -15 & 0 & -14 & -29 & -4 & -9 & 5 & 7 \\
\hline Difference, down & 50 & -5 & 2 & 11 & 9 & 1 & 3 & 12 & 10 & -8 & 60 & 19 & 13 & 24 & 7 & 6 & 9 & 4 & 1 & 38 & 4 & 31 & 24 & 6 \\
\hline
\end{tabular}

The load-following requirement is decreased by 14.06 MW for ramping up (Inc) and decreased by 15.47 MW for ramping down (Dec), on average. 


\section{F.3.5.3 August 2020}
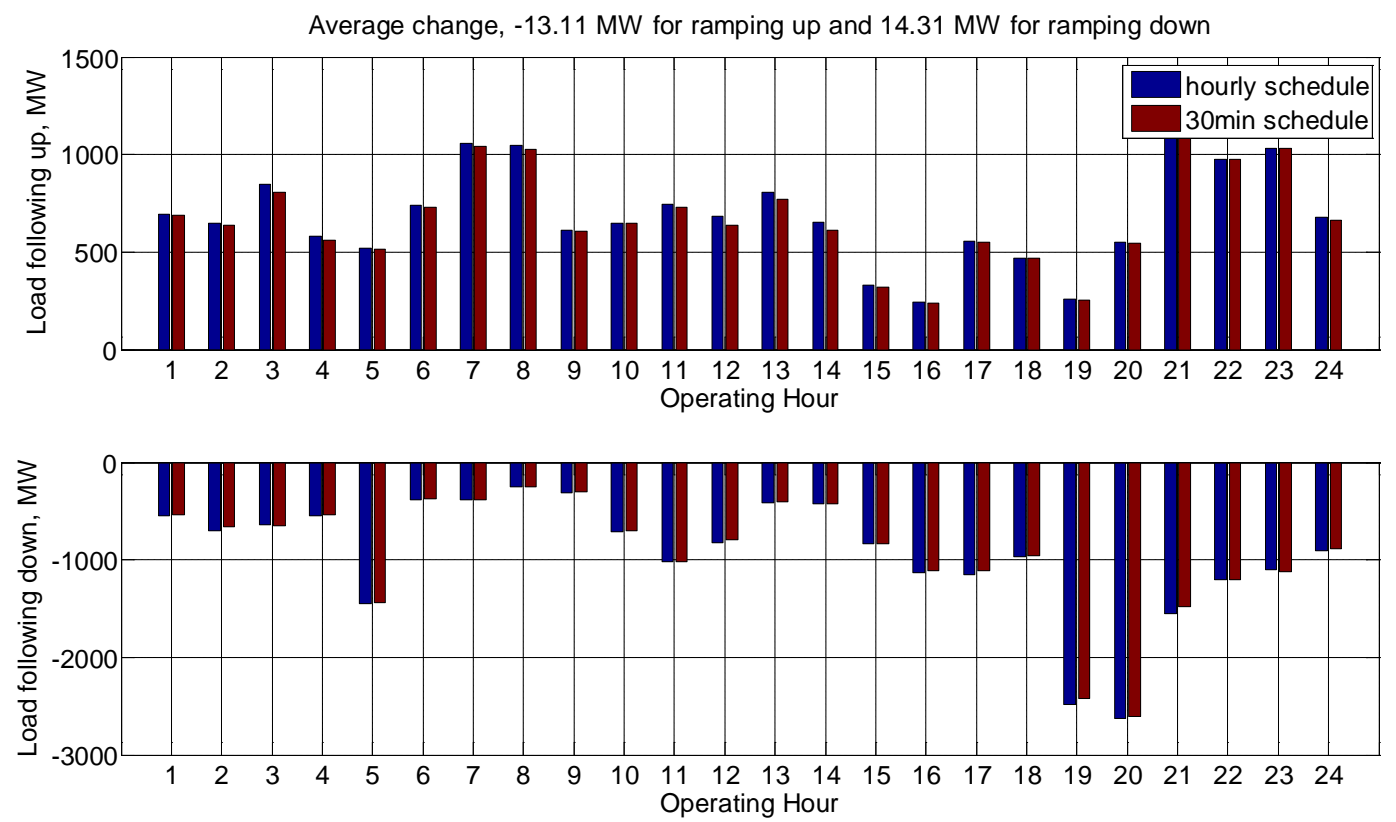

Figure F.13. Impact on BPA Load Following, 99.5\% CL, August 2020

Table F.6. Difference between 30-Minute Schedule and Hourly Schedule in Figure F.13 (MW)

\begin{tabular}{|l|c|c|c|c|c|c|c|c|c|c|c|c|c|c|c|c|c|c|c|c|c|c|c|c|}
\hline Operating Hour & 1 & 2 & 3 & 4 & 5 & 6 & 7 & 8 & 9 & 10 & 11 & 12 & 13 & 14 & 15 & 16 & 17 & 18 & 19 & 20 & 21 & 22 & 23 & 24 \\
\hline Difference, up & -3 & -10 & -43 & -23 & -3 & -14 & -17 & -18 & -7 & -1 & -17 & -42 & -34 & -40 & -8 & -3 & -5 & 0 & -4 & -6 & 0 & 0 & -1 & -14 \\
\hline Difference, down & 12 & 35 & -4 & 8 & 10 & 2 & 0 & 0 & 10 & 5 & 0 & 26 & 7 & -1 & 1 & 16 & 39 & 12 & 64 & 20 & 74 & 6 & -20 & 21 \\
\hline
\end{tabular}

The load-following requirement is decreased by 13.11 MW for ramping up (Inc) and decreased by 14.31 MW for ramping down (Dec), on average.

\section{F.3.6 Impact on PGN Load Following with 95\% Confidence Level}

This section shows the impact of the modified wind schedule on load-following requirements in PGN, with a CL of $95 \%$. 


\section{F.3.6.1 January 2020}
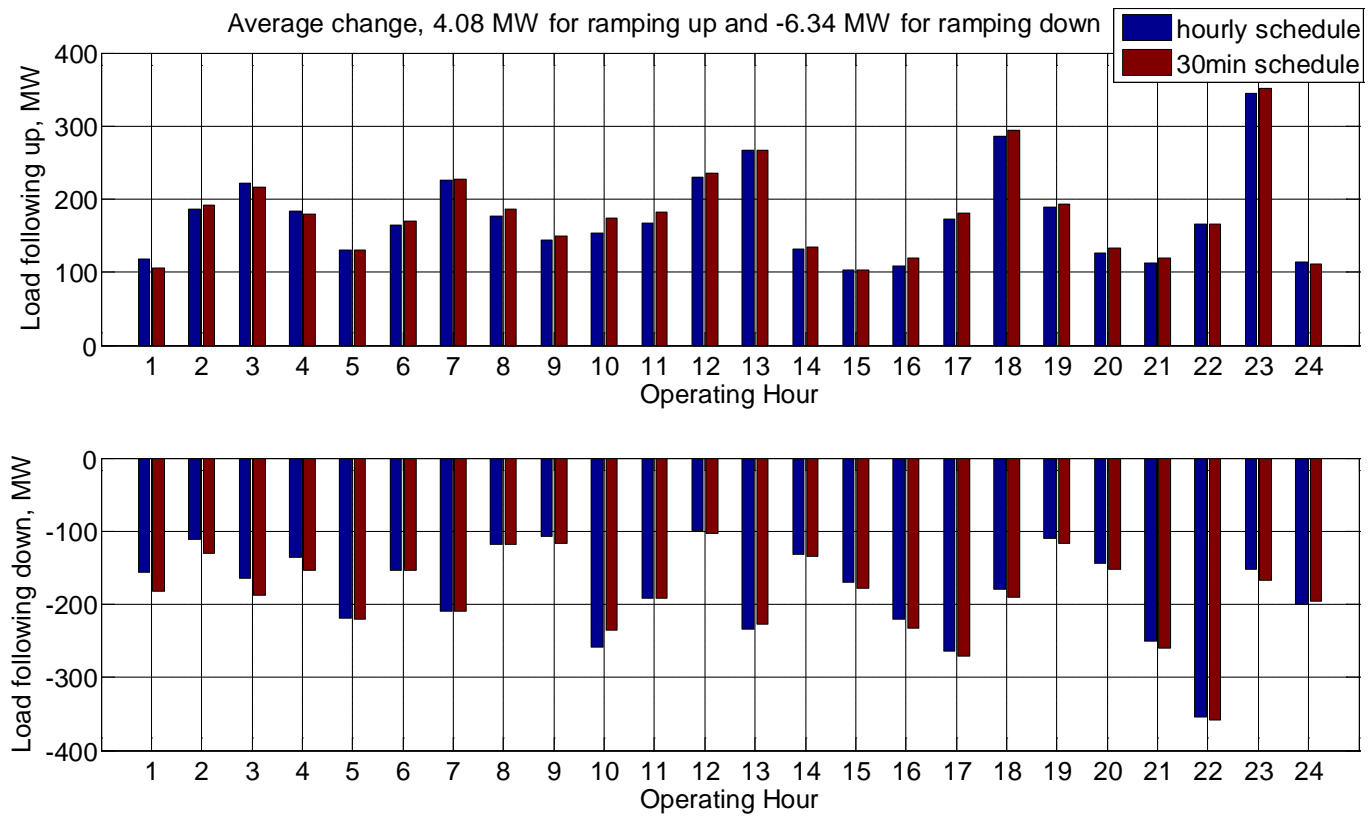

Figure F.14. Impact on PGN Load Following, 95\% CL, January 2020

Table F.7. Difference between 30-Minute Schedule and Hourly Schedule in Figure F.14 (MW)

\begin{tabular}{|l|c|c|c|c|c|c|c|c|c|c|c|c|c|c|c|c|c|c|c|c|c|c|c|c|}
\hline Operating Hour & 1 & 2 & 3 & 4 & 5 & 6 & 7 & 8 & 9 & 10 & 11 & 12 & 13 & 14 & 15 & 16 & 17 & 18 & 19 & 20 & 21 & 22 & 23 & 24 \\
\hline Difference, up & -11 & 6 & -6 & -4 & 1 & 5 & 2 & 10 & 5 & 21 & 15 & 6 & 0 & 3 & -1 & 11 & 8 & 7 & 5 & 7 & 6 & 0 & 7 & -3 \\
\hline Difference, down & -25 & -19 & -23 & -17 & -1 & 0 & 0 & 0 & -9 & 23 & 0 & -4 & 7 & -2 & -8 & -12 & -8 & -11 & -8 & -9 & -9 & -4 & -15 & 4 \\
\hline
\end{tabular}

The load-following requirement is increased by 4.08 MW for ramping up (Inc) and increased by 6.34 MW for ramping down (Dec), on average. 


\section{F.3.6.2 April 2020}
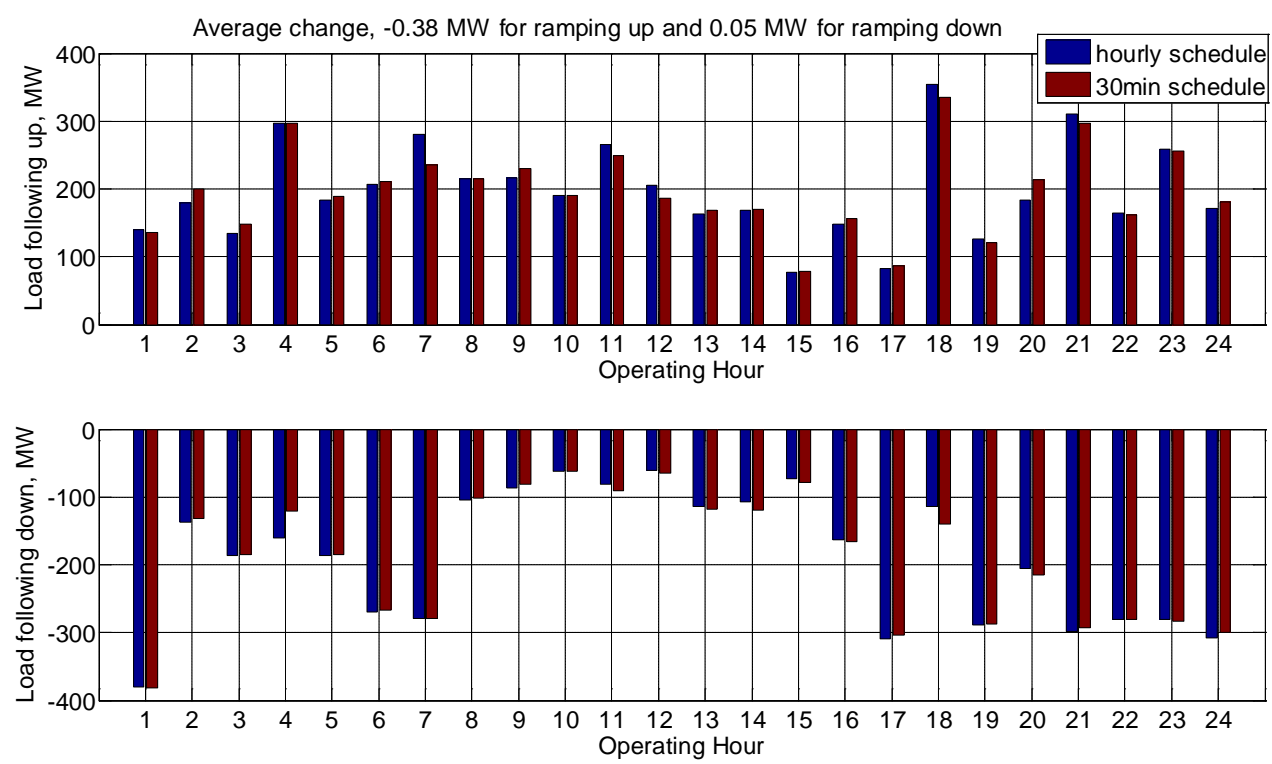

Figure F.15. Impact on PGN Load Following, 95\% CL, April 2020

Table F.8. Difference between 30-Minute Schedule and Hourly Schedule in Figure F.15 (MW)

\begin{tabular}{|l|l|l|l|l|l|l|l|l|l|l|l|l|l|l|l|l|l|l|l|l|l|l|l|l|}
\hline Operating Hour & 1 & 2 & 3 & 4 & 5 & 6 & 7 & 8 & 9 & 10 & 11 & 12 & 13 & 14 & 15 & 16 & 17 & 18 & 19 & 20 & 21 & 22 & 23 & 24 \\
\hline Difference, up & -3 & 20 & 13 & 0 & 6 & 4 & -44 & -1 & 15 & 0 & -17 & -19 & 5 & 1 & 1 & 9 & 5 & -19 & -6 & 31 & -13 & -3 & -3 & 10 \\
\hline Difference, down & -1 & 6 & 1 & 39 & 1 & 2 & 0 & 3 & 5 & 0 & -9 & -5 & -4 & -12 & -6 & -2 & 6 & -25 & 1 & -9 & 6 & 1 & -4 & 9 \\
\hline
\end{tabular}

The load-following requirement is decreased by $0.38 \mathrm{MW}$ for ramping up (Inc) and decreased by 0.05 MW for ramping down (Dec), on average. 


\section{F.3.6.3 August 2020}
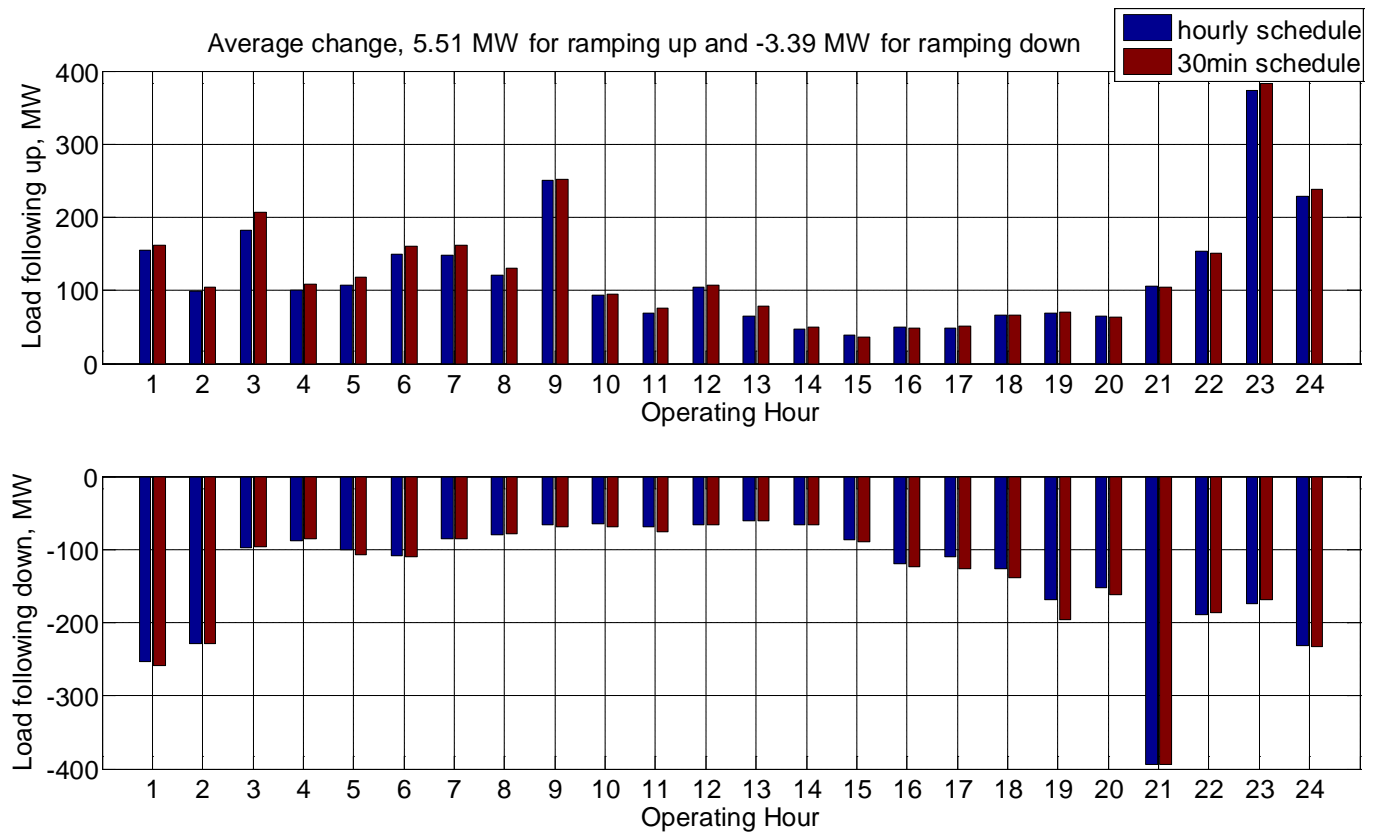

Figure F.16. Impact on PGN Load Following, 95\% CL, August 2020

Table F.9. Difference between 30-Minute Schedule and Hourly Schedule in Figure F.16 (MW)

\begin{tabular}{|l|l|l|l|l|l|l|l|l|l|l|l|l|l|l|l|l|l|l|l|l|l|l|l|l|}
\hline Operating Hour & 1 & 2 & 3 & 4 & 5 & 6 & 7 & 8 & 9 & 10 & 11 & 12 & 13 & 14 & 15 & 16 & 17 & 18 & 19 & 20 & 21 & 22 & 23 & 24 \\
\hline Difference, up & 8 & 5 & 25 & 8 & 11 & 12 & 14 & 9 & 2 & 1 & 7 & 2 & 14 & 2 & -3 & -2 & 3 & 0 & 1 & -1 & -1 & -2 & 9 & 9 \\
\hline Difference, down & -5 & 0 & 1 & 3 & -6 & -1 & 0 & 0 & -2 & -5 & -7 & 0 & 0 & 0 & -2 & -5 & -17 & -12 & -27 & -8 & 1 & 3 & 6 & -1 \\
\hline
\end{tabular}

The load-following requirement is increased by $0.38 \mathrm{MW}$ for ramping up (Inc) and increased by 3.39 MW for ramping down (Dec), on average. 


\section{F.3.7 PGN Load Following with 99.5\% Confidence Level}

This section shows the impact of the modified wind schedule on load-following requirements of PGN with a higher CL, 99.5\%.

\section{F.3.7.1 January 2020}
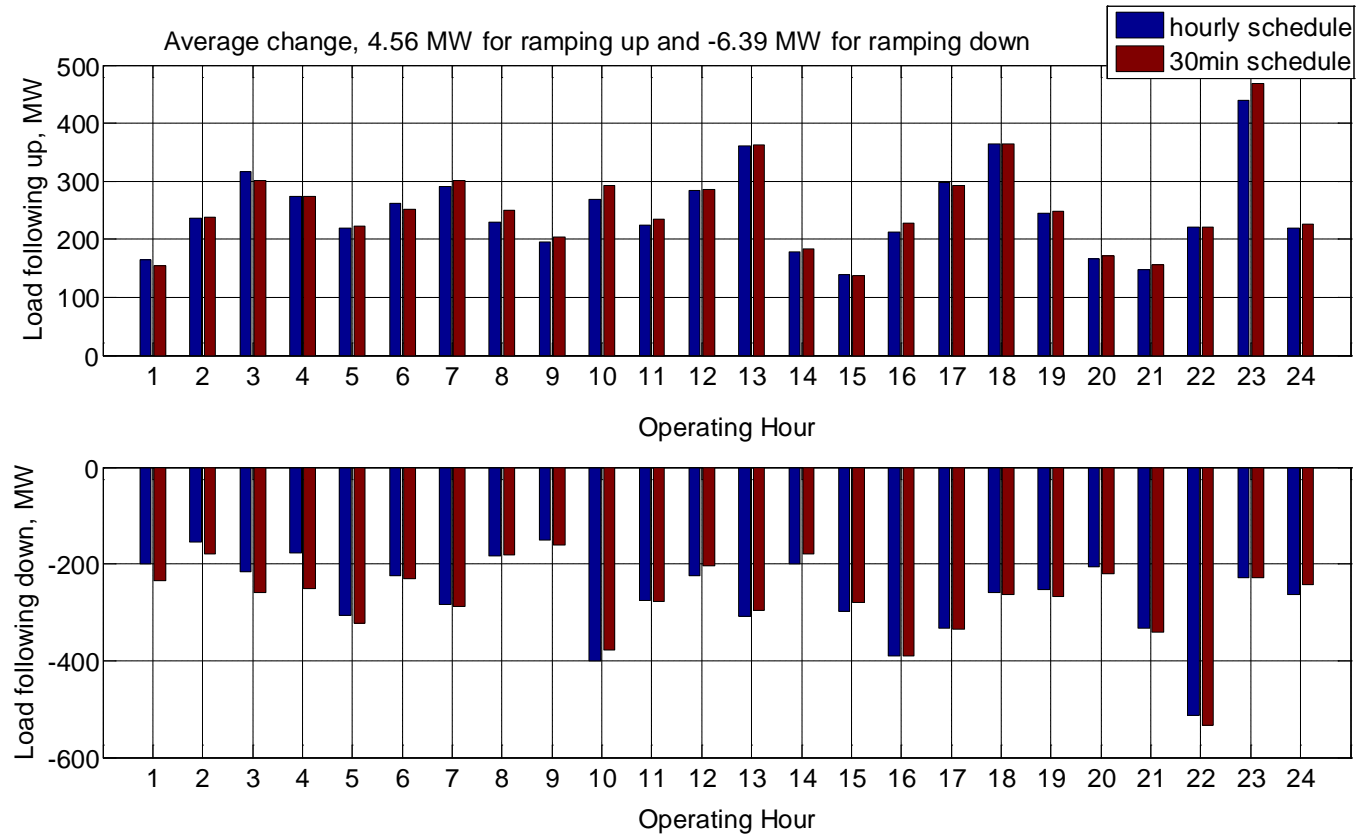

Figure F.17. Impact on PGN Load Following, 99.5\% CL, January 2020

Table F.10. Difference between 30-Minute Schedule and Hourly Schedule in Figure F.17 (MW)

\begin{tabular}{|l|c|c|c|c|c|c|c|c|c|c|c|c|c|c|c|c|c|c|c|c|c|c|c|c|}
\hline Operating Hour & $\mathbf{1}$ & $\mathbf{2}$ & $\mathbf{3}$ & $\mathbf{4}$ & $\mathbf{5}$ & $\mathbf{6}$ & $\mathbf{7}$ & $\mathbf{8}$ & $\mathbf{9}$ & 10 & 11 & 12 & 13 & 14 & 15 & 16 & 17 & 18 & $\mathbf{1 9}$ & $\mathbf{2 0}$ & 21 & $\mathbf{2 2}$ & 23 & 24 \\
\hline Difference, up & -10 & 3 & -17 & -1 & 3 & -10 & 9 & 20 & 8 & 25 & 10 & 2 & 1 & 4 & -1 & 16 & -5 & 1 & 3 & 5 & 9 & 0 & 28 & 7 \\
\hline Difference, down & -33 & -25 & -45 & -73 & -15 & -4 & -3 & 0 & -9 & 21 & -2 & 20 & 12 & 20 & 20 & 0 & -2 & -3 & -14 & -13 & -8 & -20 & 0 & 21 \\
\hline
\end{tabular}

The load-following requirement is increased by 4.56 MW for ramping up (Inc) and increased by 6.39 MW for ramping down (Dec), on average. 


\section{F.3.7.2 April 2020}
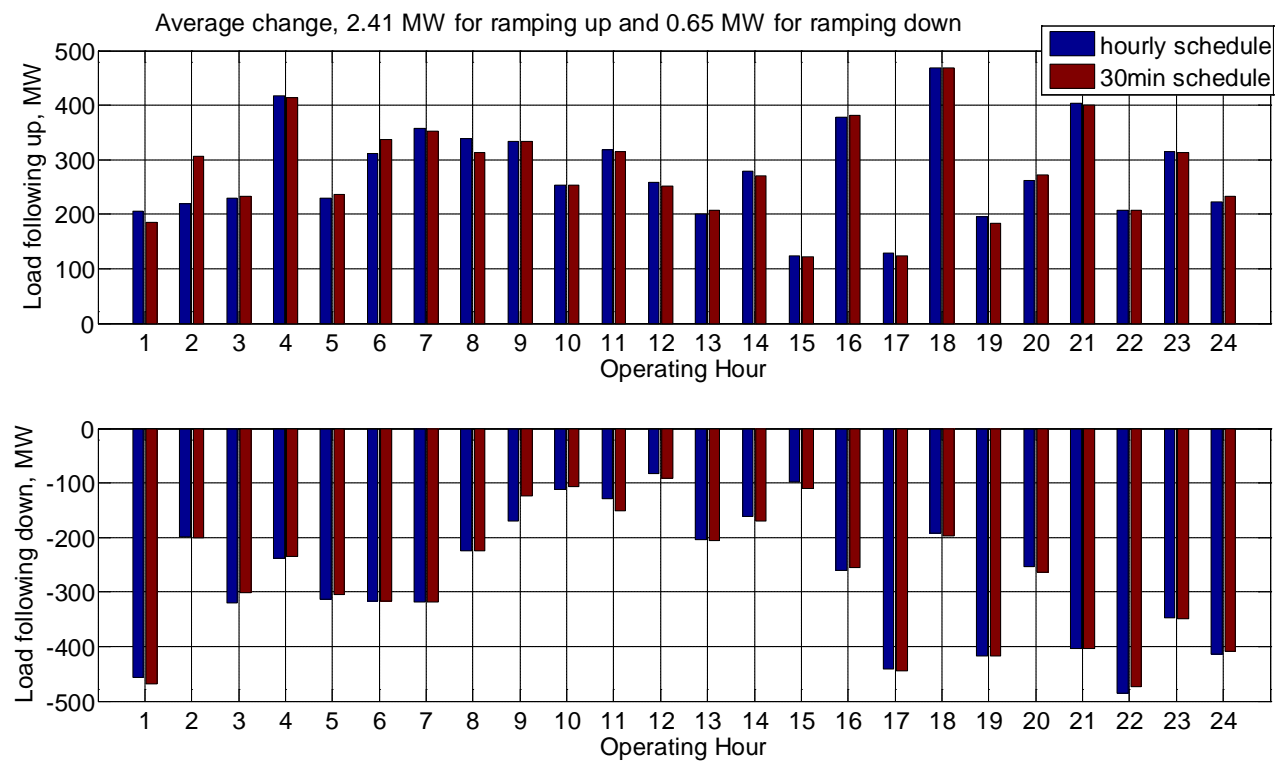

Figure F.18. Impact on PGN Load Following, 99.5\% CL, April 2020

Table F.11. Difference between 30-Minute Schedule and Hourly Schedule in Figure F.18 (MW)

\begin{tabular}{|l|c|c|c|c|c|c|c|c|c|c|c|c|c|c|c|c|c|c|c|c|c|c|c|c|}
\hline Operating Hour & 1 & 2 & 3 & 4 & 5 & 6 & 7 & 8 & 9 & 10 & 11 & 12 & 13 & 14 & 15 & 16 & 17 & 18 & 19 & 20 & 21 & 22 & 23 & 24 \\
\hline Difference, up & -20 & 87 & 3 & -3 & 6 & 26 & -6 & -26 & -1 & 0 & -2 & -7 & 6 & -8 & -2 & 4 & -6 & 0 & -12 & 11 & -3 & -1 & -2 & 10 \\
\hline Difference, down & -11 & -1 & 18 & 3 & 8 & -1 & 0 & 0 & 46 & 6 & -22 & -8 & -1 & -10 & -12 & 4 & -4 & -5 & 0 & -10 & 0 & 12 & -2 & 5 \\
\hline
\end{tabular}

The load-following requirement is increased by 2.41 MW for ramping up (Inc) and decreased by 0.65 MW for ramping down (Dec), on average. 


\section{F.3.7.3 August 2020}
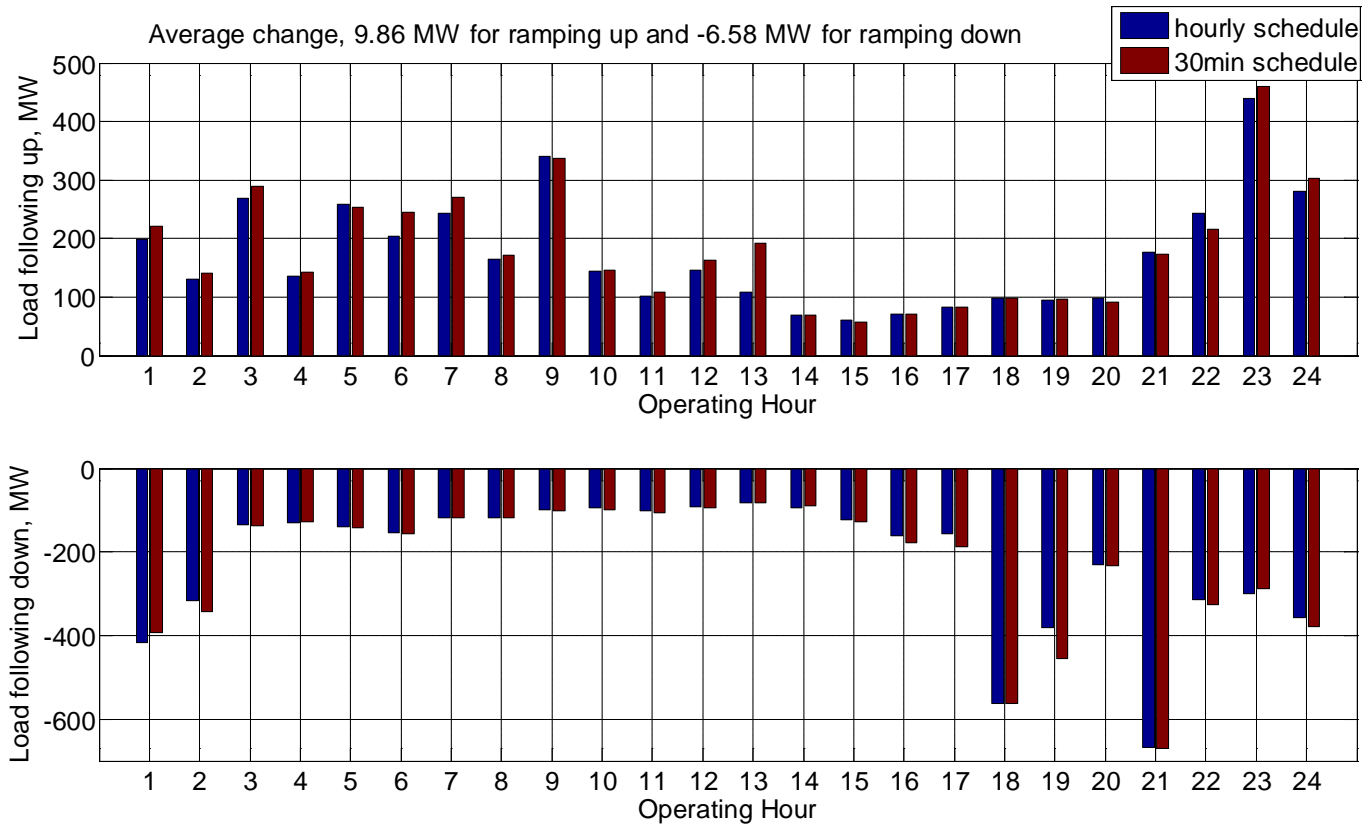

Figure F.19. Impact on PGN Load Following, 99.5\% CL, August 2020

Table F.12. Difference between 30-Minute Schedule and Hourly Schedule in Figure F.19 (MW)

\begin{tabular}{|l|c|c|c|c|c|c|c|c|c|c|c|c|c|c|c|c|c|c|c|c|c|c|c|c|}
\hline Operating Hour & $\mathbf{1}$ & $\mathbf{2}$ & $\mathbf{3}$ & $\mathbf{4}$ & $\mathbf{5}$ & $\mathbf{6}$ & $\mathbf{7}$ & $\mathbf{8}$ & $\mathbf{9}$ & 10 & 11 & 12 & 13 & 14 & 15 & $\mathbf{1 6}$ & $\mathbf{1 7}$ & 18 & $\mathbf{1 9}$ & 20 & 21 & $\mathbf{2 2}$ & 23 & $\mathbf{2 4}$ \\
\hline Difference, up & 22 & 9 & 20 & 8 & -6 & 41 & 27 & 6 & -2 & 2 & 7 & 17 & 84 & 0 & -4 & 0 & 0 & 0 & 2 & -7 & -3 & -28 & 21 & 22 \\
\hline Difference, down & 26 & -27 & -2 & 3 & -3 & -1 & 0 & 0 & -1 & -4 & -5 & -1 & 0 & 5 & -3 & -17 & -29 & 0 & -74 & -2 & 0 & -13 & 12 & -21 \\
\hline
\end{tabular}

The load-following requirement is increased by 9.86 MW for ramping up (Inc) and increased by 6.58 MW for ramping down (Dec), on average.

Table F.13 summarizes the impact of a half-hour wind schedule on the load-following requirements in a source BA and a sink BA. It shows that with the modified wind schedule, the load-following requirements are decreased for a source BA; however, the load-following requirements for a sink BA are increased, on average. 
Table F.13. Summary of the Impact of 30-Minute Wind Schedule on the Load Following of BPA and PGN (MW)

\begin{tabular}{|c|c|c|c|c|c|c|}
\hline \multirow{2}{*}{$\begin{array}{c}\text { Load } \\
\text { Following }\end{array}$} & \multicolumn{3}{|c|}{ 95\% CL } & \multicolumn{3}{|c|}{ 99.5\% CL } \\
\hline & January & April & August & January & April & August \\
\hline BPA, up & -12.39 & -8.96 & -9.6 & -19.92 & -14.06 & -13.11 \\
\hline BPA, down & -10.77 & -11.65 & -8.48 & -21.55 & -15.47 & -14.31 \\
\hline PGN, up & 4.08 & -0.38 & 5.51 & 4.56 & 2.41 & 9.86 \\
\hline PGN, down & 6.34 & -0.05 & 3.39 & 6.39 & -0.65 & 6.58 \\
\hline
\end{tabular}

(Note: a negative number indicates decrease in the load-following requirement)

\section{F.4 Case Study Two: One Source BA and Multiple Sink BAs}

In this section, the method to analyze the impact of a 30-minute schedule of selected wind farms on load-following capacity is further investigated and implemented on a list of BAs with several wind transfers. BPA is the only source BA in this study and there are five sink BAs considered, including Portland General Electric (PGN), Puget Sound Energy (PSE), British Columbia Hydro (BCHA), Turlock Irrigation District (TID) and SMUD. The list of wind transfers from the source BA to the five sink BAs with proposed wind transfers are shown in

Table F.14. The power outputs of these five wind transfers are shown in Figure F.20 through Figure F.24, using the same method discussed in Section F.3.1. The following sections show the impact of a half-hour schedule of selected wind transfers on the required load-following capacities of both source and sink BAs. Two CLs are used in this study: 95\% and 99.5\%. The calculated load-following capacity for different study months in the year 2020 considers several wind transfers between BPA and other sink BAs simultaneously.

Table F.14. Proposed Wind Transfer Scenarios between Source BA and Sink BAs

\begin{tabular}{|c|c|c|c|c|}
\hline No. & $\begin{array}{c}\text { Source } \\
\text { BA }\end{array}$ & $\begin{array}{c}\text { Sink } \\
\text { BA }\end{array}$ & $\begin{array}{l}\text { Wind } \\
\text { Capacity }\end{array}$ & Wind Plants and Connected Buses \\
\hline 1 & BPA & PGN & 485 & $\begin{array}{l}\text { Vansycle (47550), Biglow Canyon (47906, } 47327 \text { 40477), PaTu } \\
\text { Wind (41402) }\end{array}$ \\
\hline 2 & BPA & PSE & 500 & $\begin{array}{l}\text { Hopkins Ridge (47801), Lower Snake Wind (42063) } \\
\text { Willow Creek (40125), Pebble Springs (47814), Wheatfiled }\end{array}$ \\
\hline 3 & BPA & BCHA & 220.5 & (47327) \\
\hline 4 & BPA & TID & 68.5 & Tuolumine (47327) \\
\hline 5 & BPA & SMUD & 100 & Star Point (47975) \\
\hline
\end{tabular}




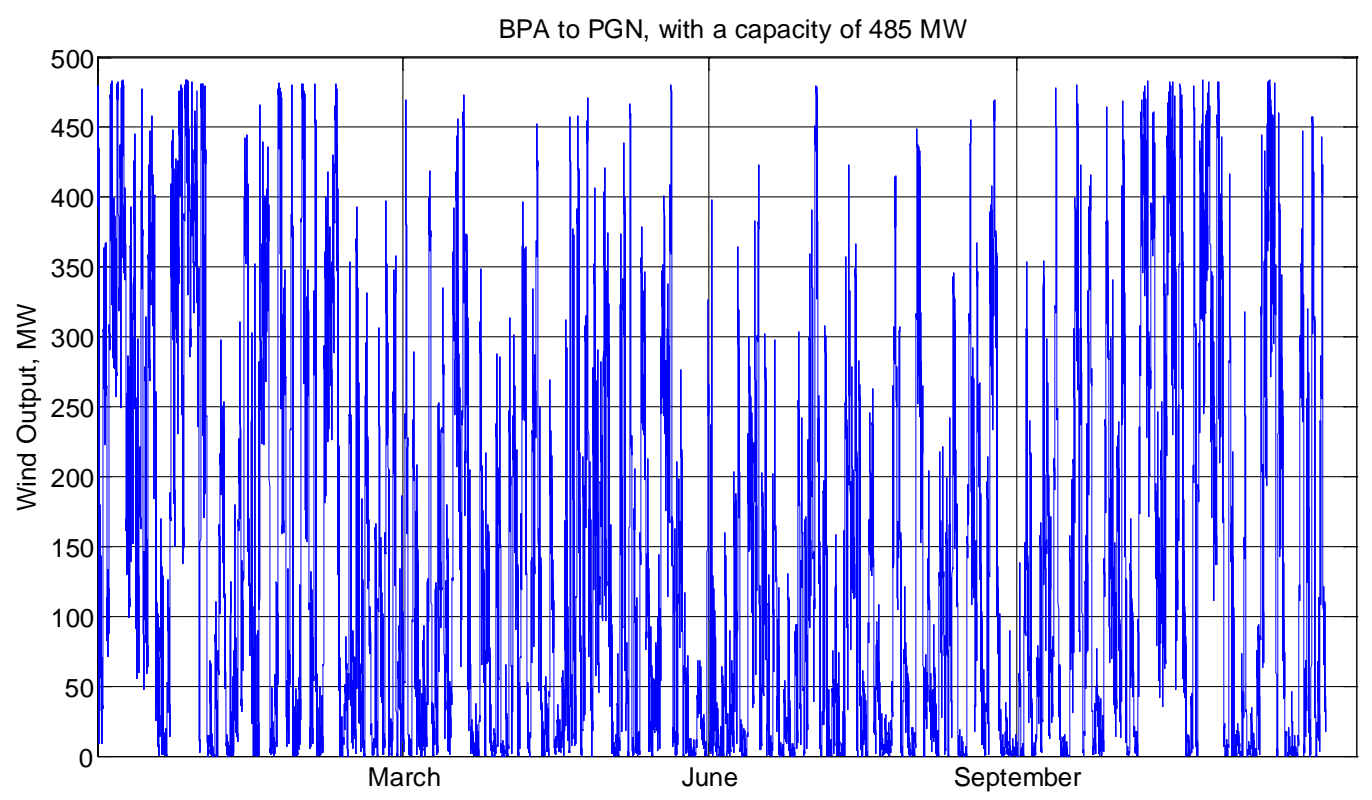

Figure F.20. Profile of the Wind Transfer between BPA and PGN, 2020

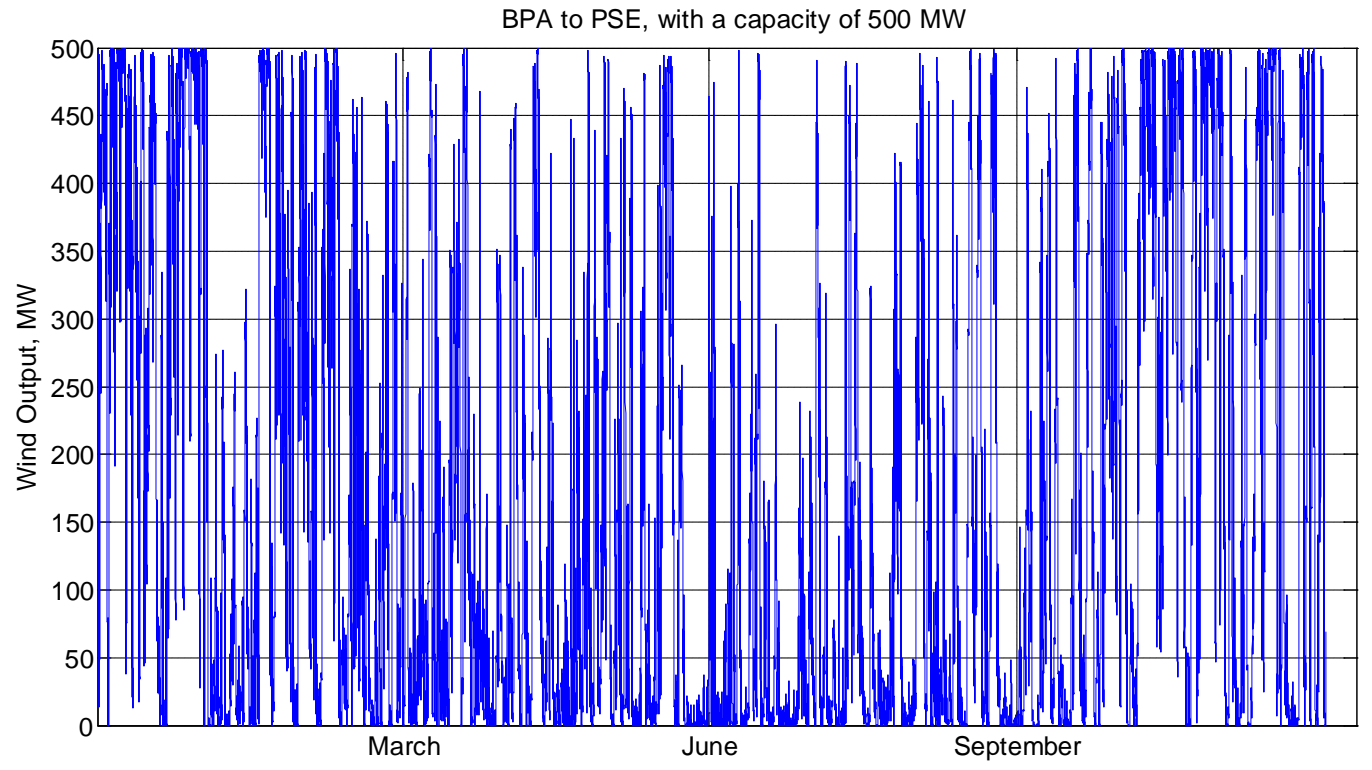

Figure F.21. Profile of the Wind Transfer between BPA and PSE, 2020 


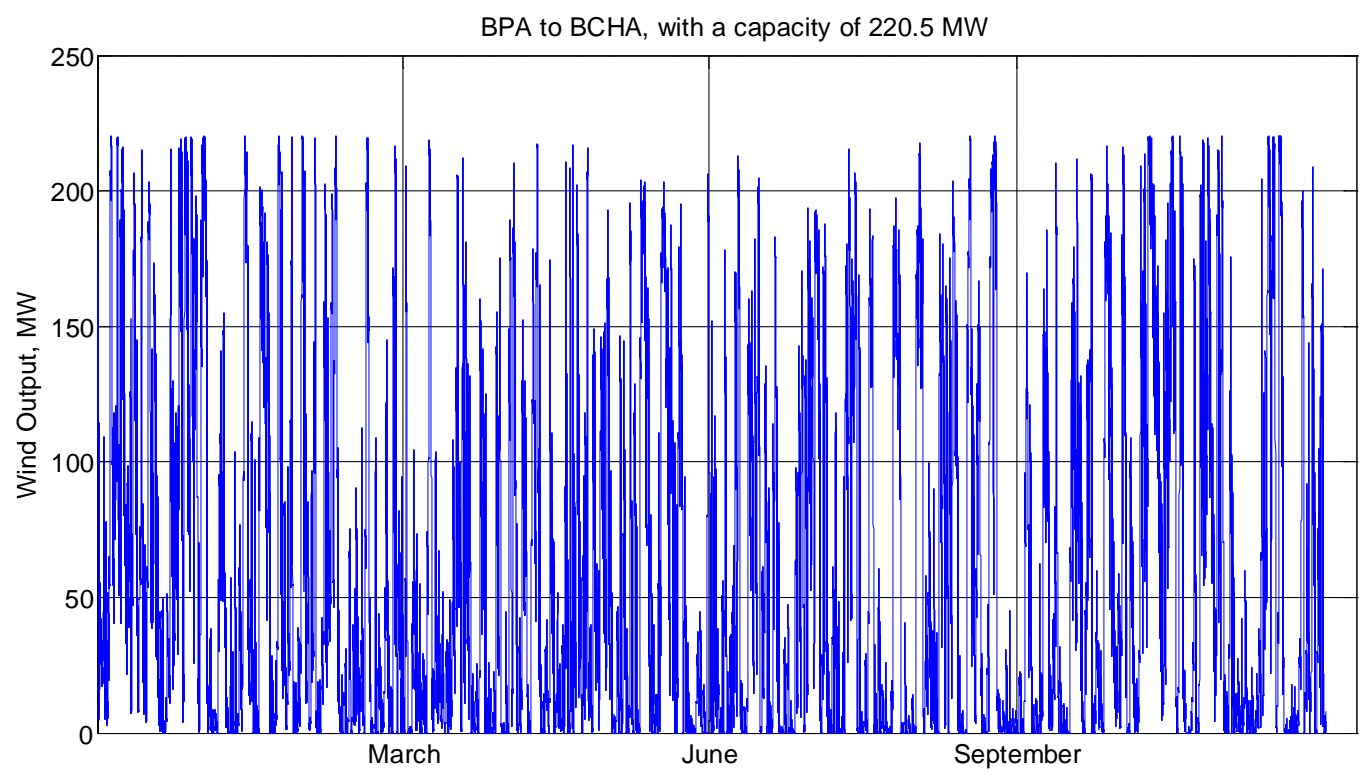

Figure F.22. Profile of the Wind Transfer between BPA and BCHA, 2020

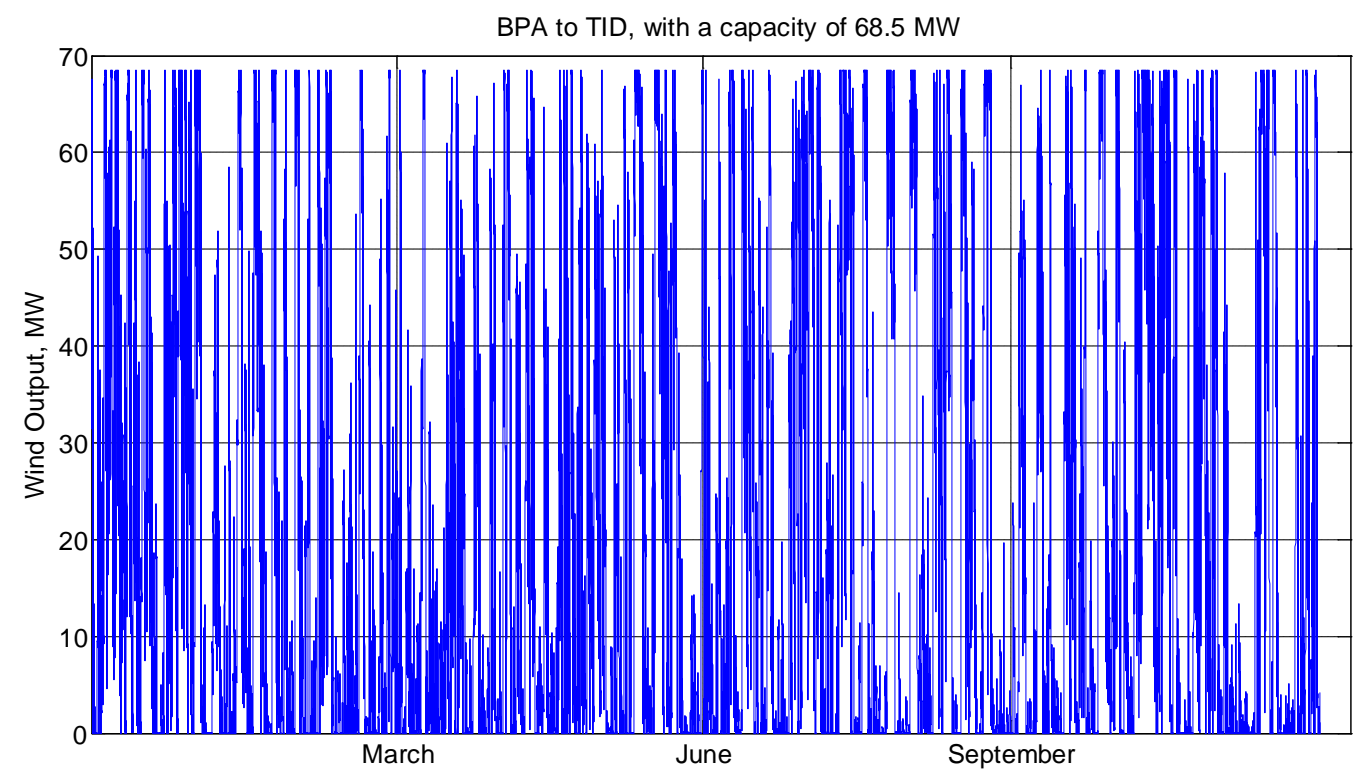

Figure F.23. Profile of the Wind Transfer between BPA and TID, 2020 


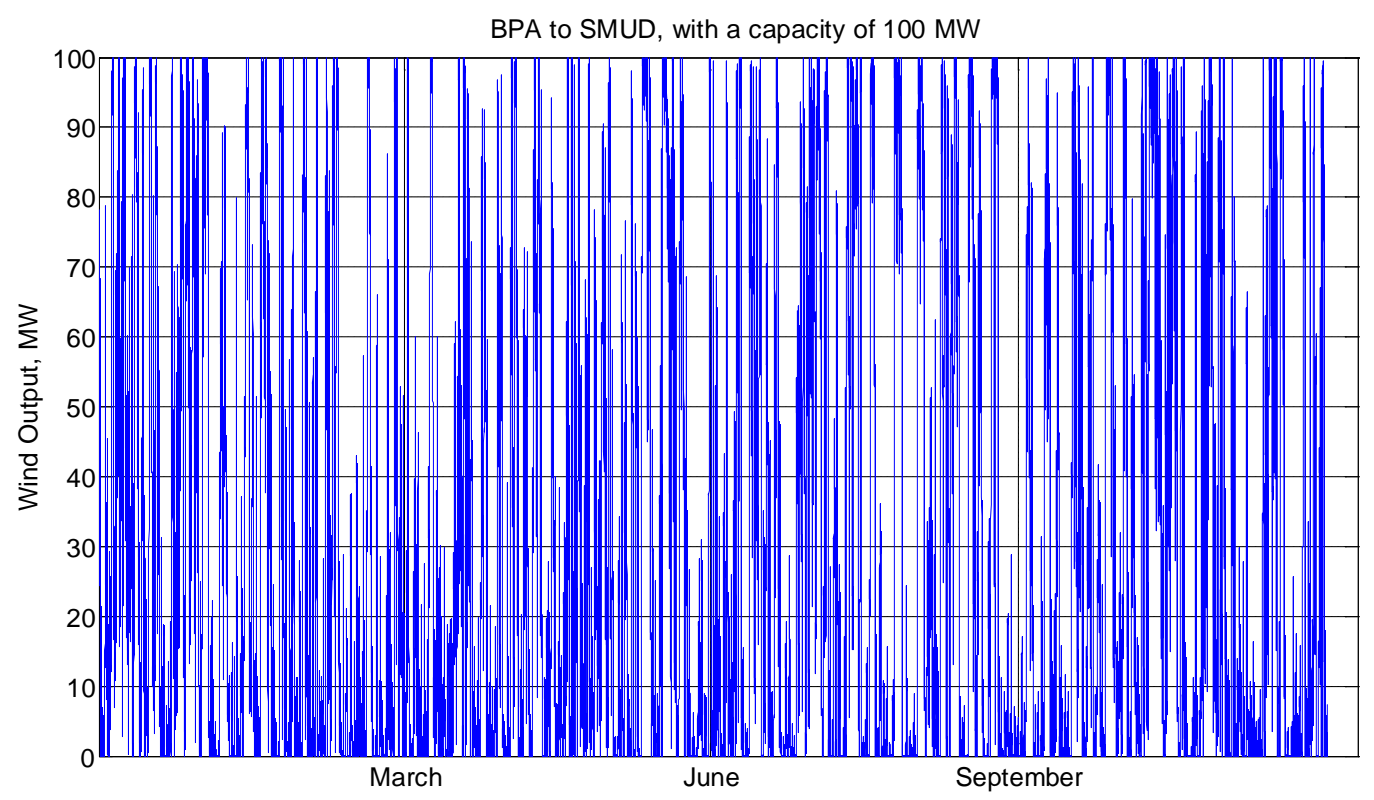

Figure F.24. Profile of the Wind Transfer between BPA and BANC, 2020

In Table F.15, the changes in load-following requirements for source and sink BAs in this study are summarized.

Table F.15. Summary of Changes in Load Following for Source and Sink BAs

\begin{tabular}{lcccccc}
\hline & \multicolumn{3}{c}{ 95\% Confidence Level } & \multicolumn{3}{c}{ 99.5\% Confidence Level } \\
& January & April & August & January & April & August \\
\hline BPA, up & -31.8 & -25.61 & -28.31 & -43.82 & -43.79 & -36.53 \\
BPA, down & -31.89 & -35.44 & -39.39 & -58.19 & -50.1 & -40.08 \\
PGN, up & 4.17 & -0.39 & 5.64 & 4.83 & 2.47 & 10.16 \\
PGN, down & 6.02 & 0.11 & 3.57 & 6.75 & -1.21 & 6.86 \\
PSE, up & 1.39 & 3.35 & 4.17 & 3.68 & 11.21 & 7.18 \\
PSE, down & 6.32 & 6.99 & 7.94 & 2.66 & 19.34 & 15.33 \\
BCHA, up & 0.95 & 0.59 & 0.62 & 2.09 & -0.18 & 1.36 \\
BCHA, down & 0.52 & 0.86 & 0.7 & 0.06 & 0.88 & 1.01 \\
TID, up & 3.37 & 1.56 & 1.27 & 6.87 & 2.48 & 4.39 \\
TID, down & 3.12 & 2.15 & 1.15 & 6.52 & 4.98 & 3.28 \\
SMUD, up & 0.75 & 0.64 & 0.55 & 1.18 & 1.27 & 0.73 \\
SMUD, down & 1.1 & 0.55 & 0.54 & 1.43 & 0.48 & 0.97 \\
\hline
\end{tabular}




\section{F.4.1 Impact on BPA Load Following with 95\% Confidence Level}

\section{F.4.1.1 January 2020}
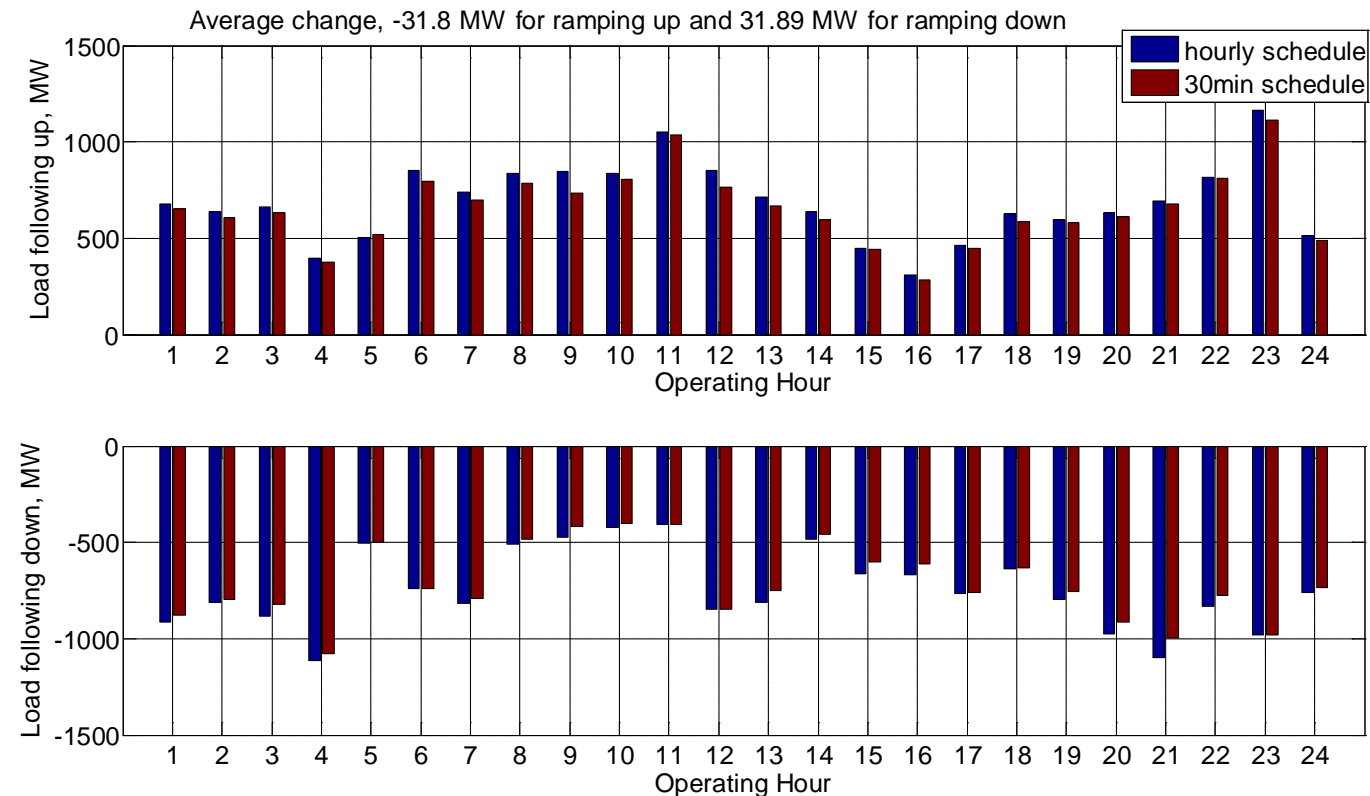

Figure F.25. Impact on BPA Load Following, 95\% CL, January 2020

Table F.16. Difference between 30-Minute Schedule and Hourly Schedule in Figure F.25 (MW)

\begin{tabular}{|l|l|l|l|l|l|l|l|l|l|l|l|l|l|l|l|l|l|l|l|l|l|l|l|l|}
\hline Operating Hour & $\mathbf{1}$ & $\mathbf{2}$ & $\mathbf{3}$ & $\mathbf{4}$ & $\mathbf{5}$ & $\mathbf{6}$ & $\mathbf{7}$ & $\mathbf{8}$ & $\mathbf{9}$ & $\mathbf{1 0}$ & $\mathbf{1 1}$ & $\mathbf{1 2}$ & $\mathbf{1 3}$ & $\mathbf{1 4}$ & $\mathbf{1 5}$ & $\mathbf{1 6}$ & $\mathbf{1 7}$ & $\mathbf{1 8}$ & $\mathbf{1 9}$ & $\mathbf{2 0}$ & $\mathbf{2 1}$ & $\mathbf{2 2}$ & $\mathbf{2 3}$ & $\mathbf{2 4}$ \\
\hline Difference, up & -23 & -26 & -30 & -18 & 15 & .53 & -40 & .52 & -.11 & -30 & -15 & -85 & -42 & -42 & -4 & -24 & -11 & -40 & -15 & -21 & -17 & -6 & -50 & -23 \\
\hline Differenc, dovn & 34 & 13 & 59 & 32 & 2 & -1 & 29 & 28 & 54 & 22 & 0 & 0 & 62 & 23 & 63 & 57 & 1 & 7 & 41 & 60 & 103 & 53 & -2 & 27 \\
\hline
\end{tabular}

The load-following requirement is decreased by 31.8 MW for ramping up (Inc) and decreased by 31.89 MW for ramping down (Dec), on average. 


\section{F.4.1.2 April 2020}
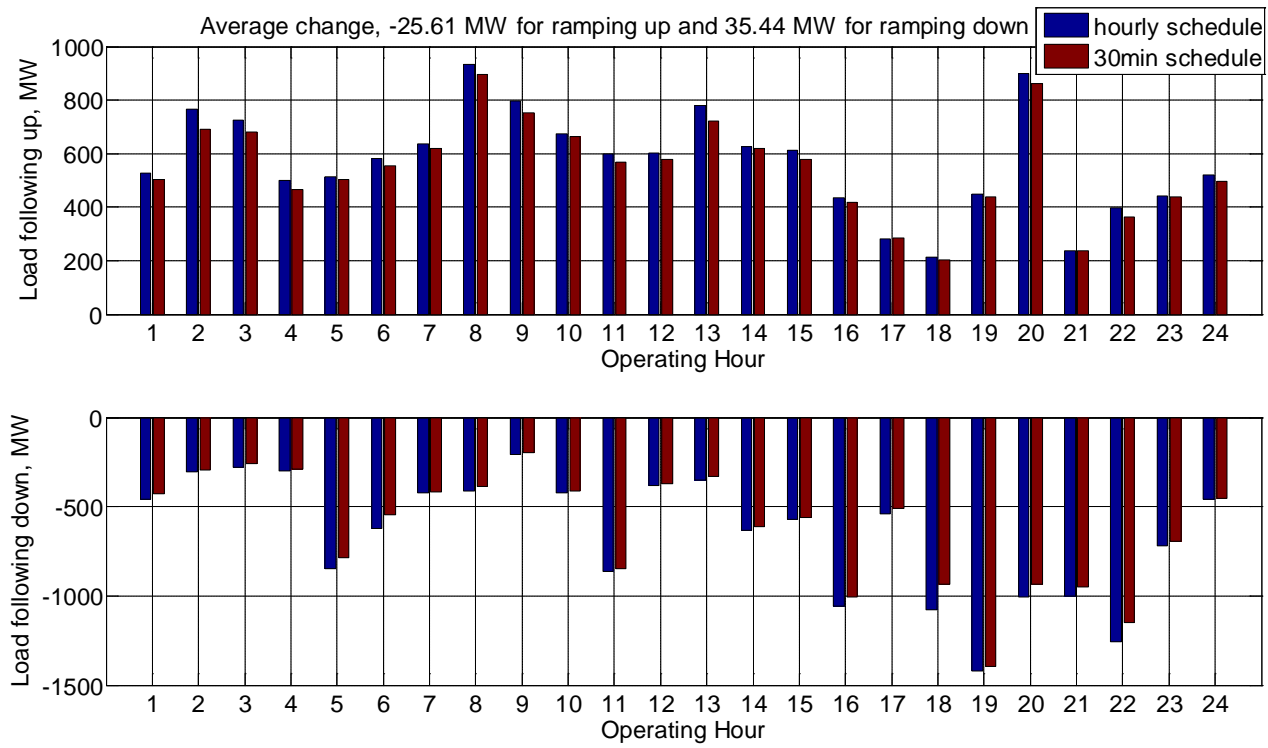

Figure F.26. Impact on BPA Load Following, 95\% CL, April 2020

Table F.17. Difference between 30-Minute Schedule and Hourly Schedule in Figure F.26 (MW)

\begin{tabular}{|l|l|l|l|l|l|l|l|l|l|l|l|l|l|l|l|l|l|l|l|l|l|l|l|l|}
\hline Operating Hour & $\mathbf{1}$ & $\mathbf{2}$ & $\mathbf{3}$ & $\mathbf{4}$ & $\mathbf{5}$ & $\mathbf{6}$ & $\mathbf{7}$ & $\mathbf{8}$ & $\mathbf{9}$ & $\mathbf{1 0}$ & $\mathbf{1 1}$ & $\mathbf{1 2}$ & $\mathbf{1 3}$ & $\mathbf{1 4}$ & $\mathbf{1 5}$ & $\mathbf{1 6}$ & $\mathbf{1 7}$ & $\mathbf{1 8}$ & $\mathbf{1 9}$ & $\mathbf{2 0}$ & 21 & $\mathbf{2 2}$ & $\mathbf{2 3}$ & $\mathbf{2 4}$ \\
\hline Difference, up & -22 & -75 & -45 & -35 & -11 & -27 & -16 & -40 & -45 & -11 & -33 & -24 & -57 & -6 & -34 & -19 & 2 & -8 & -11 & -38 & -3 & -32 & -4 & -21 \\
\hline Difference, down & 33 & 12 & 20 & 9 & 62 & 75 & 4 & 22 & 12 & 12 & 17 & 11 & 21 & 20 & 8 & 52 & 26 & 146 & 26 & 74 & 53 & 109 & 24 & 2 \\
\hline
\end{tabular}

The load-following requirement is decreased by 25.61 MW for ramping up (Inc) and decreased by 35.44 MW for ramping down (Dec), on average. 


\section{F.4.1.3 August 2020}
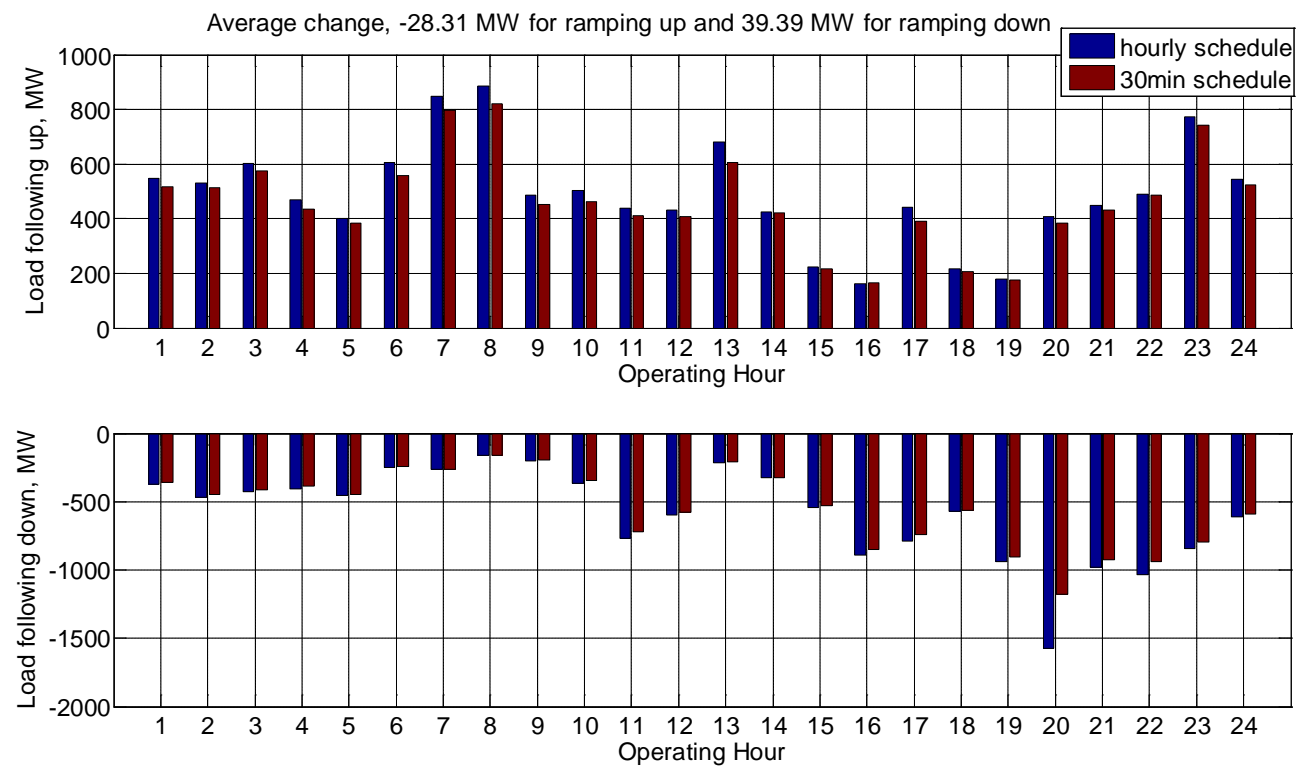

Figure F.27. Impact on BPA Load Following, 95\% CL, August 2020

Table F.18. Difference between 30-Minute Schedule and Hourly Schedule in Figure F.27 (MW)

\begin{tabular}{|l|l|l|l|l|l|l|l|l|l|l|l|l|l|l|l|l|l|l|l|l|l|l|l|l|}
\hline Operating Hour & $\mathbf{1}$ & $\mathbf{2}$ & $\mathbf{3}$ & $\mathbf{4}$ & $\mathbf{5}$ & $\mathbf{6}$ & $\mathbf{7}$ & $\mathbf{8}$ & $\mathbf{9}$ & $\mathbf{1 0}$ & 11 & 12 & 13 & 14 & 15 & 16 & 17 & 18 & 19 & $\mathbf{2 0}$ & 21 & 22 & 23 & 24 \\
\hline Difference, up & -32 & -17 & -27 & -34 & -18 & -50 & -53 & -64 & -35 & -40 & -28 & -27 & -76 & -4 & -9 & 3 & -52 & -10 & -5 & -26 & -17 & -3 & -33 & -21 \\
\hline Difference, down & 15 & 21 & 14 & 20 & 8 & 11 & 5 & 1 & 6 & 21 & 50 & 14 & 6 & 2 & 15 & 35 & 48 & 1 & 39 & 396 & 56 & 92 & 51 & 18 \\
\hline
\end{tabular}

The load-following requirement is decreased by 28.31 MW for ramping up (Inc) and decreased by 39.39 MW for ramping down (Dec), on average. 


\section{F.4.2 Impact on BPA Load Following with 99.5\% Confidence Level}

\section{F.4.2.1 January 2020}
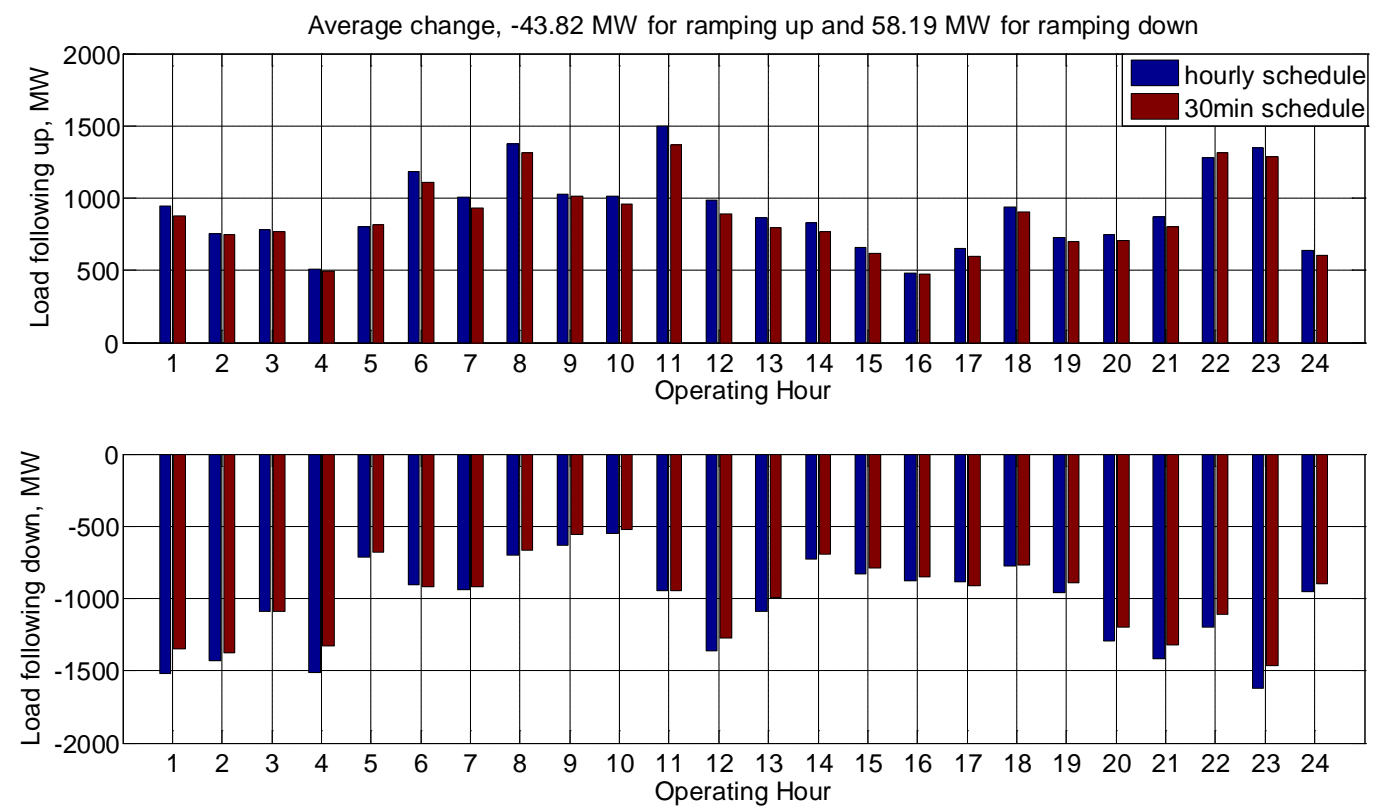

Figure F.28. Impact on BPA Load Following, 99.5\% CL, January 2020

Table F.19. Difference between 30-Minute Schedule and Hourly Schedule in Figure F.28 (MW)

\begin{tabular}{|c|c|c|c|c|c|c|c|c|c|c|c|c|c|c|c|c|c|c|c|c|c|c|c|c|}
\hline Operating Hour & 1 & 2 & 3 & 4 & 5 & 6 & 7 & 8 & 9 & 10 & 11 & 12 & 13 & 14 & 15 & 16 & 17 & 18 & 19 & 20 & 21 & 22 & 23 & 24 \\
\hline Difference, up & -63 & -11 & .9 & -14 & 12 & .78 & .74 & -58 & -16 & -51 & -135 & -98 & -68 & -63 & .35 & -5 & .53 & -31 & .27 & -41 & .70 & 36 & -62 & -38 \\
\hline Difference, down & 169 & 56 & .1 & 187 & 28 & -14 & 17 & 32 & 73 & 32 & -2 & 87 & 99 & 39 & 36 & 22 & .30 & 2 & 66 & 94 & 94 & 92 & 162 & 58 \\
\hline
\end{tabular}

The load-following requirement is decreased by 43.82 MW for ramping up (Inc) and decreased by 58.19 MW for ramping down (Dec), on average. 


\section{F.4.2.2 April 2020}
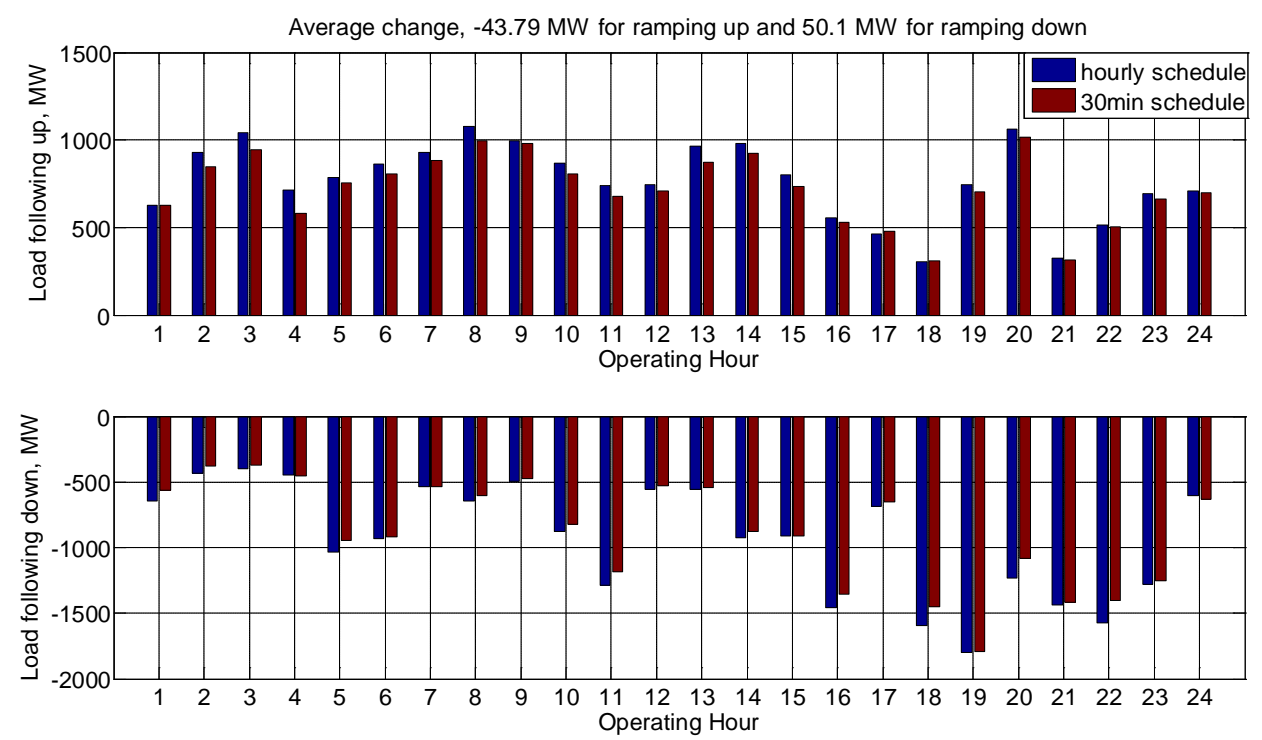

Figure F.29. Impact on BPA Load Following, 99.5\% CL, April 2020

Table F.20. Difference between 30-Minute Schedule and Hourly Schedule in Figure F.29 (MW)

\begin{tabular}{|c|c|c|c|c|c|c|c|c|c|c|c|c|c|c|c|c|c|c|c|c|c|c|c|c|}
\hline Operating Hour & 1 & 2 & 3 & 4 & 5 & 6 & 7 & 8 & 9 & 10 & 11 & 12 & 13 & 14 & 15 & 16 & 17 & 18 & 19 & 20 & 21 & 22 & 23 & 24 \\
\hline Difference, up & 1 & .80 & .97 & .133 & .30 & .52 & .4 & .80 & .15 & .62 & .60 & .35 & .90 & .57 & .69 & -22 & 16 & 3 & .38 & -49 & -8 & -10 & .30 & .11 \\
\hline Difference, down & 82 & 51 & 30 & -8 & 91 & 16 & 2 & 45 & 22 & 55 & 98 & 25 & 8 & 47 & -1 & 108 & 33 & 144 & 9 & 151 & 20 & 170 & 30 & .26 \\
\hline
\end{tabular}

The load-following requirement is decreased by 43.79 MW for ramping up (Inc) and decreased by 50.1 MW for ramping down (Dec), on average. 


\section{F.4.2.3 August 2020}
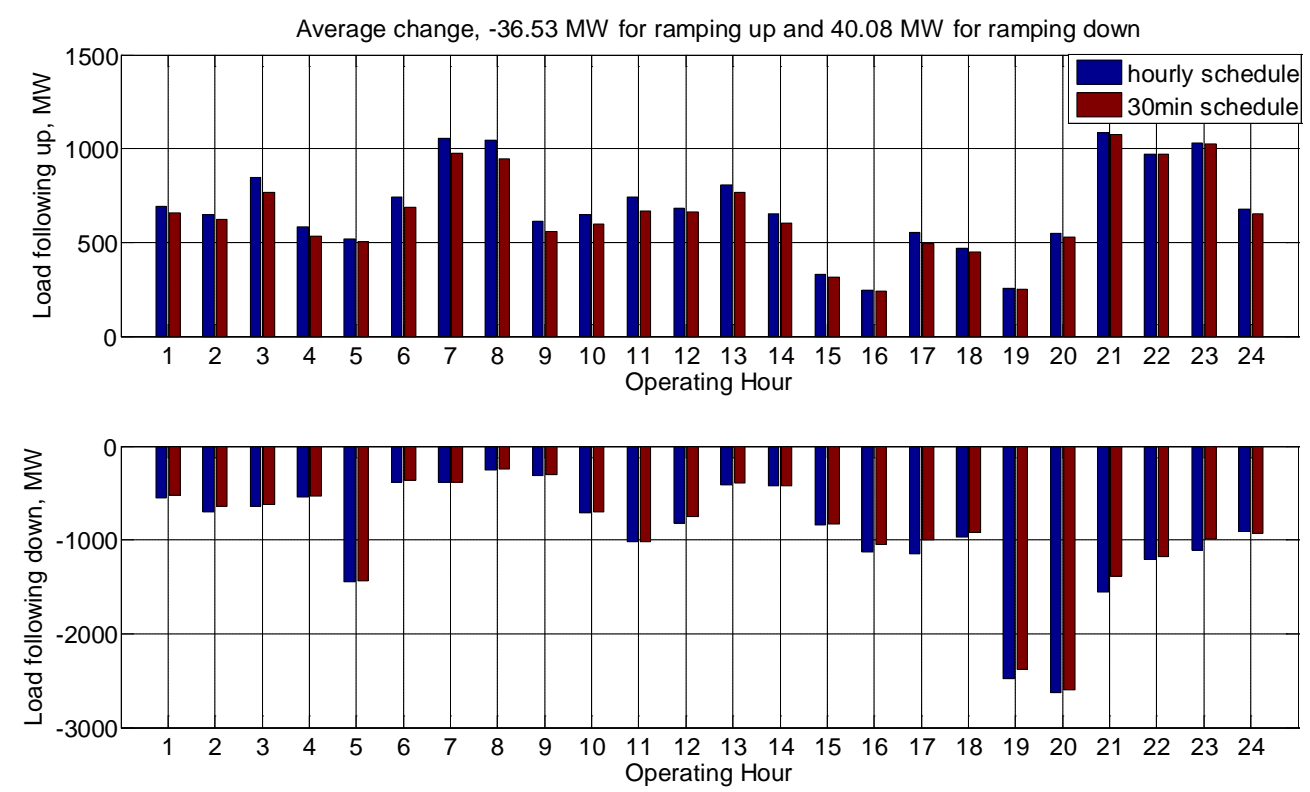

Figure F.30. Impact on BPA Load Following, 99.5\% CL, August 2020

Table F.21. Difference between 30-Minute Schedule and Hourly Schedule in Figure F.30 (MW)

\begin{tabular}{|l|c|c|c|c|c|c|c|c|c|c|c|c|c|c|c|c|c|c|c|c|c|c|c|c|}
\hline Operating Hour & $\mathbf{1}$ & $\mathbf{2}$ & $\mathbf{3}$ & $\mathbf{4}$ & $\mathbf{5}$ & $\mathbf{6}$ & $\mathbf{7}$ & $\mathbf{8}$ & $\mathbf{9}$ & $\mathbf{1 0}$ & 11 & 12 & 13 & 14 & 15 & 16 & $\mathbf{1 7}$ & 18 & $\mathbf{1 9}$ & 20 & $\mathbf{2 1}$ & 22 & $\mathbf{2 3}$ & 24 \\
\hline Difference, up & .35 & .23 & .82 & .48 & .15 & .51 & .84 & .98 & .51 & .47 & .78 & .19 & .37 & .49 & .15 & -1 & -60 & -20 & -8 & -20 & -8 & 0 & -4 & .22 \\
\hline Difference, down & 22 & 61 & 24 & 14 & 13 & 12 & 0 & 3 & 6 & 4 & 0 & 73 & 16 & 7 & 7 & 80 & 150 & 48 & 100 & 29 & 163 & 33 & 119 & .27 \\
\hline
\end{tabular}

The load-following requirement is decreased by 36.53 MW for ramping up (Inc) and decreased by 40.08 MW for ramping down (Dec), on average. 


\section{F.4.3 Impact on PGN Load Following with 95\% Confidence Level}

\section{F.4.3.1 January 2020}
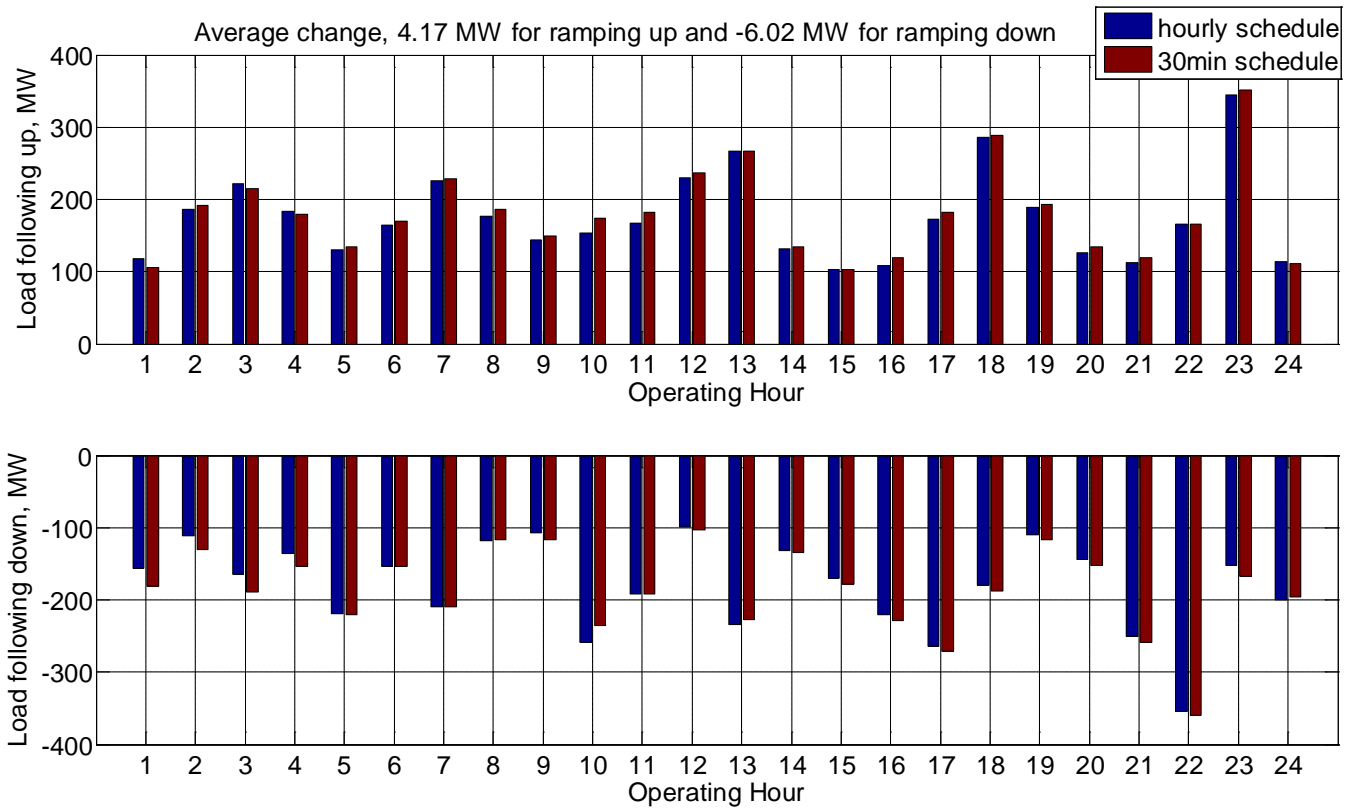

Figure F.31. Impact on PGN Load Following, 95\% CL, January 2020

Table F.22. Difference between 30-Minute Schedule and Hourly Schedule in Figure F.31 (MW)

\begin{tabular}{|l|c|c|c|c|c|c|c|c|c|c|c|c|c|c|c|c|c|c|c|c|c|c|c|c|}
\hline Operating Hour & $\mathbf{1}$ & $\mathbf{2}$ & $\mathbf{3}$ & $\mathbf{4}$ & $\mathbf{5}$ & $\mathbf{6}$ & $\mathbf{7}$ & $\mathbf{8}$ & $\mathbf{9}$ & 10 & 11 & 12 & 13 & 14 & 15 & 16 & 17 & 18 & 19 & 20 & 21 & 22 & $\mathbf{2}$ & 24 \\
\hline Difference, up & -12 & 6 & -6 & -5 & 3 & 6 & 3 & 10 & 6 & 21 & 15 & 7 & 0 & 3 & -1 & 11 & 9 & 3 & 4 & 7 & 6 & 0 & 7 & -3 \\
\hline Difference, down & -24 & -19 & -24 & -17 & -1 & 0 & 0 & 0 & -9 & 24 & 0 & -4 & 7 & -2 & -8 & -8 & -7 & -8 & -8 & -9 & -8 & -4 & -16 & 3 \\
\hline
\end{tabular}

The load-following requirement is increased by $4.17 \mathrm{MW}$ for ramping up (Inc) and increased by 6.02 MW for ramping down (Dec), on average. 


\section{F.4.3.2 April 2020:}
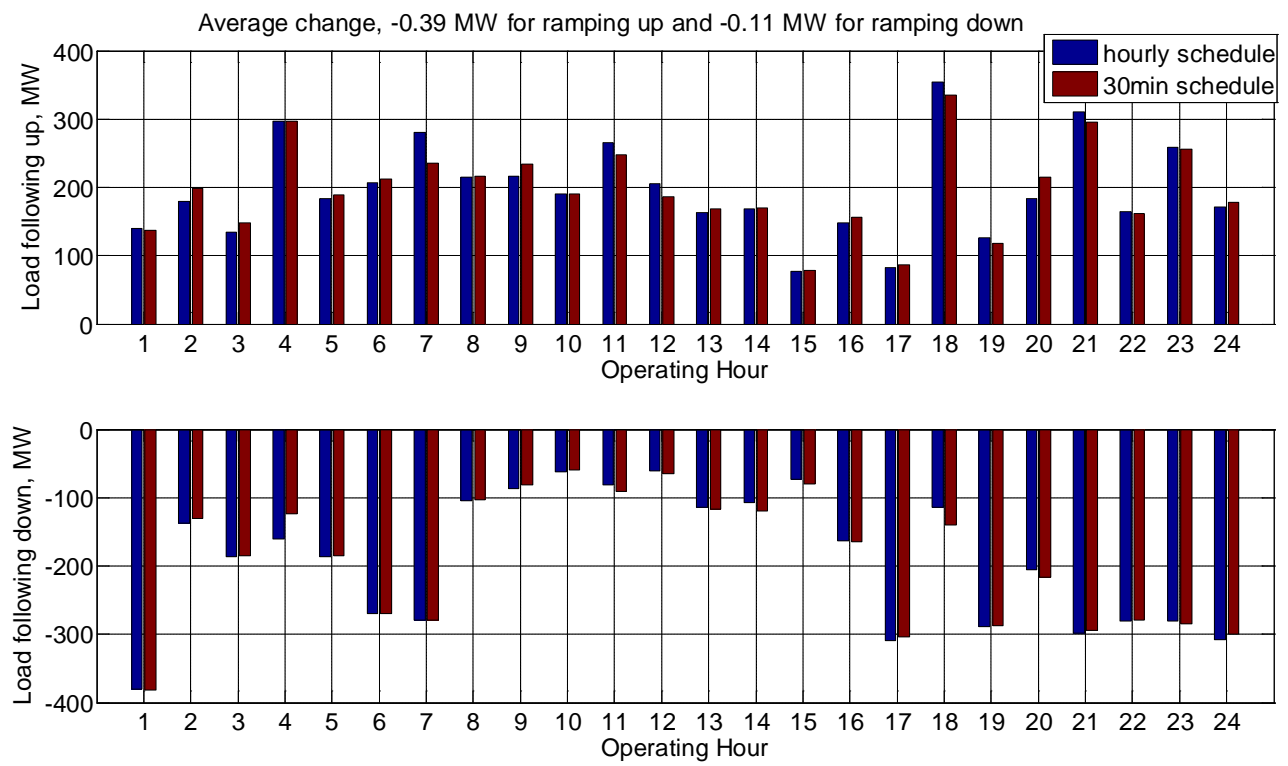

Figure F.32. Impact on PGN Load Following, 95\% CL, April 2020

Table F.23. Difference between 30-Minute Schedule and Hourly Schedule in Figure F.32 (MW)

\begin{tabular}{|l|l|l|l|l|l|l|l|l|l|l|l|l|l|l|l|l|l|l|l|l|l|l|l|l|}
\hline Operating Hour & $\mathbf{1}$ & $\mathbf{2}$ & $\mathbf{3}$ & $\mathbf{4}$ & $\mathbf{5}$ & $\mathbf{6}$ & $\mathbf{7}$ & $\mathbf{8}$ & $\mathbf{9}$ & 10 & $\mathbf{1 1}$ & $\mathbf{1 2}$ & 13 & $\mathbf{1 4}$ & $\mathbf{1 5}$ & $\mathbf{1 6}$ & $\mathbf{1 7}$ & $\mathbf{1 8}$ & 19 & $\mathbf{2 0}$ & $\mathbf{2 1}$ & 22 & 23 & 24 \\
\hline Difference, up & -2 & 20 & 14 & 0 & 5 & 5 & -45 & 1 & 19 & 0 & -18 & -19 & 6 & 1 & 1 & 9 & 4 & -19 & -9 & 31 & -14 & -3 & -3 & 7 \\
\hline Difference, down & -1 & 7 & 1 & 36 & 1 & 0 & 0 & 2 & 5 & 3 & -9 & -5 & -2 & -12 & -7 & -2 & 5 & -26 & 1 & -10 & 4 & 1 & -4 & 9 \\
\hline
\end{tabular}

The load-following requirement is decreased by $0.39 \mathrm{MW}$ for ramping up (Inc) and increased by 0.11 MW for ramping down (Dec), on average. 


\section{F.4.3.3 August 2020}
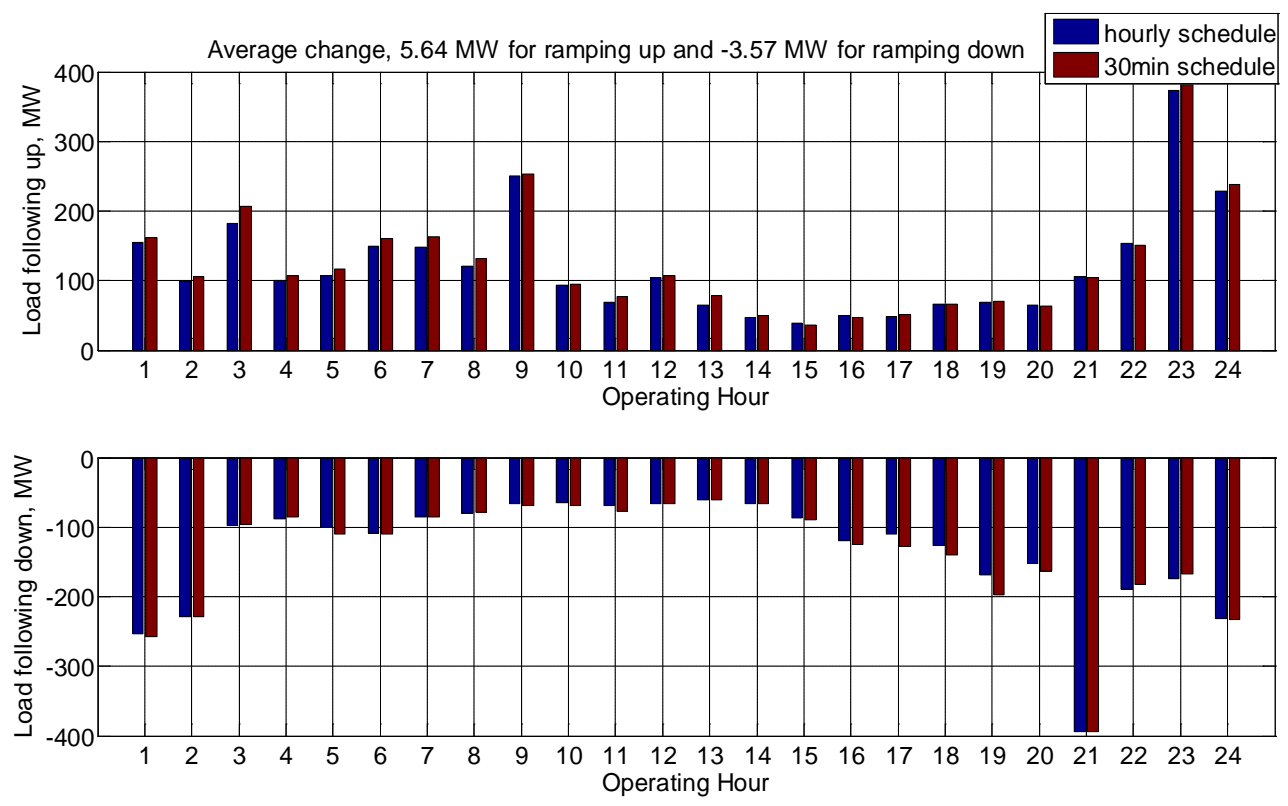

Figure F.33. Impact on PGN Load Following, 95\% CL, August 2020

Table F.24. Difference between 30-Minute Schedule and Hourly Schedule in Figure F.33 (MW)

\begin{tabular}{|l|l|l|l|l|l|l|l|l|l|l|l|l|l|l|l|l|l|l|l|l|l|l|l|l|}
\hline Operating Hour & $\mathbf{1}$ & $\mathbf{2}$ & $\mathbf{3}$ & $\mathbf{4}$ & $\mathbf{5}$ & $\mathbf{6}$ & $\mathbf{7}$ & $\mathbf{8}$ & $\mathbf{9}$ & 10 & 11 & 12 & 13 & 14 & 15 & 16 & $\mathbf{1 7}$ & $\mathbf{1 8}$ & $\mathbf{1 9}$ & $\mathbf{2 0}$ & 21 & 22 & 23 & 24 \\
\hline Difference, up & 8 & 7 & 24 & 8 & 10 & 12 & 15 & 10 & 3 & 2 & 7 & 3 & 13 & 2 & -3 & -2 & 2 & 0 & 1 & -1 & -1 & -2 & 8 & 9 \\
\hline Difference, down & -4 & 0 & 1 & 3 & -9 & -1 & 0 & 0 & -2 & -5 & -7 & 0 & 0 & 0 & -2 & -5 & -18 & -14 & -28 & -10 & 1 & 6 & 8 & -1 \\
\hline
\end{tabular}

The load-following requirement is increased by 5.64 MW for ramping up (Inc) and increased by 3.57 MW for ramping down (Dec), on average. 


\section{F.4.4 Impact on PGN Load Following with 99.5\% Confidence Level}

\section{F.4.4.1 January 2020}
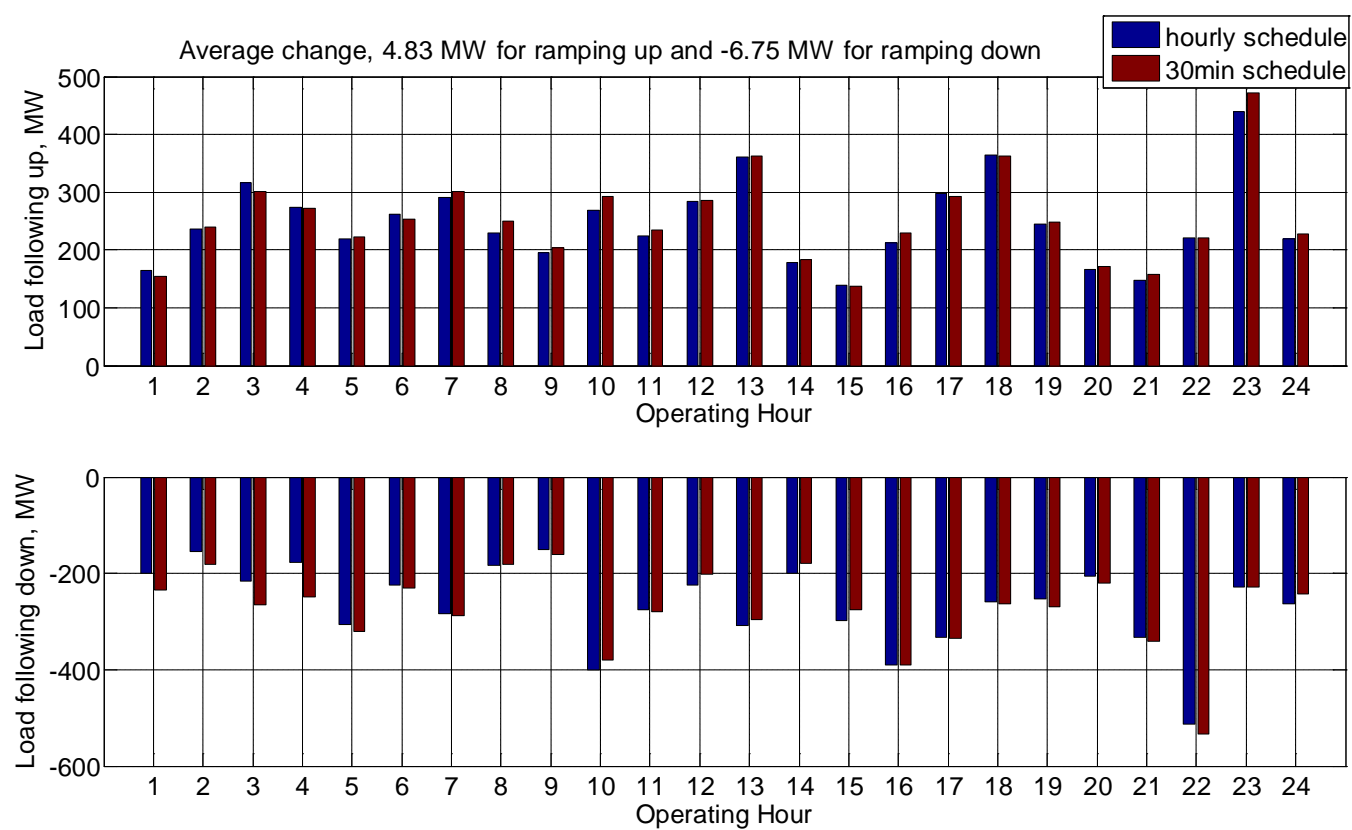

Figure F.34. Impact on PGN Load Following, 99.5\% CL, January 2020

Table F.25. Difference between 30-Minute Schedule and Hourly Schedule in Figure F.34 (MW)

\begin{tabular}{|l|c|c|c|c|c|c|c|c|c|c|c|c|c|c|c|c|c|c|c|c|c|c|c|c|}
\hline Operating Hour & $\mathbf{1}$ & $\mathbf{2}$ & $\mathbf{3}$ & $\mathbf{4}$ & $\mathbf{5}$ & $\mathbf{6}$ & $\mathbf{7}$ & $\mathbf{8}$ & $\mathbf{9}$ & 10 & 11 & 12 & 13 & 14 & 15 & 16 & 17 & 18 & $\mathbf{1 9}$ & $\mathbf{2 0}$ & 21 & $\mathbf{2 2}$ & 23 & 24 \\
\hline Difference, up & -11 & 3 & -17 & -2 & 3 & -9 & 9 & 21 & 9 & 25 & 11 & 2 & 1 & 4 & -1 & 16 & -5 & -1 & 3 & 6 & 10 & 0 & 31 & 7 \\
\hline Difference, down & -34 & -26 & -51 & -72 & -15 & -4 & -3 & 1 & -9 & 20 & -3 & 21 & 13 & 20 & 22 & 0 & -2 & -3 & -15 & -13 & -7 & -20 & 0 & 20 \\
\hline
\end{tabular}

The load-following requirement is increased by 4.83 MW for ramping up (Inc) and increased by 6.75 MW for ramping down (Dec), on average. 


\section{F.4.4.2 April 2020}
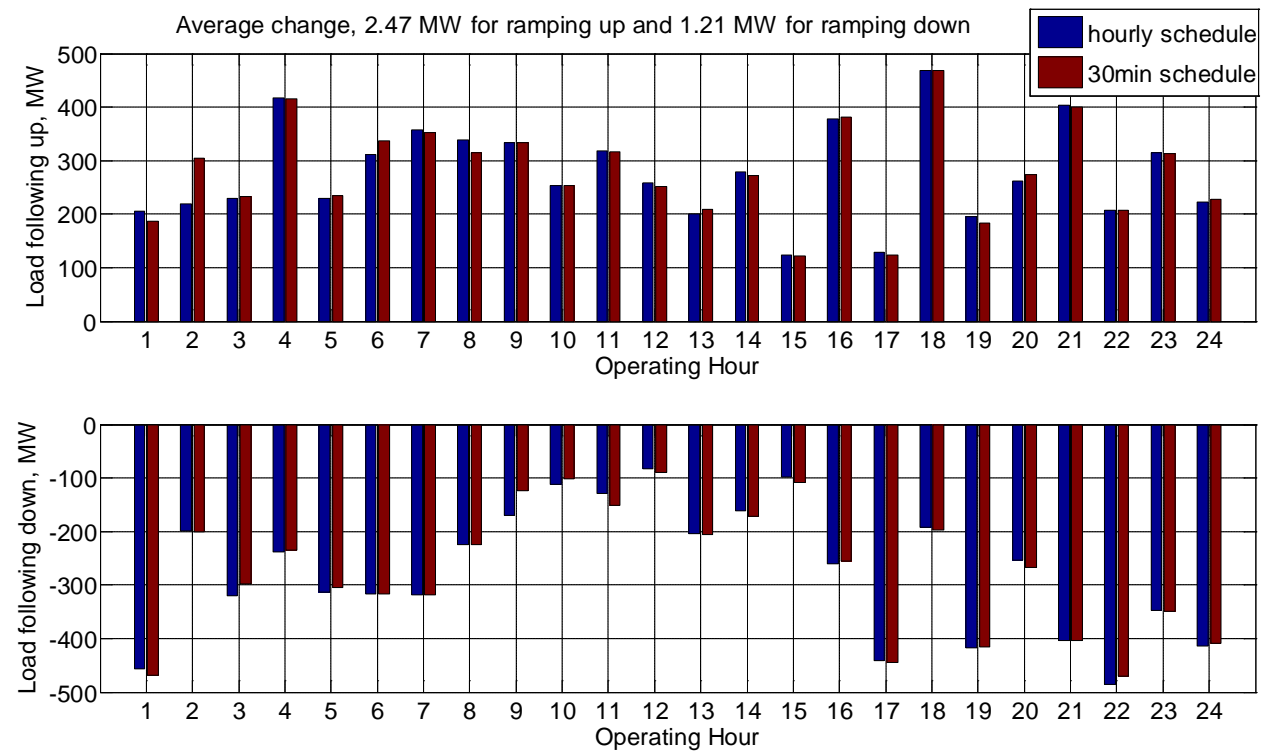

Figure F.35. Impact on PGN Load Following, 99.5\% CL, April 2020

Table F.26. Difference between 30-Minute Schedule and Hourly Schedule in Figure F.35 (MW)

\begin{tabular}{|l|c|c|c|c|c|c|c|c|c|c|c|c|c|c|c|c|c|c|c|c|c|c|c|c|}
\hline Operating Hour & $\mathbf{1}$ & $\mathbf{2}$ & $\mathbf{3}$ & $\mathbf{4}$ & $\mathbf{5}$ & $\mathbf{6}$ & $\mathbf{7}$ & $\mathbf{8}$ & $\mathbf{9}$ & $\mathbf{1 0}$ & $\mathbf{1 1}$ & 12 & 13 & $\mathbf{1 4}$ & $\mathbf{1 5}$ & $\mathbf{1 6}$ & $\mathbf{1 7}$ & $\mathbf{1 8}$ & $\mathbf{1 9}$ & $\mathbf{2 0}$ & 21 & 22 & 23 & 24 \\
\hline Difference, up & -19 & 86 & 4 & -2 & 4 & 26 & -7 & -23 & -1 & 0 & -2 & -7 & 9 & -7 & -2 & 4 & -5 & 0 & -12 & 12 & -3 & -1 & -2 & 6 \\
\hline Difference, down & -12 & -1 & 22 & 3 & 8 & 0 & 0 & 0 & 47 & 10 & -22 & -6 & -1 & -10 & -12 & 5 & -4 & -6 & 1 & -13 & 0 & 15 & -2 & 5 \\
\hline
\end{tabular}

The load-following requirement is increased by $2.47 \mathrm{MW}$ for ramping up (Inc) and decreased by 1.21 MW for ramping down (Dec), on average. 


\section{F.4.4.3 August 2020}
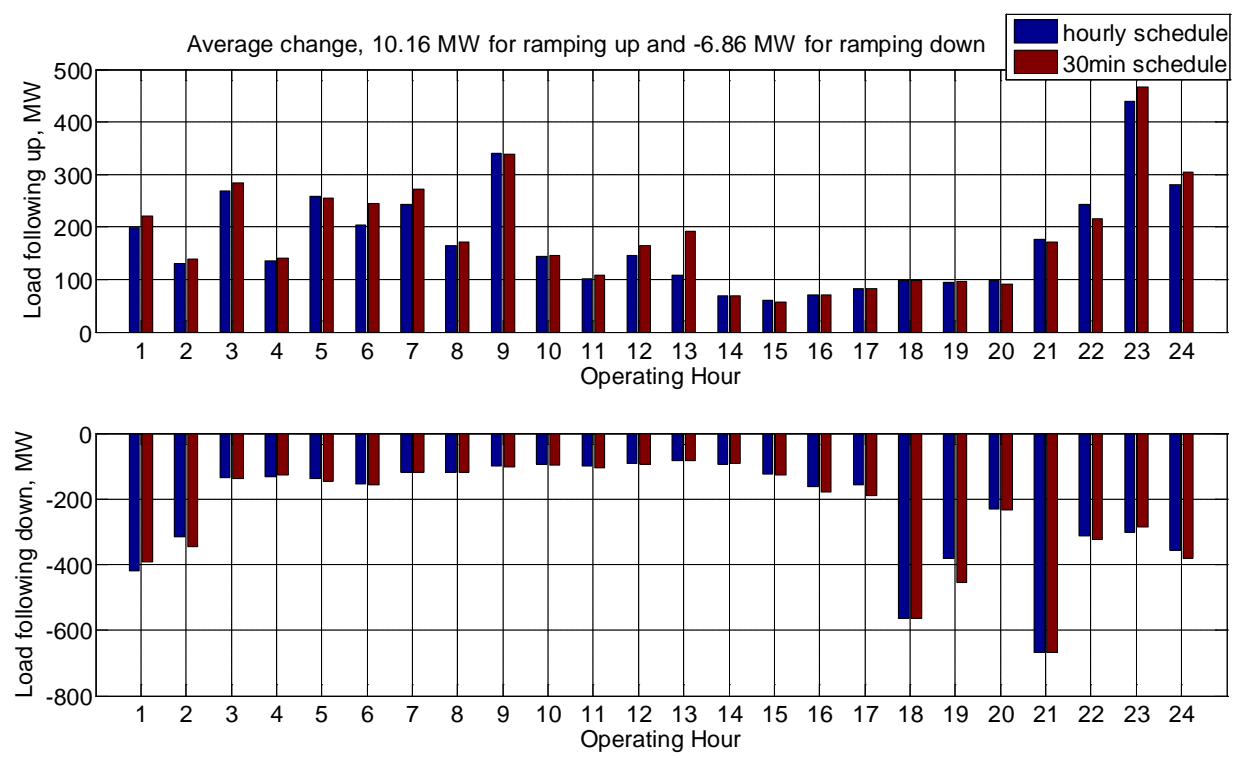

Figure F.36. Impact on PGN Load Following, 99.5\% CL, August 2020

Table F.27. Difference between 30-Minute Schedule and Hourly Schedule in Figure F.36 (MW)

\begin{tabular}{|l|c|c|c|c|c|c|c|c|c|c|c|c|c|c|c|c|c|c|c|c|c|c|c|c|}
\hline Operating Hour & $\mathbf{1}$ & $\mathbf{2}$ & $\mathbf{3}$ & $\mathbf{4}$ & $\mathbf{5}$ & $\mathbf{6}$ & $\mathbf{7}$ & $\mathbf{8}$ & $\mathbf{9}$ & 10 & 11 & 12 & 13 & 14 & 15 & $\mathbf{1 6}$ & $\mathbf{1 7}$ & 18 & $\mathbf{1 9}$ & 20 & 21 & $\mathbf{2 2}$ & 23 & $\mathbf{2 4}$ \\
\hline Difference, up & 23 & 8 & 16 & 6 & -4 & 41 & 28 & 6 & -1 & 2 & 7 & 18 & 84 & 0 & -4 & 0 & 0 & 0 & 1 & -7 & -5 & -28 & 28 & 24 \\
\hline Difference, down & 27 & -29 & -2 & 3 & -7 & -2 & 0 & 0 & -1 & -4 & -5 & -1 & 0 & 5 & -3 & -19 & -31 & 0 & -75 & -2 & 0 & -11 & 16 & -22 \\
\hline
\end{tabular}

The load-following requirement is increased by 10.16 MW for ramping up (Inc) and increased by 6.86 MW for ramping down (Dec), on average. 


\section{F.4.5 Impact on PSE Load Following with 95\% Confidence Level}

\section{F.4.5.1 January 2020}
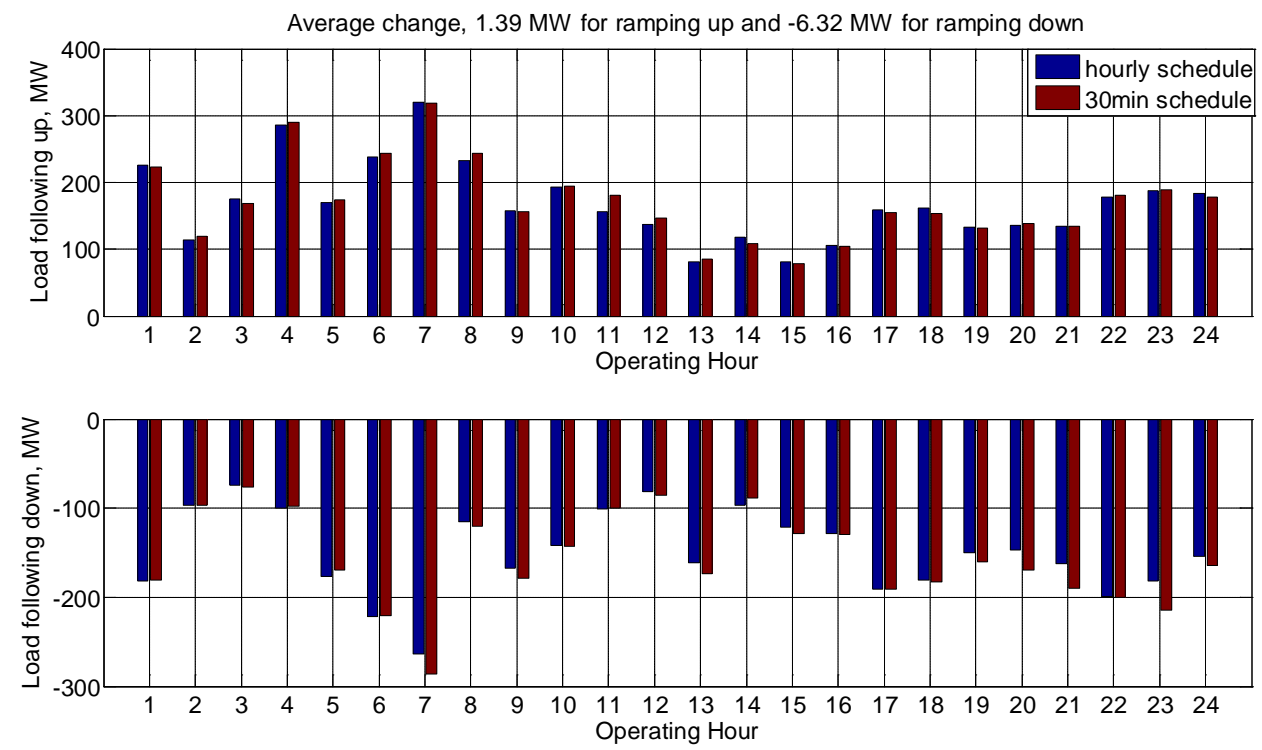

Figure F.37. Impact on PSE Load Following, 95\% CL, January 2020

Table F.28. Difference between 30-Minute Schedule and Hourly Schedule in Figure F.37 (MW)

\begin{tabular}{|l|l|l|l|l|l|l|l|l|l|l|l|l|l|l|l|l|l|l|l|l|l|l|l|l|}
\hline Operating Hour & $\mathbf{1}$ & $\mathbf{2}$ & $\mathbf{3}$ & $\mathbf{4}$ & $\mathbf{5}$ & $\mathbf{6}$ & $\mathbf{7}$ & $\mathbf{8}$ & $\mathbf{9}$ & $\mathbf{1 0}$ & 11 & 12 & $\mathbf{1 3}$ & 14 & 15 & 16 & 17 & 18 & $\mathbf{1 9}$ & $\mathbf{2 0}$ & $\mathbf{2 1}$ & 22 & $\mathbf{2 3}$ & $\mathbf{2 4}$ \\
\hline Difference, up & -3 & 6 & -7 & 3 & 4 & 6 & -2 & 11 & -1 & 1 & 25 & 10 & 5 & -9 & -2 & -1 & -3 & -9 & -1 & 3 & 0 & 2 & 2 & -5 \\
\hline Difference, down & 1 & 0 & -2 & 1 & 7 & 1 & -22 & -6 & -12 & -1 & 2 & -4 & -11 & 9 & -8 & -2 & 0 & -2 & -10 & -23 & -27 & -2 & -32 & -11 \\
\hline
\end{tabular}

The load-following requirement is increased by 1.39 MW for ramping up (Inc) and increased by 6.32 MW for ramping down (Dec), on average. 


\section{F.4.5.2 April 2020}
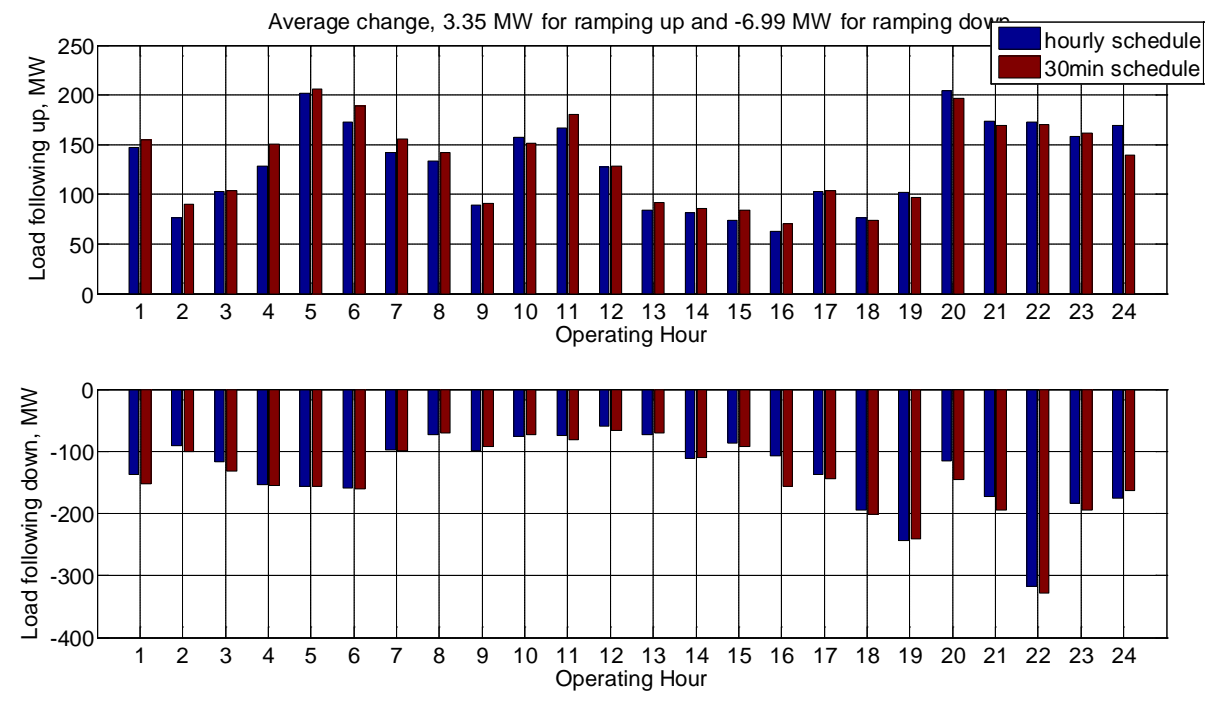

Figure F.38. Impact on PSE Load Following, 95\% CL, April 2020

Table F.29. Difference between 30-Minute Schedule and Hourly Schedule in Figure F.38 (MW)

\begin{tabular}{|l|l|l|l|l|l|l|l|l|l|l|l|l|l|l|l|l|l|l|l|l|l|l|l|l|}
\hline Operating Hour & $\mathbf{1}$ & $\mathbf{2}$ & $\mathbf{3}$ & $\mathbf{4}$ & $\mathbf{5}$ & $\mathbf{6}$ & $\mathbf{7}$ & $\mathbf{8}$ & $\mathbf{9}$ & 10 & 11 & 12 & 13 & 14 & 15 & $\mathbf{1 6}$ & 17 & 18 & 19 & $\mathbf{2 0}$ & $\mathbf{2 1}$ & $\mathbf{2 2}$ & $\mathbf{2 3}$ & $\mathbf{2 4}$ \\
\hline Difference, up & 8 & 13 & 1 & 23 & 4 & 16 & 13 & 9 & 2 & -6 & 13 & 1 & 7 & 4 & 10 & 8 & 1 & -3 & -5 & -8 & -4 & -2 & 3 & -29 \\
\hline Difference, down & -14 & -10 & -14 & -1 & 0 & -1 & -1 & 4 & 7 & 2 & -7 & -7 & 3 & 1 & -5 & -50 & -7 & -7 & 3 & -30 & -22 & -11 & -12 & 11 \\
\hline
\end{tabular}

The load-following requirement is increased by 3.35 MW for ramping up (Inc) and increased by 6.99 MW for ramping down (Dec), on average. 


\section{F.4.5.3 August 2020}
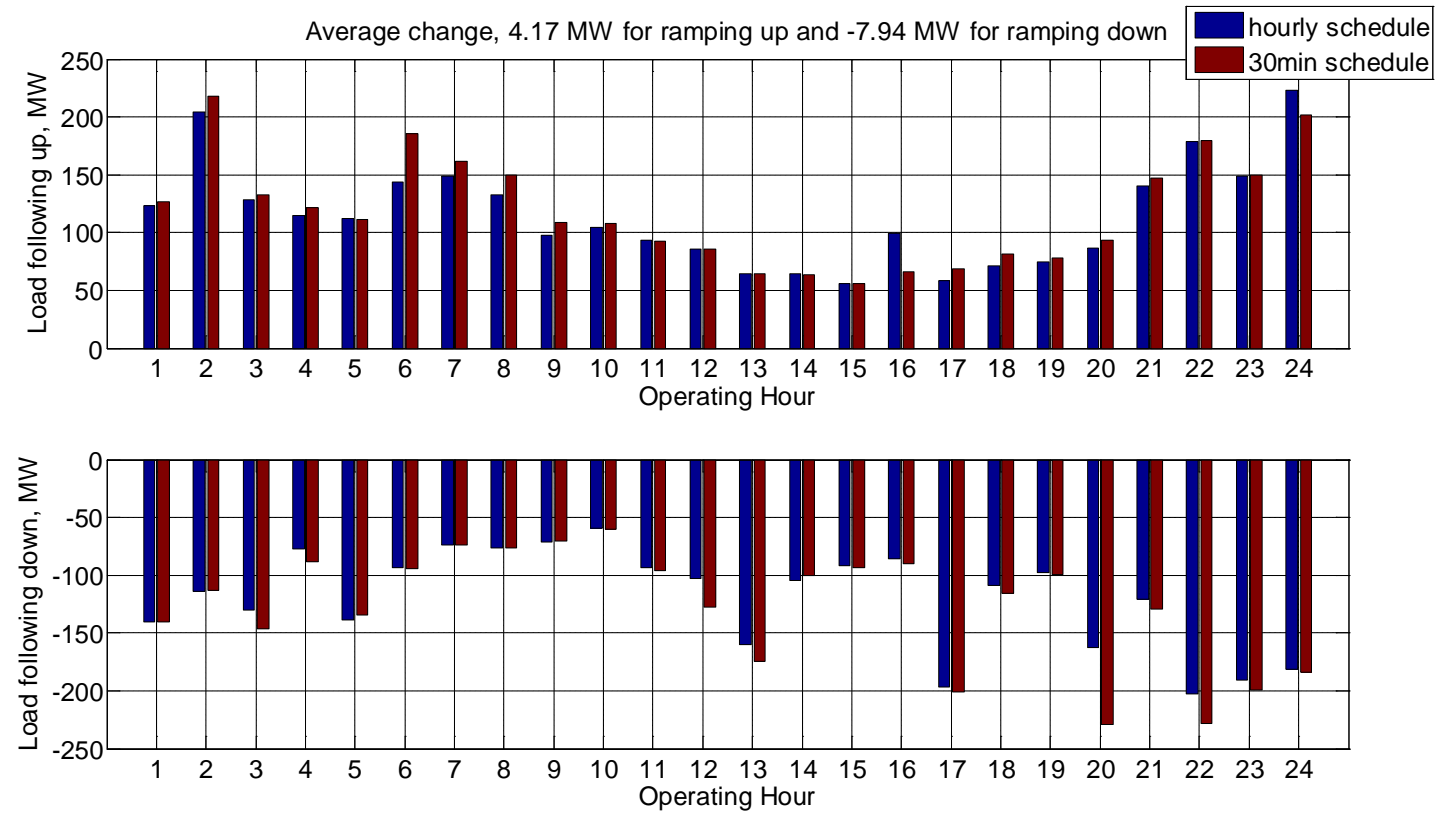

Figure F.39. Impact on PSE Load Following, 95\% CL, August 2020

Table F.30. Difference between 30-Minute Schedule and Hourly Schedule in Figure F.39 (MW)

\begin{tabular}{|l|r|r|r|r|r|r|r|r|r|r|r|r|r|r|r|r|r|r|r|r|r|r|r|r|}
\hline Operating Hour & $\mathbf{1}$ & $\mathbf{2}$ & $\mathbf{3}$ & $\mathbf{4}$ & $\mathbf{5}$ & $\mathbf{6}$ & $\mathbf{7}$ & $\mathbf{8}$ & $\mathbf{9}$ & $\mathbf{1 0}$ & $\mathbf{1 1}$ & $\mathbf{1 2}$ & $\mathbf{1 3}$ & $\mathbf{1 4}$ & $\mathbf{1 5}$ & $\mathbf{1 6}$ & $\mathbf{1 7}$ & $\mathbf{1 8}$ & $\mathbf{1 9}$ & $\mathbf{2 0}$ & 21 & $\mathbf{2 2}$ & 23 & $\mathbf{2 4}$ \\
\hline Difference, up & 3 & 13 & 4 & $\mathbf{7}$ & -1 & 42 & 13 & 18 & 11 & 4 & -1 & 0 & 0 & -1 & 0 & -33 & 10 & 10 & 3 & 8 & $\mathbf{7}$ & 1 & 1 & -21 \\
\hline Difference, down & 0 & 0 & -16 & -12 & 5 & -1 & 0 & 0 & 1 & 0 & -3 & -25 & -15 & 4 & -1 & -4 & -4 & -7 & -2 & -67 & -8 & -26 & -9 & -3 \\
\hline
\end{tabular}

The load-following requirement is increased by 4.17 MW for ramping up (Inc) and increased by 7.94 MW for ramping down (Dec), on average. 


\section{F.4.6 Impact on PSE Load Following with 99.5\% Confidence Level}

\section{F.4.6.1 January 2020}
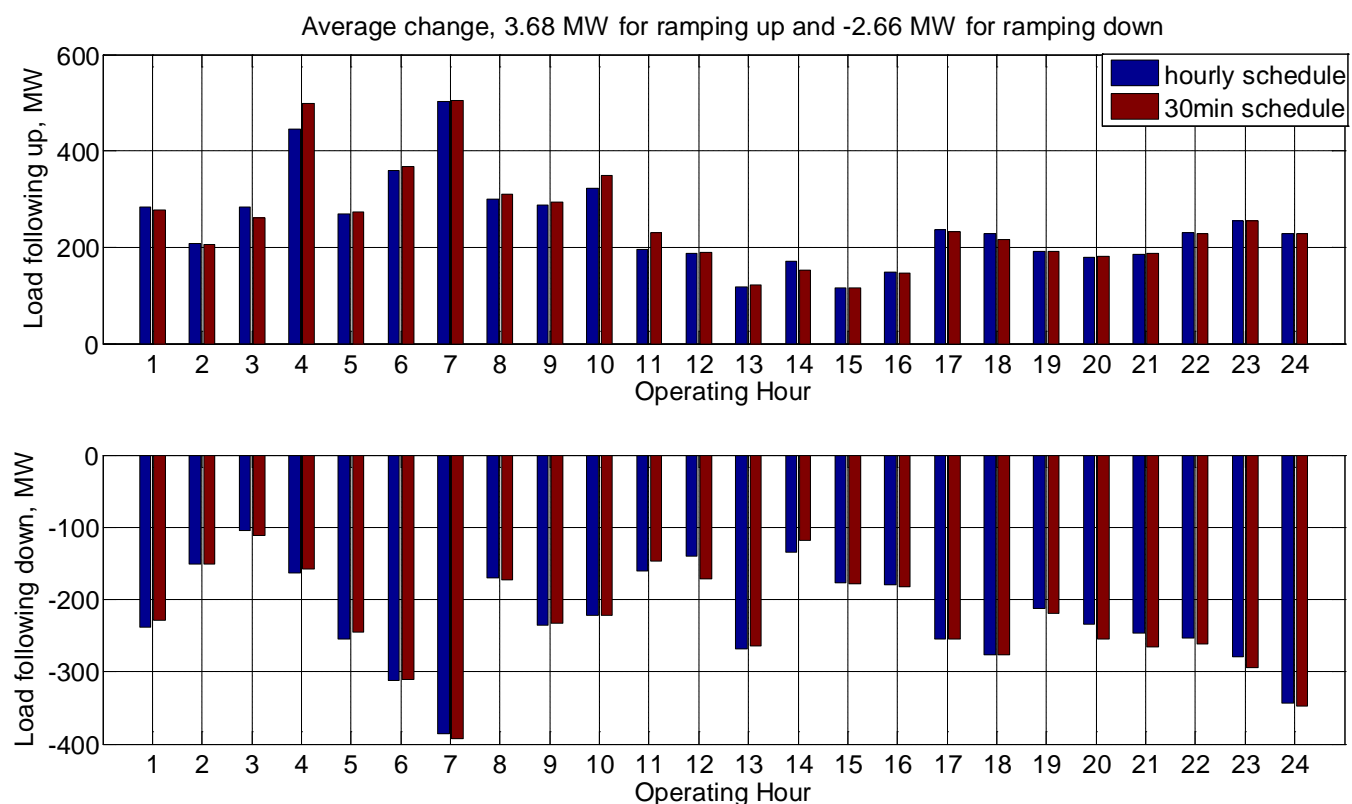

Figure F.40. Impact on PSE Load Following, 99.5\% CL, January 2020

Table F.31. Difference between 30-Minute Schedule and Hourly Schedule in Figure F.40Error! Reference source not found. (MW)

\begin{tabular}{|l|r|r|r|r|r|r|r|r|r|r|r|r|r|r|r|r|r|r|r|r|r|r|r|r|}
\hline Operating Hour & $\mathbf{1}$ & $\mathbf{2}$ & $\mathbf{3}$ & $\mathbf{4}$ & $\mathbf{5}$ & $\mathbf{6}$ & $\mathbf{7}$ & $\mathbf{8}$ & $\mathbf{9}$ & $\mathbf{1 0}$ & $\mathbf{1 1}$ & $\mathbf{1 2}$ & 13 & $\mathbf{1 4}$ & 15 & 16 & 17 & $\mathbf{1 8}$ & 19 & $\mathbf{2 0}$ & $\mathbf{2 1}$ & 22 & $\mathbf{2 3}$ & 24 \\
\hline Difference, up & -5 & -1 & -22 & 54 & 5 & 8 & 2 & 11 & 5 & 25 & 35 & 2 & 3 & -18 & 0 & -1 & -2 & -11 & -1 & 1 & 2 & -2 & 1 & -1 \\
\hline Difference, down & 9 & 0 & -6 & 6 & 9 & 2 & -7 & -3 & 3 & 0 & 13 & -31 & 5 & 16 & -2 & -3 & 0 & -1 & -7 & -20 & -19 & -9 & -15 & -4 \\
\hline
\end{tabular}

The load-following requirement is increased by 3.68 MW for ramping up (Inc) and increased by 2.66 MW for ramping down (Dec), on average. 


\section{F.4.6.2 April 2020}
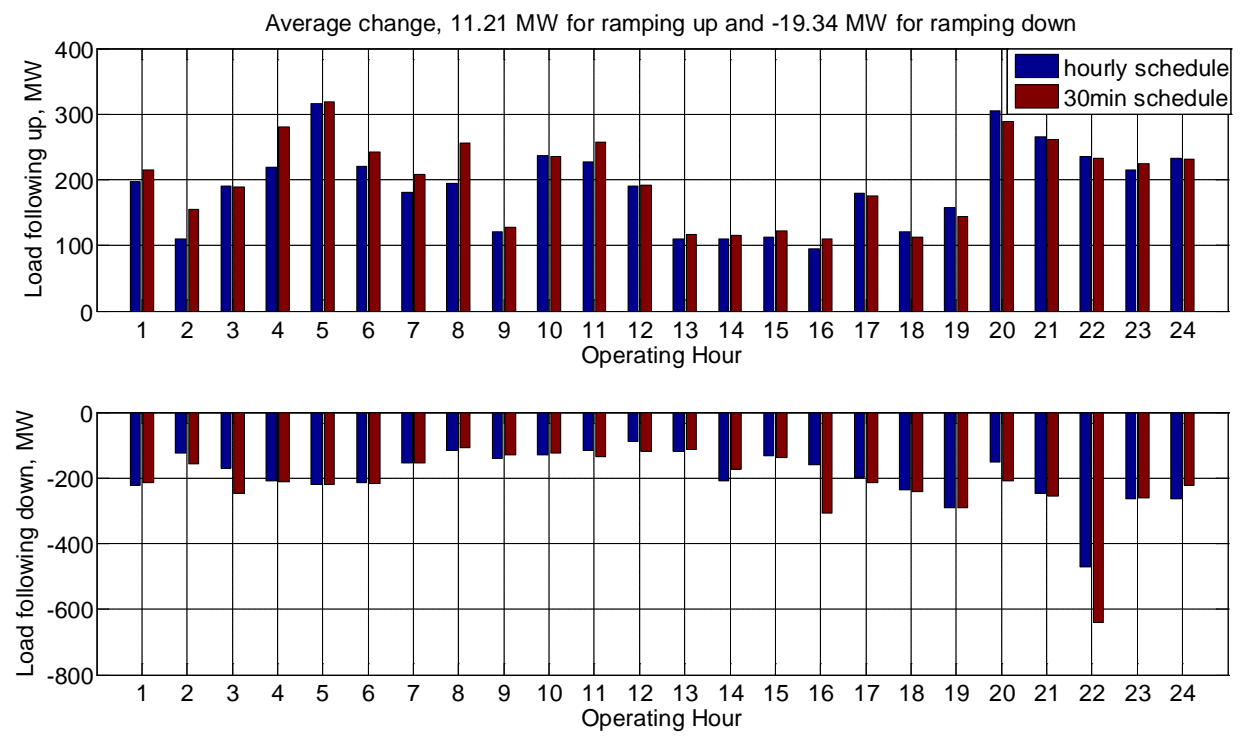

Figure F.41. Impact on PSE Load Following, 99.5\% CL, April 2020

Table F.32. Difference between 30-Minute Schedule and Hourly Schedule in Figure F.41 (MW)

\begin{tabular}{|l|r|r|r|r|r|r|r|r|r|r|r|r|r|r|r|r|r|r|r|r|r|r|r|r|}
\hline Operating Hour & $\mathbf{1}$ & $\mathbf{2}$ & $\mathbf{3}$ & $\mathbf{4}$ & $\mathbf{5}$ & $\mathbf{6}$ & $\mathbf{7}$ & $\mathbf{8}$ & $\mathbf{9}$ & 10 & $\mathbf{1 1}$ & $\mathbf{1 2}$ & 13 & 14 & 15 & $\mathbf{1 6}$ & $\mathbf{1 7}$ & 18 & $\mathbf{1 9}$ & $\mathbf{2 0}$ & 21 & $\mathbf{2 2}$ & 23 & 24 \\
\hline Difference, up & 18 & 45 & -1 & 61 & 3 & 22 & 26 & 61 & 7 & -1 & 31 & 2 & 7 & 5 & 10 & 15 & -3 & -8 & -14 & -16 & -5 & -3 & 9 & -2 \\
\hline Difference, down & 7 & -32 & -75 & -2 & 0 & -2 & -1 & 9 & 10 & 4 & -17 & -29 & 5 & 34 & -7 & -148 & -18 & -6 & 0 & -59 & -9 & -171 & 2 & 42 \\
\hline
\end{tabular}

The load-following requirement is increased by 11.21 MW for ramping up (Inc) and increased by 19.34 MW for ramping down (Dec), on average. 


\section{F.4.6.3 August 2020}
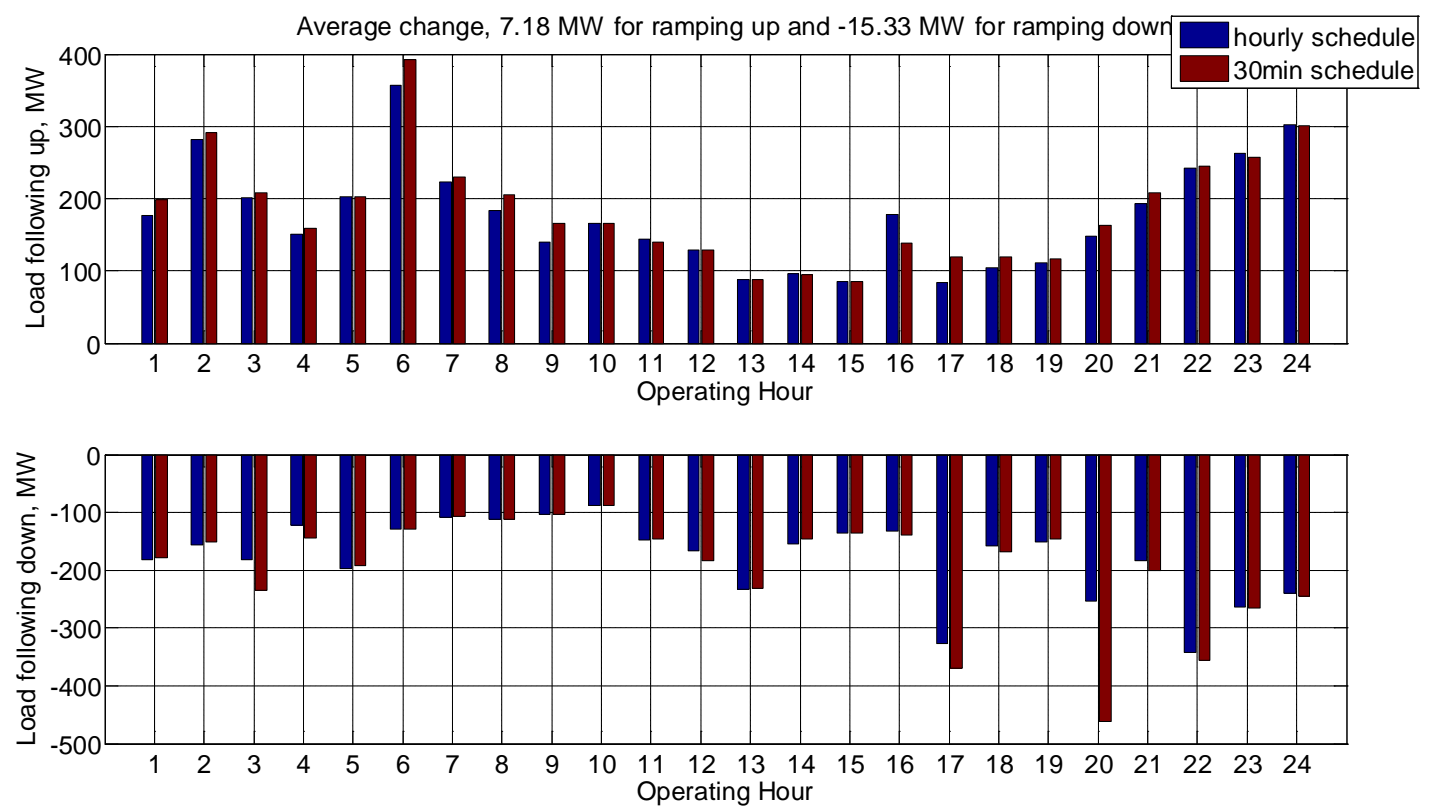

Figure F.42. Impact on PSE Load Following, 99.5\% CL, August 2020

Table F.33. Difference between 30-Minute Schedule and Hourly Schedule in Figure F.42 (MW)

\begin{tabular}{|l|r|r|r|r|r|r|r|r|r|r|r|r|r|r|r|r|r|r|r|r|r|r|r|r|}
\hline Operating Hour & $\mathbf{1}$ & $\mathbf{2}$ & $\mathbf{3}$ & $\mathbf{4}$ & $\mathbf{5}$ & $\mathbf{6}$ & $\mathbf{7}$ & $\mathbf{8}$ & $\mathbf{9}$ & 10 & 11 & $\mathbf{1 2}$ & 13 & 14 & 15 & $\mathbf{1 6}$ & $\mathbf{1 7}$ & 18 & 19 & $\mathbf{2 0}$ & 21 & 22 & 23 & 24 \\
\hline Difference, up & 23 & 11 & 7 & 8 & 0 & 36 & 6 & 22 & 26 & 0 & -3 & -1 & 0 & -1 & 0 & -40 & 35 & 14 & 6 & 14 & 14 & 2 & -5 & -1 \\
\hline Difference, down & 2 & 6 & -53 & -22 & 5 & 0 & 0 & 0 & 0 & 0 & 1 & -18 & 1 & 10 & 0 & -6 & -44 & -9 & 5 & -208 & -18 & -14 & -2 & -5 \\
\hline
\end{tabular}

The load-following requirement is increased by 7.18 MW for ramping up (Inc) and increased by 15.33 MW for ramping down (Dec), on average. 


\section{F.4.7 Impact on BCHA Load Following with 95\% Confidence Level}

\section{F.4.7.1 January 2020}
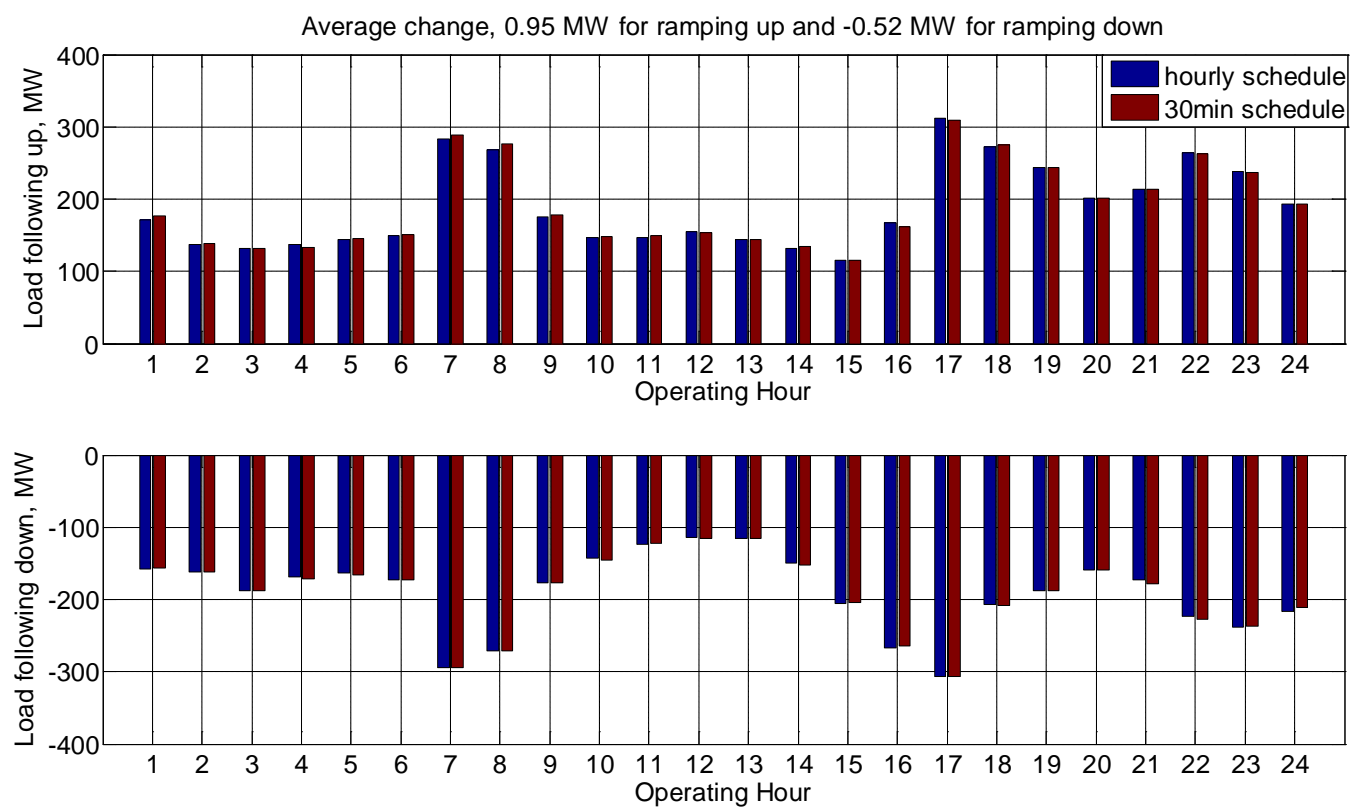

Figure F.43. Impact on BCHA Load Following, 95\% CL, January 2020

Table F.34. Difference between 30-Minute Schedule and Hourly Schedule in Figure F.43 (MW)

\begin{tabular}{|l|c|c|c|c|c|c|c|c|c|c|c|c|c|c|c|c|c|c|c|c|c|c|c|c|}
\hline Operating Hour & $\mathbf{1}$ & $\mathbf{2}$ & $\mathbf{3}$ & $\mathbf{4}$ & $\mathbf{5}$ & $\mathbf{6}$ & $\mathbf{7}$ & $\mathbf{8}$ & $\mathbf{9}$ & $\mathbf{1 0}$ & $\mathbf{1 1}$ & $\mathbf{1 2}$ & $\mathbf{1 3}$ & $\mathbf{1 4}$ & $\mathbf{1 5}$ & $\mathbf{1 6}$ & 17 & 18 & 19 & 20 & 21 & 22 & 23 & 24 \\
\hline Difference, up & 6 & 0 & 0 & -3 & 1 & 2 & 5 & 8 & 2 & 1 & 2 & -1 & 0 & 3 & -1 & -6 & -2 & 4 & 0 & 0 & 0 & -1 & 0 & 1 \\
\hline Difference, down & 1 & 0 & 0 & -4 & -3 & -1 & 0 & 0 & 0 & -2 & 2 & 0 & -1 & -3 & 1 & 2 & 0 & -1 & 0 & 0 & -6 & -4 & 0 & 6 \\
\hline
\end{tabular}

The load-following requirement is increased by $0.95 \mathrm{MW}$ for ramping up (Inc) and increased by 0.52 MW for ramping down (Dec), on average. 


\section{F.4.7.2 April 2020}
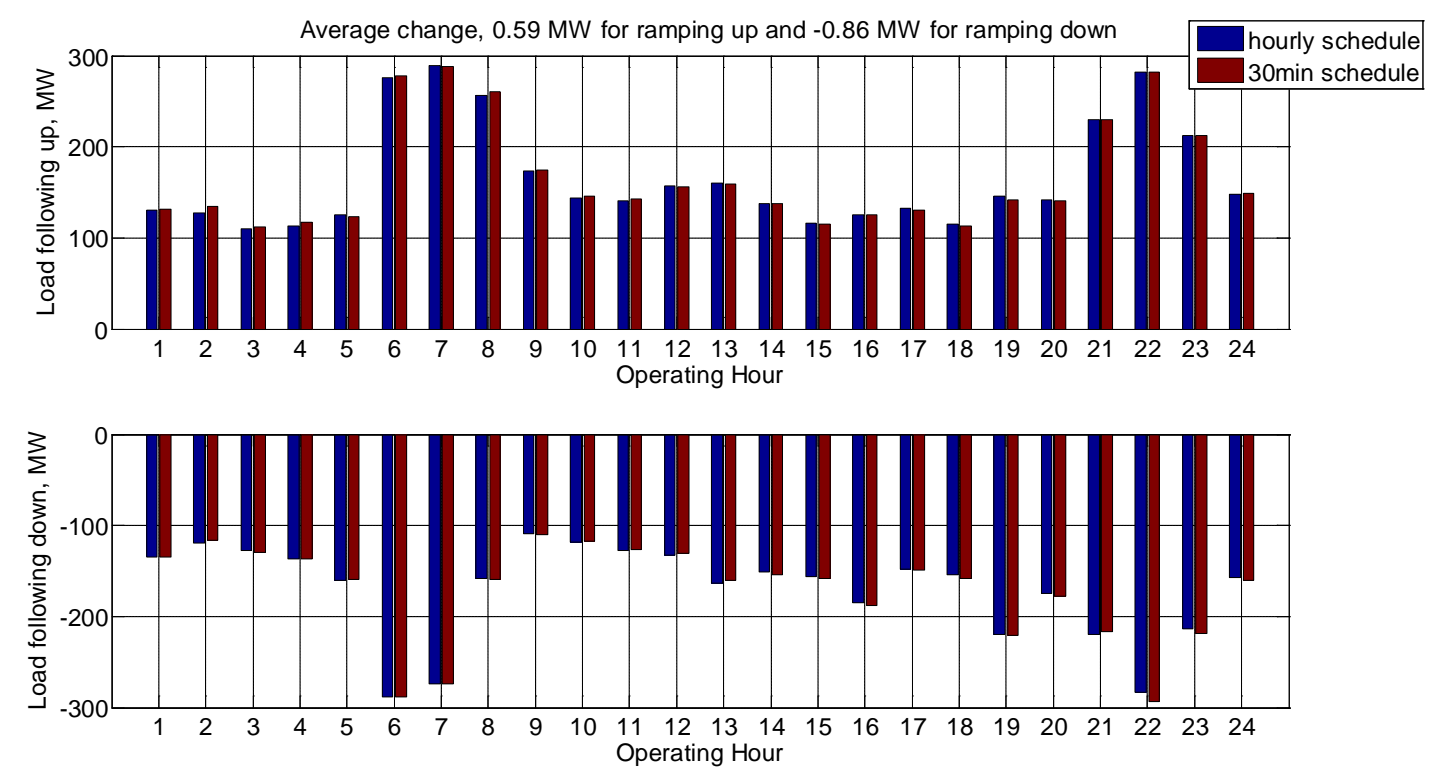

Figure F.44. Impact on BCHA Load Following, 95\% CL, April 2020

Table F.35. Difference between 30-Minute Schedule and Hourly Schedule in Figure F.44 (MW)

\begin{tabular}{|l|l|l|l|l|l|l|l|l|l|l|l|l|l|l|l|l|l|l|l|l|l|l|l|l|}
\hline Operating Hour & $\mathbf{1}$ & $\mathbf{2}$ & $\mathbf{3}$ & $\mathbf{4}$ & $\mathbf{5}$ & $\mathbf{6}$ & $\mathbf{7}$ & $\mathbf{8}$ & $\mathbf{9}$ & $\mathbf{1 0}$ & $\mathbf{1 1}$ & $\mathbf{1 2}$ & $\mathbf{1 3}$ & $\mathbf{1 4}$ & $\mathbf{1 5}$ & $\mathbf{1 6}$ & $\mathbf{1 7}$ & $\mathbf{1 8}$ & $\mathbf{1 9}$ & $\mathbf{2 0}$ & $\mathbf{2 1}$ & $\mathbf{2 2}$ & $\mathbf{2 3}$ & $\mathbf{2 4}$ \\
\hline Difference, up & 1 & 7 & 2 & 4 & -1 & 2 & -1 & 4 & 1 & 2 & 3 & -1 & 0 & 0 & -1 & 0 & -2 & -2 & -4 & 0 & 0 & 0 & 0 & 1 \\
\hline Difference, down & 0 & 3 & -1 & 1 & 2 & 0 & 0 & -1 & -1 & 1 & 2 & 3 & 3 & -3 & -2 & -3 & -1 & -3 & -1 & -3 & 3 & -10 & -5 & -3 \\
\hline
\end{tabular}

The load-following requirement is increased by 0.59 MW for ramping up (Inc) and increased by 0.86 MW for ramping down (Dec), on average. 


\section{F.4.7.3 August 2020}
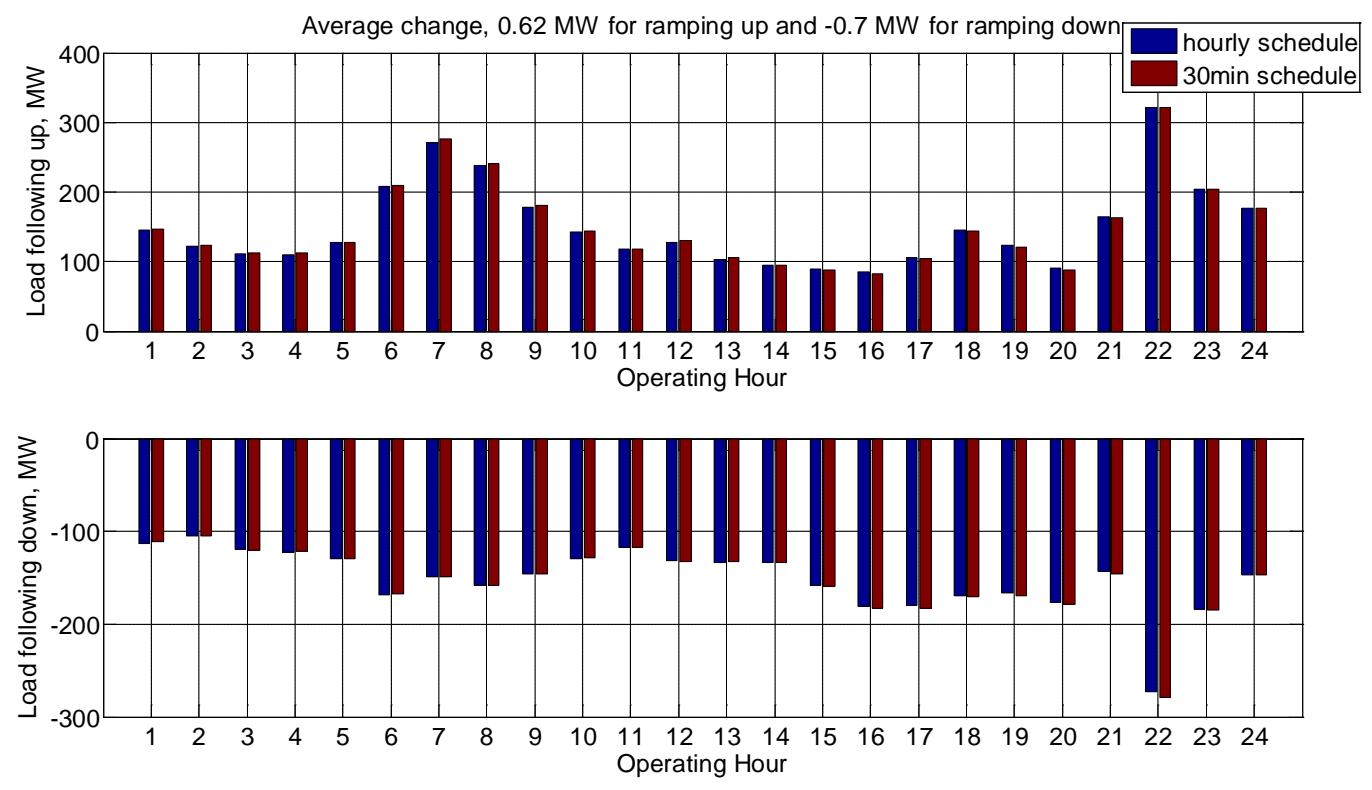

Figure F.45. Impact on BCHA Load Following, 95\% CL, August 2020

Table F.36. Difference between 30-Minute Schedule and Hourly Schedule in Figure F.45 (MW)

\begin{tabular}{|l|l|l|l|l|l|l|l|l|l|l|l|l|l|l|l|l|l|l|l|l|l|l|l|l|}
\hline Operating Hour & $\mathbf{1}$ & $\mathbf{2}$ & $\mathbf{3}$ & $\mathbf{4}$ & $\mathbf{5}$ & $\mathbf{6}$ & $\mathbf{7}$ & $\mathbf{8}$ & $\mathbf{9}$ & $\mathbf{1 0}$ & $\mathbf{1 1}$ & $\mathbf{1 2}$ & 13 & 14 & $\mathbf{1 5}$ & $\mathbf{1 6}$ & 17 & 18 & 19 & 20 & 21 & 22 & 23 & 24 \\
\hline Difference, up & 2 & 1 & 2 & 3 & 1 & 1 & 5 & 3 & 3 & 1 & 0 & 3 & 3 & 0 & -1 & -2 & -2 & 0 & -2 & -3 & -1 & 0 & 0 & 0 \\
\hline Difference, down & 2 & 1 & 0 & 1 & 0 & 0 & 0 & 0 & 1 & 0 & 0 & 0 & 1 & -1 & -1 & -2 & -4 & -1 & -3 & -1 & -3 & -6 & -1 & 0 \\
\hline
\end{tabular}

The load-following requirement is increased by $0.62 \mathrm{MW}$ for ramping up (Inc) and increased by 0.7 MW for ramping down (Dec), on average. 


\section{F.4.8 Impact on BCHA Load Following with 99.5\% Confidence Level}

\section{F.4.8.1 January 2020}
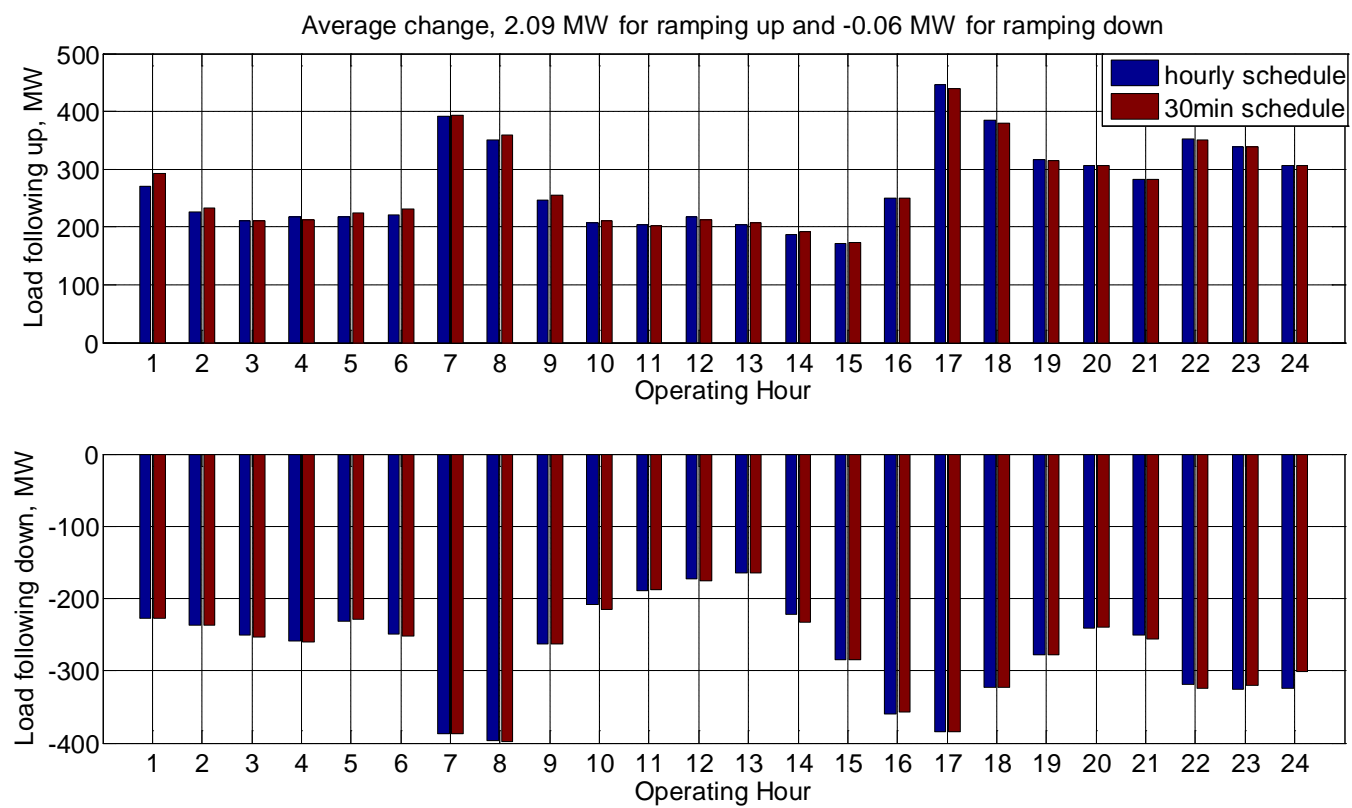

Figure F.46. Impact on BCHA Load Following, 99.5\% CL, January 2020

Table F.37. Difference between 30-Minute Schedule and Hourly Schedule in Figure F.46 (MW)

\begin{tabular}{|l|c|c|c|c|c|c|c|c|c|c|c|c|c|c|c|c|c|c|c|c|c|c|c|c|}
\hline Operating Hour & $\mathbf{1}$ & $\mathbf{2}$ & $\mathbf{3}$ & $\mathbf{4}$ & $\mathbf{5}$ & $\mathbf{6}$ & $\mathbf{7}$ & $\mathbf{8}$ & $\mathbf{9}$ & $\mathbf{1 0}$ & $\mathbf{1 1}$ & $\mathbf{1 2}$ & $\mathbf{1 3}$ & $\mathbf{1 4}$ & $\mathbf{1 5}$ & $\mathbf{1 6}$ & $\mathbf{1 7}$ & $\mathbf{1 8}$ & 19 & 20 & 21 & 22 & 23 & 24 \\
\hline Difference, up & 22 & 6 & 0 & -6 & 6 & 10 & 2 & 9 & 9 & 3 & 0 & -4 & 3 & 6 & 1 & 0 & -7 & -5 & 0 & 0 & 0 & -2 & -1 & 0 \\
\hline Difference, down & 1 & 0 & -3 & -2 & 3 & -2 & 0 & -1 & 0 & -6 & 1 & -3 & 0 & -11 & -1 & 4 & 0 & 0 & 0 & 1 & -5 & -5 & 5 & 23 \\
\hline
\end{tabular}

The load-following requirement is increased by 2.09 MW for ramping up (Inc) and increased by 0.06 MW for ramping down (Dec), on average. 


\section{F.4.8.2 April 2020}
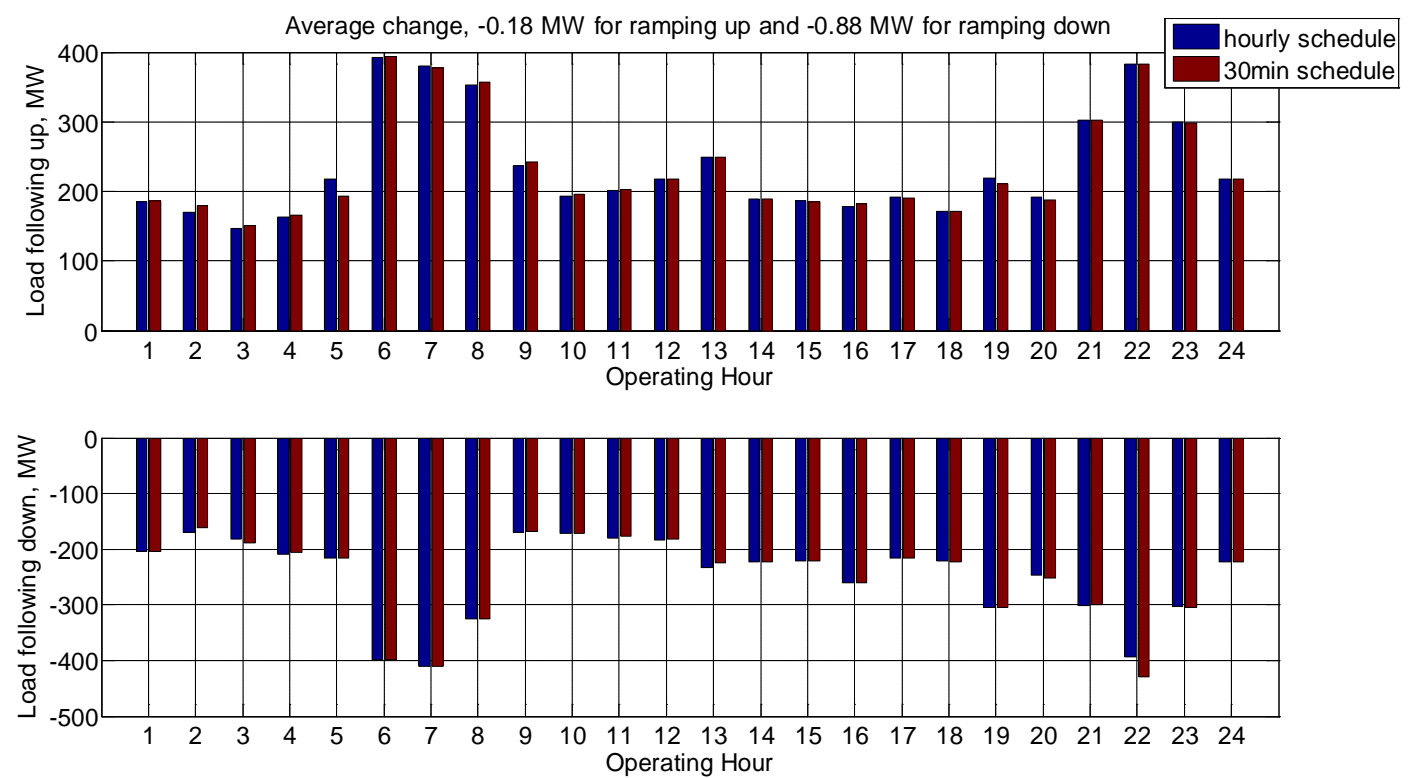

Figure F.47. Impact on BCHA Load Following, 99.5\% CL, April 2020

Table F.38. Difference between 30-Minute Schedule and Hourly Schedule in Figure F.47 (MW)

\begin{tabular}{|l|r|r|r|r|r|r|r|r|r|r|r|r|r|r|r|r|r|r|r|r|r|r|r|r|}
\hline Operating Hour & $\mathbf{1}$ & $\mathbf{2}$ & $\mathbf{3}$ & $\mathbf{4}$ & $\mathbf{5}$ & $\mathbf{6}$ & $\mathbf{7}$ & $\mathbf{8}$ & $\mathbf{9}$ & $\mathbf{1 0}$ & $\mathbf{1 1}$ & $\mathbf{1 2}$ & $\mathbf{1 3}$ & $\mathbf{1 4}$ & $\mathbf{1 5}$ & $\mathbf{1 6}$ & 17 & 18 & 19 & 20 & 21 & $\mathbf{2 2}$ & 23 & 24 \\
\hline Difference, up & 1 & 10 & 5 & 2 & -25 & 1 & -3 & 4 & 5 & 2 & 2 & 0 & -1 & 0 & 0 & 4 & -1 & 0 & -7 & -4 & 0 & 0 & -1 & 0 \\
\hline Difference, down & 1 & 10 & -7 & 3 & 1 & 0 & 0 & 1 & 2 & 0 & 2 & 1 & 9 & 0 & 0 & -1 & -1 & -2 & 0 & -5 & 3 & -37 & -3 & 1 \\
\hline
\end{tabular}

The load-following requirement is decreased by $0.18 \mathrm{MW}$ for ramping up (Inc) and increased by 0.88 MW for ramping down (Dec), on average. 


\section{F.4.8.3 August 2020}
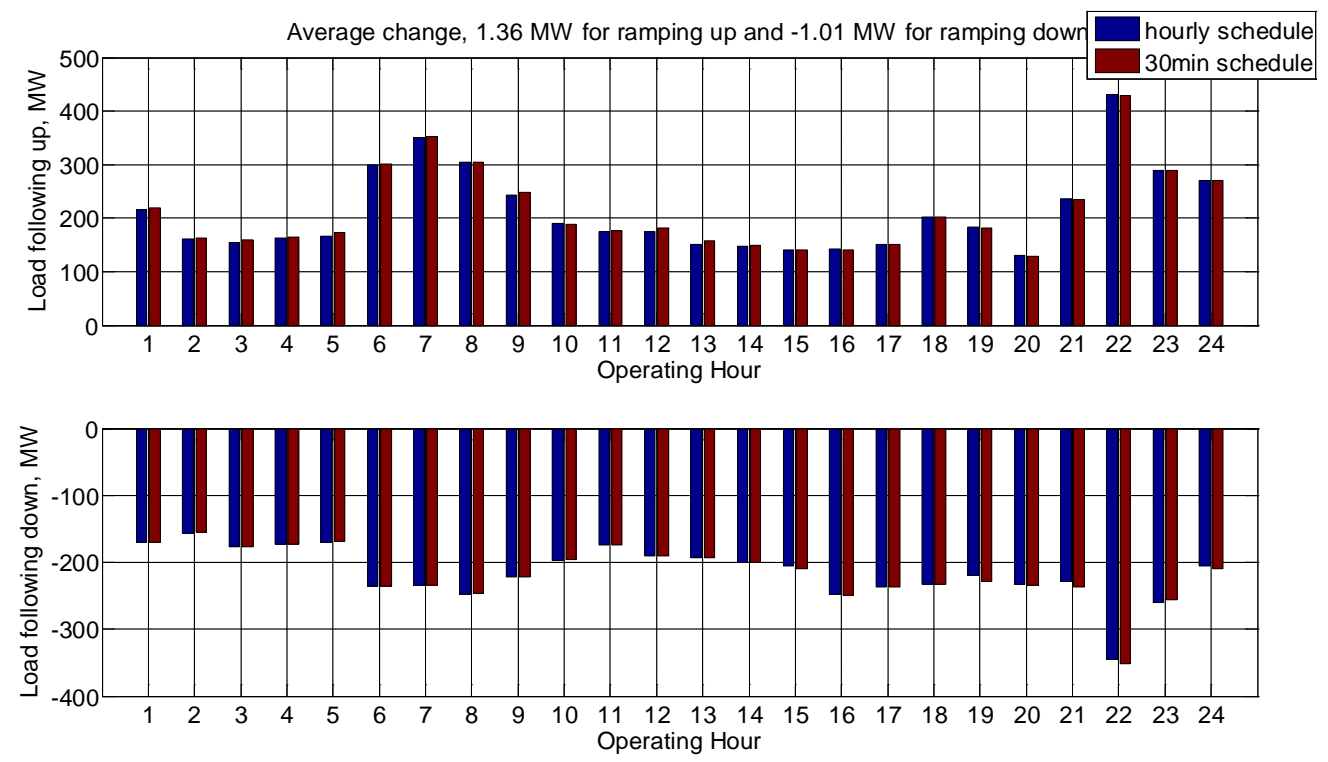

Figure F.48. Impact on BCHA Load Following, 99.5\% CL, August 2020

Table F.39. Difference between 30-Minute Schedule and Hourly Schedule in Figure F.48 (MW)

\begin{tabular}{|l|r|r|r|r|r|r|r|r|r|r|r|r|r|r|r|r|r|r|r|r|r|r|r|r|}
\hline Operating Hour & $\mathbf{1}$ & $\mathbf{2}$ & $\mathbf{3}$ & $\mathbf{4}$ & $\mathbf{5}$ & $\mathbf{6}$ & $\mathbf{7}$ & $\mathbf{8}$ & $\mathbf{9}$ & $\mathbf{1 0}$ & 11 & 12 & 13 & 14 & $\mathbf{1 5}$ & $\mathbf{1 6}$ & $\mathbf{1 7}$ & 18 & $\mathbf{1 9}$ & $\mathbf{2 0}$ & $\mathbf{2 1}$ & $\mathbf{2 2}$ & 23 & $\mathbf{2 4}$ \\
\hline Difference, up & 3 & 2 & 5 & 1 & 7 & 2 & 2 & 1 & 5 & -2 & 3 & 6 & 6 & 0 & 0 & -3 & 0 & 0 & -1 & -2 & -1 & -2 & 1 & 0 \\
\hline Difference, down & 0 & 0 & 0 & 0 & 1 & 0 & 1 & 1 & 0 & 2 & 0 & 0 & 0 & 0 & -4 & -2 & -1 & 0 & -9 & -1 & -8 & -6 & 5 & -4 \\
\hline
\end{tabular}

The load-following requirement is increased by 1.36 MW for ramping up (Inc) and increased by 1.01 MW for ramping down (Dec), on average. 


\section{F.4.9 Impact on TID Load Following with 95\% Confidence Level}

\section{F.4.9.1 January 2020}
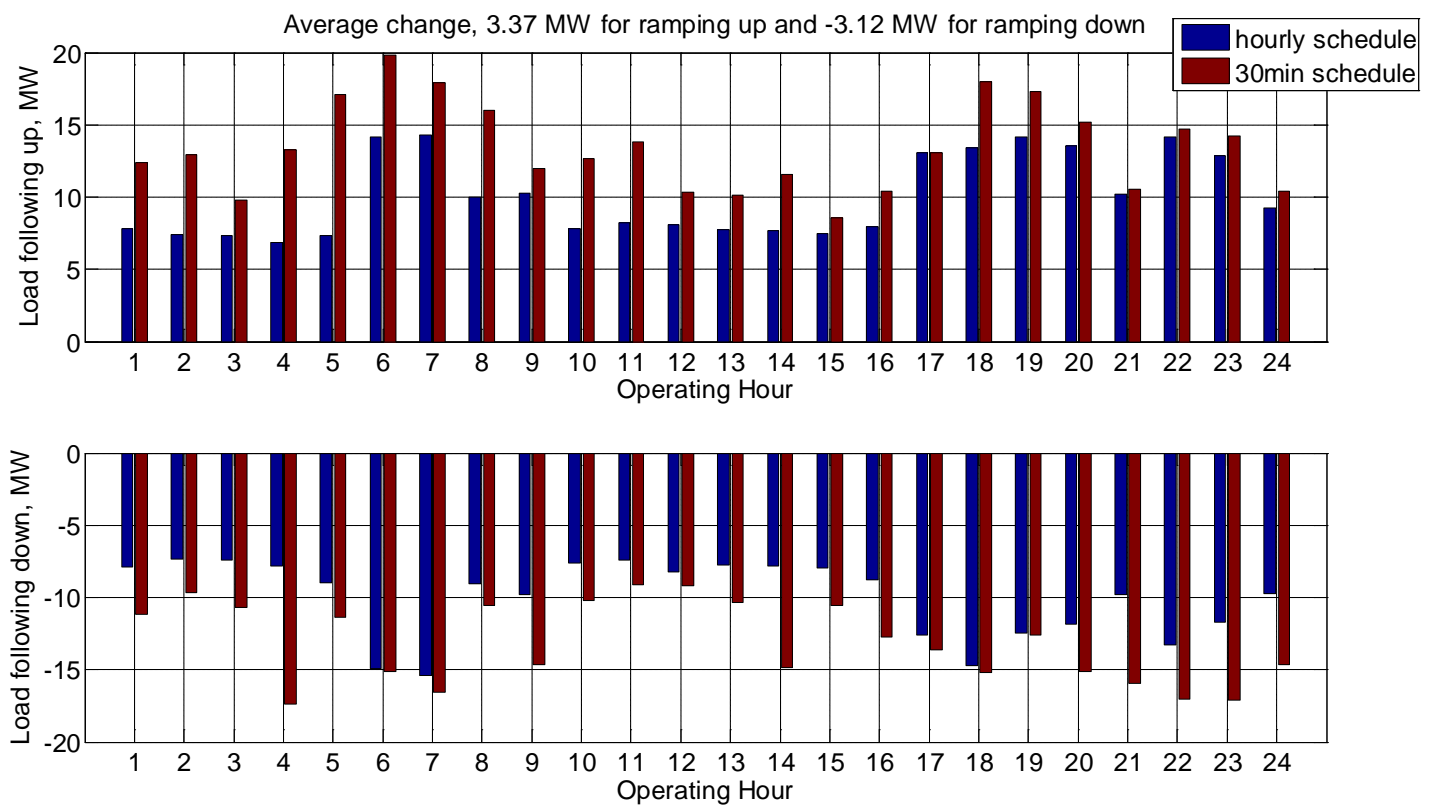

Figure F.49. Impact on TID Load Following, 95\% CL, January 2020

Table F.40. Difference between 30-Minute Schedule and Hourly schedule in Figure F.49 (MW)

\begin{tabular}{|l|c|c|c|c|c|c|c|c|c|c|c|c|c|c|c|c|c|c|c|c|c|c|c|c|}
\hline Operating Hour & $\mathbf{1}$ & $\mathbf{2}$ & $\mathbf{3}$ & $\mathbf{4}$ & $\mathbf{5}$ & $\mathbf{6}$ & $\mathbf{7}$ & $\mathbf{8}$ & $\mathbf{9}$ & 10 & 11 & 12 & 13 & 14 & 15 & 16 & 17 & 18 & 19 & 20 & 21 & 22 & 23 & 24 \\
\hline Difference, up & 5 & 6 & 2 & 6 & 10 & 6 & 4 & 6 & 2 & 5 & 6 & 2 & 2 & 4 & 1 & 2 & 0 & 5 & 3 & 2 & 0 & 1 & 1 & 1 \\
\hline Difference, down & -3 & -2 & -3 & -10 & -2 & 0 & -1 & -1 & -5 & -3 & -2 & -1 & -3 & -7 & -3 & -4 & -1 & 0 & 0 & -3 & -6 & -4 & -5 & -5 \\
\hline
\end{tabular}

The load-following requirement is increased by 3.37 MW for ramping up (Inc) and increased by 3.12 MW for ramping down (Dec), on average. 


\section{F.4.9.2 April 2020}
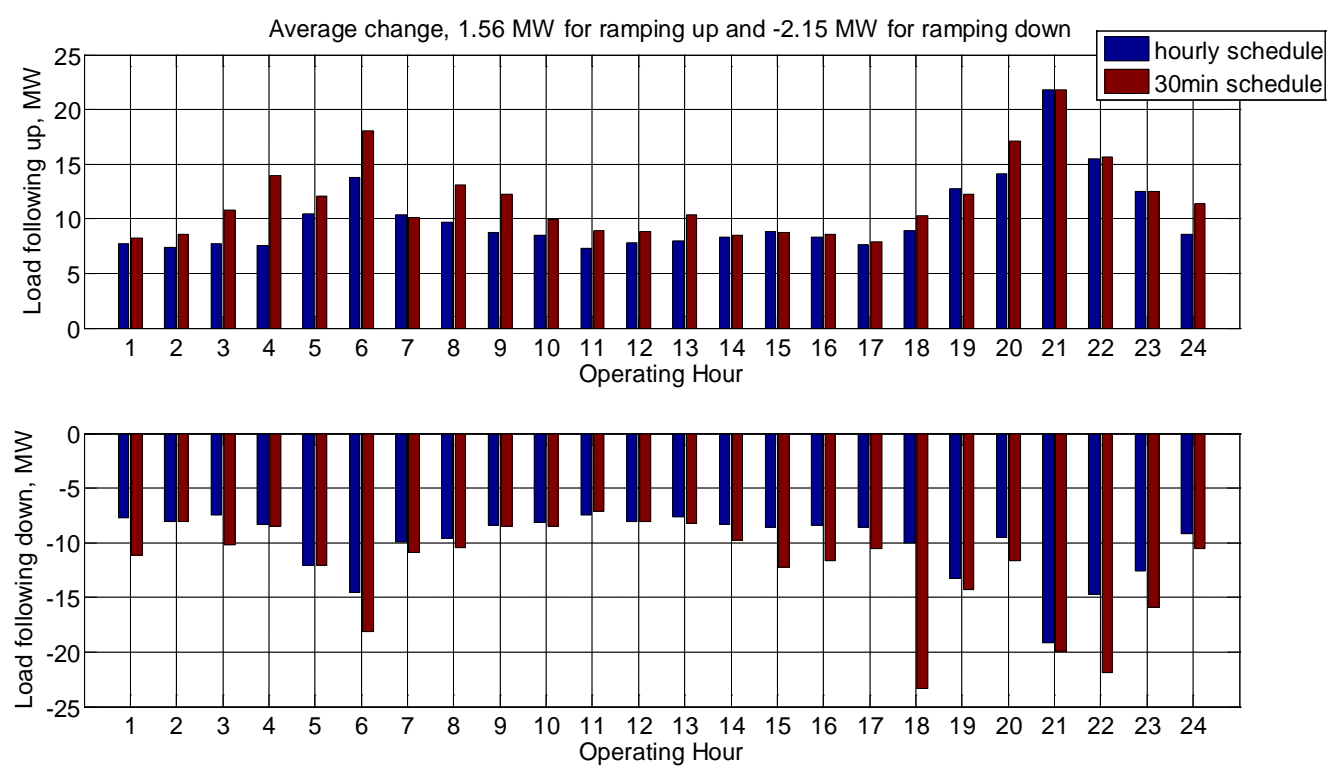

Figure F.50. Impact on TID Load Following, 95\% CL, April 2020

Table F.41. Difference between 30-Minute Schedule and Hourly Schedule in Figure F.50 (MW)

\begin{tabular}{|l|c|c|c|c|c|c|c|c|c|c|c|c|c|c|c|c|c|c|c|c|c|c|c|c|}
\hline Operating Hour & $\mathbf{1}$ & $\mathbf{2}$ & $\mathbf{3}$ & $\mathbf{4}$ & $\mathbf{5}$ & $\mathbf{6}$ & $\mathbf{7}$ & $\mathbf{8}$ & $\mathbf{9}$ & $\mathbf{1 0}$ & $\mathbf{1 1}$ & $\mathbf{1 2}$ & $\mathbf{1 3}$ & $\mathbf{1 4}$ & $\mathbf{1 5}$ & $\mathbf{1 6}$ & $\mathbf{1 7}$ & $\mathbf{1 8}$ & $\mathbf{1 9}$ & $\mathbf{2 0}$ & $\mathbf{2 1}$ & $\mathbf{2 2}$ & $\mathbf{2 3}$ & $\mathbf{2 4}$ \\
\hline Difference, up & 0 & 1 & 3 & 6 & 2 & 4 & 0 & 3 & 3 & 1 & 2 & 1 & 2 & 0 & 0 & 0 & 0 & 1 & -1 & 3 & 0 & 0 & 0 & 3 \\
\hline Difference, down & -3 & 0 & -3 & 0 & 0 & -4 & -1 & -1 & 0 & 0 & 0 & 0 & -1 & -1 & -4 & -3 & -2 & -13 & -1 & -2 & -1 & -7 & -3 & -1 \\
\hline
\end{tabular}

The load-following requirement is increased by 1.56 MW for ramping up (Inc) and increased by 2.15 MW for ramping down (Dec), on average. 


\section{F.4.9.3 August 2020}
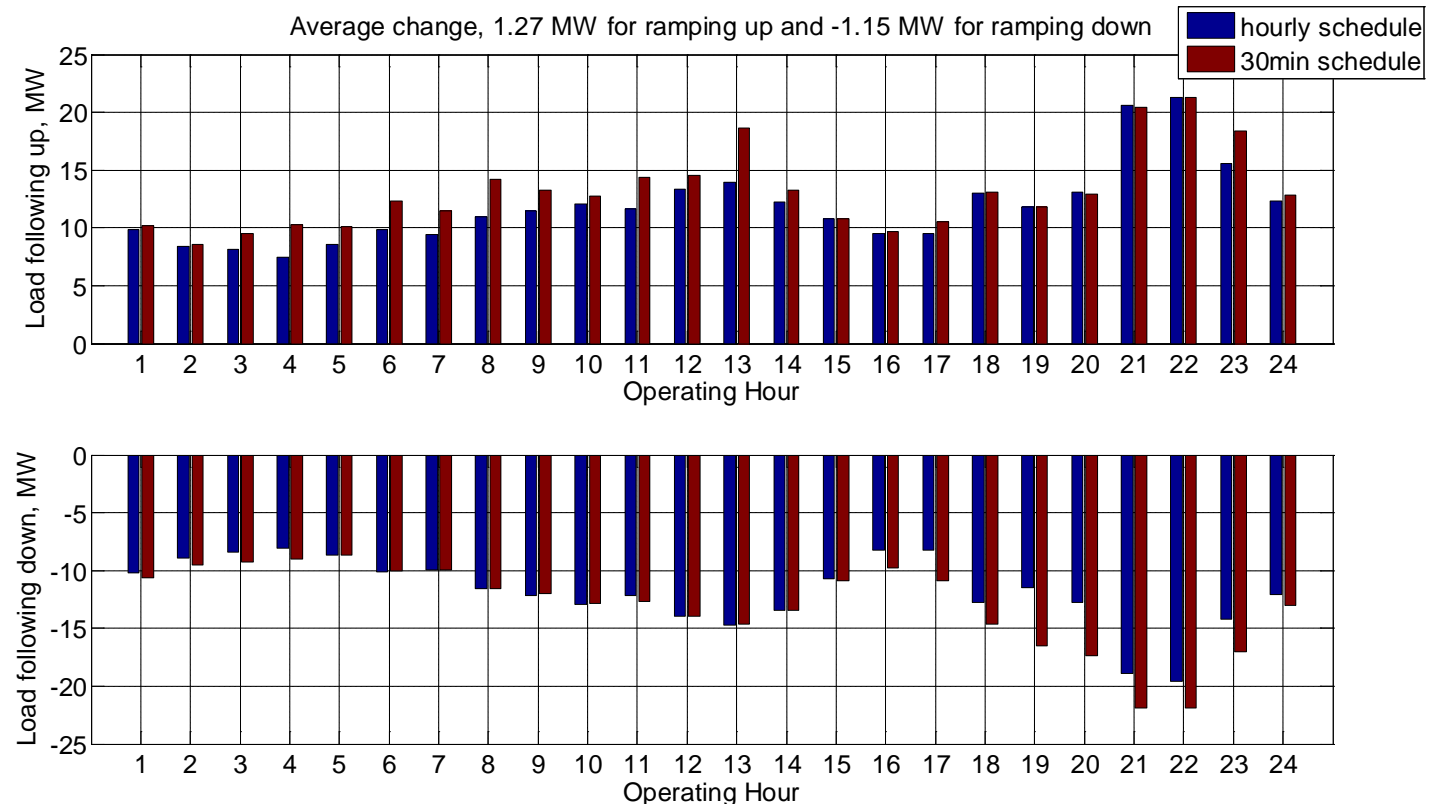

Figure F.51. Impact on TID Load Following, 95\% CL, August 2020

Table F.42. Difference between 30-Minute Schedule and Hourly Schedule in Figure F.51 (MW)

\begin{tabular}{|l|r|r|r|r|r|r|r|r|r|r|r|r|r|r|r|r|r|r|r|r|r|r|r|r|}
\hline Operating Hour & $\mathbf{1}$ & $\mathbf{2}$ & $\mathbf{3}$ & $\mathbf{4}$ & $\mathbf{5}$ & $\mathbf{6}$ & $\mathbf{7}$ & $\mathbf{8}$ & $\mathbf{9}$ & $\mathbf{1 0}$ & 11 & 12 & 13 & 14 & 15 & 16 & 17 & 18 & 19 & 20 & 21 & 22 & 23 & 24 \\
\hline Difference, up & 0 & 0 & 1 & 3 & 2 & 2 & 2 & 3 & 2 & 1 & 3 & 1 & 5 & 1 & 0 & 0 & 1 & 0 & 0 & 0 & 0 & 0 & 3 & 1 \\
\hline Difference, down & 0 & -1 & -1 & -1 & 0 & 0 & 0 & 0 & 0 & 0 & -1 & 0 & 0 & 0 & 0 & -2 & -3 & -2 & -5 & -5 & -3 & -2 & -3 & -1 \\
\hline
\end{tabular}

The load-following requirement is increased by 1.27 MW for ramping up (Inc) and increased by 1.15 MW for ramping down (Dec), on average. 


\section{F.4.10 Impact on TID Load Following with $99.5 \%$ Confidence Level}

\section{F.4.10.1 January 2020}
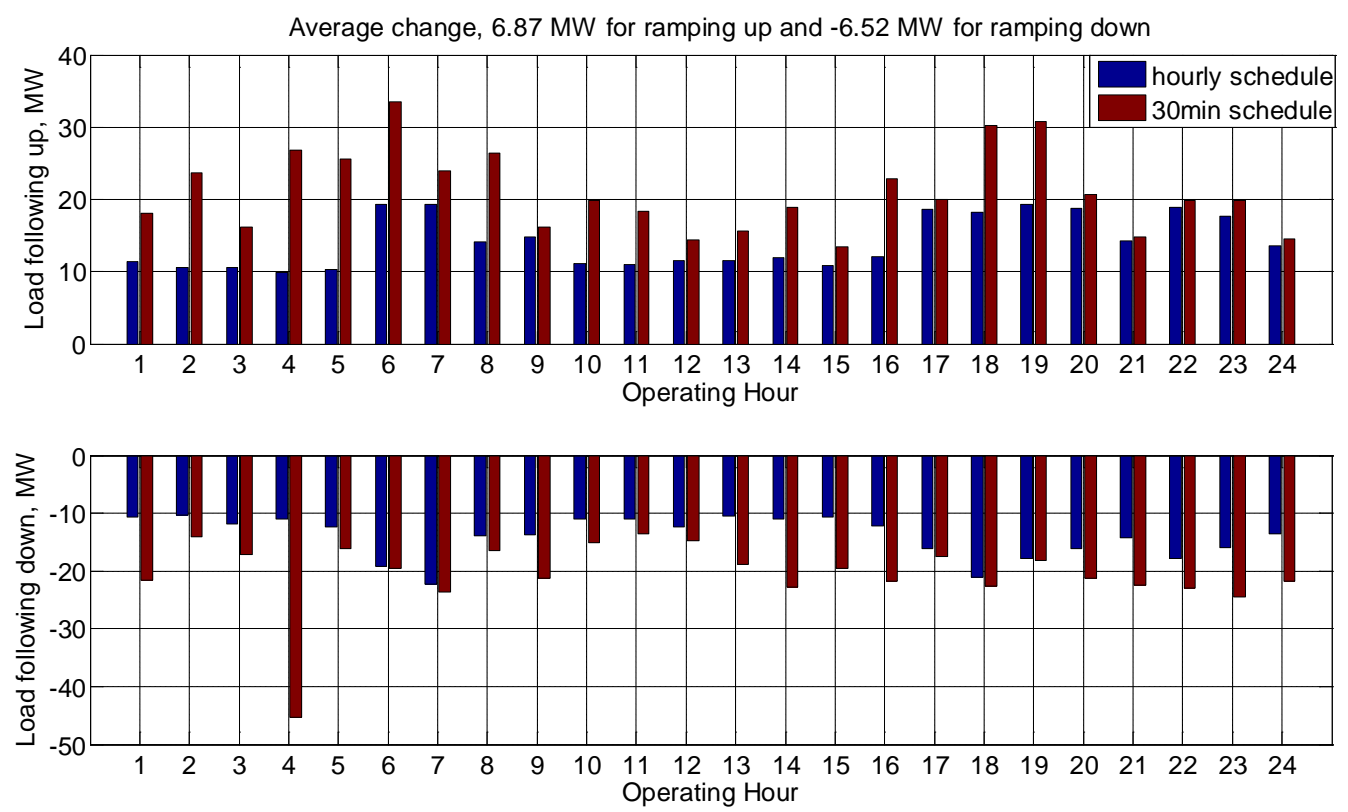

Figure F.52. Impact on TID Load Following, 99.5\% CL, January 2020

Table F.43. Difference between 30-Minute Schedule and Hourly Schedule in Figure F.52 (MW)

\begin{tabular}{|l|r|r|r|r|r|r|r|r|r|r|r|r|r|r|r|r|r|r|r|r|r|r|r|r|}
\hline Operating Hour & $\mathbf{1}$ & $\mathbf{2}$ & $\mathbf{3}$ & $\mathbf{4}$ & $\mathbf{5}$ & $\mathbf{6}$ & $\mathbf{7}$ & $\mathbf{8}$ & $\mathbf{9}$ & $\mathbf{1 0}$ & $\mathbf{1 1}$ & $\mathbf{1 2}$ & $\mathbf{1 3}$ & $\mathbf{1 4}$ & $\mathbf{1 5}$ & $\mathbf{1 6}$ & 17 & 18 & 19 & 20 & 21 & 22 & 23 & 24 \\
\hline Difference, up & 7 & 13 & 6 & 17 & 15 & 14 & 5 & 12 & 1 & 9 & 7 & 3 & 4 & 7 & 3 & 11 & 1 & 12 & 11 & 2 & 1 & 1 & 2 & 1 \\
\hline Difference, down & -11 & -4 & -5 & -34 & -4 & 0 & -1 & -3 & -7 & -4 & -3 & -2 & -8 & -12 & -9 & -10 & -1 & -1 & -1 & -5 & -8 & -5 & -9 & -8 \\
\hline
\end{tabular}

The load-following requirement is increased by 6.87 MW for ramping up (Inc) and increased by 6.52 MW for ramping down (Dec), on average. 


\section{F.4.10.2 April 2020}
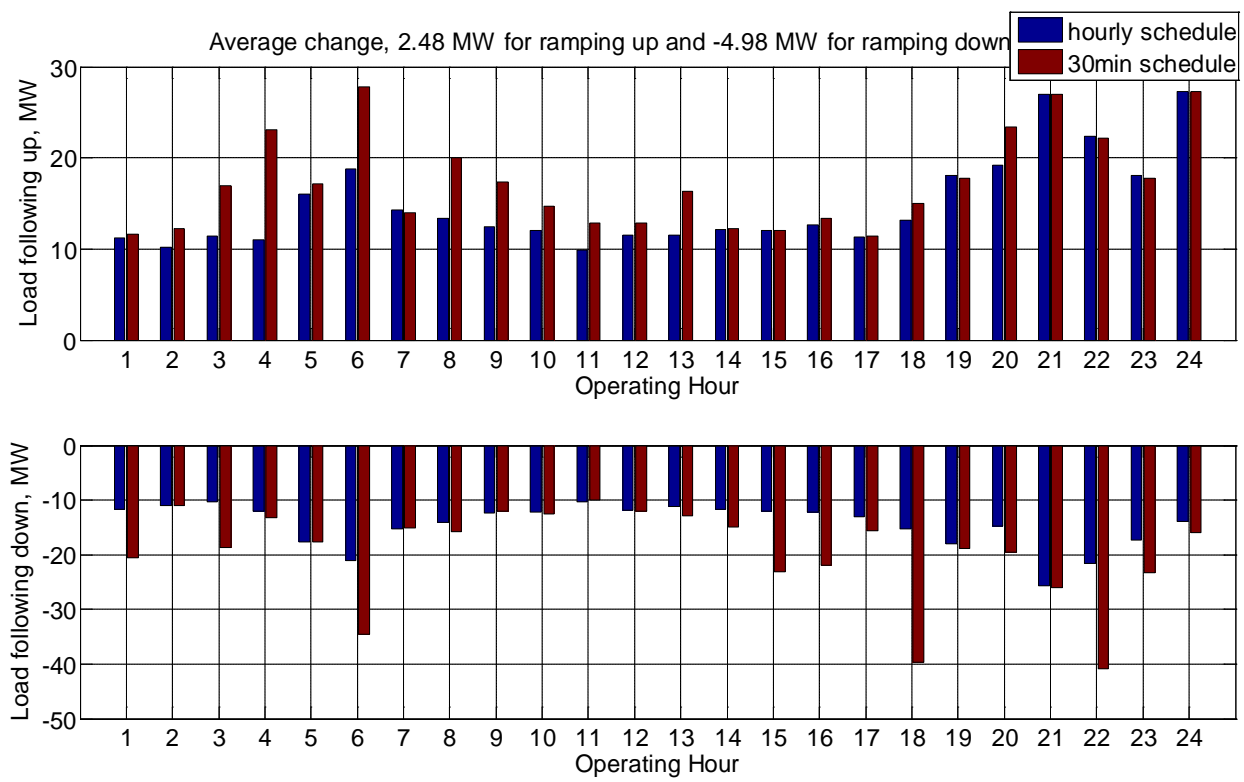

Figure F.53. Impact on TID Load Following, 99.5\% CL, April 2020

Table F.44. Difference between 30-Minute Schedule and Hourly Schedule in Figure F.53 (MW)

\begin{tabular}{|l|r|r|r|r|r|r|r|r|r|r|r|r|r|r|r|r|r|r|r|r|r|r|r|r|}
\hline Operating Hour & $\mathbf{1}$ & $\mathbf{2}$ & $\mathbf{3}$ & $\mathbf{4}$ & $\mathbf{5}$ & $\mathbf{6}$ & $\mathbf{7}$ & $\mathbf{8}$ & $\mathbf{9}$ & 10 & 11 & 12 & 13 & 14 & $\mathbf{1 5}$ & $\mathbf{1 6}$ & 17 & $\mathbf{1 8}$ & 19 & 20 & 21 & $\mathbf{2 2}$ & 23 & 24 \\
\hline Difference, up & 0 & 2 & 6 & 12 & 1 & 9 & 0 & 7 & 5 & 3 & 3 & 1 & 5 & 0 & 0 & 1 & 0 & 2 & 0 & 4 & 0 & 0 & 0 & 0 \\
\hline Difference, down & -9 & 0 & -8 & -1 & 0 & -14 & 0 & -2 & 0 & 0 & 0 & 0 & -2 & -3 & -11 & -10 & -3 & -24 & -1 & -5 & 0 & -19 & -6 & -2 \\
\hline
\end{tabular}

The load-following requirement is increased by 2.48 MW for ramping up (Inc) and increased by 4.98 MW for ramping down (Dec), on average. 


\section{F.4.10.3 August 2020}
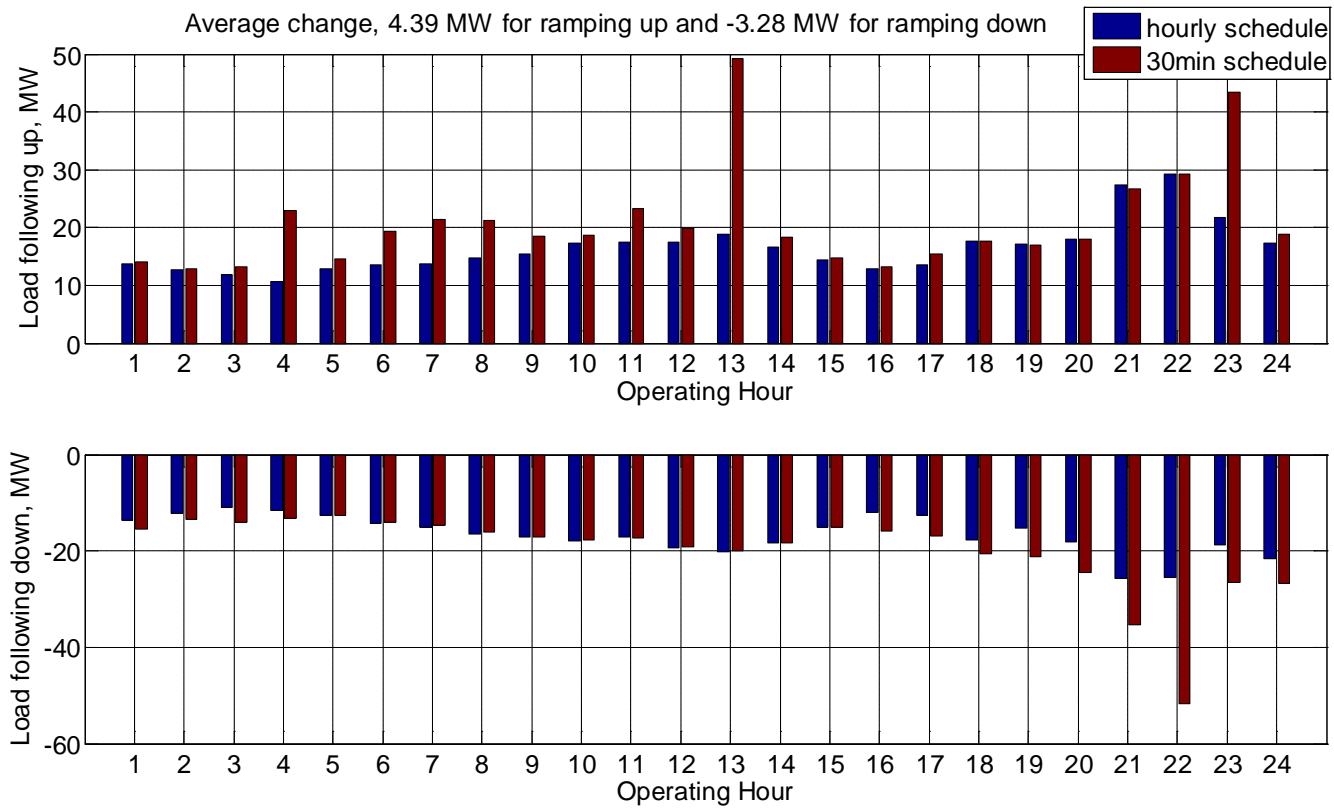

Figure F.54. Impact on TID Load Following, 99.5\% CL, August 2020

Table F.45. Difference between 30-Minute Schedule and Hourly Schedule in Figure F.54 (MW)

\begin{tabular}{|l|r|r|r|r|r|r|r|r|r|r|r|r|r|r|r|r|r|r|r|r|r|r|r|r|}
\hline Operating Hour & $\mathbf{1}$ & $\mathbf{2}$ & $\mathbf{3}$ & $\mathbf{4}$ & $\mathbf{5}$ & $\mathbf{6}$ & $\mathbf{7}$ & $\mathbf{8}$ & $\mathbf{9}$ & $\mathbf{1 0}$ & $\mathbf{1 1}$ & $\mathbf{1 2}$ & $\mathbf{1 3}$ & $\mathbf{1 4}$ & $\mathbf{1 5}$ & $\mathbf{1 6}$ & $\mathbf{1 7}$ & $\mathbf{1 8}$ & $\mathbf{1 9}$ & $\mathbf{2 0}$ & $\mathbf{2 1}$ & $\mathbf{2 2}$ & 23 & 24 \\
\hline Difference, up & 0 & 0 & 1 & 12 & 2 & 6 & 8 & 7 & 3 & 1 & 6 & 2 & 30 & 2 & 0 & 0 & 2 & 0 & 0 & 0 & -1 & 0 & 22 & 2 \\
\hline Difference, down & -2 & -1 & -3 & -2 & 0 & 0 & 0 & 0 & 0 & 0 & 0 & 0 & 0 & 0 & 0 & -4 & -4 & -3 & -6 & -6 & -10 & -26 & -8 & -5 \\
\hline
\end{tabular}

The load-following requirement is increased by 4.39 MW for ramping up (Inc) and increased by 3.28 MW for ramping down (Dec), on average. 


\section{F.4.11 Impact on SMUD Load Following with 95\% Confidence Level}

\section{F.4.11.1 January 2020}
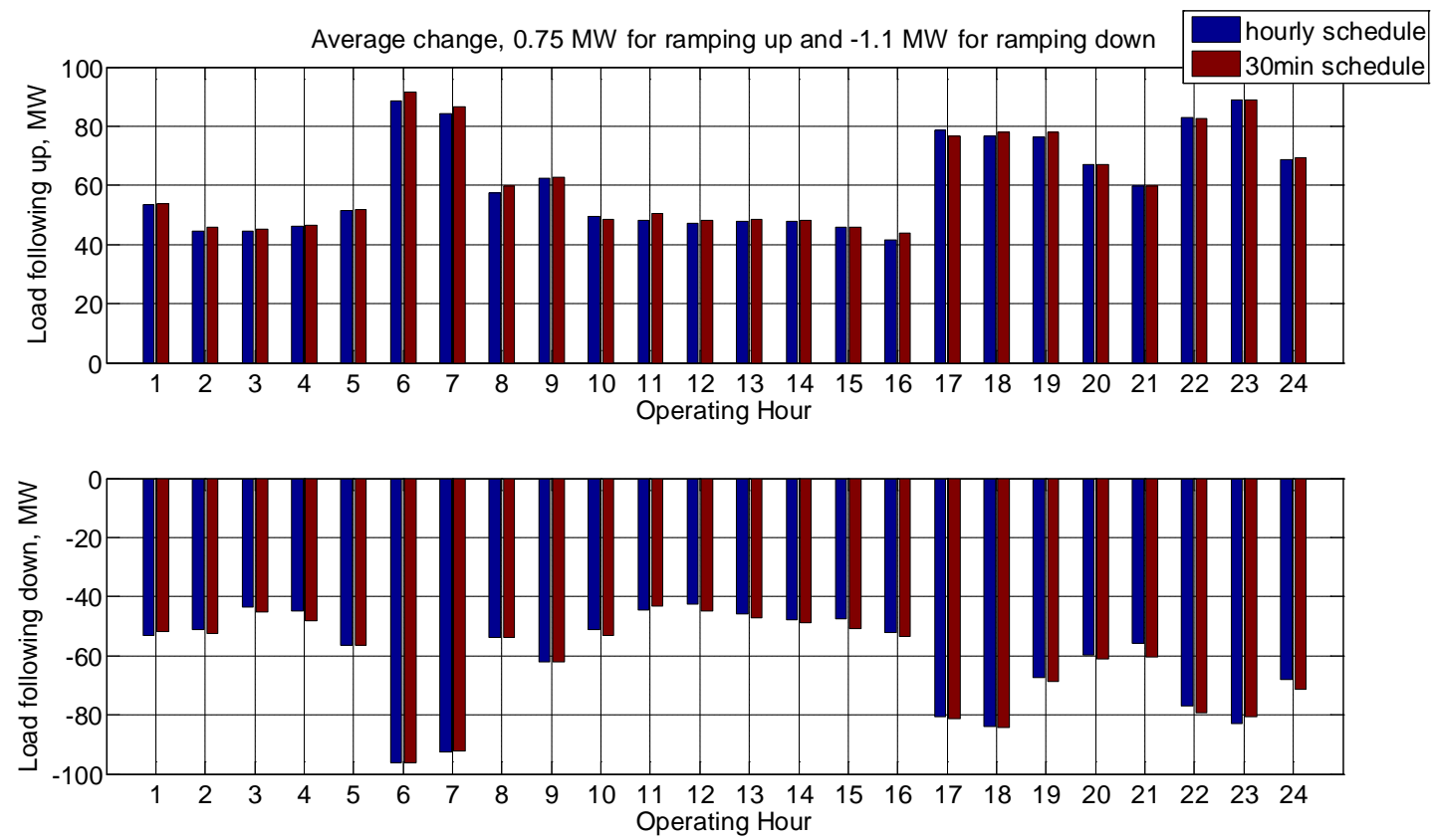

Figure F.55. Impact on SMUD Load Following, 95\% CL, January 2020

Table F.46. Difference between 30-Minute Schedule and Hourly Schedule in Figure F.55 (MW)

\begin{tabular}{|l|r|r|r|r|r|r|r|r|r|r|r|r|r|r|r|r|r|r|r|r|r|r|r|r|}
\hline Operating Hour & $\mathbf{1}$ & $\mathbf{2}$ & $\mathbf{3}$ & $\mathbf{4}$ & $\mathbf{5}$ & $\mathbf{6}$ & $\mathbf{7}$ & $\mathbf{8}$ & $\mathbf{9}$ & $\mathbf{1 0}$ & $\mathbf{1 1}$ & $\mathbf{1 2}$ & 13 & 14 & $\mathbf{1 5}$ & $\mathbf{1 6}$ & $\mathbf{1 7}$ & $\mathbf{1 8}$ & 19 & 20 & 21 & 22 & 23 & 24 \\
\hline Difference, up & 0 & 1 & 1 & 0 & 1 & 3 & 3 & 2 & 0 & -1 & 2 & 1 & 1 & 0 & 0 & 2 & -2 & 1 & 2 & 0 & 0 & 0 & 0 & 0 \\
\hline Difference, down & 1 & -1 & -2 & -4 & 0 & 0 & 0 & 0 & 0 & -2 & 1 & -2 & -1 & -1 & -3 & -1 & 0 & 0 & -1 & -1 & -5 & -2 & 2 & -3 \\
\hline
\end{tabular}

The load-following requirement is increased by $0.75 \mathrm{MW}$ for ramping up (Inc) and increased by 1.1 MW for ramping down (Dec), on average. 


\section{F.4.11.2 April 2020}
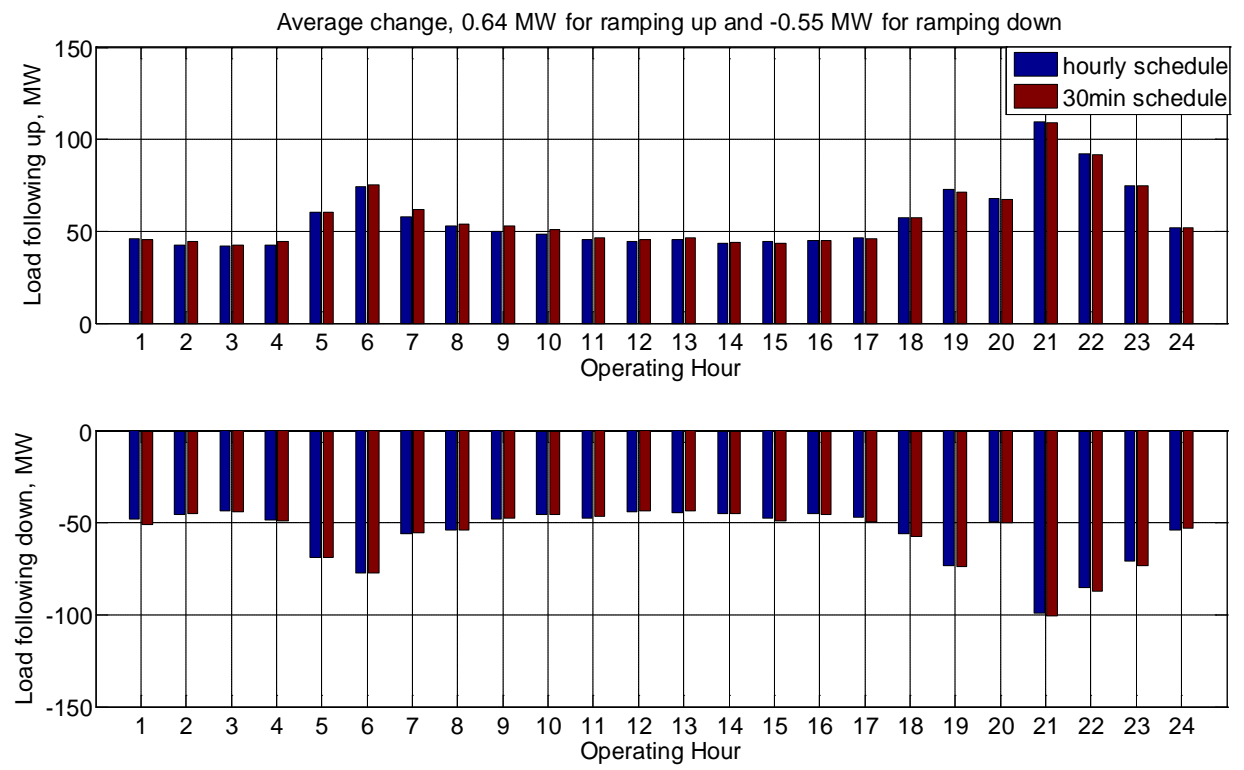

Figure F.56. Impact on SMUD Load Following, 95\% CL, April 2020

Table F.47. Difference between 30-Minute Schedule and Hourly Schedule in Figure F.56 (MW)

\begin{tabular}{|l|r|r|r|r|r|r|r|r|r|r|r|r|r|r|r|r|r|r|r|r|r|r|r|r|}
\hline Operating Hour & $\mathbf{1}$ & $\mathbf{2}$ & $\mathbf{3}$ & $\mathbf{4}$ & $\mathbf{5}$ & $\mathbf{6}$ & $\mathbf{7}$ & $\mathbf{8}$ & $\mathbf{9}$ & $\mathbf{1 0}$ & $\mathbf{1 1}$ & $\mathbf{1 2}$ & 13 & $\mathbf{1 4}$ & $\mathbf{1 5}$ & $\mathbf{1 6}$ & $\mathbf{1 7}$ & $\mathbf{1 8}$ & $\mathbf{1 9}$ & $\mathbf{2 0}$ & 21 & 22 & 23 & 24 \\
\hline Difference, up & 0 & 2 & 0 & 2 & 0 & 1 & 4 & 1 & 3 & 3 & 1 & 1 & 1 & 1 & -1 & 0 & 0 & 0 & -1 & 0 & 0 & -1 & 0 & 0 \\
\hline Difference, down & -3 & 1 & 0 & 0 & 0 & 0 & 0 & 0 & 0 & 0 & 1 & 0 & 1 & 0 & -2 & -1 & -2 & -2 & 0 & 0 & -2 & -2 & -2 & 1 \\
\hline
\end{tabular}

The load-following requirement is increased by $0.64 \mathrm{MW}$ for ramping up (Inc) and increased by 0.55 MW for ramping down (Dec), on average. 


\section{F.4.12 August 2020}
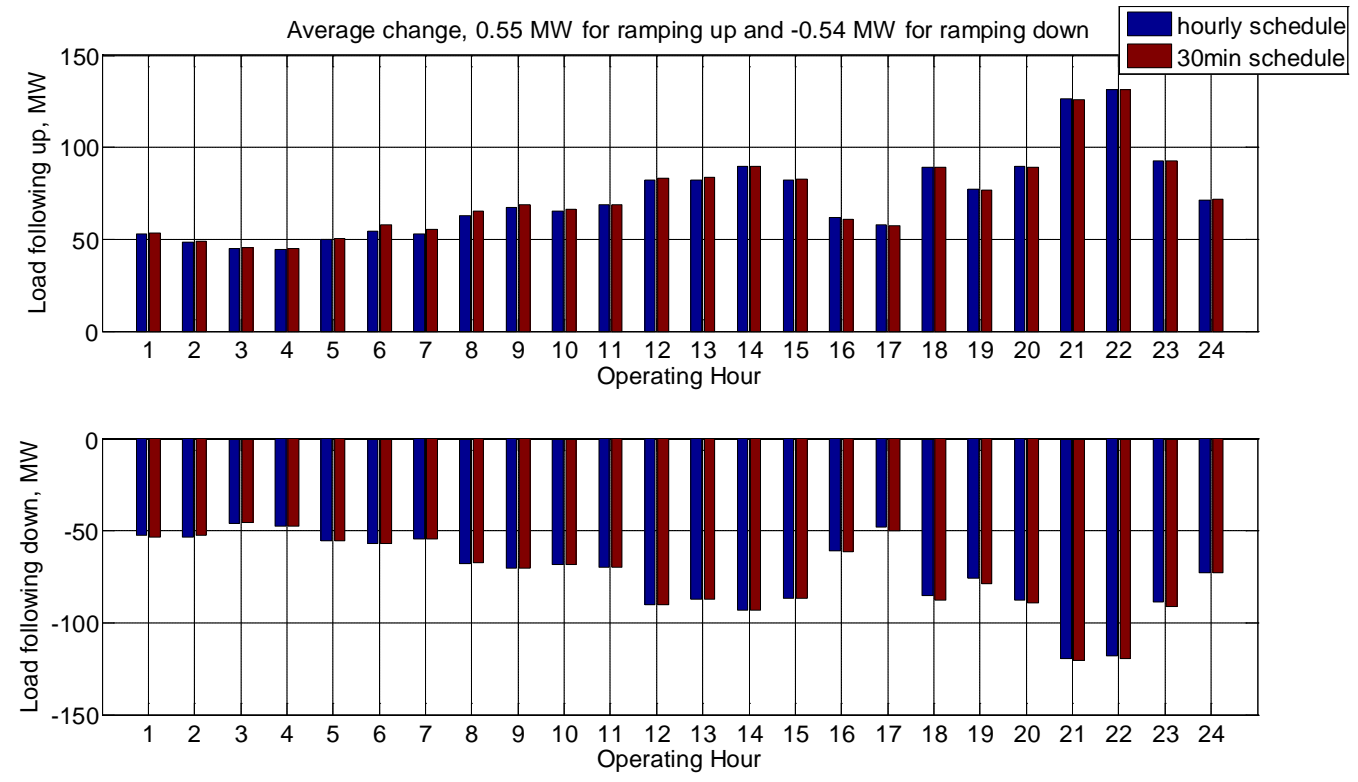

Figure F.57. Impact on SMUD Load Following, 95\% CL, August 2020

Table F.48. Difference between 30-Minute Schedule and Hourly Schedule in Figure F.57 (MW)

\begin{tabular}{|l|r|r|r|r|r|r|r|r|r|r|r|r|r|r|r|r|r|r|r|r|r|r|r|r|}
\hline Operating Hour & $\mathbf{1}$ & $\mathbf{2}$ & $\mathbf{3}$ & $\mathbf{4}$ & $\mathbf{5}$ & $\mathbf{6}$ & $\mathbf{7}$ & $\mathbf{8}$ & $\mathbf{9}$ & $\mathbf{1 0}$ & $\mathbf{1 1}$ & $\mathbf{1 2}$ & $\mathbf{1 3}$ & $\mathbf{1 4}$ & $\mathbf{1 5}$ & $\mathbf{1 6}$ & $\mathbf{1 7}$ & $\mathbf{1 8}$ & $\mathbf{1 9}$ & $\mathbf{2 0}$ & $\mathbf{2 1}$ & 22 & $\mathbf{2 3}$ & $\mathbf{2 4}$ \\
\hline Difference, up & 0 & 0 & 1 & 0 & 0 & 3 & 3 & 2 & 1 & 1 & 0 & 1 & 2 & 0 & 1 & -1 & 0 & 0 & 0 & 0 & 0 & 0 & 0 & 0 \\
\hline Difference, down & -1 & 1 & 0 & 0 & 0 & 0 & 0 & 0 & 0 & 0 & 0 & 0 & 0 & 0 & 0 & 0 & -2 & -2 & -3 & -1 & -1 & -2 & -3 & 0 \\
\hline
\end{tabular}

The load-following requirement is increased by $0.55 \mathrm{MW}$ for ramping up (Inc) and increased by 0.54 MW for ramping down (Dec), on average. 


\section{F.4.13 Impact on SMUD Load Following with 99.5\% Confidence Level}

\section{F.4.13.1 January 2020}
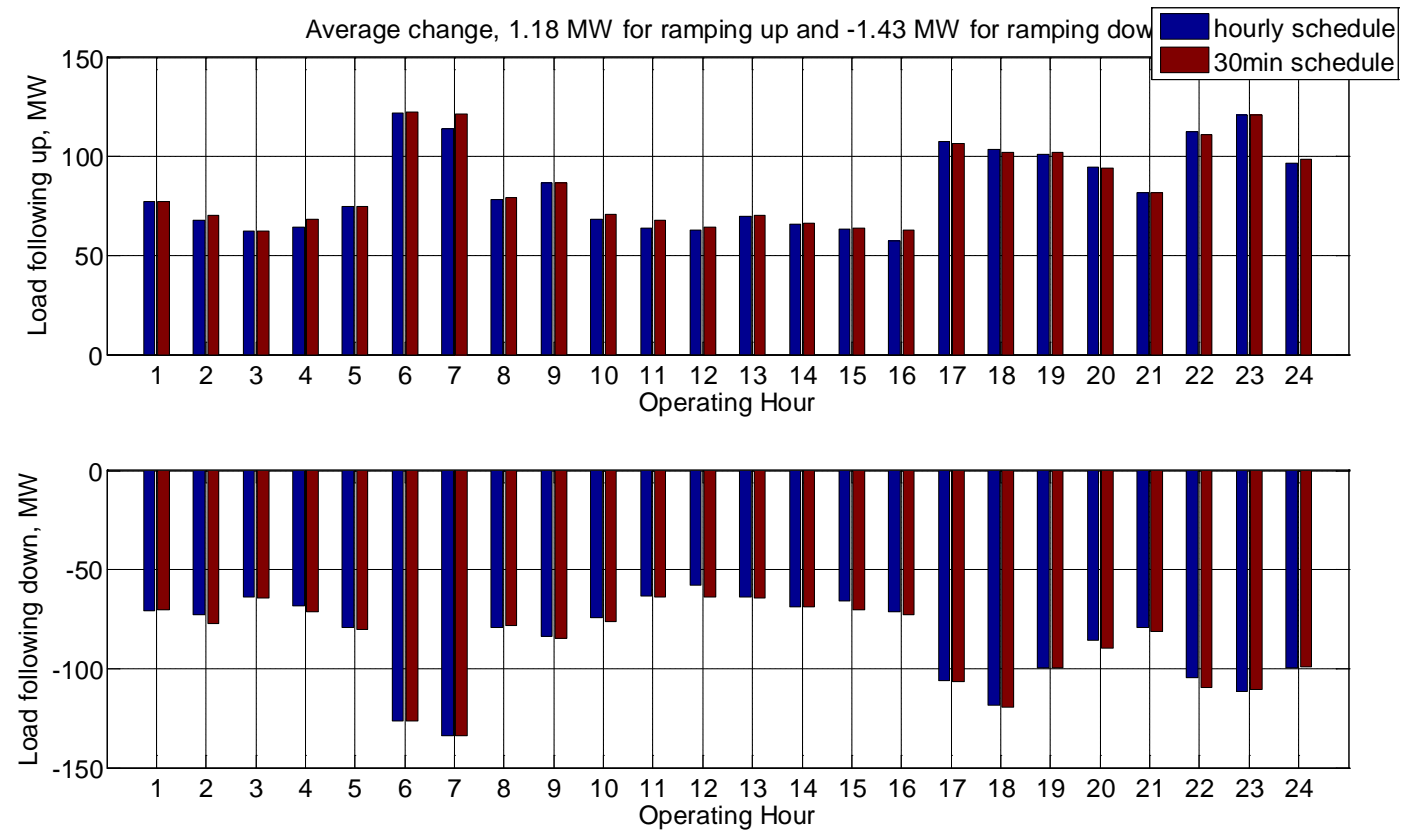

Figure F.58. Impact on SMUD Load Following, 99.5\% CL, January 2020

Table F.49. Difference between 30-Minute Schedule and Hourly Schedule in Figure F.58 (MW)

\begin{tabular}{|l|c|c|c|c|c|c|c|c|c|c|c|c|c|c|c|c|c|c|c|c|c|c|c|c|}
\hline Operating Hour & $\mathbf{1}$ & $\mathbf{2}$ & $\mathbf{3}$ & $\mathbf{4}$ & $\mathbf{5}$ & $\mathbf{6}$ & $\mathbf{7}$ & $\mathbf{8}$ & $\mathbf{9}$ & $\mathbf{1 0}$ & $\mathbf{1 1}$ & $\mathbf{1 2}$ & $\mathbf{1 3}$ & $\mathbf{1 4}$ & $\mathbf{1 5}$ & $\mathbf{1 6}$ & 17 & $\mathbf{1 8}$ & 19 & 20 & 21 & 22 & 23 & 24 \\
\hline Difference, up & 0 & 3 & 0 & 4 & 0 & 1 & 8 & 1 & 0 & 2 & 4 & 1 & 1 & 0 & 0 & 6 & -1 & -1 & 1 & 0 & 0 & -2 & 0 & 2 \\
\hline Difference, down & 0 & -5 & -1 & -3 & -1 & 0 & 0 & 1 & -1 & -2 & -1 & -6 & 0 & 0 & -4 & -2 & 0 & -1 & 0 & -4 & -2 & -5 & 1 & 0 \\
\hline
\end{tabular}

The load-following requirement is increased by $1.18 \mathrm{MW}$ for ramping up (Inc) and increased by 1.43 MW for ramping down (Dec), on average. 


\section{F.4.13.2 April 2020}
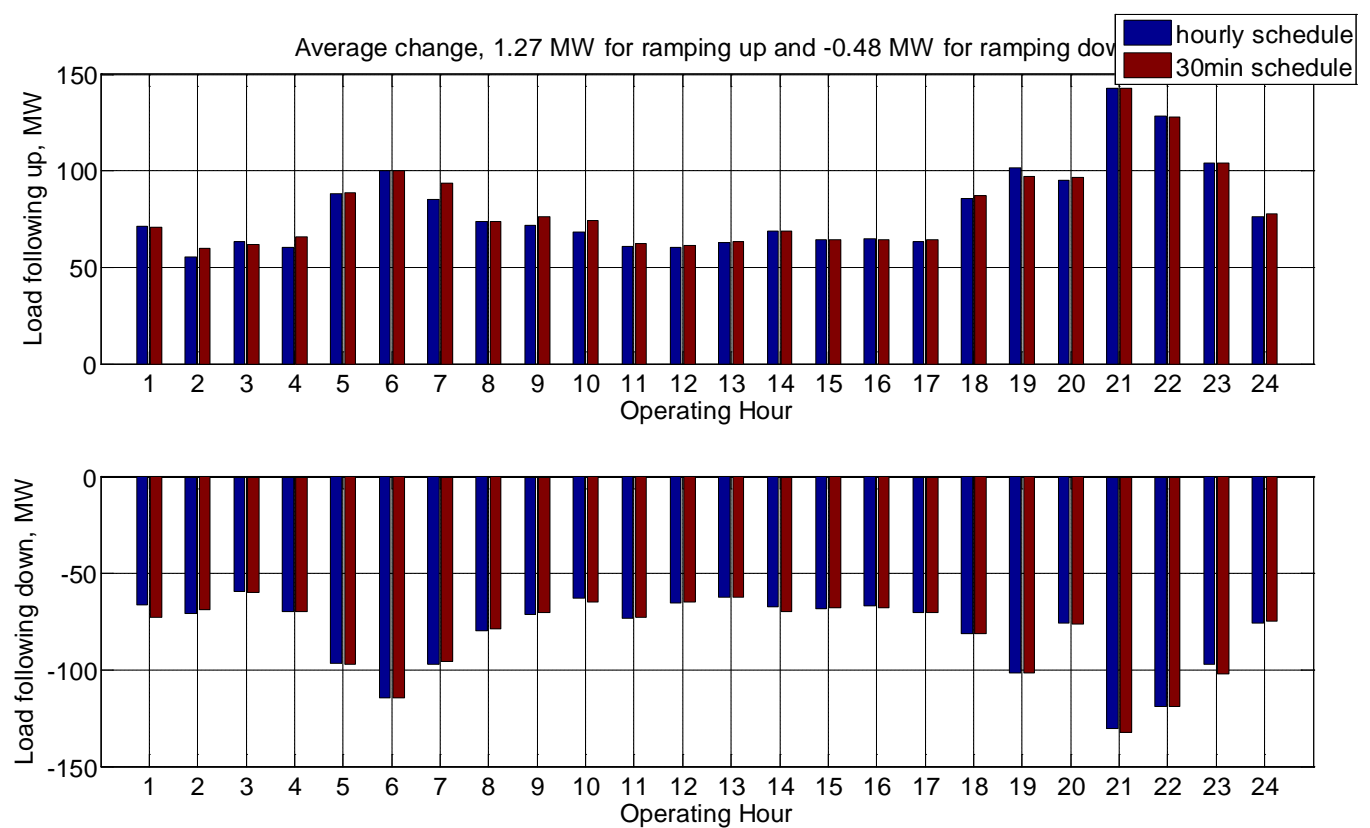

Figure F.59. Impact on SMUD Load Following, 99.5\% CL, April 2020

Table F.50. Difference between 30-Minute Schedule and Hourly Schedule in Figure F.59 (MW)

\begin{tabular}{|l|r|r|r|r|r|r|r|r|r|r|r|r|r|r|r|r|r|r|r|r|r|r|r|r|}
\hline Operating Hour & $\mathbf{1}$ & $\mathbf{2}$ & $\mathbf{3}$ & $\mathbf{4}$ & $\mathbf{5}$ & $\mathbf{6}$ & $\mathbf{7}$ & $\mathbf{8}$ & $\mathbf{9}$ & $\mathbf{1 0}$ & 11 & 12 & 13 & 14 & 15 & 16 & 17 & 18 & 19 & 20 & 21 & 22 & 23 & 24 \\
\hline Difference, up & -1 & 5 & -1 & 6 & 1 & 0 & 9 & 0 & 4 & 6 & 1 & 1 & 1 & 0 & 0 & -1 & 1 & 2 & -4 & 1 & 0 & 0 & 0 & 1 \\
\hline Difference, down & -6 & 2 & -1 & 0 & 0 & 0 & 1 & 1 & 1 & -2 & 1 & 0 & 0 & -2 & 1 & -1 & 0 & 0 & 0 & 0 & -2 & 0 & -5 & 1 \\
\hline
\end{tabular}

The load-following requirement is increased by $1.27 \mathrm{MW}$ for ramping up (Inc) and increased by 0.48 MW for ramping down (Dec), on average. 


\section{F.4.13.3 August 2020}
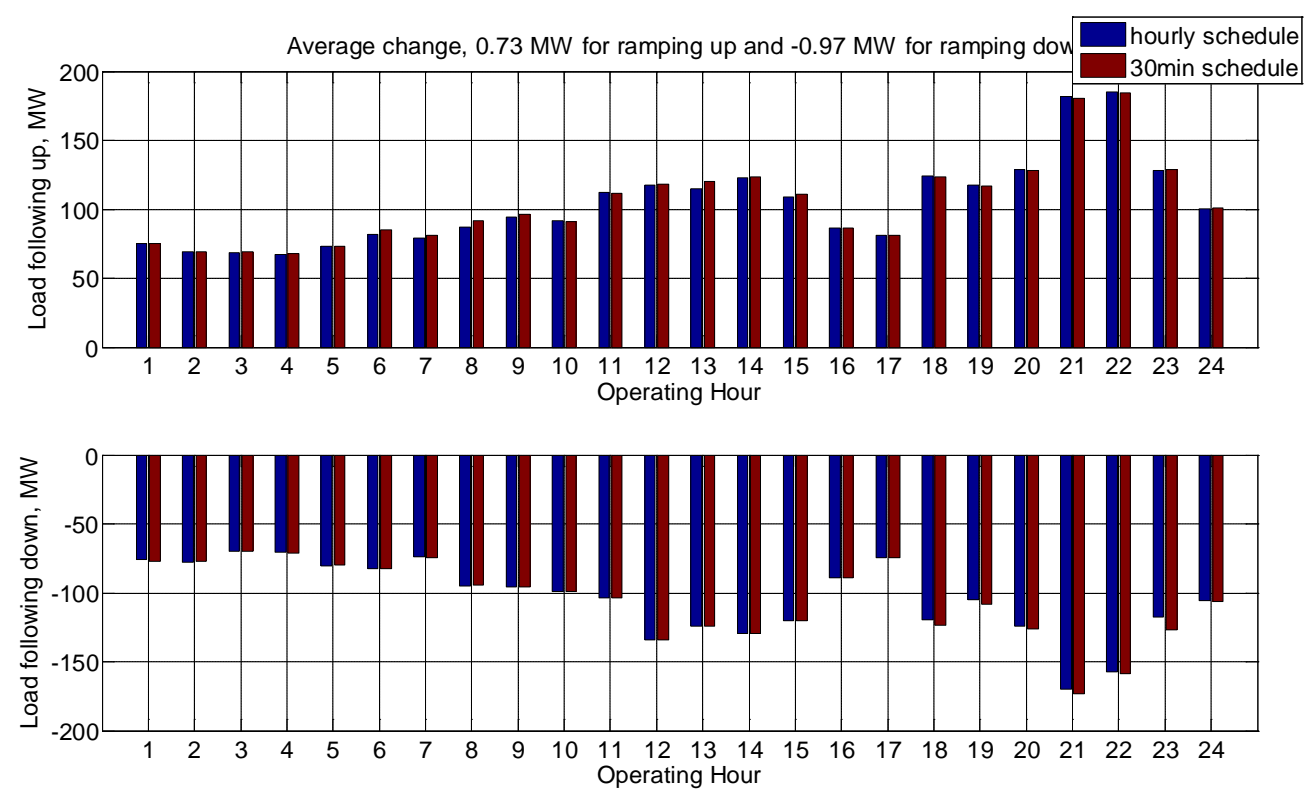

Figure F.60. Impact on SMUD Load Following, 99.5\% CL, August 2020

Table F.51. Difference between 30-Minute Schedule and Hourly Schedule in Figure F.60 (MW)

\begin{tabular}{|l|r|r|r|r|r|r|r|r|r|r|r|r|r|r|r|r|r|r|r|r|r|r|r|r|}
\hline Operating Hour & $\mathbf{1}$ & $\mathbf{2}$ & $\mathbf{3}$ & $\mathbf{4}$ & $\mathbf{5}$ & $\mathbf{6}$ & $\mathbf{7}$ & $\mathbf{8}$ & $\mathbf{9}$ & $\mathbf{1 0}$ & $\mathbf{1 1}$ & $\mathbf{1 2}$ & 13 & $\mathbf{1 4}$ & $\mathbf{1 5}$ & $\mathbf{1 6}$ & 17 & 18 & 19 & 20 & 21 & 22 & 23 & 24 \\
\hline Difference, up & 0 & 0 & 1 & 0 & 0 & 4 & 2 & 5 & 2 & 0 & -1 & 0 & 5 & 0 & 2 & 0 & 0 & 0 & -1 & 0 & -1 & 0 & 0 & 0 \\
\hline Difference, down & -1 & 1 & 0 & -1 & 0 & 0 & 0 & 1 & 0 & 0 & 0 & 0 & 0 & 0 & 0 & 0 & 0 & -4 & -3 & -2 & -3 & -1 & -9 & 0 \\
\hline
\end{tabular}

The load-following requirement is increased by $0.73 \mathrm{MW}$ for ramping up (Inc) and increased by 0.97 MW for ramping down (Dec), on average.

\section{F.5 Reserve Shifting Analyses Conclusions}

A modified algorithm to calculate the load-following requirements for BAs implementing half-hour wind transfer schedules is developed and tested on the NWPP system models. Five wind transfers are defined with different capacities, including BPA-PGN, BPA-PSE, BPA-BCHA, BPA-TID and BPASMUD. For the half-hour wind schedules, a T-31 persistence model is used to generate the first halfhour wind schedule for the next operating hour and a $\mathrm{T}-1$ persistence model is used to generate the second half-hour wind schedule for the next hour. With the five wind transfers implemented simultaneously, the load-following requirements for the source BA and sink BAs are calculated and then compared with the original hourly schedule scenario. From the simulation results, it is observed that the load-following requirements are decreased for both ramping up and ramping down requirements in the source BA. The average increased magnitude ranges from 25.61 to $58.19 \mathrm{MW}$, varying in different study months and with different confidence levels. In general, the load-following requirements for the sink BAs are increased as a result of the half-hour wind schedule. 


\section{Distribution}

No. of

Copies

\# Name

Organization

Address

City, State and ZIP Code

\# Organization

Address

City, State and ZIP Code

Name

Name

Name

Name

Name (\#)

\# Name

Organization

Address

City, State and ZIP Code
No. of

Copies

\# Foreign Distribution

\# Name

Organization

Address

Address line 2

COUNTRY

\# Local Distribution

Pacific Northwest National Laboratory

Name

Name

Name

Name

Name
Mailstop

Mailstop

Mailstop

Mailstop

(PDF) 




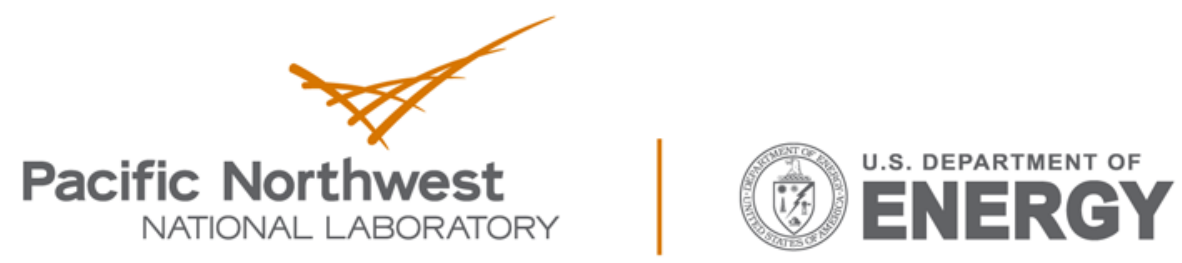

Proudly Operated by Battelle Since 1965

902 Battelle Boulevard

P.O. Box 999

Richland, WA 99352

1-888-375-PNNL (7665)

www.pnnl.gov 